


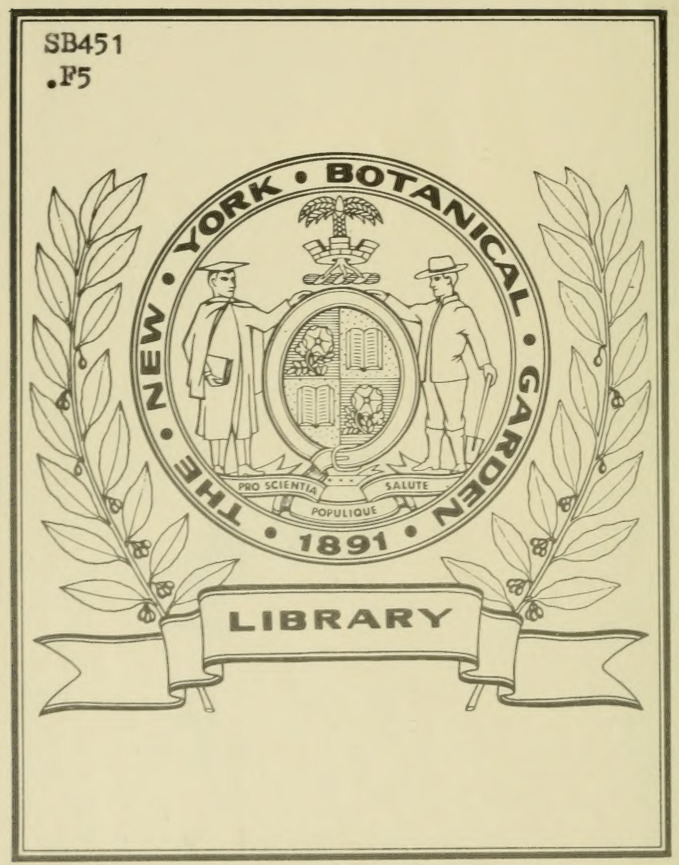








\title{
Altdeutsche Gartenflora.
} 580.9 F524

\section{Untersuchungen}

\author{
über die
}

Nutzpflanzen des deutschen Mittelalters, ihre Wanderung und ihre Vorgeschichte im klassischen Altertum

von

\section{Prof. Dr. R. v. Fischer-Benzon}

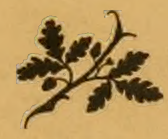

Kiel und Leipzig

Verlag von Lipsius \& Tischer.

1894. 


\section{Ergebnisse der in dem atlantischen Ocean} von Mitte Juli bis Anfang November 1889 ausgeführten

\section{Plankton-Expedition der Humboldt-Stiftung.}

Auf Grund von gemeinschaftlichen Untersuchungen einer Reihe von FachForschern herausgegeben

\section{V i c t o r H e n s e $n$, Professor der Physiologie in Kiel,}

in 5 Quartbänden mit über 300 Tafeln.

Erschienen sind bereits:

Bd. I A.

Reisebesch reibung. Von Dr. 0. Krümmel nebst Einleitung ron Dr. Hensen und Vorberichten von Drr. Dahl, Apstein, Lohmann, Borgert, Sehiitt und Brandt. 380 Seiten. $4^{\circ}$. Mit 100 Figuren im Text, sowie 5 Karten, 2 Tafeln und einer Photogravüre. Preis kart. Mk. 30. Eleg. gebunden Mik. 32.

Bd. I C.

Geophysikalische Beobachtungen. Von Dr. Krïmmel. 120 S. $4^{0}$. Mit 2 Karten. Preis brosch. Mlk. 10.

Bd. II Ea. A. Die Thaliacea. Systematische Bearbeitung. Von M. P.A. Transtedt. 16 Seiten. $4^{\circ}$. Mit 1 Tafel. Preis brosch. Mk. 2.

Bd. II Ga. a Halobatiden. Von Prof. Dr. Fr. Dahl und

$\beta$ Halacarinen. Von Dr. Lohmann. $96 \mathrm{~S}$. $4^{\circ}$. Mit 11 Fig. im Text, sowie mit 13 Taf. Preis brosch. Ink. 16.

Bd. II Gb. Decapoden und Schizopoden der Plankton-Expedition. Von Dr. Arnold 0rtmann. 120 S. $4^{0}$. Mit 7 Tafeln, 3 Karten und einer Figur im Text. Preis brosch. Mk. 14.

Bd. II Ke. Die craspedoten Medusen d. Plankton-Expedition. Von Dr. Otto Maas. $107 \mathrm{~S} .4^{0}$. Mit 6 Tafeln, 2 Karten u. 3 Fig. im Text. Preis brosch. Mk. 14.

Bd. II Kd. Die Akalephen. Von Dr. E. Vauhöffen. 28 Seiten. $4^{0}$. Mit 4 Tafeln und einer Karte. Preis brosch. Mik. 8.

Bd. IV Mg. Die Bakterien des Meeres nach den Untersuchungen der Plankton-Expedition unter gleichzeitiger Berücksichtigung einiger älterer und neuerer Untersuchungen von Prof. Dr. Bernhard Fiseher. $83 \mathrm{~S} .4^{\circ}$. Mit 3 Figuren im Text und 1 Karte. Preis brosch. Mk. 6.

Abonnenten, welche sich zur Abnahme des ganzen Werkes verpflichten, haben Anspruch auf einen um $10 \%$ ermässigten Subseriptionspreis. Die Namen der Subseribenten sollen bei Ausgabe des Sehlussheftes veröffentlicht werden.

Le Ausführliche Prospekte über das gross angelegte Werk stehen gratis und franko zur Verfügung.

Die Plankton-Expedition und Haeckels Darwinismus.

Von Prof. V. Heusen.

Ueber einige Aufgaben und Ziele der beschreibenden Naturwissenschaften. Mit 2 Steindrucktafeln. Preis $M k .3$.

Diese erste z. Z. einem grösseren Leserkreise dar. gebotene Veröffentlichung dilrfte als Entgegnung auf die Haeckel'sche Schrift ,Plankton-Studien", in der er die Expedition schon vor der Bekanntgabe ibrer Ergebnisse in Misskredit zu bringen versucht, auch jetzt noch von hohem Interesse sein.
Analytische Plankton-Studien.

Von Prof. Dr. Franz Schütt.

Ziele u. Methoden der Plankton-Forschung.

$$
\text { Preis Mk. } 3 .
$$

Diese Schrift, in der die genannte Methode, die Planktonfänge nach Maass, Zahl und Vertheilung zu bestimmen, beschrieben wird, ist für Zoologen und Botaniker von gleicher Bedeutung.

\section{Das Pflanzenleben der Hochsee.}

\section{Von Dr. Franz Schütt.}

Professor an der Universität zu Kiel.

76 Seiten. 4" mit 35 Textabbildungen und einer Karte.

Preis kart. Mk. 7. 


\section{Altdeutsche Gartenflora.}

\section{Untersuchungen}

über die

Nutzpflanzen des deutschen Mittelalters, ihre Wanderung und ihre Vorgeschichte im klassischen

Altertum

von

\section{Prof. Dr. R. v. Fischer-Benzon}

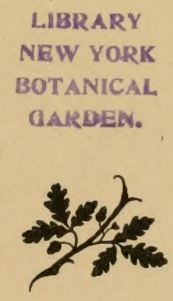

Kiel und Leipzig

Verlag von Lipsius \& Tischer.

1894. 
SB 451

. F 5

Druck von A. Hopfer in Burg b. M. 


\title{
Ernst H. F. Meyer
}

\author{
geb. zu Hannover, den 1. Januar 1791
}

gest. zu Königsberg i. Pr., den 7. August 1858

und

\section{Victor Hehn}

geb. zu Dorpat, den 8. Oktober 1813

gest. zu Berlin, den 21. März 1890

zum Gedächtnis. 

Ein reges Interesse an der gesamten Geschichte der Botanik im Zusammenhange mit der allgemeinen Kulturgeschichte, das war es, wie Ernst Meyer selbst sagt, was die Hauptrichtung seiner wissenschaftlichen Thätigkeit bestimmte. In der That sind seine Arbeiten ïber Geschichte der Botanik zahlreicher und zugleich bedeutender als seine systematischen. Seine Geschichte der Botanik, an deren Vollendung ihn leider sein früher Tod hinderte, ist ein schönes Denkmal seines Geistes und seiner Gelehrsamkeit. Mit Lifer hat er sich in die Schriften der verschiedenen Autoren vertieft und besondere Sorgfalt hat er darauf verwendet, ihren.Lebensgang darzustellen. Dadurch schafft er uns nicht nur ein Bild von den einzelnen Persönlichkeiten, sondern auch von ihrer Zeit. Mit ausgesprochener Vorliebe verweilt er bei den botanischen Schriftstellern des deutschen Mittelalters. Er war es, der zuerst die Bedeutung der heiligen Hildegard und des Albertus Magnus, seines erklärten Lieblings, nicht nur für die Geschichte der Botanik überhaupt, sondern namentlich auch für die Geschichte und Wanderung unserer Nutzpflanzen erkannte. So arbeitete er an demselben Zweige des Wissens wie Victor Hehn, der indes, im Gegensatze zu ihm, nicht von den Botanikern der früheren Jahrhunderte ausging, vielmehr die einzelnen Pflanzen zum Mittelpunkte seiner Darstellung machte und ihre Wanderung an der Hand der Alten verfolgte.

Nicht nur der Dank, den ich selbst den beiden genannten Männern für die aus ihren Werken geschöpfte Anregung und Belehrung schulde, hat mich veranlasst mein Buch ihrem Andenken zu widmen, mich bewog ebensosehr die Verehrung und Hochachtung, die wir alle diesen echt deutschen Forschern schuldig sind. 


\section{Vorwort.}

Karl der (irosse erliess im Jahre 812 eine Verurdnung über die Verwaltung seiner Besitztïmer, das "Capitulare de villis." Das siebzigste und letzte Kapitel dieser Verordnung ist dem Gartenbau gewidmet und zïhlt die Pflanzen auf, die der Kaiser in seinen Gärten gebaut wissen wollte. Mit Recht hat man diesem Pflanzenverzeichnisse eine grosse Bedeutung für die Geschichte des Gartenbaues beigelegt, denn die darin genamnten Gemüse- und Obstarten werden fast alle auch heute noch gebaut. Deshalb sind Historiker, Landwirte und Botaniker bemüht gewesen, die lateinischen Namen dieses Verzeichnisses zu deuten und zu enträtseln. Aber je nach den bot:nischen Kenntnissen der Deuter und nach den benutzten Hülfsmitteln waren diese Bemühungen von verschiedenem Erfolge, und uiber den Sinn mancher Namen wurde eine Einigung überhaupt nicht erzielt.

Eine langjälırige Beschäftigung mit den Bauerngärten meiner Heimat hat mich dazu geführt, die Pflanzennamen des Capitulare aufs Neue aufinerksam zu prüfen, namentlich dadurch, dass ich die betreffende P’llinze zeitlich mö̈glichst weit rïckwärts und vorwärts verfolgte. Was aher anfänglich nur Mittel war, wurde schliesslich Zweck: die Untersuchung wurde unf unsere alten Nutzpflanzen uiberhaupt ausgedehnt, und ihre Wanderung aus dem Südosten und Süden nach Norden wurde thunlichst bis auf die Gegenwart verfolgt. Auf die Weise ist mein Buch zu dem Titel "Altdeutsche Gartenflora" gekommen.

Auf absolute Vollstiindigkeit macht die folgende Arbeit keinen Anspruch; doch hoffe ich, dass Pflanzen von einiger Wichtigkeit nicht ansgelassen sein werden. Der Raum, der den einzelnen Pflanzen eingeräumt worden ist, ist sehr versehieden; die Schwierigkeit, welche die Untersuchumg darbot, oder das Interesse, das ich selbst an dem behandelten Gegenstande nahm, haben hierbei den Ausschlag gegeben. In manchen Punkten weiche ich von meinen Vorgüngern ab; da ich aber auf 
ihren Schultern stehe, und da ich Hülfsmittel benutzen konnte, die jenen zum Teil nicht bekannt waren, so habe ich es unterlassen, meine abweichende Ansicht jedesmal ausdruicklich hervorzuheben. Wiederholungen haben sich ebensowenig vermeiden lassen wie Verweisungen von einer Stelle auf die andere; hoffentlich empfindet der Leser eine Wiederholung gelegentlich als Bequemlichkeit.

Hülfe und Rat sind mir in reichem Masse zu Teil geworden, in botanischen und pflanzengeographischen Fragen von Dr. med. ERNST H: L. Krause, bei sprachlichen Schwierigkeiten von den Professoren Dr. A. Funck und Dr. P. Caugr, sowie von Oberlehrer Dr. E. Bruhr, meinen früheren Collegen. Eine Reihe wertvoller Angaben über Gemüse und Gemüsebau lieferte mir Herr Handelsgärtner ANDr. Böттснег, Inhaber der Firma Joh. Eckardt in Kiel. Ihnen allen sei hiermit herzlicher Dank ausgesprochen!

Aber damit sind noch nicht alle genannt, die zum Gelingen meiner Arbeit beigetragen haben. Meinem Herrn Verleger schulde ich Dank einmal dafür, dass er mir gestattet hat die Ergebnisse fortgesetzter Untersuchung während des Druckes in den Text einzufügen, und zweitens für die hübsche Ausstattung, die er meinem Buche gegeben hat. Bei der peinlichen Arbeit der Korrektur hat mir Dr. A. Fuxck unermüdlich beigestanden. Endlich ist es mir eine angenehme Pflicht an dieser Stelle auszusprechen, dass die Nühe des Korrigierens durch das ausgezeichnete Setzerpersonal der Hopfer'schen Druckerei in ungewöhnlichem Grade vermindert worden ist.

Kiel, Ostern 1894.

R. v. Fischer-Benzon. 


\section{Inhaltsübersicht.}

Einleitung. Allgemeines, Hülfsmittel und Quellen........ . 1

1. Frühere Deutungsversuche . . . . . . . . . . . . . . . . . . 7

2. Die botanischen, medicobotanischen und landwirtschaftlichen Schriften des

Altertums . . . . . . . . . . . . . . . . . . 8

antike Wandgemälde . . . . . . . . . . . . . . 13

3. Die Pflanzenglossare .. . . . . . . . . . . . . . . . . . 14

4. Botanische Schriften des deutschen Mittelalters . . . . . . . . . . 17

5. Die Kräuterbücher des 16. Jahrhunderts . . . . . . . . . . . . . . . 20

6. Die pflanzlichen Arzneimittelnamen der alten Apotheken und Pharmakopöen 21

7. Die volkstümlichen Pflanzennamen im heutigen Griechenland und Italien 22

8. Schriften, die sich mit der Geschichte der Nutzpflanzen beschäftigen . . 23

9. Untersuchung des Bestandes an Nutz- und Zierpflanzen in alten Gärten - 24

Verzeichnis der gebrauchten Abkürzungen . . . . . . . . . . . . 27

Unsere Nutzpflanzen . . . . . . . . . . . . . . . . . . . . . . . . . . . 29

1. Zierpflanzen . . . . . . . . . . . . . . . . . . . . . . . . . . . . . . . . .

Die Lilie . . . . . . . . . . . . . . . . . . . 33

Rosen . . . . . . . . . . . . . . . . . . . . 34

Narcissen . . . . . . . . . . . . . . . . . . 37

Die Hyacinthe . . . . . . . . . . . . . . . . . . . . 38

Veilchen, Levkoje, Goldlack und Viole . . . . . . . . . . . . . . 39

Goldblume und Vexiernelke . . . . . . . . . . . . . . . . . 42

Schwertlilie und Gladiolus ..... . . . . . . . . . . . 43

Lorbeer, Myrte und Buchsbaum . . . . . . . . . . . . . . . 47

2. Heilpflanzen . . . . . . . . . . . . . . . . . . . 49

Kalmus . . . . . . . . . . . . . . . . . . . . . . 49

Drachenwurz, Esdragon, Schlangenwurz . . . . . . . . . . . . 51

Koloquinte und Zaunrübe . . . . . . . . . . . . . . . . . . . 54

Haselwurz und Osterluzei . . . . . . . . . . . . . . . . . 56

Springkraut und Wunderbaum . . . . . . . . . . . . . . . . 58

Klette, Pestwurz und Grindlattich . . . . . . . . . . . . . ธ9

Schöllkraut, Schwalbenwurz . . . . . . . . . . . . . 61

Mutterkraut und Nieswurz . . . . . . . . . . . . . . . . 62

Alant . . . . . . . . . . . . . . . . 63

Eibisch . . . . . . . . . . . . . . . 63

Mohn . . . . . . . . . . . . . . . . . . . . . 64

Laserkraut, Ammi und Liebstöckel . . . . . . . . . . . . . . . 65

Diptam und Raute . . . . . . . . . . . . . . . 67

Minze, Frauenminze und Rainfarn . . . . . . . . . . . . 69 
Eberraute und Heiligenpflanze (Cypresse)

Wermut und Beifuss .................... 75

Odermennig und Betonika. . . . . . . . . . . . . . 76

Andorn und Ballota . . . . . . . . . . . . . . . 77

Eisenkraut . . . . . . . . . . . . . . . 78

Hauslauch und Johanniskraut . . . . . . . . . . . 79

Sadebaum und Wachholder ............... . . 80

Meerzwiebel . . . . . . . . . . . . . . . . . . . . . 81

Griechisch Heu . . . . . . . . . . . . . . . 81

3. Technisch verwertbare Pflanzen . . . . . . . . . . . 82

Färberröte, Waid, Wau und Safflor . . . . . . . . . . . . 82

Seifenkraut und andere Waschmittel . . . . . . . . . . . . 84

Flachs; Leinenappretur . . . . . . . . . . . . . . . . . 85

Hanf und Nessel . . . . . . . . . . . . . . . . . 87

4. Pflanzen des Gemüsegartens . . . . . . . . . . . . . . . . . 89

Kürbis, Gurke und Melone . . . . . . . . . . . . . . . . . . 89

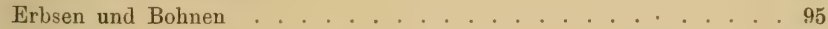

Kicher und Linse . . . . . . . . . . . . . . . . . . . . . 101

Kresse, Brunnenkresse und Pfefferkraut . . . . . . . . . . . 102

Salat, Endivie, Cichorie und Ringelblume. . . . . . . . . 104

Rauke, Senf und Portulak . . . . . . . . . . . . . . . 107

Kohl und Rüben . . . . . . . . . . . . . . . . 108

Kohl . . . . . . . . . . . . . . . . . 108

Steckrübe und Rübe . . . . . . . . . . . . . . . 112

Rettich und Radies.................. . . . 113

Meerrettich . . . . . . . . . . . . . 114

Mohrrübe, Pastinak und Zuckerwurzel . . . . . . . . . 116

Sellerie, Petersilie und schwarzes Gemüse . . . . . . . . . . . . 119

Artischocke und Weberkarde . . . . . . . . . . . 121

Weisswurzel und Schwarzwurzel . . . . . . . . . . 122

Spargel . . . . . . . . . . . . . . . . . . . . 124

Kerbel und Myrrhenkerbel . . . . . . . . . . . . . . . 126

Spinatpflanzen . . . . . . . . . . . . . . . 127

Gartenmelde, Malve . . . . . . . . . . . . . . . . . 127

Mangolt, Amarant . . . . . . . . . . . . . . . . . . 129

Spinat . . . . . . . . . . . . . . 130

Erdbeerspinat . . . . . . . . . . . . . . 130

Kreuzkümmel, Kümmel und Schwarzkümmel . . . . . . . . . . 131

Fenchel, Dill, Anis und Koriander . . . . . . . . . . . . . . 132

Würzpflanzen aus der Familie der Labiaten . . . . . . . . . . . 133

Salbei . . . . . . . . . . . . . . . . . . 133

IIuskatellersalbei, Basilikum . . . . . . . . . . . . . . 134

Bohnenkraut, Thymian, Majoran . . . . . . . . . . . . 135

Lavendel, Rosmarin . . . . . . . . . . . . . . . . . 136

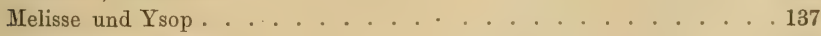

Zwiebeln und Lauch . . . . . . . . . . . . . . . . . . 137

Schalotte . . . . . . . . . . . . . . . . . 138

Sommerzwiebel . . . . . . . . . . . . . . . . . . . 139

Winterzwiebel . . . . . . . . . . . . . . . . 140

Schnittlauch, Porree . . . . . . . . . . . . 141

Knoblauch . . . . . . . . . . . . . . . . . . . . 142

Nachtschatten .................. . . . 143 
5. Obstbäume . . . . . . . . . . . . . . . . . . . . . . . . . . . . . . . . . . . . .

Apfel, Birne und Quitte .................... . . 144

Speierling und Mispel . . . . . . . . . . . . . . . . . . . . . 147

Kirsche und Pflaume . . . . . . . . . . . . . . . . . . . 148

Pfirsich und Aprikose. . . . . . . . . . . . . . . . . . . . . . . 154

Maulbeere und Feige . . . . . . . .. . . . . . . . . . . . . . 1 ๖

Der Weinstock . . . . . . . . . . . . . . . . . . . . . . . . 157

Mandel, Kastanie, Walnuss und Haselnuss . . . . . . . . . . . . . 158

Pinie . . . . . . . . . . . . . . . . . . 161

6. Bemerkungen über unsere Getreidearten . . . . . . . . . 162

Anhang I . . . . . . . . . . . . . . . . . . . . . . . 171

1. Aus den "Hermeneumata" des Corpus Glossariorum Latinorum, Bd. 3, Leipzig 1892 . . . . . . . . . . . . . . . . . . 173

A. De floribus, über Blumen . . . . . . . . . . . . . . 174

B. De oleribus, über Gemüse . . . . . . . . . . . . . 175

2. Zwei Inventare Kaiserlicher Gärten aus dem Jahr 812 . . . . . . . 181

3. Kapitel 70 des "Capitulare de villis (vel curtis) imperialibus" . . . . . . 183

4. Entwurf zu einem Klostergarten aus dem 9. Jahrhundert. . . . . . . . 184

5. Der „Hortulus“ des Walafridus Strabus, Inhaltsübersicht . . . . . . . . 187

6. Glossae Theotiscae . . . . . . . . . . . . . . . 188

Anhang II. Die Pflanzennamen in der "Physica" der heiligen Hildegard . . . 191

Nachtrag zu S. 95 . . . . . . . . . . . . . . . . . . 221

Register . . . . . . . . . . . . . . . 225 


\section{Einleitung.}

\section{Allgemeines, Hülfsmittel und Quellen.}

Es gab eine Zeit, wo die Mode auf das Aussehen der Gürten wur einen sehr geringen Einfluss hatte, und diese Zeit liegt gar niclt so sehr weit hinter uns, vielleicht 40 oder 50 Jahre. ') Damals unterschieden sich die Gärten der Stälter in allgemeinen nur werig von denen der Bauern; der Stälter baute vielleicht einige Gemüserassen mehr und hatte in seinem Blumengarten auch wohl einige Zierpflanzen stehen, die man auf dem Lande vergebens suchte. Die Wanderung der Pflanzen ging früher eben nur lingsam von statten. Der Verbreitungsmittelpunkt für neue Nutzpflanzen jeder Art war auf dem Lande der Pastorengarten; aber bevor eine nene Pflanze ihren Weg aus der Stadt dorthin nahm, konnte immerhin einige Zeit vergehen, und bevor der Baner den neuen Gast in seinen eigenen Garten aufnahm, musste er sich auch durch eigene Anschauung von dessen guten Eigenschaften überzeugt haben. Heute, wo es auch Gärtuereien in Dörfern giebt, verbreiten die Gartempflanzen sich sehr viel rascher, und die grosse Übereinstimmung, die unsere Bauerngärten früher zeigten, ${ }^{2}$ ) ist jetzt in der Nähe grösserer Städte und wichtigerer Verkehrsstrassen nicht mehr vorhanden. Zierpflanzen mit prunkenden Blüten haben die alten bescheideneren verdrüngt; auch glaubt der Baner nicht mehr an die Kraft der alten Heilpflanzen und

1) Vollkommen unbeeinflusst durch die Mode waren unsere Gärten in den vorangehenden Jahrhunderten auch nicht: man denke nur an den Tulpenschwindel in der ersten Hälfte des 17. Jahrhunderts. Indessen wurden den Gärten früher in einem Jahrhundert kaum so viele neue Pflanzen zugeführt, wie jetzt in einem Jahrzehnt.

2) A. Kenner, Die Flora der Bauerngärten etc.; Verhandl. d. zool.-bot. Vereins in TVien, Bu. 5, 18555, S. 788; Göper'T, Über Geschichte der Gürten, insbesondere in Sehlesien; 42. Jahresbericht und Al,handlungen der schlesischen Gesellschaft für vaterländische Kultur für das Jahr 1864, Breslau 1865, S. 176-185. 
wirft sie ïber den Zaum. So wirken verschiedene Ursachen, um die Physiognomie des Bauerngartens vollständig umzugestalten.

Da man seit etwa einem Jahrhundert angefangen hat, sich genauer un Heimatland und Verbreitung der einzelnen Pflanzen zu kümmern, so ist es meistens nicht sehr schwierig, diejenigen Pflanzen auszusondern. die während der letzten Jahrhunderte in unsere Gärten eingedrungen sind, und dadurch ein Bild von deren ursprünglichem Aussehen zu gewinnen. Nehmen wir eine solche Aussonderung vor, so ergiebt sich, dass die Gärten in gauz Deutschland, in Deutsch-Österreich, und zwar bis in die entferntesten Gebirgsthäler hinein, in den östlichen und westlichen Grenzländern, in Dänemark, Norwegen und Schweden dieselbe Physiognomie zeigen: sie sind arm an eigentlichen Zierpflanzen, reich an Nutzpflanzen der mannigfaltigsten Art, denn ausser denjenigen Pflanzen, die zur Speise und zur Würze der Speise dienen, begegnen uns auch solche: die als Heilmittel etc. benutzt werden. Betrachten wir die Namen dieser Pflanzen etwas genauer, so erfahren wir, dass sie fast sämtlich entweder direkt, höchstens mit geringfügigen Änderungen, aus dem Lateinischen entnommen siud, oder dass der lateinische Name im Munde des Volkes so lange verändert und umgemodelt worden ist, bis er berquem zu sprechen war. Namen der ersten Art sind Rose aus rosa, Lilie aus lilium, Raute aus rutu, Salbei aus sulcia, etc.; Namen der zweiten Art: Eberrante aus "lrotumu, Liebstöckel ans libisticum, Rettich ans molix etc. Ausnalimen sind Bohne für faba, Dill für anethum etc.

Unsere Bauerngärten liefern uns ein möglichst getreues Bild ron dem Zustande der ersten Gärten, die auf deutschem Boden gegründet wurlen; ihre Entstehung reicht bis ins Ende des achten oder bis in den Anfing des neunten Jahrhunderts zurück. Die Übereinstimmung, welche sie in ihren Pflanzen und diese wieder in ihren Namen zeigen, macht es wahrscheinlich, dass unsere Gartenpflanzen von einem und demselben Mittelpunkt ausgegangen sind und ihre Verbreitung einer und derselben treibunden Kraft verdinken. Der Umstand nun, dass die Pflanzen der Bauerngärten sich fast rollstindig in 70). Kapitel von Karls des Grossen „Capitulare de villis“ 1) wiederfiulen, führte zu der Annahme, dass die Gärten des grossen Kíaisers der Verbreitungsmittelpunkt gewesen seien, und dass das hervorragende Ansehen, welches er genoss, die Ausbreitung dieser Pflanzen begünstigt habe. Für Südwestileutschland oder einen Teil davon mag das richtig sein, aber darüber hinaus wird Karls Einfluss katum gereicht haben, dazu verfiel das Reich zu früh unter seinen Nachfolgern; auch hat man zu bedenken, dass das "Cappitulare de villis" nur zwei Jahre vor srinem Tode erlassen wurde. Wem man aber, wie

1) Das "Capitulare de villis" stammt aus dern Jahre 812 und enthält Verordnungwn ülser die Verwaltung der Hofgüter (Capitulare hiess eine in Kapitel geteilte Verordnung); das 70. Kapitel ist nebst Übersetzung abgedruckt in Anhang I, 3. 
ganz nenerdings von GAREIS ${ }^{1}$ ) gezeigt worden ist, wahrscheinlich Nordfrankreich als das Geltungsgebiet des Capitulare zu betrachten hat, so kann diese Kaiserliche Verordnung aut' den Inhalt unserer Gürten keinen merkbaren Einfluss geübt haben.

Es kann wohl kaum zweifelhaft sein, dass der Verfasser und Schreiber des Capitulare ein Mönch war, und zwar ein Benedictinermönch. GAREIS macht es sogar wahrscheinlich, ${ }^{2}$ ) dass der Benedictinermönch Ansegis, der später (823) Abt ron St. Wandrille (ehemals Fontenella) wurde und der als besonders geschickt in allem, was zur Landwirtschaft gehört, gerühmt wird, von Karl dem Grossen zu dieser Arbeit herangezogen worden sei. Das mag dahingestellt bleiben, jedenfalls wird Karl der Grosse sich einen fähigen und klugen Mann für die Ausführung seines Willens ausgesncht haben. Man hat sich die Frage rorgelegt, ob der Schreiber des Capitulare eine bestimmte Quelle für das Pflanzenrerzeichnis des 70 . Kapitels benutzt habe. Die meisten der daselbst angeführten Pflanzen sind nämlich solche, die seit alten Zeiten bei den Römern in Gebrauch waren und sich daher in den Werken von COLUniELLA und PLINILS verzeichnet finden; das Wort unio, das Zwiebel bedeutet, findet sich bei keinem anderen Schriftsteller: als bei ColumelLA, hat aber Aufnahme in das Capitulare gefunden. Indessen sind die Namen des Capitulare gegenüber denjenigen, die sich bei den römischen Schriftstellern finden, zum Teil stark verändert, z. B. lucterida für lathyris, olisatum für olusatrum. adripre für atriplex; einige altlateinische Namen sind durch neue ersetzt. wie rubia durch warentia, und verschiedene Pflanzen des Capitulare werden bei den Römern überhaupt nicht erwïhnt, jedenfalls nicht dentlich kemntlich gemacht, wie "ostux, tunasita etc. Die Quelle für das Pflanzenverzeichnis des Capitulare dürfen wir also nicht bei einem Schriftsteller des Altertums suchen; sein Inhalt weist auf eine spätere Zeit.

Ein Werk, das bestimmt zu sein scheint, unsere Kenntnisse auf selur vielen Gebieten des IVissens zu erweitern, das „Corpus Glossariorum Latinorum", enthält in seinem 3. Bande ") Schriften, die „Hermeneumata Pseudodositheana', die uns sehr wertvolle Beiträge zur Geschichte unserer Nutzpflanzen liefern, und ausserlem am Schlnsse alte Pflanzenglossare, die sich als ein unschätzbares Hïlfsmittel zur Deutung spätlateinischer Pflanzennamen erweisen. Die „Hermeneumata“, von ilen Lateinern

1) CARL Gareis, Bemerkungen zu Kaiser Karls des Grossen Capitulare de villis in "Germanistische Abhandlungen zum LXX. Geburtstage Konrad ron Haurers, Göttingen 1893", S. 207-247.

2) a. a. O. S. $236-238$.

$\left.{ }^{3}\right)$ Corpus Glossariorum Latinorum, Vol. III, Hermeneumata Pseudodositheana, ed. G. Goetz, Lipsiae 1892, $8^{\circ}$. Nach einer Anzeige dieses Bandes von K(arl) K(rumbacher) in No. 48 des litterarischen Centralblattes vom 26. Nov. 1892 hat man die Entstehung der Hermeneumata Pseudodositheana in die Zeit vom 3. bis 5. Jahrhundert unserer Zeitrechnung zu verlegen. 
Interpretamenta genannt, waren praktische Hülfsbücher für Schulen, in denen „die beiden Sprachen“, d. h. Lateinisch und Griechisch, gelehrt wurden. Sie enthalten zu dem Ende teils Gespräche, teils systematische Verzeichnisse derjenigen Wörter, die im wissenschaftlichen und praktischen Trrkehr notwendig waren. Für mseren Zweck sind von diesen Verzeichnissen namentlich diejenigen von Wichtigkeit, die Blumen und Gemuise enthalten, ${ }^{1}$ ) ausserdem diejenigen über Bäume, Landwirtschaft und Feldfrüchte (dr leguminibus.). Da uns diese Hermeneumata durch die Klöster erhalten worden sind, und da in den Klöstern ganz ähnliche Schriften in lateinischer und deutscher Sprache verfasst wurden, die nur den abweichenden Namen Sumnurium oder Abecedurius: ${ }^{2}$ ) führten, so dürfen wir annehmen, dass die Hermeneumata als Lehrbicher Eingang in die Klosterschulen fanden, aber wir dürfen auch annehmen, dass die in ihmen aufgefiihrten Gartenpflanzen im Klostergarten Platz und Pflege fauden: sind es doch dieselben Pflanzen, denen wir bei Columbla und PLIxIts als Bürgern römischer Gärten begegnen, dieselben, die wir noch jetzt in unseren Gärten ziehen. Entstellungen haben die Namen in den Pflanzenverzeichnissen der Hermeneumati auch erfahren, namentlich die griechischen, und diese sind im Laufe der Zeit, wie die alten Pflanzenglossare des Corpus Glossariorum Latinorum beweisen, erheblich grösser geworden, decken sich auch zum Teil mit denen der Namen im Capitulare. Hat also der Mönch, der das Pflanzenverzeichnis des Capitulare zusammenstellte, eine schriftliche Quelle benutzt, so kïnnte diese eines der Hermeneumata oder auch ein ïlteres Pflanzenglossar gewesen sein; wahrscheinlicher ist es aber, dass er dasjenige aus dem Gedächtnis niederschriel, was er in seinem Heimatkloster gelernt und gesehen hatte. vielleicht auch selbst hatte bauen helfen. Wenn wir aber in seinem Verzeichnisse Pflanzen antreffen, die bei den Römern im Altertum nicht vorkommen, so hat das seinen Grund darin, dass die Mönche im Verkehr mit den Nachbarn des Klosters nicht nur Kenntnisse austeilten. sondern auch aufnahmen.

Wir besitzen ein sehr merkwürdiges Dokument aus dem 9. Jahrhundert, einen Bauriss des Kloster's St. Gallen,") der von einem Benedictinermönch herrührt; dieser Bauriss ist zwar niemals vollständig zur

1) Ein Verzeichnis von Blumen, sowie die drei ältesten Verzeichnisse von Gemüsen sind mitgeteilt in Anhang $\mathrm{I}, 1$.

2) HoFmand vox FALlERsLeben hat ein von seinem Verfasser selbst summarium genanntes Glossar in seinen Althochdeutschen Glossen, Breslau 1826, $4^{\circ}$, S. 1-19, unter dem Titel "Glossae Trevirenses" herausgegeben, einen Abecedarius in seinen "Sumerlaten", Wien 1834, 8 ", S. 25-43.

$\left.{ }^{3}\right)$ Bauriss des Klosters St. Gallen aus dem Jahr 820, herausgegeben und erläutert von Ferdinand Keller. Zürich $1844,4^{\circ}$ (mit 1 lithogr. Tafel), - DIERal:Ek, Üher die Gartenanlagen im St. Gallisehen Klosterplan vom Jahre 830 (mit einer Tafel); Bericht, über die Thätigkeit der St. (iallischen naturw. Gesellschaft wälırend des Vereinsjahres 1872-73, St. Gallen 1874, S. 434-446. 
Ausführung gelangt, er zeigt uns aber, wie die Benedictiner selbst sich ein begütertes Kloster vorstellten. Ausser den zahlreichen Gebäuden für Bewohner und Bedienstete des Klosters ist auch neben der Wohnung der Aerzte ein Gärtchen mit 16 verschiedenen Heilpflanzen, und neben der Wohnung des Gürtners ein Gemüsegarten mit 18 Arten von Gemüsen angegeben, und zwar sind die Namen der betreffenden Pflanzen in die Beete der Gürten hineingeschrieben. Zwischen den Gräbern des Friedhofes befinden sich arabeskenartige Zeichnungen, neben die der Name eines Baumes geschrieben ist; im ganzen werden 15 Obstbäume genannt. ${ }^{1}$ ) Die Pflanzemmamen scheint der Verfertiger des Baurisses aus dem Gedächtnis niedergeschrieben zu haben, denn einmal sind Heilund Gemüsepflanzen nicht strenge auseinandergehalten, und zweitens fehlen manche sehr viel benutzte Pflanzen, wie Eberraute, Bohnen ( $f a b a$ ) und Gurken; das Bohnenkraut kommt als Heil- und als Gemüsepflanze ror. und der Mohn wird unter zwei verschiedenen Namen, also zweimal aufgeführt. Dem Baumeister lag eben daran, den leeren Platz der Beete etwas auszufüllen, da wird er eine sehr sorgfältige systematische Sonderung nicht vorgenommen haben. Den Inhalt eines grösseren Klostergartens dürfen wir uns zweifellos reicher vorstellen, als er auf dem Bauriss angegeben ist; immerhin bestïtigt aber dieser Entwurf dasjenige, was wir oben über die Klostergärten gesagt haben.

Wie es in den Gärten Karls des Grossen aussah, wissen wir aus zwei Garteninventaren, die in einem aus dem Jahre 812 stammenden Dokumente, „Beneficiorum fiscorumque regalium describendorum formulae". $\left.{ }^{2}\right)$ mitgeteilt sind. Danach befanden sich in dem Garten von Asnitpium 20 Arten Blumen und Gemüse, sowie 8 Arten von Obstbäumen, in dem ron Treola ${ }^{3}$ ) 27 Blumen- und Gemüse- und 10 Obstarten. Der Vergleich dieser Gürten mit den reichhaltigeren Klostergärten kann Karl den Grossen veranlasst haben. seinem Capitulare de Villis, das zeitlich den „Beneficiorum fiscorumque regalium describendorum formulae" folgt, ${ }^{+}$) das 70 . Kapitel über die Gartenpflanzen, die er gebaut wissen wollte, anzuhängen. In diesem Kapitel, das keineswegs alle in den Klostergärten gebauten Pflanzen enthielt, werden 73 Kräuter und 16 Arten von Bäumen aufgeführt; es fehlen darin aber zwei in deu Inventaren genannte Heilpflanzen, nämlich Betonika (vittonirt. Invent. I, 20, II, 16) und Odermennig (acrimonia Invent. II, 17).

1) Eine Deutung der Pflanzennamen ist Anhang I, 4 versucht.

2) Dies Dokument hiess früher kurz „Breviarium“ und stellt Formulare dar, nach denen die Beamten des Kaisers ïber die Krongüter zu berichten hatten; abgedruckt ist es bei PERT\%, Monumenta Germaniae etc. Bd. 3, Hannover 1835, S. 17ó it - Die beiden Garteninventare finden sich in unserem Anhang I, 2.

3) Über die Lage von Asnapium und Treola ist nichts bekannt.

4) M. Guerard, Explication du Capitulaire de Villis, in Mémoires de l'Institut Impérial de France etc., tome 21, 1, Paris 185̌7, S. 167. 
Niach dem Gesagten haben wir unsere Bauerngärten als mehr oder minder rollst:̈ndige Wiederholungen oder Nachbildungen der ehemaligen Klostergärten zu betrachten. Die Ausbreitung des Christentums aber hat es bewirkt, dass die Bauerngärten bis nach Nordeuropa hinauf eine so reitgehende Übereinstimmung zeigen. Denn wenn die Mönche auszogen, um ein neues Kíloster zu grïnden, so nahmen sie in den neuen Flostergarten die Pflanzen des alten mit hinüber und verteilten sie von da aus weiter. Einen direkten Einfluss auf den Inhalt unserer Bauerngürten kömmen wir also Karl dem Grossen nicht zugestehen, wohl aber einen inclirekten, insoferm er die Ausbreitung des Christentums mit allen ihm zu Gebote stehenden Mitteln förderte.

Ursprünglich wurde die folgende Arbeit unternommen, um womöglich die zweifelhaften Namen des Capitulare sicherer zu deuten. Die in diesem Aktenstuick genannten Pflanzen stellen immerhin die Mehrzahl der ron uns noch heute gebauten Obst- und Gemüsearten dar. Da es sich indessen sehr bald herausstellte, dass die Deutung der einzelnen Namen un so mehr an Sicherheit gewinnen musste, je mehr Pflanzen berücksichtigt und auf ihre alten Namen hin untersucht wurden, so wurde das Untersuchungsgebiet wesentlich erweitert und auf die Nutzpflanzen der alten Welt, soweit sie für Deutschland in Betracht kommen, ausgedehnt.

Für Untersuchungen der vorliegenden Art giebt es eine grosse Zahl ron Hülfsmitteln, und unter diesen finden sich sorrohl ganz neu entstandene, als auch alte, offenbar übersehene. Es wird nötig sein, etwas eingehender bei sämtlichen zu verweilen. Wir bringen sie in folgende Abteilungen:

1) Frühere Deutungsversuche.

2) Die botanischen, medicolotanischen und landwirtschaftlichen Schriften des Altertums. Antike Wandgemälde.

3) Die Pflanzenglossare.

4) Botanische Schriften des deutschen Mittelalters.

5) Die Kräuterbücher des 16. Jahrhunderts.

(j) Die pflanzlichen Arzneimittelnamen der alten Apotheken und Pharmakopöen.

7) Die volkstümlichen Pflanzennumen im heutigen Griechenland und Italien.

8) Schriften, die sich mit der Geschichte der Nutzpflanzen beschäftigen.

9) Endlich gieht es noch ein Hülfsmittel: eine sorgfältige Untersuchung des Bestandes an Nut\%- und Zierpflanzen in alten Gärten und in Reschreibungen früherer Gürten. 


\section{Frühere Deutungsversuche.}

Eine vollständige Aufzählung der verschiedenen Abdrücke des Capitulare und der darauf bezüglichen Schriften bis zum Jahre 1855 findet sich bei ERNST MEYER, Geschichte der Botanik, Bd. 3, 1856. S. 398-401. Hier sind nur diejenigen Arbeiten aufgefülırt, die im Folgenden wirklich benutzt sind.

P. J. BRuxs, Beyträge zu den deutschen Rechten des Mittelalter's etc. Helmstïdt 1799. 8 ${ }^{\circ}$ : darin ist S. 1-42 das ganze Capitulare, begleitet ron kurzen kritischen Anmerkungen, abgedruckt. Besonder's wertvoll sind die von J. FR. A. KNDDERLING herrührenden Ammerkungen (S. 359 his 421), die entschieden zu den gründlichsten und besten Deutungsversuchen gehören.

K. G. Anton, Geschichte der teutschen Landwirthschaft von den ältesten Zeiten bis zum Encle des 15. Jahrhunderts. Theil 1, Görlitz 1799, $8^{\circ}$; enthält \$. $177-243$ cine deutsche Ü̉bersetzung des Capitulare, die von Erlïuterungen begleitet ist; unahlü̈ngig von BRUNS unr IIJNDERLING, aber in den Resultaten meistens mit ihmen übereinstimmend.

KURT SPRENGEL, Geschichte der Botanik, Theil 1. Alteniburg und Leipzig 1817, 8"; das 70 . Kapitel des Capitulare wird in Übersetzung mit kurzen Deutungen unter Anlehnung an BRtss und AxTor auf S. 196, 197 abgedruckt.

F. A. REuss, Walatridi Strabi Hortulus. Wirceburgi 18:34. $8 "$ ". In den "Analecta ad antiquitates florae germanicae". die anf den "Hortulus" folgen, wird S. 69-72 das 70 . Kapitel des Capitulare. begleitet von kurzen Deutungen. abgerlinckt: enthïlt manches eigentiimliche und von seinen Vorgängern abweichende.

A. KERNER, Die Flora der Banerngürten in Deutschland. Ein Beitrag zur Geschichte des Gartenbancs. Terhandlungen des zoologischhotanischen Vereins in Wien. Bcl. 5. 1855, S. 787-826; enthält auf S. 789 einen Abdruck ron Kapitel 70 des Capitulare, und ron S. 791 bis 824 sehr eingehende Deutungen; KERNER geht zurïck auf THE(1phrast, Diostorides, Galex, Cotdurella und Plixids, herïcksichtigt die lateinisch-dentschen Pflanzenglossare und die Krrïnterbücher des 16. Jahrhunderts. Eine sehr wertrolle Arbeit, die sich zugleich durch anregende Darstellung auszeichnet.

ERsst MEIER. Geschichte der Botanik, Bd. 3, Königsberg, 1856. 8": ein Abdruck ron Kapitel 70 des Capitulare (nach PERTZ. MIonumenta Germaniae historica etc., Bd. 3, Hannover 1835, fol., S. 186, 187), findet sich S. 401. 402, darauf bezïgliche Deutungen S. 402-409. Einen so kundigen Deuter, wie MEIER einer war, wird man so leicht nicht wiederfinden. Er hatte die botanischen Schriften der Alten sehr gründlich kennen gelernt, ebenso diejenigen der Deutschen aus dem 10., 12., 13. und 16. Jahrhundert, und hatte selbst ein Pflanzenglossar 
herausgegeben (siehe weiter unten). Da er auch die erschienenen Schriften ïber das Capitulare in ungewöhnlichem Umfange kamnte, so wird er an Kenntnis der einschlägigen Litteratur ron Niemand übertroffen. Es ist ein merkwürdiger Zufall, dass KERNER und MEYER unabhängig ron einander fast gleichzeitig an die Deutung der Pflanzennamen des Capitnlare gingen; begreiflicherweise stimmen sie in sehr viel Punkten miteinander überein. MEYER hat noch das Verdienst, auf die in den ersten Kapiteln des Capitulare genannten Pflanzen besonders hingewiesen zu haben, ebenso auf die beiden Garteninventare im sogenannten „Breviarium " Karls des Grossen. Diese Inventare sind nebst dem "Breviarium" al)gedruckt bei BRUNS S. 55-79 und bei ANTON S. 244-267.

II. GuÉRARD, Explication du Capitulaire de Villis (Mémoires de l'Institut Impérial de France, Académie des Inscriptions et Belles-Lettres, Tome 21,1, Paris 1857, p. 165-309). Diese sehr eingehende und gründliche Abhandlung beschäftigt sich mit dem ganzen Capitulare und berücksichtigt die deutsche Litteratur vollstündig bis BRUNS, ANTON und SPREN(iEL; die Arbeiten von KERNER und MEYER sind dem Verfasser entgangen. Für die Deutung der Pflanzennamen des 70. Kapitels benutzte der Verfasser ein Mauuskript aus dem 9. Jahrlhundert, das dex Kaiserlichen Bibliothek in Paris angehört; dieses Mannskript enthält (in altes lateinisches und griechisch-lateinisches Pflanzenglossar, das in seinem Inhalt vielfach übereinstimmt mit den älteren Glossaren, die neuerding im 3. Bande des Corpus Glossariorum Latinorum, Leipzig 1892, ron G. GOETZ veröffentlicht sind. Durch dieses Hülfsmittel ist der Verfasser im Deuten der Pflanzennamen des Capitulare häufig glïcklicher gewesen als seine Vorgänger. Den Schluss der Arbeit bildet eine französische Übersetzung des ganzen Capitulare.

H. StEINVORTH, Die fränkischen Kaisergärten, die Bauerngärtenı der Niedersachsen und die Fensterflora derselben. Tahreshefte des naturwissenschaftlichen Tereins für das Fürstentum Lüneburg, XI, 1888, 1889. Lüneburg 1890, S. 33-66. Auf Seite 37 ist Kapitel 70 des Capitulare nach PERT\% abgedruckt; daran schliesst sich eine Übersetzung, der ausführliche Erläuterungen folgen.

\section{Dir botanischen, medicobotanischen und landwirtschaftlichen Schriften des Altertums.}

Unter der grossen Zahl von Schriften dieses Gebietes musste eine Auswahl getroffen werden, dem alle zu berücksichtigen ist unmöglich. Ausgeschlossen sind deshalb diejenigen, die nur oder vorwiegend Pflanzennamen geben ohme Beschreibung oder ohne Bemerkungen, aus denen sich auf die Bedleutung der gegehenen Pflanzemnamen schliessen liesse. wie dir Schriften des THEOKRIT, NIKANIEER etc. Benutzt wurden:

THEOPHRASTI ERESI quae supersunt opera etc.; herausgegeben von .J. G. SChNen)ER, Leipzig 1818-1821, 5 Bände 8". Band 1 ('nt- 
hiilt den griechischen Text, Band 2 die berichtigte lateinische Übersetzung des THEODOR GAZA, Band 3 den Commentar zur Geschichte der Pflanzen, Band 4 denjenigen zu den Ursachen der Pflanzen, Band 5 Nachträge, Berichtigungen etc. und einen Index. Benutzt ist im wesentlichen nur die Geschichte der Pflanzen. Der reiche Index dieser Ausgabe und die beigegebene gute lateinische Übersetzung erleichtern dem Nichtphilologen die Benutzung ganz ansserordentlich. Mit grosser Vorsicht ist zu benutzen:

K. SPREX(iEL, Theophrasts Naturgeschichte der Gewächse. Theil 1 Uebersetzung. Theil 2 Erläuterungen. Altona 1822, 8“. Die Übersetzung ist oft ungenau, stellenweise falsch, also ohne Vergleichung mit dem Original garnicht zu gebrauchen; die Erläuterungen enthalten viel nuitzliches.

THEOPHRASTs Geschichte der Pflanzen ist ein ausserordentlich merkwürdiges Buch. Neben vielen Ülıerlieferungen, die von THEOPHRAST zum Teil schou bezweifelt werden, enthält es selbständige Beobachtungen, z. B. über das Kieimen der Samen (8.2), über die Befruchtung der Dittelpalme $(2,8)$ etc. etc. Wem die Geschlechter auf zwei Individuen verteilt sind, wie bei der Dattelpalme, so spricht er von männlichen und weiblichen Pflauzen im heutigen Sinne: ausserdem unterscheidet er PHanzen, die sich, wenn auch nur oberflïchlich, ähnlich sehen, nach ilnrem grösseren oder geringeren Nutzen als männliche und weibliche, wie es bis ins 18. Jahrhundert hinein üblich war. Die Beschreibungen, die er liefert, überraschen uns zuweilen durch die Hervorhebung treffender Ziige; will man ihn verstehen, so muss man allerdings unsere heutige Terminologie heiseite lassen und versuchen sich auf seinen Standpunkt. nenne man ihn nun naiv oder kindlich. zu stellen. Das wird uns modernen Menschen freilich sehr schwer, aber bei Kindern, jungen Mädchen und Frauen, die noch nicht durch eine Unmasse auswendig gelernten Wissens ihre Natürlichkeit verloren laben. kam man älnnliche Tergleiche und Beschreibungen hören. wie man sie hei THEOPHRAST findet.

THEOPHRAST lehte vor mehr als 2200 Jahren (v. 371 .286r. Chr.), ein Schüler des ARIstoteles, dessen Hauptwerk über die Pflanzen uns leider nicht überliefert worden ist, abgesehen ron einigen wenigen Bruchstiicken. Es ist deshalb um so mehr zu bedauern, dass THEOPHRASTS TVerke auch bedeutende Verstiimmelungen erlitten haben. Von vielen Schriftstellem ist er als Quelle benutzt worden, aber schon Plinius rerstand ihn nicht mehr ganz. So kam es, dass der immerhin weniger bedeutende DIOSlioRIDEs ihn schliesslich ganz oder fast ganz verdrängte. In neuerer Zeit jedoch scheint man seine Verdienste mehr anerkennen zu wollen.

PEDANir DIOSKoRldis ANAZARBei de materia medica libri quinque; rec. Cl:RTIUS SPRENGEL, Lipsiae 1829; (Medicorum Graecorum opera (quae exstant, cur. C. G. Kய̈Hx, Vol. 25). Jede Seite trägt unten 
đie lateinische Übersetzung des oben stehenden griechischen Textes. Ein z.weiter Band, der dem genamnten im Jahre 1830 folgte, enthält von demselben Herausgeber in entsprechender Bearbeitung auf S. 1-338 lie übrigen Schriften res DInshorIDES, von S. 339-675 einen Commentar zur "Materia medica“.

Schon Theophrast hatte bei verschiedenen Pflanzen ihre merlicinische Terwendbarkeit angegeben, aber im ganzen doch nur so wenig. dass man seine Geschichte der Pflanzen ein botanisches Werk nennen muss. Bei DIOSKorides ist es gauz anders, denn er ist in erster Linie Mediciner. und das muss man festhalten, um ihn richtig beurteilen zu können. Jedes Kapitel beginnt mit dem Namen der darin behandelten Pflanze, darauf folgen meistens Synonymen; ist die angefiihrte Pflanze bekimnt ( $\pi$ ó rvẃpuos), so fehlt eine Beschreibung, sonst folgt eine solche. Diese Beschreibungen tragen einen ähnlichen Charakter, wio diejenigen des THEOPHRAST, jedıch sind viele von ihnen nach unseren Begriffen bestimmter gehalten, erstrecken sich auch oft über alle Teile der Pflanze: zuweilen werden ähnliche Pflanzen miteinander verglichen.

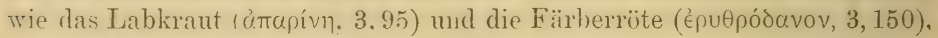
zuwilen auch ein einzclues. für die Bestimmung entscheidendes Kennzeichen angeführt, wie die purpurrote Terminaldolde rer Mohrü̈be,

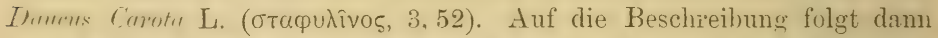
eine Anfzählung der medicinischen Eigenschaften mud eine Anleitung zur Benutzung; bei einzelnen Arzneimitteln, wie beim Opium $(4,65)$. wird nicht nur angegeben, welche andere Substanzen zu ihrer Verfilschung dienen, sondern auch, wie man die verschiedenen Verfälschungen als solche erkennen kann.

Erstamulich ist der Einfluss, den DroskonInes durch seine Materia merlira während einer Zeit von mehr als anderthalh Jahrtansenden auss'iibt hat. Seine Beschreibungen galten fuir so mustergültig, dass (AALEN etwa 100 .Jahre später ${ }^{1}$ ) in seiner Arzneimittellehre sich ein fiir allemal auf DIOSKorides bezieht und selbst keine Beschreibungen siebt. DIoskoriDes blieh die Hauptruelle; ans der spriter die Mönche ihre botanischen Kenntnisse schöpiten. Der grosse lateinische Commentar, den MATTIOL, der Materia medicar widmete (man vergl. weiter unten bei den Kräintroüehern), liess den Rulm des Droskomides neu erstrahlen, mol wem wir uns die Kränterbücher von HLERosymus Bock,

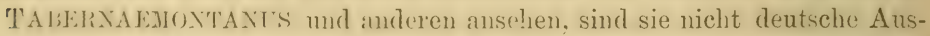
salben der Materia modica, nur zeitgemiiss erweitert und vervollstindigt? und liisst sich nicht anch bei LixNé der Einfluss des DIOSKOrIJEs an sehr vielen Stellen nachweisen?

DIOSKoli[d) Lis war der bedentendste Merlicu-Butaniker des Alter-

1) Droskorides aus Anazarba in Kilikien schrieb etwa um das Jahr $70 \mathrm{n}$. Chr.; GALEx aus Pergamon lebte von $131-200 \mathrm{n}$. Chr. 
tums. Die Verbindung zwischen Medicin und Botanik hat sich von seiner Zeit bis weit in dieses Jahrhundert hinein erhalten, ist aber an den Universitäten nunmehr definitiv aufgegeben. Weil DIOSKORIDEs über die einfachen Heilmittel (medicamenta simplicia) schrieb, so kann man von ihm auch sagen, dass er die Reihe derjenigen Mediciner eröffnet. die später die Simplicisten genannt wurden.

THEOPHRAST unl DIOSKORIDES haben sicher auch die Schriften von Vorgängern und Zeitgenossen benutzt, aber daneben haben sie sehr viel selbst beobachtet und niedergeschrieben. Wir begegnen jedenfalls in der späteren Zeit keinen botanischen Schriften mehr, die in ähnlicher Weise originell wären wie diejenigen dieser beiden M̈̈nner, wohl aber treffen wir Compilationen und Sammelwerke besserer und schlechterer Art. Alle Werke hier aufzuführen, die in der folgenden Untersuchung. benutzt sind, wïrde zu weit führen, zwei Sammelwerke mögen aber noch genannt werden.

ATHENAEI NaUcratitae dipnosophistarum libri XV rec. G. KaIBEL. 3 voll. Lipsiae $1887-90,8^{\circ}$.

Die Abfassung dieses merkwiirdigen Werkes, „lie schmausenden Gelehrten", fällt in den Anfang des dritten Jahrhunderts muscrer Zeitrechnung. Künstler, Dichter und Gelehrte sind hei einem Römer zu Gast geladen und geben, ankuiipfend an die dargereichten Speisen, ihre Gelehrsamkeit zum Besten. Dabei werden Stellen aus etwa 80u Schriftstellem, von denen sehr viele verloren gegangen siml, wörtlich recitiert. Manche dieser Citate sind für unseren Zweck sehr wertroll. - Die oben genannte sehr handliche und mit ausgezeichneten Registern verschne Ausgabe gilt hente als die heste; man muss es aber herlanern, dass dem griechischen Texte nicht eine liteinische Übersetzung hinzugefiigt ist, denn es wird nicht lange dauern, his der Inhalt des griechischen Textes nicht blos den Naturforschern ganz und gar verborgen sein wird. Anf den naturwissenschaftlichen Inhalt hat der Herausgeher keine Rïcksicht genommen.

C. PLINI SECUNDI naturalis historiae libri XXXVII; rec. J. SILLIG. Hamburgi et Gothas, \& voll. 1851-1858, 8. Fïr unseren Zweck kommen nur in Betracht Band 2 bis 4 , die die botanischen Bücher 12-27 enthalten, und die Registerbände 7 und 8.

Die Silligsche Ausgahe empfiehlt sich zur Benutzung durch ihr ausgezeichnetes Register. - Es ist schwierig, PLIxIUs ganz gerecht zu werden, denn seine Naturgeschichte der. Pflanzen ist ein vielfach kritiklos zusammengerrïrfeltes Durcheinander, so dass eine und dieselbe Pflanze oft an zwei verschiedenen Stellen unter zwei verschiedenen Namen vorkommt. Oft ist seine Quelle leicht zu erkennen, oft ist sie überhaupt unbekannt. Manche seiner Darstellungen tragen den Charakter des wirklich Beobachteten: vielleicht sind sie dies in der That, oder sie sind Berichte von Sklaven, die als Gürtner Dienste thaten. Aber mag man 
seiner Naturgeschichte der Pflanzen auch noch so viele Mängel nachsagen. sie ist ein Buch ron ausserordentlichem Einfluss gewesen, ein Buch, das ebensoriel benutzt wurde wie die Materia medica des DioskoRIDES. Dafür lassen sich verschiedene Gründe angeben. Einmal war seine Naturgeschichte der PHanzen ebenso wie die Materia medica des DIOSKORIDES eine praktische Botanik, die sich um den Nutzen der Gewächse, namentlich um den medicinischen, kümmerte; ferner zählte sie weit mehr PHanzen auf, als wir bei DioskoRIDEs finden, und endlich war sie lateinisch geschrieben, war also während des Mittelalters allen Gebildeten oder Schriftkundigen verständlich. So kommt es. dass die Pflanzennamen des PLixius in die Ptlanzenglossare und in den Gebrauch der Apotheker iibergingen; in den Pharmacopöen fand man sie noch vor wenig Jahrzehnten. Will man also lateinische Pflanzennamen des Mittelalter's deuten, so ist es sehr wohl angehracht, bis auf PLINIUS zurückzugehen.

Von den landwirtschaftlichen Schriftstellern der Römer, CATO, VARro. Columella und Palladius, ist Columella der weitans bedeutendste. Er ist ein sorgfältiger Beobachter und Darsteller; eigentliche PHanzenbeschreibungen liefert er nicht, aber oft führt er Bemerkungen an, die es möglich machen, die behandelte PHanze zu bestimmen. Seine Werke finden sich zusammen mit denen von CATU, VARRo und PALLADIUS in

Scriptores rei rusticae veteres latini; cur. J. M. GESSNER. Lipsiae 1735; 2 voll. 4"; eine nene Ausgahe daron hesorgte ERAESTI $1773-74$.

Unter gleichem Titel hat auch J. G. SCHxEIDER die landwirtschaftlichen Schriften der Römer herausgegehen, Leipzig 1793-96, 8": es ist zu bedauern, dass GESsNER und SCHNEUEER in der KapitelEinteilung bei COLUMELLA nicht übereinstimmen.

Hier ist auch der Ort, auf einige Buicher aufmerksam zu machen. die sich die Aufgabe gestellt haben, anch denjenigen, die nicht sellst Lateinisch und Griechisch lesen können, die Bekamischaft mit dem botanischen Wissen der Alten zu vermitteln; dies sind

J. BILLerBeck, Flora classica. Leipzig 1824, $8^{0}$

Der Verfasser stiitzt sich im wesentlichen auf SIBTHORP, SPREN(rEL und LiNk. Manche hier vorgetragenen Ansichten sind veraltet: als Quellemnachweis ist das Buch aber recht gut $\mathrm{zu}$ gebrauchen.

H. O. LENz, Botanik der alten Griechen und Römer, deutsch in Ausziigen aus deren Schriften, nelst Anmerkungen. Gotha 1859, 8".

LEX\% lietet eine sehr vollständige Zusammenstellung der den Alten bekarnten Pflanzen und ihrer ökonomischen Anwendung. Sein Buch lïsst sich deshalh, vortrefflich als Quellemachweis benutzen; es enthelut ms aher keineswegs der Mühe selbst nachzusehen, denn einmal wird man nicht immer so ïhersetzen, wie LEx\% es gethan, und 
zweitens fehlen bei LENZ oft Stücke des Textes, die für die Bestimmung einer Pflanze von entscheidender Wichtigkeit sein kömnen. - Ähnlicher Art, wenn auch keineswegs so vollständig, aber dafür reich an eigenen Beobachtungen, ist

C. FRAAS, Synopsis plantarum florae classicae oder: Ühersichtliche Darstellung der in den klassischen Schriften der Griechen und Römer vorkommenden Pflanzen, nach autoptischer Untersuchung im Florengebiete entworfen und nach Synonymen geordnet. München 1845, 8". Hierher gehört auch noch

B. LANGKA VEL, Botanik der späteren Griechen vom 3. bis 13. Jahrhundert. Berlin 1866. $8^{\circ}$.

\section{Antike Wandgemälde.}

Ein vortreffliches Mittel, um die Deutung der bei COLUMELLA, PLINiUs und auch bei DlOskORIDES vorkommenden PHanzennamen sicherzustellen, würden die antiken Wandgemälde von Pompeji und Rom sein. Sie sind aber nur wenigen zugänglich und verkleinerte Reproduktionen von ihnen scheinen nicht recht verwendbar zu sein. Die Maler dieser Gemälde haben in einzelnen Teilen, nämlich in Blüten und Früchten, die Natur sehr sorgfältig wiedergegeben, aber bei den grünen Blätterı ist das keineswegs immer geschehen, vielmehr begegnen wir hier oft einer gewissen Stilisierung und Schablone. Aber auch davon abgesehen rerlieren die Gemälde bei der Verkleinerung und Reproduktion eine Reihe charakteristischer Züge, so dass sich viele Pflanzen nicht mehr mit Sicherheit erkemnen lassen. Das gilt namentlich von den vieleu verkleinerten Wiedergaben pompejanischer Wandgemälde, deren Massstab ausserordentlich klein ist, weniger aber von den Wandbildern aus der Villa der Livia in Primaporta (Antike Denkmäler. herausgegeben vom Kaiserlich Deutschen Archacologischen Institut, Bd. 1, Berlin 1891, gr. $4^{\circ}$, Taf. 11, 24 und 60). Auf der farbigen Tafel 11 erkennt man leicht Granatapfel, Quitte, Lorbeer, den Mohn und die Goldblume (Chrysenthemem coronarium L., gelb und weiss); wenn aber die rote Blume in der Mitte als Rose gedentet wird (Dr. MIÖLLER, Die Botanik in den Fresken der Villa der Livia. Mittheilungen des Kaiserlich Deutschen Archaeologischen Instituts, Römische Abtheilung Bd. 5, Rom 1890, S. 78 ff.), so sträubt sich unser Gefühl dagegen; inclessen muss man sich sagen, dass nur jemand, der an Ort und Stelle Studien gemacht hat, uiber die Richtigkeit einer solchen Bestimmung ein Urteil hat.

Zuverlässige Nachrichten über die Pflanzen der pompejanischen Wandgemälde und über in Pompeji gefundene Pflanzenreste finden sich in J. F. Schouw, Die Errle, die Pflanzen und der Mensch etc. Aus dem Dänischen von H. ZEISE, und zwar S. 39-45: Die pompejanischen Pflanzen.

Eine Schrift, die allein der Dentung dieser Pflanzen gewidmet ist, ist die folgende: 
O. Costes, Illustrazione delle piante rappresentate nei dipinti pompeiani. Napoli $1879,4^{\circ}$.

Sie enthült eine an sich schätzbare Zusammenstellung; es ist aber sehr fraglich, ob der Verfasser überall Recht hat.

\section{Die Pflanzenglossare.}

Wer sich mit der Deutung älterer Pflanzennamen beschäftigt, der wird seine Zutlucht sicher auch zu den PHanzenglossaren nehmen, die den Sprachgebrauch eines bestimmten Zeitraumes darstellen. Aber diese Glossare haben meist sehr wechsehnde Geschicke erlebt: ursprünglich ron einem Kundigen herrührend, sind sie später durch Abschriften vervielfältigt worden, und da kam es denn sehr darauf an, von welcher Art der Abschreiber war. Am besten war immer derjenige, der möglichst sorgfailtig nachschrieb ohne sich etwas dabei zu denken; einem solchen Abschreiber kann es allerdings passieren, dass er die Wörter der einen Columme gegen die der anderen um etwas rerschiebt; ein derartiger Fehler ist aber in der Regel leicht benerkt und verbessert, und um ihn entdecken zu kömmen ist es jedenfalls besser, die Glossare bei der Herausgabe nicht alphabetisch strenge zu ordnen. Es hat aber offenbar auch Abschreiber gegeben, die ihre eigene Weisheit in die Abschrift mit hineingebracht haben, und diese auszuscheiden wird nicht immer möglich sein. So kommt es, dass die Glossare neben sehr viel Gutem und Vortrefflichem auch oft sehr viel Simnloses und Unbrauchbares enthalten: ihre Benutzung hat deshalb mit viel Sorgfalt zu geschehen.

Von den lateinisch-deutschen Pflanzenglossaren sind eine ganze Anzahl benutzt worden, wie man unten unter den gebrauchten Abkürzungen nachsehen wolle. Die Zusammenstellungen von LORENZ IDEFENBA('H: Glossarium latino-germanicum mediae et infimae aetatis etc. Frankfurt a. M. 1857, 4" , und Novum Glossarium latino-germanicum mediae et infimae aetatis etc., Frankfurt a. MI. 1867, $8^{\circ}$, sind vorzugsweise zur allgemeinen Orientierung benutzt worden; die grosse Zahl ron Pflanzentamen, dic hiei an einzehen Stellen zusammengehïuft ist, macht es in der Regel unmöglich, sich für einen bestimmten von ihnen zu entscheiden. Das grosse "Glossarium mediae et infimae latinitatis" etc. von DI; (ANciE, Paris $1840 \mathrm{ff}$., 4", enthält nur ganz ausseror lentlich wenig Pflanzemnamen, so dass man es ohne den geringsten Schaden ganz unberiicksichtigt lassen kann. Dagegen ist ein neuerdings erschienenes Werk von sanz hervorragender Wichtigkeit für Untersuchungen ïber ältere Pflanzennamen, nämlich das oben S. 3 schon geuannte

Corpus Glossariorum Latinorum, Band 3, Leipzig 1892.

Dieser dritte Band bringt ausser den bereits oben erwähnten Hermeneumata auf seinen letzten Seiten griechisch-lateinische Glossare, die IIrmenemmata medicobotanima retustiora, S. 533-633. Es sind dies mit Ausnahme eines rein merlicinischen Glossars. S. 596-607, lauter 
PHanzenglossare (Tiere und Mineralien kommen nur selten ror), und zwar sind diese ursprünglich griechisch-lateinisch angelegt gewesen; sie sind jedoch alle mit lateinischen Buchstaben geschrieben und mit der Zeit haben sich nicht nur unter die griechischen Namen viele lateinische gemischt, sondern unter die lateinischen auch einige wenige deutsche.') Es dauert eine geraume Zeit, bis man sich in diese Glossare hineingelesen hat. Zuerst steht man ziemlich ratlos daror: die Schreibweise ist sehr schwankend, die Namen kommen in jedem beliebigen Casus vor. häufig im Dativ oder Ablativ, werden nach mehr als einer Deklination abgewandelt und sind seln oft bis zu einem hohen Grade entstellt, namentlich die griechischen. Wer vermutet unter "camuri" trotz des daneben geschriebenen "coliculi" $(555,29 ; 619,56)$ das griechische

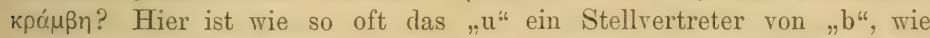
"cambri“ $(537,13)$ berreist, und dieses "cambri“ ist durch Versetzung des "r" entstanden aus "crambi", das nichts anderes ist als das mit

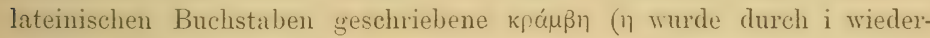
gegeben). Die Glosse „zion.i.semperuinum" erscheint wie ein Ausfluss der frommen Simesart des Glossarenschreibers: indessen ist ,zion “ nur eine gewaltsame Verküizung des griechischen ủeízwov, von dem .,emprerrivum" die getreue Übersetzung ist, und bezeichnet unseren Hauslauch, S'smpervicum tectorm L. Hat man jedoch gelernt sich mit derartigen Schwierigkeiten abzufinden, so erkennt man, welches mächtige Huilfsmittel diese Glossare bieten. Sie iiberliefern uns den Sprachgehrauch der Zeit etwa vom 3. bis zum 9. und 10. Jahrhundert und füllen dadurch eine grosse Liicke in der botanischen Litteratur aus; Srnonyme, die man bis dahin nur aus den „Libri Dynamidiorum* (vergl. MEIEk, Geschichte der Botanik, Bd. 3, S. $495 \mathrm{ff}$.) kannte, kommen in diesen Glossaren, ebenso wie in den eigentlichen Hermeneumata vor.

Im Folgenden sind diese medicobotanischen Glossare als die Pflanzenglossare des "Corpus Glossariorum Latinorum" bezeichnet, wïhrend die eigentlichen Hermeneumata als Hermeneumata aufgeführt werden. Eine Unterscheidung der einzehnen Glossire ist beim Citieren derselben nicht vorgenommen, die Citate sind jedoch nach dem Alter geordnet. Aus dem 9. Jahrhundert stammen die Handschriften der Glosisur Cussinenst's, S. 535-542 und eines Glossars des Codex Parisinus Lat. 11218, S. 631 bis 633 ; aus dem 10. bis 11. Jahrhundert diejenige der Hermeneumutu Senensia, S. 542_-548; aus dem 10. Jahrhundert diejenigen der Hermeneumatu Codicis Vuticani Reginae C'nistinae 1260. Von den unter dem letzten Titel abgedruckten Glossaren ist das erste, S. 549-57y, das reichhaltigste und beginnt folgendermalsen: Incipiunt hermeneumata. derlecem speciebus medicamentorum . haec sunt deanimalibus terrenis. et marinis . herbis . uel seminibus . lignis . uel lapidibus . floribus . nel

1) Hranca vitis alba (591, 31 und sonst); uirgulta .i. uualda ( 579,35 und sonst). 
lacrimis . sucibus . atque metallis . degraeco inlatinum translatis; das zweite, S. 579-586, ist weniger reichhaltig; das dritte, S. 586-596. hat eine sehr auffallende Ähnlichkeit mit den Hermeneumata Bemensin S. $607-616$, die aus dem 11. Jahrhundert stammen, und mit einem Glossar des Codex Vaticanus 4417 aus dem 10. bis 11. Jahrhundert, S. $616-630$; das vierte, S. 596-607 ist rein medicinisch.

Die angeführten Pflanzenglossare zeigen untereinander eine melır oder weniger hervortretende Übereinstimmung. Da sie teils griechische, teils lateinische Pflanzennamen enthalten, so wirl man die Quelle füir sie bei verschiedenen Schriftstellern suchen müssen, und man findet selır bald. dass ausserordentlich viele Namen mit den bei DIOSKORIDEs und PJiNius angeführten übereinstimmen. Von den bei DIOSKORIDES angeführten Synonymen findet man eine ganze Anzahl, ebenso solche Namen, die nur bei PLivius vorkommen, z. B. pullacum Plin. 19, 6, 32, das allerdings entstellt ist, aber eine Zwiebelart bezeichnen soll: palicolon. i.scalonia 573, 15. Im Laufe der Zeiten sind dann in diese Glossare auch Namen eingedrungen, die bei DIOSKORIDES und PLINII's nicht vorkommen, z. B. derretimm oder derretimu, das als Synonym von comelu auftritt $(589,52 ; 610,64$ etc.) und auch in dem von KLEEJAXY herausgegebenen Colmarer Glossar (Decrecium Conele 276) vorkommt.

Das eben genaunte Colmarer Glossar hängt auch noch aus anderen Gründen mit den Glossaren des Corpus Glossariorum Latinorum zusammen: wahrscheinlich wird es mit anderen lateinisch-deutschen Glossaren ähnlich sein, aber eine dahingehende Untersuchung kamn hier füglich unterbleiben.

Hier ist vielleicht der Ort, um zwei medicinische oder medicinischbotanische Wörterlücher anzuführen. von denen das erste aus dem Ende des 13. Jahrhunderts stammt, das zweite aus dem Anfang des 14. Die Zahl der griechischen und arabischen (morgenlündischen) Pflanzennamen war bis ins Ungeheure gewachsen, und viele ron ihnen waren durch Ühersetzen und Abschreiben so entstellt, dass eine Wiederherstellung lerselben, damals wenigstens, unmöglich war. Den Versuch aber, den Sim dieser Namen zu erraten und aus dem überlieferten Sprachgebrauch zu erklären, machten die beiden nachbenannten Lexikographen; eine Deutung durch Zurïckgehen auf die Quellen war ihnen durch ihre mangelhafte Kenntnis der griechischen (nach Meyer IV, 160 auch der arabischen) Sprache unmöglich gemacht. Die gedruckten Ausgaben dieser Wörterbücher stammen aus relativ früherer Zeit und sind durch die grosse Zahl der darin vorkommenden Al,kürzungen sehr schwer lesbar.

SIMONIS IANUENSIS opusculum cui nomen clavis sanationis simplicia merlicinalia Latina greca et arabica ordine Alphabetico mirifice elucidans recognitum ac mendis purgatum : et (quotationibus Plinii maxime: ac aliorum in marginibus ornatum: et quam diligentius ac correctius id fieri potuit Impressum. 
Dieser Titel ist in Form eines Dreiecks mit nach unten gewendeter Spitze angeordnet; die Spitze bildet ein Kreuz. Das Buch zählt 65 numerierte Blätter in Folio. Am Schlusse steht:

Finis Simonis Januensis additis auctoritatibus Plinii locis propriis per Georgium de ferrariis de Uarolengo montisferrati . Artium et medicine doctorem.

Impressum Venetiis per Gregorium de Gregoriis Anno Domini Mcecce . xiiii . die - xxii mensis Maii.

Der Titel des zweiten Werkes lautet:

Opus Pandectarum MatTher Syluatici cum Quotationibus anctoritatum Ply. Gal. et aliorum in locis suis: nec non cum Simone Januense: ac Tabula.

Venetiis per Simonem de.Luere. XII. Januarii M. D. XI. Enthält 198 numerierte Blätter in Folio.

\section{Botanische Schriften des dentschen Mittelalters.}

Wir fassen hier den Begriff „botanisch“ etwas weit, denn wir berücksichtigen auch solche Schriften, in denen sich überhaupt Nachrichten über Pflanzen in grösserer Zahl finden.

IVALAFRIDI STRABT Hortulus auct. F. A. REUSS, Wirceburgi 1834, 8". Der "Hortulus" ist ein Gedicht von 444 Versen (Hexameteru) und 25 Abschnitten, in dem IVALAFridus STRABUs, Abt des Klosters Reichenau, die Pflanzen seines Gartens, 23 an der Zahl, besingt; im Text werden noch 4 Pflanzen erwähnt (ïber die Pflanzen des Hortulus vergl. man Anhang 1,5). Da WALAFRIDUS STRABLS 849 starb, so darf man annehmen, dass die Pflanzen, die er in seinen Garten setzte, solche waren, die auch in den Gärten Karls des Grossen vorkamen. Nach den Überschriften der einzelnen Abschnitte ist das auch der Fall; obgleich eigentliche Beschreibungen ganz fehlen, so werden gelegentlich doch bei den einzelnen Pflanzen so charakteristische Eigentümlichkeiten hervorgehoben, dass man danach eine sichere Bestimmung vornehmen kann. Die kleine Schrift hat deshalb ein nicht geringes botanisches Interesse.

S. HILDEgardis ABbatissaE Subtilitatum Diversarum Naturarum Creaturarum libri IX. Patrologiae cursus completus, series latina prior, acc. J. P. Migne, Tom. 197. Parisiis 1882, coll. 1117-1352.

Die hier genannte Schrift der heiligen HILDEGARD führte in der Strassburger Ausgabe von 1533 den T'itel "Physica“; da sie unter diesem Titel bekannter ist, als unter dem neuen, so ist im Folgenden der alte beibehalten worden; von den Büchern dieser Schrift kommen für uns nur das iiber die Kräuter (Buch 1) und dasjenige über die Bäume (Buch 3) in Betracht.

Die heilige HILDEGARD (geb. 1098, gest. 1179) besass freilich gelehrte Bildung, denn sie schrieb Latein, aber man sieht es diesem Latein 
an, dass ihr das Deutsche geläufiger war: sehr oft wählt sie ein deutsches Wort, um sich deutlicher auszudrïcken. Die „Physica" enthält dadurch ausser deutschen Pflanzennamen auch noch eine grosse Anzahl anderer deutscher Wörter, die wissenschaftlich noch nicht verarbeitet $\mathrm{zu}$ sein scheinen. Bemerkenswert ist es, dass wir kein Werk kennen, welches der "Physica“ zu Grunde gelegen haben kann, denn die heilige HILDEGARD teilt zwar die Arzeneimittel, wie es seit GALEN üblich war, in warme und kalte, daneben auch, obwohl seltener, in trockene und feuchte, aber ausserdem erimert kein Wort und keine Wendung an einen bekannten älteren medicobotanischen Schriftsteller. Sie muss ihre medicinischen und botanischen Kenntnisse durch den Umgang mit Kräutersammlern und älnlichen Leuten gewonnen haben, so dass sie nur mittelbar unter dem Einflusse des Altertums steht. Obgleich die "Physica" ihrem Sinne nach ein medicinisches Werk ist, das die Naturprodukte nur insofern beriicksichtigt, als sie Heilmittel darstellen, und obgleich es an Beschreibungen ron Pflanzen etc. ganz fehlt, so stellt sie democh, namentlich wegen der vielen darin gebrauchten deutschen Namen, die in der Strassburger Ausgabe von 1533 vielfach durch lateinische ersetzt sincl, die erste Naturgeschichte Deutschlands dar. Bei der grossen Wichtigkeit, welche die "Physica“ nicht nur für die Geschichte der deutschen Flora, sondern namentlich auch für die Geschichte des Gartenbaues ${ }^{1}$ ) im 12. Jahrhundert besitzt, schien es geboten, alle in ihr enthaltenen Pflanzennamen einer Deutung zu unterwerfen; das Resultat dieser Untersuchung ist in Anhang II mitgeteilt.

ALBERTI MAGNi ex ordine praedicatorum de Vegetabilibus libri VII, historiae naturalis pars XVIII. Editionem criticam ab ERNESTO MEYERo coeptam absolvit CAROLUS JE8SEN. Berolini 1867, 8

ALBERTUS MAGNus (geb. 1193, gest. 1280) ist nach ARISTOTELES und THEOPHRAST der erste bedeutende botanische Schriftsteller, ein Mann von umfassendem Wissen, der sich zwar auf seine Torgïnger stützte, aber das Überlieferte durch eigene Beobachtungen nach vielen Seiten hin ergünzte und vervollständigte. Sein Werk über die Pflanzen zerfällt in sieben Buicher; von diesen behandeln die ersten fünf die allgemeine Botanik, das sechste die specielle und das siebente die ökonomische Botanik. Seine Bemerkungen über Physiologie und Anatomie der Pflanzen setzen uns an mehr als einer Stelle in Erstamnen, ebenso die vielen sorgfältigen Pflauzenbeschreibungen, die wir um so mehr bewunderu müssen, als es ihm an einer streng systematischen Terminologie fehlte. Er hat sich wirklich in die Betrachtung der Natur vertieft; dass die Beolsachtung der Natur ihm Freude und Genuss ver-

1) In der zweiten Vision des ersten Buches von "Scivias" (Patrologie, Bd. 197, col. 401, B-D) vergleicht die heilige HILDEGARD den Menschen mit einem Garten; tie beschreibung dieses frartens ist aber so allgemein gehalten, dass man daraus keine Schlüsse auf' den Gartenbau damaliger 'Zeit ziehen kann. 
schaffte, sehen wir auch aus den Bemerkungen, die er gelegentlich den Singvögeln widmet $(6,376$ und 467$)$.

Das 6. Buch, De speciebus quarundam plantarum, zerfällt in zwei Traktate. Der erste handelt von den Büumen (de arboribus), der zweite vou den Kräutern (de herbis specialiter secundum ordinem alphabeti); in beiden sind die Pflanzen alphabetisch geordnet. Das 7. Buch, De mutatione plantae ex silvestritate in domesticationem, handelt in einem ersten Traktat (de quatuor, quae faciunt domesticam plantam) über den Einfluss von Boden, Bodenbearbeitung, Pfropfen etc. auf die Nutzpflanzen; im zweiten Traktat (de plantis in speciali, quae usibus hominum domesticantur) wird angegeben, wie Feldfrüchte, Gemüsepflanzen und Obstbänme zu pflanzen und zu behandeln seien; der Kultur des Weinstocks ist das Schlusskapitel gewidmet. In diesem 7. Buch haben wir also eine Darstellung von der Beschaffenheit des Feld- und Gartenbaus im 13. Jahrhundert.

Die von ERNST MEYER begonnene, ron C. JESSEN vollendete neue Ausgabe der Schrift de Vegetabilibus des AlBertus Magnus ist sehr bequem und brauchbar. Den im Texte vorkommenden Pflanzennamen sind Deutungen hinzugefügt; einige von diesen wird man für verfehlt halten dürfen.

KONRAD VON MEGENBERG, Das Buch der Natur, herausgegeben von Franz PFEIFFer. Stuttgart, 1861, $8^{0}$.

Man kann die "Physica" der heiligen HIJUEGARD als die erste Naturgeschichte Deutschlands ansehen; in ihren lateinischen Text ist eine grosse Zahl von deutschen Namen aufgenommen. Die Naturgeschichte des ALBERTUs MIAGNus war ganz und gar lateinisch geschrieben. Die erste deutsche Naturgeschichte in deutscher Sprache ist das oben genannte Buch der Natur von KONRAD VON MEGENBER(i (geb. 1309, gest. 1374), aber auch dieses Buch ist nicht rein naturgeschichtlich, sondern es bringt, namentlich bei den Pflanzen, die medicinischen Wirkungen der Naturkörper zur Sprache.

Nach KONRAD VON MEGENBERGS eigenem Geständnis stützt er sich auf eine lateinische Schrift. Diese heisst „Liber de natura rerum" and ist verfasst von THOJAS CANTIMPRATExsis (so genannt nach der ehemaligen Abtei Cantimpré in der Nïhe von Cambrai, Dép. du Nord, früher Hennegau), einem Schüler des Albertus MAgNus. KONRAD hat seine Vorlage aber sehr frei bearbeitet und mit allerlei Zuthaten versehen; dass er in manchen Stücken mit ALBERTUS MAGNUS übereinstimmt, hat seinen Grund darin, dass Thomas CANTImPRatensis als Schüler von ALBERTUS MAGisus viel von diesem entuommen haben mag. (Im übrigen wolle man die eingehende Einleitung von FRANZ PFEIFFER vergleichen.)

Für unseren Zweck kommen nur das 4. und 5. Kapitel vom Buch der Natur in Betracht; das 4. handelt "von den paumen" und zwar "des 
êrsten ron gemainen paumen, dar nîch von wohlschmeckenden und gar edeln paumen", das 5. "von den kräutern in einer gemain" (im allgemeinen). In beiden Kapiteln ist die Ordnung alphabetisch nach den lateinischen Namen der Gewächse. Diese Zusammenstellung ron lateinischen und deutschen Namen ist besonders wertvoll und erleichtert die Deutung in hohem Grade. Manchmal werden auch kurze aher treffende Beschreibungen geliefert.

\section{Die Kräuterbücher des 16. Jahrhmmlerts.}

Für das 15. Jahrhundert fehlte es an einer besonderen botanischen Schrift, die hätte benutzt werden können; reichlicher dagegen flossen die Quellen für das 16. Jahrhundert.

Zuerst sei der Commentar zum DIOsKoRIDES von PETRUs ANDREAS MATTHIOLus (latinisiert aus Pierandrea Mattioli) erwähnt, der benutzt wurde nach

PETRI ANDREAE MATTHIOLI Medici Caesarei et Ferdinandi Archiducis Austriae, Opera quae extant omnia: Hoc est, Commentarif in VI libros Dioscoridis etc. ed. a CASPARo BAUHixo. Francofurti ex officina Nicolai Bassaei 1598 fol.

Diese schöne Ausgabe ist besonders bequem zu benutzen, weil ron C. BAUHIN eine grosse Zahl von Synonymen hinzugefügt ist. Ein Kräuterbuch von MATTIOLI führt den Titel

Kreutterbuch Desz Hochgelehrten vnnd weitberiihmten Herrn D. PETRI Axdreae MATthiol, Jetzt wiederumb mit vielen schönen newen Figuren, auch nützlichen Artzeneyen, vnd anderen guten Stücken. zum dritten Mal ausz sonderm Fleisz gemehret, vnnd verfertigt, Durch .JoAChinum CaMeRaRium, der löblichen Reichsstatt Nürnberg Medicum. Doct. etc. Frankfurt am Mayn 1600. fol. - Nicht die Seiten, sondern die Blätter sind gezählt; jerles Blatt ist durch die Buchstaben A, B, C und $\mathrm{D}$ in vier Viertel geteilt.

JOACHIJUS CAMERARIUS, Hortus medicus et philosophicus etc. Frankfurt a. Main 1580, kl. 4".

I)erselbe Band enthält die auf dem Titelblatt auch genannte Sylva Hercynia von JoHandes THaL, Arzt in Nordhausen, die erste Flora des Harzes. Cadlerarius geht ziemlich kritisch zu Werke und giebt bei einigen Pflanzen auch die Zeit ihrer Einführung in Deutschland an.

HilRonydus Bock, Kreutterbuch. Das Titelblatt des benutzten Exemplares fehlt. Nach der ersten Vorrede ist die Ausgabe von MELCHIOR SEBIZI's zu Strassburg 1577 besorgt, und zwar nach dem Tode des Verfassers (Bock starb 1554); die zweite Vorrede ist von BOCK selbst und stammt aus dem Jahre 1551. - Die einzehen Bliitter sind gezählt. aber nicht weiter eingeteilt.

SEBIzIUS hat den Text von BOCK ganz unverändert gelassen und seine Zusïtze durch Einschliessen zwischen Stern und Kreuz kenntlich 
gemacht. Bock wurde von seineu lateinisch schreibenden Zeitgenossen TRAGUS genannt und nannte sich selbst so, wenn er lateinisch schrieb. Sein Kräuterbuch ist reich an eigenen Beobachtungen und liest sich angenehm, denn es finden sich nicht wenige witzige und humoristische Bemerkungen eingestreut.

JACOBUs THEODORUS TABERNAEjontanus, Neuw vollkommentlich Kreuterbuch etc.; vermelirte Ausgabe von C. BAUHIN, Frankfurt a. Main 1613, fol. - Enthält 3 Teile; der erste ist für sich paginiert; der zweite und dritte bilden ein Ganzes, das für sich und fortlaufend paginiert ist.

\section{Die pflanzlichen Arzneimittelnamen der alten Apotheken und Pharmakopöen.}

Wenu wir von denjenigen Droguen absehen, die seit dem 16. Jahrhundert in Europa eingeführt sind, so lassen sich die Namen der weitaus meisten Arzneimittel bis zu PLINIUS und DJOSKORIDES zurückverfolgen. Mit bewunderungswürdiger Zähigkeit haben nicht nur Apotheker und Ärzte, sondern auch das grosse Laienpublikum an diesen Namen festgehalten; durch die Kräuterbïcher wurden deutsche Namen eingeführt. und wie sehr diese nebst vielen anderen, aus dem Lateinischen entstellten, ins Publikum gedrungen sind, sieht man aus der folgenden Schrift:

J. HoLFERT, Volksthümliche Arzueimittelnamen. Eine Sammlung der im Volksmunde gebräuchlichen Benennungen der Apothekerwaaren. Unter Berücksichtigung sümtlicher Sprachgebiete Deutschlands zusammengestellt. Berlin 1892, $8^{\circ}$.

Diese Sammlung von Arzueimittelnamen ist hervorgegangen aus der Vergleichung und Verarbeitung ron Verzeichnissen, die der Verfasser seit 1886 aufgestellt und im Verein mit zahlreichen Berufsgenossen vermehrt und ergänzt hat. Jetzt, wo in der deutschen Pharmakopöe die alten Namen durch die modernen botanischen ersetzt werden, war eine Arbeit wie die genannte nötig, um den Verkehr mit dem grossen Publikum aufrecht zu erhalten. Die Sammlung ist offenbar sehr sorgfältig angelegt und lässt sich, wie an vielen Beispielen erprobt wurde, benutzen, um eine ganze Anzahl von alten Pflanzennamen zu deuten. Als ganz besonders nützlich für solche Deutungen hat sich erwiesen

W. L. Peterdanx, Das Pflanzenreich in vollständigen Beschreihungen aller wichtigen Gewächse dargestellt etc. und durch naturgetreue Abbildungen erläutert. Zweite Ausgabe, Leipzig 1847. 2 Bände, gross 8", einer mit Text, der zweite mit 282 Tafeln.

Dieses Buch ist namentlich für den Unterricht von Pharmaceuten geschrieben. Es liefert recht gute Beschreibungen und Abbildungen und führt bei jeder Pflanze die in den Apotheken gebräuchlichen lateinischen Namen an. Da es ein sehr gutes Register besitzt, das auf alle diese Nimen auch Rücksicht nimmt, so ist es für jeden, der nicht speciell 
pharmakologische Kenntuisse besitzt, ein sehr schätzenswerter und zugleich zuverlässiger Ratgeber. Brauchbar ist ferner

T. W. C. MaRTits, Grundriss der Pharmakognosie des PHanzenreichs etc. Erlangen 1832.

Die Arzneimittel sind alphabetisch nach ihrem Hauptnamen geordnet innerhalb der Gruppen Radix, Cortex, Folia, Herba, Flores etc. Auf die Hauptnamen folgen Synonyme in rerschiedenen Sprachen. namentlich lateinische und deutsche. Leider hat das Buch kein Register. man muss also, wenn man es benutzen will, schon ungeführ wissen, was man sucht; zur Controle bereits ermittelter Namen eignet es sich deshall, am besten.

\section{\%. Die volkstiimlichen Pflanzennamen im hentigen Griechenland und Italien.}

Von den alten griechischen und lateinischen Pflanzemnamen sind nicht ganz wenige ins Neugriechische und Italienische übergegangen; sie haben dabei gewisse Änderungen erfahren, aber diese sind durchweg nicht so bedeutend, dass man den ursprünglichen Namen nicht in ihnen erkennen könnte.

SIBTHORP hatte auf seinen Reisen in Griechenland (1785 uncl 1793-95) eine grosse Zahl griechischer Vulgärnamen gesammelt, :n denen FRAAS in seiner Synopsis plantarum florae classicae Kritik iibt, wobei er manche zurückweist oder durch neuere ersetzt. Eine grosse Anzahl neugriechischer Pflanzennamen findet sich in

TH. V. Heldreich', Die Nutzpflanzen Griechenlands. Mit besonderer Berüicksichtigung der neugriechischen und pelasgischen Trulg̈̈irnamen. Athen $1862,8^{\circ}$.

Über die Wichtigkeit der neugriechischen Vulgärnamen für di* Deutung der altgriechischen Pflanzennamen äussert sich V. HELDRELCH in der Einleitung S. 5, 6. Er selbst hat solche Namen mit grosser Sorgfalt gesammelt und sie mit Erfolg für die Deutung der Namen bei THEOPHRAST verwertet. Wo in der später folgenden Darstellung nengriechische Pflanzennamen olme Zusatz angeführt sind, da stammen sie aus dem genannten Buche V. HELDRËTCHS.

Italienische Pflanzennamen sind im Folgenden aus verschiedenen Quellen entuommen, teils aus MATTIOLIS Commentar zum DIOSKOLIJES, teils ans BERTOLONI, F'lora italica, Bononiae 1833 bis 1854 , teils aus o. Conls, Illustrazione delle piante rappresentate nei dipinti pompeiani. Napoli 1879; zur Controle wurde überdies ein italienisches Lexikon benutzt.

Der Vollstïndigkeit wegen sind auch französische Pflanzennamen hinzugefügt; diese sind vorzugsweise ans ALPH. DE CANDOLLE, Der Ursprung der Culturpflanzen, Leipzig 1884, entlehnt. 


\section{Schriften, die sich mit der Geschichte der Nutzpflanzen beschïftigen.}

Hier ist an erster Stelle zu nennen

VICTOR HEHx, Kulturpflanzen und Hausthiere in ihrem Übergang aus Asien nach Griechenland und Italien sowie in das übrige Europa. Historisch-linguistische Skizzen. 5. Aufl. Berlin 1887.

Die Urteile über HEHss „Kulturpflanzen und Hausthiere“ lauten sehr verschieden. Einige sagen, dass dieses Buch für die Naturgeschichte nichts geleistet habe; wer aber so spricht, der hat entweder das Buch nicht gelesen, oder er hat es, trotzdem er es gelesen hat, nicht verstanden. HEHN war kein Naturforscher von Beruf, auch scheint ihm von Naturforschern kein eingehender Rat erteilt worden zu sein. Es haften deshalb an seinem Buche gewisse Mängel, und zwar, soweit es den botanischen Teil angeht, etwa folgende. HEHN hat es ausser Acht gelassen, dass die Ínlturrasse einer Pflanze in ein Gebiet eingeführt werden kounte, wo die wilde Form ihr natiurliches Wohngebiet hatte, z. B. beim Feigenbaum, Lorbeer, Buchsbaum etc.; aber auf diese Verhältnisse ist man wohl erst neuerdings aufmerksam geworden. An einzelnen Stellen macht es sich deutlich und zum Nachteil des Ergebnisses fühlbar, dass HEH. keine genaue Kenntnis der Arten besass, in die die eine oder andere der von ihm behandelten Gattungen zerfällt. So ist ilmm Kürbis ein Begriff, der nicht nur den gewöhnlichen, sondern auch den Flaschenkürbis umfasst, wïhrend diese beiden nach heutiger Auffassung verschiedenen Gattungen angehören. Da HEHs Italien aus eigener Anschaumg kamnte. so musste er auch den Flaschenkürbis kemnen; hätte ex gewusst, dass dieser rom gemeinen Kürbis verschieden war, so hätten seine Untersuchungen mit iem Ergebnis abschliessen müssen, dass den Griechen und Römern nur der Flaschenkürbis bekannt gewesen sein konnte. Endlich scheint bei ihm die Freude am Etymologisieren gelegentlich etwas weit zu gehen.

Dem sei aber wie ihm wolle; wenn ein Buch von dem Umfange wie HeHNis "Kulturpflanzen und Hausthiere“ die 5. Auflage ${ }^{1}$ ) erlebt, so muss doch etwas darin stecken, und in der That finden wir es hei vielen Gebildeten, nicht blos bei Philolıgen von Beruf, und können ron diesen hören, wie oft es ihnen Anregung und Genuss verschafft hat. Die naturwissenschaftliche Bedeutung des Buches liegt wesentlich darin, dass HEHN die Naturforscher auf die geschichtliche Seite ihrer Wissenschaft hingewiesen hat, dass er gezeigt hat, wie das Studium der älteren Litteratur die direkte Naturbeobachtung zu ergänzen imstande ist. Wenn wir gerecht gegen HEHN sein wollen, so müssen wir zugeben, dass sein Buch der Pflanzengeographie der Mittelmeerländer wesentliche Dienste geleistet hat, und begrifien.

1) Die 6. Auflage, besorgt von SCHradir und Exgler, ist im Erscheinen 
el)enso müssen wir ihm danklbar sein für die immense Anzahl sorgfältiger Quellennachweise. Wir sind heute so in Spezialuntersuchungen vertieft. dass uns der Überblick über grössere Gebiete leicht abhanden kommt. Bei der sorgfältigen Bemühung, Arten, Formen, Varietiiten etc. zu unterscheiden und aufzuzïhlen, haben wir die Geschichte der deutschen Flora so ziemlich aus den Augen verloren, und mancher will es nicht einmal glauben, dass die Schriftsteller des Mittelalters orler die Kräuterbücher des 16. Jahrhunderts viel enthalten, was sich für die Pflanzengeographie Deutschlands verwerten lässt. Wie notwendig es ist, ältere Schriften sowie den Inhalt der Archive zu berïcksichtigen, wenn es sich um die Verbreitung der deutschen Waldbäume und der sie begleitendeu Pflanzen handelt, hat E. H. L. KrAUSE zu wiederholten Malen gezeigt: ${ }^{1}$ ) seine Forschungsmethode ist aleer mit derjenigen HEHss identisch.

ALPhoxse DE CANDOLLE, Der Ursprung der Kulturpflanzen. Übersetzt von E. GOEZE. Leipzig 1884.

Ein berühmtes, wie es scheint viel gelesenes, gelegentlich als klassisch bezeichnetes Buch. In der That wird es kaum jemand geben, der das Buch aus der Hand legen könnte ohme Belehrung und Amregung daraus empfangen zu haben. Trotzdem wird man nicht alle Ausspruiche und Ansichten des Verfassers für richtig zu halten branchen. Das hat seinen Grund einmal darin, dass der Verfasser den sprachlichen Forschungsergebnissen von ADOLPHE PICTET (Les origines des peuples indo-européens, Paris 1878) ein viel zu grosses Gewicht beigelegt hat. Wie viel oder wie wenig durch blosse Vergleichung ron Namen herauskommt, hat kürzlich E. H. L. KRAUSE an dem Beispiel ler Birke und Buche gezeigt (Die indogermanischen Namen der Birlie und Buche in ihrer Beziehurg zur Urgeschichte. Globus, Bd. 62, 1892. No. 10 und 11). Ferner hat ALPH. DE CANDOLLE auf die botanischen Schriften der Alten nicht selten zu wenig Rücksicht genommen, wie sich aus der folgenden Darstellung ergeben wird; im übrigen verfügt er aber iiber eine sehr ausgebreitete Litteratur- und Pflanzenkemntnis, so dass man in sehr vielen Fällen seinem Urteile wird beipflichten müssen.

\section{Untersuchung des Bestandes an Nut\%- und Zierpflanzen in alten Gärten.}

Eine Deutung alter Pflanzennamen, oder aber die Bekräftigung einer. Deutung, lässt sich auch dadurch erreichen, dass man die Pflanzen

1) Beitrag zur Kenntniss der Verbreitung der Kiefer in Norddeutschlanil (Englers Bot. Jahrbücher, Bil. 11, Heft 2, 1889, S. 123-133). Die Heide. Beitray zur Geschichte des Pflanzenwuchses in Nordwesteuropa (Englers Bot. Jahrb, Bd. 14, Helt 5, 189:- S. 517--539). Die natiirliche Pflanzendecke Norddeutschlands (Globus. Bd. 61, 1892, No. 6 und. 7). Florenkarte von Norddeutschland für das 12. bis 15. Jahrhmulert (Petermanns Mitteilungen, 1892, Heft 10, S. 231-235; mit Karte, Taf. 18) und vieles andere. 
alter, durch die moderne Kultur wenig beeinflusster Gärten zusammenstellt. Auf diesem Gebiete ist noch wenig geschehen, und doch nähert sich schon die Zeit, wo solche Untersuchungen nicht mehr möglich sein werden, denn der Schwarm neueindringender Pflanzen verdrängt mehr und mehr die alten. Eine Übersicht über diejenigen Pflanzen, die in Necklenburg bis in das 3. Decennium dieses Jahrhunderts gebaut wurden, lieferte ERNST BOLL in seiner Geschichte Mecklenburgs etc., Bd. 2, Neubrandenburg 1856, S. 629, 630. Für die Provinz Schleswig-Holstein veröffentlichte der Verfasser :̈hnliche Zusammenstellungen, sowie zwei ältere Garteninventare. ${ }^{1}$ )

Ein Verzeichnis derjenigen Pflanzen, die in den Gärten der Niedersachsen bis zum Jahre 1830 etwa gebaut wurden, findet sich bei STEINVORTH (vergl. oben S. 8) auf S. 51-53.

Für die Pflanzen der salzburgischen Gärten vergleiche man

L. GLAAB, Über Pflanzen der salzburgischen Banerngärten und Bauerngärten im allgemeinen. Deutsche hotanische Monatsschrift. Jahrg. 10, 1892, S. $155-158$, Jahrg. 11, 1893, S. 38-41.

Eine Tremung zwischen alten und neneingefuihrten Gartenpflanzen ist in diesem Verzeichnisse nicht gemacht.

Über die Gartenpflanzen, welche in der ersten Hälfte des 18. Jahrhunderts in Nitteldeutschland (Umgebung von Regensburg) gebaut wurden, liefert genaue Auskunft

J. W. IVernuans, Phytanthozaiconographia, oder eigentliche Torstellung etlicher Tausend, sowohl einheimischer als auslïndischer, aus allen vier Welttheilen etc. gesammelter Pflanzen, Bäume etc., in Ḱupfer gestochen ron B. Seuter. J. E. Ridinger und J. J. Haid etc. etc. Tier Bände Fol. Regensburg 1737-45.

Dies grossartig angelegte Werk enthält 1025 kolorierte Kuupfertafehn, allerdings von verschiedenem Werte, denn die drei Ǩupferstecher waren in ihren Leistungen sehr ungleich. Neben vielen Apothekerpflanzen und exotischen Gewächsen finden sich auch unsere gewöhnlichen Gartenpflanzen. Will man untersuchen, welche Fortschritte (oder Rückschritte) in den letzten 150 Jahren in der Zucht von Nelken, Tulpen, Camna etc. etc. gemacht worden sind, so findet man in WEINdAsws Phytanthozaiconographia ein vorzügliches Vergleichsmaterial.

Für die Bestimmung der Rassen von Gemüsen und Obstbäumen wurde benutzt

1) Unsere Bauerngärten, Schleswig-Holsteinische Zeitschrift fïr Obst- und Gartenbau, 1891, No. 1, S. 4-7; Nachtrag dazu in No. 3, S. 19; abgedruckt in Heimat, Bd. 1, Kiel 1891, S. 166-173; Die Gärten der Insel Röm, Schl.-Holst. Zeitschrift f. Obst- u. Gartenbau, 1893, No. 1, S. 1-3; Unsere Bauerngärten, II (in Verbindung mit H. Eschenburg), Heimat, Bd. 3, Kiel 1893, Heft 2, S. 36-45. - Zwei ältere Dokumente zur Geschichte des Gartenbaus in Schleswig-Holstein, Schriften des naturw. Ver. f. Schl.-Holst., Bd. 10, Kiel 1893, S. 1-20. 
TH. Rய̈ßPLER, Illustrierte Gemüse- und Obstgärtnerei, Berlin $1879,8^{\circ}$.

In allen Dingen, die sich auf praktischen Obst- und Gemüsebau beziehen, ist RÜJPLERS Buch ein vortrefflicher Ratgeber; die bei deu einzelnen Pflanzen angefügten historischen Bemerkungen sind aber sehr oft ganz falsch.

Damit könnten wir die Liste der vorzugsweise benutzten Bücher schliessen. Aber ein Buch, das in keiner der genannten Rubriken sich zwanglos unterbringen liess, muss noch erwähnt werden, nämlich

Erxst H. F. MEyer, Geschichte der Botanik. Studien. 4 Bände, Königsberg $1854-57$.

Leider ist MEYERS Geschichte der Botanik unvollendet geblieben. denn ein fünfter und sechster Band, die die Geschichte der neueren Zeit enthalten sollten, sind nicht erschienen. Trotzdem haben wir alle Ursache, dem Verfasser dankbar zu sein: jedem, der sich mit älteren botanischen Schriftstellem und deren Werken beschäftigen will, ist sein Buch ein zurerlässiger Ratgeber und Führer, den man un so melı schätzen lernt, je mehr man mit ihm umgeht. 


\section{Verzeichnis der gebrauchten Abkürzmingen.}

Da die folgende Abhandlumg ein öfteres Citieren der angeführten Bücher sowie einer Reihe anderer notwendig macht, so erscheint es zweckmässig, wenn nicht notwendig, sich einiger Abkürzungen zu bedienen. Es ist der Versuch gemacht, diese Abkürzungen möglichst so einzurichten, dass der Titel des betreffenden Buches sich leicht daraus erkennen lässt. In solchen Fällen, wo nur e in Werk eines Terfassers existierte oder benutzt wurde, ist allein der Name des Verfassers, ganz oder abgekürzt, zur Verwendung gelangt; hier wird eine besondere Aufzïhlung wohl nicht nötig sein; einige Beispiele mögen aber angeführt werden.

Athen. = Athenaei Naucratitae dipnosophistae.

Diosk. = Dioskoridis materia medica.

Lenz $=$ H. O. Lenz, Botanik der alten Griechen und Römer.

Matt. comm. = P. A. Matthioli opera omuia: hoc est, commentarii in VI libros Dioskoridis etc.

Matt. Kräutb. = P. A. Matthioli Krentterbuch durch J. Camerarium. Meyer I, II, III, IV = Emrnst H. F. Meyer, Geschichte der Botanik, Bd. 1, 2, 3, 4 .

Plin. = C. Plini Secundi naturalis historia, etc. benutzt:

Für die hänfiger benutzten Glossare sind folgende Abküirzungen

ahd. Gl. = A. H. Hoffmann (v. Fallersleben), Althochdeutsche Glossen, Breslau 1826, $4^{0}$.

CGL III = Corpus Glossariorum Latinorum, Vol. III, ed. Georgius Goetz, Lipsiae 1892.

Colm. Gloss. = M. Kleemann, Ein mitteldeutsches Pflanzenglossar, aus dem 14. Jahrh., in Zeitschrift für deutsche Philologie, Bd. 9, 1878, S. 197-209.

K̈̈nigsb. Gloss. = Ernst Meyer, vergleichende Erklärung eines bisher noch ungedruckten Pflanzenglossars. Zweiter Bericht iiber das naturw. Seminar bei der Universität zu Königsberg. Königsberg 1837, $4^{0}$. 
MIone $=$ Botanisches Glossar aus dem Ende des 13. oder Anfang des 14. Jahrh.; Mone, Anzeiger für die Kunde der teutschen Vorzeit, 4. Jahrg., Karlsruhe 1835, S. 239-250.

Sum. = Hoffmann von Fallersleben, Sumerlaten. Mittelhochdeutsche Glossen etc. WVien $1834,8^{\circ}$.

Aus der Zeitschrift für deutsches Altertum (Zfd A):

Prag. Gl. = Prager Glossen, 11. Jahrh., redigiert von Hoffmann von Fallersleben. Zfd A 3, Leipzig '1843, S. 468-477.

Schl. Gl. = Schlettstälter Glossen, 12. Jahrh., redigiert von Wilh. Wackernagel. Zfd A 5, 1845, S. 318-368.

Tit. = Vocabularius latino-teutonicus, 11. Jahrh., redigiert von Hoffmann von Fallersleben. Zfd A 3, S. 368-381.

Die älteren Schriften sind nach Buch, Kapitel etc. citiert, nur ATHExaEts nach Buch und Seite, das letztere nach der Zählung von CASAl:Bonts. -- Wemn ausser der Seite auch noch eine Zeile citiert werden musste, so wurde das Zeichen für Seite (S.) fortgelassen. 


\section{Unsere Nutzpflanzen.}

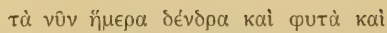

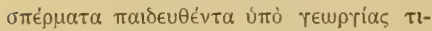

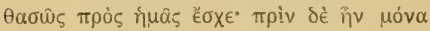

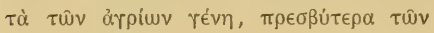

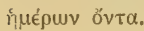

Plat. Tim. p. 77a. 

Vergleichen wir die Abbildungen in den Kräuterbüchern des 16. Jahrhunderts und in WeINHANys Phytanthozaiconographia mit den Pflanzen, die gegenwärtig in unseren Gürten gezogen werden, so sehen wir deutlich, dass der Gartenbau in Deutschland während der letzten 300 Jahre bedeutende Fortschritte gemacht hat. Mit gleicher Geschwindigkeit wird sich aber der Fortschritt auf diesem Gebiete nicht immer bewegt haben.

Über die ersten Anfünge des Gartenbanes in Deutschland wissen wir nur sehr wenig; vor dem 5. Jahrhundert kann davon wohl überhaupt nicht die Rede sein. Die Gärten der Merowingerzeit bestanden aber wahrscheinlich nur aus einem eingehegten Rasenplatz mit einigen Obstbäumen und Bienenstöcken (K. TH. von INaira-STERnegG, Deutsche Wirthschaftsgeschichte bis zum Schluss der Karolingerperiode, Leipzig 1879, S. 172). Erst vom 8. und 9. Jahrhundert an datiert ein regelrechter Gartenbau in Deutschland, hervorgerufen und beeinflusst durch die Benediktinermönche, die eine grosse Anzall römischer Kulturpflanzen über die Alpen brachten.

Im ersten Jahrhundert unserer Zeitrechnung hatte der Gartenbau in Italien auf grosser Höhe gestanden, war aber in der Folgezeit von dieser Höhe allmählich mehr und mehr herabgeglitten. Legen wir uns die Frage vor, ob wir heutigen Tages im Gartenbau ebensoviel oder melır leisten als die Römer vor 2000 Jahren, so dürfen wir uns sagen, dass wir bei vielen Arten eine bedeutend grössere Anzahl von Kulturrassen gezüchtet haben als die Römer kannten, wührend andere Pflanzen heute wie zur Zeit des PLINIUS nur in einer einzigen Form auftreten. Dabei dürfen wir nicht vergessen, dass manche in Deutschland geziichtete Kulturrassen das wärmere italienische Klima nicht vertragen können, während wir durch Treibhäuser und Mistbeete imstande sind, im Süden gezogene Rassen weiter zu ziehen.

Wenn wir uns nun im Folgenden mit der Yerbreitung der Nutzpflanzen von Griechenland und Italien nach Deutschland beschäftigen wollen, so werden wir uns wohl gelegentlich die Frage stellen dürfen, ob eine bestimmte Pflanze schon den Alten bekannt gewesen ist. Wir werden uns aber sorgfältig davor hüten müssen, alles, was wir an besonderen und eigentümlichen Rassen von Nutzplanzen besitzen, bei den Alten wiederfinden zu 
wollen; gerade ein solches Bestreben ist die Ursache für so manchen Irrtum gewesen.

Da unsere Untersuchung sich auf mehr als 200 Arten erstreckt, so kommt es darauf an, die Aufzählung dieser möglichst übersichtlich zu gestalten. Aber welchen Weg man hierzu auch einschlagen mag, stets zeigt sich die Unmöglichkeit, das Zusammengehörige auch wirklich nebeneinander zu stellen, mag man nun systematisch oder alphabetisch oder sonstwie verfahren. $\mathrm{Da}$ aber doch eine Entscheidung getroffen werden musste, so sind Gruppen gebildet, in die sich eine ganze Zahl von Pflanzen leidlich natürlich einreihen lüsst. Führte die Untersuchung aber nebenher auf Pflanzen, die dieser Gruppe nicht eigentlich angehören, so sind sie dennoch hier stehen geblieben, um die Darstellung nicht gewaltsam zu zerreissen; das Aufsuchen einer bestimmten Pflanze muss doch jedesmal oder meistens durch das Register erfolgen. Die gewählten Gruppen sind folgende:

1. Zierpflanzen.

2. Heilpflanzen.

3. Technisch verwertbare Pflanzen.

4. Pflanzen des Küchengartens.

5. Obstbäume.

6. Bemerkungen ïber die Getreidearten.

Am zahlreichsten sind die Pflanzen des Küchengartens vertreten; deshalb sind unter diesen wieder mehrere Unterabteilungen gebildct, zum Teil nach der systematischen Stellung der eingereihten Pflanzen, aber auch in den übrigen Abteilungen sind zuweilen mehrere Pflanzen zu einer kleinen Gruppe vereinigt.

Im Folgenden sind die Namen aus dem Capitulare und dem Breviarium vorangestellt und fett gedruckt; da sich bei diesen nicht immer entscheiden liisst, wie ihr Nominativ ausgesehen haben mag, so sind sie nach KERxEls Vorgange in der Form aufgenommen, in der sie im Capitulare stehen; dam folgt der botanische Name, der in den Fällen, wo Namen aus dem Capitulare etc. fehlen, voransteht. Hieran reihen sich die griechischen Namen bei THEOPHRAST, DIOSKORIDES etc. und die neugriechischen; daran die lateinischen bei CoLUMLLLA, PLINIUs etc., sowie dic italienischen und französischen. Man gewinnt dadurch meistens eine bequeme Übersicht. Die deutschen Namen sind in den Text aufgenommen.

Was die botanischen Namen betrifft, so ist vielfach auf die älteren von Lİ̃É herrührenden zưückgegangen. Einmal werden diese allen denen, die nicht Botmiker von Beruf oder Neigung sind, bequemer sein als diejenigen, die in den letzten Decennien so viele Linnéische Namen verdrängt hathen; zweitens aber sind die Namen LiNvés vielfach Sammelnamen, die mehrere heute abgegrenzte Arten umfassen und deshalb oft den etwas unbestimmten Sinn alter Pflanzennamen besser wiedergeben. 


\section{Zierpflanzen.}

Unter den Gewächsen, welche die Alten in ihren Gärten zogen, hat es wohl kaum ein einziges gegeben, dem sie nicht besondere Heilkräfte oder sonst irgend einen praktischen Nutzen zugeschrieben hätten. Zierpflanzen in unserem Simne waren ihnen im Ganzen fremd. Wie sehr sie es jedoch verstanden, Bäume, Sträucher und blühende Pflanzen jeder Art zum Schmuck des Gartens und des Hauses zu verwenden, das wissen wir aus ihren Schriftstellern und aus antiken Wandgemälden Roms und Pompejis. Die Zahl der in dieser Weise benutzten Pflanzen ist aber immerhin eine verhältnismässig kleine.

\section{Die Lilie.}

Lilium Capitulare 70, 1; Invent. I, 1; II, 6; Lilium candidum L., Lilie, weisse Lilie.

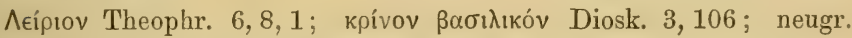
кріvoร, wie alle lilienartigen Gewächse (Fraas).

Candidum lilium Vergil Aen. 6, 709, Colum. 9, 4, 4; album lilium Plin. 21, 5, 11; it. giglio; fr. lis.

Bei den Schriftstellern des Altertums finden wir mehrere Lilien erwähnt. Eine heisst kpivov (krinon); diese hat nach THEOPHRAST

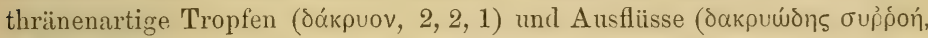
$6,6,8)$, die erhärten und zur Fortpflanzung dienen. Gemeint sind hier offenbar Brutzwiebelchen, die in den Blattachseln vorkommen, und zwar bei der Feuerlilie, Lilium bulbiferum L.; diese selben Brutziviebelchen machen es möglich, die Feuerlilie dadurch zu vermehren, dass man Stiicke des Stengels oder den ganzen Stengel in die Erde legt, wie THEOPHRAST $(2,2,1)$ scheinbar nicht ohne Verwunderung und mit dem Bemerken erzählt, dass die Rose sich ebenso vermehren lasse. Eine andere Lilie wird von den Griechen $\lambda$ eípıov (leirion) genannt; aus dem Gebrauch der Adjectiva, die mit leirion zusammengesetzt sind, gelit hervor, dass hiermit die weisse Lilie, Lilium candidum L., gemeint ist. Diese scheint hauptsächlich kultiviert worden zu sein, wenigstens bei den Römern, die sie lilium allum oder candidum, die weisse Lilie, nennen. PLINIUS schildert den Eindruck, den die weisse Lilie zwischen blühenden Rosen hervorbringt $(21,5,11)$; DIOSKORIDES nennt sie die königliche Lilie.

Die genannten Lilienarten kommen beide in unseren Bauerngärten vor; aber sie sind uicht zur selben Zeit hineingelangt. Denn im Mittelalter ist immer nur von einer einzigen Lilie die Rede, die stets lilium genannt wird, und in der Symbolik der christlichen Kirche als Sinnbild der jungfräulichen Reinheit und der Unschuld eine grosse Bedeutung bat; 
diese kann nach dem, was uns überliefert ist, nur die weisse Lilie sein. WALAFRIDUS STRABUS rühmt in seinem "Hortulus" die blendende Weisse und den Wohlgeruch der Lilie. Auch ALBERTus Magnus (6,370 u. 371) beschreibt unter dem Namen lilium die weisse Lilie sehr genau. Wir werden also annehmen dürfen, dass das lilium im Capitulare eben diese Lilie bedeutet.

Bei KONRad von MEgenberg $(5,47)$ wird die weisse Lilie lilig genannt, im 16. Jahrhundert heisst sie Gilgen, weiss Gilgen. Sie ist eine der häufigsten Blumen unserer Bauerngärten und noch heute dienen ihre mit Öl übergossenen Blumenblätter als Mittel gegen Brandwunden.

Die Feuerlilie wird im 16. Jahrhundert unter dem Namen Goldlilie vielfach genannt. Sie muss um diese Zeit oder etwas frïher in unsere Gürten gelangt sein. Unter den "Lilien auf dem Felde" (Matth.

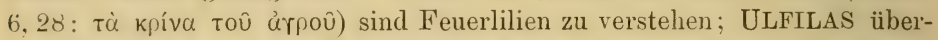

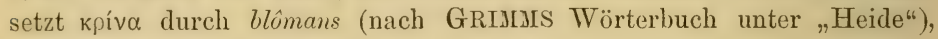
scheint also überhaupt keine Lilie gekannt zu haben.

\section{Rosen.}

Rosas Capitulare 70,2; Rosa gallica L., Zuckerrose, Essigrose; Rosa centifolia L., Centifolie.

'Pódov Homer, Anakreon, Herodot; Theophr. 6, 6, 4-6; 6, 8, 5;

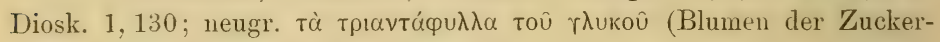

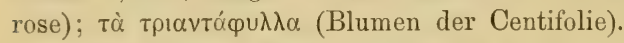

Rosa Varro, Vergil; Colum. 9, 4, 4; 10, 282; de arboribus 30 ; Plin. 21, 4, 10; 21, 18, 73; it. rosa comune, rosa d'orto; rosa di cento foglie, rosa a bottoni; fr. rose.

Die ersten gefüllten Rosen $\left.{ }^{1}\right)$ scheinen bei HERODOT $(8,135)$ erwähnt zu werden. Er erzählt, dass in den Gärten des Midas in Macedonien von selbst Rosen wuchsen, die jede sechzig Blätter hatten und an Wohlgeruch die übrigen übertrafen.

THEOPHRAS'T unterscheidet fünfblïttrige Rosen, zwölf- und zwanzig-

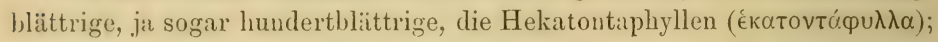
die letzteren wuchsen um Philippi, wohin man sie vom Pangïusgebirge verpflinzt hatte. Die fünfblätrigen Rosen dürfen wir wohl der Hauptsache nach als wilde Rosen oder Heckenrosen deuten, von denen Rosu sempercirens L. im heutigen Griechenland und im Orient die häufigste ist. Die Rosen mit mehr als fünf Blättern, nach unserem Ausdruck gefüllte Rosen, werden wir aber vornehmlich in den Gürten zu suchen haben.

1) Den alten Lgyptern war die Rose nicht bekannt, auch nicht den alten Hebräcrn; wo in den ailteren Teilen des alten Testaments (Prophet Hosea, im Hohen Liede) in Luthers Übersetzung das Wort "Rose" vorkommt, da ist es durch Feuerlilie zu ersetzen (HEHN, S. 202). 
DIOSTORIDES berichtet über die Rosen sehr wenig; bei COLUMELLA finden wir jedoch rote und gelbliche Rosen erwähnt (9,4,4 puniceae rosae luteolaeque; 10, 287 rosa Sarrano clarior ostro, schimmernder als Sarranischer Purpur). PLINIUS folgt $(21,4,10)$ der Hauptsache nach dem THEOPHRAST; die Rose, die auf dem Pangäusgebirge wächst, hat Zilhlreiche und kleine Blätter, wird aber dadurch veredelt, dass die Anwolner sie in die Gärten pflanzen, zeichnet sich indessen nicht durch besonderen Geruch aus. Diese Rose wird nach ilın centifolia genannt und findet sich auch in Campanien.

In den Hermeneumata des CGL III kommt das Wort centifolium zrveimal vor, einmal in den Monacensia unter den Blumen, und zweitens in den Einsidlensia unter den Gemüsen; ${ }^{1}$ ) ob wir es hier in beiden Füllen mit der Rose zu thun haben, ist doch wohl zweifelhaft, es müsste denn schon im zweiten Falle an eine Benutzung der Rose zu Konfekt,

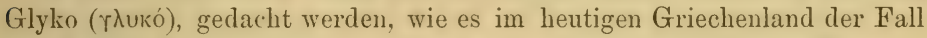
ist. Später ündert nämlich centifolium seine Bedeutung. In den Pflanzenglossaren des CGL III bedeuten centifolium und millefolium die, offenbar gefüllte, Blüte des Granatapfels, ebenso wie myriopluyllum in den „Libri Dynamidiorum“. $\left.{ }^{2}\right)$ Dieser eigentümliche Sprachgebrauch ist über das 11. Jahrhundert, wie es scheint, nicht hinausgegangen und vollständig in Vergessenheit geraten. Gefüllte Granatblüten erwähnt übrigens schon THEOPHRAST $1,13,5$.

In der Zeit uach Karl dem Grossen sind die Angaben über Rosen zunïchst sparsam, werden aber allmählich häufiger. WVALAFRIDUS STRABUS besingt die Gartenrose im allgemeinen. Die heilige HILDEGARD führt die Rose (rosa) unter den Kräutern auf $(1,22)$ und rühmt sie als Heilmittel; unter den Bäumen nennt sie die Heckenrose, luyffa $(3,52)$, mit lateinischem Namen tribulus $(3,63)$, die in den lateinisch-deutschen Glossaren licefeltra, lieffaldra heisst. Sehr viel eingehendere Berücksichtigung findet die Rose bei ALBERTus MAGNus. Unter dem Namen beclegar ${ }^{3}$ ) beschreibt er $(6,42)$ die Wein- oder Apfelrose (Rosa mubiginosa L.), die zu dem Geschlecht (genus) der Dornsträucher (spinae) gehört; in ihren Blättern, die namentlich im Frühjahr einen Weingeruch ausströmen, gleicht sie der Gartenrose (rosarius), ebenso in den Blumen, nur sind diese kleiner. Ferner errvähnt er $(6,43)$ die Heckenrose (Rosa canina L.), die auch zu den spince gehört und tribulus genannt wird; ihre Blume ist grösser als die der WVeinrose und wird wilde Rose (rosa silvestris) genannt, obgleich sie in Wahrheit nicht von der Natur der

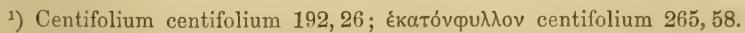

2) Balaostium . idest flores granate 536,45; balaostium idest centufolia 536,53; balistion idest milfolius 587,61; 608,48; die Blume des wilden Granatapfels hiess

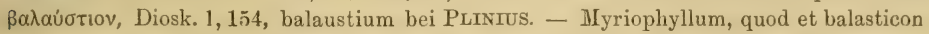
seu centifolium (Dynamidiorum libri duo, cur. A. Maï, S. 443; nach Meyer III, S. 498).

${ }^{3}$ ) Das Wort bedegar stammt wahrscheinlich aus dem Arabischen. 
Rose ist (sed non est vere de natura rosae). Die eigentliche Rose (ro: hat sehr viele Blumenblätter, oft mehr als 50 oder 60 (6, 212 u. 213): besonders gross wird der Stamm der weissen Rose (Rosa alba L.), der armdick werden kann $(6,212)$. Rote Gartenrosen werden 6, 213 erwähnt, daneben eine wilde Rose, die nach der gegebenen Beschreibung Rosa arvensis Hudson ist. Mit ganz besonderer Sorgfalt beschreibt ALBERTUS MAGGUS die Kelchblätter der Rose $(6,214)$. Bei KONRAD VON MEGENBERG finden wir bedegar wieder $(4 \mathrm{~A}, 8)$, der auf deutsch liagdorn oder weithagen genaunt wird und dessen Blätter und Früchte kleiner sind als diejenigen des rôsendorns oder velttorns (Rosa canina L.). Die Gartenrose wird rosarius und rôsenpaum genannt (4 A, 44), ihre Blumen rosa und rôs, und von diesen sind die frisch aufgeblühten starkroten (zemâl rôten) besser als die bleichen; aus Rosenblüttern wird gemacht: rôsenhonig (mel rosaceum), zukkerrôsât, rôsensyrop, rôsenöl, rôsenwazzer.

Im Vorhergehenden haben wir für eine Anzahl wildwachsender Rosen die botanischen Namen angeführt, von den Gartenrosen ist aber nur eine einzige mit Namen belegt worden, nämlich die weisse Rose (Rosa alba L.). Zu welcher Art oder zu welchen Arten mögen die übrigen gehören? Die Beantwortung wird dadurch erschwert, dass die in Betracht kommenden Rosenarten nicht nur stark variieren, sondern auch zu Bastardbildungen sehr geneigt sind, und ferner dadurch, dass gewisse Rosennamen, wie Centifolie, von verschiedenen Schriftstellern offenbar in sehr verschiedenem Sinne gebraucht werden. Nach W. O. FOCKE, ${ }^{1}$ ) dem wir uns in allen wesentlichen Punkten anschliessen, ist die Zuckeroder Essigrose, Rosa gallica L., die wichtigste Stammart unserer vorzüglichsten Garten- oder Edelrosen. In der That bietet sie eine grosse Anzahl von Formen dar, ist teils niedrig, teils stark strauchig und hoch, hat mehr oder weniger gefüllte, dunkelrote, hellrote, gescheckte oder fast weissliche Blumen; ausserdem variieren die Blumenblätter auch noch in der Grösse. Die Zuckerrose wächst wild in Südeuropa und Kleinasien; im heutigen Griechenland wird sie häufig kultiviert und ans ihren Blumenblïttern wird ein sehr beliebtes Konfekt oder Glyko ( (ruкó) bereitet. Die Centifolie ist vielleicht eine Varietät der Zuckerrose, mit grösserer Wahrscheinlichkeit aber ein Bastard derselben, da sie in Tracht, in Bau und Farbe der Blume recht erheblich von der Zuckerrose abweicht. In den Krüuterbiichern des 16. Jahrhunderts und selbst in Wernaranns Phytanthozaiconographie ist keine Rose abgebildet, die auch nur entfernt derjenigen Centifolie gliche, die früher in unseren Bauerngärten gebaut wurde. Diese Centifolie, mit ihren nickenden, zart rosenfarbenen Blumen, die sich eigentlich niemals vollständig öffneten, scheint ein ziemlich spätes Produkt der Rosenzucht zu sein. Die weisse Rose

1) W. O. Focke, Rosaceae, in A. Engler und K. Prantl, Die natürlichen Pflanzenfamilien, Teil 3, Abteilung 3, Leipzig 1888. - Über die Edelrosen vergl. $\operatorname{man}$ S. $47 \mathrm{ff}$. 
hält man für einen Bastard zwischen der Zuckerrose und der Heckenrose, Rosa canina $\mathrm{L}$; sie ist noch niemals wildwachsend gefunden.

Wenn wir uns nun die Frage vorlegen, welche Rose bei den Schriftstellern des Altertums gemeint sein kann, so werden wir wohl an die Zuckerrose (Rosa gallica L.) mit ihren Varietäten denken müssen. Die sechzigblättrige Rose HERODOTS braucht nichts anderes zu sein, denn die gefüllten Rassen der Zuckerrose duften zum Teil stark, jedenfalls stärker als die wilden Rosen. Auch die roten Rosen COLUnELLAS werden kaum etwas anderes sein; wenn er ausserdem eine gelbliche (luteola) Rose anführt, so deutet dits vielleicht darauf, dass die Römer schon die in Kleinasien bis Afghanistan vorkommende gelbe Rose, Rosa lutea Miller, kultiviert haben. Die im Capitulare genannte Rose werden wir aber auch wohl als die Zuckerrose deuten müssen, die durch die folgenden Jahrhunderte bis in die Gegenwart hinein eine häufig kultivierte Gartenpflanze war und jetzt ebenso wie die Centifolie den Remontanten oder Hybridrosen weichen muss.

Im 16. Jahrhundert werden schon eine grosse Zahl von Rosen kultiviert. So finden wir bei TABERNAEIIONTANus (2, S. 808 ff.) die weisse Rose, die Zuckerrose, Provinzrosen, die der Zuckerrose nahe stehen, Muskatrosen (Rosa moschata Miller), die Pimpernellrose oder Dünenrose (Rosa pimpinellifolia L.), gelbe Roseu und eine unbewehrte, die vielleicht die Zimmtrose (Rosa cinnamomea L.) ist, oder aber eine Monatsrose.

\section{Narcissen.}

Die Blume vájкıббos (narkissos), die vou THeophrsat 6, 6, 9 erwähnt wird, muss wegen ihrer späten Blütezeit Narcissus serotinus L, die späte Narcisse, sein. Da sie bei uns nicht gebaut wird, so kommt sie für uns nicht in Betracht, ebensowenig wie die Tazette, Narcissus Tazetta L., die wohl in Töpfen, aber sehr selten im freien Lande gezogen wird. Die Alten verstanden unter dem Namen Narcissus ebenso wie wir mehrere Arten, von denen für uns namentlich die beiden folgenden in Betracht kommen.

Narcissus poeticus L., weisse Narcisse, Pfingstlilie. Diese meint DIOSKORIDES 4,158 , wenn er vom vápкıббos sagt, dass seine Blume weiss sei und in der Mitte eine safrangelbe, bei einigen auch purpurfarbige Höhlung (коî̀v) habe. Auch gehört hierher die zweite Art des unreissus bei PLINIUS $(21,5,12)$ mit weisser Blume und purpurnem Kelch.

Narcissus Pseudonarcissus L., gelbe Narcisse, Osterlilie, wird bei den Alten nicht deutlich erwähnt, fehlt in Griechenland ganz, kommt in Italien stellenweise häufig vor, und findet sich wie die vorhergehende auf pompejanischen Wandgemälden (COMES, S. 42 und 43). Beide heissen bei den Italienern giracapo und narcisso.

In den Pflauzenglossaren kommt das Wort narcissus selten vor; es 
wird durch $Z$ wiebel (bulbus), Waldlilie, wilde Zwiebel etc. ${ }^{1}$ ) erklärt, so dass man zweifelhaft werden kann, ob von Narcissen die Rede ist. ALBERTUS MLANUS spricht $(6,394)$ ron narcissus als einem Kraut, das in Blättern dem Porree ein wenig ähnlich sei; er könnte also sehr wolıl eine echte Narcisse meinen. Bei den übrigen Schriftstellern des deutschen Mittelalters wird die Narcisse nicht erwähnt, im 16. Jahrhundert finden wir aber in den Kräuterbüchern eine grosse Zahl von Narcissen unter dem Namen Narcissenröslein, Zeitlusen, Hornungsblumen etc. Es ist möglich, dass diese plötzliche Fülle durch die Blumenliebhaberei der Türken beeinflusst ist, wenigstens nennt CAMERARIUS (Hortus Medicus S. 104, 105) zwei Narcissenarten konstantinopolitanisch, und sagt, dass eine von diesen ihm aus Konstantinopel von einem Freunde geschickt worden sei. Narcissen sind bis auf die Gegenwart beliebte Gartenpflanzen gewesen, fangen nun aber an unmodern zu werden.

\section{Die Hyacinthe.}

Der Hyakinthos (úḱkıvos) der griechischen Dichter ist unser G'ladiolus communis L (vergl. unten S. 46); es wird aber bei THEOPHRAS'I lind DIOSKORIDES und auch bei COLUMELLA eine ebenso genannte Pflanze erwähnt, die nach den Beschreibungen und sonstigen Unständen (sie wird bei THEOPHRAsT neben Eıpiov, unserem Gladiolus, erwähıt $6,8,1)$ etwas anderes sein muss. Aus dem, was THEOPHRAS'T sagt. lässt sich nicht viel entnehmen. DIOSKORIDES giebt 4,63 eine ziemlich eingehende Beschreibung seines Hyakinthos: er hat Blätter, die denen dis Bolbos gleichen, einen Stengel von der Lünge einer Spame, glatt, duinner als ein kleiner Finger, grün; dessen Blüten tragendes Ende ist

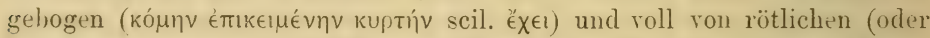

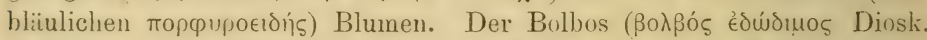
2, 200) ist eine Traubenhyacinthe, Muscuri comosum Miller, deren Zwiebehn, heute noch ßoגßoí genannt, gekocht oder in Essig gelegt von den griechischen Landleuten gegessen werden. ") An diese Traubenhyacinthe dürfen wir also nicht denken. Schwierigkeiten macht der unbestimmte oder unsichere Begriff roppur.ous oder purpurens, und die Abschwächung zu

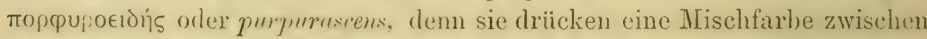
rot und blau aus, die bald mehr nach der Seite des Roten, bald mehr nach derjenigen des Blauen gehen kamn. Aber gerade deswegen könnte die Hyacinthe des DIoskORIDES unsere Hyacinthe. Hyacintlus orimtalis

1) CGL III: narcissus . i. uuluus (statt bulbus) 570, 4; narcissus lilius silvaticus 570, 19; narcissus bulbus agrestis 593, 11; - nareisso holtlilie (Königsb. Gloss.).

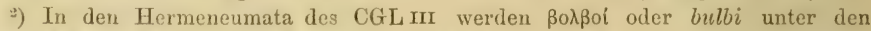

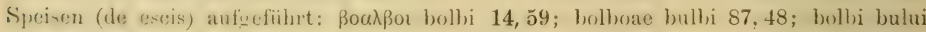

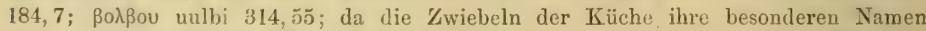
haben und unter den Gemüsen aufgeführt sind, so werden hier wohl die Zwiebeln von Muscari comosum gemeint sein, die heute noch in Italien gegessen werlen. 
L., sein, deren Heimat man heute sogar in Südeuropa sucht. Das einzige, was man dagegen einwenden könnte, ist der Umstand, dass die Hyacinthe in allen Pflanzenglossaren und bei den botanischen Schriftstellern des deutschen Mittelalters fehlt, und erst bei den Schriftstellern des 16. Jahrhunderts wieder erscheint. Aber warum soll es der Hyacinthe nicht haben gehen können, wie es beispielsweise der Narcisse ergangen ist? Die etwas zärtliche Hyacinthe war zunächst kein Gewächs für deutschen Boden, und wo es sich vor allem darum handelte, nutzbringende Pflanzen in fremdes Erdreich zu verpflanzen, da musste die nur durch Farbe und Geruch erfreuende Hyacinthe vorläufig zurückbleiben.

Bei COLUנIELLA ist auch an mehreren Stellen von einer Hyacinthe die Rede. Wo im 9. Buche die Pflanzen aufgezählt werden $(9,4,4)$, die den Bienen Honig darbieten, wird auch "caelestis numinis hyacinthus" genannt, etwa eine Hyacinthe von blauer Farbe, wenn man "luminis" statt des unverständlichen „numinis" lesen darf? Im zehnten Buche (v. 100) wird verlangt, dass schneeweisse und blaue Hyacinthen gepflanzt werden („nec non vel niveos, vel caeruleos hyacinthos, “ sc. pangite); die rostroten Hyacinthen (ferruginei hyacinthi), die v. 305 erwähnt werden, entsprechen wahrscheinlich unserem Gladiolus (vergl. unten S. 46).

Haben wir nun den Hyakinthos des DIOSKORIDES als unsere wohlriechende Hyacinthe gedeutet, so liegt eigentlich kein Grund vor, den Hyacinthus des COLUNELLA als etwas anderes zu nelimen.

Die Hyacinthe heisst im heutigen Italien diacinto, giacinto, iacinto; denselben Namen führen aber auch noch audere Pflanzen, wie Scillı bifolia L, die sowohl blau wie weiss vorkommen und in Gïrten gezogen werden. Ob COLUMELLA statt unserer Hyacinthe etwa Scilln bijolic gomeint lat, liisst sich nicht bestimmt verneinen, aber ebensowenig bestimmt bejahen.

Die Einführung der Hyacinthe nach Deutschland erfolgte von Konstantinopel aus, wohin sie von den blumenliebenden Türken gebracht worden war. Zunïchst verbreitete sie sich langsam. HIERoxTyUs BOCK kennt sie iiberhaupt noch nicht. In MATTIOLIs Kräuterbuch ist Musconi comosum Niller unter dem Namen Hyurinthus abgebiliet; der Herausgeber CAjeraRius hat aber Abbildungen von Hyacintlus orientalis L. hinzugefügt, und zwar nach Exemplaren, die er dem Reisenden Rauw olf verdankte. Im 17. Jahrhundert gah) es schon sehr viele Spielarten, so dass PAUL HeRRMANN in seinem Katalog des Leydener Gartens, 1687, mehr als zwei Seiten gebrauchte, um die von ihm gebauten aufzuzählen.

\section{Veilchen, Levkoje, Goldlack und Viole.}

Eine Anzahl Pflanzen mit angenehm duftenden Blumen wurde von den Griechen ìov (ion), von den Römern viola genannt; die besonderen Arten wurden dann durch hinzugefügte Adjektive kenntlich gemacht, ein Verfahren, das sich bis ins 16. Jahrhundert und später erhalten hat. 
Diese Pflanzen gehören nach unseren Begriffen nicht nur verschiedenen Gattungen, sondern sogar verschiedenen Familien an.

\section{Das Veilchen, Märzveilchen, Viola odorata L.}

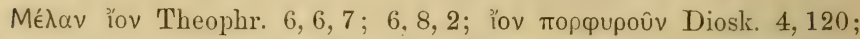
wird in Griechenland riel in Gärten kultiviert, namentlich mit gefüllten Blumen, und daselbst mit dem türkischen Namen $\mu \in v \in E$ és genannt; wild wächst in Griechenland eine der Viola odorata L. verwandte, aber weniger stark duftende Art, die Viola Thessala Boiss. et Sprun. (v. Heldreich).

Nigra viola Terg. Ecl. 10, 39; viola purqurea Plin. 21, 6, 14; 21, 19, 76; viola quae ion appellatur et purpurea Plin. 21,11,38; it. viola mammoln, viola maura, violetta, auch bloss mammola, mammoletta; fr. violette.

Bei HOMER (Od. 5,72) wird schon ein iov erwähnt, das unser Veilchen oder eine nahe verwandte Art sein kann. Die Römer nannten das Veilchen, wenn sie es genau bezeichnen wollten, viola purpurea, was

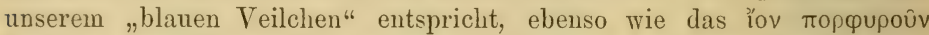
(ion porphyrūn) des DIOSKORIDES; THEOPHRAST nennt es dunkles Veilchen, und ähnlich spricht WALAFRIDUS STRABUs (v. 220) von einer riola nigella. Bei der heiligen Hildegard ist 1,103 von einer viola die Rede, ebenso bei KONRAD VON MEgENBERG $(5,85)$, wo als deutscher Name viol angegeben wird. Obgleich an beiden Stellen keine Beschreibung und kein charakteristisches Beiwort gegeben wird, so deutet dennoch an der ersten die frühe Blütezeit, an der zweiten die Anwendung (Veilchensirup) auf das Veilchen; freilich wurde auch vom Goldlack Teilchensirup gemacht. AJBERTUS MAGNUS beschreibt das Veilchen 6.464 ; an einer andern Stelle $(5,117)$ nennt er es echtes oder wahres Teilchen (viola vera) im Gegensatz zum Goldlack (viola crocea).

Das Veilchen heisst im 16. Jahrhundert Viol, Veiel, Mertzenveiel. Es ist bis auf die Gegenwart eine beliebte Zierpflanze geblieben und findet sich in Norddeutschland vielfach als Folge der Kultur verwildert.

\section{L e vkoje, Matthiola incana R. Br.}

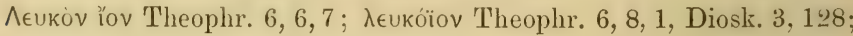

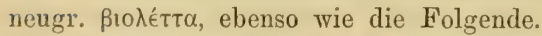

Pallens viola Verg. Ecl. 2,47; leucoium Colum. 9, 4, 4; candidum lencoinem Colum. 10, 97; viole alba Plin. 21, 6, 14; it. fior bono, fior bianco, lencoio bianco und purpurco, viola bianca, violaciocea bianca, pallida und rossa; fr. violier, giroflée.

Nach DIOSKoRIDES ist das Leukoïon (wörtlich „helles Veilchen“) seinen Blumen nach verschieden und entweder weiss, oder gelb ( $\mu$ ń $\lambda$ เvov,

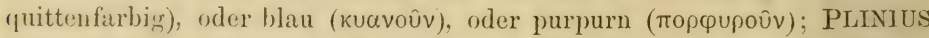
unterscheirlet purpurne, gelbe und weisse Veilchen, und in einem Glossar des CGL III werden weisse, rote und blaue Veilchen genannt. ${ }^{1}$ ) Als

1) Violarum genera sunt tria . i a alba rosea et celina $(579,13)$. 
Levkojen im heutigen Sinne dürfen wir die weissen Veilchen und das weisse Leukoïon nehmen; das purpurne und das blaue Veilchen ist unser Veilchen, das gelbe, sowie das gelbe Leukoïon unser Goldlack. Zweifelhaft bleiben das blaue und purpurne Leukoïon bei DIOSKORIDES, während das rote Veilchen des Glossars wohl den Levkojen zuzuzählen ist.

Bei den botanischen Schriftstellern des deutschen Mittelalters begegnen wir der Levkoje nicht, wohl aber bei denen des 16. Jahrhunderts, von denen sie Leucoium") und "Welsch Veiel" genannt wird; TABERNAEIONTANUS bemerkt, sie sei kürzlich aus Welschland gekommen. Die Levkoje wird heute in vielen Varietäten und Spielarten gebaut; sehr schöne gefüllte weisse Levkojen kommen schon im März aus Norditalien und Südfrankreich.

\section{Goldlack, Cheiranthus Cheiri L.}

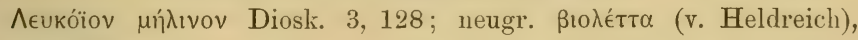
$\tau \grave{\alpha}$ kítpiva (Fraas).

Viola lutea Plin. 21, 6, 14; it. leucodio, leucoio, leucoio giallo, cheiri, viola, violaciocca; fr. violier.

Ausser den schon angefiilhrten Stellen, an denen der Goldlack bei den Sclıriftstellern des Altertums erwälnt wird, giebt es noch eine, wo vom Goldlack die Rede zu sein scheint, nämlich bei CoLunELLA 10,101: "viola, quae frondens purpurat auro", das Veilchen, welches sich belaubend von Gold glänzt, oder wie wir sagen würden, das Veilchen, dessen Blüten zwischen dem Laube goldig schimmern.

ALBERTUS MAGNUS spricht von einem safrangelben Veilchen (viola crocea 5, 117), das das wahre Veilchen im Geruch nachahmt; hier kann also nur an den Goldlack gedacht werden, der bei der heiligen, Hildegard und bei KONRAD vON MEGENBERG nicht erwähnt zu werden scheint.

Im 16. Jahrhundert heisst der Goldlack viola lutea, leucoium luteum und aureum, auf Deutsch geel Veiel, gelb Veiel, gelb Nägelveiel etc. Er wurde mit einfachen und gefüllten Blumen kultiviert und zeigte viele Varietäten in Farbe und Grösse der Blumen. Noch jetzt ist er beliebt, namentlich als Topfpflanze. Auf der Insel Helgoland ist er zusammen mit dem Kohl am felsigen Abhange unter dem Garten des Gouverneurs verwildert.

\section{Nachtviole, Hesperis matronalis L.}

Die Nachtriole ist in Norddeutschland eine sehr beliebte Zierp)flanze und wird in zwei verschiedenen Formen kultiviert: einmal mit

1) Neben Levkoje und Goldlack wurden im 16. Jahrhundert auch noch mehr Pflanzen Leucoium genannt, nämlich ausser unserem Schneeglöckchen, Galanthus nivalis L., auch noch solche, die der heutigen Gattung Leucoium angehören. TABFrNAEMontanus (2, S. 328) nennt Leucoium vernum L. und das Schneeglöckchen beide Leucoium bulbosum, auf deutsch weiss Hornungsblume, Sommerthïrlein und Schmeetropfen. 
einfachen lilafarbigen Blumen, und zweitens mit gefüllten weissen, zıweilen hellila angelaufenen Blumen. Während sie im ersten Falle lis meterhoch wird und ilre Blumen in einer ausgesperrten Rispe trägt, bleibt sie im zweiten Fall niedrig und ihre Blumen sind meist in eine einfache Traube zusammengedrängt. Gewöhnlich wird sie Viole oder Nachtriole genannt, man hört auf dem Lande aber auch den Namen ,Viōl matternäl". Die kresseartig schmeckenden grünen Blätter und die Samen dieser Pflanze wurden früher in den Apotheken als Ilerba et Semen Fesperidis s. Violae matronalis s. damascenare geführt. Im 16. Jalırhundert heisst die Nachtriole Viola matronalis und auf Deutsch IVinterveiel, Winterviole (ТАВ.). Der Name viola matronalis findet sich schon bei DIOSKORIDES $(3,128)$ als Synonym von lencoium, wird allerdings von Manchen für einen Zusatz von späterer Hand gehalten. PLINIr's erwähnt 21, 7, 18 eine Pflanze hesperis, die bei Nacht stïrker riecht (hesperis noctu magis olet). Da unsere Nachtviole diese Eigenschaft in sehr hohem Grade zeigt, da sie in Italien wild wächst und dort heute esperide und viola mutronale genamnt wird, so kann es nicht zweifelhaft sein, dass die Römer auch diese Zierpflauze gekannt haben; eine strenge Trennung von der Levkoje werden sie aber kaum vorgenommen haben.

\section{Goldblume und Vexiernelke.}

Die bisher genannten Zierpflanzen zeichneten sich durch ihren Duft aus; wir haben jetzt zwei anzuführen, die nur ihrer Farbe wegen Eingang in die Gärten gefunden haben.

Chrysanthemum coronarium L., Goldblume.

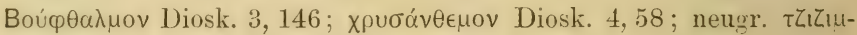

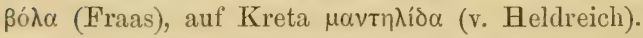

Buphthalmus Plin. 25, 8, 42; it. fior d'oro, bambegelle.

Die Nachrichten über die Goldblume fliessen nur spärlich; dass sie aher, wenigstens von den Römern, gebaut worden ist, geht aus der schönen Abbildung auf dem Wandgemälde in der Villa der Livia in Primaporta mit Sicherheit hervor, und zwar werden hier zwei Rassen dargestellt, eine mit gelben und eine mit weisslichen Blüten (Aritike Denkmäler, herausgegeben vom Kaiserlich Deutschen Archäol. Institut. Bi. 1, Berlin 1891, 'Taf. 11). Dioskorides und PLrNiUs erzïhlen, dass ihre jungen Triebe gegessen würden; das geschieht in Griechenland und Italien moch heute. Es ist uns nicht ganz verständlich, wie die Alten die Goldhlume haben Ochsenauge (bouphthalmon) nemen können; die Italiener bezeichnen aber heute noch die grosse Wucherblume (Chrysanthemum Leucanthemum L.) mit demselben Namen (ochio di bove).

Sehr viele .Jahrhunderte ist von der Goldblume nicht die Rede, erst in 16. Jahrhundert begegnen wir ihr in den Kräuterbiichern und zwar unter diesem Namen. Aber im Bestreben, das Chrysanthemum des D)LSK()RIIES' zu denten, wurde bald die Satutweherblume (Chrysanthemum 
segetum L.), bald die echte Goldblume (Chr. coronarium L.), herangezogen. In Norddeutschland ist die Goldblume eine ziemlich alte Kulturpflanze, aber da ihre Samen jedes Frühjahr neu gesät werden müssen, so sieht man sie auf dem Lande nur in solchen Gärten, die sich einer besonder's sorgfältigen Pflege erfreuen.

Coronaria tomentosa R. Br. (Agrostemma coronaria L.), Vexiernelke, Stechnelke.

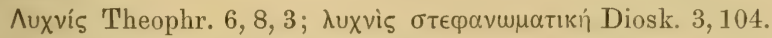

Lychnis Plin. 21, 4, 10; 21, 11,39; rosa graeca Plin. 21, 4, 10; it. coronaria, erba coronaria, lichnide.

Die Vexiernelke erscheint ebenso wie die Goldblume nach langem Vergessensein wieder im 16. Jahrhundert. Sie heisst Lyclmis coronarin hei MatTioli und Tabernaejontanus, rosa Mariann und flos Jovis bei BOcK und wird auf deutsch Margenröslein oder Märgenröslein genannt; heute wird sie in weissen und roten Farben gezogen und ist inmer noch eine leidlich beliebte Zierpflanze.

\section{Schwertlilie und Gladiolus.}

Gladiolum Capitulare 70,17; Iris germanica L. und I. florentina L. Iris, Schwertlilie, Schwertel.

"Ipıs Theophr. 4, 5, 2; Diosk. 1, 1; neugr. kpívos.

Iris Colum. 12, 27; 12, 28, 1; iris Illyrica Colum. 12, 20,5; iris Graeca Colum. 12, 51, 2; iris Plin. 21, 6, 19; 21, 20, 83; chiaggiolo, giglio azzurro, ireos, iride; Iris florentina heisst giglio bianco; fr. glaieul.

Nach DIOSKORIDES wurde die von ihm als Iris bezeichnete Pflanze von den Römern auch gladiolus genannt, ebenso wie die von ilım Xiphium (Eıpíov, 4, 20) und Xrris (Eunís, 4, 22) benamnten nebenher yladiolus hiessen; von den beiden letzten ist Xiphium unser Siegwur\% oder Gladiolus (Gludiolus rommunis L.) und Xyris eine nicht ganz sichrer bestimmte, aber in Italien wildwachsende Irisart. Die Verwirrung wird durch die allen angeführten Pflanzen gemeinsamen schwertförmigen Blätter herbeigeführt, die die Ursache für die Namen Gladiolus (kleines Schwert) und Schwertel sind.

Der Name Iris ist bei den angeführten Schriftstellem vielleutig, denn er unfasst alle ihnen bekannten Arten, von den wilken bis zn den in Gïrten angepflanzten; von cliesen ist iris illyrien wahrscheinlich unsere Iris germanica L., vielleicht auch Iris, flometinn L., deren nach Veilchen duftende Wurzel nach PLIxiUs $(21,20,83)$ damals den zalnenden Kindern ebenso um den Hals gehängt wurde, wie es noch heute geschieht. Aus den Glossaren des CGL III geht nun hervor, dass in spüterer Zeit iris durch gladiolus und gladiola verdrïngt wurde, denn es wird iris (und seine Formen) ${ }^{1}$ ) fast jedesmal durch eines von diesen Worten übersetzt.

1) Hyrius . gladiolo 546,65 ; hyrius . i . gladiolus 583, 32; gladiolus irius 591, 25; 612,41 ; ireus gladiolo 632,23 ; xiris . $i$. gladiolus 579,44 . - ius . illirica . idest 
Iris illyrica leisst einmal lilium celinum, einmal lilium purpureum, also blaue Lilie, unsere Iris gemanica L., im übrigen, wie auch das einfache iris, yladiolus hortensis; wegen ihrer Heilkräfte werden die Irisarten auch solidago und soliclago minor genannt. ${ }^{3}$ )

WALAFRIDUS STRABUS hat eines der Gedichte in seinem Hortulus Gladiola ïberschrieben, und REuss hat diese Gladiola als Gladiolus communis L. gedeutet, aber mit Unrecht.

Zunaichst nennt IVALAFRIDUS die Farbe der Blume blau oder dunkelblau und spricht dann allerdings vom Hyacinthus und von dem auf seinen Blumenblättern aufgezeichneten Namen oder Buchstaben. ${ }^{2}$ ) Der letztere Umstand hat wahrscheinlich REUSS zu seiner Deutung veranlasst, denn der Hyacinthus (úúkı $\theta$ os) der griechischen Dichter ist unser gewöhnlicher Gladiolus (Gladiolus communis L.), der auf den drei unteren Perigonzipfeln je einen gelblich weișsen Streifen trägt. Diese drei Streifeu wurden rou den Alten als AI gelesen und sollten den griechischen Klageruf darstellen: der Jüngling Hyacinthus war von Apollo beim Discuswerfen erschlagen worden, und aus seinem Blute sprosste die nach ihm benannte Blume hervor. Dieser Hyacinthus ist aber nicht dunkelblau wie das Veilchen, sondern rot. WVir stehen hier also ror einem Widerspruche. Sehen wir uns zunächst den Schluss des Gedichtes an, so erfahren wir, dass die Wurzel der gladiola als Mittel gegen Blasenleiden benutzt wird und dass sie den Tuchwalkern dient, um Leineuzeug zu stärken und mit Wohlgeruch zu versehen. Nun müsste gladiola nach damaligem Sprachgebrauch Iris germanica L. sein; dazu wiirde die blaue Farbe stimmen, ebenso die Anwendung in der Medizin und Technik (über die letztere wolle man unten unter Flachs vergleichen), aher dagegen scheinbar die Buchstaben auf den Blumenblättern. Indessen träigt Iris germanica auf den äusseren Perigonzipfeln je einen von fädlichen Hervorragungen gebildeten gelben Streifen, Bart genannt, und einem dichterisch angelegten Gemüt kann es nicht schwer fallen, diese drei Streifen als A I zu lesen. So wird es auch WVALAFrIDUS STRABUs gemacht haben, denn unseren Gladiolus hat er wahrscheinlich nie zu Gresicht bekommen.

Pei der heiligen HILDEGARD steht in der Strassburger Ausgabe gladiolu, in der neusten Ausgabe $(1,118)$ swertula; auch hier geht aus

lilium . celinum 539,52; iris illirica . idest lilium purpureum 539,66; irisilirica glartiolus hortensis 591, 36; 612,63; gladiolus ortensis. i. yrius 564,68; eine iris africae wird auch als gladiolus bezeichnet 562,$29 ; 56568$.

1) Iris illirica idest soldagine. 540, 5; 547,9; solagominor irius 595, 30; gladiolo radix idest solago minor 612,19 .

2) „Tu mihi purpurei progignis floris honorem,

Prima aestate gerens violae jucunda nigellae

Munera, vel qualis mensa sub Apollinis alta

Investis pueri pro morte recens Hyacinthus

Exiit et regis signavit vertice nomen." 
der Anwendung als Heilmittel hervor, dass eine Iris gemeint ist. ALBERTUS MAGNUS $(6,355)$ unterscheidet zwei Arten gladiolus; die eine Art wächst an trockenen Orten und hat eine blaue Blume (florem iacinctinum), ist also Iris germanica L., die andere wächst im Wasser und hat eine ähnliche Blume wie die vorhergehende, aber gelb (croceus), wird von ALBERTUS auch gladiolus aquosus genannt und ist daher Iris Pseudacoms L. Die Pflanze, welche ALBebtus Magnus (6, 473-475) unter dem Namen yreos beschreibt, scheint Iris florentina L. zu sein; was er über die Blume sagt (compositus est ex albo et citrino et coelesti et purpureo, et propter hanc varietatem vocatur yreos), stimmt zwar nicht, wohl aber das über die Wurzel angeführte, und vielleicht hat er nur diese aus eigener Anschauung gekannt. Zu damaliger Zeit wurde übrigens Irisflorentina mit yreos bezeichnet, denn MATTHAEUS SYLUATICUS sagt, dass yreos eine weisse Blume habe.

KONRAD VON MEGENBERG nennt gladiolus auf deutsch slatenkraut, nach der Gestalt der Blätter auch swertlinch oder swertelkraut und unterscheidet wie Albertus Magnus zwei Arten. Die eine wächst an trocknen Orten und hat blaue Blumen (pluomen in ains jâchandes varb), die andere hat gelbe Blumen und wächst an nassen Stellen; das Kraut der letzteren heisst auch carectum. Andere Irisarten kennt er nicht.

Im 16. Jahrhundert ist die Zahl der kultivierten Irisarten seln gestiegen. Sie führen jetzt den lateinischen Namen Iris, dem nach Farbe, Vaterland etc. noch ein oder mehrere Adjektive hinzugefügt werden; der deutsche Name ist Veyelwurtz, Himmelschwertel, Schwertel, auch Gilgen und Lilgen. Iris germanica L. wird „blaw Schwertel" oder "blaw Gilgen“ genannt.

Nach dem Gesagten werden wir mit KERNER annelımen müssen, das der Gladiolus des Capitulare eine Irisart gewesen ist; welche es war, bleibt zweifelhaft, doch wird man in erster Linie an Iris germanica L. denken dürfen, die noch heute mit ihren schönen blauen Blumen den Schmuck so vieler Gürten ausmacht. Iris florentina L., die ebenso wie Iris sambucina L. nach Süden zu in den Gärten häufiger wird, wurde wohl nicht immer genau von Iris germanica geschieden; sie könnte also auch mit gemeint gewesen sein.

Der Voliständigkeit wegen möge hier unsere gemeine Iris oder Wasser-Schwertlilie, Iris Pseudaconus L., erwähnt werden, obgleich sie keine eigentliche Zierpflanze, sondern eine Arzneipflanze ist oder war; ihre WVurzel wurde in den Apotheken als Radix Pseudacori s. Acori palusiris s. adulterini geführt. Sie wächst ebenso wie in Deutschland auch in Italien wild und ist lange Zeit, bis ins 16. Jahrhundert hinein, statt des echten Kalmus benutzt worden, wie von HIERONYנIUs BOcK, C. BAUHIN und anderen ausdriicklich bezeugt wird. Dadurch ist eine Verwirrung unter den Namen entstanden, durch die wir selbst heute 
noch nur mühsam durchfinden. Wahrscheinlich ist $I r$ is Psendacoms L. unter dem acoron (ǘopov) des DIOSKORIDES $(1,2) \mathrm{zu}$ verstehen, vielleicht auch unter dem acoron des PLINIUS $(15,13,100)$; heute heisst sie in Italien iride giulla, acoro falso, acoro adulterino. In den Glossaren des CGLIII wird acoms eimmal ïbersetzt durch die von DIOSKORIDES angegebenen Symonyme: aphrodisia, venerea, piper apium, Namen, die sich zum Teil auch in den lateinisch-deutschen Glossaren finden; zweitens durch gladiolus paludensis, Sumpfschwertel, und dem entsprechend übertragen die lateinisch-deutschen Glossare acorus durch Schwertel und gelbe Schwertel. ${ }^{1}$ ) Wenn man die Glossare allein zu Rate zieht, so kann man eigentlich nicht zweifelhaft sein, dass acorus nur die WVasser-Schwertlilie bedeutet. Im 16. Jahrhundert heisst sie gelbe Sumpfiris (Iris paludosa lutea), gelbe wilde Iris (Iris silvestris lutea), Pseudoiris und Pseudoacomum, daneben Wasserschwertel, Wasserlilie, geel Schwertel etc.

Das Wort gladiolus, ${ }^{2}$ ) das bis ins 14. Jahrhundert und wahrscheinlich darïber hinaus Irisarten bezeichnet hatte, wechselt nummehr seine Bedeutung: die Irisarten werden Iris genannt und Gladiolus bedeutet fortan

Gladiolus communis L., Siegwurz, Gladiolus.

三ıíov Theophr. 6, 8, 1; páбravov Theophr. 7, 12, 3; 7, 13, 1 u. 4;

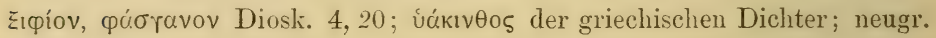
$\sigma \pi \alpha \theta$ óхортоv.

Xiphion, pleasganion Plin. 25, 11, 89; hyacinthus ferrugineus Colum. 10,305; liyacinthus Plin. 21, 11, 38; 21, 26, 97 ; it. gladiolo, gigliarello.

Es wurde schon oben S. 44 die Sage erwähnt, wonach aus dem Blute des Hyacinthus eine Blume hervorsprosste, die den Namen Hyacinthe erhielt und auf ihren Blättern die Buchstaben A I trug. Diese beiden Buchstaben, die den griechischen Klageruf darstellen, wurden auch als

1) CGL III : afrodesia" acoro 550,$53 ; 552,3$; beneria . i acoro 553, 64 ; piper apiu . agoro 573,64; agoro gladiolus paludensis 586, III, $21 ; 616,21$; agoro . id est radicis lisa aqualis $5+3,45$; kann das unser Wasserliesch sein? Ein mittelniederreutsches Glossar (Jahrbuch d. Ver. f. niederdeutsche Sprachforschung, XVII, S. 81-84) iibersetzt grladiolus durch lisc. - Accorus swertele, affiodissa sverdele (Königsb. Gloss.); acorus sucrdule, affrodisia swerdele (Colm. Gloss.); accorus gelswerdele (Mone); acorus geilswertele (Sum. ǒl, 5:3).

$\left.{ }^{2}\right)$ Wie vieldeutig das Wort Gladiolus war, geht daraus hervor, dass Gladiolus prelustris ausser. für Iris Pseudacomes L. auch noch für Sparganium ramosum Hudson, den Igrelkollhen und Butomus umbellatus L., Wasserliesch oder Was-erveilchen, gebraucht wurde; bei diesen beiden war die schwertförmige Form der Blätter die Ursache fïr die Benennung, die allerdings beim Wasserliesch, das bei den alten Botanikern meist juncus floridus (Blumeuhinse) heisst, nicht mehr sehr zutreffend ist. CARouds Cuusius bezeichnet in seinen Curae posteriores (Antverpiae 1611 S. 40) Lobelia Dortmanna L., eine PHanze der seichten Süsswasserseen, als Gladiolus lacustris Dortmanni; in diesem Falle haben die Blätter nicht mehr den Grund für die Benennungr ahgegełsen, sontern die Blumen, die eine oberflichliche Ähnlichkeit mit denen des Gladiolus oder der Siegwurz haben. 
Anfangsbuchstaben von Ajax (griechisch Aì g) genommen; so spricht Colunelua $(10,174-175)$ von Blumen, die aus dem Blute des Ajax hervorspriessen (flores qui sanguine surgunt Aeacii) und meint damit unseren Gladiolus.

DIOSKORIDES beschreibt den Gladiolus unter dem Namen Xiphion (zıpíov) so genau, dass man über die Pflanze, die er meint, nicht im Zweifel sein kann. Als Standort giebt er Saatfelder an, auf denen er noch jetzt in Italien häufig gefunden wird; in Griechenland kommt er nur sehr selten vor. Das Synonym segetolis, das DIOSKORIDES für Xiphion anführt, ist ilhm lange Zeit als Name geblieben. ${ }^{1}$ ) Von den Alten wurde dem Gladiolus eine ganze Reihe von Heilwirkungen zugeschrieben, aber trotzdem scheint er jahrhundertelang ganz und gar in Vergessenheit geraten zu sein, denn in den lateinisch-deutschen Pflanzenglossaren, bei der heiligen HILDEGARD, bei ALBERTUS MAGNus und KONRAD VON MEGENBERG kommt er nicht vor, ja er fehlt sogar bei Hieronyaus Bock. Sonst wird er in den Kräuterbüchern des 16. Jahrhunderts erwähnt und auch gerühmt.

Seine Wiederaufnahme unter die Zauber- und Heilmittel verdankt der Glarliolus im wesentlichen der netzigen Hüllhaut seiner Wurzelknollen. Beim Allermannsharnisch (Allium Victorialis L.), der den Alten nicht bekannt gewesen zu sein scheint und auch in den Pflanzenglossaren fehlt, sind die Zwiebeln in mehrere netzförmige Schalen gehüllt; der ganze Wurzelstock mit Zwiebeln und Häuten stand in dem Rufe, Geister abzuhalten, Zauber zu bannen und denjenigen, der ihn trug, unverwundbar zu machen, und hiess Victorialis longa oder Victorialis mas. Die viel kleinere Wurzel des Gladiolus, die dementsprechend weniger kräftig gewesen sein mag, wurde Victorialis rotunda oder femina genannt.

An die Heil- und Zauberwirkungen des Gladiolus denkt man heute nicht mehr, aber man schätzt ihn als Zierpflanze und als solche ist er bis Norddeutschland und weiter hinauf vorgedrungen. Gegenwärtig findet man ihn nur noch in Bauerngärten: die Hybriden von Gladiolus floribunclus, psittacinus etc. haben ihn ganz in den Schatten gestellt.

\section{Lorbeer, Myrte und Buchsbaum.}

Lauros Capitulare 70, 85; Laurus nobilis L., Lorbeer.

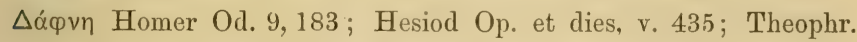

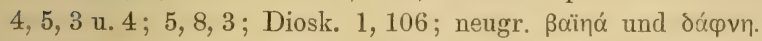

Laurus der Römer; it. alloro und lauro; fr. laurier.

HEHN (S. 187) vermuthet, dass der Lorbeer aus Asien nach Europa gekommen sei. Wenn aber, wie er selbst anführt, HESIOD die Vorschrift giebt, einen Balken am Pfluge aus Lorbeerholz zu machen,

3) CGL III: gladioloregetali (statt segetali) . i . sifion 564,28; sigitale . i . gladiolus 568, 65 . 
der Lorbeer also im 9. Jahrhundert v. Chr. in Böotien am Helikon "schon nicht ungewöhnlich" gewesen sein muss, so ist eigentlich kein rechter Grund einzusehen, weshalb man dem Lorbeer das Heimatrecht auf der Balkanhalbinsel nicht zusprechen soll. Auch war in der latinischen Ebene der Lorbeer nach THEOPHRAST $(5,8,3)$, also mindestens 300 Jahre v. Chr., schon häufig; man wird daher das natürliche Wohngebiet des Lorbeers etwas weiter nach Westen ausdehnen dürfen, als HEHN es gethan hat.

Der Lorbeer hat in Deutschland keinen festen Fuss fassen können: die Winter sind ihm zu kalt, so dass er im Freien kein Gedeihen findet. Von jeher sind seine Blätter und Beeren ein geschätztes Arzneimittel gewesen und auch in der Küche als Würze an mancherlei Speisen benutzt worden. Ausserdem fristet er in Kübeln mit grausam zurechtgestutzter Krone ein kümmerliches Dasein; in dieser unnatürlichen Form schmückt er die Säle bei ernsten und heiteren Festen.

PLINIUS führt $(15,30,39)$ einen timus auf, "den einige für wilden Lorbeer, andere für ein eigenes Genus halten"; es ist dies Viburnum Tinus L., ein Strauch, der in Italien, Südfrankreich, Spanien und Nordafrika wild wächst und unter dem Namen Laumustinus in Deutschland ein beliebtes Topfgewächs ist. Als solches möge hier angeschlossen werden

Myrtus communis L., die Myrte.

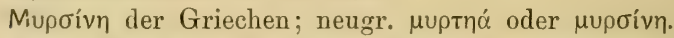

Myrtus der Römer, it. mirto, mortella, mortellina; fr. myrte.

Dieser immergrüne Strauch gehört den Mittelmeerländern an und wurde schon sehr früh, ebenso wie der Lorbeer, bei religiösen Handlungen gebraucht; wie der Lorbeer dem Apollo, so war die Myrte der Aphrodite geweiht. Als Brantkranz wird die Nyrte heute noch gebraucht und deswegen namentlich in Töpfen gezogen; man findet sie vor den Fenstern der ärmlichsten Wohnungen. Ausserdem stand sie als Heilmittel in Ansehen.

Bei der heiligen HILDEGARD $(3,42)$ wird ein mirtelbaum genannt; da dieser auch beim Bierbrauen gebraucht wird, $\left.{ }^{1}\right)$ so wird vermutlich dieselbe Pflanze gemeint sein, die Albertus Mafrnus $(6,138)$ unter dem Namen mirtus beschreibt, KONRAD vON MEgEnBERG unter den Namen myrtus und mirtelpaum. Diese kommt nach ALBERTUS am Neeresgestade gegen Dänemark hin (versus Daniam) massenhaft vor, konserviert das, wozu sie gethan wird, wie der Hopfen (conservans ea, quibus commiscetur sicut humulus), und muss nach der Beschreibung der Gagel (Myrica Gale L.) sein. Henrik Harpestreng, Dansk Läge bog, Kopenlagen 1826, S. 120, hat auch eine Pflanze mirtus und führt als

1) „Et si quis cerviseam parare voluerit, folia et fructus ipsius arboris cum cervisea coquat, et sana erit, et bibentem non laedit". 
deren dänischen Namen Pors an; Pors ist aber der dänische Trivialname für Myrica Gale (Leclum palustre L. fehlt in Dänemark) und diese Pflanze wurde früher in Dänemark und in Norddeutschland wie in Norwegen zum Bierbrauen benutzt. Dieser Gebrauch muss also auch bis nach Westdeutschland verbreitet gewesen sein. (Man vergl. Anhang II unter mirtelbaum.)

Buxus sempervirens L., Buchsbaum.

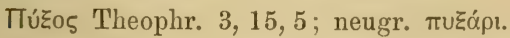

Buxus Plin. 16, 16, 28; 16, 40, 76 u. sonst vielfach; it. bosso, busso; fr. buis.

Der Buchsbaum scheint bei den Alten nicht als Heilpflanze betrachtet worden zu sein, wie es bei uns später geschehen ist; deshalb wird er auch von DIOSKORIDES nicht erwähnt. Bei HosזER (Il. 24, จ. 269), bei VERGIL, OvID und COLuneLLA wird das Holz des Buchsbaums als Nutzholz erwähnt, ebenso bei PLINIUS. MaRTIAL und auch spätere Schriftsteller sprechen von beschnittenem Buchsbaum (tonsile buxetum etc.). Als Zierstrauch ist er seit alten Zeiten auch bei uns benutzt worden, namentlich als Einfassung von Gartenbeeten. Zu solchen Einfassungen dient die niedrige Varietät (Buxus suffiruticosa Lam.), die sich übrigens auch gefallen lassen muss, durch Beschneiden in die wunderlichsten Formen gezwungen zu werden; im Hochsommer nimmt sie unter den Strahlen der Mittagssonne einen etwas unangenelimen Geruch an, der sich aber nicht vergleichen lässt mit dem widerlichen Geruch oder Gestank, den die schmalblüttrige höhere Varietät (Buxus arborescens Lam.) auch in kalter Jahreszeit verbreitet. Von diesem Geruch spricht schon THEOPHRAST $(3,15,5)$.

\section{Heilpflanzen.}

\section{Der Kalmus.}

Acorus Calamus L., Kalmus, Ackerwurz.

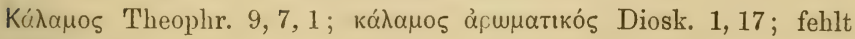
in Griechenland.

Calcmus odloratus Plin. 12, 22, 48; vielleicht auch acoron Plin. 25, 13, 100 ; it. acoro, acoro vero, calamo aromatico; fr. acore.

Nach THEOPHRAST wächst der Kalmus jenseit des Libanos, nach DIOSKORIDES in Indien; ähnlich äussert sich PLINIUS. Die Alten werden den Kalmus also wesentlich nur als Drogue gekannt haben. Sicher 
kannten ihn Albertus Magids $(6,77)$ und KonRAd von MEgENBERG $(4 \mathrm{~B}, 11)$ nur als solche, und beide geben Indien als sein Heimatland an.

Es wurde oben S. 46 schon erwähnt, dass der echte Kalmus in den Glossaren nicht vorkomme, sondern dass das dort vorkommende Wort acorus als Iris Pseudacorus L. gedeutet werden müsse. Wenn wir nun die Angaben bei den Schriftstellern des 16. Jahrhunderts etwas genauer ansehen, so finden wir, dass der Kalmus erst nach der Mitte dieses Jahrhunderts nach Deutschland gekommen sein kann.

MATTIOLI beschreibt in seinem Commentar S. 20 den Kalmus unter dem Namen Acorus: „er hat einen glatten Stengel, aus dem kleine Zweige hervorkommen, an deren Spitze (wie der Arzt Wilhelm Quakelbeen gesehen zu baben versicherte) zapfenartige Bildungen entstehen, die ich bis dahin nicht gesehen habe, ähnlich den Kätzchen der Haselnuss oder dem langen Pfeffer". ${ }^{1}$ ) (IVilhelm Quakelbeen, der Arzt beim kaiserlichen Gesandten Busbecq in Constantinopel war, hatte den Kalmus von da an MATTIOLI gesandt; die übersandten Exemplare waren in Nicomedien gesammelt worden.) Der Kalmus scheint also damals auch nicht in Italien vorgekommen zu sein, denn sonst müsste. MATTIOLI doch seine Blüte gesehen haben.

HienONymus Bock sagt in seinem Kräuterbuch fol. 448: „im Teutschen land hab ich den Calmus nicht mögen grün sehen", und CAJIERARIUS berichtet (Hortus medicus S. 5), dass der ,acorum Dioskoridis sive Calamus aromaticus officinarum" vor einigen Jahren in unsere Gärten gebracht worden sei und selbst sehr strenge Kältegrade ertragen könne.

Wir besitzen aber noch genauere Angaben über die Zeit, zu der der Kalmus in Deutschland eingeführt wurde. CAROLUS CLUsIUS bemerkt in seiner "Rariorum Plantarum Historia“, Antwerpen 1601, S. 230, dass er 1574 zum ersten Male die lebende Pflanze des echten Kalmus gesehen habe; diese sei ihm von Constantinopel aus durch Busbecq und andere Herren gesandt und damn von ihm in seinem Garten gezogen worden. $\left.{ }^{2}\right)$ Er berichtet ferner, dass er den echten Kalmus zum ersten Male in "Appendix ad Hispanicarum Plantarum Observationes" beschrieben und abgebildet habe; die dort hinzugefügte Abbildung sei aber olne Blüte (nucamentum) gewesen, denn die Pflanze habe damals, 1576, noch nicht geblüht. Von 1577 an aber blühte sie, und num setzte er neben die frühere Abbildung olıne Blüte eine solche mit derselben

1) "Caule est laevi, e quo ramuli prodeunt, in quorum cacuminibus, (vt Guilelmus Quacelbenus se vidisse affirmal)at) nucamenta quaedam exoriuritur, mihi hactenus non visa, nucis Ponticae iulis, aut longo piperi similia."

$\left.{ }^{2}\right)$ "Anno septuagesimo quarto supra millesimum et quingentesimum, mihi primum conspecta est Viennae Austriae legitimi Acori planta virens, quam deinde in hortulis alui, munere illustrium virorum . . Busbecq etc. 
(S. 231). Endlich erwähnt CLUSIUS auch das Vorkonmen des echten Káalmus bei Wilna und östlich davon und fügt hinzu, dass die Pflanze dort von den Einwolnern Tartarsky genannt würde, weil die Tartaren ihnen den Gebrauch derselben übermittelt hätten. Durch diese Angabe wird es wahrscheinlich, dass der Kalmus in Südrussland (Krim) im Gebiete des Pontus wild wächst, und das oben angeführte acoron des PLINIUS könnte also doch den Kalmus bedeuten.

Der Kalmus hat sich seit dem 16. Jahrhundert über Norddeutschland und darüber hinaus verbreitet und kommt an manchen Orten in solchen Massen in Flusslüufen und Sümpfen vor, dass man ihn für eine inländische Pflanze halten könnte. Der Umstand aber, dass er niemals reife Früchte trägt, zeigt deutlich, dass wir seine Heimat in wärmeren und also südlicheren Gegenden zu suchen haben.

\section{Drachenwurz, Dragon, Schlangenwurz.}

Dragantea oder dragontea Capitulare 70, 18.

Dieser Name hat zwei verschiedene Deutungen erfahren. Einmal soll er Artemisia Dracunculus L. bedeuten, nach KINDERLING, SPRENGEL, KERNER, MEYER und LANGKAVEL; zweitens wird er von REUSS als Arum Dracunculus L. gedeutet, und dieser Deutung scheint sich ANTON anzuschliessen, wenn er das Wort dragontea nach einem alten Glossar mit "Schlangenwurz" übersetzt. Wir wollen beide Deutungen prüfen.

Artemisia Dracunculus L. Dragon, Esdragon.

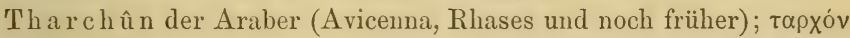
Simeon Seth (Syntagma de alimentorum facultatibus etc. ed. B. Langkavel, Leipzig 1868, S. 107).

Hortensis dracunculus, draconcellus Mratt. Comm. S. 446, 447; draco hortensis Camerarius (Hortus medicus S. 56); dragoncello, dragone der Italiener nach MATTIOLI, drago nach BRASAVOLA; ${ }^{1}$ ) esdragon der Franzosen.

Vergleicht man die verschiedenen Namen dieser Pflanze mit einander, so sieht man, dass sie sich allesamt auf das Wort Tharchûn zuriickführen lassen. Der Orientale Simeon Seth schrieb das arabische Wort mit griechischen Buchstaben tapxóv (tarchon); es kommt aber auch die Form tpaxóv vor, wie LAngKAvEL angiebt. Der erste abendländische Schriftsteller, bei dem das Wort vorkommt, und zwar "tarcon" geschrieben, ist der Italiener SIMION JANUENSIS oder GENUENSIS, Ende des 13. Jahrhunderts (Clavis sanationis, Venetiis 1514, fol. 60). Da lag denn für den Italiener die Angleichung drago oder dragone sehr nahe, und dies Wort ist dann mit geringen Veränderungen in die modernen Sprachen übergegangen. Bei MATTIOLI kommt noch kein deutscher

1) Anton IIusa Brasavola, Examen omnium simpl. medicam. S. 366 (nach Drerbach, Flora Apiciana, Heidelberg 1831, S.63). 
Name vor; TABERxAEMONTANUS hat als solchen "Drakonkraut", also keinen eigentlich deutschen Namen, wenigstens keinen, den sich der Volksmund zurecht gemacht hätte, wie Liebstöckl aus libisticum etc. Vielleicht darf man schon aus diesem Umstand schliessen, dass die Pflanze noch nicht so sehr lange in Deutschland eingeführt war. Für diese Anschauung sprechen aber auch noch andere Gründe. Zunächst kommt in den Glossaren des CGL III kein einziges Wort vor, welches sich auf tarchon beziehen liesse, ebensowenig in den lateinisch-deutschen Pflanzenglossaren; denn das Wort dragant, das LANGKA VEL hierherziehen möchte, bedeutet Gummi (Albertus Magius, 6, 94). Ferner wird der Dragon in Griechenland nicht gezogen, denn er fehlt bei FRAAS und HELDREICH; er scheint also den Weg von Kleinasien nach Europa gemacht zu haben, ohne Griechenland zu berühren. Sollten nicht die Kreuzfahrer das Kraut aus Kleinasien mitgebracht haben? Soweit bis jetzt bekannt, spricht kein Umstand dagegen. Aus den unklaren Worten bei PLINIUS $(24,16,23)$ kaun man nichts schliessen; aber es liegt auch kein Grund vor, an eine Identität von tarchion und dem $\pi u ́ \rho \in \theta \rho o v$ (pyrethron) des DIOSKORIDES $(3,78)$ zu glauben, wie SIJON JANUENSIS und BRASAvolA thun: die Beschreibung bei DIOSKORIDEs passt in keinem einzigen Stück. Ebensowenig darf man annehmen, dass das pyretlirum bei APICIUS (de re coquinaria libri decem; ed. Lister, Amstelodami 1709; 2,2 und 4,5) unser Küchenkraut Dragon sei; hier fehlt jede Beschreibung, und wenn DiERBACH (Flora Apiciana, Heidelberg 1831, S. 63) Wert auf den Zusatz minimum legt, den das pyretlirum an der ersten der angeführten Stellen erhält (er deutet ihn auf die kleinen Blütenköpfe des Dragon), so geht aus dem Zusatz modicum an der zweiten Stelle hervor, dass diese Worte die Quantität bezeichnen sollen: sehr wenig (eine Messerspitze) und müssig viel oder etwas. - Der Dragon kann also nicht unter dragantea des Capitulare verstanden sein. Wir wenden uns deshalb der zweiten Deutung zu, die wir gleich insofern modificieren, als wir ausser der schon oben genaunten auch noch andere Arten der Gattung Arum hinzunehmen.

Arum Dracunculus L., A. italicum L., A. maculatum L., Drachenwurz, Schlangenwurz.

Das Wort dragantea, dragontea, dracontea etc. wird in den Glossaren des CGL III erklärt durch colubrina, corcodrillion, herba varia ut serpens (ein Kraut, bunt wie eine Schlange) und durch eine Fülle anderer Namen, von denen noch einige angeführt werlen mögen: auricula asinina (Eselsohr), proserpinale, asclepias, affrissa, dorchadion, pitonion, (pythonion) $\left.{ }^{1}\right)$ etc. Die lateinisch-deutschen Glossare fügen noch den lateinischen Namen serpentina hinzu und verzeichnen als deutsche Namen drakenwort, naderwort,

1) Asclepias dragontea 5̌50, 57; afrissa dracrontea 550, 59; colul)rina . i . dracontea 557,62 ; corcodrillion dracontea 557,63; dragontea proserpinale 559,41 ; oricula asinina . i. dracontea 570, 48; dragantea erba uariaut serpens 589, 38. 
slangwrz (Schlangenwurz). Nun wird bei THEOPHRAST $(7,12,2)$ eine Arumart wegen ihres bunten Stengels opakóvtiov (drakontion, etwa unserem Drachenwurz entsprechend) genannt, und diese hält man für identisch mit einer der beiden Arten von Spakovtió bei Diosionides (2, 193 und 194), von denen jedenfalls eine Arum Dracunculus L. ${ }^{1}$ ) bedeutet. Diese Pflanze heisst noch jetzt in Griechenland Spakovtı́́, in Italien dragontea, dragonzio, serpentaria; sie war von Alters her ihrer Heil- und Zauberkräfte wegen berühmt, namentlich als Heilmittel bei Schlangenbissen und als Schutzmittel gegen solche und ist lange officiell gewesen (Raclix Dracunculi seu Serpentariae majoris). Möglicherweise hat der Schreiber des Capitulare an diese Pflanze gedacht, die noch hin und wieder in Gärten gebaut wird, aber wegen ihrer grossen Empfindlichkeit gegen Kälte in Deutschland niemals sehr grosse Verbreitung gefunden hat. Aber ebensowohl ist es möglich, dass man schon zu Karls des Grossen Zeiten mit Arum Dracunculus L. schlechte Erfahrungen gemacht hatte, und dass deshalb unter dragantea diejenige Pflanze zu verstehen ist, die bei ALBERTus MAgnus $(6,290)$ basilicus, $\left.{ }^{2}\right)$ dracontea oder serpentaria genannt wird und der dieselben Kräfte zugeschrieben werden, wie dem Arum Dracunculus L. Da von dieser Pflanze gesagt wird, sie habe eine gelbe Blume (florem autem habet croceum), so muss sie Arum italicum L. sein, denn dieses hat einen gelben Blütenkolben. Diese Arumart ist früher in Deutschland verbreitet gewesen. In Rostock steht sie, nach Mitteilung von E. H. L. KRAUSE, am ehemaligen Festungswall in unmittelbarer Nähe des Gartens, der vor Zeiten dem Nonnenkloster zum heiligen Kreuz gehörte, und zwar steht sie hier unter Arum maculatum L., wird also wohl mit diesem aus dem Garten hinausgeworfen sein. Der ältere REICHExBACH giebt sie von Beurtheim bei Carlsruhe, und vom Kaiserstuhl im Breisgau an (Mösslers Handbuch der Gewächskunde, 3. Aufl., Altona 1833-34, S. 1748). Wahrscheinlich kommt sie auch anderswo vor und wird, namentlich da sie später blüht als Arum maculatum L., wohl übersehen sein; es ist aber auch keineswegs ausgeschlossen, dass da, wo Arum italicum fehlte, Arum maculatum genommen wurde. - Erwähnt mag noch werden, dass die Knollen der Arumarten im Altertum gegessen wurden und noch jetzt an manchen Orten gegessen werden.

Die im Capitulare dragantea genannte Pflanze muss also eine Arumart gewesen sein, aber welche gemeint ist, lässt sich nicht mit absoluter Ge-

1) Die Pflanze heisst bei Plinius $(24,16,93)$ dracunculus.

2) Da mehrere Codices basiliscus schreiben, so scheint dieses Wort das richtigere zu sein, es passt zwanglos in die Reihe dracontea, serpentaria, colubrina etc. Bei Langhavel (S. 119) finden sich sehr viele Namen, die sich aus den Glossaren des CGL III bedeutend vermehren liessen. Im Colmarer Glossar scheint aschepa (74) verschrieben zu sein für asclepias, columbaria und columbina $(241,212)$ für colubrina, das übrigens im CGL III, 622, 18 auch columbrina geschrieben wird. 
wissheit ermitteln. In der Provinz Schleswig-Holstein werden Arumarten in Gärten überhaupt nicht mehr gezogen; Arum maculatum L. kommt aber an vielen Stellen vor (Schlossgarten von Glücksburg, Schleswig, Gelting, Husum etc.), die auf eine frühere Kultur mit Sicherheit schliessen lassen.

Noch eine Pflanze ist hier anzuführen, die mit den Arumarten in den volkstümlichen Namen übereinstimmt, nämlich

Polygonum Bistorta L., eine Knöterichart; sie heisst im mittelalterlichen Latein Bistorta, Serpentaria, Colubrina, italienisch bistorta und serpentina, französisch bistorte, und wird bei den Vätern der Pflanzenkunde Natterwurz, Schlangenwurz etc. genannt. Diese harmlose Pflanze verdankt ihren Namen nicht ihrem gefleckten Stengel, wie Arum Iracunculus L., sondern ihrer Wurzel (Rhizom), die bis fingerdick wird und sich im Erdboden hin- und herwindet, äusserlich braun und inwendig fleischrot ist. Als adstringierendes Mittel ist sie früher viel in unseren Apotheken gebraucht (Radlix Bistortae s. Colubrinae s. Serpentariae vulgaris rubrae) und deshalb auch mehrfach angebaut worden und verwildert. Jetzt kommt sie gelegentlich in Gürten als Zierpflanze vor. Übrigens gehört sie der deutschen Flora an und finclet sich sowohl auf Bergwiesen als auf moorigen Wiesen und Waldplätzen der Ebene.

\section{Koloquinte und Zaunrübe.}

Coloquentidas Capitulare 70,20. Citrullus Colocynthis Schrader, Koloquinte.

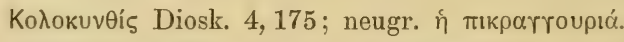

Colocynthis $^{1}$ ) Plin. 20, 3,8; it. coloquintida; fr. coloquinte.

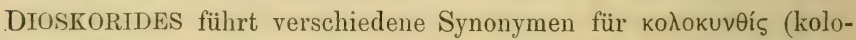

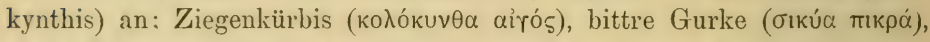

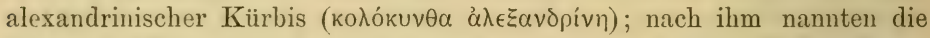
Römer die Koloquinte cucurbita silvatica, also „wilder Kürbis“. ${ }^{2}$ ) Von diesen Namen hat sich der zweite, bittre Gurke, im Griechischen erhalten; es ist aber das Wort úrroúpı (anguria) an die Stelle von бıкúa (sikya) getreten. Die römische Bezeichnung "wilder Kürbis“ blieb im Lateinischen erhalten. ${ }^{3}$ )

$\left.{ }^{1}\right)$ Wahrscheinlich ist die Pflanze, die Pusxius 20,3,7 cucurbita silvestris nenut, nichts anderes als die Koloquinte, obgleich er beide von einander zu unterscheiden sucht; aber seine Unterscheilung ist gekünstelt: die Koloquinte soll voll von Samen sein, die cucurbita silvestris, die er "inanis" nennt, aber nicht; mit „inanis" übersetzt er jedoch das Wort бoupós, das vielmehr "schwammig, locker" bedeutet und vortrefflich auf den Inhalt der Koloquinte passt.

2) Wildwachsende Pflanzen werden im Lateinischen durch die Adjektive silvaticus, silvester, agrestis und erraticus bezeichnet, gebaute oder zahme durch hortensis, hortulanus und domesticus; im Griechischen wird wild durch ärpıs, zahm durch

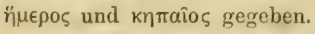

${ }^{3}$ ) In den Glossaren des CGL III finden wir: coloquintida idest cucurbita acrestes 537,12 ; coloquintide cocurbita saluatica 631,57 ; coloquintida agria. i. cocur- 
Dass dem Schreiber des Capitulare die Koloquinte als Drogue bekannt gewesen ist, kann kaum bezweifelt werden; wahrscheinlich hat er den Wunsch gehabt, diese früher viel gebrauchte Arzneipflanze auch in Deutschland zu ziehen; da die in den Handel kommenden Koloquinten reich an Kernen zu sein pflegen, so konnte ein solcher Versuch leicht gemacht werden. Aber es ist unzweifelhaft, dass der Versuch, eine Wüstenpflanze nach Deutschland zu versetzen, melır oder minder missglücken musste. Merkwürdig ist nur, dass man noch im 16. Jahrbundert die Koloquinte zu bauen versuchte, allerdings mit wenig Erfolg (Camerarius, Hortus medicus, S. 45); noch später hat man dann eine kleine Kürbisart als Koloquinte gebaut (PETERJIANN, Das Pflanzenreich, Leipzig 1847, S. 438). Gegenwärtig findet man sie in deutschen Gärten überhaupt nicht mehr.

Der Name „wilder Kürbis" wurde aber noch einer zweiten Pflanze beigelegt, deren Wurzel in ihren Wirkungen der Koloquinte ziemlich gleich kam, nämlich der Zaunrübe mit ihren verschiedenen Arten. ${ }^{1}$ ) Für uns kommt Bryonia cretica L., die bei den Neugriechen nach FRAAS

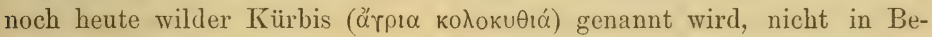
tracht, sondern nur

\section{Bryonia alba L. und B. dioica Jacquin, Zaunrübe.}

Die erste von diesen, die weisse Zaunrübe, trägt schwarze Beeren und wurde deshalb im Altertum schwarze Rebe genannt: $\ddot{\alpha} \mu \pi \epsilon \lambda \circ \varsigma \mu \epsilon \in \lambda \alpha v \alpha$ Diosk. 4, 182, vitis nigra Plin. 23, 1, 17; die zweite, die rote Beeren hat,

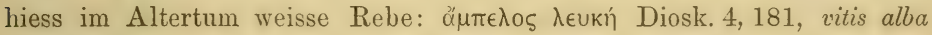
Plin. 23, 1, 16; diese Namen sind teilweise stark entstellt in die Glossare des CGLIII übergegangen. ${ }^{2}$ ) In Italien wächst namentlich Bryonia dioica und wird dort ausser brionia noch vite bianca, vite salvatica und zucca salvatica (wilder Kürbis) genannt.

In den Glossaren des CGLIII kommt schon ein althochdeutscher Name vor, nämlich liranca, ${ }^{3}$ ) der sich auch in den von HOFFJIANN herausgegebenen althochdeutschen Glossen findet. Andere deutsche Namen aus früherer Zeit sind helegeberen (Colm. Gloss. 143) und hilgebern (Mone 241, 18).

bita siluestris 559, 2; dem entspricht das "wilda churpitza“ der altdeutschen Glossare. Auch als Pepo ist die Koloquinte bezeichnet worden: pepon agro (statt $\pi \dot{\epsilon} \pi \omega v$ örploৎ) idest coloquintida CGL III, 542, 7.

1) CGL III: brionia . cucurbite agrestis 543,57 ; brionia . i cucurbita siluatica 553,20 ; brionia idest cucurbita 617,36 ; ferner 608,34 und 631,27 , wo die brionia beidemale cucurbita agrestis genannt wird.

$\left.{ }^{2}\right)$ Ampelus leo coagrias uites alba agrestes 631, 13; ampelus melina acria ums nigra agrestes 631,14 ; ampilos . milane . idest uites nigra 536,5; ampiololeuce . idest brionia 536, 6 ; ampelus leuco . uitis alba 542,18 (unten) etc. etc.

3) Hranca uitis alba 591, 31 und 625,1 ; uitis alba . i . hranca 596, 29; hancra idest uitis alba 612,58 ; -. hranca vitisalba ahd. Gl. $22,19$. 
Da die Wurzeln der beiden genannten Arten der Zaunrübe gleiche Wirkung haben, so wurden sie früher nicht weiter von einander unterschieden und beide wurden in den Apotheken als Radlix Bryoniae oder weisse Zaunrübe geführt. Bei älteren Angaben lässt sich also nicht immer feststellen, welche der beiden Arten gemeint ist.

Bei der heiligen HILDEGARD $(1,43)$ heisst die Zaunrübe brionia und stichurutz, bei ALBERTUS MAGNUS $(6,245)$ viticella; da er nur sagt, dass der Weinstock (vitis) sich ron viticella nach Farbe und Grösse der Trauben unterscheide (differt autem a viticella secundum colorem et quantitatem uvarum viticellae), so lässt sich nicht bestimmen, welche Art er meint; seine vitis alba ist nach der Beschreibung unser Teufelszwirn, Clematis vitalba L. Im 16. Jahrhundert heisst unsere Bryonia alba wegen ihrer Beeren Bryonia nigra oder Bryonia baccis nigris, unsere Bryonia dioica aber Bryonia alba und Vitis alba; an deutschen Namen kommen ausser Zaunrübe noch vor Stickwurz, Schmerwurzel, Hundskürbis etc. etc. Das Vorkommen der Zaunrübe in Norddeutschland ist durchaus an die Nähe von Städten und Gehöften gebunden, so dass man über ihren fremden Ursprung nicht zweifelhaft sein kann.

\section{Haselwurz und Osterluzei.}

Vulgigina Capitulare 70, 49; Asamum europaeum L., Haselwurz.

"Aбapov Diosk. 1, 9, fehlt im heutigen Griechenland.

Asaron Plin. 21, 6, 16; it. asaro, baccara, asara baccara, cariofillata sulvatica, nardo salvatico, spigo salvatico; fr. asaret, cabaret, nard sauvage.

Die Beschreibung, welche DIOSKORIDES von seinem asaron giebt, lïsst unsere Haselwurz mit Sicherheit erkennen; als Synonyme führt er an: vápঠos ärpı (wilde Narde), das damit gleichbedeutende nardus rusticus,

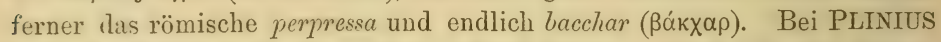
liegt die Sache nicht so einfach. Er will baccar $(21,6,16)$, für das er das Synonym nardus rusticus anführt, von asaron trennen; an einer anderen Stelle $(21,19,77)$ identificiert er baccar mit perpressa. Die Verwirrung scheint herbeigeführt zu sein durch die Pflanze baccharis (ßákxapıs), die bei DiosKorides $(3,44)$ als wohlriechende Kranzpflanze aufgeführt, aber so eigentuimlich beschrieben wird, dass man sie bis jetzt nicht hat deuteu kimmen. ${ }^{1}$ ) Trotz dieser Verwirrung kann es nicht zweifelhaft sein, dass die Römer die Haselwurz gekannt haben.

In den Glossaren des CGLIII erscheint die Haselwurz unter dem Namen vulgago, der dem offenbar verschriebenen vulgigina (statt vulgagina) des Capitulare zugruude liegt, und heisst ausserdem baccara und nardus

1) Bertolont meint, Flora italica, 2,403, dass die bei Veryil Ecl. 4, 19 und 7, 27 erwälinte Pflanze baccaris unser Alpenveileheu, Cyclamen europaeum L., sein könne, das in der Gegend von Brescia noch heute baccara heisse und zu den belicbtesten Kranzpflanzen gehöre. 
musticus; ${ }^{1}$ ) in den lateinisch-deutschen Glossaren finden sich die Namen asarum, baccara, asara baccara, gariofilus agrestis neben verschiedenen Formen von Haselwurz. ${ }^{2}$ )

Bei der heiligen HILDEGARD finden wir haselwurtz $(1,48)$ und asarum $(1,212)$. Albertus MagrNus beschreibt die Haselwurz unter dem Namen ungula caballina (Pferdehuf) sehr genau und giebt an, dass sie gewöhnlich herba leporis (etwa Hasengras) genannt werde; bei KONRAD roN MEGENBERG fehlt sie. Im 16. Jahrhundert heisst sie gewöhnlich Asarum und Haselwurz.

Die Haselwurz war vor Einführung der Ipecacuanha das wichtigste Brechmittel und unsere Apotheken haben lange Zeit Radix Asari s. Nardi rusticani s. Vulgaginis geführt. In den mitteleuropäischen Gebirgswäldern ist sie zwar heimisch, aber in die Ebenen ist sie künstlich verpflanzt und alle ihre Standorte auf der cimbrischen Halbinsel und den dänischen Inseln sind durch Auswildern aus Gärten entstanden. Gebaut wird sie heute nicht mehr.

\section{Aristolochia Clematitis L., Aristolochia, Osterluzei.}

'Apıбтоһохі́ Theophr. 9, 13, 3; 9, 14, 1 und sonst; Diosk. 3, 4.

Aristolochia Plin. 25, 8, 54; it. aristolochia; fr. aristoloche.

Die Alten unterschieden verschiedene Arten von Aristolochia, eine runde oder weibliche, eine lange oder männliche, und eine dritte, die clematitis genannt wurde. Da es in Südeuropa ziemlich viele Arten von Aristolochia giebt, so ist es nicht ganz sicher, welche Art jedesmal gemeint ist; jedenfalls scheint man in Griechenland andere Arten mit diesen Namen gemeint zu haben als in Italien.

Die Aristolochia war ein berülnmtes Heilmittel; deshalb begegnen wir ihr auch im Mittelalter wieder. Bei der heiligen HILDEGARD finden wir uristologiı $(1,126)$ und aristologia longa $(1,111$ u. 167) erwähnt; die letztere könnte Aristolochía longa L. sein, deren Kúultur sich ziemlich lange in Apothekergärten erhalten hat; ausserdem kommt aber auch noch biwerwurtz vor $(1,146)$, das unserer heutigen Aristolochia Clematitis L. entspricht. ALBERTUS MAGNUS unterscheidet nach dem Vorgange von DIUSKORIDES drei Arten von aristologia (6, 277-278), ebenso KONRAD VON MIEGEnberG $(5,4)$, der als deutschen Namen hobwurz anführt.

Ausser den schon genannten biwerwurtz oder bywerwurtz, das im 16. Jahrhundert als Biberwurtz vorkommt, findet sich der mittelhochdeutsche Name holworz (Sum. 52, 19 u. 20), der sich gleichfalls erhalten hat, zuweilen aber auch auf den hohlwurzeligen Lerchensporn, Corydalis cava L., angewendet worden ist.

1) Asaro - bulgagine 542,22; asaro uulgagine 631,16; nardorustico . i baccara $570,20$.

2) Assarab acaca (statt asara baccara) hasselewort, borlbotz (Königsb. Gloss.); im Colmarer Glossar: asarum haselworth 73; baccara haselworth 104; asara bacra haselworth 78; gariofilus agrestis haselworth 354 . 
Von den verschiedenen Aristolochiaarten hat sich in Norddeutschland nur Aristolochia Clematitis L. gehalten, die an verschiedenen Stellen verwildert ist und sich offenbar ganz acclimatisiert hat.

\section{Springkraut und Wunderbaum.}

Lacteridas Capitulare 70, 71; Euphorbia Lathyris L., Kreuzblättrige Wolfsmilch, Pillenkraut, Springkraut.

NaOupís Diosk. 4, 164; fehlt in Griechenland.

Lathyris Plin. 27, 11,71; it. cacapuzza, catapuzia; fr. catapuce, épurge.

Diese Pflanze war früher in den Gärten sehr verbreitet. Jetzt zieht man sie nur noch selten, aber an vielen Orten kommt sie verwildert vor. Die Namen Springwurz, Springkraut etc. verdankt sie dem Umstande, dass die Früchte bei voller Reife aufspringen und die Samen fortschnellen. Eine andere Reihe lateinischer und deutscher Namen erhielt sie wegen ihrer stark abführenden Eigenschaften. ${ }^{1}$ ) In der alten Medicin hiess sie Cataputia minor (von dem griechischen ko.tattótıov, das etwas, was verschluckt wird, bedeutet, und also Pillen, Pulver und Trank sein kann); ausserdem führt sie in den Glossaren des CGL III noch verschiedene Namen, wie coctus nidus, septegrania ${ }^{2}$ ) etc. Als Tithymalus und Tithymalus major wird sie später aufgeführt. Frühzeitig erkannte man ihre gefährlichen Eigenschaften; deshalb kam sie mehr und mehr in Vergessenheit und an ihre Stelle trat der weniger gefährliche Wunderbaum, der Cataputia major genannt wurde.

Ricinus communis L., Wunderbaum, Ricinus.

Kро́тwv Theophr. 1, 10,1; кі́кı und кро́тшv Diosk. 4, 161; neugr. кі́кı. fr. ricin.

Cici, croton, ricinus Plin. $15,7,7 ; 16,23,35 ; 23,4,41$; it. ricino;

Der Wunderbaum, aus dem tropischen Afrika oder Asien stammend, ist in Egypten seit uralten Zeiten kultiviert worden, und zwar wegen

1) In den Glossaren des CGL III heisst sie purgaturia und purgaturia dulcis 568,$20 ; 573,35$; 592, $2 ; 613,32$; ferner citochacim 577,44 , citochacun 621,68 , wozu die aus anderen Glossaren bekannten Namen citocatia und citocotia stimmen. - VIxCENTIUS Bellovacenois, der allerdings das Unglück hat, dem harmlosen Kohl das unterzuschieben, was für das Springkraut bestimmt war, sagt in seinem Speculum naturale 11; 33: „Brassica est oleris genus que et citocacia vocatur. Dicta est autem citocacia eo quod ventrem depurgat quam vulgus corrupte citocociam vocant."

2) Coctus nidus lacteridas 557,$25 ; 621,45$; laterico septegranica 592,16 ; septegrania lacteria 595, 3; lacteria idest septem grana 613,42 ; lacteria, lactiria, latiria

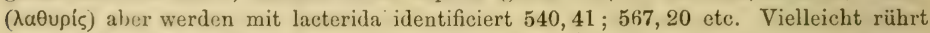
der Name septem grana etc. aus einer lateinischen Übersetzung des Dioskorides her,

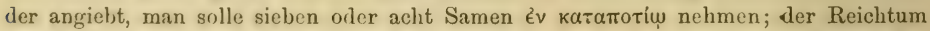
der Pflanze an Mtilchsaft (lac) ist wahrscheinlich die Ursache, dass aus lathyris allmählich lactiris wurde; dass dieses Wort mit seiner Genitivendung, also lactiridos, schliesslich nach der ersten Declination abgewandelt wurde, darf nicht Wunder nehmen, da ähnliche Gewaltthätigkeiten sehr viel vorkommen. 
seines Öles, das als Brennöl benutzt wurde. HERodot $(2,94)$, nenut

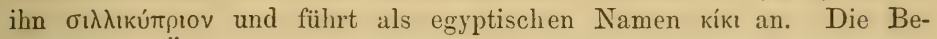
reitung des Öles wird bei DIOSKORIDES $(1,38)$ sehr genau beschrieben, auch bei PLINIUS $(23,4,41)$. Der griechische Name кро́тuv (kroton) und der lateinische ricinus, die beide zugleich die Holzteke oder den Holzbock (Ixodes Ricinus L.) bedeuten, sollen der Pflanze deshalb gegeben sein, weil ihre reifen Samen einem solchen voll Blut gesogenen Tier sehr ähnlich sehen.

Nach PLINIUS fehlt es zunächst fast vollständig an Nachrichten über den Wunderbaum, denn auch in den Pflanzenglossaren kommt er wenig oder garnicht vor. ${ }^{1}$ ) Erst bei ALBERTUs MAGNUS wird er wieder erwähnt $(6,20)$ und zwar als arbor mirabilis; ebenso nennt ihn KONRAD VON MEGENBerg $(4 \mathrm{~A}, 4)$, der als deutschen Namen wunderleich paum hinzufügt, in seiner Beschreibung aber sehr genau mit derjenigen bei ALBERTUS MAGNUS übereinstimmt. Im 16. Jilhrhundert heisst er Ricinus, Cataputia major und Palma Christi, auf deutsch ausser Wunderbaum noch Zeckenkörner, türkischer Hanf etc. Die Apotheken führten seine Samen als Semen Ricini s. Cataputiae majoris, das daraus gewonnene Öl als Oleum Ricini s. Castoris s. Palmae Christi.

Früher wurde der Wunderbaum seiner Samen wegen auch in Deutschland gezogen; jetzt dient er wohl nur noch als Zierpflanze.

\section{Klette, Pestwurz und Grindlattich.}

Parduna Capitulare 70, 28.

Die frühere Lesart war bardana und es ist wohl möglich, dass Parduna aus Bardana oder aus dem auch vorkommenden Bardona entstellt ist. In den Glossaren des CGL III kommt Bardana nicht vor, aber an zwei Stellen $(594,5,10$. Jahrh.; 615, 63, 11. Jahrh.) wird das äh11liche parada mit lapacium identificiert. Nun bedentet Bardana unsere Klette, und diese ist von jeher mit Pflanzen verwechselt worden, die sich durch mehr oder weniger ähnliche, namentlich durch grosse Blätter auszeichnen, wie Huflattich- und Ampferarten. Es ist daher nicht möglich mit Bestimmtheit anzugeben, welche Pflanze in Capitulare gemeint ist.

$$
\text { Klette, Arctium Lappa L. }
$$

"Apкєıv Diosk. 4, 105; neugr. $\pi \lambda \alpha \tau \epsilon \dot{\alpha}, \pi \lambda \alpha \tau u \mu \alpha v \tau u \lambda i \delta \alpha$; kommt in Griechenland sehr selten und nur in Hochgebirgsschluchten vor (Fraas).

Persolata, arcion Plin. 25, 9, 66; it. bardana, lappa, lappa maggiore; fr. glouteron, bardane.

Der vorangestellte Linnéische Name bezeichnet nach heutiger Auffassung mehrere Arten von Kletten (Lappa officinalis Allioni, L. tomentosa Lam. und L. minor DC.) und ist gerade deshalb gewählt worden,

1) CGLIII: Crotones . i . ericini 556,40; ricinus croconia 594, 49; ricinus idest crotonia 628,36 . 
denn im täglichen Leben unterscheidet man nicht so strenge. DIOSKORIDES fülırt rerschiedene Synonyme für äpкєiov (arcion Plin.) an:

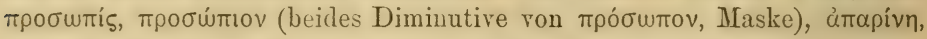
$\left.\lambda a^{\pi} \pi \pi \alpha^{1}\right)$ und das römische personacea, das etwa maskenartig bedeuten würde. $\left.{ }^{2}\right)$

In den verschiedenen Glossaren kommt die Klette unter sehr verschiedenen Namen vor. An lateinischen finden sich: bardana, bardo, fiardona, ${ }^{3}$ ) lappa (auch bei ALBERTUS MAGNUS 6,376), personatia; an deutschen: clette (clettu bei der heiligen HILDEGARI 1,98), chlette, clive, letteche, grosz leteche, breitleteche.

Die Klettenarten, die durch den grössten Teil von Europa verbreitet sind, gelten seit uralten Zeiten als Heilmittel; die WVurzeln und jungen Triebe sollen auch gegessen werden.

Pestilenzwurz, Pestwurz.

Petasites officinalis Mönch. (Tussilago Petasites L.)

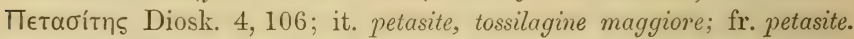
Die jugendlichen Blätter der Petasitesarten sind schon frühzeitig mit denen des Huflattichs, Tussilago Farjara L., verwechselt worden. Dieser wird genannt

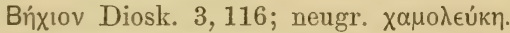

Chamacleuce, farjugium Plin. 24, 15, 85; bechion, tussilago Plin. 26, 6, 16 (quidam eandem (sc. tussilaginem) esse arcion putant); it. farjara, ugna di cavallo, ugna d'asino; fr. tussilage, pas d'âne.

Hujlatich, roszlhuf und huf kommen in den Glossaren auch als Deutung von barduna vor, werden aber mit sehr viel mehr Recht auf die Pestwurz und den Huflattich bezogen, ebenso wie grosz leteche. Der Huflattich ist eine gemeine und als Ackerunkraut gefürchtete Pflanze und wurde deshalb sicher nie gebaut, sondern nur gesammelt. Die Pestwurz hat aber hier im Norden so eigentümliche Standorte, dass man annehmen muss, sie sei eingefülırt und gebaut worden: sie findet sich in der Nähe

1) Lappa bedeutet, wie Klette bei uns, nicht nur die ganze Pflanze, sondern atuch den einzelnen Blütenlkopf, der sich mittels seiner Haken an Kleider, Haare etc. anhängt. Er ist dann auf solche Pflanzen übertragen, die mit Haken versehene

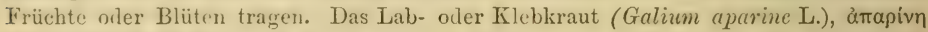
1)roskrides $(3,94)$, wird Lappa greuannt (lappa quae in frumentis est oder crescit C(FL III 535, 37; 549,45); wegen der Anlïinglichkeit seiner Früchte an menschliche

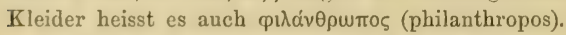

?) Man sieht zuweilen, dass Kinder ein grosses grünes Blatt als Maske vor das Gesicht balten, nachdem für die Augen, für Nase und MIund Löcher hineingemacht sind; da derartige Spiele oder Gebräuche sehr alt zu sein pflegen, so könnten die Namen Prosopis uni personata etc. einem solchen Gebrauch ihren Ursprung verdanken.

${ }^{3}$ ) Bei Diefenbach, Novum Glossarium etc. ist angegeben: bardona cletes vel burres; im Dänischen heisst die Klette Burre. - In den Glossaren des CGL III werden lappa und personatia vielfach mit drauoca identificiert z. B. 592, 30; 594, 2; das Wort drauoca scheint sonst nicht vorzukommen. 
ehemaliger Klöster und dazu gehöriger Höfe, von wo aus sie sich dann, wie in den Elbmarschen, weiter verbreitet hat. Ehemals war sie ein sehr hoch geschätztes Arzneimittel. Die heilige HILDEGARD nennt sie Huflatta major (1,210). - Endlich ist noch eine Pflanze namhaft zu machen, ${ }^{1}$ ) die unter den Synonymen von Bardana etc. mit verstanden

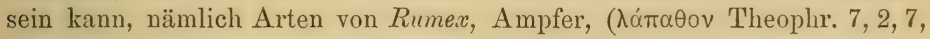
Diosk. 2, 140; lapathon und rumex Plin. 20,21,85) und zwar grossblättrige Arten, wie Rumex obtusifolius L., stumpfblättriger Ampfer. Auf diesen beziehen sich lapathum, und namentlich das deutsche Grindlattich. Die Wurzel dieses Ampfers wurde in den Apotheken als Grindwurzel, Radlix Lapathi acuti s. Oxylapathi, geführt und als Nittel gegen chronische Hautausschläge, Kopfgrind, Schorf etc. gebraucht. Es würde deshalb nicht richtig sein, wenn man Oxylapatlum immer mit Sauerampfer übersetzen wollte. Die heilige HILDEGARD nennt Rumex obtusifolius L. menua, (1,102), ALBERTUs MAGNUS lappatiun (6,377); die grintwurtz der heiligen HILDEGARD $(1,138)$ ist aber unser Schöllkraut, da als ihr lateinischer Name chelidonia angegeben wird.

\section{Schöllkraut, Schwalbenwurz.}

Chelidonium majus L., Schöllkraut.

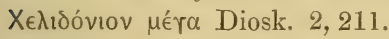

Cheliclonia Plin. 25, 8,50; 25, 12, 91 , it. celidonia, chelidonia maggiore; fr. chélicloine.

Die Pflanze trägt nach DIoskorides den Namen Chelidonium (von $\chi \in \lambda_{\imath} \delta \dot{w} v$, die Schwalbe), weil sie bei Ankunft der Schwalben aus der Erde hervorbreche und bei deren Weggang dahinwelke, oder auch deshalb, weil eine blindgewordene junge Schwalbe von der Schwalbenmutter durch dieses Kraut wieder sehend gemacht werde; PLINIUS erzählt sogar, dass junge Schwalben, denen die Augen ausgestochen sind, durch dieses Kraut ihr Sehvermögen wiedergewinnen. Der Glaube an diese weitgehende Heilkraft hat sich bis ins 16 . Jahrhundert und drüber hinaus erhalten und der Pflanze auch im Deutschen den Namen Schwalbenwurz eingetragen; sonst hiess sie gewölnlich Scheliwurz orler Schellkraut, ganz früh und bei der heiligen HILDEGARD $(1,138)$ auch grintwurtz; aber ihr lateinischer Name blieb Chelidonia major und chelidonium magnum. Nicht nur als Mittel gegen Augenleiden, sondern auch noch gegen eine grosse Zahl von anderen Gebrechen stand das Schöllkraut in Ansehen;

1) Um die Verwechselung der Namen zur Anschauung zu bringen, seien hier einige dersilben angeführt. Sumerlaten: lappa, letteche vel clette 11,12; lapatium hufleticha 22, 55; lapatium pleteche 40,60 ; bardana groz letheche 5 4,62 ; - Colm. Glossar: bardana hôflodecke 96 ; lapacium scorflodecke 412 ; perysonantia grôtelodeke 5:8. - Mone: bardana schorfladeke vel uofladeke vel huf; - Diefenbach Glossarium: bardana gryntlattich, huflatich, grote ladiken; personatia grosz kletten, krotenbleter, huflatig vel roszhuf etc. etc. 
TABERNAEJTONTANUS braucht mehr als vier und eine halbe Folioseite, un alle Heilwirkungen desselben aufzurechnen. Hier im Norden Deutschlands deutet das ausschliessliche Vorkommen der Pflanze an Gartenwällen und Dorfstrassen auf eine frühere Kultur.

DIOSKORIDES unterscheidet noch ein kleines Chelidonium ( $\chi \in \lambda_{t}-$

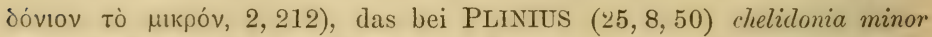
genannt wird. Es ist dies unsere Feigwurz (Ranunculus Ficaria L.), auch Scharbockskraut genannt, ehemals ein bekanntes Heilmittel und als solches in den Apotheken Chelidonium minus genannt. Die Blätter sind auch als Salat gegessen worden. - Die in den Blattachseln sich entwickelnden Brutknöllchen, die kleinen Weizenkörnern gleichen, bleiben nach dem Absterben der Stengel und Blätter auf dem Erdboden liegen; bei DIOSKORIDEs heisst die Pflanze deshalb auch wilder Weizen (Tupòs urpros), bei uns ist gelegentlich von "Weizenregen" geredet worden.

\section{Mutterkraut und Nieswurz.}

Febrefugiam Capitulare 70,46; Chrysanthemum Parthenium Persoon (Matricaria Parthenium L.), Mutterkraut, Mater, Bertram, römische Kamille.

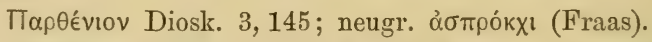

Parthenium Plin 21,30,104; it. matricale, matricaria, partenio; fr. matricaire.

Die Deutung des Namens febrefugiam ist mit einigen Schwierigkeiten verbunden, denn es giebt viele Pflanzen, die als Fiebermittel gegolten haben. So wird artemisia einmal als febrefugia gedeutet (CGLIII, 543,44); auch das Tausendgüldenkraut (Erythraea Centaurium Persoon), Erdgalle (fol terrae) und Aurine genannt, im späteren Latein auch noch Centaurium minus (od. Centauria minor) und Helleborites, wurde als febrifugia bezeichnet und heisst noch heute in Italien caccia feblre und erba da febbre; es war in der That ein Fiebermittel und ist es stellenweise heute noch, aber es lässt sich nicht nachweisen, dass es jemals gebaut wurde, vielmehr scheint es nur gesammelt worden zu sein.

Weitaus die meisten Glossare deuten felrefugia durch matrona, metere, matre, ${ }^{1}$ ) also durch Chrysanthemum Parthenium Persoon, das noch leute die Namen Mutterkraut und Mater trägt und schon von der heiligen HILIEGARD $(1,116)$ metra genannt wurde. Das Mutterkraut findet sich in Norddeutschland vielfach in Gartenzäunen verwildert, wird aber auch noch gebant. Es stammt aus Südcuropa. - In den Apotheken führte es die Namen Matricaria oder Partlienium.

KERNER (S. 818) hat febrefugiam als Helleborus viridis L., die grüne Nieswurz, deuten wollen; er hielt nämlich I'arduna (vergl. S. 59)

1) CGL III; febrefugia . i matrona 563, 56; matrona febrefugia 592,58 und sonst; - Febrifuga Matre Colm. Gloss. 326; febrifuga, metere Sum. 57, 5. 
für eine Verdrehung von Parthenium und deshalb für gleichbedeutend mit Mutterkraut. Von der Annahme ausgehend, dass zwei Pflanzen wie Mutterkraut und grüne Nieswurz, die in den Bauerngärten so häufig sind, auch im Capitulare genannt sein müssten, hat er dann febrefugiam als gleichbedeutend mit Helleboms viridis genommen, weil febrefugia und eleborites gleichbedeutend im Helmstädter Glossar genannt werden.

Nach den älteren Glossaren aber ist eine solche Deutung nicht zulässig, denn es wird eleborites (statt helleborites) ${ }^{1}$ ) allerdings vereinzelt mit febrefugia, meist aber mit centauria minor identificiert, und dieses wieder mit fel terrae, lauter Namen für das Tausendguildenkraut. Ein eigentliches Fiebermittel scheint die grüne Nieswurz auch nicht gewesen zu sein, wohl aber sonst ein sehr geschätztes Arzneimittel. Sie ist vielfach mit der schwarzen Nieswurz (Helleborus niger L.) oder Christrose verwechselt worden, ja sie wurde sogar als "schwarze Gartennieswurz mit grünen Blumen" (Helleborus niger hortensis flore viridi) bezeichnet (IVEINMANN, Phytanthozaiconographia Tab. 569).

\section{Alant.}

Inula Helenium L., wahrer oder ächter Alant.

'E $\lambda$ évıov Diosk. 1, 27.

Inula Colum. 10,118; 11, 3,35; 12,46; Plin. 19,5, 29; it. elenio, enula campana; fr. aunée.

Der Alant hat seine eigentliche Heimat in der südlichen Hälfte Europas. In Norddeutschland wurde er früher viel kultiviert und findet sich jetzt in Grasgärten und auf Wiesen verwildert.

Die Römer benutzten den Alant nicht nur als Arzneimittel, sondern auch als Genussmittel: die Wurzel wurde mit verschiedenen Substanzen für die Küche eingemacht. COLUMELLA braucht ein ganzes Kapitel $(12,46)$, um verschiedene Methoden des Einmachens darzustellen. Ähnliches ist auch in Deutschland geschehen, meistens hat man den Alant aber als Arzneimittel benutzt. In den Apotheken führt er die Namen Enula, Enula campana (schon DIOSKORIDES führt als Synonym

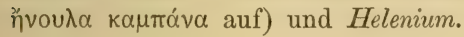

\section{Eibisch.}

Mismalvas Capitulare 70, 50; Invent. II, 19; Althaea officinalis L., Althee, Eibisch.

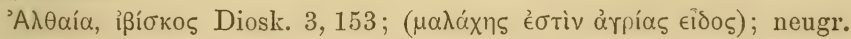

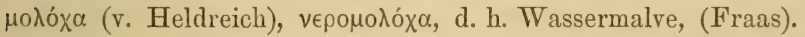

Althaea, plistolochia Plin. 20, 21, 84; hibiscus, moloche agria, $\pi \lambda \in € \sigma \tau o-$

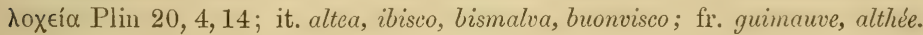

1) CGL III: eleborites . centauria minora 546, 11; eleboritis centauria minor 560,61; felterrae centauria 590,59. - centauria minor, ertgalle Sum. 56, 47. 
Die ganze Pflanze, namentlich aber die schleimige Wurzel, hat seit alten Zeiten als heilkräftig gegolten. Sic kommt in ganz Europa mit Ausnahme des Ostens und Nordens vor und liebt namentlich feuchte, salzige Stellen. Hier in der Provinz findet sie sich mehrfach an Buchten und Seen der Ostseeküste; im Innern des Landes ist sie stellenweise in Folge früherer Kultur verwildert.

Die Beliebtheit der Pflanze fiudet ihren Ausdruck in der grossen Zahl von Namen, mit denen sie zu verschiedenen Zeiten genannt wurde. In den Glossaren des CGL III heisst sie altea, euiscus, ibiscus und uismalva $(548,30 ; 580,2$ etc.), bei ALbERTUS MAGNUs $(6,285)$ altea, bismalva und malvaviscus, bei KONRAD VON MEGENBERG $(5,10)$ alcea und bismalva; alle diese Namen haben sich erhalten. Bismalva ist offenbar aus uismalva, dem das französische guimauve entspricht, hervorgegangen; es ist deshalb wahrscheinlich, dass das mismalvas im Capitulare ein Schreibfehler ist. An deutschen Namen sind anzuführen: ybischa (heilige HILDEGARD 1, 141), weizpapel (KONRAD VON MEGENBERG 5,10 ), ywesche (Colm. Gloss. 22, 319, 399), ibesche (Sum. 55, 6), grote pepele (statt popele Königsb. Gloss.), Eibisch und Althee.

\section{Mohn.}

Papaver Capitulare 70, 47; Papaver somniferum L.

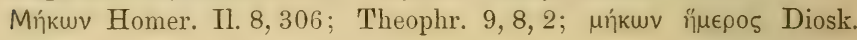

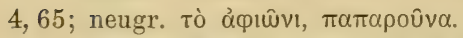

Papacer Verg. Georgic. 1, 78 u. 212; 4, 545; Colum. 10, 104 u. 314; 11, 3, 42; Plin. 19, 8, 53; it. papavero; fr. pavot.

Der Mohn ist eine uralte Kulturpflanze, deren Heimat das südliche Europa ist. Ursprünglich wurde er seines Samens wegen gebaut, nach dessen Farbe man weissen und dunklen Mohn unterschied; bei diesen beiden Rassen sind die Blumenblätter auch entsprechend heller und dunkler gefürbt. Die Alten kannten aber auch schon die schmerzstillenden und sonstigen Wirkungen des Mohnsaftes (ỏmós), und sie verstanden es, ihn rein zu gewinnen und seine Verfälschungen mit Gummi

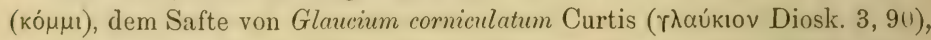
und demjenigen vom wilden Salat (Lactuca Scariola L., $\theta p i ́ \delta \alpha z$ ảrpía Diosk. 2, 165) zu erkennen.

Die wilden Mohnarten, Klatschrosen, waren den Alten teilweise bekannt, aber sie wurden ebensowenig strenge geschieden wie es jetzt

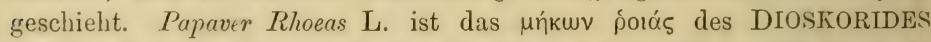
$(3,44)$; Papaver Argemone L. ist das polás des Theophrast $(9,12,4)$

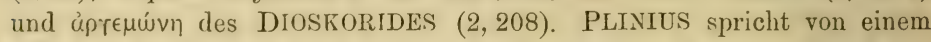
wilden Moln, papaver erraticum, den die Griechen rhoeas nennen $(19,8,53$; 2), 19,77). In Griechenland heissen die wilden Mohnarten mit Einschluss von Papaver dubium L. jetzt $\pi \alpha \pi \alpha \rho o ̂ v \alpha$, in Italien papavero salvatico, papavero erratico und rosolaccio. 
Der althochdeutsche Name des Mohns ist mago ${ }^{1}$ ) (ahd. Gl. 7, 13) in den Sumerlaten findet sich man $(58,32)$ und magesumo $(63,23)$ als Übersetzung von papaver, aber auch veltmage $(23,27)$, so dass man für den zahmen und den wilden Mohn nur eine Bezeichnung gehabt zu haben scheint. Die heilige HILDEGARD kennt nur papaver $(1,96)$; ALBERTUS MAGNUS unterscheidet papaver hortense et campestre $(6,419)$ und nennt den letzteren, den Feldmohn, ein Unkraut des Hafers (zizania avenae); beim Gartenmohn erwähnt er die Varietäten mit weissem und dunklem Samen, ebenso wie KONRAD von MEgEnBERG, der den Mohn migenkraut nennt $(5,61)$. Im 16. Jahrhundert wird der Mohn viel gebaut und unter anderem auch Ölmagen genannt.

In Deutschland findet der Mohn kaum noch seiner medicinischen Eigenschaften wegen Anbau und Pflege, denn das Opium wird aus südlicheren Gegenden importiert. Mohnsamen wird aber in manchen Gegenden in Backwerk und an Speisen genossen, auch wird ein wohlschmeckendes Öl daraus gewonnen. In Mittel- und Süddeutschland sieht man Mohnfelder; in Norddeutschland findet man den Mohn wohl nur in Gärten.

\section{Laserkraut, Ammi und Liebstöckel.}

Silum Capitulare 70, 23. Siler montumum Crantz (Lıserpitium siler L.), Laserkraut; it. seseli, sermontano, sileos, silermontano; fr. séséli?

Das Wort silum hat sehr verschiedene Deutungen erfahren und es ist wahrscheinlich, dass unter diesem oder einem ähnlich klingenden Namen mehrere Pflanzen in Gebrauch waren, wie die Seseliarten des DIOsKorides $(3,53-55)$ und das sil des Plinitus $(20,5,18)$. In den Glossaren des CGL III wird Silus mehrfach durch Sisileus erklärt, und dieses wieder durch Silus montanus. ${ }^{\prime)}$ Da nun unsere Apotheken unter dem Namen Semen Sileris montani s. Seseleos die Samen der in der Überschrift genannten Pflanze führten, so erscheint es jedenfalls nicht unwahrscheinlich, dass unter dem silum des Capitulare das Laserkraut gemeint gewesen ist. Das Fehlen der Pflanze in den Gärten kann als Gegenbeweis nicht angesehen werden, denn das Capitulare drückt zunächst nur Wünsche aus, schildert aber nicht vorhandene Zustände. Die Samen des Laserkrauts, das auf den Gebirgen des südlichen Europas wïchst, stehen bei den Gebirgsbewohnern als Heilmittel noch in demselben Ansehen, das sie früher allgemein genossen.

1) In den Glossaren des CGL III findet man folgende Zusammenstellungen:

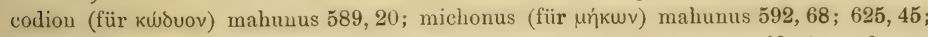
codion idest ma unus 610,37 ; miconus idest manus 614,41 ; papaver idest ma hunus 616,5 ; das Wort mahunus erfuhr noch weitere Veränderungen, deun machones (Sum. 40,79 ), das durch magesame übersetzt wird, dari man wohl als Umformung von mahunus ansehen.

2) Silus . i. sisileus 576,72 ; siseleos sile 632,52 ; sisileos . i . silos montanus 586,4 ; ähnlich $595,7$.

v. Fischer-Benzon, altd. Gartenflora. 
A LBERTLS MAGNUS $(6,448)$ und KONRAD VON MEGENBERG $(5,72)$ führen beicle das Laserkraut unter dem Namen siler montamum auf, dem KONRaI TON MEgENberG den deutschen Namen gaizvenichel hinzufügt. Im 16. Jahrhundert hiess es Sesel, Zirmet und Silermontan.

Ameum Capitulare 70, 22; Ptychotis coptica DC. (Ammi copticum L.), koptische Haardolde, Ammi.

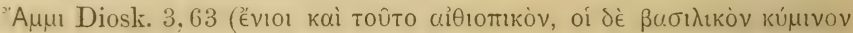

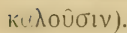

Ammi Plin. 20, 15, 58.

DIOSKORIDES sagt, dass das ammi ebenso wie cuminum :ithiopisch

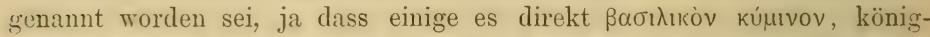
liches cuminum, ebenso wie das cuminum selbst genannt hätten. Dieselbe Sache findet sich bei PLINIUS und ist von ihm oder von DIOSKORIDES ans in die Glossare des CGL III übergegangen. ${ }^{1}$ ) Es hat also in alten Zeiten eine Verwechselung ziwischen Ammi und dem Kreuzkümmel stattgefunden. Die Samen von der, aus den südöstlichen Mittelmeerlündern stammenden, koptischen Haardolde wurden früher in den Apotheken als Semen Ammeos veri s. cretici geführt. Dass die Pflanze selbst früher in Deutschland gebaut wurde, geht aus dem Kräuterbuch des TABERNAEJONTANUS hervor, der 1,299 eine Abbildung bringt, unter dem Namen Ammium Alexandrinum; er bemerkt, dass dieses Ammium alle Jahr erneuert werden müsse aus frischem Samen, „sintemal es ein recht Sommergewächs ist, das gar keinen Frost leiden kann". Die schwierigkeit des Anbaus wird denn auch die Ursache dafür gewesen sein, dass dies Gewächs allmählich ganz aus den Gärten verschıunden ist. In den Apotheken wurden die Samen des grossen Ammi, Ammi majus L., (it. ammi, comino nostrale), als gemeine Ammeisamen, Semen Ammeos vulgaris, geführt. Da das grosse Ammi schon in Südeuropa vorkommt und härter ist als die Haardolde, so wäre es immerhin möglich, lass mit dem ameum des Capitulare Ammi majus gemeint sein köınte.

Lenisticum Cippitulare 70, 33; libesticum Invent I, 7; licesticum Invent II, 3. Ligusticum Levisticum L. (Levisticum officinale Koch), Lieh)stöckel.

Mıruotikóv Diosk. 3, 81?

1) Baselice . i . amaeos 554,45; 618,75; cuminum aethiopicum . i a ameos 5.58, 62, 范nlich 622, 49. - Unter den viclen Deutungen, die das CGL 1II bringt, seieu noch dis: folmenten erwïhnt. Ameus wird als semen nuclei gedeutet 535, 16; 544, 25; dic nuclei sind aber $\sigma \tau \rho \circ \beta\{\lambda \iota \alpha 15,44 ; 88,7 ; 185,11 ; 256,14$, also T'annenzapfen, und da diese unter den Näschereien des Nachtisches genannt werden, werden wir darunter Pinienzapfen $z u$ verstehen haben, also unter den amei Pignolen oder Piniennüsse. Ferner wird ameus als pes milvinus gedeutet 549, 46; 535, 38, Fuss des Falken oder der Gabelweihe; dieser Name kommt verschiedenen Pflanzen zu, unter anderen dem Plantrigo coronopus L. Auch findet sich die wenig sagende Bemeikung, dass ameus ein Kraut sei, dessen Samen denjenigen des Sellerie glichen (ameus idest erba semen eius similat apii semen 607,5 ) etc. 
Ligusticum Colum, 12, 57, 5; Plin. 19, 8, 50; 20, 15, 60; 20, 17, 73; it. levistico, ligustico; fr. ligusticum.

Bei Columella findet sich nur der Name ligusticum; etwas mehr finden wir bei PLINIUS, aber das was er sagt, stimmt ziemlich genau überein mit demjenigen was DIOSKORIDES mitteilt, und bei diesem passt die gegebene Beschreibung nicht auf Ligusticum Levisticum L. PLINIUS giebt keine Beschreibung; nach ihm wird die Pflanze auch pana $x^{1}$ ) genannt, nach DIOSKORIDES mávakes. Wir sind also jerlenfalls im Unklaren darüber, was die Alten unter ligusticum verstanden, um so mehr, weil sie diese Pflanze assen, was uns etwas wunderbar vorkommen würde. Indessen kann es nicht zweifelhaft sein, dass mit dem leuisticum des Capitulare die Pflanze gemeint ist, die jetzt im Volksmunde Liebstöckel heisst; denn dies Wort ist ebenso wie die älteren Formen lubesteche, lulistechel, levestock etc. nichts anderes als eine Angleichung an leristicum oder libesticum, und Liebstöckel (Ligusticum Levisticnm L.) war früher eine sehr geschätzte Heilpflanze.

Schon WALAFRIDUS STRABUS besingt libysticum in seinem Hortulus. Die lieilige HuLDEGARD $(1,139)$ hat neben dem lateinischen Namen levisticum den deutschen lubestuckel; ALBERTUS MAGNUS erwähnt livisticum gelegentlich bei der Vergleichung von Pflanzen (6, 349 und 414), widmet ihm aber keinen besonderen Abschnitt, ein Verfahren, das er bei sehr bekannten Pflanzen anzuwenden pflegt.

Im Laufe der Zeit hat die Pflanze viel von ihrem Werte verloren und spielt gegenwärtig nur noch eine Rolle in der Volksmedicin. Früher ist sie hier in der Provinz viel kultiviert, jetzt findet sie sich nur noch selten; an einigen Stellen ist sie ausgewildert.

\section{Diptam und Raute.}

Diptamnum Capitulare 70, 38.

Zwei Pflanzen haben seit langer Zeit den Namen Diptummus oder richtiger Dictamnus geführt: der Diptamdosten, Origanum Dictamnus L., und der gemeine Diptam, Dictamnus albus L.; nur der erste war den Alten bekannt und seine Eigenschaften scheinen in späterer Zeit vielfach auf den zweiten übertragen worden zu sein.

Origanum Dictamnus L., Diptamdosten, kretischer Diptam.

1) In den meisten Glossaren des CGL III wird die Wurzel von Levisticum panacus regius genannt. Es scheint, dass dieser Name, der sich bei keinem älteren Schriftsteller findet, durch falsches Abschreiben entstanden ist. Das letzte der mitgeteilten Glossare, dessen Handschrift aus dem 9. Jahrhundert stammt, hat panacos rizos libertici radicis 632,45 ; daneben finden wir: pancugirius 548, 39, 9. Jahrh., panicus rigius $585,22,10$. Jahrh., panicus regius $593,49,10$. Jahrh. und panacus reius 615,33 , 11. Jahrh., und zwar als griechisch dem lateinischen levistici radices gegenübergestellt; schon die erste von den hier mitgeteilten Glossen ist verschrieben und müsste heissen:

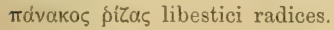




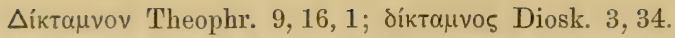

Dictamnum Vergil Aen. 1, 412; dictumnus Plin. 25, 8, 52; 26, 14, 87; it. dittamo cretico.

Der Diptamdosten, dessen Heimat der Orient ist, kommt in Europar

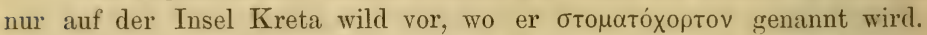
In Italien wird er angebaut und auch in Töpfen gezogen. Nach Meinung der Alten brachten die wilden Ziegen, wenn sie angeschossen waren, den Pfeil dadurch zum Ausfallen aus der Wunde, dass sie Diptamdosten frassen; deshalb wurde dies Kraut zu einem Wundmittel gemacht, und mit Eisen geschlagene WVunden sollten leicht heilen, wenn Diptamsaft hineingeträufelt wurde und wenn der Verwundete diesen Saft trank. Später wurde die Wirkung der Pflanze noch dahin vergrössert, dass sie überhaupt Geschosse (belli tela) aus dem Körper herausschleuderte, und

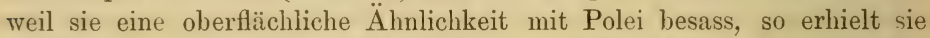
den Namen poleium Martis (Vinc. Bellovacensis, Speculum naturale 10,66).

Es ist nun sehr wohl möglich, dass der Schreiber des Capitulare den Diptamdosten in Italien kennen gelernt hatte; dann musste er auch den Wunsch haben, ein so ausgezeichnetes Wundmittel in Deutschland aus dem Garten holen zu köınen. Ob der Anbau dieses Gewächses von Erfolg begleitet war, ist mindestens zweifelhaft, denu TABERNAEIONTANUS kennt es garnicht und HIERONYMUS BOCK, der es Dittam nennt, hat es erst kuirzlich kennen gelernt, da er (fol. 10, vers.) sact: „Er ist aber nün mehr als ein frembder gast ausz Creta vud Venedig zü uns kommen, denselbigen Dictam haben Herr Jörg Olling e r ron Nürnberg, vnd D. Conrad Geszner von Zürich, denen ich höchlich danck sage, mir zügeschickt." Der gewöhnliche Name in Deutschland wurde Dictumnus creticus. Der Dictammu, welcher in den Glossaren des CGL III erwähnt wird, scheint der Diptamdosten zu sein, wenigstens teilweise, denn als Synonyme werden poleium Martis und Hasenohr (leporis

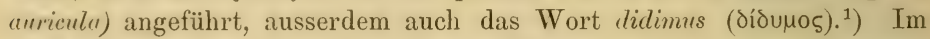
9. Jahrhundert wird aber auch schon Diptamms mit vizwur übersetzt (vergl. Glossae Theotiscae im Anhang I,6); hierbei wird man wohl an die weisse Wurzel von

Dictamnus albus L., Diptam, denken müssen, die als Radix Dictamni s. Diptamni s. Fraxinellae officinell war. Wenn die heilige HILDEGARD 1, 115 von dictamnus oder dictampmus

1) Jictamnu leoboris auricula siue benedicta 632,3 ; dictamnum leporis auricula 545, 21; didimus auricula leporis 560,37; leporis auricula idest didimus 613, 53; poliomartis didimus 593, 62; poleium martis idest didamus 615,58 ete. etc. - Im ( ‘lmarer Glossar wird didymus durch Hasenohr übersetzt (dydimia hasenôre 283); in Norddeutschland wird Stachys germanica L. viel in Gïrten gebaut und Hasenohren genannt; da diese Pflanze eine oberflächliche Ähnlichkeit mit dem Diptamdosten hat, si) ist es immerhin möglich, dass sie mit ihm verwechselt worden oder überhaupt sein Stellvertreter geworden ist. 
spricht, so wird das wohl auch der weisse Diptam sein, der in den Rheingegenden von der südlichen Hälfte der Rheinprovinz an wächst. Bei ALBERTUS MAGNUS finden wir diptammus angeführt $(6,327)$, bei KONRAD VON MEGENBERG diptamus mit dem deutschen Namen ifefferkraut $(5,34)$; beide rühmen ihrer Pflanze die Eigensehaften nach, die sonst dem Diptamdosten zugeschrieben werden, aber da beide sie als sehr gemein bezeichnen (communis satis ALB. MAGNUS, gar gemain KONR. V. MegenberG), so ist es fraglich, welche Pflanze sie meinen, und ob sie diejenige, von der sie sprechen, überhaupt gesehen haben.

Im 16. Jahrhundert führt der Diptam neben dem von LINNE angenommenen Namen Dictammus albus auch noch den Namen Fraxinella.

Rutam Capitulare 70,6; Invent I, 5; Ruta grareolens L., Raute, Gartenraute, Weinraute.

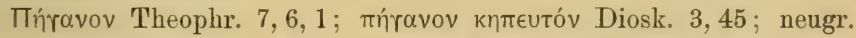
$\pi$ ríravov (selten gebaut).

Ruta Colum. 6, 4, 2; 11, 3, 38; 12, 7, 5; Plin. 19, 8, 45 und sonst viel; it. ruta; fr. rue.

Die Raute hat allezeit in grossem Ansehen gestanden als Arzneimittel und als Mittel gegen Gift und Schlangen; TABERnaEMonTANuS braucht acht und eine halbe Folioseite, um alle Heilwirkungen der Raute zu beschreiben. Während sie im südlichen Deutschland häufig ist, findet sie sich in norddeutschen Gürten nur vereinzelt. In ihrer Anwendung als Riechstrüusschen wird sie in Norddeutschland durch die Eberraute (Artemisia Abrotanum L.) vertreten.

\section{Minze, Frauenminze und Rainfarn.}

Die Arten der Gattung Menthu, Minze, sind ganz ausserordentlich reränderlich: bald sind sie stark, bald wenig behaart oder gan\% kahl; neben Abänderungen mit breiten Blïttern kommen solche mit schmalen vor, und wem die gewöhnlicheren Formen schlichte Blätter haben, so giebt es auch nahezu bei allen solche mit krausen. Dazu kommt, dass Bastardbildung bei den Menthaarten etwas sehr gewöhnliches ist, und hierdurch wird dann der Formenreichtum noch um ein Bedeutendes vermehrt. Es hat lange gedanert, his man in dies Formengewirre Einsicht gewonnen hat. Während noch vor etwas über 60 Jahren ron Specialisten weit iiber 29 Arten unterschieden wurden, ist man jetzt geneigt, nur noch etwa vier oder fünf anzunehmen: Mentha rotundijolia L., die als westliche Pflanze für uns kaum in Betracht kommt, sich aber in Nordund Mittelitalien wildwachsend findet, $\boldsymbol{H}$. silvestris L., wilde Minze, $\boldsymbol{U}$. uquatica L., Bachminze, II. arvensis L., Ackerminze, und 1 . pulegium L., Polei oder Poleiminze. Abänderungen von Mentha silvestris und M. aquatica wurden als M. crispa L., Krauseminze, gebaut; schmalblïttrige und besonders gewürzhafte Formen führten den Namen Menthı piperitu I., Pfefferminze. 
Die grosse Veränderlichkeit der Menthaarten war schon den Alten aufgefallen. Wenn THEOPHRAST sagt $\left.(2,4,1):{ }^{2}\right)$ "das Sisymbrion scheint sich in Mintha zu verwandeln, weun es nicht durch Pflege zurückgehalten wird, deshalb pflanzt man es oft um," so kann dieser Äusserung die Beobachtung zu Grunde liegen, dass die Krauseminze sich in die gewöhnliche Bachminze verwandelt hat, eine Beobachtung, die man auch heute noch machen kann. Jedenfalls bedeutet Sisymbrion an dieser Stelle eine Kulturpflanze, und da die Krauseminze diesen Namen später führte, so kann sie auch hier gemeint sein. Die Römer glaubten, dass man wilde Minze in zahme verwandeln könne, weun man die wilde mit der Spitze nach unten in die Erde stecke (COLLM. 11, 3, 37; PLIN. 19, 8, 47).

Wenn wir jetzt noch Mühe haben die verschiedenen Arten der Minze auseinanderzuhalten, so dürfen wir uns nicht wundern, wenn es den Alten noch schwieriger wurde. Dazu kam, dass Pflanzen mit duftenden Blättern, namentlich wenn diese in der Form mit denen ron Mentha Ähnlichkeit hatten, oder wenn sie grau waren, früher als Minze angesprochen wurden und gegenwärtig noch werden. Solche Pflanzen sind Nepeta cataria L., das Katzenkraut oder die Katzenminze, die mit der wilden Minze verwechselt wurde, Tanacetım Balsamita L., Frauenminze, die nicht einmal zu den Labiaten, sondern zu den Compositen gehört, aber nichtsclestoweniger in der verschiedensten Weise als Minze, zuweilen auch als Salbei, bezeichnet wurde und wird, und andere mehr. Wenn also im Folgenden versucht wird die Namen des Capitulare, die sich auf Mentha und ähnliche Pflanzen beziehen, zu deuten, so mag noch einmal bemerkt werden, dass die hier versuchten Deutungen auf absolute Richtigkeit keinen Anspruch erheben wollen.

Sisimbrium Capitulare 70,41; mentam Capitulare 70,42; Invent. I, 3 ; Invent II, 2. Mentha aquatica L., Bachminze, mit den Rassen Krauseminze und Pfefferminze.

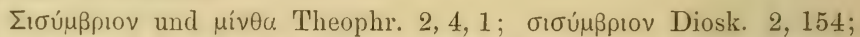

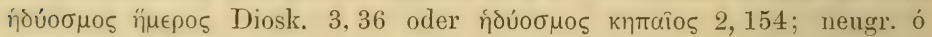

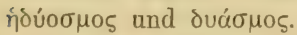

Menta Colum. 11, 3,37; sisimbrium Plin. 19, 10,57; menta Plin. 19, 8, 47 und sonst; it. menta aquatica, mentastro d'aqua; sisembro domstico, balsamita, menta crespa; menta romana, menta peperina; fr. mentlie; menthe frisée, menthe crépue; menthe poivrée.

Dass Sisymbrion bei THEOPHRAST eine Kulturpflanze bedeutet, ist schon oben gesagt; dann ist Mintha bei ihm eine wilde Art, etwa die Bachminze, deren eine Rasse, die Pfefferminze, noch heute viel in Griechenland kultiviert wird. Die menta bei Coludrelda, die einen

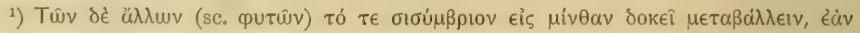

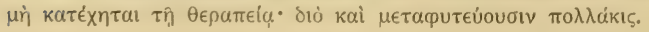


sumpfigen Boden verlangt und deshalb an eine Quelle gepflanzt wird, 11, 3,37 ${ }^{1}$ ) muss ebenfalls die Bachminze oder eine ihrer Kulturrassen sein. Was DIOSKORIDES unter sisymbrion versteht, ist nicht ganz klar; es wächst an unbebauten Orten, gleicht der Gartenminze, ist aber breitblättriger und wohlriechender und wird zu Kränzen benutzt; ${ }^{2}$ ) als Synonyme führt er an: Kranz der Aphrodite ('Appodíns otépavos), Pflanze

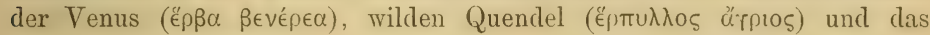
unverständliche usteralis. Das griechische herpyllos, dem das römische serpyllum entspricht, kann Thymian bedeuten, aber auch die Poleiminze. Beide Pflanzen sind aber zu klein, um mit der Gartenminze verglichen werden zu können. Möglich wäre es, dass DIOSKORIDES mit Sisymbrion die wilde Minze, Mentha silvestris L., meint; aber ebenso wahrscheinlich ist es, dass er die wilde Bachminze gemeint hat, namentlich weil er die Brunnenkresse als zweites Sisymbrion aufführt $(2,155)$ und weil er nachler bei mentastrum (seinem ídúoguov ärprov, 3,36) bemerkt, dass es an den Blättern behaarter und in allen Stücken grösser sei als sisymbrion. ${ }^{3}$ )

Das griechische íoúoguos wird in den Glossaren des CGL III stets mit menta oder menta nigra übersetzt. Menta nigra, soviel wie „dunkle Minze", passt vortrefflich auf die Pfefferminze, die in der That ungewöhnlich dunkel aussieht. In den Hermeneumata des CGL III erscheinen menta und nepeta unter den Gemüsen. Jedenfalls sind die Menthaarten seit langer Zeit gebaut worden und ihre Anwendung war eine sehr mannichfaltige. WALAFRIDLS STIRABL's spricht von dell zahlıleichen Formen, Farben und Kräften der Minze. Die heilige HILDEGARD unterscheidet bachmyntza $(1,75)$ und ausserdem eine myntza major und minor, von denen wir die eine wohl als Gartenminze oder Krauseminze, die kleinere als Ackerminze denten dürfen. ALBERTUS MAG.its und KONRAD VON MEgENBER(* unterscheiden nicht viele besondere Arten, machen aber beide die Bachminze namhiaft und rühmen die Heilkräfte der Menthaarten im allgemeinen.

In den lateinisch-deutschen Pflanzenglossaren und in den Kräuterbüchern des 16. Jahrhunders begegnen wir einer grosseu Zahl von Mentha-Arten und -Rassen, aber auch einer ziemlich weitgehenden Namenverwirrung. Mit balsamum und bulscmitu werden im Garten gezogene Minzen bezeichnet, die auch die Namen Balsam und krauser Balsam führen, also wahrscheinlich unsere Pfefferminze und Krauseminze sind; diese führen in der Medicin den Namen Mentha piperita und M. crispa. Die Bachminze wurde Balsamum palustre und Mentha aquatica genaunt.

$\left.{ }^{1}\right)$ Menta dulcem desiderat uliginem; quam ob causam juxta fontem mense Martio recte ponitur.

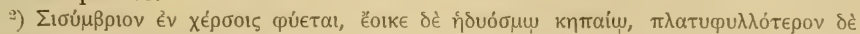

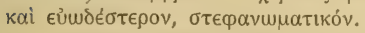

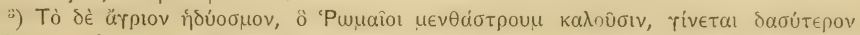

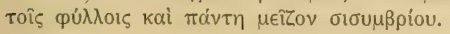


Mentastrum Capitulare 70,43; Invent. I, 14; II, 15. Mentha silvestris L., Waldminze, wilde Minze.

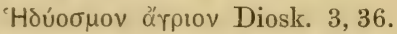

Mentastmum Plin. 20,14,52, ${ }^{1}$ ) it. menta salvatica, mentastio, mentastro, mentone; fr. menthastre.

Was in Italien "wilde Minze" genannt werden konnte, braucht es bei uns nicht zu sein. In der That kommt die Mentha silvestris mit ihren Formen hier im Norden immer nur in der Nähe menschlicher Trohnungen vor, so dass man sie als Gartenflüchtling bezeichnen muss; in Gärten wird sie nicht mehr gebaut. Früher scheint sie ebenso läufig wie Mentha aquatica kultiviert worden $\mathrm{zu}$ sein. Da es auch von der Waldminze krausblättrige Formen giebt, und da sie ebenso wie die Bachminze feuchte Standorte liebt, so darf man sich nicht wundern, wenn sie die meisten Namen mit der Bachminze teilt. Nur Balsam oder Balsamita scheint sie nicht genannt worden zu sein, während wilde Minze und Rossminze ihr allein angehören. Bei der heiligen HILDEGARD heisst sie rossemyntza und romische myntza $(1,78)$, in der Medicin Mentha equina und Mentha romana.

Puledium Capitulare 70, 29. Mentha Pulegium L., Polei, Flöhkraut.

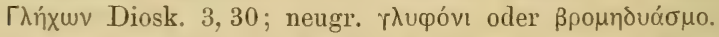

Puleium, pulegium der Römer; it. poleggio, polezzo; fr. chasse-puce.

Das puledium des Capitulare ist verschrieben für pulegium. Der Polei stand früher in einem ausserordentlich hohen Ansehen. Von den Rïmern wurde er gegessen; bei APICIUS CAELIUS wird er vielfach erwähnt und in den Hermeneumata des CGL III kommt er unter den Gemüsen vor. In Deutschland ist er früher ausser als Arzneimittel auch als Mittel gegen die Tiere gebraucht worden, die ihm seinen zweiten deutschen Namen verschafft haben. Früher muss er gebaut worden sein (Augsburger Statuten von 1276, bei K. W. Volz, Beiträge zur Kulturgeschichte, Leipzig 1852, S. 201), aber gegenwärtig findet man ihn nicht mehr in Gärten.

Neptam Capitulare 70, 45, Invent. II, 11. Nepeta Cataria L. Katzenminze.

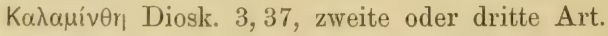

Nepeta Colum. 7, 5, 18, 12, 7, 1; Plin. 19, 7, 37; 19, 8, 47; it. cataria, gattaria, menta de'gatti,

1) Mentastrum bedeutet ebenso wie Mentha silvestris "wilde Minze"; das Suffix "aster" soll ursprünglich eine Entartung ausdrücken, z. B. criticaster, bei Pflanzen hat es aber die Bedeutung nwild“, z. B. oleaster, wilder Ölbaum; piraster, wilder Birnbaum; pinaster, die Kiefer, im Gegensatz zu pinus oder pinus hortorum, die Pinie. - Columerta spricht von einem silvestre mentastrum $(11,3,37)$, das von den Brachäckern (de novalibus) gesammelt wird; dies kann wohl nur die Ackerminze, Mentha arvensis L., sein. 
Eine früher viel gebrauchte Arzneipflanze, deren Namen in den Hermeneumata des CGLIII auch unter den Gemüsen vorkommt. ${ }^{1}$ ) Sie teilt einzelne Namen, wie Weissminze, mit den eigentlichen Minzearten. Hier in der Provinz kommt sie in Gärten kaum noch vor, findet sich aber ziemlich häufig in Dörfern und in der Nähe von Gehöften am Wege und in Zäunen, so dass man auf eine bedeutendere Kultur in früheren Zeiten schliessen darf.

Costum Capitulare 70, 4; Invent. I, 2, II, 1. Tanacetum Balsamita L. Frauenminze.

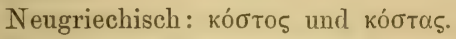

Spätlateinisch: costus hortorum, costus hortensis; balsamita; mentha graeca sive saracenica, mentha corymbifera, salvia romana; herba divae Mariae.

Italienisch: erba costa, erba costina, erba amara, erba buona, erba della Madonna, erba santı, erba Santa Laria, Maria santı; menlita greca; salvia romana.

Französisch: menthe de Notre-Dame, coq des jardins, herbe au coq, grand coq.

Schon von KINDERLING wurde costus als Frauemminze gedeutet, und die späteren Bearbeiter des Capitulare haben diese Deutung festgehalten; sie wird richtig sein, da die Frauenminze in Griechenland, wo sie Kulturpflanze ist und als Gewürz benutzt wird, noch heute den Namen costus führt, der sich auch im Italienischen erhalten hat. Ursprünglich bedeutet der Name ein aus Ostindien stammendes Gerwürz (die Wurzel ron Costus speciosus Smith); auf eine Gartenpflanze scheint er nicht viel vor dem 9. Jahrhundert angewandt worden zu sein.") In den Pflanzenglossaren begegnet man ihm sehr selten, ${ }^{3}$ ) was in seltsamem Kontrast zu der ehemaligen Beliehtheit der Pflanze steht. Während sie früher in Gärten viel gebaut wurde, fängt sie jetzt allmählich an zu verschwinden; in abgelegenen Gegenden findet man sie etwas häufiger.

Die deutschen Namen sind: unser Frawen Müntz, welsche Minthe; Papenplatte; brēdn Sophie (im Gegensatz zum Salbei: smalln Sophie). ${ }^{4}$ )

1) Miv $\theta \in$ nepete 16,42 ; minthen nepita 88,65 ; minthi nepeta 186,15 ; $\gamma \alpha \lambda \alpha u v \tau \alpha$ nepeta 317,34; die Zusammenstellung mit calamintha findet sich auch in den Glossaren des CGL III : calamites . idest nepita 537,10; calamantis . i . nepta 555, 26 etc. $\mathrm{Da}$ nun in den lateinisch-deutschen Glossaren nepeta durch verschiedene Namen gedeutet wird, z. B. durch steinminze Sum. 58,5 , durch minza Sum. 63 , 1 ø̌ etc. etc., so ist es ziemlich sicher, dass früher unter nepeta verschiedene Pflanzen verstanden wurden; hierher gehören wahrscheinlich Calamintha officinalis Mönch, die noch jetst in Gïrten gebaut und als Gewürz benutzt wird, und C'alamintha Nepeta Clairville.

2) In dem letzten Glossar des CGL III, dessen Handschrift aus dem 9. Jahrhundert stammt, steht lamasoma costo ortenso 631,59. WVALAkRIDUS STRABUs spricht v. $281 \mathrm{im}$ Gedicht ïber sclarea von hortensis costus.

s) Colm. Gloss.: costi we(1)scheminthe 233; Hone: costus kost 194 (ähnlich in den Sumerlaten); custos ortorum papenplat 211.

4) $\mathrm{Da}$ die Frauenminze in Italien heimisch ist, so ist es kaum zu verstehen, dass Droskorides sie nicht erwähnt oder nicht deutlich bezeichnet hat. Sie könnte 
Tanazitam Capitulare 70, 44, Invent. I, 13; tanezatum Invent. II, 8, Tanacetum vulgare L., Rainfarn, Wurmkraut.

Italienisch: atanasia, tanaceto, daneto; fr. tanaisie.

Der Name Tanacetum stammt aus späterer Zeit und ist vor dem 9. Jahrhundert wohl kaum nachweisbar. In einem Glossar des CGLIII, dessen Handschrift aus dem 10. Jahrhundert stammt, findet sich tanacipan artemisia tuguntis $(578,27)$. Das erste Wort kann verschrieben sein für tanacetum. Aber auch hiervon abgesehen, würde man eine Pflanze ron so starkem Geruch, wie der Rainfarn ihn hat, unter den Artemisiaarten der Alten suchen dürfen, wie es beispielsweise ron TABERNAEIIONTANUS geschehen ist.

In den Glossaren findet man als deutschen Namen reynevane oder rinevare, so dass der jetzt gebräuchliche Name Rainfirn durch falsche Etymologie gebildet zu sein scheint; jedloch steht im Colmarer Glossar Reyneuar (722). Da der Rainfarn in Norditalien und ganz Deutschland wild wächst, so war ein Bedürfnis ihn anzubauen eigentlich nicht vorhanden. Die zum Anbau empfohlene Pflanze wird also wohl die Abart mit krausen Blättern sein, die einen viel stärkeren Duft hat als die wildwachsende und gegenwärtig noch in Bauerngärten ziemlich häufig vorkommt.

Bei dieser Abart sind die Blätter so fein zerteilt, dass sie recht wohl unter dem millefolium des Mittelalters mit einbegriffen sein kann; da nun ambrosia und nillefolium als gleichbedeutend einander gegenübergestellt werden (CGL III 536, 13; 550,8), so ist es möglich, dass die ambrosia, welche IVALAFRIDUS STRABLS besingt, die krausblätterige Abart des Reinfarns ist.

\section{Eberraute und Heiligenpflanze (Cypresse).}

Abrotanum Capitulare 70, 7, Invent. II, 7. Artemisia Abrotanum L. Eberreis, Eberraute, Stabwurz.

'Aßpótovov Theophr. 6, 1, 1; ảßpótovov üj̉jev Diosk. 3, 26; nengr.

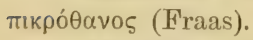

Abrotonum Colum.; habrotonum mas Plin. 21, 21,92 und mehrfach; ') it. abrotano, abrotano maschio, abrotono; fr. aurone, abrotone.

Eine seit alten Zeiten sehr geschätzte Heilpflanze, die sich auch einer grossen Kahl von Namen erfreut. Man unterschied vom Altertum

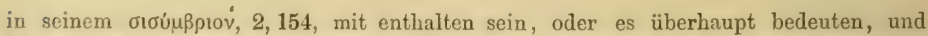
MATrirul hat auch kein Berlenken getragen (Commentar, S. 527) das Sisymbrion doppelt zu deuten, als Bachminze und als Frauenminze. Das von Dioskorides angrorebene Synonym ë $\beta \beta \alpha \beta \in v \in ́ \rho \in \alpha$ könnte, wie so manches andere, aus dem Dienste der Venus in den der Jungtrau Maria übergegangen sein unł dabei die Umwandlung in erba Santa Maria erfahren haben.

1) Das Habrotanum, welches Plinius 19, 10, 34 erwähnt, kann, weil es goldgelb blüht, nicht hierher gehören; ob zu tanacetum? 
bis ins vorige Jahrhundert zwei Arten, die man männlich und weiblich nannte. Die hier genannte ist die männliche; die weibliche folgt unten. Verwechselungen zwischen beiden und mit anderen Arten von Artemisia haben vielfach stattgefunden, so daass es nicht wohl möglich ist, die von DIOSKORIDES angeführten Synonymen auf die männliche oder weibliche Art allein zu beziehen. Der Grad ihrer Beliebtheit wird vielleicht durch heracleum ausgedrüclit. Sisymbrium wird sie auch genannt; ausser als Heilmittel ist sie noch als Ersatz für Weihrauch benutzt worden. ${ }^{1}$ ) Bei der heiligen HILDEGARD $(1,106)$ heisst die Eberraute stagwurts und abrotanum, im 16. Jahrhundert Stabwurz und Gertwurz.

Die deutschen Namen Eberraute und Eberreis sind darlurch entstanden, dass man mittel- und niederdeutsche Angleichungen an Abrotanum (auerute, euerute, euerritte etc.) ins Hochdeutsche über'setzt hat. Eine häufige Pflanze unserer Bauerngärten.

Santolina Chamaecyparissus L., Heiligenpflanze, Cypresse.

'Aßрóтovov $\theta \hat{\jmath} \lambda$ u Diosk. 3, 26.

Habrotonum femina Plin. 21, 21,92; it. abrotano femmina, canapiclia, cupressina, crespolina, santolina, vermicolare; fr. santoline, petit cyprès.

Die spätlateinischen Namen dieser Pflanze sind Centonia, Centonica und Santonica. Im Königsberger Glossar heisst sie deutsch vinterut, bei Mone wrincrut, im Colm. Glossar Woremworth. Von diesen Namen hat sich keiner erhalten, vielmehr wird die Pflanze schon in 16. Jahrhundert "Cypresz" genannt. Früher als Heilmittel viel benutzt, findet sie jetzt nur noch Anwendung als Zierpflanze; namentlich dient sie als Gräberschmuck, und zivar bis nach Jütland hinein, wo sie dam allerdings während des Winters ins Zimmer genommen werden muss.

\section{Wermut und Beifuss.}

Artemisia Absinthium L., Wermut, Absinth.

'A yiverov Diosk. 3, 23; in Griechenland nicht bekannt, aber vertreten durch Artemisia arborescens L.

Apsinthium Plin. 27, 6, 28; it. assenzio, assenzio romano; fr. absinthe.

Unter dem Namen absintlium wurden bei den Alten mehrere Arten unserer Gattung Artemisia benutzt; bei uns ist der Name an der auch Wermut genannten Pflanze hängen geblieben. Der Wermut war als Heilmittel seit alten Zeiten berühmt; er fehlt zwar im Capitulare, wird aber von WALAFRIDUS STRABUS unter dem Namen Absintlivim hesungen. Bei der heiligen HLLDEGARD $(1,109)$ heisst er wermuda, bei KONRAD VON MEGENBERG $(5,1)$ wermuot. Im 16. Jahrhundert führt der Wermut dieselben Namen. Wie hoch man ihn als Heilmittel schätzte, geht unter anderem daraus hervor, dass TABERNAEIIONTANUS ihm über 14 Folioseiten widmete.

1) CGLIII: eraclea idest sisimbrius vel abrotanus 611,41; - dentrolibanus abrotanus 589,44; ähnlich 545, 27 und 610,50 . 
Artemisia vulgaris L., Beifuss.

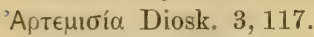

Artemisia Plin. 26, 15,89; it. amarella, artemisia, matricala; fr. armoise.

Der Name artemisia ist bei DIOSKORIDES und PLINIUS vieldeutig und umfasst mehrere Pflanzen von ähnlichem Aussehen, denen man eine ganze Reihe von besonderen Kräften zuschrieb. In den Glossaren des CGL III kommt artemisia sehr viel vor und zwar mit sehr verschiedenen Deutungen, die zur Genüge beweisen, dass man lieine einzelne bestimmte Pflanze vor Augen hatte; ein besonders eigentümlicher Name ist mater herbarum $(569,48 ; 607,18)$; da dieser im Colmarer Glossar (500) mit bifôth iibersetzt wird, so kommt er der von uns jetzt Beifuss genannten Pflanze zu.

PLINIUS berichtet $(26,15,82)$, dass ein Wauderer, der artemisia und elelisphacus (Salbei) angebunden trage, wie gesagt werde, keime Müligkeit oder Abgespanntheit fühle. $\left.{ }^{1}\right)$ Dieser Glaube hat sich lange erhalten und zwar an unseren Beifuss geknüpft, so dass wir anmehmen dürfen, PLiNiUs habe eben diesen gemeint. ALBERTUS MAGxT'S erzählt olne Vorbehalt $(6,286)$, dass artemisia, getragen und an die Schenkel gebunden, die Müdigkeit der Reisenden aufhebe. ${ }^{2}$ )

KOXRAI TON MEGENBERG ist schon nicht melu so gläubig; er sagt ron artemisia, die er auf deutsch peipôz nennt: „e\% sprechent auch die maister, wer ez an diu pain pind, ez benem den wegraisern ir mïed. da\% versuoch, wan ich gelaub sein nicht, e\% waer dann bezaubert."

Der iiltere deutsche Name des Beifusses ist biboz, den auch die heilige HILDEGRAD benutzt $(1,107)$; in den Sumerlaten steht einmal bijuz $(65,1)$. Unser „Beifuss" ist wohl nichts anderes als eine Angleichung an biboz, wobei die eben erwähnte Benutzung der Pflanze bervusst oder unbewusst mitgespielt haben kann.

Der Beifuss ist eine in ganz Deutschland riemlich häufig wild Wachsmrle Pflanze; ob friihere Kultur auf ihre Verbreitung Einfluss gehabt liat, liisst sich jetzt nicht mehr entscheiden. Ubrigens wird der Beifuss in manchen Gegenden, namentlich im Osten, als Küchenkrant benutzt.

\section{Odermennig und Betonika.}

Arrimonia Invent. II, 17; Ayrimonia Enpatoria L., Odermemig.

Eủratúpıov Diosk. 4, 41; neugr. povóxoptov (Fraas).

Eupatoria Plin. 25, 6, 29; it. acrimonia, agrimonia, eupatorio; fr. aigremoine.

Dex Oilermemig war friher ein geschät\%tes Mittel gegen Leiden der Tseber und der Unterleibsorgane überhaupt. In den Apotheken

1) „Artemisiam et elelisphacum adligatos qui habeat viator negatur lassitudinem sentire."

2) "Portata etiam et alligata cruribus, tollit lassitudinem itinerantium." 
führte er deshalb neben Agrimonia und Eupatorium veterum den Namen Lappula hepatica, der sich stellenweise im Deutschen als Leberklette erhalten hat. Den Namen Lappula verdankt er den hakig gekrümmten Borsten seiner Früchte, die sich mittels dieser Borsten ebenso anhängen wie Kletten; da die Früchte abwärts gebogen sind, so heisst er auch sehr viel Lappa inversa. Lappa incisa wird er im Colmarer Glossar (440) genannt, wahrscheinlich wegen der zusammengesetzten Blätter.

In den Glossaren des CGL III bedeutet eupatorium, das friiher die ganze Pflanze bezeichnete, nur noch die $W$ urzel, $^{1}$ ) und die ganze Pflanze heisst hier wie später bei der heiligen HILDEGARD $(1,114)$ und ALBERTUs MAGNus $(6,283)$ agrimonia. Die deutschen Namen Ackermennig und Odermennig sind wohl nur Entstellungen aus Agrimonia, das selbst aus Argemone entstanden zu sein scheint.

Vittonicam Invent. I, 20; II, 16; Betonica officinalis L., Betonika. Betonie.

Kéotpos Diosk. 4, I.

Vettonica (dicitur in Gallia, in Italia autem serratula, a Graecis cestros etc.) Plin. 25, 8, 46; it. betonica, bertonica, brettonica, vettonica.

In den Glossaren des CGL III heisst die Pflanze neben betonica

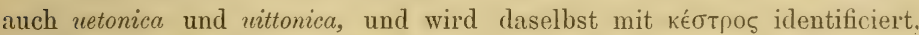
wahrscheinlich nach PLINIUS. Sie muss früher ein sehr beliebtes und viel besprochenes Heilmittel (auch Zaubermittel) gewesen sein, denn ihr Name ist zum Teil stark entstellt. Bei der heiligen HILDEGARD heisst sie pandonia, ${ }^{2}$ ) deutsch bathenia (I, 128); andere Namen, die in anderen Kapiteln vorkommen, wie bathemem $(1,37)$, bathemen und bachenia $(3,5)$. sind wohl verschrieben oder verlesen. ALBERTUS MAtiNus nennt sie betonica $(6,289)$, ebenso KONRAD VON MEgENBER( $(5,12)$, der den deutschen Namen patönig hinzufügt.

Die Betonica ist in Deutschland wie in Norditalien häufig und wildwachsend. Wegen ihrer medicinischen Eigenschaften wurde sie früher nicht nur gesammelt, sondern auch vielfach kultiviert.

\section{Andorn und Ballota.}

Marrubium vulgare L., Andorn.

Пра́бıv Theophr. 6, 2, 5; Diosk. 3, 109; neugr. бки入óхортоv.

Marrubium Colum. 6, 4, 2; 6, 12.5; 10,356, Plin. 20, 22, 89; it. marrubio, marrobio, mentastio; fr. marmbe.

Der älteste deutsche Name der Pflanze ist andorn, von dem auch die Form andron vorkommt (bei der heiligen HILDEGARD I, 33; man vergleiche andron im Anhang II); ein anderer deutscher, aber seltener

1) Ipaturium . radices argemonio 547, 7; hispaturio . i . radix agrimoniae 583, 33; -eopaturio radicis agrimina 632,14 ; ipaturio radicis argimoniae 632,24 etc.

2) Der Name pandonia kommt auch im CGL II vor: pandonia . i . uittonica 573, 49 . 
Name ist Gottestergessen. Im Lateinischen laufen marmbium und prassium nebeneinander her, wie bei ALBERTus Magrus 6,389 und bei CONRAD) ION MEGENBERG 5,51, der die sonst kaum noch vorkommenden deutschen Namen marobel und sigminz hat.

Die Pflanze war ehemals als Heil]flanze sehr geschätzt. Da ihre Heimat in Südeuropa und Süddeutschland ist, so wird ihr sprungweises Torkommen in Norddentschland an Dorfstrassen und auf Schutthaufen auf früheren Anbau zurückzuführen sein.

Von dem Andorn, der marmbium album genannt wurde, unterschied schon DIOSKORIDES, ebenso wie später Ā̈BERTUs MAGnds 6,389 und andere, die Ballota (Ballota nigra L.) als marmbium nigrum, eine Bezeichnung: die sich in den Apotheken bis auf die Gegenwart erhalten hat. Die Ballota wird von PLINius $(27,8,30)$ ballote genannt; er hat

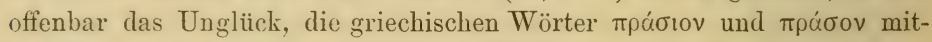
einander zu verwechsels, demn sonst würde er nicht von pormum nigrum, schwarzem Porree, haben reden können. DIOSKoRIDES $(3,107)$ nennt

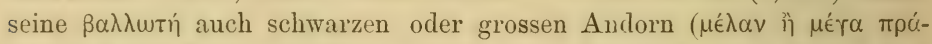
бıv); er beschreilot die Pflanze recht gut und sagt unter anderem, dass ihre Blätter mit denen der Melisse (Melissa officinalis L.) Ähnlichkeit haben, weshalb einige sie auch Melisse nennen.

\section{Eisenkraut.}

\section{Verbena officinalis L., Eisenkraut, Eisenhart.}

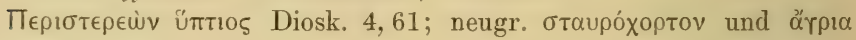

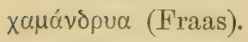

Hierabotane, peristereon, verbenaca Plin. 25, 9, 59; it. verbena; fr. verveine.

Bei den Römern werden verschiedene Pflanzen, die bei feierlichen Gelegenheiten benutzt wurden, verbena (und sagmen) genannt (vergl. LENZ, Botanik der alten Griechen und Römer S. 191, 192). Unser Eisenkraut ist in Griechenland noch gegenwärtig eine Glückspflanze und soll es auch noch in Süddeutschland sein (Fraas). Bei den Alten stand es in

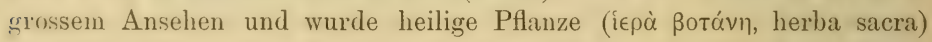
genanut. Dieses Ansehen hat es lange behalten. Bei der heiligen HILIEGAli ) lieisst es verbena und ysena $(1,154)$; in den Sumerlaten finden wir isincllete $(24,9)$, isenarre $(40,54)$, isere $(59,1)$ und endlich iiverenluent und isenbart $(66,40)$; der letzte Name ist vielleicht ein Druckorler Lesefehler, deun für gewölnlich findet man isenhart. Als Heilpflanze fund das Fisenkrant früher vielfache Verwendung, doch ist es jetzt ganz in Vergessenheit geraten. In Norddeutschland kommt es nur zerstreut und zwar in Iorfstrassen vor, was auf eine frühere Kultur schliessen lässt. Die Pflanze, die AlberTus Magrus $(6,471)$ verbena nennt, ist nicht rlas Eisenkrant, ebensowenig wie verbena und eisenlurat bei CONRAD VON MEGENBETG $(5,83)$; an beiden Orten werden zwei Arten unter- 
schieden, die eine mit safrangelben, die andere mit blauen Blumen. Der Herausgeber des ALBERTUS MAGNUS vermutet, dass Anagallis arvensis L. gemeint sein könnte, aber schwerlich mit Recht.

\section{Hauslauch und Johanneskraut.}

Jovis barbam Capitulare 70,73; Sempervivum tectorum L., Hauslauch, Hauswurz.

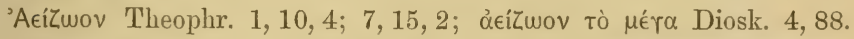
Aizoum, sechum Plin. 18, 17, 45; 25, 13, 101; it. semprevivo maggiore; fr. joubarbe.

Es kann nicht zweifelhaft sein, dass die Alten unseren Hauslauch gekannt haben, denn sie beschreiben ihn unter den Namen ảeízwov (immerlebend $=$ sempervivum) und sedum sehr genau, und zwar als grosses sedum, während das kleine unserem Mauerpfeffer (Sedum acre L.) vorzugsweise entspricht. In den Schriften der Alten wird auch angegeben, dass der Hauslauch auf Dächern wachse oder in Töpfen gezogen auf Dächer gestellt werde; die Angabe, dass die Pflanze den Blitz vom Gebäude abhalten solle, findet sich nicht, wohl aber wird sie als Mittel gegen Brandwunden und sonst als Arzneimittel gerühmt; auch wird behauptet, dass Getreide nnd Sämereien, die mit dem Saft von Hauslauch befeuchtet worden würen, gegen Ungeziefer geschützt seien.

Als Mittel gegen Brandwunden ist der Hauslauch auch später noch geschätzt worden, aber das grösste Ansehen genoss er (loch deshalb, weil man glaubte, er schütze ein Gebäude, auf dessen Dach er wüchse, gegen das Einschlagen des Blitzes. Dieser Glaube hat dem Hauslauch eine ausserordentliche Verbreitung verschafft, so dass er sich früher fast auf jedem Bauernhause fand. AlBertus Magiv's scheint der Sache schon nicht mehr ganz zu trauen, denn er sagt, „diejenigen, welche sich mit Hexerei abgeben, behaupten, er verjage den Blitz: und deshalb wird er auf Dächern gepflanzt" $\left.(6,288)^{1}\right)$; neuerdings hat der Hauslauch die Konkurrenz des Blitzableiters nicht mehr ertragen können, und deshall) sieht man ihn nur noch selten.

Bei der heiligen HIJDEGARD finden wir huszuntz $(1,42)$ und den lateinischen Namen semperviva $(1,203)$, bei KONRAD TON MEGENBERG hauswurz und barba Jovis $(5,14)$. Hauswurz heisst die Pflanze auch im 16. Jahrhundert.

Aus der Familie des Crassulaceen ist noch eine Pflanze anzuführen, die früher viel kultiviert wurde, heute aher nur noch selten in Gärten vorkommt, das ist

Sedum Telephium L., Johanneskraut, Fetthenne.

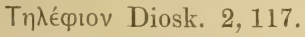

Teleplion Plin. 27, 13,110; it. fava grassa; fr. grassette.

1) "Qui autem incantationi student, dicunt ipsam (sc. barbam Jovis) fugare fulmen tonitrui : et ideo in tectis plantatur." 
DIOSKORIDES und PLIXIUS geben beide an, dass das telephion in Blatt und Stengel dem Portulak gliche, und rühmen es als Wundmittel etc. In den Glossaren scheint es ganz zu fehlen, sein Gebrauch muss deshalb lange in Vergessenheit geraten sein. Zuerst begegnen wir ihm wieder bei AJBERTus MAgnus $(6,402)$, wo es die Namen orpinum und crassula trägt; "wenn man es um die Zeit der Sommersonnenwende pflückt, so bleibt es lange Zeit frisch, wenn man es in der Luft aufhängt, ohne dass es aus der Erde Nahrung zieht, und wenn es an der einen Seite vertrocknet ist, so wird es frisch an der anderen, sobald es gepflanzt wirl"..") Ähnlich drückt sich KONRAD VON MEGENBERG aus $(5,57)$, der den beiden genannten lateinischen Namen den deutschen krässelliraut hinzufügt. Noch heute wird hier in der Prorinz die Pflanze um Johanni gepflückt (Johameskraut) und auf dem Lande in die Ritzen zwischen Zimmerdecke und Balken geschoben; langes Grünbleiben bedeutet langes Leben für denjenigen, der es an die Zimmerdecke gesteckt hat.

Im 16. Jahrhundert wird das Johanneskraut allgemein als Wundmittel benutzt und deshalb auch Wundkraut genannt; in den Apotheken führt man Wurzel und Kraut als Radix et Herba Telepliii s. Crassulue majoris s. Fabariae.

LINNÉS Sedum Teleplium umfasst nach heutigen Begriffen eine Reihe von Arten, unter denen das rotblühende Sedum murpureum Link besonders bemerkenswert ist; dieses findet sich an Wegrändern in der Nähe von Städten, Dörfern und einzelnen Gehöften, woraus man auf eine frühere Kultur schliessen darf.

\section{Sadebaum und Wachholder.}

Savinau Capitulare 70, 34; Inrent. I, 10; II, 12; Juniperus Sabina L., Sadebaum.

Bрá日u Diosk. 1, 104.

Herba sabina Plin. 24, 11, 61; it. sabina, savina; fr. sabine.

Der Sadebaum besitzt ausserordentlich giftige Eigenschaften, su dass sein Anbau schon mehrfach durch Verordnungen untersagt wurde. I)iese Eigenschaften waren auch schon DIOSKORIDES bekannt und waren später keineswegs vergessen, wie die Benenuung atiron (ảinpós, schädlich, verderllich) in den Vokabularen bezeugt. ${ }^{2}$ ) Nichtsdestoweniger muss man aber annehmen, dass der Schreiber des Capitulare von diesen Eigenschaften nichts gewusst habe, vielmehr wird er an die Anwendungen gedacht haben, die der Bauer in Süd- und Mitteldeutschland (denn in die Bauerngärten Norddeutschlands ist der Sadebaum nicht gelangt)

1) „Quae circa augem solis collecta, diu erigitur suspensa in aëre sine terrae nutrimento; et sicca in parte una, convalescit in altera, si plantetur."

2) Atiron . idest sabina . foliaiuniperi CGL III, 535, 51; atiron Seuenbôm Colm. Gloss. 85. 
noch jetzt von ihm macht: mit dem Alsud der Zweige werden die Würmer bei Pferden vertrieben und mit den getrockneten und pulverisierten Blättern werden alte Geschrwüre geheilt. Die letztgenannte Anwendung ist übrigens in der wissenschaftlichen Medicin nicht unbekannt.

Die zahlreichen deutschen Namen des Sadebaums sind alle aus sabina oder savina entstellt: sarenbom, savinbom, seuenbôm. Bei der heiligen HILDEGARD $(3,21)$ heisst er sybenbaum, bei ALBERTUS MAGNUS und KONRAD VON MEGENBERG wird er uiberhaupt nicht erwähnt.

Gelegentlich scheint der aus Südeuropa stammende Sadebaum mit dem bei uns heimischen Wachholder (Juniperus communis L.) verwechselt zu sein, wie aus der ersten der unten angeführten Glossen hervorgeht. Vom Wachholder benutzte man namentlich die Beeren, die zum Räuchern etc. benutzt wurden. Diese heissen Baccae Juniperi, in Handschriften des 9. Jahrhundert bacas giniperi und bagas geniperi ${ }^{1}$ ), wie dem der Wachholder noch jetzt in Italien ginepro heisst. Aus diesen alten Formen stammt das hollïndische "Genever" und wahrscheinlich auch das dïnische "Jenbär“, das dann mit Beere (bär) garnichts zu thun hat.

\section{IMeerzwiebel.}

Squillam Capitulare 70, 16; Scilla maritima L., Meerzwiebel.

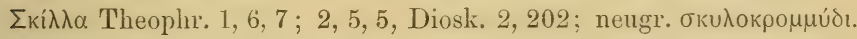

Scilla (scylla) Colum. 5, 10, 16; 6, 12, 5; 12, 33 u. 34, Plin. 19, 5, 30 und sonst vielfach; it. scilla, squilla, cipolla marina; fr. scille.

Die Meerzwiebel wächst an den sandigen Küsten des Mittelmeeres und des atlantischen Oceans (Portugal); sie lässt sich deshalb in Deutschland nur schwierig im Freien ziehen, und kommt hier in Norden kaum noch als Topfyflanze vor. THEOPHRAsT schreibt der Zwiebel einen Einfluss auf das Gedeihen von Stecklingen des Feigenbaumes, COLUMELLA einen solchen auf das Wachsen des Granatapfelbaumes zu. Ausserdem war die Meerzwiebel als Arzneimittel bis in die Gegenwart hoch geschätzt. Neuerdings wird sie als Mäusegift empfohlen; als solches kennt sie schon ALBERTus Magnus $(6,431)$, der erzïhlt, die squilla werde auch cepa muris (Müusezwiebel) genannt, weil sie die Mäuse tödte. KONRAD VON MEGENBERG $(5,77)$ nennt sie müuszwivel.

\section{Griechisch Heu.}

Fenigrecum Capitulare 70, 3; Trigonella Foenum graecum L., Bockshornklee, Griechisch Heu. ${ }^{2}$ )

1) CGL III: sabina . foliaiuniperi 535, 51 ; arcitidon (entstellt aus $\alpha$ $\rho \kappa € \cup \theta 0 \varsigma)$. idest giniperu . idest bacas giniperi 535,2l; arciheut idest bagas geniperi 631, 3 .

$\left.{ }^{2}\right)$ Den Namen "Griechisch Heu" hat die Pflanze wegen ihres starken Cumarin- geruchs erhalten, den sie mit dem Ruchgras, Waldmeister etc. teilt; dieser Name ist zuweilen eigentümlich verdreht worden, z. B. fenogrecum crischowe Sum. 57, 3. - 


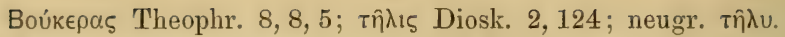

Foenum graecum Colum. 2, 11, 1; 11, 2, 71 u. 76; Plin. 18. 16, 39; 24, 19, 120; it. fieno greco; fr. fenu grec.

DIOSKORIDES bezeugt uns, dass $\tau \hat{\lambda} \lambda ı \mathrm{~s}$ von den Römern foenum yrecum, griechisches Heu, genannt werde, und führt unter den Synonymen

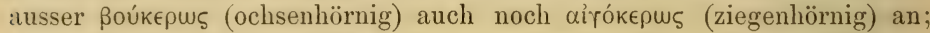
die den beiden letzteren Namen entsprechenden Worte buceras (Ochsenhorn) und aegoceras (Bockshorn) finden sich bei PLINIUS $(24,19,120)$. Bei den römischen Landleuten führte die Pflanze nach CoLUsrella den Namen siliqua (Schote); PLINIUS nennt sie auch silicia.

Im Altertum sowohl wie im Mittelalter galt der Bockshornklee für ausserordentlich heilkräftig und wurde deshalb viel gebaut. Jetzt hat er seine Bedeutung fast ganz verloren und verschwindet mehr und melrr aus den Gürten. Bis Hannover und Mecklenburg ist er nach Norden vorgedrungen gewesen und im niederdeutschen Volksmunde hiess er "fine Gretje" (Angleichung an foemum graecum).

\section{Technisch verwertbare Pflanzen.}

\section{Färberröte, Waid, Wau und Safflor.}

Warentiam Capitulare 43 und 70, 65. Rubia tinctonum L., Färberröte, Krapp.

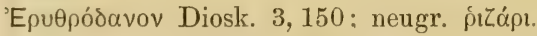

Rubia Plin. 19, 3, 17; 24, 11, 56; it. robbia; fr. garance.

Die Färberröte, die in Südeuropa heimisch ist, wurde schon von den Alten gebaut und zum Fïrben von Wolle und Leder benutzt. In Deutschland ist ihr Anbau wohl nie von grosser Ausdehnung gewesen.

Der französische Name garance stammt aus dem spätlateinischen barentia, unarentic, marantia, $\left.{ }^{1}\right)$ das auch zur Bezeichnung der Fïrberröte im Capitulare dient. In Deutschen führte die Pflanze den Namen Röte oder Rode (niederdeutsch); das Colmarer Glossar unterscheidet Rubea maior Rode (623) und Rubea minor der kledere (624); das letztere ist unser Klebkraut (Galium Aparine L.).

"Siebengezeit" wird von einigen als gleichbedeutend mit Foenum graecum gebraucht. Hier liegt ein Irrtum vor, denn Siebengezeit ist der Volksname für Melilotus caeruleus Lam.

$\left.{ }^{1}\right)$ CGL III: barentia . i . rubia 554, 34; 618,62; uuarentia . i . rubia 579, 30; erizodrano rubia siue uarancia $632,12$. 
Waisdo Capitulare 43; Isatis tinctoria L., Waid.

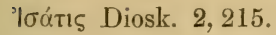

Vitrum Caesar Bellum Gall. 5, 14; glastum Plin. 22, 1, 2; it. guado, glasto; fr. guède.

Den verschiedenen modernen Namen des Waid liegt wohl das spätlateinische masdus zu Grunde, ${ }^{1}$ ) das neben isatis im Mittelalter vorkommt. Ausser zum Blaufärben wurde der Waid auch noch als Heilmittel benutzt. Bei der heiligen $\operatorname{HILDEGARD}(1,208)$ heisst er weyt.

ALBERTUS MAgnus hat $(6,430)$ eine Farbepflanze sandix, $\left.{ }^{2}\right)$ ebenso KonRad von MLEgenberga $(5,71)$, der als deutschen Namen waitkraut angiebt. Die Beschreibung könnte bei beiden auf den Waid passen, nur stimmt die rote Wurzel, die der Färberröte angehört, nicht dazu. Indessen wird in den Glossaren sandix mit weit und weituur übersetzt. ${ }^{3}$ ) Die sandix genannte Pflanze scheint früher viel gebaut worden zu sein, wenigstens sagt KONRAD VON MEGENBERG von ihr: "des krautes ist in Dürgen viel umb Erfurt". Man wird diese Pflanze wohl als Waid deuten dürfen.

In Folge früheren Anbaues ist der Waid in Norddeutschland an manchen Stellen verwildert. Gegenwärtig findet man ihn selten gebaut, da Indigo und die Anilinfarben ihn aus seiner Stellung verdrängt haben.

\section{Reseda luteola L., Wau.}

Lutum Vergil Ecl. 4, 44; Vitruv, de arch. 7, 14, 2; Plin. 33, 5, 26 (herba quam lutum appellant); it. erba gialla, erba guada, guaidone, luteola; fr. gaude.

Eine genaue Beschreibung der Pflanze, welche die Römer lutum nannten, besitzen wir nicht, wir wissen aber von VERGIL, dass sie gelb färbte (er nennt sie croceum lutum), und von VITRUV, dass man ein schönes Gıün erhielt, wemn man etwas blau gefärbtes mit der gelben Farbe des lutum tränkte. Da die genannten Eigenschaften dem in Italien wachsenden Wau zukommen, und da man unter den dort wachsenden Pflanzen eine andere nicht kennt, die ebenso färbte, so hat man lutum als Wau gedeutet.

In den Pflanzenglossaren scheint der Wau ganz zu fehlen, aber im 13. Jahrhundert finden wir ihn bei ALBERTus MAgNus $(6,352)$, der ihn unter dem Namen gauda sehr sorgfältig beschreibt und ihm ganz ähnliche Eigenschaften beilegt wie VITRUV: blaues Zeug wird durch Wau grün gefürbt und weisses gelb; als Medicament ist er aber nicht tauglich oder nicht versucht (utilitas autem ejus ad medicamina aut nulla est, aut inexperta). deutet blau.

1) Isatis . i . uuas dus unde tingunt persum CGLUI, ǒ83, 48; persus be-

9) Puinius $(35,6,12 u .23)$ versteht unter sandy $x$ eine rote Mineralfarbe, wahrscheinlich IIennige; bei VERGIL, Ecl. 4, 45, wird auch sandyx erwähnt.

$\left.{ }^{3}\right)$ Weit-Sandix ahd. G1. 25, 10; sandix, weitwurz Sum. 63, 56. 
Ton Hieronyarus Bock wird der Wau Orant oder Sterckkraut genannt, ron TABERNAEJONTANUS und anderen auch Streichkraut. Früher ist er ziemlich viel gebaut worden; jetzt findet man ihn in Norddeutschland vielfach verwildert und eingebürgert.

Carthamus tinctorius L., Safflor.

Кvทิко Theophr. 6, 4, 3; кvíкоక Diosk. 4, 187.

Cnecos Plin. 21, 15, 53; it. cartamo, zaffrone; fr. carthame, safre, safran bâtard.

Stammt aus Egypten. Die Samen dienten früher als Arznei. Die getrockneten Blumen enthalten einen gelben und, in geringerer Menge, einen roten Farbstoff (spanisches Rot, zu roter Schminke verarbeitet); sie dienten vielfach zur Verfälschung des teuren und jetzt aus der Mode gekommenen Safrans. ALBERTUS MAGNUS nennt den Safflor crocus $(6,297)$ und weiss ihm nicht viel Gutes nachzusagen; den Safran nenut er crocus hortensis.

\section{Seifenkraut und andere Waschmittel.}

Saponaria officinalis L., Seifenkraut.

Das Seifenkraut kommt hier im Norden nur in unmittelbarer Nähe menschlicher Wohnungen, namentlich in Gartenzäunen, und fast nur mit gefüllten Blumen vor: es ist offenbar eine verwilderte Pflanze. Die Blïtter und ganz besonders die Wurzel enthalten Seifenstoff, Saponin, in grösserer Menge; deshalb wurde die Wurzel früher viel zum Waschen gebraucht. Jetzt, wo die Pflanze durch die billigen Seifenpreise ausser Kurs gesetzt ist, wird die Wurzel nur noch zum Waschen hellgefärbter Wollstoffe angewandt, aber offenbar selten.

Der Name saponaria, der bei Albertus Magnus $(2,110)$ genannt wird, scheint in den Pflanzenglossaren nur sehr selten vorzukommen; den Römern war er unbekannt. Das Struthion des THEOPHRAST ( $\sigma \tau$ foutiov, $6,8,3)$, das eine schöne aber geruchlose Blume hat, könnte unser Seifenkraut sein, da diese Pflanze im heutigen Griechenland $к \alpha \lambda$ -

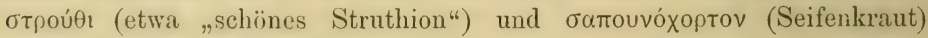
heisst. Das Wort Struthion bezeichnet aber bei THEOPHRAST mehrere nnd von einander verschiedene Pflanzen. PLINIUs identificiert $(19,3,18)$ die römischen Bezeichnungen radicula und herba lanaria (COLUMELLA lässt die Wolle der tarentinischen Schafe vor der Schur mit radix lanaria waschen, 11, 2,35) mit dem griechischen struthion, verlegt die Heimat der Pflanze nach Asien, und schildert sie als gut aussehend, geruchlos, dornig und mit flaumig hehaartem Stengel (grata adspectu, verum sine odore, spinosa et caule lanuginis). Er könnte Gypsopliila Struthium L. meinen, deren Wurzel als levantische, egyptische oder spanische Seifenwurzel in den Handel kommt; ihr Stamm ist jedenfalls so rauh, dass er ihn als "spinosus" bezeichnen könnte, und ihre Wurzel ist reich an 
Saponin. Auch noch andere Gypsophilaarten mit saponinhaltigen Wurzeln können ron den Römern als herba lanaria bezeichnet worden sein, z. B. Gypsopliila fastigiata L., und die in Süditalien und auf Sicilien vorknmmende Gypsophila Arrostii Gussone, die noch heute von den Italienern radicetta und erba lanaria genannt wird. Übrigens kommt unser Seifenkrant in Italien nicht selten vor und wird dort saponaria genannt; die Wurzel benutzt man auch dort zum Waschen.

Albertus Magnus beschreibt $(6,396)$ unter dem Namen nigella unsere Kornrade, Agrostemma Githago L., sehr genau und bemerkt zum Schluss von ihr: "Tuchbereiter erzählen auch, dass ihr Mehl Wollenzeug selır weiss und rein wasche, ebenso wie die Pflanze, die borith genannt wird." 1) Bei KONRad von MEgenberG, der dieselbe Pflanze nigella und rôteu kornpluom nennt, findet sich nahezu die gleiche Bemerkung: „ez sprechent auch etleich wollenweber, daz ez daz wullein tuoch gar weiz rainig"; nur ist hier nicht vom Mehl der Kornrade die Rede. Beide Autoren kennen augenscheinlich diese Anweuduug der Kornrade nicht aus eigener Anschauung und berichten, wenn das, was sie sagen, überhaupt richtig ist, über eine damals schon in Vergessenheit geratene Technik.

\section{Flachs und Leinenappretur.}

Linum Capitulare 43 u. 62; Limum usitatisimum L., Flachs, Lein.

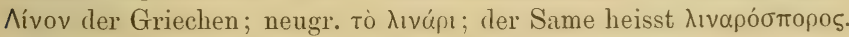
Linum der Römer; it. lino; fr. lin, der gehechelte Flachs filasse.

Die Untersuchung über die Heimat des Flachses ist noch nicht als völlig abgeschlossen zu betrachten. HEHN kommt durch Prüfung der Angaben, welche sich bei den Schriftstellern des Altertums finden, zu dem Resultat, dass die Flachskultur aus Egypten und dem babylonischen Reich stamme. Damit ist aber die Frage nach der eigentlichen Heimat des Flachses noch nicht beantwortet, wemn es auch wahrscheinlich ist, dass der Flachs aus der Mittelmeerregion oder aus dem gemässigten Westasien stammt. Er hat sich eben an alle Klimate gewöhnt: im gemässigten ist er Sommerpflanze, im heissen Winterpflanze. Dass der Flachs über Italien nach Deutschland gekommen ist, ist sicher; da aber die Flachskultur in den nordeuropäischen Ländern sehr alt ist, älter als das Eindringen römischer Kultur, so muss er seinen Weg hierher durch andere Lünder, vielleicht durch das lieutige Ungarn oder Russland genommen haben. Gebaut wurde er liauptsächlich seiner Fasern wegen, an manchen Orten aber auch wegen seiner Samen. Leinsamen liefert ein sehr brauchbares Ol, das anch an Speisen Verwendung finclet, und wird ausserdem vielfach in der Medicin benutzt.

1) „Fullones etiam quidam tradunt quod farina ejus lavat laneos albissime et mundissime, sicut herba, quae vocatur borith;““ die Pflanze borith wird von C. JEsSEN als Salsola fruticosa L. gedeutet. 
An dieser Stelle mag noch eine technische Frage kurz erörtert werden.

WALAFRIDUS STRABUS sagt bei der Besprechung der blauen Schwertlilie (Iris germanica L.) in den letzten Zeilen des Gedichtes, dass der Tuchbereiter mit ihrer Hülfe bewirke, dass das Leinen steif werde und Wohlgeruch annehme. ${ }^{1}$ ) Hier dient die Wurzel der Schwertlilie, denn an andere Teile der Pflanze kann man füglich nicht denken, dazu, dem Leinen Appretur zu verleihen; da diese Wurzel nach Veilchen duftet, so ergiebt sich der Duft nebenher. Wir werden durch diese Stelle an eine gänzlich in Vergessenheit geratene Technik erinnert: niemand denkt heute noch daran, mit dem in der Iriswurzel enthaltenen Pflanzenschleim dem Leinengewebe Steife und Glanz zu verleihen; dass diese Technik aber verbreiteter war, bezeugt die Glosse: irius follonicatoria (CGI, III, $546,69)$; irius ist soviel wie Iris, und follonicatoria kommt von fullonicare, einem Verbum, das die Tätigkeit der Tuchbereiter (fullones) bezeichnete. ${ }^{2}$ ) Gepulverte Iriswurzel, namentlich die von der Iris florentina stammende Veilchenwurzel, wird noch heute zum Waschen von seidenen Bändern benutzt; vielleicht hat man diesen Gebrauch als Rest der eben genannten Technik zu betrachten.

Das lateinische Wort candor stimmt seinem Sinne nach mit dem heutigen "Appretur" überein, das nicht nur Glanz, sondern schönes Aussehen überhaupt, und bei Leinen auch noch Weisse bedeutet. Dem gebleichten Leinen wird gegenwärtig die Appretur durch Dextrin erteilt. Die Römer verstanden auch die Kunst, das Leinen mit candor zu versehen (HUGO BLÜMNER, Technologie und Terminologie der Gewerbe und Künste bei Griechen und Römern, Bd. 1, Leipzig 1875, S. 185̃), auch benutzten sie dazu nach PLINIUS ${ }^{3}$ ) Pflanzen, und zwar eine Art von Mohn (papaver). PLINIUS war nicht so strenge in der Unterscheidung von Gattungen und Arten, wie wir es heute zu sein versuchen.

1) „Pignore fullo tuo lini candentia texta

Efficit ut rigeant dulcesque imitentur odores."

2) Man vergl. A. Funck, Glossographische Studien, im Archiv für lateinische Lexikographie, Bd. VIII, S. 376.

$\left.{ }^{3}\right)$ 19, 1, 4 am Schluss: „Est et inter papavera genus quoddam quo candorem lintea praecipuum trahunt". - 20, 19, 79 spricht PLinius von einer willen Mohnart, die heraclion oder aphron genannt wird und von der er sagt: „ex hoc lina splendorem

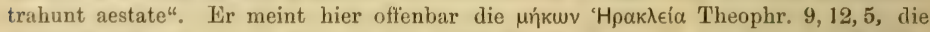
identisch mit der uๆjkwv ủppúons bei Dioskorides $(4,67)$ zu sein scheint. Welche Pflanzenart mit diesen Namen gemeint sein mag, ist bis jetzt nicht $\mathrm{zu}$ entscheilen gewesen, vielleicht hat man es auch zu DrosKonides' Zeit nicht mehr gewusst. 'THEOpHras' sagt von ihr, sie habe ein Blatt wie das Seifenkraut, womit man die

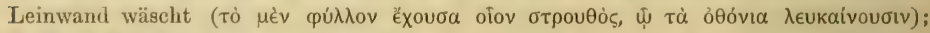

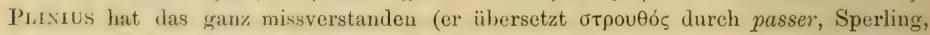
was an und für sjch möglich ist, aber an dieser Stelle nicht gemeint sein kann) und sein Ausspruch „ex hoc lina splendorem trahunt aestate" ist garnicht auf den herakleïschen ذIohn zu beziehen, sondern auf das Seifenkraut. 
Seine Mohnart braucht deshalb garnicht der heutigen Gattung Papaver anzugehören, sondern nur eine äussere Ähnlichkeit mit ihr zu haben, und da lenken sich denn unwillkürlich die Gedanken auf die grossblumigen Anemonen, wie Anemone coronaria L., die in Italien vorkommen, und deren rotblühende Formen an die Klatschrose (Papaver Rhoeas L.) erinnern. PLINIUS selbst, der diese Anemone anemone coronaria nennt (21, 23, 94), giebt $\mathrm{zu}$, dass diejenige mit roter Blume (quae phoenicium florem habet), die zugleich die häufigste sei, mit den wilden Mohnarten verwechselt werde, nämlich mit argemone und rhoeas. Ihm selbst kamn diese Verwechselung trotzdem passiert sein, denn viele Pflanzen, über die er schreibt, hat er offenbar nie gesehen und gelegentlich hat er seine Vorlage überhaupt nicht verstanden.

Die genannte Anemonenart besitzt eine knollige, fleischige Wurzel, und diese enthält, nach einer von hülfsbereiter Hand vorgenommenen Analyse, grosse Mengen von Pflanzenschleim und Stärkemehl, würde sich also zum Appretieren sehr wohl eignen. Deshalb erscheint es nicht zu kuihn, wenn man diese Anemone als das "quoddam genus inter papavera" bei PLINIUS anspricht.

\section{Hanf und Nessel.}

Canava Capitulare 62 ; canabis im Breviarium; Cannalis sativa L., Hanf. Kávvaßıs Herodot 4, 73, 74 u. 75 ; Diosk. 3,155 ; neugr. кavváßı.

Cannabis der Römer, auch cannabus; it. canape, canapa; fr. chanvre. Dass der Hanf eine asiatische und keine europäische Pflanze ist, darüber sind sich alle einig; aber während einige seine Heimat nach dem gemässigten Mittelasien und Sibirien verlegen, suchen andere sic in Indien. Über die Art und Weise, wie der Hanf sich verbreitet hat, weiss man nicht sehr viel. Während die erste Nachricht über ihu bei römischen Schriftstellern sich etwa 100 Jahre vor Chr. findet, nämlich beim Satiriker LUCILIUS (HEHN S. 158), wird andererseits bei ATHEN̈̈US erzählt (5, 206 f), dass König Hiero II. von Syrakus den Hanf für sein Prachtschiff vom Flusse Rhodanus (Rhone) in Gallien habe kommen lassen. Im dritten Jahrhundert vor Chr. wurde also im heutigen Südfrankreich Hanf gebaut, während es um diese Zeit an Nachrichten über einen derartigen Bau für Italien fehlt. Da wird es denn wenigstens wahrscheinlich, dass der Hanf seinen Weg nach Gallien nördlich von den Alpen genommen habe.

Dass der Hanf eine zweihäusige Pflanze ist, wurde verhältnismässig früh bemerkt, ${ }^{1}$ ) aber auch hier fand, wie früher fast überall, eine Verwechselung statt: die kleinere männliche Pflanze wurde, eben weil sie klein und weniger zu verwerten war, lie weibliche, "femella“, genamnt, die grössere weibliche aber männlich, "masculus", und beide Namen haben

1) CGLIII : canape . i agre genera sunt duo masculus et femina quae est efficax 587, 73; 608,68 . 
sich in manchen Gegenden Deutschlands als Fimmel und Maschel oder Masch in demselben Sinne erhalten, wie sie früher gebraucht wurden. Sonderbarer IV eise führt der Hanf in alten Pflanzenglossaren ${ }^{1}$ ) sehr viel die Namen agrius und agre, die "wild" bedeuten. ${ }^{2}$ ) Deutsche Namen des Hanfs sind haneph, hanif, henp, hemp, kempenkrut (im Holländischen Kemp).

Die grosse Brennnessel (Urtica dioica L.), die auf feuchten Waldplützen, an Wällen und auf wüsten Stellen wächst, dient noch jetzt Tölkerschaften an der Grenze Asiens und Europas zur Bereitung von Garn und Zeug (HEHN, S. 481, 482). Auch in Deutschland ist sie friiher in gleicher Weise benutzt worden. ALBERTUS NAGNUS führt $(6,462)$ noch die Nessel als Gespinnstpflanze an und schreibt dem aus Nesselfaser bereiteten Zeuge Eigenschaften zu, die dem aus Flachs oder Hanf hergestellten nicht zukommen. Den Römern war eine solche Technik unbekannt, wohl aber kannten sie, wie auch die Griechen, die Nessel als Gemüse- und Arzneipflanze. In Italien ist die grosse Nessel, die daselbst ortica genannt wird, häufig, in Griechenland selten. Die Pillennessel (Urtica pilulifera L.) ist in Griechenland die häufigste, in Norditalien seltener, bei uns in Deutschland zuweilen verwildert und manchmal bis nach Norddeutschland verschleppt. Wem von essbaren Nesseln die Rede ist, so sind die genannten beiden rorzugsweise gemeint. Bei den

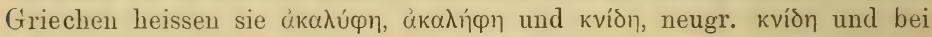

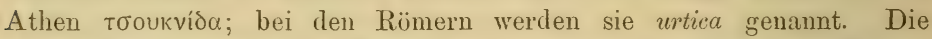
jungen Frühjahrstriebe der Nesseln wurden gegen Brustleiden empfohlen, dienteu aber ganz besonders als Gemüse, wie noch jetzt in Ungarn und dem östlichen Deutschland; nach Westen hin ist dieser Gebrauch seltener. Die Triebe werden abgebrüht, wie schon THEOPHRAST $(7,7,2)$ empfiehlt, und dann wie Spinat behandelt.

ALBERTLS MAGNUs spricht $(6,642)$ vou einer griechischen Nessel, urtic graeca, KONRAD VON MEGENBERG $(5,82)$ von einer kriechisch nezzel, die klein an Stamm und Blättern ist, aber viel stärker brenut als die grosse. Es ist dies die kleine Brennnessel (Urtica urens L.), die ein sehr lästiges Gartenunkraut ist, aber sich auch an Schuttplätzen ansiedelt. Bei der heiligen HILDEGARD heisst sie eyter neszel, was so

1) CGLIII: agrio canapin 631,21; agrius . canape 543,4; agre . i . canape 552,44 . - Culm. Gloss. a . . ion (d. h. agrion) haneph 17.

2) Sollte dies daher kommen können, dass der Hanf auf wüsten Plätzen gesät wurde, ïhnlich wie früher der Flachs in Mecklenburg, der sich mit den Rändern der Dorfistrassen uud Wege begnïgen musste? (Vergl. E. H. L. Krausk, Pflanzengeographisclic Übersicht der Flora von Mecklenburg, im Archiv d. Ver. d. Freunde (1. Ntg. in Mecklenburg, Bd. 38, Güstrow 1884, S. 124). Im Grossen ist er in Deutschland überhaupt selten gebaut worden, wohl aber fand und findet man in den Gärten von Fischern und Tandleuten ein grösseres mit Hanf bestandenes Beet, das die häuslichen Bectürfnisse an Hanffaser befriedigen konnte. 
viel wie Feuer- oder Brennnessel bedeutet, bei den Schriftstellern des 16. Jahrhunderts Eiter- oder Heiternessel. Wenn ALBERTus MAGNUS sie "griechisch" nennt, so könnte dies andeuten, dass er sie für fremd in Deutschland hält. Wahrscheinlich ist sie aus Südeuropa nach Deutschland gebracht.

\section{Pflanzen des Gemüsegartens.}

\section{Kürbis, Gurke und Melone.}

Cucurbitas Capitulare 70, 10; Cucurbita lagenaria L., Flaschenkürbis.

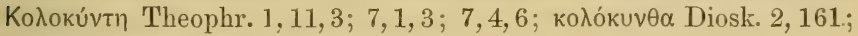
neugr. vєрокодокиөเа́ (d. h. Wasserkürbis).

Cucurbita Colum. 10, 381-388; 11, 3, 49 u. 50; Plin. 19, 5, 24; it. zucca, zucca lunga, zucca da vino, zucca da pesce; fr. gourde, cougourde, calebasse.

Bei den griechischen Schriftstellern der vorchristlichen Zeit erfahren wir über die Pflanze, die ebenso wie ihre Frucht коภoкúvтๆ (kolokynte) genannt wurde, nur sehr wenig: die kolokynte war roh nicht essbar, wohl aber gekocht oder gebraten (Phainias bei Athen. 2,68d); es gab nur eine Art, aber innerhalb dieser waren die einen besser, die anderen schlechter (Theophr. 7,4,6). Ausserdem hatte sich die Sage erhalten, dass die kolokynte aus Indien stamme (Athen. 2, 59).

Die römische cucurbita hält man für identisch mit der griechischen kolokynte. In der That findet sich keine Angabe, aus der man auf das Gegenteil schliessen könnte. DIOSKORIDES bringt nur den Namen коภóкuv $\theta \alpha$ ohne Beschreibung; wäre die von ihm gemeinte Pflanze etwas anderes gewesen als die römische cucurbita, so würde er es bestimmt zum Ausdruck gebracht haben. Vom dritten Jahrhundert an finden wir die beiden Namen als identisch gegenübergestellt (CGL III, 16, 22: 185,$38 ; 265,38$ etc. etc.); wir wollen sie als solche nehmen und mit Kürbis bezeichnen, und demnächst untersuchen, ob sich aus den überlieferten Angaben die Art bestimmen lässt.

COLUnIELLA beschreibt $(10,381-388)$, wie man dem Kürbis verschiedene Formen geben könne, je nachdem der Same aus der Mitte oder aus den Enden der Frucht genommen werde; nimmt man z. B. - den Samen mitten aus dem Bauche, so erhält man eine Frucht, die 
geräumige Flaschen (lagena) zum Aufbewahren von Pech, Honig, Wasser und Wein liefert, die auch sogar zum Schwimmunterricht der Knaben benutzt wird. ${ }^{1}$ ) Ziemlich dasselbe sagt COLUMELLA 11, 3, 49, und fügt hier hinzu, dass die langen und dünnen Früchte zum Essen am besten seien.

PLINIUS stimmt in seinen Mitteilungen $(19,5,24)$ ziemlich genau mit denjenigen COLUMELLAS überein; er sagt, dass man den Kürbis zwingen kaun, beliebige Formen anzunehmen, wenn man die junge Frucht in ein Gefüss von der verlangten Form hineinsteckt; dass der Kürbis sich auf verschiedene Art als Gemüse benutzen lüsst und dass er vor einiger Zeit in den Bädern an die Stelle der thönernen Gefässe getreten sei, während er schon früher statt der Thongefässe zur Aufbewahrung des Weines benutzt wurde. ${ }^{2}$ )

Nach dem hier Angeführten kann der Kürbis der Römer und Griechen nur unser Flaschenkürbis gewesen sein, denn kein anderer Kürbis hat eine erhärtende Schale, die sich zu Gefässen verarbeiten lässt.

Das Einzige, was sich gegen diese Auffassung geltend machen liesse, ist eine Bemerkung bei PLinius (19, 5, 24): "Kräfte, um ohne Stütze zu stehen, sind nicht vorhanden, die Geschwindigkeit (des Wachstums) ist gross, mit leichtem Schatten Gewölbe und Laubengänge bedeckend. Daher diese beiden Hauptgeschlechter, der Gewölbekürbis und der plebejische, insofern er am Boden kriecht." ${ }^{3}$ ) Indessen wird kaum jemand nach den hier gegebenen Unterschieden auch nur Rassen, geschweige denn Arten unterscheiden wollen.

Wir würden schon jetzt kein Bedenken tragen den Kürbis des Capitulare als Flaschenkürbis anzusprechen, aber ehe wir uns definitiv entscheiden, wollen wir untersuchen, ob nach Karl dem Grossen ron anderen Kürbisarten die Rede ist. Die erste ausführliche Nachricht über den Kürbis finden wir bei WALAFRIDUS STRABUS. Er sagt am Schlusse seines „Cucurbita" überschriebenen Gedichtes etwa Folgendes: "Setzt man den Kürbis den Sonnenstrahlen aus und schneidet ihn nach erlangter Reife ab, so lassen sich aus ihm dauerhafte Gefässe anfertigen, wenn man das Fruchtfleisch herausnimmt und die Wände mit einem Schabeisen vorsichtig abkratzt; bisweilen fasst ein solches Gefäss eiuen gewaltigen Sextarius (Schoppen), ja ein noch grösseres Maass kann es

1) „Ventre leges medio, sobolem dabit illa capacem

Naryciae picis, aut Actaei mellis Hymetti,

aut habilem lymphis hamulam, Bacchove lagoenam;

tum pueros eadem fluviis innare docebit."

2) "Nuper in balneorum usum venere urceorum vice, iampridem vero etiam cadorum ad vina condenda."

3) "Vires sine adminiculo standi non sunt, velocitas pernix, levi umbra camaras ac pergulas operiens. Inde haee prima duo genera, camararium et plebeium quo humi repit." 
aufnehmen, eine Amphora (48 Sextarien), und wenn man es verpicht, so bewahrt es den Wein lange unverdorben" ${ }^{1}$ )

Die heilige HILDEGARD spricht von kurbesa, lateinisch cucurbita $(1,87)$, ohne eine Beschreibung zu liefern, aber ALBERTUS MAGNuS sagt $(6,312)$ : „Der Kürbis bringt seine Samen (grana sui germinis) in einem grossen Gefüsse hervor, das, wenn es reif ist, die Mitte hält zwischen gebranntem Thon und Holz (medium est inter testam et lignum), obgleich der Kürbis selbst nichts Holziges (nihil ligneitatis) in Stamm und Blättern hat"; und weiterhin $(6,314)$, wo von der Gurke die Rede ist, bemerkt er: „Die Gurke hat eine gelbe Blume und der Kürbis eine weisse" (et florem habet croceum, et cucurbita album). KONRAD VON MEGENBERG erwähnt nur den kürbiz oder cucurbita, ohne eine Beschreibung zu liefern.

Was aus der Zeit nach Karl dem Grossen über den Kürbis gesagt wird, lässt sich also auch nur auf den Flaschenkürbis beziehen. Von besonderer Wichtigkeit sind die Bemerkungen des ALBERTUS MAGNus; denn da er in Italien gewesen war, so hätte er bei der Aufmerksamkeit, die er den Pflanzen widmete, es sicher erwähnt, wemn er andere Arten als den Flaschenkürbis gesehen hätte. Wir müssen daher RELiss recht geben, der die cucurbitu des Capitulare als Flaschenkürbis gedeutet hat.

HEHN, der den Flaschenkürbis vom gemeinen Küurbis nicht unterschied, sondern beide für eine Art gehalten haben muss, spricht immer nur vom Kürbis, nimmt also an, dass man im Altertum nur einen Kürbis kannte. Nach dem oben Gesagten kann dies nur der Flaschenkürbis gewesen sein, als dessen Heimat man heute die Tropen ansieht; die griechische Sage von seinem indischen Ursprung ist also mehr als Sage. In Egypten ist er seit uralten Zeiten gebaut worden und wird es hente noch; man findet ihn auf egyptischen Wandgemälden dargestellt (UNGER, die Pflanzen des alten Egyptens, Sitzungsber. d. math.-natw. Classe d. Akad. d. W. in Wien, 1860, Bd. 38, S. 125) und ebenso auf pompejanischen (Comes, S. 21, 22). ${ }^{2}$ )

1) „Si vero aestivi sinitur spiramina solis cum genitrice pati, et matura falce recidi, idem foetus in assidnos formarier usus vasorum poterit, vasto dum viscera ventre egerimus, facili radentes ilia torno, nonnunquam hoc ingens sextarius abditur alvo, clauditur aut potior mensurae portic plenae amphora, quae piceo linitur dum glutine, servat incorrupta diu generosi dona Lyaei."

2) Comes will (S. 22) auch Cucurbita Pepo L. auf pompejanischen Wandgemälden erkaunt haben. Es erscheint aber mindestens zweifelhaft, ob die genannte Art sich allein an ihren Früchten erkennen lässt; die Früchte des Flaschenkürbis sind nämlich von so erstaunlich wechselnder Form und Grösse, dass die von Cones 
WITTנAсK ist zu dem Resultat gelangt, dass unser gemeiner Kürbis, Cucurbita Pepo L., aus Amerika stammt (Die Heimat der Bohnen und Kürbisse, Berichte d. Deutschen Botan. Gesellschaft, Bd. 6, 1888, S. 374-380); dazu würde das Ergebnis unserer Untersuchungen stimmen.

Aber wir besitzen auch noch ein direktes Zeugnis dafür, dass Cucurbita Pepo L. aus Amerika zu uns gebracht ist. In seinem Commentar zum DIOSKORIDES, S. 393, sagt MATTIOLI, nachdem er den Flaschenkürbis beschrieben und auch angegeben hat, dass er weisse Blumen habe $\left.{ }^{1}\right)$ : „Es giebt auch verschiedene andere, Italien fremde, Kürbisarten, welche sich weit in den Winter hinein frisch aufbewahren lassen. Man sagt, sie seien aus Westindien nach Italien gekommen: deshalb werden sie mehrfach indische genannt. Sie kommen aber schon lange auf italienischem Boden vor." Darauf folgt eine Aufzählung des ungeheuren Formenreichtums und die Angabe, dass die Blumen dieser Kürbisse gelb seien. Zu Anfang des 16. Jahrhunderts mag wohl der gemeine Kürbis nach Italien gekommen sein; MATTIOLi konnte also schon von dein „ältesten Leuten“ über den Anbau dieser Kürbisart gehört haben.

In den Kräuterbüchern des 16. Jahrhunderts finden wir neben dem Flaschenkürbis, welcher Kürbs, auch wohl Fläschen Kürbs (TAB.) genannt wird, auch schon verschiedene Rassen des gemeinen Kürbis abgebildet. Diese heissen meistens Indianischer Kürbs, Cucurbita indica; HIERONYJus BOCK (fol. 297, vers.) nennt sie Indianisch öpffel oder Zuccomarin; er bemerkt, sie seien erst seit kurzer Zeit nach Deutschland aus fremden Landen über das Meer gekommen, und das italienische Wort "Zuccomarin" zeigt uns, welchen Weg die Pflanze von Amerika aus genommen hat. Der gemeine Kürbis hat nach und nach, wenigstens in Norddeutschland, den Flaschenkürbis ganz verdrängt.

Cucumeres Capitulare 70,8; Cucumis sativus L., Gurke.

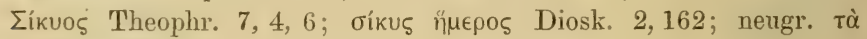
arroúpıla (die Früchte).

Cucumis der Römer; it. cocomero, cetriolo; fr. concombre.

Schon THEOPHRAST erwähnt drei verschiedene Rassen der Gurke, und ebenso finden wir bei den römischen Schriftstellern mehrere genannt. Wiihrend des Mittelalters scheint die Kultur der Gurke zurückgegangen zu sein, demn bei der heiligen HILDEGARD und bei KONRAD VON

genannten Abbildungen sich vielleicht zwanglos auf diese beziehen lassen. Comes ilentificiert Cusurbita lagenaria mit cucurbita Psiñus, Cucurbita Pepo mit koגokúvтn THeopurast; Gründe dafür giebt er nicht an; er irrt aber sicher, wenn er die cucurbita bei Columella 11, 3, 48 für Cucurbita Pepo L. hält, denn daselbst wird weiter unten 11, 3,49 von den Kürbissen gesagt: „nam sunt ad usum vasorum satis idoneae, cum exaruerint", was offenbar nicht vom gemeinen Kürbis gilt.

1) "Sunt et alia Cucurbitarum varia genera Italiae peregrina, quae diu per hyemem recentes asservari possunt. Ferunt has ab occidentalibus Indiis in Italiam venisse: unde Indicae a pluribus vocitantur. Sed iam diu Italico solo proveniunt." 
MEGENBERG wird sie nicht erwähnt, wohl aber bei ALBERTUS MAGNUS $(6,314)$, der sie cucumer nennt. In den Glossaren kommt sie selten vor, wird lateinisch cucumer und deutsch erdaphil (Sum. 56, 21), erthappl (Königsb. Gloss.) und ertappel (Mone, Colm. Gloss.) genannt, scheint aber gelegentlich mit Kürbis verwechselt worden zu sein (kurbiz-Cucurbita vel cucumer ahd. Gl. 7,21), auch mit der Melone. Im 16. Jahrhundert erscheint die Gurke wieder als beliebte und häufige Gemüsepflanze.

\section{Pepones Capitulare 70, 9; Cucumis Melo L., Melone.}

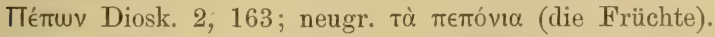

Melopepo Plin. 19, 5, 23; it. popone; fr. melon.

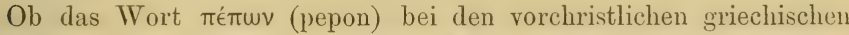
Schriftstellem sich schon auf unsere Melone bezieht, lässt sich nicht mit vollständiger Sicherheit entscheiden; es ist ein Adjektivum, das reif bedeutet, und das bald allein gebrancht, bald mit бíkus (Gurke) verbunden wurde. Beachtet man aber, dass im Nittelalter noch Gurke, Küurbis und Melone mit einander verwechselt wurden, und dass die Melonen im heutigen Griechenland $\pi \epsilon$ Tóvia (pejonia) genannt werden, so ist jedenfalls die Möglichkeit vorhanden, dass auch die Griechen des Altertums die Melone gekannt haben; dagegen spricht freilich der Umstand, dass nirgendwo von ihrem Dufte die Rede ist.

Von einer gurkenähnlichen Frucht mit Duft spricht zuerst PLINIus 19, 5, 23, wo er erzählt, dass in Campanien eine Gurke entstanden sei vom Aussehen einer Quitte (mali cotonei effigie); diese sei durch Aussaat fortgepflanzt und melopepo genannt werden, bewunderungswiirdig durch Form, Farbe und Duft. Diese Worte passen zwanglos auf die Melone, deren Namen überdies von melopepo herzuleiten ist; aus dem langen Worte melopepo ( munde melo, und daraus unser Melone. An ein spontanes Entstehen. der merkwiirdigen Frucht werden wir heute nicht mehr glauben, aber bei den weitverzweigten Verbindungen des ramaligen römischen Reiches war die Einfuhr von Samen aus Südasien, dem Heimatlande der Melone, leicht möglich; dass der Bericht über ihr erstes Auftreten in Italien den Charakter der Fabel trägt, ist nicht weiter wunderbar. Dass übrigens die Römer die Melone kannten, wird dadurch zur Gewissheit erhoben, dass unter den auf einem antiken Mosaik des Vatikans dargestellten Früchten sich auch eine Melone befindet (Alph. de Candolle, S. 327); auch will COMIES (S. 20) die Hälfte einer Melone auf einem pompejanischen Wandgemälde erkannt haben.

Ehe wir weiter gehen, wollen wir uns noch einen Augenblick mit der Frucht beschäftigen, die PliniUs pepo nennt (19, 5, 23, zu Anfang); hier berichtet PLINIUS über die Gurken: "sie wachsen in jeder Form, zu der sie gezwungen werden, in Italien grün und sehr klein, in den - Provinzen sehr gross und wachsfarben oder dunkel (quam maxumi et 
cerini aut nigri). Beliebt sind die reichtragenden (copiosissimi) Afrikas, die kolossalen (grandissimi) Moesiens. Wenn sie sich durch Grösse auszeichnen, werden sie pepones genannt". Die Frucht, von der PLINIUS hier spricht, kennt er offenbar selbst nicht sehr genau, aber aus dem was er sagt, folgt immerhin, dass sie Ähnlichkeiten mit der Gurke und der Melone hatte: er spricht ja von ihr als einer Art oder Rasse der Gurke und wenn die Melone melopepo genannt wurde, so kann das doch nur deshalb geschehen sein, weil sie in gewissen Eigentümlichkeiten mit der pepo genannten Frucht übereinstimmte. Deshalb wird man wohl die pepo des Plinius als Wassermelone, Citrullus vulgaris Schrader, deuten dürfen; diese dem intertropischen Afrika angehörige Pflanze ist seit uralten Zeiten Kulturpflanze in Egypten gewesen, ist es heute im ganzen Orient, in Griechenland, in Serbien und Bulgarien (Moesien), in Südrussland und Ungarn; aber während sie in den nördlicheren Ländern auch auf dem Tische der Reichen erscheint, ist sie weiter nach Süden Nahrungs- und Genussmittel der Armen und Ärmsten, wird aber von den Reichen verschmäht. Älnnlich konnte es zu PLIxIUS' Zeiten gewesen sein: der vornehme Römer hatte von der Wassermelone gehört, ron ihrem Heimatlande Afrika, von ihrer Verbreitung, aber er selbst hatte sie vielleicht nur gesehen; denn wenn er sie gegessen hätte, würde er doch wohl ihre dunklen Kerne oder ihr rotes Fruchtfleisch erwähnt haben. Aber freilich findet sich eine Angabe dieser besonders hervorragenden Kennzeichen der Wassermelone erst im 16. Jahrhundert (Matt., Tab. etc.) Andererseits würde es geradezu unbegreiflich sein, wenn die Römer die Wassermelone nicht sollten gekannt haben, denn dazu waren ihre Verbindungen mit Egypten viel zu zahlreich.

Wir deuten also von den bei PLINIUs erwähnten Cucurbitaceen die cucurbita als Flaschenkürbis, cucumis als Gurke, pepo als Wassermelone und melupepo als Nelone, halten es aber für möglich, dass unter diesen Benennungen damals, ebenso wie in späterer Zeit, manche Verwechselungen vorgekommen sind; es ist deshalb nicht immer möglich mit Bestimmtheit zu sagen, welche Pflanze an irgend einer bestimmten Stelle unter cucumis, pepo etc. zu verstehen ist. Das pepo des Capitulare dürfte aber unsere Melone sein.

In den ersten Jahrhunderten unserer Zeitrechnung war die Melone in Italien und den Nachbarländern bekannt. In den Hermeneumata des CGLIII wird unter den Gemüsen pepo mehrfach erwähnt und teilweise durch melo iibersetzt, während melopepo nur selten vorkommt; ${ }^{1}$ ) hier scheint also pepo die Melone selbst zu bedeuten. In den Glossaren des CGL III werden melo und pepo identificiert, aber auch pepo und cucumis, $\stackrel{\text { ) }}{\text { (1) }}$ das letztere vielleicht nach PLINIUS.

1) T€тuv pepo 16,$24 ; 88,47 ; 317,49 ; 359,45$ etc.; $\pi \dot{\pi} \pi \omega v$ melo 265,40 ;

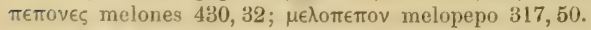

$\left.{ }^{2}\right)$ Melonis . i . pepenus 592,74 ; meleonis idest peponis 614,47 ; 626,51 ; peponus cucumeris 594,$12 ; 609,39 ; 616,3$. 
In den lateinisch-deutschen Glossaren werden pepo und melo als gleichbedeutend behandelt und übersetzt mit pjedemo, phedema, pedeme, bibenna, zuweilen auch durch erdapfel, ${ }^{1}$ ) das freilich besser auf die Melone als auf die Gurke passt, aber möglicherweise doch eine Verwechselung der beiden Früchte andeutet. Bei der heiligen HILDEGARD fehlt pepo in der neuen Ausgabe, in der Strassburger wurde es im 56. Kapitel des zweiten Buches abgehandelt, und es ist nicht recht verständlich, weshalb es nicht auch in die neue Ausgabe mit hinübergenommen ist. ALBERTUS MAGNUs widmet den Cucurbitaceen einen verhältnismässig grossen Abschnitt. Die melones, welche auch pepones genannt werden, sind in Blättern und Blumen beinahe so wie die Gurke $(6,314)$; gewöhnlich ist pepo von gelber Farbe und von unebener Oberfläche, gleichsam als wäre er regelmässig aus scheibenförmigen Halbkreisen zusammengesetzt (quasi sit ordinate compositus ex semicirculis rotundis 6,315 ); er enthält sehr viele Samen regellos (inordinate), die in einer gewissen Flüssigkeit schwimmen, im Gegensatz zum Kürbis, bei dem sie in einer trockenen Substanz sitzen $(6,313)$; nach diesen Worten kann man wohl nicht sweifeln, dass von der Melone die Rede ist. ALBERTUS MAG.NUS spricht noch von einer ähnlichen Frucht, citrulus; während er die Melone an verschiedenen Stellen beiläufig abhandelt, widmet er dem citrulus einen besonderen Abschnitt $(6,315)$, beschreibt ihn aber ganz ausserordentlich kurz, denn er sagt nur, der citrulus ist ein pepo von grüner, ebener Rinde (citrulus autem est pepo viridis plani corticis). KONRAD VON MEGENBERG behandelt citrulus und Melone in demselben Abschnitt $(5,22)$ : "citrullus haizet ein erdapfel und ist nîhent gestalt sam die Pfedem, die ze latein pepones haizent;" aber der Erdapfel ist grün und die Melone ist gelb. Es ist möglich, dass der citrullus bei ihm und ALBEBTUS MAGrNus nur eine kurzfrüchtige Rasse der Gurke ist, ebenso wie bei MatTioli (comm. S. 395). Man vergleiche den Nachtrag.

Melonen werden in den Kräuterbüchern des 16. Jahrhunderts melo, pepo und melopepo, auf deutsch Melone und Pfebe genamit, aber oft werden kleine Kürbisformen zu den Melonen gezogen. Die Wassermelone führt den Namen citrullus und Citrullen (TAB., BOCK), anch anguria und Angurien (MATT. comm. und Krï̈utb.); da ihre dunklen Kerne erwähnt werden, so kann man nicht zweifelhaft sein, dass sie hier gemeint ist.

\section{Erbsen und Bohnen.}

Pisos Mauriscos Capitulare 70,68. Tisum aremse L., Graue Erbse, preussische Erbse, Felderbse.

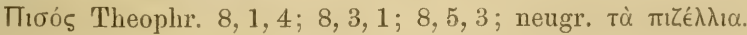

1) Pfedemo-pepo ahd. Gl. 7,22; pepo, pfedeme Sum. 22,34; pepones pedeme, melones pedemen Königsb. Gloss.; pepo, phedema vel erdapfel Sum. 12,66; pepones. 'erdeapfel Sum. 41, 3; melon, bibenna Sum. 63, 2. 
Pisum Colum. und Plin.; it. pisello, mubiglio, rubilli (die Samen); fr. pois, pois gris, bisaille.

Die Nachrichten über das pisum der Alten fliessen sehr spärlich. Columella sagt $(2,10,19)$, dass cicercula der Erbse :̈hnlich sei. Cicercula ist aber unser Lathyrus saticus L., Saat-Platterbse, die auf den griechischen Gebirgen unter dem Namen $\lambda \alpha \theta o u ̂ p ı$, in Italien unter den Namen cicerclia, cicercula, cece nero noch jetzt gebaut wird; ihre Samen sind grünbräunlich, gross, kantig, unregelmässig viereckig oder kurzpyramidenförmig. Auch PLINIUS berichtet nur, dass die Erbse unebene und eckige Samen labe $\left.(18,12,32) \cdot{ }^{1}\right)$ Nimmt man hierzu, dass THEOPHRAST die Erbse nicht unter den Hülsenfrüchten anführt, die auch weisse Samen haben $\left.(8,5,1),{ }^{2}\right)$ so wird man nicht fehl gehen, wenn man die Erbse der Alten als graue Erbse oder Felderbse (Pisum (rvense L.) bezeichnet; denn die Samen der Felderbse sind dunkelfarbig, uneben und eckig. Hierzu stimmt es, wenu in den Glossaren des CGL III die Kichererbse, deren Samen gleichfalls eckig sind, weisse Erbse genannt wird. ${ }^{3}$ )

Wenu num in dem sogenamnten Breviarium Karls des Grossen (Pertz, Monumenta etc. Bd. 3, S. 178) neben Spelt, Gerste, Weizen, Roggen, Hafer und Bohneu (faba) auch pisos namhaft gemacht werden, so wird man hierbei nur an die Felderbse denken können. Im Capitulare selbst ist zu pisus das Adjektivum Mauriscus gestellt: REUSS übersetzt "Mohrenerbsen", was dem Wortlaute genau entspricht. Vielleicht soll es garnichts anderes heissen als „braune Erbsen". Noch heute wird eine Spielart der Felderbse gebaut, deren Samen gross, runzelig, eckig und lebhaft

1) „Est et cicercula minuti ciceris, inaequalis, angulosi, veluti pisum."

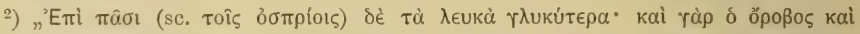

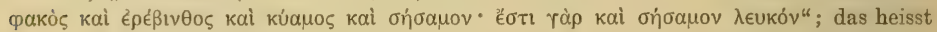
etwa: „bei allen Hülsenfrüchten sind die weissen (hellen) die süsseren; nämlich sowohl Erwe, als Linse, Kicher, Bufbohne und Sesamon; denn es giebt auch weisses Sesamon." Unter ópoßos ist Ervum Ervilia L. zu verstehen, das noch heute in Griechen-

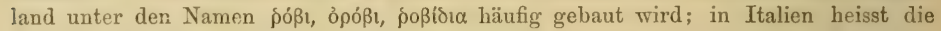
Pflanze ervo, orobo etc.; ihre Samen sind hellfleischfarbig bis ledergelb. Die Linse (рако́) hat gelblichweisse, gelbe, grünliche und fast sehwarze Samen; über die Kicher vergleiche man unten S. 101; bei der Bufbohne oder Saubohne (vergl, unten S. 100) sind die Samen der grossfriichtigen Gurtenrasse hellfarbig bis fast weiss, diejenigen der kleinfrüchtigen Rasse, der Pferdebohne, bräunlich bis dunkelbraun. - Das Sesamum ist nach unseren Begriffen keine Hülsenfrucht; es stellt eine besondere Familie, di: Sesamaceen, dar, die der Familie der Serophulariaceen oder Personaten nahe steht. Sesamum orientale L. ist eine im Orient vielfach kultivierte Pflanze, deren weisse Samen ein vortreffliches Öl liefern, das schon den Balyloniern bekannt war; das ebenso benutzte Sesamum indicum L. hat schwarze Samen. Bei den Neu-

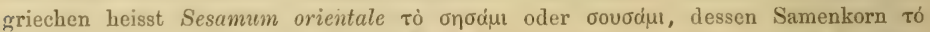

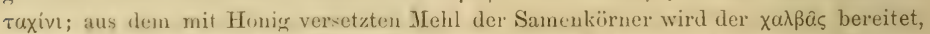
cine in granzen Grient sehr beliebte und gewöhnliche Nahrung wïhrend der Fastenzoit (v. HELDREICH).

${ }^{3}$ ) Cicer pisalbus 589,35 ; cicer idest pis albus 609,62 . 
braun sind, die "Kapuzinererbse"; eine solche beschreibt schon BOCK (Kräuterbuch fol. 219) unter dem Namen Füselen ${ }^{1}$ ): „die zeittigen fäseln seind nit ganz rund, sonder geprefzt mit ecken, ganz Kestenbraun, gröffer und vollkommlicher dann Erweissen geschlecht, zeittigen mit den Erweissen". Eine ähnliche oder dieselbe Spielart wird unter den ,prisos Mauriscos" zu verstehen sein. Von der weissen Erbse ist zum ersten Male zu Anfang des 14. Jahrhunderts die Rede und zwar bei PETRUs de CRESCEnTIIS, lib. 3, cap. 20: "Pisum est robilia alla et grossa“. (Nach Meyer IV, S. 154).

ALPH. DE CANDOLle hat die Frage, ob die Gartenerbse (Pisum sativum L.) und die Felderbse ( $P$. arvense L.) zwei Arten ausmachen oder beide derselben Art angehören, unentschieden gelassen (Kultur'ptlanzen, S. 411-415). Seine Annahme, dass die Griechen zu THEoPHRASTS Zeiten die Gartenerlose gekannt hätten, ist nach dem oben Gesagten offenbar unrichtig. Es handelt sich für uns also im wesentlichen darum, zu entscheiden, ob die Gartenerbse aus der Felderbse durch Kultur hervorgegangen sein kamm. Die einzigen Unterschiede, die zwischen diesen beiden Erbsenarten angegeben werden, sind folgende: die Gartenerbse hat weisse Blumen und kugelige, glatte Samen; die Felderbse hat furbige Blumen mit bleichvioletter Fahne und purpurnen Flügeln, und kantig-eingedruickte Samen. Unter den weissblühenden Gartenerbsen hat aber die sogenamnte Markerbse kantig-eingedrüickte Samen. Die angegregebenen Unterscheidungsmerkmale sind also nicht stichhaltig. Man überzengt sich auch leicht, dass unter den Rassen der Gartenerbse ebenso grosse Verschiedenheiten in der Ausbildung der Früchte und Samen vorkommen ${ }^{2}$ ), wie zwischen den Frïchten und Samen der Gartenerbse und der Felderlose. Wir tragen daher kein Bedenken, unsere Gartenerbse als eine Kulturform der Felderbse zu bezeichnen. Dies ist schon 1855 von BENTHA geschehen; ${ }^{3}$ ) 1860 hat ALEFELD dieselbe Ansicht ausgesprochen; ${ }^{4}$ ) ob, wie ALEFELD meint, Felderbse und Gartenerbse beide von dem am Nordrand des Mittehmeeres und am Caspi-See wildwachsenden Pisum elutins Steven (bei M. Bib.) abstammen, muss hier unerörtert bleiben.

1) Bock hat also den Namen phaseolus auf eine Erbsenart iibertragen.

־) Charles Darwin, Das Variiren der Thiere und Pflanzen im Zustande der Domestication. Übers. v. J. Vietor Carus. Bd. 1, Stuttgart 1868, S. 408-413. Es wurde Darwin mitgeteilt (S. 408), dass Andrew Knight die Felderbse mit einer bekannten Gartenvarietät der preussischen Erbse gekreuzt habe und dass die Nachkommen dieser Kreuzung dem Anschein nach vollkommen fruchtbar gewesen seien; dieser Versuch kann, da die beiden genannten Erbsenrassen beide zu Pisum arvense gehören, die Einheit von Pisum arvense und P. sativum nicht beweisen.

Anm. 78).

${ }^{3}$ ) Horticult. Journ. vol. IX, 1855 , S. 141 (uach DARwin, a. a. O. S. 408,

$\left.{ }^{4}\right)$ Über Pisum. Botanische Zeitung, Jahrg. 18, 1860, S. 204.

v. Fischer-Benzon, altd. Gartenflora. 
Fasiolum Capitulare 70,11. Dolichos melanoplithalmus DC.

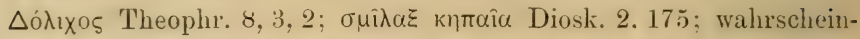

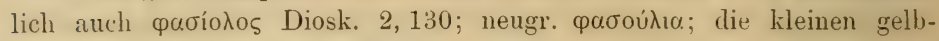

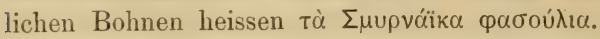

Phaselus, faseolus Colum. 2, 10, 4; 11, 2, 72; 12, 9, 1; phasiolus Plin. $18,7,10 ; 18,12,32$ und mehrfach.

Bisher hielt man die Phaseolusarten der Alten für identisch mit unseren Gartenbohnen (Plaseolus vulgaris L. und andere). WITTIACK hat aber gezeigt, dass unsere Gartenbohnen aus Amerika stammen miissen, $\left.{ }^{1}\right)$ und dass der Phaseolus der Alten ein Dolichos sei, und zwar nach KöRNIoKE Dolictos melanoplitalmus DC. Die Einführung der neuen Bohnen hat sich so unbemerkt vollzogen, weil ihr amerikanischer Name frizules oder frisules, aus dem das spanische frejoles oder frijoles gebildet ist, einen gewissen Gleichklang mit phaseolus hat; ausserdem weichen die Gattungen Phaseolus und Dolichos in ihrem Äusseren und zum Teil in ihren Früchten so wenig von einander ab, dass der Laie sie nicht von einander zu unterscheiden vermag.

Die Beschreibung, die uns DIOSKORIDES von seiner smilax hortensi: giebt, enthält nichts, woraus man die Art mit Sicherheit bestimmen kömnte. Die Früchte werden $\lambda o ́ \beta ı \alpha$ (Schoten) genamnt; die Blättchen sind epheuartig, aber weicher; die feinen Stengel winden sich mittels Ranken am benachbarten Gesträuch in die Höhe und kömnen Lauben bilden; die Frucht hat Ähnlichkeit mit derjenigen des Bockshornklees, ist aber länger und Heischiger; die Samen in ihr sind nierenfürmig, nicht gleichfarbig, sondern teilweise rötlich; die Frucht, mit den Samen gekocht, wird wie Spargel genossen.

In den Hermeneumata des CGL III wird fasioli durch lobia erk] ïrt: ${ }^{2}$ ) es finden sich aber auch die Zusammenstellungen lobia suriare

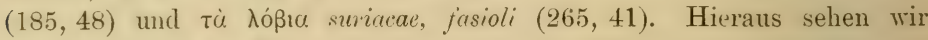
zunächst, dass ein Unterschied zwischen den Früchten von faseolus und smilax nicht gemacht wurde, und suriace (von бuprakós) deutet vielleicht an, dass man Syrien für die Heimat dieser Pflanzen hielt.

Nach MaT'THAEUs SYLVATICUS sind faseolus, lobia und dolirlio: dasselbe. AlBERTL's MAcrots $(6,341)$ teilt eine Beschreibung ${ }^{*}$ ) von juseulus mit; danach ist diese Bohne in allen Teilen kleiner als jalua, unsere Grosse Bohne; ihre Samen sind von mancherlei Farbe, aber jeder hat an der Seite einen schwarzen (dunklen) Fleck an Stelle des Nabels.

$\left.{ }^{1}\right)$ Berichte der Deutschen Botanischen (resellschaft, Bd. 6, Berlin 1888, S. $374 \mathrm{ff}$; Natw. Wochenschrift von Potonié, Bil. 5, Berlin 1890, S. 337-39.

2) 16,$20 ; 88,44 ; 317,28 ; 354,53$.

$\left.{ }^{3}\right)$,Faseolus est species leguminis et grani, quod est in quantitate parum minus quam faba, et in figura est columnale sicut faba et herba eius minor est aliquantulum quam herha fabae. Et sunt faseoli multorum colorum, sed quodlibet granorum habet maculam nigram in loco cotyledonis." 
Bei den Schriftstellern des 16. Jahrhunderts kehrt Smilax hortensis ziemlich regelmässig wieder; der deutsche Name dafïr ist Fasehn (Fäselen), welsche oder türkische Bonen, Steigfaseln. In MatTroLIS Krräuterbuch (fol. 123 D, 124 A, B) werden zwei Arten unterschieden: eine niedrige, die fast wie unsere Buschbohne (Krupbohne) aussieht, im „ausgehenden Frühling aufs Feld gesähet" wird und deren nierenförmige Samen „auff der seiten ein schwartz Tüppel" haben, Faselu, Phasoli, und eine rankende, Steigfaseln. Tabernaenrontanus (Teil 2. S. 205) hat nur e in en rankenden Smilax, dem er eine Beschreibung nach DIOSKORIDES hinzufügt; jedoch macht sein Herausgeber C. Bauhin besonders auf den schwarzen Fleck aufmerksam, den die Samen an des Seite haben; neben Smilax hat er aber noch Phaseolus albus Americanus, Phaseolus Brasilianus und Phaseohs Aegyptiacus, „von wegen der Oerter, da sie erstlich herkommen seyn".

Eine Zusammenfassung desjenigen, was bei den Schriftstellern des 16. Jahrhunderts gesagt wird, finden wir in C. BAUHINs Pinax, S. 339. Er nimmt Smilax hortensis sive Phaseolus vulgaris voran, und lässt darauf I'huseolus peregrinus, americanus etc. folgen; von Smila' giebt es grössere und kleinere Sorten; die Samen sind weiss mit schwarzem Fleck oder schwärzlich mit weissem Fleck; es giebt auch eine kleinere, weisslichi mit rötlichem oder schwärzlichem Ringe. ${ }^{1}$ )

Nun wird man wohl annehmen dürfen, dass bei den verschiedenen Schriftstellern Smilax hortensis immer dieselbe Pflanze oder dieselben Pflanzen bedeutet; dann weist aber der wiederholt hervorgehobene schwarze Nabelfleck mit Notwendigkeit auf eine Dolichosart, wahrscheinlich auf $D$. melanophthalmus DC., die noch jetzt in Griechenland gebaut wird. Und wenn BAUHIx, der die fremden Phaseolusarten von den bisher gekannten trennt, unter den letzteren solche anführt, die dunkle Samen mit weissem Nabelfleck haben, so könnte das Dolichos Catjang L. sein. Es liegt jedenfalls nicht der mindeste Zwang vor, die Phaseolusarten der Alten der Linnéischen Gattung Phaseolus zuzurechnen. Auch bei Dolichos kommen niedrige und windende Arten vor.

Wir werden also das fasiolum ${ }^{2}$ ) des Capitulare als eine Dolichosart zu betrachten haben. IVie weit nach Norden hat sich die Kultur ron Dolichos erstreckt? Das ist jetzt sehr schwer festzustellen, denn die fruchtbaren und wenig empfindlichen amerikanischen Phaseolusarten haben die zarteren Dolichosarten wohl iiberall verdrängt. Es kömnte sich in-

$\left.{ }^{1}\right)$ "Sunt majores et minores; sunt albi, subnigri, illi macula nigra li alba notati: est et minor albidus cum orbita rubente aut nigricante."

2) Das Wort fasiolus wird auch noch zur Bezeichnung der Erbse und der Kicher gebraucht: fasiolus, arwiz Sum. 62, 10 (11. Jahrh.); chichera-faselus et cicer, ahd. Gl. 7,34; wie oben S. 97 angegeben wurde, versteht HiEnonrmus Bock unter -Fäselen die Kapuzinereruse. 
dessen doch lohnen, Nachiforschungen anzustellen. Noch vor 15 Jahren wurde in der Propstei, Kreis Plön, unter dem Namen „Gesichterbohnen" eine Bohnenart gebant, bei deren Samen der Nabel mit einem dunklen Ringe umgeben war; das kïnnte immerhin eine Dolichosart gewesen sein.

Fabas majores Capitulare 70, 67: Viria Falua L.. grosse Bohne, Bufbolne, Saubohne.

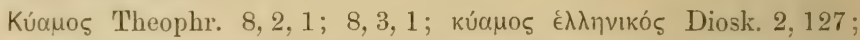

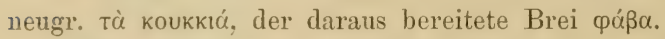

Faba der römischen Schriftsteller; it. fava; fr. fëve.

Seit uralten Zeiten wird die Bufbohne kultiviert: schon bei HosreR (Il. 13,589) und HERODOT $(2,37)$ wird sie erwähnt. Sie diente rorwiegend als Nahrungsmittel; daneben schrieb man ihr aber anch mancherlei medicinische Trirkungen zu, wie wir bei Drostrorides sehen. Dieser nannte sie ..griechische Bohne" im Gegensatz zu der "egyptischen": die ..egyptischen Bohnen" der Alten waren die Samen von einer Nymplacacee. Nelnmbium speciosum Willd. Noch jetzt ist die Bufbohne das gewöhnlichste Nahrungsmittel der griechischen Landhevölkerung: sie wird in Griechenland und in Italien ebenso wie bei uns viel kultiviert. In den Hermeneumata des CGL III kommt sie unter den Speisen und sonst liäufig vor: daselbst werden neben der ganzen Bohne (faba solirla) anch gestampfte oder geschrotene Bohnen (faba fracta. fressa oder pilata) erwähnt, ausserdem noch als Nachtisch saure Bohnen (fabae acetatae oder acetosae). ${ }^{1}$ ) Mit Essig wird die Bohne auch jetzt noch in manchen Gegenden Deutschlands gegessen.

Wenn die Bufbohnen im Capitulare fabae majores genannt werden, so soll dies offenbar den Unterschied gegen die kleinfriichtige Rasse angeben, die auf dem Felde gebaut wird. Diese kleine Rasse ist wohl mit der jaba gemeint, die im sogenamnten Breviarium Karls des Grossen unter den Feldfrüchten aufgeführt wird; sie heisst bei uns Pferdebohne (in Italien java racallin, fure mulste) und wird in den Marschgegenden als Pferde- und Schweinefutter im Grossen gebaut. Übrigens scheinen schon die Griechen zwei Abarten der Bufbohne gekannt zu haben (vergl. die Anm. 2, S. 96). Der Name jabr major, unserem "Grosse Bohne" entsprechend, kommt schon in den Glossaren des CGLIII vor, $\stackrel{2}{)}$ wird also nichts Ungewöhnliches gewesen sein. Der alte deutsche Name der Bufbohne ist einfach Bohne; Saubohne wurde sie genannt, un sie leichter von den amerikanischen Phaseolusarten unterscheiden zu kömnen.3)

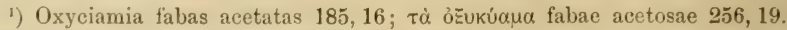

2) Ciamos . i . faba maior 5̃5̆, 70; 620,69.

$\left.{ }^{3}\right)$ K. E. H. Krause, Die Bohne und die Vietzebohne. Jahrb. d. Ver. für niederdeutsche Sprachforschung, Jahrg. 1890, Norden und Leipzig, 1891, S. 5̌3-65. 


\section{Kicher und Linse.}

Cicerum Italicum Capitulare 70, 15; Cicer arietimun I., Kicher, Kichererbse, Kaffeeerbse.

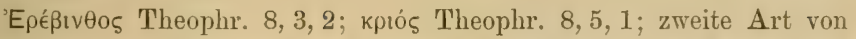

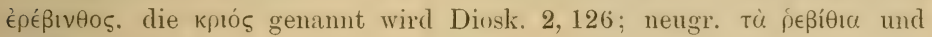
ровіөıка.

Cicer Colum. 2, 10, 20, (quod arietinum vocatur); Plin. 18, 12, 32 (est enim arietino capite simile, unde ita appellant); it. cece; fr. pois chiche.

Die Kicher wird bei Horren zugleich mit der Bufbolne erwïhnt (Il. 13,589), was auf eine sehr lange Kultur deutet. In Griechenland und Italien wird sie noch jetzt sehr viel gebaut; rlie Griechen essen die grïnen Kichererbsen roh, die trocknen gekocht; die letzteren heissen

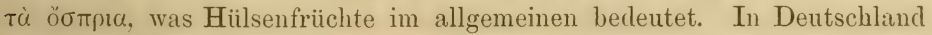
hat die Kichererbse früher einen ansgebreiteteren Anban erfahren als gegenwärtig. Die heilige HILDEGARD erwälnt die kicher $(1,190)$ als leichte und angenehme Speise und als Mittel gegen das Fieber. ALBERTUs

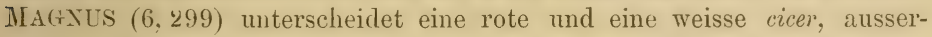
dem eine schwarze oder dunkle; auch giebt er an, dass es zahme und wilde gebe (domesticum et silvestre). Dieselben Unterscheidungen trifft KONRAD VON MEgENBER(- $(5,18)$ bei cicer oder dem kitherkraut: die zahme Pflanze nennt er "haimisch". Von den Botanikern des 16. Jahrhunderts wird die Kicher Ziser, Zisererbsen etc. genamnt. Zu Anfang des vorigen Jahrhunderts (Weinmann, Phytanthozaiconographia, Bd. 2, Regensburg 1739, s. 167) wurde sie als Kaffeesurrogat vielfach benutzt. Anch hier in der Provinz wurde früher eine Leguminose gebaut, deren Samen einen vorzüglichen Kaffee geben sollten; jetzt scheint sie bereits verschwunden zu sein, so dass es nicht möglich gewesen ist, die Pflanze sicher zu bestimmen.

Der Zusatz Italicum, den das cicer des Capitulare erhalten hat, könnte daher ruihren, dass man diese aus Italien stammende Gartenpflanze deutlich hervorheben wollte gegenüber deujenigen Pflanzen, die den Namen wilde Kicher, cicer silvestre, führten. Es ist aber ebensowohl möglich, wie KERNER meint, dass damit das cicer arietinum des COLUMELLA im Gegensatz zu dessen cicer punicum bezeichnet werden sollte; das Adjectivum punicus bezeichnet nicht nur punisch, sondern auch eine tiefrote Farbe, so dass COLUIELLA vielleicht durch die beiden Zusätze arietinum und punicum die hell- und dunkelfarbigen Kichern hat unterscheiden wollen; solche Farbenvarietäten kannte schon THEOPHRAST (vergl, die Anm. 2, S. 96).

Im Breviarium Karls des Grossen (Pertz. Monumenta etc. Bd. 3, S. 177) wird unter den Feldfriichten auch lenticula aufgeführt; es ist dies

Ervum Lens L., Linse.

Факó Theophr. 2, 4, 2; 8, 5, 1; Diosk. 2, 129; neugr. факи́. 
Lens und lenticula der Römer; it. lente; fr. lentille.

Im südlichen und istlichen Deutschland ist die Linse eine sehr häufige Kulturpflanze; hier in der Provinz ist sie hauptsächlich erst seit 1864 bekamnter geworden. Dass die Alten mehr als eine Kulturrasse der Linse kannten, scheint aus einer Bemerkung bei THEOPHRAST 8. 5, 1 hervorzugehen (man vergl. Anm. 2, S. 96).

\section{Kresse, Brunnenkresse und Pfefferkraut.}

Gartenkresse.

Nasturtium Capitulare 70, 27. Lepidium sativum L.; Kresse,

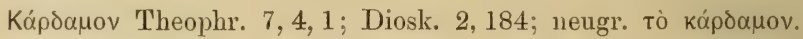

Nasturcium oder nasturtium Colum. und Plin.; nasturtio, agretto, crescione; fr. nasitort, cresson, cresson alénois. ${ }^{1}$ )

Dass kúpóapov (kardamon) und nasturcium identisch sind, wird uns durch DIOSKORIDES bezeugt $(2,184)$, dass aber nasturcinm unsere Gartenkresse und nicht die Brumnenkresse ist, folgt aus einer Stelle bei CoLUMIELLA $\left.(10, \text { v. 230, 231 })^{\circ}\right)$, wo angegeben wird, dass das nasturcium in Furchen ron kleinem Abstande zu säen sei; auch bei PLINIUS ist nasturcium Gartenpflanze. Bei COLUMELla wird ebenso wie bei DIOSKORIJES darauf aufmerksam gemacht, dass die Pflanze ein Mittel gegen Schlangen und deren Biss ist, ein Umstand, der ihre Kultur entschieden begünstigt hat. Ausserdem schrieb man ihr dieselben Eigenschaften zu, wie dem Senf und der Rauke.

Die heilige HILDEGARD spricht nur ganz kurz von crasso $(1,72)$; ausführlicher verbreitet sich ALBERTUS MAGNUS über nasturcium $(6,393)$, ehenso wie KonRaD von MEgenberg $(5,53)$, der die Pflanze auf deutsch kress nennt. In den Kräuterbiichern des 16. Jahrhunderts werden meist zwei Rassen der Kresse beschrieben und abgebildet. eine mit krausen und breiteren Blättern, eine mit schlichten und schmäleren.

Als Heimat der Gartenkresse betrachtet man Persien oder Kleinasien. - Zn bemerken ist noch, dass die orientalische Kresse (Ermcuric aleppiç Gürtn.), die in den griechischen Küstengegenden, namentlich in Weinbergen, sehr häufig ist und deren junge Triebe und etwas fleischige Blïtter roh und gekocht als Salat verspeist werden, bei den Neugriechen anch to kúpoanov heisst. Vielleicht ist sie früher in Griechenland kultiviert worden.

Es giel,t noch ein Wort, das zur Bezeichnung der Kresse dient,

1) Das Wort alénois ist entstanden aus orlénois, das dem lateinischen aurelianensis, zu Aurelianum (Orléans) gehïrig, entspricht, und zwar volksetymologisch clurch begriffliche Anlehnung an alêne (Pfriemen). (Körting, Lat.-roman. Wörterbuch, Paderborm 1891, S. 82.)

2) „Quare age quod sequitur, parvo discrimine sulei spargantur caecis nasturcia dira colubris". 
nämlich damasonium oder damas:onium. In den Glossaren ${ }^{1}$ ) des CGL III wird es durch nasturtium oder nasturtium hortulanum erklärt, und zwar in denselben Glossaren, in denen nasturtium durch crissonus oder crissomus hortensis gedeutet wird. Auch in den lateinisch-deutschen Glossaren wird damasonium durch Kresse übersetzt. Es ist zweifelhaft, oh damasonium von nasturtium verschieden ist; möglich wäre es, und damn kömnte es die Brunnenkresse sein, die in den lateinisch-deutschen Glossaren auch den Namen nasturcium oder den durch Verdrehung daraus entstandenen Namen ostrucium führt. ${ }^{2}$ ) Verwechselung der Kressenpflanzen kam frïher ebenso häufig vor, wie jetzt.

Nasturtium officinale R. Br. (Sisymbrium Nasturtium L.), Brunnenkresse.

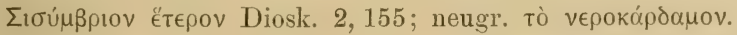

Sisimbrinm Plin. 19, 8, 55 ?; it. agretto, crescione, nasturzio acquatico, sisembro, sisembro aquatico; fr. nasturce, cresson d'eau, cresson de fontaine.

Die von DIoskorides gemachten Angaben lassen die Identität seines sisymbrium alterum mit der Brunnenkresse nicht zweifelhaft erscheinen; er hat sogar beobachtet, dass die ersten Blätter der jungen Pflanze rund und ungeteilt sind. Er giebt an, diss die Pflanze auch den Namen cardamine führe, weil sie den Geschmack der Kresse (кúpঠauov) habe, dass sie eine Wasserpflanze sei, roh gegessen werde etc. Die heilige HILDEGARD erwähnt die Brunnenkresse unter dem Namen burnarase $(1,73)$; AlBertus MAGNUS spricht von ihr unter dem Namen. masturcium aquaticum in seinem Buche de mimalibus; bei KONRAD ros MEGEnPERG fehlt sie. Bei den Botanikern des 16. Jahrhunderts finclet man gute Abbildungen ron der Brunnenkresse. HIERonyar's Bock (Tragus) bemerkt in seinem Krïuterbuch (Strassburg 1577, fol. 31): ..Brumnenkresz nennet man Xasturtium aquaticum, ctliche Agriocardamon und Agreste Nasturtium." Die beiden letzten Namen bedenten wilde Ḱresse. Ursprünglich wird die Brumnenkresse mehr Heilmittel als Genussmittel gewesen sein; ihre Kultur im Grossen stammt erst aus dem 17. Jahrhundert. Nach V. HELDREICH wird sie in Athen erst seit wenig Jahren als Salat gegessen. -- Gelegentlich wird die Brumnenkiresse auch senecium und senerio genamnt (MATTIOLI, Commentar, S. 380; Colm. Gloss. 653 etc.).

Noch eine Kressenpflanze ist hier namhaft zu machen:

Lepidium latifolium L., Pfefferkraut.

$\Lambda \in \pi i ́ \delta ı v$ Diosk. 2, 205.

1) Damasonius nasturgius 589,37; damassonius idest nasturcius ortolanus 610,47 ; 622,73 ; nastorcius . i. crisonus 570,37; nasturcius siue crissonus ortensis 581,34 ; 592,8 ; nasturcius idest crison demesticus 614,$56 ; 626,66$. - Damosionum Kerse Colm. Gloss 271.

2) Colm. Gloss.: Narstucium Wâterkerse 501; ostruzium Brûnkerze 542; Königsberger Gloss.: ostrucium brunnekerse. 


\section{$-104-$}

Lepidium Colum. 11, 3,41; Plin. 19, 8,51; it. piperite, piperella: fr. passerage oder grand passerage.

Plinius bezeichnet die PHanze als ansländisch (peregrinum); die grusse Empfindlichkeit gegen Kälte, die Columella ihr zuschreibt, spricht auch dafür, dass sie ror nicht langer Zeit eingeführt wurde. In Griechenland wird sie zur Zeit nicht kultiviert, findet sich aber nach Fraas in allen Meeresniederungen häufig. ${ }^{1}$ ) Bei der heiligen HILI)EGARD heisst sie pefferkrut (1.38), bei den Botanikern des 16. Jahrhunderts Pfefferkraut. Lepuilium latifolium und Piperitis. Sie muss damals viel mehr gebaut sein als jetzt, wo sie allmählich in Vergessenheit gerät.

Ebenso wie in Griechenland kommt das Pfefferkraut auch bei uns an salzhaltigen Stellen, namentlich an Meeresstrande vor; an einigen Stellen hält es sich lange, an inderen verschwindet es rasch; wenn es irgendwo eingeschleppt ist, pflegt es nur kurze Zeit zu bleiben.

\section{Salat, Endivie, Cichorie und Ringelblume.}

Lactucas, Capitulare, 70, 24; Lactuca Scariola L. var. sativa, Salat.

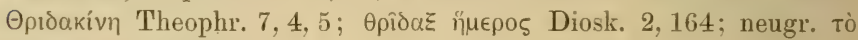

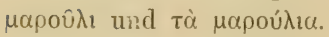

Lactuca der Römer, Colum. 11,3, 26 u. 27 ; 10, 180 ff.; Plin. 19, 8, 38 und sonst vielfach; it. lattuga, lattuca; fr. laitue.

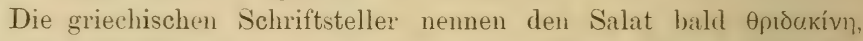
bald $\theta$ piodoz, die Römer kemnen nur den einen Namen lutuca, der ins Italienische und Französische übergegangen ist und sich auch in unserem Lattich wiederfindet. THEOPHRAST unterschied schon 3 oder 4 Rassen. aher sehr viel mehr finden wir hei CoLUnLELL; er kennt solche ron brauner und gleichsam purpurroter oder auch grïner Farbe und mit krausem Blatt, den Cücilianischen Salat, solche mit bleichen, kammförmig eingeschnittenen und dicken Blättern aus Kappadocien, ferner solche mit weissen und sehr krausen Blättern aus der Provinz Baetica, endlich rïtlich-weissen Salat mit glatten, sehr zarten Blättern von Cypern, aber unseren Kopfsalat scheint er nicht zu kennen, ebensowenig wie ihn die Griechen früher gekannt haben. In Athen, wo der Kopfsalat jetzt

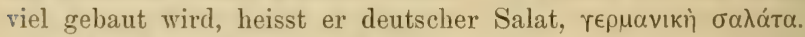

Die Römer machten den Salat ein, wie CoLtulELLA ausführlich beschreiht (12,9), und zwar mit Essig und Salzlake; zwischen den Salat packten sie Schichten ron grünen Gartenbohnen (jaseoli, die man rergleichen wolle) und würzten das Ganze mit Dill, Fenchel, Raute und gehacktem Porree. In ähnlicher Weise wurden Endivien eingemacht. aher beides geschah im Fruihling, um frischen Salat während der Sommermonate zu haisen.

1) Nach Frass (S. 121) wird das Pfefferkraut von den Neugriechen ürpia $\lambda a \dot{x} \alpha a v \alpha$ genannt; hier muss ein Irrtum rorliegen, denn ürpia ^áxava heissen nach r. Het.DREICH (S. 75) alle essbaren wilden Kräuter. 
Im Nittelalter wird der Salat lactuce genannt; die heilige HILDE(iAliD neunt ihm ausserdem lutich (1,90, vergl. Anhang II), KONRAI) VON MEGENBERG $(5,46)$ lactukenkraut.

DIOSKORIDES und AJBERTUS MAGNLS $(6,36 t)$ glaubten, dilss der gekochte Salat nahrhafter sei als der rohe. Hente wird er wohl meistens roh mit Essig und Öl gegessen, und zwar um so häufiger, je weiter man nach Süden kornmt.

Die Mittelmeerländer und der mittlere Teil ron Westasien bilden die Heimat des Salats; ob Mitteleuropa mit dazugerechuet werden darf. bleibt zweifelhaft.

Intubas Capitulare 70, 37; C̈̈horium Ẻulivia L., Endivie, Scariol. Escariol.

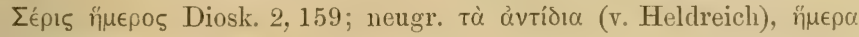
påíkı (Fraas).

Intybus Colum. 10, v. 111; 11, 3, 27; intubus Plin. 19, 8, 39; 20, 8, 29; it. endivia, scariola; fr. endive, scarole, scariole, chicorée frisée.

Die Endivie trägt stellenweise den Namen Escariol noch heute (Th. Rümpler, Illustrirte Gemüse- und Obstgürtnerei, S. 196). MatTIOLI nennt sie zahme Scariol und Gartenscariol (Krïuterbuch, fol. $150 \mathrm{~A}$ ). Derselhe Name hat sich im Französischen und Italienischen erhalten. scheint aber weniger gebräuchlich zu sein. TABERNAEMONTANUS hat als Synonym für eine kleinere Spielart der Endivie den lateinischen Namen Scariolu (Kriäiterbuch, 1, S. 492, F) und behauptet, er werde fälschlich der Gänsedistel (ronclus usper L.) beigelegt. Der Name Scuriulu. Escarioln stammt aus früher Zeit, und ist wohl nichts anderes als ein Diminutivum rom lateinischen Adjectivum excorius. das etwas zur Speise Gehöriges oder Essbares bedeutet, dann aber, da es mit dem griechischen

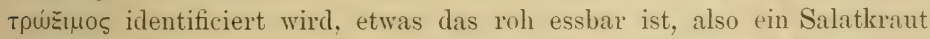
überhaupt, ${ }^{1}$ ) - Die Apotheken führten früher Blïtter und Samen der Endivie als Herba et Semina Endiviae s. Scariosae.

Der Name indivia kommt schon in den Hermeneumata Einsidlensia des CGL III vor.") Entstanden ist er aus intyba, intibu, wie schon Tabernaejontanus bemerkt. Bei den Schriftstellern des 16. Jahrhunderts gilt Endivia im allgemeinen als gleichbedentend mit Intylus. ALBERTUS MAgNus $(6,331)$ kennt nur endivia, nicht intybus.

Ob THeOphrast die Endivie gekannt hat, ist zweifelhaft. Den Römern war sie aber bekannt und ebenso dem DioshokIDES. Dieser unterschied bei der Endivie, die er breitblättriger und wohlschmeckender

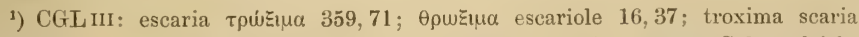
88,$60 ; 185,63$; - $\tau \rho \circ \varepsilon 1 \mu \alpha$ acetaria 317,22 ; acetaria ist mit unserem Salat gleichbedeutend: es bezeichnet Kräuter, die rolı oder gekocht mit Essig etc. verspeist

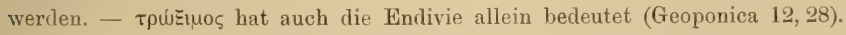

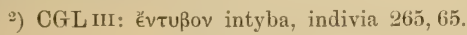


als die Cichorie nennt, zwei Rassen: die eine ist dem Salat ähnlich und breitblättrig, die andere schmalblättrig und bitterlich; ganz ähnliche Spielarten unterscheiden wir auch heute noch, wo die Endivienkultur wieder mehr in Aufnahme kommt.

ALPH. DE CANDOLLE hält die Endivie für einen Abkömmling des in den Mittelmeerländern häufig wachsenden Cichorium pumilum Jacquin (C. divaricatum Schousboe). ${ }^{1}$ )

Solsequium Capitulare 70, 21; solsequia Invent II, 14; Cichonimu Intybus L. Cichorie, Wegwarte.

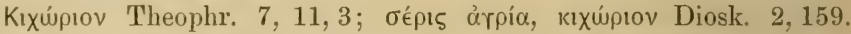

Cichorium Plin. 20, 8, 30; intubus erraticus 21, 15, 52; it. cicorea, cicoria, radicchio; fr. chicorée, barbe de capucin.

Die Beschreibung, die THEOPHRAST von kıxẃpıov liefert, lässt kaum einen Zweifel daran aufkommen, dass unsere Cichorie gemeint ist, deren Heimat die Mittelmeerländer und das westliche mittlere Asien sind. Der gewöhnliche Name, den die Cichorie bei den lateinischen S'chriftstellern, ron PLINIUS an gerechnet, führt, ist "wilde Endirie" (intulus erruticus, agrestis, siluticus:). Zu diesen gesellen sich aber in späterer Zeit noch andere, wie solsequium oder solsequia, Sonnenwirbel (sumerirbel, heilige HILDEGARD 1,60), dem das aus dem Griechischen entnommene eliotropium (ił braut, lauter Namen, die sich anf die Lichtempfindlichkeit der Blumen beziehen; diese schliessen sich bei trübem und reguerischem Wetter, ïffnen sich aber wieder unter den Strahlen der Sonne. Da anch andere Pflanzen wegen ähnlicher Eigenschaften dieselben Namen erhalten haben, so ist daraus vielfach Verwirrung entstanden.

Ursprünglich war die Cichorie wohl nur Heilmittel, doch scheint sie schon im Altertum gegessen, wenn auch nicht sonderlich geschätzt worlen zu sein.") Im vorigen Jahrhundert fing man an die Wurzel als Kaffeesurrogat zu benutzen, und jetzt dienen die Blätter oft als Salat.

Als ältere deutsche Namen kommen hintlope, hintloftr, lintloifte vor. ${ }^{4}$ )

Calenclula officinalis L., Ringelblume; it. calta, for rancio; fr. souci.

Die Ringelblume hat mit der Cichorie eine ganze Reihe ron Tamen gemeinsam, die aher aus späterer Zeit zu stammen scheinen und vielleicht erst seit ALBERTUS MAfiNrs gebränchlich sind. Dieser sagt

1) Diese Pflanze, die nach v. Heldneicr in Griechenland die gemeine Cichorie

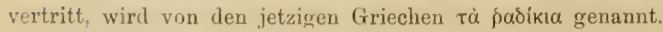

2) CGLIII: eliotropiun intuba agrestis siue solsequia uel sponsa solis 560,62 ;

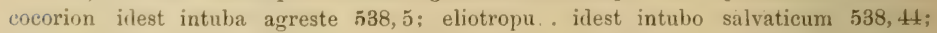
cicorion idest solsequia 609,45 etc. - Albertus Mugnus sagt 6,321, dass cicorea auch sponsa solis genannt werde.

3) Hornz, Od. 1, 31: „. . . . me pascunt olivae, me cicorea levesque malrae."

1) Cicorea, hintloifte Sum. 5̌n, 68; cicorea, hintlophte Sum. 56, 29; cicorea hintlope Königsb. Glosş.; intuba hintlôpe Colm. Gloss. 407. 
von der Pflanze, die er sponsa solis oder solsequium nennt $(6,451)$, dass sie „dicke, aber nicht grosse Blätter habe und eine citronengelbe Blume. die sich beim Untergang der Sonne schliesse und bei ihrem Aufgange öffne" $;^{1}$ ) hier kann man nicht an die Cichorie denken, sondern nur an die Ringelblume, die in den lateinisch-deutschen Glossaren des 13. und der folgenden Jahrhunderte solsequiu, solsequium mims, sponsu solis und eliotropium neben calendula genannt wird. ${ }^{2}$ )

Bei der heiligen HILDEGARD $(1,122)$ kommt der Name ringulu vor, der sich mit geringen Änderungen bis auf die Gegenwart erhalten hat. Gegenwärtig sind im nördlichen Deutschland die Namen Totenblume, Morgen- und Abendrot, ausser Ringelblume, Ringelrose in Gebranch.

Früher wurden der Ringelblume Heilkräfte zugeschrieben und diese sind vielleicht zuerst die Ursache ihres Anbaus gewesen. Jetzt dient sie nur noch als Zierpflanze, gelegentlich auch als Gräberschmuck. Auf der nordfriesischen Insel Röm erreicht diese aus Südeuropa stammende Pflanze eine auffallende Grösse und Schönheit.

\section{Rauke, Senf und Portulak.}

Eruca alba Capitulare 70,26; Emea kativa Lam., Rokka, Rauke.

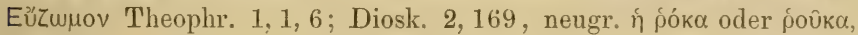

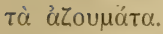

Emeca Colum. 10, 108, 109 u. 372; Plin. 19, 8, 44; 20, 13, 49 und sonst; it. emuca, rucola, muchetta; fr. roquette.

Die Rauke kommt mehr und mehr in Vergessenheit. Früher erstreckte sich ihr Anbau bis hier hinauf, jetzt begegnet man ihr eigentlich nicht mehr. Aber in ihrer Heimat, dem südlichen Europa, wird sie noch vielfach roh als Salat und als Zusatz zu solchem genossen. Als solcher stand sie ehemals in grossem Ansehen, denn die Eigenschaften, die ihr COLumELLA an den angeführten Stellen beilegt und die ihr von fast allen älteren Schriftstellern zuerteilt werden, waren nach Meinung der Alten denen des gewöhnlichen Salats gerade entgegengesetzt; durch Zusatz ron Rauke machte man also den Salat unschädlich. Dieselben Eigenschaften, welche der Rauke nachgerülmt wurden, kamert auch der Kresse und dem Senf zu.

$\left.{ }^{1}\right)$ "Sponsa solis sive solsequium est herba habens folia spissa, sed non magna, florem citrinum, qui claudit se sole occidente, et aperit oriente."

2) Zu den älteren lateinischen Namen der Ringelblume gehören auch aureola und arcola, die in Folgenden mit berücksichtigt sind. Sumerlaten: arcola ringele 54,19 , calendula ringele 55,30 , sponsa solis ringele 58, 51; Colmarer Glossar: arcola ringele 69 , aureola ringele 89 , elitropium ringele 296 , solseqium minus ringele 689 (solsequium majus hintlope 688), sponsa solis ringele vel hintlope 709 ; Kr̈nigsberger Glossar: solsequia ringele, aureola ringhelen, calendula und kalendula ringele. Verschiedentlich ist die Caltha der Römer (Colum. 10,97, "flaventia lumina calthae"; Plin. 21, 6, 15) mit Calendula identificiert worden; die Sache mag richtig sein, da die Ringelblume noch heute in Italien calta genannt wird. 
Sinape Capitulare 44 und 70,39; Sinupis nigm L. (Brussica nigru Koch) und S. alba L., schwarzer und weisser Senf.

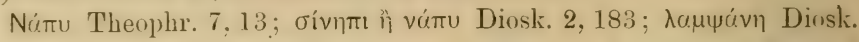
2. 142 (meisser Senf); neugr. tò ó́vamı (schwarzer Senf), sein Same ó

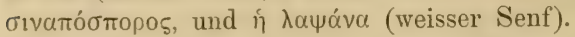

Sinapis Colum. 10, 122; sinapi Colum. 11,3, 29; 12, 55; Plin. 19, 8,$54 ; 20,22,87$; it. senapa, senape; der weisse: rapicello salvatico, muchettone, senapa bianca; fr. sénevé.

Möglicherweise ist im Capitulare mit sinupe an der ersten Stelle der schwarze, an der zweiten der weisse Senf gemeint. Beide Senfarten merden noch heute in Griechenland in Küchengïrten gebaut, und ihr zartes Kraut wird als Spinat oder gekochter Salat im Winter viel gegessen (V. HELDREICH); des Samens wegen wird der schwarze Senf anch im Grossen gebaut und dabei verwildert er bisweilen; häufig wild-

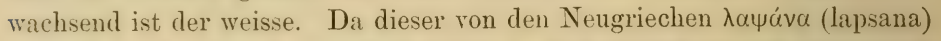
genaunt wird, so ist es sehr wohl möglich, dass DIOSKORIDES mit seinem wilden Gemüse $\lambda \alpha \mu \psi \alpha ́ v \eta$ den weissen Senf gemeint hat.

Die heilige HILI)E(iARD unterscheidet zwischen senff herba $(1,93)$, d'm Senfkraut, das auf dem Felde und in Weinbergen wïchst und gegessen wird, und sinape $(1,94)$, dem Senfsamen. ALBERTUs Magrats nennt den Senf, simupis, ein bekanntes Gemüse $(6,446)$; es giebt einen wilden und einen Gartensenf (et est silvestris et hortulana); Bliitter und Wurzeh des wilden werden gegessen. KONRAD voN MEGENBER(i $(5,79)$ rïhmt dagegen Blïtter und Wurzeln vom Gartensenf, haimisch strnij. Die Erwähnung der Wurzeln könnte Zweifel erwecken; indessen war der Name sinapis von altersher so bekannt, dass hier eine Verwechselung kaum vorkommen komnte. Im 16. Jahrhundert kennt man den weissen Senf, wie es scheint, nicht mehr als Gemüse.

Portulaca oleracea L., Portulak.

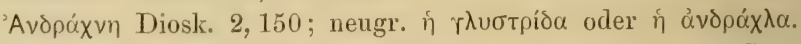

Porcillaca Plin. 13, 22, 40; 20, 20,81; it. portulaca, procacchia, porcellana; fr. pourpier.

PLINILS identificiert seine forrilluce mit andrachne, sonst könnte man zweifelhaft sein, was er meint, denn er giebt keine Beschreibung; vielleicht ist das italienische porcellana aus porcillara entstanden. Die älteren deutschen Namen sind Burtzel, Purzella, Borgel.

Bis vor Kurzem war der Portulak als Zuthat zu Salaten und Fleischsuppen sehr belieht; jetyt sieht man ihn ausserordentlich selten.

\section{Kohl und Rüben.}

Ciunlos Capitulare 70,57; ranles Invent. I, 18; caulu: Invent. 2, 20; Brassica oleracea I. Kohl.

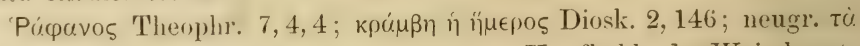

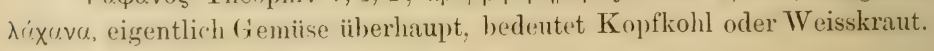


Brassica Cato, de re rustica, 156, 157; Colum. 11,3, 23 u. 24; 10,128 bis 139; caulis Colum. 12, 7, 5; 10,369; olus caulisque, brassica Plin. 19, 8.41; brassica Plin. 20, 9, 33, 34 u. 35 und sonst vielfach; it. cavolo; fr. chou.

Wenn wir die jetzt bei uns gebauten Kohlrassen mit denjenigen rergleichen, welche wir beispielsweise bei TABERNAEIIONTAXUs abgebildet finden, so dürfen wir uns sagen, dass die Gemüsezucht bei uns in den letzten 300 Jahren grosse Fortschritte gemacht hat. Der Kopfkohl, den TABERAAEIONTANT's abbildet, hat mit dem jetzigen glattblättrigen, der ein Gervicht von 20 Kilo erreichen kamn, nicht viel mehr als den Namen gemeinsam, und ähnlich geht es mit vielen anderen Rassen auch. Wir werden vielleicht erwarten diirfen, dass die Kohliassen des Altertums hinter den vor TABERNAEIIONTANL's beschriebenen noch zurückgeblieben sind.

THEOPHRAST unterscheidet den krausblättrigen, den glattblättrigen und den wilden Kohl; $\iota \mathbf{u}$ seiner Zeit ist dem Kohl aber nicht viel Aufmerksamkeit zugewanat worden. PLINIUS wirft denn auch den Griechen vor, dass sie den KJhl nicht genügend respektiert hätten; im heutigen Griechenland ist es aber noch nicht viel anders. Das Vaterland der jetz.t so zahlreichen Kohlrassen ist Italien. CATo kannte nur drei: den glatten Kohl, der gross (grandis) und breitblättrig war und einen grossen Stengel oder Stamm (Strunk, caulis) hatte; den krausen, der „apiacon", d. h. petersilienähnlich, genannt wurde, und endlich den "weich" (lenis) genamnten, zart mit kleinem Stanm, der der schärfste (acerrima) von allen sein soll. Columella zählt im 10. Buch 14 Namen ohne Beschreibung auf, man kamn also keine von diesen mit unseren Kohlrassen identificieren. Besser sind wir bei PLINIUS daran $(19,8,41)$, wenn er auch nicht immer ganz genau zu verstehen ist.

Vom Kohl wurden die Blätter und der Stengel oder Strunk gegessen; der letztere (caulis) treibt Sprossen (cauliculi), und einer von diesen, nämlich derjenige, der blühen will, heisst cyma (кûмa). Die Cyma erscheint im Fruiljahr und ist normalerweise der Endtrieb; die cauliculi können zu jeder Jahreszeit erscheinen. Übrigens wird ein besonders zarter Strunk von PLINIUS auch couliculus genannt (beim Tritianischen Kohl). Es kam beim Kohlbau darauf an, dass die Pflanzen nicht zu früh die Cyma entwickelten (in cymam prosilire Colum. 11,3, 24); wir sprechen in solchem Falle von "durchschiessen" oder in täglichen Leben anch wohl von "in Saat schiessen". PLINIUS drückt sich etwas verwickelter aus: „lie zweite Saat des Kohls hat bald nach dem Frühlingsaequinoctium zu geschehen, und die dadurch gewonnene Pflanze ist ganz am Ende des Frühlings (extremo vere) auszupflanzen, damit sie nicht eher mit der Cyma als mit dem Stengel fortwuchere" (ne prius cyma quam caule pariat).

Die wichtigsten von PLINIts beschriebenen Kohlrassen sollen nun kurz erwähnt werden. 
Der Tritian ische Kohl. Man erhält einen Stengelkohl (caulis), der durch Geschmack und Grösse sich auszeichnet, wenn man den Stengel der jungen Pflanze niederlegt und mit Erde bedeckt, und damit fortführt. so dass immer nur die äusserste Spitze (cacumen) aus der Erde herrorsieht. - Ein ähnlicher Kohl wird heute nicht gebaut: der dicke und zarte Stengel des Blumenkohls mag wohl etwas ähnliches bieten. Bemerkenswert bleibt es. dass gerade diese eine nicht mehr kultivierte Rasse, der Stengelkohl, den Namen für den allgemeinen Begriff abgegeben hat, dem Kohl, cavolo und chou sind weiter nichts als ein rerändertes caulis.

Cumaner Kohl mit niedrigen Blättern und ausgebreiteter Krone ${ }^{1}$ ) (sessili folio, capite patulum). - Man muss sich hier einen Kohl mit niedrigem Stengel vorstellen, und es ist nicht unwahrscheinlich, dass der Cumaner ein Torläufer des Wirsing- oder Saroyenkohls ist (it. verzo, d. h. grüner Kohl, cavolo verzotto, cavolo di Milano; fr. chou de Savoie,

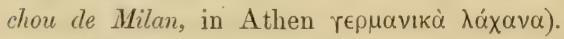

A ricischer Kohl, zeichnet sich nicht durch besondere Höhe aus. und hat um so mehr Blätter, je dïnner diese sind; man hält ihn für den nützlichsten, weil er fast unter jedem Blatt besondere Sprossen herrortreibt (sub omuibus paene foliis fruticat cauliculis peculiaribus). Küinnte der Torläufer des Rosenkohls sein, der allerdings erst ziemlich spät wieder in Kultur genommen zu sein scheint; es fehlt hier jedoch noch an eingehenden Uutersuchungen.

Pompejanischer Kohl ist schlanker; sein Stengel ist oberhalb der Wurzel dünn, verdickt sich aber zwischen den Blättern (caule ab radice tenui, intra folia crassescit). - Dieser entspricht genau dem, was man jetzt Markkohl nennt (RÜMIPLER, S. 108); er ist als der Vorlüufer des Kohlrabis zu betrachten, der im Capitulare 70,56 Ravacaulos genannt wird, im Invent I, 19 ravacmles ${ }^{2}$ ), und der in Norddeutschland meist Kohlral,i über der Erde und Oberkohlrabi heisst (it. carolo rupa; fr. chou rave).

Bruttischer Kohl hat hesonders grosse Blätter, einen dünnen Stengel und einen scharfen Geschnack; die Blätter des Sabellischen Kohles sind bewunderungswürdig kraus, so dass ihre Dicke den Stengel

1) Wenn man über die von Puixus beschriebenen Kohlrassen ins Reine kommen will, so muss man sich über die Bedeutung des von ihm gebrauchten Wortes caput klar sein. "Kopf", in dem Sinne, wie wir dies Wort beim Kohl gebrauchen, kaun es nicht heissen; dagegen spricht das capite futulum neben sessili folio beim Cumaner Kohl, das reprite praegrandes, folio inmumeri etc beim Lacuturrisehen, und namentlich auch der Unstand, dass bei dem Tritianischen Kohl ein fusslanges caput vorkommt (vergl. unter Lacuturrischer Kohl). Aus den angeführten Stellen folgt vielmehr, dass unter caput der ganze beblätterte Teil des Stengels zu verstehen sei; im Folgenden ist caput deshalb durch Krone iibersetzt.

2) Der Name raua caulis, Rübe des Stengels oder Kohls, findet sich auch ein-

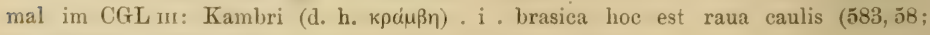
10. Jahrh.); später sagte man caulorapa oder cauli rapa. 
diim macht (usque in admirationem crispa sunt folia quorum crassitudo caulem ipsum extenuet); diesen Kohl hält man für den schmackhaftesten (dulcissimum) ron allen. - Diesen Beschreibungen entsprechen Rassen unseres Blattkohls oder Krauskohls, hier im Norden grüner Kohl genannt, etwas weiter südlich „brauner Kohl".

Die Lacuturrischen Kohlrassen haben eine überaus grosse Krone und zahlreiche Blätter, einige sind zur Rundung gezogen, andere so. dass sie sich breit ausdehnen und fleischig sind (Lacuturres (sc. caules) capite praegrandes, folio innumeri, alii in orbem correcti, alii in latitudinem torosi); und nach dem Tritianischen Kíohl, bei dem man bisweilen eine fusslange Krone sieht, hat keiner eine grössere Krone als der Lacuturrische, und keiner eine spätere Cyma (nec plus ullis capitis post Tritianum cui pedale aliquando conspicitur et cyma nullis serior). Das Verbum corrigere, welches PLINIUs hier braucht, (alii in orbem correcti). deutet den vom Züchter auf die Pflanze ausgeiibten Einfluss, vielleicht auch Zwang an; man muss sich, wie es scheint, vorstellen, dass die Blïtter zusammengebunden waren, um zart und dünn zu bleiben; waren sie sich selbst überlassen, so breiteten sie sich aus und wurden fleischig.

Einen Kohl, der unserem Kopfkohl genau entspricht, scheinen die Rümer also nicht gekamnt zu haben, denı wemm es der Fall gewesen wäre, so müsste man gerade diesen am leichtesten aus der Beschreibung erkennen können. Auch ist es kaum denkbar, dass der Kopfkohl nicht Veranlassung zu der einen oder anderen witzigen Bemerkung gegeben haben sollte. Übrigens ist das italienische Klima dem Bau des Koptkohls nicht günstig.

Nach PLINIUS sind die Nachrichten über den Kohl zunächst nicht sehr reichlich. APICIUS kennt nur cymae und coliculi. In den Hermeneumata und Glossaren des CGL III kommen die cauliculi oder

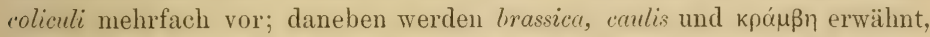
einmal wird krauser Kohl genamnt (brasica . i . caulis crispus 580, 35, 10. Jahrh.). Die heilige HILDEGaRD $(1,84)$ nemnt liole et weydenkole et kochkole und kappus: das letzte Wort, aus caput abgeleitet, ist der Vorläufer des späteren und noch jetzt gebräuchlichen Wortes Kappes und bedeutet Kopfkohl (it. capuccio; fr. chon pommé, chon cabus). Dieser wird, wie es scheint, hier zum ersten Male erwähnt. Caputium findet sich bei ALBERTUS MaGNus (7,90), der im übrigen den Kohl curlis nennt $(6,304 ; 7,137)$ und nicht brassica. Die lateinisch-deutschen Glossare haben brassica und caulis und übersetzen es vielfach mit Römischer Kohl, ferner mit Kraut, Weisskraut, Kappeskraut, Kumpstkohl, brauner Kohl, krauser Kohl. Im 16. Jahrhundert begegnen wir dann einer grossen Zahl von Kohlrassen, Köhl oder Köhlkraut. Auch Blumenkohl wird hier erwähnt. MatTIOLI nenut ihn in seinem Commentar (S. 367) Brassica cauliflora, im Kräuterbuch (fol. 140 c) Blumenköl, it. caulifiori und lateinisch Brassica Cypriu; der beste soll nach ihm ron Genua 
kommen. Bei TABERIAEjoxtayts (2, S. 117) lieisst er Blumen-Kühl, Brasia prolifere forida. Der Blumenkohl scheint also in Italien, jerleufalls in Sïdeuropa, zuerst gezüchtet worden zu sein.

Rotkohl kommt schon bei der heiligen HILIEGARI) vor (rubere runles 1, 84). scheint aber sonst nicht viel erwähnt zu werlen. Bei Mone findet sich die Zusammenstellung brassica witeol vel rosinko: wenn wir bei dem letzten Wort ein „l" am Schluss ergänzen, so bedeutet es Rotkohl.

Wo haben wir das Heimatland des Kohls zu sucheu? Er wird von der dïnischen Insel Lolland angegeben, ferner hat man ihn auf Helgoland, und an den Küsten West- und Südeuropas grefunden. Nun hat sich vor einigen Jahren herausgestellt, dass die auf Lolland gefunlene Pflanze gar kein Kohl ist, sondern die Steckriibe, Brasxicu Napus L.; diese wird aber Niemand für ursprünglich wild halten (H.JALJAR KIAERSKOL, Er Brassica oleracea L. nogensinde funden villtroxende i Danmark? Botanisk Tidsskrift, Bd. 17, Kjübenharn 1890, S. 178). Der Kohl aber auf Helgoland am Ostrande der Insel befindet sich unmittelbar unter den Gärten der Einwohner; da er hier zusammen mit dem Goldlack (Cheiranthrs Cheiri L.) und der Tulpe rorkommt, so kamn man eigentlich nicht daran zweifeln, dass er ein blosser Gartenflüchtling ist. Wie es an den ïbrigen angefuihrten Orten stelit, lïst sich aus der Ferne nicht beurteilen, aber man ist heutigen Tages greneigrt, das Vaterland des Kohls nicht mehr in Westeuropa zu suchen. Dann würde man wohl an die Mittelmeerländer denken müssen; sichere Angaben lassen sich aber zur Zeit darüber nicht machen. Indessen weist der Umstand, dass der Kohl, ebenso wie der Mangolt, schon früh römischer Kohl heisst, auf eine südliche Heimat.

Napos Capitulare 44; Brassira Napus L., Steckliibe, Kohlriibe, Kohlrabi (unter der Er(e), Wruke (Mecklenburg und Pommem); als (̈)lfrucht Raps; Brossicr Rıpa L., Rübe, weisse Rübe; als Ölfrucht Rübsen.

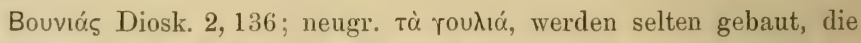
iilgebende Rasse von dieser und der folgenden überhaupt nicht (v. Heldreich).

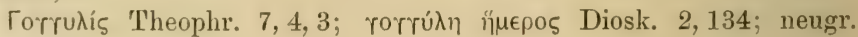
î jaípars.

Napus und rapum oder rapa Colum. 2, 10, 23; 11, 3, 16 und 59 und 62: 12, 54; uирu. Plin. 18, 13, 35; 20, 4, 11; rapum Plin, 18, 3, 33 Schlusszeile und 34 und 35; 20, 3, 9; it. luminula, rapacrione, rarolo navone: navone, rapa; fr. chou navet, mutabaga; navet, rave.

Ganz genan lässt es sich nicht mehr entscheiden, welche Rüben die Griechen unrl Rïmer mit den angeführten Namen bezeichnet haben; an manchen Stellen hat es sogar den Anschein, als ob sie nur eine Art sckannt hätten, deren Rassen dann mit den verschiedenen Namen be- 
nannt gewesen sein müissen. Aber selbst hente sind Terwechselungen zwischen den beiden Riibenarten nicht ausgeschlossen. Im CGL III wiid im allgemeinen rorrúkn mit rapa, und ßouviús mit napus übersetzt; aber einmal wird rapa als napus major bezeichnet $(539,25)$ und einmal werden rugre und nopus als gleichbedeutend genannt $(575,33)$. Die heilige HILIEGARD kemnt nur ruba $(1,88)$. ALBERTL's MAGGUS unterscheidet mpo $(6,390)$ und ropa $(6,424)$; die erste ist lang, die zweite kugelig und rötlich (aliquantulum rubea): hier scheint also eine Verwechselung vorzuliegen, denn die eigentliche Rübe (rapa) kann wohl gelblich werden, aber nicht rötlich. TABERNAEMONTANt's kennt nicht die Steckrïbe, sondern nur die eigentliche Rübe. die er Rapum nennt; nach der Form unterscheidet er lange, runcie etc. Rüben oder Nappen, ferner Stoppfelriiben, und sagt ron ihmen allen: ,ihre Blätter seyn rauch und scharpff, gleich dem Rettich". Durch diese Bemerkung schliesst er die Steckrübe aus, die entweder nur auf den Adern der Blattunterseite einzelne Borsten trägt oder ganz kahl ist. In HIERONYMLs BocKs Krïuterbuch kommt der Name Steckrübe vor, der hier möglicherweise richtig angewandt ist. In MATTIOLIS Kräuterbuch scheint die eine Rübe (rapum), "lang und rund, eines Arms dick, und braunrot" die Steckrübe zu sein, aber das was er Steckrübe nennt (fol. 128C) ist eine Rübe mit langer Wurzel. - Heute werden beide Rübenarten auf dem Felde und im Garten gezogen und dienen teils als Wurzelgemïse, teils als Viehfutter.

Über die Heimat der Rübenarten ist man nicht genau unterrichtet. doch ist man geneigt Südeuropa dafür zu nehmen.

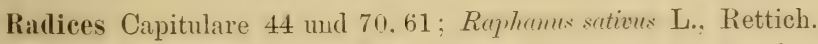

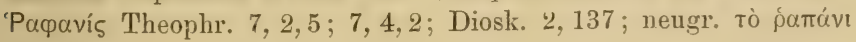

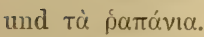

Radix Colum. 11, 3, 18; quae Assyrio semine venit 10, 114; Syriaca 11, 3, 16 und 59; raphanus Colum. 11, 3,47 und 59 u. 62; Plin. 19, 5, 26; 20, 4, 13; it. radice, rafano, ramoraccio, ramolaccio; fr. raifort.

Der Rettich scheint bei den Griechen sehr geschätzt gewesen zu sein, da sie verschiedene Spielarten von ihm bauten (THEOPHR. 7, 4,2). Bei COLUMELLA kann man zweifelhaft sein, ob raphanus und radix bei ihm wirklich dasselbe bedeuten. Die heilige $\operatorname{HILDE}(\dot{x} \mathrm{ARD}(1,89)$ und ALbERTUS MAgists $(6,423)$ kennen beide den Rettich, die erstere nennt ihn retich, der letztere ralix. Im 16. Jahrhundert begegnen wir dem Rettich in fast allen Kräuterbüchern und gegenwärtig wird er in Mittel- und namentlich in Süddeutschland massenhaft gebaut. In Norddeutschland ist er bis dahin nicht sehr verbreitet gewesen, seine Benutzung hat aber in den letzten Jahren zugenommen. - Als Heimat des Rettichs betrachtet man das gemässigte Westasien.

Bei den Schriftstellern des Altertums finden wir keine Angaben, aus denen man sicher schliessen könnte, dass Radieschen damals bekannt 
gewesen wären. Auch bei den Botanikem des 16. Jahrhunderts und noch später kommen Rarlies nicht vor; nur eine Bemerkung in MATTIOLIs Kräuterbuch (fol. 129 D) liesse sich vielleicht dahin deuten: „Noch ein ander Geschlecht desz Rüttichs hat man in Welschlandt, vnnd ist sehr gebräuchlich in Salaten, wechst Fingersdick oder grösser, biszweilen Armslang, ist lieblicher, zärter und mürber zu essen, denn der gemeine Rättich." Armlange Radies sind allerdings für unsere Vorstellung etwas wunlerbar; immerhin könnten die genannten zarten Rettiche die Vorläufer unserer Radieschen sein. Denn wenn das Bestreben der Gärtner auch im allgemeinen darauf gerichtet ist möglichst grosse Wurzeln zu ziichten, wie bei den Steckriiben, Sellerie etc., so kommt es bei den Radies gerade darauf an, kleine und zarte Wurzeln hervorzubringen: fingerlange Radies sieht man übrigens auch hente bei uns. In der ersten Hiiltte des vorigen Jahrhunderts kannte man bei Regensburg nur die langen Radieschen, die sich rom Rettich nicht viel unterschieden (IVErNMANx, Phytanthozaiconographie Bd. 4, Regenshurg 1745, Tafel 860).

\section{Cochlearia Armoracia L., Meerrettich.}

Ob dasjenige, was COLUMELLA und PLINIUS armoracia nemnen, wirklich unser Meerrettich ist, ist mehr als zweifelhaft. DIOSKORIDEs identificiert seinen wilden Rettich (jaqavis àrpía 2, 138) mit der römischen armoracia; nach der Peschreibung aber, die er liefert, kann er unmöglich an den Meerrettich gedacht haben, sondem viel eher an den Hederich, Raphanus Raphanistrum L., oder auch an eine wilde oder verwilderte Kohl- oder Senfart. Dazu würde es stimmen, wenn Coludella $(12, y .3)$ sagt, dass die cyma amoracionum, also der Trieb von armoracia, welcher blühen will, eingemacht wird, ähnlich wie Salat, Endivien etc.

Im CGL III, wo der Rettich radix oder radix hortulana und pápavos (raphanus) genannt wird, steht einmal $(16,28)$ papavídes armoratia, wahrscheinlich nach DIOSKORIDES; an anderen Stellen wird armoracia mit lnp:sena identificiert $(536,18 ; 567,10)$, das wir als weissen Senf gedeutet haben; einmal $(575,44)$ steht rudistria . $i$. armoraciu, worans nichts weiter zu entuehmen ist. Aus den Angathen im CGL III kamu man also auch nicht mit Sicherheit schliessen, dass der Meerrettich gemeint ist.

Bei der heiligen HILDEGARD (1,119) finden wir merrich, merrech, merrerlich und mirredich, als lateinischen Namen raphamem. ALBERTC's MAfiNes $(6,425)$ beschreibt den Meerrettich unter dem Namen raphamus, so dass die Pflanze gut erkennbar ist; nur irrt er sich, wenn er sagt, dass die Blume gelb (croceus) sei. Wenden wir uns nun zu den lateinischdeutschen Glossaren, so finden wir, dass raphanus oder ruphanum übersetzt wird durch merratich, mirredich (ahd. Gl. 7, 17 und 23, 12), merretich (Sum. 17, 74; 2:3, 3s etc. etc.), meriratich, merredik (Mone 520); zu diesen Namen gesellt sich in späterer Zeit, wie es scheint nicht viel vor dem 12. Jahrhundert, das slavische direne, chen, Kren, das lateinisch auch 
rabigulium (radigudium) genannt wird. In einem aus dem 15. Jahrlum dert stammenden Glossar (Mone, Anzeiger für die Kunde der teutschen Vorzeit, Bd. 8, 1839, S. 103-104) wird ruphanus major, Rätich, unterschieden von ruphanus minor, Khren. Zu dem hier angeführten Sprachgebrauch stimmt es, wemn bei den Botanikern des 16. Jahrhunderts der Meerrettich Raphanus genannt wird. MATTIOLI nennt ilın Ruphanus rusticanus sive vulgaris, deutsch Gren (Comment.), und Rripliamus rusticus s. major, deutsch Kreen, Merrättich (Kräuterbuch); CAJERARIUS sagt Raplunus rusticus: vulgo Armoracia; TABERNAEJIONTANLS schreibt Meerrettich und übersetzt Raphanus marinus; HIERONYIUS BOCK hat nur Merrhetich. Der Name Raphanus rusticanus hat sich in unseren Apotheken bis auf die Gegenwart neben Armoracia erhalten.

Welche Bedeutung hat denn armoracia in den lateinisch-deutschen Glussaren? Hier laufen 3 oder 4 Namenreihen nebeneinander her. Zunächst wollen wir armoratio mênva und armoratia manua (Sum. 21, 21 ; 60, 28) ausschliessen; menu ist ein alter Name von Rumex obtusifolius L. Es bleiben dann:

1) Hederich, heidenmb, heidenrettich, zuweilen armoriaca genannt; entweder ist dies unser Hederich, Raphanus Ruphanistrum L., oder ein anderes Ackerunkraut, wie der Ackersenf, Sinapis arvensis L.

2) Bevenelle, bibenella, jetzt Pimpernell und Bibernell genannt. Es ist dies Pimpinella Saxifraga L., eine Pflanze, die früler mehr als jetz.t in den Apotheken benutzt wurde.

3) Neerrettich und Kren. Diese beiden Deutungen von armoracin treten am spätesten auf, wie es scheint nicht ror dem 16. Jahrhundert.

In der „Heimat" (Bd. 3, Kiel 1893, S. 44) sind die plattdeutschen Nimen des Meerrettichs: Marrak, Maressig, Maredig, Marretig, als Angleichungen an Armoracia aufgefasst, ${ }^{1}$ ) (lie ihrerseits wieder als Meerrettich rerhochdeutscht worden seien. Das könnte nı̈glich sein; aber die Namen Merradich, Meiretich etc. kommen schon vor dem 12. Jahrhundert ror, kömmen also noch älter sein, und würden in unserem Hochdeutsch „Meerrettich" geschrieben werden müssen oder wenigstens können, denn das kurze "e" der ersten Silbe widerspricht nicht der Ableitung von Meer (cfr. Herzog von Heer, Kluge, Etymologisches Wörterbuch). Die Deutung Mïhrrettich (Pforderettich) ist sprachlich unmöglich; sie stammt auch erst aus diesem Jahrhundert oder frühestens aus dem Ende des vorigen.

Wie kommt die Pflanze zu dem Namen Meerrettich? Weil sie in der Nähe des Meeres besonders gut gedeiht? Es wäre immerhin möglich, aber sie könnte auch wohl ursprünglich eine Küstenpflanze Italieus und Griechenlands gewesen sein, wie sie denn jetzt noch die Kiisten des Schwarzen Meeres bewohnt. Dann wäre am Ende doch die wilde Abart

1) Vergl. Неим, S. 40 ร. 
von raphanus bei PLINIUS $(19,5,26)$, „die die Anwohner des Pontus amon neunen, andere die weisse (leucen), die Römer armoracin, und die an Blättern reicher ist als an Körper" (fronde copiosius quam corpore), unser Meerrettich? Was PLINIU's sagt, spricht nicht dagegen; es könnte sogar sowohl in armoracia wie in armon ein Wort stecken, das Meer bedeutet: aber zu Termutungen neue Vermutungen hinzuzufügen bringt uns nicht weiter.

Man sieht heute das östliche Europa und das angrenzende gemässigte Asien als die Heimat des Meerrettichs an. MATTIOLI sagt ron ihm in seinem Commentar, dass er auf IViesen, Grasplätzen und an Wegrändern wild wachse, aber diese Standorte sind verdächtig; im Kräuterbuch giebt er an, er werde in Italien raphanus montanus genannt, "dafz er von sich selbst in Gebirgen wechset". Auch BERTOLONI betrachtet ihn als inländisch für Italien, wo er nach ihm die Namen rajuno volgare und rajano mustirano führt; trotzdem bleibt sein Indigenat dort zweifelhaft. Im heutigen Griechenland kommt er nicht vor und wird auch nur iusserst selten gebaut. - Frankreich hat den Meerrettich von Osten her erhalten, wie die Namen cran, cranson (aus Kren), moutarde des Allemands, moutarde des capucins, mérédic etc. beweisen; der französische Name raifort ist nicht besonders charakteristisch: er bedeutet eine starke Wurzel und gilt auch für den Rettich selbst.

\section{Mohrrübe, Pastinak und Zuckerwurzel.}

(arvitas ${ }^{1}$ ) Capitulare 70,52; Daucus Carota L., Möhre, Mohrrübe, gelbe Rübe, gelbe Wurzel, Karotte.

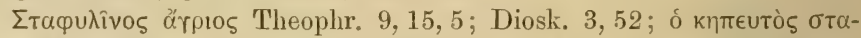
pulîvos Diosk. 3,52; kaputóv ${ }^{2}$ ) Diphilos bei Athen. 9, $371 \mathrm{de}$; neugr.

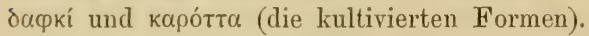

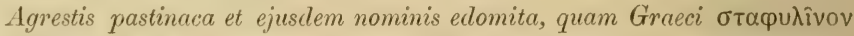
rorcunt, Colum. 9, 4, 5; pastinaca agrestis Plin. 19, 5, 27; it. carota salvatira, danco marino, pasticciona, pastinaca, carota; fr. carotte.

Die Möhre und die Pastinakwurzel sind früher viel miteinander verwechselt worden und werden es bei den Italienern noch jetzt. Dass

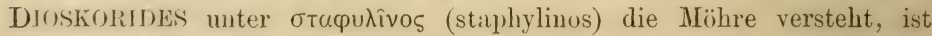
unzweifelhaft, denn er sagt, dass in der Mitte der weissblumigen Dolde sich etwas purpurfarbiges, einem Pilze ähnliches befinde: dasjenige, was wir die Terminaldolde nennen, die bei anderen Umbelliferen, wenigstens in dieser W Weise, nicht vorkommt. Als Synonymen führt DIOSKORIDES

1) Ausser carvitas kommt die Lesart carrucas vor (hei REuss, WALAFRid STram1 Hortulus etc., S. 71); carvitas ist entstellt wohl aus cariota : caroita, carvita (cfr. CGL 111, 537, 75; 556, 74; 620,66.)

2) Der neueste Herausgeber des Athenaeus, G. KAlBEL, liest an dieser Stelle кupтóv. 
unter anderen liarota (каро́та) an, das die Römer gebrauchen, und pasti-

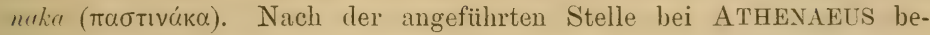

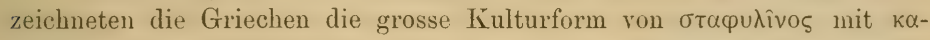
pwtóv, so dass THEOPHRAST mit otapulîvos ärplos wohl die wilde Nöhre meint. Da Coldyrelia die zahme und Plinius die wilde pastinaca mit dem griechischen staphylinus identificieren, so wird, wie DIOSKORIDEs angiebt, die pastinaca der Römer unsere Möhre sein. Stapliylinus, dancus, carota und pastinaca werden auch in den Hermenenmata des CGLIII als gleichbedeutend genannt. $^{1}$ )

Albertus Magnus erwähnt die Mohrrübe unter dem Namen dcurrus $(6,328)$; er hat auch die rote Terminaldolde beobachtet, wie es scheint selbständig, denn seine Beschreibung ,weicht von derjenigen des DIOSKORIDES ab: "et habet florem coronalem, in cujus medio est flos alius puniceus valde parvus."

Im späteren Latein wird das Wort daucus häufiger, aber es wird nicht nur als gleichbedeutend mit pastinaca gebraucht, sondern auch für den Samen von Fenchel und Anis: ") die Terbindung daucus rreticus") ist ins Deutsche als Crecemorensith übergegangen (Colm. Gloss. 269), aber nicht mehr gebräuchlich. Ältere deutsche Namen sind: morach, more, mölire.

Pastinacas Capitulare 70, 53. Pastinaca sativa L., Pastinak; niederdeutsch Pasternak, Balsternak, Moorwötteln (Moorwurzeln).

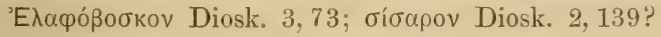

Siser Colum. und Plin.?; elaphoboscon Plin. 22, 22, 37; it. elafobosco, pastinaca, pastricciani; fr. panais, pastenade.

Die ron DIOSKoRIDES gegebene Beschreibung und der Umstand. dass die Italiener die Pastinakwurzel noch heute elajobosco nennen,

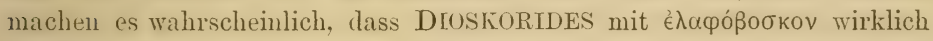
Pastinaca sativa gemeint hat. Man könnte geneigt sein carvitas und pastinacas des Capitulare für gleichbedeutend zu halten; dagegen spricht aber der häufige Gebrauch der Pastinakwurzel in früheren Jahrhunderten, der schon zu Karls des Grossen Zeit seinen Anfang genommen haben kann. Eine Folge der häufigen Kultur in früherer Zeit ist das massenhafte Vorkommen der Pastinakwurzel in verwildertem Zustande an Wegrändern und in der Nïhe von Gehöften. In Griechenland kennt man sie nicht; in Italien kommt sie selten vor, ebenso hier im Norden. wo sie fast nur noch in den Marschgegenden gebaut wird. Man wendet ihr jedoch neuerdings wieder mehr Aufmerksamkeit zu.

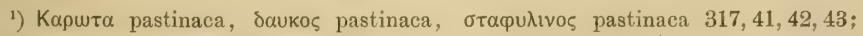

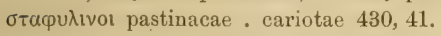

2) CGL III: dauco . feniculi semen 545,23 ; daucu . anisi semen 545, P0; efr. S. 632, Anm.; - dauco cretico pastenacae semen 589,$41 ; 610,49$. creticus.

$\left.{ }^{3}\right)$ In der alten Medicin führte Athamanta cretensis L. den Namen Daucus 
Ob CoLtjiella mit siser die Pastinakwurzel gemeint hat, bleibt zweifelhaft, da er nirgends eine Beschreibung liefert; da er aber siser. zweimal unmittelbar neben pastinace nennt (11,3,14 und 35), einmal neben radix, rapa und napus $(11,3,18)$, so wird man wohl ein rübeliartiges Gewächs darmuter vermuten dürfen, also vielleicht Pastinuca sativa L. Ähnlich steht es mit dem siser bei PLIxiUS. Er unterscheidet ein siser erruticum, d. h. ein wildes, vom satirum, dem gebauten $(20,5,17)$, was wohl auf Pastinaca passt, aber nicht auf die Zuckerwurzel (Sium sismum L.), wie schon SPRENGEL ausgeführt hat (DIOSKORIDES, Materia medica, Bd. 2, Leipzig 1830, S.462). An der genannten Stelle führt PLisius an, dass niemand drei Wurzeln von siser nacheinander essen kömne, was auch nicht auf die Zuckerwurzel passt. Wem Plixils angiebt $(19,5,28)$, dass Tiberius sich siser von der Burg Gelduba am Rhein habe kommen lassen, so kömnte das ebensowohl auf Pastinak wie auf die Zuckerwurzel passen, und beweist eben nur, dass manche Gemüse in einem kühleren Ḱlima besser gedeihen als in einem heissen. Auf den Unstand, dass PLINIt's neben siser auch noch elaphoboscon nennt $(22,22,37)$ und so beschreibt, dass man l'astinacu erkennen kann, darf man nicht viel Gewicht legen, dem er hat seine Collectaneen keineswegs immer sorgfältig verarbeitet. Elsenso kïmte DIOSKORIDES übersehen haben, dass er die

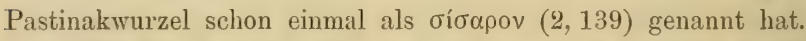

Die hier versuchte Deutung von siser wird vielleicht bestïtigt durch zwei Glossen im CGLII:

$$
\begin{aligned}
& \text { siser } \epsilon 1 \delta \circ \varsigma \text { } \sigma \tau \alpha \varphi v \lambda ı \text { เvou } 185,11 \text { und }
\end{aligned}
$$

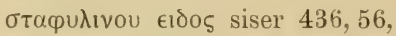

d. h. siser ist eine Art von staplyylinus; dieser wird aber, wie wir es oben gethan haben, mit pastimace identificiert $(142,48 ; 436,55)$, bedeutet also unsere Mohrrübe. Es kamn also siser eine besondere Rasse der Mohrriibe sein, aber ebensowohl eine der Mohrrübe ähnliche Wurzel wie die Pastinakwurzel.

Sium Sisaron L., Zuckerwurzel.

Italienisch: sisaro; fr. chervis, girole.

Wenn die Alten die Zuckerwurzel wirklich gekannt hätten, so wiirden sie es kaum unterlassen haben, auf die zahlreichen fleischigen Wur\%ehn anfmerksam zu machen, die diese Pflanze trägt, während die Mïhre sowohl wie der Pastinak nur eine einzige solche Wurzel hervorbringt. MATTIOLI sagt anch (Commentar S. 351), dass Siser in Italien nicht gehaut werde, und disss ihm „diesz Gewächs erstlich ausz Burgundia zukommen sei" (Kräuterbuch fol. 131 A). In 16. Jahrhundert war die Zuckerwurzel im sïdlichen, namentlich im siidwestlichen Deutschland häutig und führte eine grosse Zahl von Namen. HIERONymus Bock nennt sie Zam Garten Rapuntzel, Gier!ein oder Gerlein, MatTIoLI im Kräuterbuch Gritzelmörlein; hei TABERNAEMONTANUs führt sie ausser den genamiten noch die folgenden Namen: Geyerlein, Girgele, 
Görlein, Klingelrüblein, Klingelmöhren und Zuckerwurtzel, und wird nach ihm von "den Kreutleru" Servilla, Servillum und Chervillum genannt. Chervillum sieht wie ein entstelltes Cerejolium aus, und in der That wird Cerejolium althochdeutsch chemilla genannt (Schl. Gl. 258); dieses rhervilla, oder das lateinische chercillum, kann sehr wohl das Stammwort für das französische rhercis sein, ebenso wie Girlein oder Görlein dașjenige für girole. Die Franzosen müssten dann die Zuckerwurzel von Deutschland aus erhalten haben, was DT PRADEL (nach RÜ̉IPLER, Ill. Gemiiseund Obstgärtnerei, Berlin 1879, S. 166) in seinem Théatre d'agriculture bestätigt.

Nach ALPH. DE CANDolle ist das Vaterland der Zuckerwurzel im altaischen Sibirien und im nördlichen Persien zu suchen, jedoch wird - von anderer Seite auch China und das östliche Asien genannt. Die Pflanze scheint ihren Weg zu uns über Russland genommen zu haben, denn in Griechenland kommt sie garnicht vor: in Italien wirci sie wenig gebaut und führt hier den Namen sisaro. Wenn die Italiener die Zuckerwurzel aus Deutschland erhalten haben, so kamu hierin der Grund für diese Namengebung liegen: man hat in ihr nachträglich das siser des Tiberius zu erkennen geglaubt.

\section{Sellerie, Petersilie und schwarzes Gemüse.}

Apium Capitulare 70,32; Invent. I, 6; II, 4. Apium graveolens L., Sellerie, Eppich.

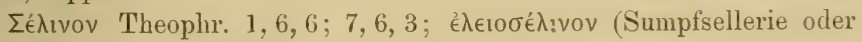

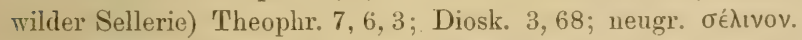

Apium ${ }^{1}$ ) Colum. 11, 3, 33; 10, 166 und 371; Plin. 19, 8, 37; 19, 8, 46; 20, 11, 44 etc.; it. sedano, selleri, apio, apio grande; fr. céleri.

Im heutigen Griechenland wird der Sellerie $\sigma \in \lambda_{\lambda} \iota v o v$ (selinon) genamnt; es ist daher wahrscheinlich, dass schon im Altertum mit demselben Namen dieselbe PHanze bezeichnet wurde. Ob dieser Gebrauch

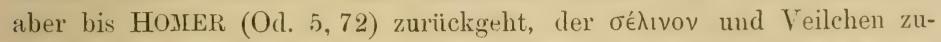
sammen als Pflanzen einer Wiese nennt, ist sehr fraglich. WVir kennen den Sellerie nur als Gemïse, die Alten brauchten ihn aber auch als Schmuck (Kranz) und unterschieden ausser dem wilden Sellerie auch den

1) Das Apium agreste und rusticum der späteren Zeit ist kein wilder Sellerie, sondern eine giftige Hahnenfussart, Ranunculus sceleratus L., die an tiefsumpfigen Plätzen wächst und deren erste Blätter eine gewisse Ähnlichkeit mit denen des Selleries haben. Man scheint die Giftigkeit dieser Pflanze gekannt zu haben, denn sie wird auch herba scelerata genaunt; ihr Geuuss sollte ein krampf haftes Lachen lerrorrufen, deshalb nannte man sie Apium risus; wegen ihres nassen Standortes erhielt

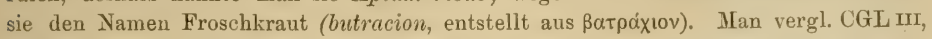
536, 39; 536, 47; 553, 27; 608, 37; 633, 2-8. - Bei Droskonides $(2,206)$ wird

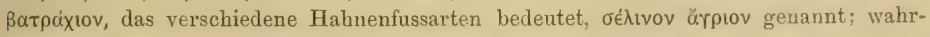
scheinlich stammt das obengenannte Apium agreste ebendaher. 
gebauten mit mehreren Abarten, ron denen allerdings einige zu unserer Petersilie gehören diirften. Die ïlteren deutschen, aus apirm entstandenen Namen sind plich, "pre, ein etc., epr (KONRAD VON MEGENBER(i 5,3), und ausserdem Merch oder Merk.

Nach den Kräuterbüchern zu urteilen ist im 16. Jahrhundert die Kultur des Selleries. der Apium palustre genannt wird, nur eine sehr geringe gewesen: sie muss gegen früher zurückgegangen sein. Nenerdings hat sie einen bedeutenden Aufschwung genommen.

Petresilinum Capitulare 70, 31; petresilum, Invent. I, 4; Apium Petroselinum L. (I'etroselinum sutivun Hoffmann), Petersilie, Petersill.

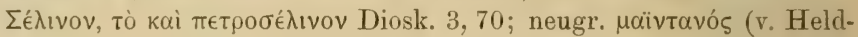

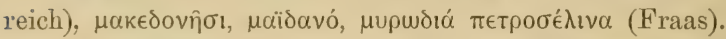

Petroselinon Plin. 20,12,47; it. apio ortense, petroselino, prezzemolo; fi. persil.

COLCMELLA, der kein petroselinum kennt, spricht $(11,3,33)$ von einem apium mit breiten (apium lati folii) und einem mit krausen Blätter'u (apium crispae frondis). Auch PLINIUs erzählt uns von apinm mit lirausen Blättern (10,s,37 u. 46). Da nun rom Sellerie wohl eine Rasse mit feiner zerschlitzten, aber keine mit eigentlich krausen Blättern existiert. und da in Italien die Petersilie heute noch "pio genannt wird, so ist es wahrscheinlich, dass unter dem apium der Alten zum Teil unsere Petersilie mitzuverstehen ist. Das Beiwort apiacon, das der krause Kohl bei CATU erhält (vergl. oben S. 109), lïsst sich auch nur verstehen, wenn apium die Petersilie bedeutet.

Im 16. Jahrhundert wird apium meist als Petersilie gedeutet; die gewöhnliche heisst Apium hortense, die krause Apium crispum. Gegenwärtig ist die Petersilie ein sehr beliebtes Küchengewächs, das kaum dem kleinsten Garten fehlt. Ihre deutschen Namen Petersilie, Peterlein etc. sind sämmtlich von petroselinum abgeleitet.

Olisatum Capitulare 70, 30; Simyrumum Olusatrum L.. Pferdeeppich, schwarzes Gemüse.

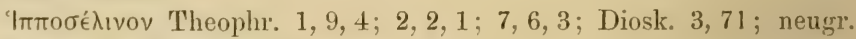

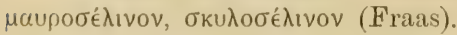

Olus atrum Colum. 11, 3, 36; 12, 7, 1; Plin. 19, 8, 48; 20, 11, 46; it. macerone, smirnio; fir. ache, maceron.

IDISKORIDEs erzählt uns, dass der Pferdeeppich (imtroбé $\lambda ı v o v$ )

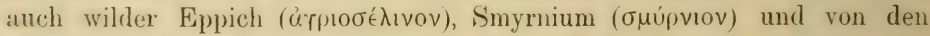
Rïmern olus "trum genannt werde. Diese Namen wurden nun in den Glossaren den gewaltsamsten Verdrehungen unterworfen, namentlich aber olusutrum, das als oliserus, oleratum, olowatrus, olixatrum, olixatrum etc. erscheint, so dass man nicht daran zweifeln kann, dass unter dem olisutum des Carpitulare das olusatrum gemeint ist. Diese Pflanze, die bei deu Römern eine weschützte Arznei- und Gemuisepflanze war, hat im Nittel- 
alter in Deutschland einen ausgebreiteteren Anbau gefunden als später; ihre Wurzel scheint sogar die Selleriewurzel vertreten zu haben. Später ging ihre Kultur zuriuck. Das geht auch daraus hervor, dass im 16. Tahrhundert, z. B. von HIERoNvmes BOck, die Meisterwurz (Imperatoria Ostruthium L.) als das smyrnion und hipposelinon der Alten dargestellt wurde.

\section{Artischocke und Weberkarde.}

Cardones Capitulare 70,66; Cynara Cardunculus und Scolymus L., Artischocke mit ihren verschiedenen Rassen.

Kákтоక Theophr. 6, 4,10; кuvápa Athen. 2,70; neugr. ảrкuvápa.

Cinara Colum. 11, 3,14 u. 28; 10, 235-241.; carchus Plin. 19, 8, 43; cactos Plin. 21, 16, 57, nach Theophr.; it. cardo, cardone, carcioso domestico, mazzuferruta; fr. artichaut (der Blütenkopf), curdon (das Blattstielgemüse, das schon THEOPHRAST unter dem Namen кákтoৎ beschreibt).

LINNÉ unterschied die Cardone oder spanische Artischocke (Cynare Cardunculus) und die eigentliche Artischocke (C. Scolymus) als zwei verschiedene Arten, aber nach den neuerdings gemachten Erfahrungen betrachtet man die Artischocke als eine Kulturrasse der Cardone. Die Artischocke war bei den Griechen als Speise wie als Heilmittel in Gebranch, ebenso bei den Römern. Dass ihre Kultur bei den Römern einen hohen Grad der Vollkommenheit erreichte, geht aus der oben citierten Stelle im 10. Buch bei CoLuneLLA hervor; hier werden mehrere Abarten unterschieden, die sich durch Grösse, Farbe und Bestachelung unterscheiden, gerade wie es noch jetzt der Fall ist.

Die Artischocke ist zu empfindlich gegen die Kälte, als dass sie das Kilima vou Norddeutschland ohne besondere Schutzmittel aushalten kömnte. Man begegnet ihr deshalb verliältnismässig selten. ${ }^{1}$ )

Ob das Wort cardones an der oben angeführten Stelle wirklich die Artischocke bedeutet, bleibt zweifelhaft; die meisten Deuter des Capitulare sind nicht der Meinung, sondern glauben, dass hier die Weberkarde gemeint ist. Sicher ist diese zu verstehen unter

cardones Capitulare 43; hier ist von dem zum Spinnen und Weben erforderlichen Gerät die Rede, und zwischen Kamm und Seife passt die Karde recht wohl hinein.

Dipsacus fullonum Miller, Weberkarde.

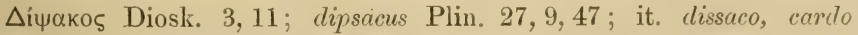
di panni, cardo da lanajoli, cardo dla cardare; fr. chardon ì carder.

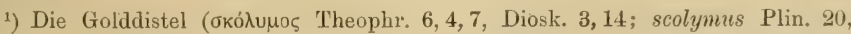
23, 99 u. 21, 16,56) Scolymus maculatus L. und S. hispanicus L., die in den Mittelmeerländern heimisch ist, liefert in ihren jungen Trieben ein wohlschmeckendes Gemüse, im heutigen Griechenland $\alpha \sigma \pi \rho \alpha \dot{\gamma} \alpha \alpha \theta \alpha$ genannt; diesseit der Alpen scheint sie wenig kultiviert worden zu sein. 
Die ron DIOSKORIJES gegebene Beschreibung ist vortrefflich und beweist, dass er wirklich die Weberkarde gekannt hat. Er leitet den

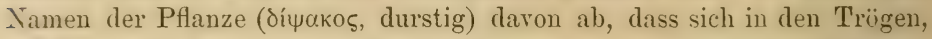
welche durch Terwachsung der Basen von je zwei gegenüberstehenden Stengelblättern entstehen, Regenwasser sammelt. Die einzeln an den Spitzen der Äste sitzenden Blütenköpfe ( $\Leftarrow \varphi \alpha \lambda \eta \dot{)}$ vergleicht er mit einem Igel ('̇xîvo૬).

Bei den Alten wurde das Tuch nicht mit der Karde, sondern mit dem Fell des Igels gerauht oder kardätscht (LENZ). Die Kultur und Benutzung der Weberkarde stammt also aus einer späteren Zeit, scheint aber zu Karls des Grossen Zeit schon bekannt und allgemeiner gewesen zu sein. In den Glossaren des CGL III ${ }^{1}$ ) wird sie cardo fullonicius genannt, also eine Distel, welche die fullones, Walker oder Tuchbereiter, benutzen. ALBERTUS MAGNus beschreibt die Karde unter dem Namen rirg" pastoris $(6,466)$, der sich auch bei HIERONYyUs BOCK und bei TABERNAEIONTANUS findet, bei dem letzteren aber die wilde Karde (I)ipacus silvestris Miller) berleutet: ${ }^{2}$ ) die Benutzung der Karde zum Tuchkratzen wird von ALBERTUS ausdrücklich angegeben. ${ }^{3}$ )

Hier im Norden findet sich die Weberkarde in Folge früherer Kultur mehrfach verwildert. - Stammt aus Südeuropa.

\section{Weisswurzel und Schwarzwurzel.}

Tragopogon porrifolius L. Bocksbart, Haferwurzel, Weisswurzel.

Tparomẃrwv Theophr. 7, 7, 1; Diosk. 2, 172; neugr. трıхоиิpu (Fraas).

Tragopogon Plin. 21, 15, 52; 27, 13, 117 ; it. scorzonera bianca, barba li becca, sassefrica; fr. salsifis, cercivis, barbe de bouc.

Was PLINIUs über den Bocksbart sagt, stimmt genau mit dem iiberein, was wir bei DIOSKORIDES und THEOPHRAst finden; in diesem Falle scheint sich aber auch DIOSKORIDEs etwas energisch auf seinen grossen Torgänger THEopHRAst gestützt zu haben. Ton THEOPHRAsT wird die Wurzel des Bocksbarts, „den einige zu den Gemüsen rechnen“, lang und suiss genamnt; DIOskorIDEs sagt, dass der Bocksbart eine usshare Pflanze sei. Ein sehr allgemein benutztes Gemüse scheint (r' ramals nicht gewesen zu sein, sonst wiirden wir ihn aluch bei COLLJELLA gefunden haben. - $\mathrm{Ob}$ das tragopogon der Alten gerade die obencrenamite rotbliihend. Art ist, und nicht etwa der gleichfalls rotblühende

1) Amilia cardo folinicius 586, 30; amilia idest cardo fullonicius 607,21 ; amilia idest cardo fulnicus 616,31; der Name amilia scheint sonst nicht vorzukommen.

$\left.{ }^{2}\right)$ Virga pastoris wird bei Matthaeus Sylvaticus ausser für Dipsacus auch für den Wegetritt (Polygonum aviculare L.) gebraucht, den er centinodia, poligonia,

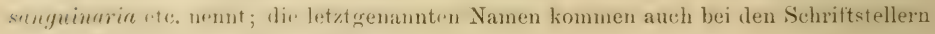
des 16. Jahrhunderts für den Wegetritt vor.

3) Die Blïtenköpfe werden sehr genau beschrieben; nachher heisst es: "Ipsa sutem spinositas optime pectit lanositatem pannorum laneorum". 
Tragopogon crorifolius L., oder gar eine der gelbblïhenden Arten, ist schwer zu entscheiden, aber auch gleichgültig, da die Wurzeln der Tragopogonarten sich ziemlich gleichen.

ALBERTUS MAGNUS beschreibt den obengenannten rotblïhenden Bocksbart sehr gut, nennt ihn aber oculus porri (Schweinsange) und rühmt seine essbare Wurzel. ${ }^{1}$ ) HIERoNyıLs BOCK beschreibt in seinem Kräuterbuch (fol. 101, vers., fol. 102) einen Bocksbart mit gelben Blumen, den er anch Gauchbrot nennt und dessen siisse W Wurzel die Kinder essen. "Bocksbart ist in seiner jugent mit seiner süssen wurtzel ein recht Kuchenkraut zum Sallat, gleich wie andere Spargen." MIATTIOLI hat sowohl in seinem Commentar wie in seinem Kräuterbuch einen gelbund einen rotbliihenden Bocksbart; den ersteren nennt er Barlulu liviri, den zweiten Tragoporfon purpureum: auch er verwendet die Wurzel zum Salat und bemerkt in seinem Commentar (S. 410), dass die Wurzel des rotblühenden Bocksbarts zwar grösser, aber weniger wohlschmeckend sei (adstringens et amariuscula). CAIIERARIts nennt in seinem Hortus medicus (S. 27) einen gelben und einen purpurfirbigen Bocksbart (Burbu hivci) und sagt, dass die zarten Wurzeln zu Salat benutzt würden (Radices tenerae expetuntur in acetariis). Im 16. Jahrhundert scheint der Bocksbart also viel gebaut oder benutzt worden zu sein: nachher ist er wohl mehr und mehr, wenigstens strichweise, in Vergessenheit geraten.

Der aus Südeuropa stammende rotblühende Bocksbart (Trayopogon porrifolius L.) ist hier im Norden in Folge frïherer Kultur gelegentlich verwildert, aber ähnliches könnte an einzehnen Stellen mit dem gelbblühenden Tragopogon matensi: L. der Fall sein; da die Wurzel dieses letzteren als besonders süss und zart gerühmt wird, so könnte es sich wohl der Mühe lohnen, wieder eimnal Anbauversuche mit ihm zu machen; vielleicht kömnten seine weissen Wurzeln die Konkurrenz mit deu schwarzen der Scorzonera erfolgreich aufnehmen.

Die Scorzoner- oder Schwarzwurzel (Scorzonera hispanica L.), auch Schlangenmord genannt, hat MATTIOLI in seinem Commental zum DIOSKORIDES zuerst beschrieben, wie er ausdrücklich anführt (haec nova est planta, nee puto esse quemquam, qui de ea ante nos scripserit); da C. BAUHIN in seinem Pinax hinter Srorsoncra jedesmal zuerst Matt. setzt, so wird das schon richtig sein. Der Name Scorzonera soll nach MATTIOLI von dem spanischen scurzo oder escorzo, das eine Schlange bedeutet, herkommen: die Pflanze galt als ein ausgemachtes Mittel gegen den Schlangenbiss, ja ein Tropfen ihres Saftes sollte eine Schlange zum Erstarren bringen; aber leider ist die Deutung falsch, denn in spanischen Wörterbüchern kommen die angegebenen Namen für Schlange nicht ror. Der Name kommt vom italienischen scorzone, das eine schwarze,

$\left.{ }^{1}\right)$,... habens radicem delectabilem, propter quod comeditur, et a porcis in pastum effoditur". 
giftige Schlange bedeutet. Aus dem Heilmittel wurde allmählich ein Nihrungsmittel. MATTIOLI rühmt die Wurzel als zart und ron süssem und lieblichem Geschmack (Kräuterbuch, fol. 317 A).

\section{Spargel.}

Asparagus officinilis $\mathrm{L}$. und verwandte Arten.

`Aбтúparos Theophr. 1. 10, 6; 6, 1,3; Diosk. 2, 151 ; neugr. бтupúrru. Asparagus Cato 6, 161; Colum. 11, 3, 43-46; Plin. 19, 8, 42; it. asparago, sparaggio; fr. asperge.

Der asparagus des THEOPHRAST ist nicht der in unseren Gärten gebaute Spargel. Asparagus officinalis L., sondern der spitzblätterige Spargel, Asparagus acutifolius L., dessen Blätter bart und stachlich sind; THEOPHRAs'T sagt ron ihm, dass er Dornen habe, aber keine Blätter. Der spitzblättrige Spargel wächst in Griechenland und Italien wild und seine sehr zarten und wohlschmeckenden jungen Triebe werden in beiden Ländern gern gegessen: in Italien heisst er sparaghella und asparago sulvatico; in Griechenland, wo die Kultur unseres Gartenspargels so gut wie unbekannt ist, geht er, wie noch andere wildwachsende Arten, Asparagus aplıyllus L. und A. horridus L., unter dem Namen omapárrı oder бqupúrrı. Die wilden Spargelarten werden auch Felsen- oder Berg-

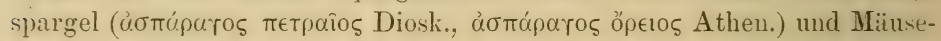

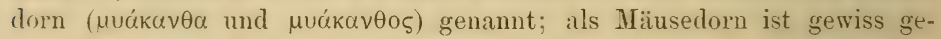
legentlich auch die jetzt so genannte Pflanze (Ruscus aculeatus L.) zu nehmen, demn ihre jungen Triebe, die den Spargelsprossen täuschend älınlich sehen, aber grün, dünn und ästig sind, werden noch heute viclfach gegessen. Unter den wilden Spargeln ist aber, wenigstens in Italien, auch dis wilde Form des Gartenspargels zu verstehen, die noch jetzt (z. B. in Siidtirol) von manchen höher gestellt wird als die zahme; diese

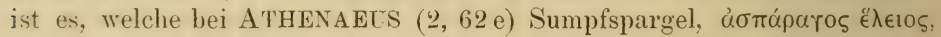

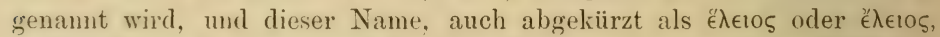
verbliel) dem Gartenspargel für die folgenden Jahrhunderte (CGI, III, 16,$18 ; 185,50 ; 317,30$ ete.) und wird noch bei MATTIOLI als griechischer Name des spargels angeführt. Bei den Römem hiess der wilde Spargel corruda.

Bei den römischen Schriftstellem CATo, CoLunella, PLIxIUs und PALLADIIS finden wir sehr genaue Angaben über die Spargelkultur. Damals machte man die Sache genau so wie jetzt. Nach CoLUMELLA werden die aus Samen gezogenen PHanzen nach zwei Jahren, wemn sich "in ordentliches Wurzelgeflecht (spongia = Schwamm) gebildet hat, versetzt und wenigstens ein Jahr lang geschont, damit die Wurzeln ordentlich fortwachsen können; dann werden die jungen Sprossen abgerissen, nicht abgebrochen orler al)geschnitten, demn man glaubte, dass der sitzengeblichene Stumplf die ïbrigen Sprossen im Wachstum hindere. Cort: MELLA baut iibrigens zwei Spargelarten, den Giatenspargel (asparagns. 
sativus) und denjenigen, welchen die Landleute comuda nemnen, also möglicherweise den spitzblättrigen. CATO, dessen Angaben die ältesten sind und dem die Spargelkultur nach PLINII's noch neu war $(19,8,42$, repentem ac noviciam viro curam (sc. asparagorum) fuisse), lïsst die aus Samen gezogenen Pflanzen 9 bis 10 Jahre stehen; erst dann setat er sie um. Es ist immerhin bemerkenswert. dass man hente beginnt dieselbe Art der Kultur anzuwenden, die der erste bekannte Spargelzüchter vor mehr als 2000 Jahren angewandt und beschrieben hat.

Die Spargel, welche die Alten zogen, standen an Grösse den heutigen nicht nach. PLINIUS erzählt an einer Stelle, wo er sicli iiber die monströsen Erzengnisse des Gemüsebaues und über Geschmacksverirrungen ereifert, dass in Ravemna drei Spargel auf ein Pfund gingen $(19,4,19)$. Nach ihm gal, es aber auch eine "Wildkultur" des Spargels, d. h. eine solche, bei der der Erdboden weder gegraben noch geptlügt wurde; es wurden vielmehr die Spargelsamen direkt in das Röhricht gesäet $(19,8,42$ : de origine eorum (sc. asparagorum) in silvestribus curis abunde dictum et quomodo eos iuberet Cato in harundinetis seri); hier bezieht er sich auf CATO, de re rustica 6 .

Bei THEOPHRAST und DIUsKorides, CATO und COLdIELla wird das Wort usparagus ausschliesslich von solchen Pflanzen gebrancht, die der heutigen Gattung Asparayus angehören; bei DIOsíoRIDEs heisst ein Spargelspross kauגíov, was dem lateinischen rauliculus entsprechen wiirde. Allmällich bekommt das Wort eine erweiterte Bedeutung: es wird überhaupt für junge Triebe oder Sprossen gebraucht. Schon PLINIUS nennt 23, 1, 17 die jungen Sprossen der Zaumrübe (ssuragi. ${ }^{1}$ ) 100 Jahre später etwa bezeichnet GALEN aber alle jungen Triebe; sie mögen essbar sein oder nicht, als asparagi; denselben Sprachgebrauch finden wir in den folgenden Jahrhunderten und noch im 16. Jahrhundert, z. B. bei HIERoxryus Bock, der in seinem Kräuterbuch bei Besprechung des Spargels fol. 82 sagt: „Sonst ist der nam Asparagus, oder wie die Athener schreiben, ein gemeiner name aller kreutter, die da erstmals jre junge Dolden oder bletter herfürstossen." Bei BOCK werden auch zarte Wurzeln „Spargen" genannt (vergl. oben S. 123). Heute kennen wir einen solchen Sprachgebrauch in Deutschland nicht mehr. Ausser den eigentlichen Spargeln werden nur sehr wenig junge Pflanzensprossen gegessen, die dam jedesmal nach der Stammpflanze benamnt werden; die Sprossen des Hopfens, Hopfenkeime genannt, sind in Süddeutschland sehr beliebt, gelangen aber im nördlichen Deutschland nur selten zur Verwendung.

Im Mittelalter ist die Spargelkultur in Dentschland sehr gering gewesen, jedenfalls fehlt es uns an Nachrichten; es ist nicht sicher, ob

1) „Asparagos eius (sc. vitis nigrae) Diocles praetulit veris asparagis in cibo urinae ciendae lienique minuendo." 
der ron ALBERTLs MAGNLs angeführte symugn: (6. 225) wirklich unserem Spargel entspricht.

\section{Kerbel und Myrrhenkerbel.}

Cerfolium Capitulare 70, 70; Invent. II, 21. Anthriscu: Cerejulinm Hoftimann, Kerbel, Gartenkerbel.

Chaerephyllum Colum. 11, 3, 14 und 42; caerefolium Plin. 19, 8, 54; it. cerfoglio, cerfolio, mescolanza; fr. cerfeuil,

II ir besitzen keine ganz sicheren Zeugnisse dafür, dass die Griechen im Altertum den Kerbel gekannt hïtten: das chaerephyllum des COLL: IIELLA ist aher ein griechisches Wort, das freilich auch auf italienischen Boden gebildet sein kam. In den Hermeneumata des CGLIII kommt

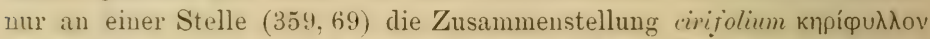
vor, wo das griechische Wort kaum etwas anderes ist als eine Transscription des lateinischen. Da man $\mathbb{D}^{\top}$ estasien für die Heimat des Kerbels hält, so scheint es, als ob die Griechen diese gewürzhafte Pflanze nicht gemocht hätten: im heutigen Griechenland kennt und benutzt man sie nicht.

Der Kerbel, Körbel, Körffel, in alter Zeit kmuele, wird auch heute noch viel gebaut und kommt nicht selten rerwildert vor.

Myrric odorata Scopoli, Myrrhenkerbel, Süssdolde.

Mup̉óis Diosk. 4, 116.

Murris, myriza, murra Plin. 24, 16, 97 ; it. mirricle, finochiella; fr. myrrthis, cerfeuil musqué.

Diese Pflanze gehört den Gebirgen von den Pyrenäen bis nach Iontenegro an und kommt auch auf dem Appennin ror, sie kam also rlen Römern sehr wohl bekannt gewesen sein. Ob sie aber identisch mit der mumplis des DIoshoriues ist, bleibt zweifelhaft: demn diese hat .*ine längliche, zarte, runde, wohlriechende Wurzel, die angenehm zu essen ist". Nun kann man zwar dem Geschmack der Römer manches zutrauen, aber die Wrurel des Myrrhenkerbels entspricht den angeführten Wrotrn nicht, sie mïsste dem schon bei den Römern durch Kultur verändert worden sein. Irit Chaeroph!yllum lnulıosum L., der Kerbelrübe. dart man aber mymhis auch nicht ohne weiteres identificieren, wie es won TABERNAEIONTANL's geschehen ist; denn die Kerbelriibe gehört dem mittleren Europa von Frankreich bis Asien an und kommt in Italien nicht vor, mol wenn sie, was jat keineswegs als ummöglich zu betrachten ist. von Gallien nach Rom gebracht worden wäre, so würde sich darüber rewiss eine Nachricht erhalten haben. Man kïnnte endlich noch an Bunimm Bublbonstumm L.. die Erdkastanie, denken, eine westliche Pflanze, die ron England bis Südfrankreich und Italien vorkommt, und von der rine ähnliche Form, Bunimm fermlaceum Sibthorp et Smith, sich auf der. Balkanhalbinsel findet; aber auch auf die linollige Wrurzel der Erdkastanie passt die von Droskorides gegebene Beschreibung nicht. 
Jerlenfalls ist der Myrrhenkerbel aus südlicheren Gegenden nach Norddeutschland gekommen und ist hier unter den Namen welscher oder spanischer Kerbel, Körbel oder Körffel und Myrrhenkerbel früher gebaut und ebenso benutzt worden wie der gewöhnliche Kerbel. Man begegnet ihm mehrfach in der Nähe grösserer Gärten und Gehöfte, aber nicht mehr in Garten selbst. In den Apotheken führte er früher die Namen Cerejolium hispanicum, Myrrhis major und Cicutaria odlorata.

\section{Spinatpflanzen.}

Gartenmelde, Malve, Mangolt, A marant, Spinat;

Erdbeerspinat.

Adripias Capitulare 70,54; Atriplex hortensis L., Gartenmelde.

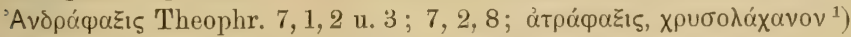

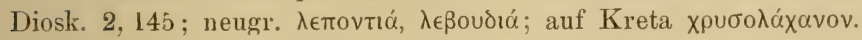

Atriplex Colum. 10, 377; 11, 3, 42; Plin. 20, 20,83; it. atriplice, bietolone, spinacione; fr. arroche, bonne dame.

Früher eine sehr beliebte Gemüsepflanze, die die Stelle unseres Spinats vertrat; jetzt ist sie sehr in Vergessenheit geraten, wie man sagt mit Unrecht, und findet sich selten gebaut, meist nur noch in halbverwildertem Zustande. Ihre Heimat wird man in Südeuropa zu suchen haben.

Die wilde Art der Gartenmelde bei DIOskokides und Plinits kömnte entweder die grüne Farbenvarietät der Gartenmelde selbst sein, die ausserdem auch noch gelb und rot vorkommt, oder aber Chenopodium album L., das auch "Melde" genannt wird.

Auch den Guten Heinrich oder Schmerbel, Chenopodium Bonus Henvicus L., al's man vor Zeiten, und zwar die jungen Triebe und die Blätter; wahrscheinlich hat man ihn damn auch kultiviert, und dann wäre sein Vorkommen an Dorfstrassen und Schuttplätzen eine Folge seiner frïheren Kultur: gegessen wird er in Norddeutschland von Menschen nicht mehr, wohl aber im heutigen Griechenland, wo er wilder Spinat, ärpı $\sigma \pi \alpha v \alpha ́ k ı \alpha$, heisst.

Malvas Capitulare 70,51; Invent. II, 18; Malva silvestris L. und 11. neglecta Wallroth, Käsepappel, Malve.

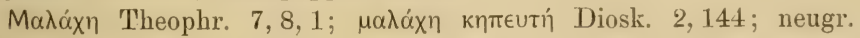

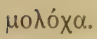

Malache (oder moloche) Colum. 10, 247; malva, alterum genus: malache Plin. 20,21,84; it. malva salvatica, malva comune; fr. mauve.

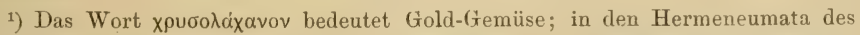
CGL III kommt dies Wort unter den Gemüsen jedesmal vor, dagegen fehlt es in den

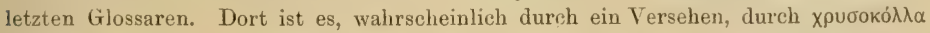

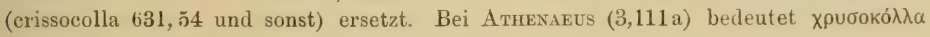
ein Gericht aus Leinsamen und Honig. 
Die beiden genaunten Malven, die vielfich verwechselt wurden und werden, waren früher nicht nur Heilmittel, sondern sie dienten auch, wie noch heute in Griechenland, als Nahrungsmittel: die Blïtter wurden als Gemiise gekocht. wie gegenwärtig der Spinat. Sie sind durch andere PHlanzen, wie den Spinat, aus den Gärten verdrängt, und so kommt es, dass man sie wohl an Dorfstrassen und Plätzen, in ummittelbarer Nähe ron Gebäuden und Gärten, aber nie im Walde und im freien Felde findet; beide stammen ursprünglich ans dem südlichen und mittleren Europa.

Die ältesten deutschen Namen sind Pappehn, (babela, heilige HILDE(iARD 1, 97, popele, Colm. Gloss. 75, 454), Käsepappeln; plattcleutsch Kattenkēs (Katzenkäse).

Einige haben die Stockrose, Althaea rosea Cavanilles, in den malvas des Capitulare erkemnen wollen, aber sehr wahrscheinlich mit Unrecht, denn bei den Schriftstellern des Altertums findet sich nichts, was sich mit Sicherheit auf die Stockrose beziehen liesse. Die Malre ( $\mu a \lambda a ́ x \eta)$ des THEOrHRAST, die baumförmig wird (ảtrodevopoûtal, 1, 3, 2; 1, 9, 2), wird zu den Gemüsen gerechnet $(1,9,2)$, ist also entweder Malva silvestris L., die bei einiger Pflege eine grosse Höhe erreicht, oder die Lavatern arboren L. (neugr. $\delta \in v \delta \rho o \mu o \lambda o ́ x \alpha$ ), die in Griechenland wild wächst und in Gärten liultiviert wird und nach r. HELDREICH dieselbe Benutzung findet wie Malva silvestris. Nach DIOSKORIDEs $(2,144)$ wurden beide ron ihm angeführten Malvenarten, die zahme und die wilde, gegessen, hier kann also auch nicht von der Stockrose die Rede sein.

Bei Albertes Magivus $(6,378)$ wird unter dem Namen malvu die niederliegende Malva neglecta Wallroth beschrieben; von einer baumförmigen Malve (arbor mulvae) ist schon früher $(1,161)$ die Rede. Da diese aber geradezu die Blätter der kleinen Malve hat (habet directe folia malvae parvae), so wird man nicht an die Stockrose denken dürfen, sondern vielmehr an Malva silvestris; über den Gebrauch des Wortes arbor dachte man damals anders als jetzt.

Erst im 16. Jahrhundert begegnen wir der Stockrose mit Sicherheit. HIERonyaus Bock nenut sie Herbst- oder Ernrosen, auch Römische Pappehı; dieselben Namen finden sich bei TABERNAEנIONTANUS und MatTiOLi. Bock berichtet auch, dass die Stockrose zu Metz Rosa ultrumarin genannt wurde. Zahlreiche Farbenvarietäten werden schon aufgeführt, aber es wird auch hervorgehoben, dass die Pflanze nicht von selbst gedeihe, sondern der Pflege bedürfe.

Dis Bestreben, alle Pflanzen des Gartens bei den Alten wiederfinden zu wollen, hat die Frage nach der Herkunft einer Pflanze erst sehr spüt auf kommen lassen, manchmal erst zu einer Zeit, wo man schon vergessen hatte, dass sie überhaupt als Fremdling eingewandert war. Wahrscheinlich ist es mit der Stockrose so ergangen. Da sie erst im 16. Jahrhundert mit Bestimmtheit nach\%nweisen ist, so gehört sie viel- 
leicht zu den Pflanzen, die durch Vermittelung der Türken nach Europa gekommen sind. Der Umstand, dass sie jetzt in Griechenland, wo sie ebenso wie Laratera arborea $\delta \in v \delta \rho o \mu o \lambda o ́ x \alpha$ genannt wird, scheinbar wild vorkommt, spricht nicht notwendig gegen unsere Ansicht: eine Zierpflanze kann recht wohl in Griechenland verwildern, ohne es bei uns zu thun.

Betas Capitulare 70,48; Invent. II, 5; Beta vulgaris L., Runkelrübe, Mangolt, Rote Beet, Rote Rübe.

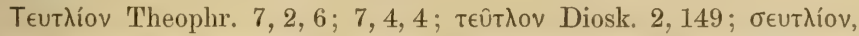

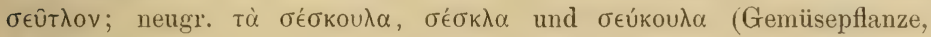

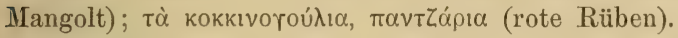

Beta Colum. 10, 254 u. 326, Plin. 19, 8, 40; it. bietola, bietola bianca, bietola rossa; fr. bette, poirée.

Von welcher Pflanze die verschiedenen Rassen der Runkelrübe stammen, ist noch nicht mit absoluter Sicherheit entschieden, aber alle scheinen sich darin einig zu sein, dass die Küsten des Mittelmeeres und eines Teiles des atlantischen Oceans als Heimat der Stammpflanze anzusehen sind.

Schon die Alten kannten Runkelrüben mit weissen und mit roten

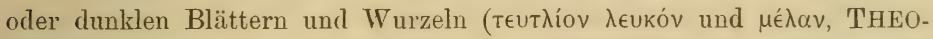
PHRAST; ähnlich bei DIOSKORIDES und PLINIUS); sie afsen sowohl die Blätter als die Wurzeln. Beides geschieht auch noch jetzt. Die Pflanze, deren Blätter als Gemüse gegessen werden, pflegt man Mangolt zu nemnen; ein althochdeutscher Name ist bieza (GRAFF, Spr. 3, 233).

Die verschiedenen Pflanzen, deren Blätter als Gemüse (Spinat) gegessen werden, die Spinatpflanzen, wurden nun schon sehr früh miteinander verwechselt. So finden wir für beta die deutschen Namen Kraut, Kohl, römischer Kohl und Melde; ferner werden beta (peta) und blitum oder blitus als gleichbedeutend behandelt (ALBERTI's MAGNUS 6, 292), und diesem Umstande ist es wohl zuzuschreiben, dass statt beta auch bleta ${ }^{1}$ ) geschrieben wird (Königsb. Gloss.). Endlich wird beta mit britanica identificiert (Colm. Gloss. Bertannica bete 116; Brittannica bete 146); dies Wort bedeutet den Wasserampfer (Rumex aquaticus L.), der früher bei uns gegessen zu sein scheint.

Blidas Capitulare 70,55; Amarantus Blitum L., Amarant.

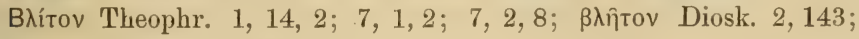

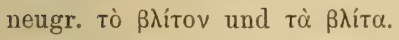

Blitum Plin. 20, 22, 93 und sonst; it. blito, biedone; fr. poirée.

Der Amarant stammt wahrscheinlich aus dem südlichen Europa

$\left.{ }^{1}\right)$ Im Colmarer Glossar steht Bleta sture (121); das Wort stur bei der heiligen Hildeg.ARD $(1,197)$ könnte also vielleicht beta bedeuten; es wird aber häufiger blitus durch stur ïbersetzt (Sum. 21, 37; 54,49; Königsb. Gloss.), und es ist wahrscheinlicher, dass bei der heiligen HiLdegard Blitum gemeint ist.

v. FISCHER-Benzon, altd, Gartenfiora. 
und den östlichen Mittelmeerländern. Friiher wurde er rielfach gebant. Sein ältester deutscher Name scheint stur oder sture zu sein (Königsh). u. Colm. Gluss., Sum); im 16. Jahrhundert hiess er Meier, Meyer; aber mit dem Aufhören seiner Kultur sind diese Namen in Vergessenheit geraten. In Deutschland kommt er wohl nur noch als Ruderalpflanze ror.

Im 16. Jahrhundert wurden auch rot- und buntblättrige Arten des Amarants unter dem Namen Blitum, Blitum rubrum gebaut (CAslERarits, Hortus medicus S. 29; Tabernaejontaxus 2, S. 147). Durch diese Arten wurde die Terwechselung mit Mangolt und Gartenmelde noch befördert.

Alle bisher genannten Spinatpflanzen wurden mehr und mehr bei Seite gedrängt durch den Spinat, Sprinacic oleracen L., dessen Heimat der Orient und das Innere Westasiens ist. Die Alten kannten ihn nicht. Zum ersten Male erwähnt finden wir ihn bei ALBERTUS MAGNC's $(6,434)$, ler ihn oder seine Blätter spinachic nemnt, und der auch seine stacheligen F'rüchte kennt. Im 16. Jahrhundert hiess er lateinisch spinachir und Spinacia, deutsch Spinat und Binetsch. Der persische Tame rles Spinats, aspanakil, isfoniudj oder ișinâulj ist fast unverändert ins Neugriechische übernommen, тù $\sigma \pi \alpha v a ́ k i \alpha$, und bildet gleichfalls die Grundlage für das italienische spinace und das französische épinard (urspruinglich espinaces; durch falsche Etymologie unter Anlehnung an épine, Stachel oder Dorn, wurde daraus épinard). - Auf welchem IVege der Spinat nach Europa gekommen ist, wissen wir zur Zeit nicht genau; es ist nicht unmöglich, dass die Kreuzfahrer ihn mit heimgebracht haben.

Man lat auch den Versuch gemacht, die bliclas des Capitulare zu deuten durch

Blitum virgatum L., den Erdbeerspinat.

Hierbei hat man aber ïbersehen, dass diese Pflanze erst seit den letzten Jahren des 16. Jahrhunderts, ja in weiteren Kreisen erst seit dem Anfang des 17. Jahrhunderts bekannt geworden ist. Die erste Nachricht darüber finden wir bei CAROLUS CLISIL's in seiner „Rariorum Plantarum Historia", Antwerpen 1601, S. CXXXV. ${ }^{1}$ ) Clusites giebt eine gute Abbildung rou der Pflanze, die er Atriplex syliestric lunijera nemint, also „Beeren tragende wilde Melde“. Er bemerkt, dass er diese zierliche (elegans) Pflanze in Spanien während seiner Reise nicht lemerkt habe, sie sei ihm aber von seinem freunde Jacob Platean, der sie aus spanischem Samen gezogen habe, in getrocknetem Zustande mach Frankfurt geschickt, begleitet von einer Zeichnung und einer Beschreibung. Eine ähnliche Pflanze versichere der Arzt Wilhelm ron II era im Jahre 1593 in Tirol gefunden zu hahen; diese sei Ende Angust mit Früchten überladen gewesen, die durch ihre S'chönheit fürm-

1) Das Buch hat zwei verschiedene Paginierungen: S. 1-364 umfassen die 3 prsten Bücher, S. I-CCCLVIII die Iet»ten. 
lich zum Essen eingeladen hätten. Ausserdem sagt CLLsius, dass er in Leyden (wo er seit 1593 Professor der Botanik war) Exemplare der Pflanze besässe, die im Jahre 1595 aus Samen aufgegangen seien, den er aus der getrockneten spanischen Pflanze herausgeschüttelt habe; die jungen Pflanzen hätten den Winter überdauert und im folgenden Jahre üppig Früchte getragen, wären aber bei Beginn des Herbstes vertrocknet.

In seiner Pinax Theatri botanici von 1623 nennt C. BAUHIN die Pflanze Atriplex sylvestris mori fructu, wilde Melde mit Maulbeer- (oder Himbeer-) früchten, also Maulbeermelde; als einziges Synonym giebt er den oben angefïhrten Namen von CLUSIUS an. Da C. BAUHIN über eine ausserordentliche Litteraturkenntnis verfügte, so dürfen wir annehmen, dass vor CLusius niemand die Pflanze erwähnt hat, wenigstens nicht so beschrieben hat, dass man sie hätte erkennen müssen. Fon Leyden aus hat der Erdbeerspinat dann, wie so viele andere Pflanzen, seine Wanderung in die botanischen Gärten Europas, und ron da in die Privatgärten angetreten.

Die Alten haben den Erdbeerspinat nicht gekannt, denn eine Melde, die maulbeerartige Frïchte trägt, wäre ihrer Aufmerksamkeit sicher nicht entgangen. Da die Kräuterbücher ilın aber auch nicht zu erwähnen scheinen, so kommt man zu dem Schluss, dass er überhaupt keine europäische Pflanze sein kann. Aber woher ist er gekommen?

\section{Kreuzkümmel, Kümmel und Schwarzkümmel.}

Ciminum Capitulare 70, 12; Cuminum Cyminum L., Römischer Kümmel, Kreuzkümmel, Pfefferkümmel.

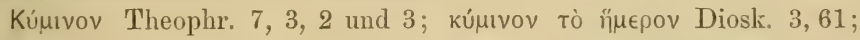
neugr. kúmıvo.

Cuminum Colum. 10, 245; cyminum Colum. 7, 13, 2; cuminum Plin. $20,15,57$; it. comino, cimino; fr. cumin.

Der römische Kümmel oder Pfefferkümmel, in alten Zeiteu kemen, comyn etc. genannt, hat in Norden Deutschlands einen besonderen Anbau kaum jemals erfahren; in Mittel- und Süldeutschland scheint es mehr der Fall gewesen zu sein. In Italien und Griechenland werden die Samen vielfach aus dem Orient bezogen. War früher eine sehr geschätzte Arzneipflanze.

Careium Capitulare 70, 14; Carum Carvi L., Kümmel.

Kápos Diosk. 3, 59.

Careum Colum.; Plin. 19, 8, 49; it. carvi, comino tedesco; fi. carvi.

Zum Unterschiede vom Kreuzkümmel ist dieser Kümmel auch Feldkïmmel, Wiesenkümmel etc. genannt worden. Er wird in Norddeutschland viel als Brotwürze benutzt, gelegentlich auch seiner Wurzeln wegen gebaut. Die Art seines Vorkommens in der Provinz SchleswigHolstein macht es wahrscheinlich, dass er dort nicht inlïndisch, sondern 
eingeführt ist; das Klima bekommt ihm jedoch sehr gut und er droht stellenweise, wie in der Marsch, ein gefährliches Wiesenunkraut zu werden.

Git Capitulare 70,25; Nigella sativa L., Schwarzkümmel.

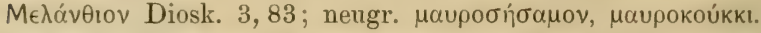

Melanthium Colum. 10, 245; git Colum. 6, 34, 1; Plin. 20, 17, 71; it. gittone, nigella, nigella muda, cominella, melanzio domestico; fr. nielle.

Der Schwarzkümmel wird in Griechenland noch hente gemischt mit Sesamkörnern auf Brot gestreut. Schon DIOSKORIDES giebt an, dass der Same ins Brot geknetet wurde, und als Brotwuirze ist er auch noch später benutzt worden, wie aus dem alten Namen "Brodtwurz" herrorgeht. Später hat man diese Anwendung mebr und mehr vergessen. Im 16. Jahrhundert heisst der Schwarzkümmel schwarzer Koriander; ausser Melanthium und Git wird er auch Nigella genannt.

Wie schon TaBernaejontanus klagt, ist der Same des Schwarzkümmels mit dem der Kornrade (Agrostemma Githago L.) vielfach verwechselt worden, wahrscheinlich weil Git oder Gith und Nigella beide mit Raden (d. h. Unkraut) übersetzt wurden (Königsb. und Colm. Glossar). ALBERTUS MIAfrats beschreibt mter nigella $(6,396)$ unverkennbar die Kornrade Agrostemma Githago L. (vergl. oben S. 85); dagegen ist die ratde der heiligen HILDEGARD $(1,12)$, die dem Menschen Kopfschmerzen macht, dem Vieh nichts nützt, aber auch nicht viel schadet, und die schliesslich als Fliegengift empfohlen wird, der Taumellolch, Lolim temulentum L.

\section{Fenchel, Dill, Anis und Koriander.}

Fenicolum Capitulare 70,36; Anethum Foeniculum L., Fenchel.

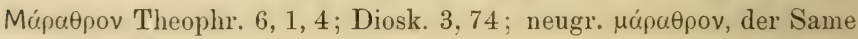
марияро́оттороц.

Foeniculum Colum. 6, 5, 2, auch marathrum 12, 35; feniculum Plin.; it. finocchio, finocchio dolee, finocchione; fr. fenouil.

Der Fenchel wird in Süddeutschland noch viel gebaut; dort werden seine Samen auch als Gewürz an das Brot gethan. In Norddeutschland sind diese Samen nie sehr beliebt gewesen, wohl aber gehören seine Blätter zu den Kräutern, die an die Aalsuppe gethan werden. Als Heilmittel war der Fenchel früher sehr geschätzt; TABERNAEIONTANUS braucht mehr als zwölf Folioseiten, um seine Heilkräfte und die aus ihm bereiteten Arzneimittel zu schildern.

Anetum Capitulare 70, 35; Anethum graveolens L., Dill.

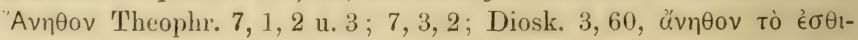

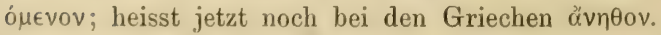

Anethum Colum. 10,120; 11, 3, 42; anetum Plin. 19 und 20 an vielen Stellen; it. aneta, aneto, neto; fr. anet. 
Stammt aus Siideuropa und kommt in Griechenland in einer kleineren Abart wildwachsend vor (Anethum segetum); aus deu Apotheken ist der Dill verschwunden, wird aber in den Gärten sehr viel gefunden, wo er sich meist selbst sät.

Anesum Capitulare 70, 19; Pimpinella Anisum L., Anis.

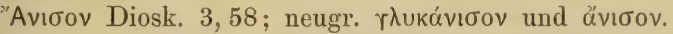

Anisum Aegyptiacum Colum. 12, 15, 3; 12, 51,2; anisum Plin. 20, 17, 72; it. aniso, granelli d'anice; fr. anis.

Eine früher sehr beliebte, aus dem Orient stammende Nutzpflanze, die teils als Arzneimittel, teils als Gewürz in der Küche benutzt wurde. Spuren ihrer Kultur hier im Norlen haben sich nicht erhalten.

Coriandrum Capitulare 70,69; Invent. II, 22; coliandrum Invent. I, 15 ; Coriandrum sativum L., Koriander.

Kopíavvov Theophr. 7, 1, 2; 7, 5,4; kópıov Diosk. 3, 64; neugr.

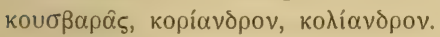

Coriandrum Colum. 6, 33, 2; 10, 244; 11, 3, 29; Plin. 20, 20, 82 ; it. coriandolo, coriandro; fr. coriandre.

Der Koriander hat seinen lateinischen Namen im Deutschen fast unverändert behalten. Früher wurde er in der Apotheke viel gebraucht und scheint auch in Apothekergärten kultiviert worden zu sein, von wo aus er gelegentlich verwildert gewesen ist, ohne sich jedoch zu halten. In Gärten begegnet man ihm nicht. - Die sogenannten Aniskügelchen, die fruiher in den Apotheken gehalten wurden und jetzt bei den Konditoren zu verschwinden beginnen, enthalten keinen Anis, sondern Koriandersamen.

\section{Würzpflanzen aus der Familie der Labiaten.}

Salbei, Muskatellersalbei, Basilikum, Bohnenkraut, Thymian, Majoran, Lavendel, Rosmarin, Melisse und Ysop.

Salviam Capitulare 70,5; Invent. I, 8, II, 9; Salviu officinalis L., Salbei, "smalln Sofie".

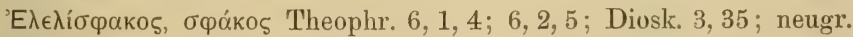
$\dot{\alpha} \lambda_{1} \varphi \alpha \sigma \kappa \eta \underline{\alpha}$ (v. Heldreich).

Elelisphacos, sphacos, salvia Plin. 22, 25, 71; it. salvia; fr. sauge.

Der Name ė $\lambda \in \lambda i \sigma \varphi \alpha \kappa o s$ bei THEOPHRAST bezieht sich wahrscheinlich nicht auf unseren Salbei, Salvia officinalis L., sondern auf andere in Griechenland wachsende Arten, wie Salvia calycina Sibthorp und S. triloba L. Da COLunELla keinen Salbei kennt, so scheint er erst spät Kulturpflanze in Italien geworden zu sein. In Deutschland fand er sich früher fast in jedem Garten und wurde als Gewuirz- und Heilpflanze sehr geschätzt; sein gewöhnlicher lateinischer Name war salvic; bei der heiligen HILDEGARD heisst er auf deutsch selba $(1,63)$, bei KONRAD VON MEGENBERG salvei $(5,76)$. 
Sclareiam Capitulare 70,72; Invent. II, 13. Salvia Sclarea L., Muskatellersalbei, Muskatellerkraut, Gartenscharlach; daneben auch Salvia Horminum L., Scharlachsalbei.

"Opuivov Diosk. 3, 135. ${ }^{1}$ )

Der Muskatellersalbei wird von den Italienern mit sehr vielen Namen bezeichnet: erba moscadella, erba san Giovanni, gallitrico, sicarlea, scarleggia, sclarea etc.; der Scharlachsalbei heisst bei ihnen gallitrico und ormino. Beide Pflanzen sind früher vielfach als Arzneimittel benutzt worden. Von der ersten führten die Apotheken Herba Sclareae s. Hormini sativis. Gallitrichi, ron der zweiten Herba Hormini s. Gallitrichi. Daneben wurden beide als Würze für Bier und Wein verwendet. Verwechselt sind beide Pflanzen auch, wie schon die Namen zeigen. Thre Terbreitung in den Gärten scheint verschieden zu sein, doch ist bisher nicht genügend darauf geachtet worden; der Muskatellersalbei scheint nicht sehr weit nach Norden vorgedrungen zu sein.

Das Wort sclareia oder scharleye (Scharlach) wird ausser den beiden obengenaunten Pflanzen noch verschiedenen anderen beigelegt; im Königsberger Glossar und vielleicht auch in den Sumerlaten (lofrago, scarleige 55, 14) wird damit.

Borrago officinalis L., der Boretsch, bezeichnet, der den Namen Scharleye sonst nicht zu führen pflegt. ALB̈ERTUS MAgivus, der ihn horago nennt, giebt ron ihm eine selır eingehende und merkwürdige Beschreibung $(6,291)$. Der Boretsch stammt aus dem Orient und wurde früher viel gebaut; seine Blätter schmecken nach Gurken und werden deshalb noch vielfach gehackt und unter den gewöhnlichen Salat gemischt.

Ocimum Basilicum L., Basilikum, Basilie.

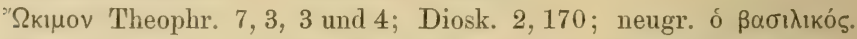

Ocimum Colum. 11, 3, 29, Plin. 19, 6 an vielen Stellen und sonst; it. bassilico; fr. basilie, herbe royale, oranger des savetiers.

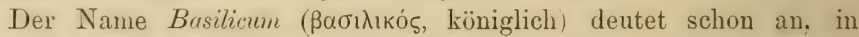
welchem Ansehen diese Gewürzpflanze seit alten Zeiten gestanden hat. Sie wird in sehr vielen Spielarten gezogen; ausser der oben genannten Art knmmt auch noch das kleinere und besonders wohlriechende Ocimum minimum L. vor. Beide werden schon bei ALBERTUs Magits $(6,293)$ uriter dem Nameu basiliron erwähnt. Da die Pflanze aus Indien stammt, () ist ihre Kultur mit Schwierigkeiten verbunden, wie schon TABERNAEMONTANC's angiebt; sie ist deshalb mehr Topfpflanze als Gartenpflanze gewesen, kommt aber noch hier in (der Provinz als Gartenpflanze *) vor,

1) Das öputvov des Theopmast $(8,1,4 ; 8,7,3)$ kann nach dem, was darïber gesagt wird, eine Salbeiart nicht sein, ebensowenig das horminum des Pursus (18, 10, 22; 22, 25, 76), der offenbar von THeоpmast abgeschrieben hat.

$\left.{ }^{2}\right)$ Das Basilikum, das zu den sogenannten Aalkräutern gehört, ist auf dem Gemüsemarkte Kiels selten und theuer, weil es hier keine Samen reift, der Samen also jedes Frühjahr neu bezogen werden muss. - „Aalkräuter" werden mehrere ge- 
namentlich in der Elbmarsch, wo sie den Namen "Brumsilk" (Entstellung aus Basilicum) führt.

Satureiam Capitulare 70,40; Invent. I, 9; II, 10; Satureja hortensis L., Bohnenkraut, Saturei, Köll, Pfefferkraut.

Satureja Colum. 10,233; 11, 3, 57; thymbra vel cunila nostras (quam saturejam rustici vocant) Colum. 9, 2, 4 und 6; cunila, satureia Plin. 19, 8, 50; it. coniella, cunilia, santoreggio; fr. sarriette.

Das Bohnenkraut kommt in Griechenland, wie es scheint, nicht vor, ist aber in Italien häufig und hat von dort seine IVanderung in unsere Gärten angetreten. Bei der heiligen HILDEGARD heisst es satereia $(1,155)$, bei ALBERTUS MA(rNUS $(6,449)$ saturegia, bei KONRAD VON MEGENBER(i saturegia und veltisp $(5,73)$; in den Glossaren wird es ausser satureia auch conula, dentsch conele, und timbra genannt. Es ist noch immer ein Gartengewächs, das als Würze an mancherlei Speisen benutzt wird.

Möglich ist es, dass die thymbra ( $\theta \dot{\mu} \mu \beta \rho \alpha)$ des DIOSKoRIDEs hierher gehört, aber es lässt sich nicht mit Sicherheit entscheiden.

Nach Ausweis der Glossare ist das Bohnenkraut mit anderen Gewürzkräutern aus der Familie der Labiaten, wie Thymus und Origanum, verwechselt worden, die genannten beiden wieder mit anderen.

Thymus vulgaris L., Garten-Thymian.

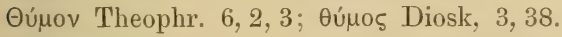

Thymum Colum. 11, 3, 39, Plin. 21, 10,31; it. timo; fr. thym.

Stammt ans Südeuropa und ist gegenwärtig eine weit verbreitete und beliebte Gewürzpflanze, die bei uns allerdings nicht die Grösse erreicht wie in ihrer Heinat. - Der Feldthymian heisst bei den Griechen

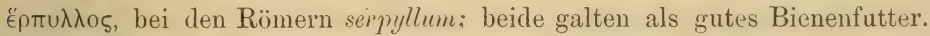
Besonders interessant sind THEopHRasts Bemerkungen über den Feldthymian $(6,7,2$ und 5$)$.

Origanum Majorana L., Majoran.

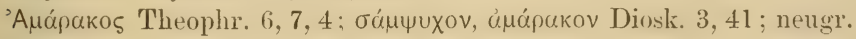

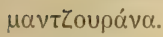

Sampsucum, amaracus Colum. 10,171 und 296; amaracum, sampsuchum Plin. 21, 11, 35; it. amaraco, maggiorana, samsuco; fr. marjolaine.

Der Name Majoran scheint erst relativ spät aufgetreten zu sein (ALBERTUS MAGNUS 6, 384: maiorana), ist aber, wenigstens in Deutsch-

wïrzreiche Kräuter genannt, die in gehacktem Zustaude einen Bestandteil der „Hamburger Aalsuppe" bilden; dahin gehören ausser Basilikum noch Fenchel, Kerbel, Majoran, Melisse, Petersilie, Pimpernell (oder Bibernell, Poterium Sanginsorba L., im 16. Jahrhundert klein welsch Bibernellen, klein Sperbenkraut und Pinpinella italica minor genannt), Portulak, Raute, Thymian, Trippmadam (Sedum reflexum L.), Sauerampfer und Schnittlauch. 
land, gegenwärtig der allein gebräuchliche. Der Mrajoran stammt aus Nordafrika und kommt deshalb in Griechenland und Italien auch nur kultiviert ror.

Der Majoran wurde mit Arten ron Lavendel ${ }^{1}$ ) verwechselt, ursprüng-

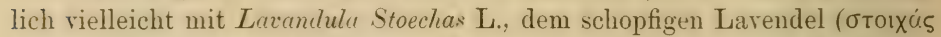
Diosk. 3.28), der in Griechenland und Italien wild wächst. Das Wort stycalos bei ALBERTUS MAGNLS $(6,433)$, ebenso wie sticalos im Königs-

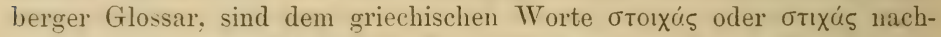
gebildet; die ron ALBERTIS MAdinL's gegebene Beschreibung passt aber schon recht gut auf

Lavandulı Spica L., den gewöhnlichen Lavendel unserer Gärten. Dieser scheint den Alten nicht bekanut gewesen zu sein, oder er ist von ihnen unbeachtet geblieben, obgleich er in Südeuropa zu Hause ist. Bei der heiligen HILdegard $(1,35)$ heisst er lavendula. Im 16. Jahrhundert war er schon sehr bekannt und wurde in rerschiedenen Arten und Spielarten gezogen. Am häungsten ist wohl die schmalblättrige Art (Lacandula offrimulis Chaix), die früher kaum einem einzigen Bauerngarten Norddeutschlands fehlte und auch in städtischen Gärten häufig war. Die Blütenähren wurden mit den getrockneten Blättern der Centifolie schichtweise in Vasen gebracht und Kochsalz und Gewürz dazwischen gestreut: die so erhaltene Masse, „Potpourri“, war ein beliebtes Räuchermittel, das im Winter auf den heissen Ofen gebracht, die Zimmer mit einem feinen und angenehmen Duft erfüllte. - Der Lavendel wird im heutigen Griechenland unter dem Namen $\lambda \in \beta \alpha ́ v \tau \alpha$ kultiviert.

Rosmarinum Capitulare 70, 13; Rosmarinus officinalis L. Rosmarin.

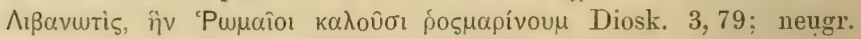

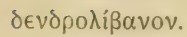

Ros marinus Colum. 9, 4, 2 und 6; ros marinum Plin. 24, 11, 59; it. ramerino, rosmarino; fi. romarin, libanotis, anthos. ${ }^{2}$ )

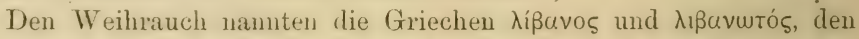

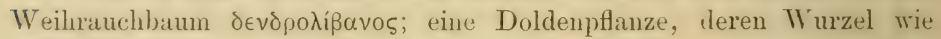

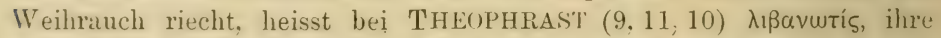
F'rucht kúxpus (wahrscheinlich Cuchrys cretica Lam. orler wie die erste

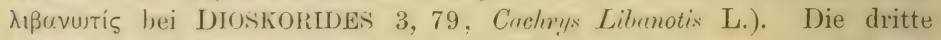
Libanotis des Duskorides (3,79), die nach ihm von den Römern ros murinus genannt wird, ist nach der gegebenen Beschreibung offenbar unser Rosmarin; dieser führte bei den Römern auch die Namen ros (Verg. Georg. 2, 213; Aen. 6, 230) und ros maris (Ovirl, Metam. 12, 410. Ars an. 3, 690), und wurde als Krimzptlanze benutzt. Dem praktischen CofidelaA ist er ein gutes Bienenfutter. Spröter verwandte man deu

1) CGL 11 : samsuco . i . leundola 577, 22; leuindola samsucus 592, 27; 595, 13; sansucus idest liuendola 629,5. - Samsucus, lauendel (Sum. 40, 52).

2) In der älteren Medicin hiess der Rosmarin auch Anthos. 
Rosmarin als Ersatz für den Weihrauch und dadurch erhielt er den Namen dendrolibanon, ${ }^{1}$ ) den er in Griechenland noch jetzt führt.

Der Rosmarin ist in Deutschland eine sehr geschätzte Pflauze gewesen, aber als eigentliche Gartenpflanze gedeilht er an den meisten Stellen nicht; man zieht ihn deshalb in Töpfen. In Griechenland und Italien kommt er wild ror, wird aber auch viel in Gärten gezogen.

Melissa officinalis L., Melisse; Citronemmelisse. Citronenkraut.

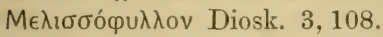

Apiastrum, melissophyllum Colum. 9, 8, 13; 9, 9, 8; melissoplyyllum, melittaena Plin. 21, 20, 86; it. melissa, cedronella; fr. mélisse.

Die Melisse war bei den Alten ein sehr geschätztes Bienenfutter; auch war nach ihrer Meinung der Geruch der Melisse den Bienen angenehm und deshalb rieb man die Bienenstöcke, in die ein neuer Bienenschmarm hineinsollte, mit den Blättern der Melisse aus. Als Arznei gebrauchte man sie auch.

In Norddentschland wird die Melisse, die in Siuddeutschland und Norditalien heimisch ist, in Gärten als Würzkraut oder auch nur ihres Geruches wegen gebaut.

\section{Endlich mag noch}

Hyssopus officinalis L., der Ysop, angeführt werden. Da er in Italien, wo er wild rorkommt und auch in Gärten gezogen wird, isopo heisst, so wird er wohl idontisch mit dem hyssopus des COLt MELLA (12,35), der

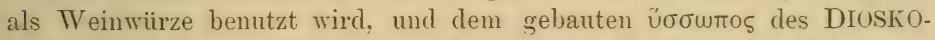
$\operatorname{RIDES}(3,27)$ sein. Die heilige $\operatorname{HILDEGARD}(1,65)$ nent ihn ysopus und hyssopus. ALBERTts MAGNes $(6,477)$ ysopus, KOxRAD VoN ME(rExBERG $i s p(5,45)$. Wurde frihher in Norddeutschland viel in Gïrten gebaut und findet sich dort anch noch. allerdings seltener.

\section{Zwiebeln und Lauch.}

Zwiebeln und Lauch sind sehr alte Kulturgerächse. Sie sind auf egyptischen Wandgemälden dargestellt und werden in der Bibel (4. Buch Mose 11,5), hei HOMER (Il. 11, 360; Od. 19. 232), HERODOT etc. erwähnt. Pflanzen, die so lange der Züchtung unterworfen gewesen sind, pflegen stark zu variieren, und in der That zeigen unsere Küchengärten aut diesem Gebiet eine ungeheure Mannigfaltigkeit. Sehr be-

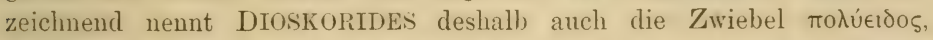
Vielgestalt $(2,180)$; ron ihm wissen wir, dass die griechischen Namen

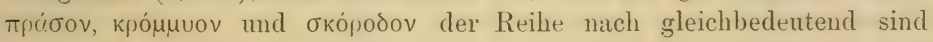

1) CGL II: $\lambda_{\imath} \beta \alpha v \omega \tau$ тó rosmarinus et tus 264,64 ; lentrolibanum rosmarinum อ68, 3; 57ら, 31; 613,36; das lentro ist durch einen Lesefehler entstanden: $\Delta$ wurde für $\wedge$ gehalten, was bei geschriebenen Buchstaben gewiss leicht möglich ist. - Ein anderes Surrogat für den Weihrauch war das Abrotanum, wie aus den Glossaren des ('GLm herrorgeht; dendro abrotano 545. 27; ilentrolihanus abrotanus 589,$44 ; 610,50$. 
mit den rïmischen porrum, cepa und allium, Namen, die sich im späteren Latein und im Italienischen mit geringfügigen Änderungen erhalten haben. Was wir uiber diese drei Pflanzen wissen, ist deshalb als ziemlich sicher zu betrachten. Für die übrigen Arten müssen wir aber vielfach bei Vermutungen stehen bleiben; ein Grund hierfür ist ausser in anderem auch in dem Umstande zu suchen, dass die Zwiebelarten unserer Küchengärten eine eingehende wissenschaftliche Untersuchung noch nicht erfahren haben.

Allium ascalonicum L., Schalotte, Aschlauch.

Ital. scalogna; fr. échalotte.

Die Schalotte wird gegenwärtig als feine Küchenzwiebel sehr geschätzt und in vielen Spielarten kultiviert. Sie wird nicht gesät, demn sie trägt in der Regel keinen Samen. Schneidet man aber eine Schalotte uner durch, so erblickt man bei den edleren Sorten auf dem Querschnitt 3-7 feine blaue Ringe mit zart gelblichgrünem Mittelpunkt; jede S'chalottenzwiebel besteht aus einer grösseren oder kleineren Zahl unentwickelter Individuen, die, wenn man die Nutterzwiebel in die Erde steckt, die gemeinsame Hülle sprengen und sich zu S'chalotten von normaler Grösse entwickeln. Im 16. Jahrhundert, z. B. hei CaSPar BaUHIN, heisst sie deshalb fruchtbare Ziviebel (cepa fertilis).

THEOPHRAST $(7,4,7$ und 8) spricht ron einer askalonischen Zwiebel. Diese kann aber unsere Schalotte nicht sein, denn sie wird gesät, spaltet sich nicht und setzt anch keine Brutzwiebehn an. Wir mïssen sie deshall) für eine Art Sommerzwiebel halten, ebenso wie die askalonische Zwiebel bei CoLumella $\left.(12,10,1),{ }^{1}\right)$ die in ihrer Eigenschaft mit der bei THEOPHRAST genannten genau übereinstimmt. Da nun zu Karls des Grossen Zeit andere als die von den Benedictinern aus Italien mit«el)rachten Zwiebehn wahrscheinlich nicht bekannt waren, so kömnen wir die ascalonicas oder ascalonicas cepas des Capitulare auch nicht als unsere Schalotte deuten.

Dazu kommt, dass sich in den älteren Pflanzenglossaren nichts findet, was sich als Schalotte deuten liesse, mur an einer Stelle im CGL III, 11ämlich 573,15, findet sich die Glosse palacolon . $i$. scalonia; hier darf man das erste Wort wohl als verschrieben ansehen für pallacana, das hei PIINius einmal vorkommt $(19,6,32)$ und von ihm als gleichherleutend mit getion (rífuov) genannt wird. Das getion der Griechen war aber, wenn wir ïherhaupt noch etwas Ähnliches kultivieren, unsere Winterzwiebel.

1) „Pompejanam, vel Ascaloniam cepam, vel etiam Marsicam simplicem, quam vocant unionem rustici, eligito: ea est autem, quae non fruticavit, nec habuit soboles "wharentes"; danach sind die drei genannten Zwiebehn als Spielarten oder Rassen einer und derselben Art zu betrachten, die, da sie sich nicht spaltet (verzweigt) oder keine Brutzwiebeln ansetzt, nur die Sommerzwiebel sein kann. 
Das Wort aschlovch kommt frühestens im 11. Jahrhundert vor (Vlt. S. 368: ascolonium aschlovch), im 12. Jahrhundert ist es häufiger. Die heilige HILDE(xARD $(1,80)$ hat aschalonia und alslanch, in den althochdeutschen Glossen Hoffmanns finden wir ascolimum und asclovch (7, 18 und 26,21), und hier wird an der ersten Stelle ausdrücklich hinzugefügt, dass ascolinum oder asolinum von der Stadt Ascalon kommen. In den Sumerlaten wird asclonium durch aschloveh übersetzt $(1,26)$, das schon stark entstellte astonium durch aschloch. Später werden die Entstellungen des Wortes immer grösser.

Ob diejenige Zwiebel, die aschlorch genannt wurde, unsere Schalotte ist, wissen wir nicht sicher. ALBERTUS MAGNUS hat leider nichts mitgeteilt, was sich als Schalotte deuten liesse, ebensowenig KONRAD VON IIEGENBERG. Käme das Wort aschlovch nicht schon in einer Handschrift des 11. Jahrhunderts vor (Vlt. ZfdA 3, S. $368 \mathrm{ff}$.), so würde man annehmen dürfen, dass heimkehrende Kreuzfahrer die Zwiebel mitgebracht hätten, und dann befände sich alles in der schönsten Klarheit; so aber sind wir noch sehr im Unsicheren.

Abbildungen und Beschreibungen, die zu der gegenwärtigen Schalotte leidlich stimmen, finden wir erst im 16. Jahrhundert. MATTIOLI lässt die einzelnen Zwiebeln seiner Caepa Ascalonia hasehnussgross sein; die Abbildung, die er (Comm. S. 420) giebt, könnte ein sehr junges Exemplar unserer Schalotte vorstellen, aber die Abbildungen, die MORISON (Plantarum Historiae universalis Oxoniensis Pars secunda, Oxonii 1680, Sect. 4 , Tab. 14, Fig. 3) und WeINiraxy (Phytanthozaiconographia, Bd. 2, Regensburg 1739, Taf. 349, b) von derselben Pflanze geben, sind auch nicht anders. Die Kultur miisste demuach während der letzten 150 Jahre einen bedeutenden Einfluss auf die Vergrösserung der Schalnttenzwiebel gehabt haben.

ALPH. 1)E CANDOLLE (Kulturpflanzen, S. 86-89) hält die Schalotte nicht für eine besondere Art, sondern für eine durch Kultur entstandene Rasse der Sommerzwiebel (Allium Cepa L.). Das wäre keineswegs unmöglich, denn wenn die Sommerzwiebel auch im allgemeinen aus einem einzigen Individuum besteht, so giebt es doch Fälle, wo neben einer grösseren Zwiebel eine oder mehrere kleinere sich vorfinden; und durchmustert man anderseits die verschiedenen Sorten der Schalotte, so findet man unter diesen solche, die der Sommerzwiebel sehr gleichen und nur aus sehr wenigen Teilzwiebeln bestehen.

Ist die Schalotte wirklich aus der Sommerzwiebel durch Züchtung entstanden, so bleibt es immerhin bemerkenswert, dass die neue Rasse den Namen der Stammart behalten hat.

Uniones Capitulare 70,58; ascalonicas cepas Capitulare 70,62 u. 63; scalonias cepas Invent. I, 16,17; repas scalonias Invent. II, 24, 25; Allium Cepa L., Zwiebel, Sommerzwiebel; Bolle, Zipolle. 


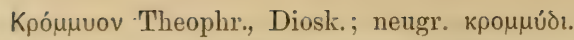

Cepa Colum. und Plin. mit vielen Beinamen; it. cipolla; fr. oignon.

Das Wort unio kommt bei COLUMIELLA $(12,10,1)$ vor und hat sich im Französischen (oignon) und Englischen (onion) erhalten; auch HENRTK HARPESTRENG (Dansk Lregebog, Kopenhagen 1826, S. 57): der die Zwiebel sonst cypul oder cipul nennt, sagt zu Anfang des Kapitels: ..cepa thiet ser micu"s, und ebenso gab es früher im Niederdeutschen ein Wort uniun (Mittelniederdeutsches Pflanzenglossar im Jahrb. d. Ver. f. nd. Sprachforschung, XVII, S. 81-84; cepe uniun 22). Unsere sïmtlichen, jetzt gebrauchten deutschen Namen sind jedoch dem italienischen cipolla, einem Diminutivum von cepa, nachgebildet.

Da ron der unio bei COLUMELLA $(12,10,1)$ ausdrücklich gesagt wird, dass sie sich nicht spaltet und keine Brutzwiebeln ansetzt, so ist es falsch, wemn man sie als Winterzwiebel deuten will, wie es von KERNER und MEYER geschehen ist. Nach dem, was bei der Schalotte gesagt ist, muss ascalonias cepas etc. auch eine Rasse der Sommerzwiebel sein; es ist dabei ziemlich gleichgültig ob man ascalonias oder scalonias mit cepa rerbinden will oder nicht. Die Sommerzwiebel wurde früher ebenso wie jetzt in zahlreichen Spielarten kultiviert.

Für uniones kommt im späteren Griechisch das 'Wort koukoußaí (DT CANGE) und какоußaı (CGL III, 359, 36) vor, das sich nicht weiter erhalten hat.

\section{Allizem fistulosum L., Winterzwiebel.}

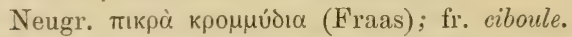

Ihre röhrigen Blätter werden im Frühjahr abgeschnitten und ersetzen daun frische Zwiebeln. Gegenwärtig wird sie viel weniger gebaut als die Sommerzwiebel. Sie kanu in dem cepa des Capitulare mit einbegriffen sein, aber sicher ist es nicht.

Vielleicht kannte man sie schon im Altertum. ${ }^{1}$ ) Das кpó $\mu \mu v o v ~ \sigma \chi_{1-}$ бTóv des THEOPHRAST $(7,4,7)$ liesse sich so deuten, mit mehr Recht viel-

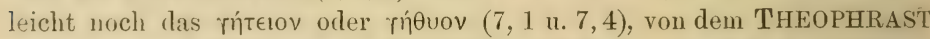
sargt, dass es hohlblüttrig sei $(1,10,8)$ und dass es mehrfach geschoren werte $(7,4,10)$. PLINIUS wiederholt ziemlich genau das von THEOPHliast Gesagte und bemerkt, dass diejenige Zwiebel, die bei den Griechen getion heisse, bei den Römern pallacanu genannt werde $(19,6,32)$. Bei ColdnistaA giebt es nichts, was sich auf die Winterzwiebel beziehen liesse.

Der Anbau der Winterzwiebel lässt sich im Mittelalter nicht mit Sicherheit nachweisen, aber auch in 16. Jahrhundert hat es noch

') Alrif. De CANpolt: bemerkt (Kulturpflanzen S. 86), dass die Alten die Winterzwiebel nicht kannten, und beruft sich dafür auf das Keugnis von Lenz. Dieser führt aber an der angezogenen Stelle (Botanik der Griechen und Römer S. 295) die Winterzwiebel unter denjenigen Alliumarten auf, die den Alten bekannt waren oder bekannt gewesen sein konnten. 
Schwierigkeiten; indessen lassen sich die von MATTIOLI im Commentar S. 420 abgebildeten Caepa sectilis und Caepa fissilis recht wohl als Winterzwiebel deuten.

Britlas Capitulare 70,59; brittolas Invent. II, 26; Allium Schoenoprasum L., Schnittlauch; Brisslauch.

Porrum sectivum, alterum genus Plin. 19, 6, 33.

Fehlt in Griechenland, heisst in Italien allio di serpe, cipollina, erba cipollina, porro settile; fr. ciboulette, civette.

Ist in Italien noch heutigen Tages sehr beliebt. Obgleich die Pflanze in Deutschland an verschiedenen Stellen vorkommt und daselbst als inländisch betrachtet wird, ist ihre Kultur doch erst von Italien aus zu uns gekommen. Sie heisst bei den Vätern der Pflanzenkunde pormu sectivum, sectile oder tonsile, was unserem Schnittlauch genau entspricht.

In den Glossaren des CGL III wird brittola ${ }^{1}$ ) erklïrt durch cepa (cip) oder ciba) mimuta $(587,49 ; 608,40)$ und cibula oder cibulla; beides bedeutet eine kleine Zwiebel; sniteloch und snitelouch kommen schon im 11. Jahrhundert als Übersetzung von pretula und brittula vor. Das prieslauch bei der heiligen HILDEGARD $(1,82)$ wird wohl als Schnittlauch zu deuten sein, der später, z. B. bei TABERNAEMONTANUs, Brifzlanch heisst.

Der Schnittlauch gehört im nördlichen Deutschland $z u$ den beliebtesten Laucharten und wird auch in Bauerngärten in Reihen und in Büscheln kultiviert.

Porros Capitulare 70,60; porrum Invent. I. 11 und II, 23. Allium Porrum L. Porree, Lauch.

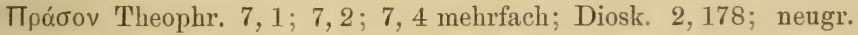
$\tau \grave{\alpha} \pi \rho \alpha \dot{\sigma} \alpha$.

Porrum Colum. 6, 4, 2; 11, 3, 30; Plin. 19, 6, 33; it. porro, porretta; fi. poirau, porreau.

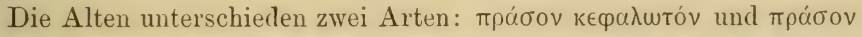
картóv, oder porrum capitatum und porrum sectivum. Die erste entspricht

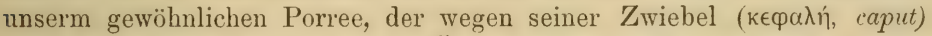
ebenso wie jetzt gebant wurde. Über die zweite Art wissen wir nicht sehr viel; sie wurde mehrmals geschoren. Ähnliches geschieht bei uns auch: man schneidet dem Porree die Blätter dann und wann ab in dem Glauben, dadurch grössere Zwiebeln zu erzielen. So ist aber das $A b-$ schneiden bei den Römern und Griechen nicht zu verstehen, sondern sie scheinen die abgeschnittenen Blätter als Gemüse gegessen zu haben.

Unter den Gemüsen des CGL III wird auch $\dot{\mu} \mu \pi \epsilon \lambda o ́ \pi \rho \alpha \sigma o v^{2}$ ) aufgeführt, das lateinisch aretillum genannt wird. In den Glossaren daselbst

1) Ausser brittola kommt auch der Name percula für Schnittlauch vor: Sumerlaten: percula snitloich (58,21); Königsb. Gloss.: percola sniteloc; Colm. Gloss: percula snêlôch (55̃).

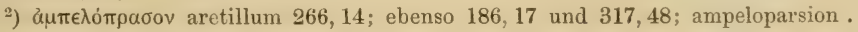
porrum agreste 549,35 ; $535,27$. 
wird dieselbe Pflanze formum agreste, also wilder Porree, genannt. Es ist dies das

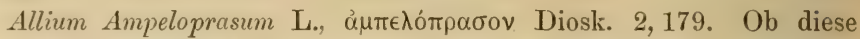
PHanze in Deutschland Heimatsrecht hat, ist zweifelhaft; in Italien kommt sie in Weinbergen etc. häufig ror, wird dort porrandello genannt und wie Knoblauch benutzt (BERTOLONI).

Schon LINNÉ hielt den Porree für eine Varietät seines Allium Ampeloprason (Spec. plant. ed. 2. Holmiae 1762, S. 423); J. GAY hat in einer Arbeit über Alliumarten, die vorzugsweise aus Algier stammten (Ann. d. sciences natur., botanique, 3. sér., t. 8, Paris 1847, S. 195-223). sich dieser Ansicht mit Bestimmtheit angeschlossen (a. a. O. S. 218). Unser Porree treibt gar nicht selten Brutzwiebeln, wie man bei sorgfailtiger Beobachtung finden wird, namentlich wenn die Porreepflanzen längere Zeit in der Erde stehen bleiben; das Fehlen der Brutzwiebeln lässt sich also gegen diese Auffassung nicht als Grund anführen.

Alia Capitulare 70,64; Invent. I, 12 und II. 27; Allium sativum L., Knoblauch.

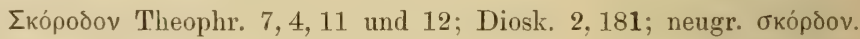

Allium Colum. 6, 4, 2; 10, 112 und 113; 11, 3, 20 und 21; Plin: 19, 6,34 ; it. aglio, aglio sativo; fr. ail.

THEOPHRAst unterscheidet mehrere Rassen des Knoblauchs, frühen und späten, kleinen und grossen; eine besonders grosse Rasse, der kyprische Knoblauch, wurde nicht gekocht, sondern zum Knoblauchbrei

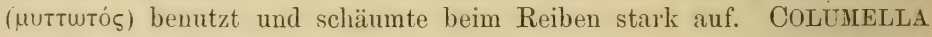
stellt jedesmal allium zusammen mit einem anderen Lauch, dem ulpicum

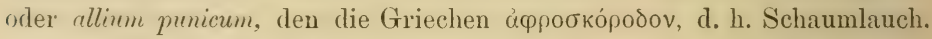
nennen. Die Zwiebel des ulpicum besteht ebenso wie die des Knnoblauchs aus einzelnen Teilzwiebeln (Knoblauchzehen, spierue, 6, 4, 2; 11, 3,21); das ulpicum macht sich weithin durch den Geruch bemerkbar (10,112 und 113) und wird ebenso behandelt wie der Ḱnoblauch $(11,3,21)$. Hieruach ist das ulproum entweder als eine Rasse des Knoblauchs, oder als eine ihm sehr nahestehende Art zu betrachten. Wir unterscheiden hente (nach Engler und Prantl, Pflanzenfamilien) beim Knoblauch zwei verschiedene Rassen, den eigentlichen Knoblauch (Allium sativum L., a. valgare Don) und die Perlzwiebel, rocambole (4. sativum L., b. Opliosrororlon Don), die auch noch andere Namen trägt; häufig heisst sie Schlangenlatuch (ophioscororlon; dieses Wort kommt schon bei DIOSKORIDES als Name des wilden Knoblauchs vor). Es liegt also nichts Gewagtes in der Annalıme, dass die Alten neben dem eigentlichen Knoblauch auch noch die Perlzwiebel gekannt haben.

Ob die beillen genannten Rassen des Knoblanchs ${ }^{1}$ ) zu allen Zeiten

1) Das Wort Knoblauch ist entstellt aus clobelouch, chlobeloch, das einen Iauch mit spaltharer Zwiebel bedeutet: Sum.: allium elobelouch 1, 25; 60,11; chlobeloch 
unterschieden worden sind, ist sehr ungewiss. In den Hermeneumata des CGL III finden wir das ulpicum unter den Gemüsen angegeben; ${ }^{1}$ ) ob es sich in den daselbst mitgeteilten Glossaren findet, ist zweifelhaft; ") dagegen wird hier der Knoblauch sehr häufig erwähnt unter den Namen allium, alius, alius ortulanus, alleus, scordon und scordion. Bei der heiligen HILDEGARD, bei AlBERTUS MAGNUS und KONRAD YON MEgENBERG scheint nur der Knoblauch allein genannt zu werden; später, eigentlich wohl erst nach dem 16. Jahrhundert, wird die Perlzwiebel wieder beruicksichtigt.

\section{Der Nachtschatten.}

Solanum nigrum L. (die Abänderungen oder nahestehenden Formen, wie s. lumile Bernhard, s. villosum Lam. etc. mit eingeschlossen), Nachtschatten, schwarzer Nachtschatten.

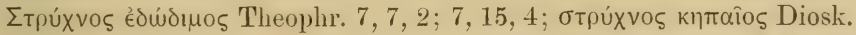

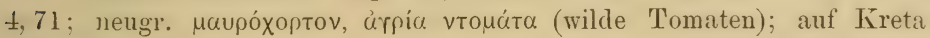
бти́ตvoร.

Solanum Plin. 27, 13, 108; it. morella, solano, solano nero, solano ortense, solatro, solatro ortulano, strigio, uva lupina; fr. morelle.

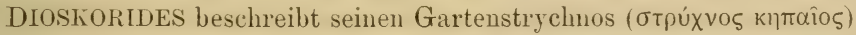
so genau, dass alle Ausleger darin den Nachtschatten erkannt haben; nur wunderte man sich darüber, dass DIOSKORIDEs ihn als Gartenpflanze und als essbar bezeichnete. Das letztere hielt man, da der Nachtschatten als giftig angesehen wird, für einen Irrtum, und das Wort

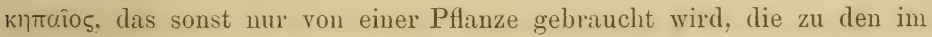
Garten kultivierten Gewächsen gehört, glaubte man hier als Bezeichnung eines Gartenunkrauts nehmen zu dürfen. Nun berichtet aber v. HELDREIC'H (Die Nutzpflanzen Griechenlands, Athen 1862, S. 79), dass nicht nur das Kraut des Nachtschattens in Griechenland als Gemüse gegessen wird, sondern dass sogar die roten oder schwarzen Beeren roh als Naschwerk verzehrt werden. Dieser Gebrauch muss sehr alt sein, demn da der Nachtschatten nicht sehr angenehm riecht, so würde die Mehrzahl heute geneigt sein, ihn für giftig zu halten, und ein solches Vorurteil lässt sich nur sehr schwer überwinden.

Der essbare Strychnos des THEOPHRAST, der auch roh gegessen wird, ist gleichfalls als Nachtschatten zu deuten, denn seine Frucht wird weinbeerenartig oder weintraubenartig ( $\rho \alpha$ fẃons) genannt; hätte THEOPHRAST das Solanum Melongenu L. gekamnt, das wir heute essbaren Nachtschatten (Eierpflanze) nemnen, und das sowohl in Griechenland wie

39, 63; clobeloich 53, 49; clufloc 65, 5; allium, scordium, wilde clobeloch 53, 37; Colm. Ġloss.: allium clufflôch 27, scordion clûflôch 666; marabatrum knûflôches bladere 465 ; tiriaca rusticorum knûflôch 735; Königsb. Gloss.: allium knoflok, ebenso bei Ione 22.

1) Afroscordon ulficu 185, 56; a

2) Asroscorde idest bulbicum 535, 9; aroscondon bubicum 549, 19. 
in Italien jetzt viel gebaut wird, so hätte seine Beschreibung wesentlich anders gelautet.

Der Nachtschatten ist also ursprünglich eine Gartenpflanze gewesen; im Laufe der Zeiten hat man seine Verwendbarkeit als Speisepflanze vergessen, hat ihn als Unkraut, darauf als Giftpflanze betrachtet und schliesslich aus dem Garten hinausgeworfen, so dass er jetzt Ruderalpflanze und Unkraut geworden ist. Als Heilpflanze ist er aber noch längere Zeit in Ansehen geblieben.

An spätlateinischen Namen ist der Nachtschatten reich. Das griechische strychnos wurde als strignus oder strignum übernommen, kam aber nachher in Vergessenheit. Uva lupina, Wolfstraube, ist ein häufiger lateinischer Name, ebenso maura, maurella und morella, mit dem wir jetzt eine dunkle Kirschenrasse bezeichnen, Schatten-Morellen; ferner finden sich solata, solatrum, millemorbia und erba ficaria. Bei der heiligen HILDEGARD heisst die Pflanze solatrum und nachtschade $(1,121)$ bei ALBERTL'S MAGNCS $(6,442)$ solatrum und uva lupi; hier werden zwei Arten unterschieden, eine mit citrongelben Beeren (uwa citrina), und eine mit schwarzen (ura nigra). Deutsche Namen sind nicht so zahlreich, was damit zusammenhängen mag, dass man der Pflanze im Laufe der Zeit allen Wert absprach. Ausser nahtscate, nachtscate, dem jetzigen Nachtschatten, findet sich luntespere, dem lateinischen uva canina entsprechend, und vielfach das ganz vergessene druswurz. ${ }^{1}$ )

Als Heimat des Nachtschattens werden wir das südöstliche Europa und den Orient zu betrachten haben.

\section{Obstbäume.}

\section{Apfel, Birne und Quitte.}

Pomarios dicersi generis Capitulare 70, 74; Invent. II, 29 ; pomarios Invent. I, 22 ; Pims Malus L., Apfelbaum.

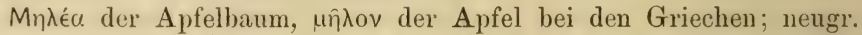
$\mu \eta \lambda \hat{\alpha} \alpha$ und $\tau \grave{\alpha} \mu \hat{\eta} \lambda \alpha$ (Äpfel).

1) CGL III: istrigno una lupina 632,29 ; 539,69 ; istrignus uua lupina 547,18 ; 5650 , 5fj; ،las vorgeschriebene $\mathrm{i}$ ist als der griechische Artikel $\dot{\eta} z u$ deuten (Dr. A. Fuxik); solata strignus 576,54 ; solata una lupina 577,21; sirugno uua canina 586,8); millemorbia . i maurella 5 650,67 ; maurella erba ficaria 592, 52; maurella milmorica erba firaria 592, 78. - Sum.: strignum nahtscate 63,70 ; solatrum uachtscate 50,61 ; solatrum huntespere 23, 63; maura drufsworz 62, 65; maura drufswurz 22, 70; morella druswr\% 63, 4; millemorbia druliswur\% 633, 10 etc. - Es wäre möglich, dass man a auch zur Bezeichnung der 'Tollkirsche (Atropa Belladonnc L.) gedient hätte. 
Malus und mahum ${ }^{1}$ ) bei den Römern; it. melo und mela, in der Lombardei pomar und pomo; fr. pommier und pomme.

THEOPHRAST giebt an $(3,3,2)$, dass Birn- und Apfelbaum in der Ebene bessere Früchte und besseres Holz liefern, als auf den Bergen; auf den Bergen wären sie klein, knotig und dornig; auch hat er die Erfahrung gemacht $(2,2,5)$, dass aus den Kernen der edlen Biruen, Äpfel und Quitten Büume erwachsen, die Früchte von sehr geringer Giite tragen. Heute gedeihen Birnen und Äpfel in Griechenland nicht besonders, im Gebirge findet man aber den wilden Apfelbaum und nach FRAAS (S. 73) auch einen verwilderten, der die Sommeräpfel, Honigïpfel ( $\mu \in \lambda i ́ \mu \eta \lambda \alpha$ DIOSKoRIDES 1,161 ; melimela PLINIUS 15, 14,15) trägt.

In Italien, wenigstens im nördlichen Teil, hat der Apfelbaum besseres Gedeihen gehabt und hat es zum Teil noch jetzt; auch hier giebt es wilde Apfelbäume (meluggino, melo salvatico). Die Römer kultirierten eine grosse Zahl von Rassen. CoLumeLLA $(5,10,19)$ zählt sieben auf, aber noch mehr finden wir bei PLINiUs $(15,14,14$ u. 15). Apfelwein zu bereiten wussten die Römer auch (PLINIUs 14, 16, 19), und ebenso verstanden sie das Pfropfen (inserere, insitio), auch geben sie verschiedene Unterlagen an, namentlich härtere für zarte Edlelreiser; bei der Angabe der Unterlagen sind sie aber nicht immer zuverlässig, demn bisweilen sollen als solche Stämme von Bäumen dienen, die den Obstarten verwandtschaftlich sehr fern stehen. Beispielsweise giebt PLiñus $(15,14,15)$ an. dass eine Apfelrasse ihre blutrote Farbe dadurch erhalten habe, dass sie auf schwarzen Maulbeerbaum gepfropft worden sei.

Zur Zeit Karls des Grossen sind verschiedene Apfelrassen kultiviert worden, von denen uns sogar die Namen überliefert sind, aber leider sind wir nicht in der Lage, sie mit den heute gezogenen Rassen zu identificieren (vergl. Anhang I, 3).

Im Althochdeutschen heisst der Apfelbaum apholtra, affaltra, bei der heiligen HIDDEGARD $(3,1)$ affaldra; der Apfel heisst im Althochdeutschen apfil.

Pirarios diversi generis ('apitulare 70, 75; Invent. II, 28; pirarios Invent. I, 21; Pirus communis L., Birnbaum.

"Orxvı Homer und Theophr.; ümos der Birnbaum, ümıv die Birne bei den Griechen; ùxpás der wilde Birnbaum einschliesslich Pinus salicifolia M. B. der in Griechenland sehr häufig ist und als Unterlage für edlere

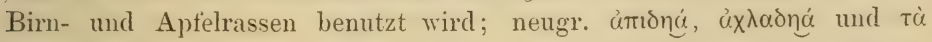

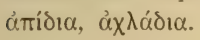

1) Das lateinische Wort malum bedeutet ursprünglich eine fleischige Frucht überhaupt, die im Innern Kerne hat, insbesondere deu Apfel; pomum, das Stammwort des französischen pomme, bedeutet wie das griechische ỏmípa Obst; im späteren Latein ist es allmählich auf die Apfelfrucht allein iibertragen worden, so dass pomarius Apfelbaum und nicht das allgemeine „Obstbaum" bedeutet.

v. Fischer-Benzon, altd. Gartenflora. 
Pirus und pirum der Römer; it. pero und pera, der wilde Birnbaum peruggino; fr. poirier und poire.

Der Birnbaum gedeiht in Griechenland nicht besonders gut, wenigstens nicht in der Ebene. Die Römer kultivierten viele Rassen und schon C'ATO $(7,4)$ führt deren eine ganze Menge an. Nach DIOsKorides (5.32) wurde aus Birnen ein Wein (〈mírn! oivos) gemacht, ähnlich wie aus Quitten, aus Johannisbrot ( Römer, Ceratonia Siliqua L.), aus Mispeln und Speierlingen.

Pirbaum, birbonm (bei der heiligen HILDEGARD 3,2) und lira sind die althochdeutschen Namen für den Birnbaum und seine Frucht, beide dem Lateinischen entsprechend. KONRAD VON MEGENBERG $(4 \mathrm{~A}, 39)$ spricht von pirpaum und pirn (Birnen). Im 16. Jahrhundert heissen die Frichte, z. B. bei Tabernaenontancs, Byren und Bymo, der Baum Bymbaum, dem unser jetziges Birnbaum entspricht.

Birnen und Äpfel werden bei uns in viel mehr Rassen kultiviert, als jemals im Altertum. Das Bestreben der Züchter ist gegenwärtig darauf gerichtet, Rassen hervorzubringen, die den verschiedenen Klimaten angepasst sind. also auch solche, die imstande sind selbst ein rauhes Klima zu ertragen. Als ein Beispiel hierfür möge auf den Åckeröapfel hingewiesen werden, der in Schweden gezïchtet wurde, alle Eigenschaften eines guten Apfels in sich vereinigt und doch in rauhen Lagen und unter ungiinstigen Verhailtnissen gedeiht (Dr. Neuberts Deutsches Gartenmagazin, Ill. Monatshefte für die Gesammt-Interessen des Gartenbaus, herausgeg. von Kolb, Lebl und Weiss, 1893, S. 65-67).

Cotoniarios Capitulare 70,81; Invent. I, 28, II, 36; Cydonia vmlgaris Persoon (Pirus Cydonia L.), Quitte.

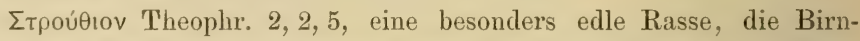

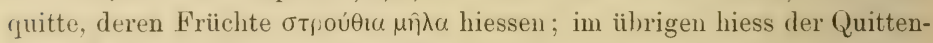

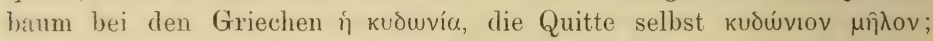

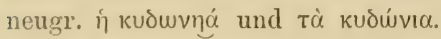

Mahum cotoneum Cato, Varro, Plinius; mahum cydonium Columella; it. der Batum cotogno, melo cotogno, die Frucht cotogna. mela cotogna, pera cotogna; fr. der Baum cognassier, die Frucht coin.

Die Kultur der Quitte reicht bis in sehr frühe Zeit zurück. Ihre Farbe trug ihr den Namen "goldener Apfel“ ein; ebenso wird ihr Duft vielfach gerïhmt. Ganz besonders wurde sie aber als Genussmittel geschätzt: man ass sie gekocht, bereitete daraus Wein (DIosk. 5, 28) und

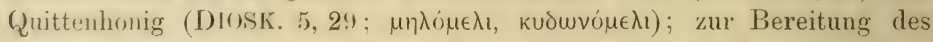
letzteren übergoss man entkernte (Quitten mit sehr viel Honig und liess die Masse ein Jahr lang stehen: damn glich sie dem Meth (oivó $\mu \in \lambda_{1}$ ). Die Alten kultivierten verschiedene Rassen, unter denen die Birnquitte

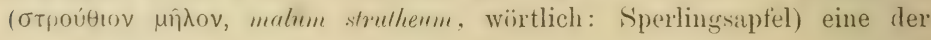
gesuclitesten war. 
In der späteren Zeit, vom 9. Jahrhundert unserer Zeitrechnung an odler auch schon früher, heisst der Quittenbaum cotanus, coctanus, cidonius etc. Sonderbarerweise heisst um diese Zeit seine Frucht „Krähenfuss", kopwvо́тоиц, coronopus ${ }^{1}$ ), vielleicht wegen der auf der Frucht sitzenbleibenden Kelchzipfel; dieser Name ist aber ganz in Vergessenheit geraten. ALBERTUS MagNus $(6,89 \mathrm{u} .90)$ nennt den Quittenbaum coctamus oder citonius und unterscheidet zwei Rassen, vou denen die eine birnförmige. die andere mehr kugelige Friichte trägt, Rassen, die noch heute bei uns kultiviert werden. Ganz ähulich ist es bei KONRAD VON MEgENBER(: (4 A, 13); dieser nennt den Baum cytonius oder cottanus, deutsch kiutenpaum, die Früchte pirn küten und gemain küten.

Der althochdeutsche Name der Quitte ist kutina, die heilige HILDEGARD spricht aber schon vom quittenbaum (3,4; quotanus); später heisst die Frucht Quitte, Quede, Kütte.

Nach den griechischen Schriftstellern stammt die Quitte von der Insel Kreta aus dem Gebiete der Kydonen; wir werden ihre Heimat wohl in den Orient verlegen dürfen. IVährend im südlichen Tirol der Quittenbaum die Grösse unserer Apfelbäume erreicht, bleibt er bei uns meist nur strauchartig; seine Friichte wurden früher auch hier im Norden sehr geschätzt, kommen aber nenerdings etwas seltener auf den Markt.

\section{Speierling und Mispel.}

Sorbarios Capitulare 70, 77; Surlus clomestica L., Speierling, Spierling.

"O $\alpha$ Theophr. 3, 12, 6-9; auch oỉ und ov̂ $\alpha$ geschrieben; die Frucht

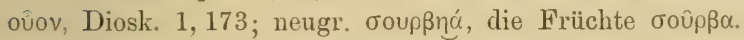

Sorbus bei den Römern, die Frucht sorbum; it. sorbo und sorba; fr. cormier und corme, ${ }^{2}$ ) sorbier und sorbe.

Der Speierling hat es in Deutschland kaum jemals zu grossem Ansehen gebracht, nach Norddeutschland ist. er überhaupt nur wenig oder gar nicht gekommen. Trotz seiner geringen Verwendung hat er doch eine Menge von Namen. Im späteren Latein wird er aesculus:3) und exculus genannt, doch nennt ALBERTUS MAGNUS (f, 224) ihn schon wieder sorbus. Deutsche Namen sind sperebcum, spirbaum, woraus später

1) CGLIII: cronopos . idest milicidonia 538,15 ; coronopus maledonia 631 , ว2, beide aus Handschriften des 9 . Jahrh.; cronopus mala cedonia 544,24 ; coronopodia . i . malacidonia 558,34 und sonst vielfach.

2) Diese Worte sind wahrscheinlich gebildet nach curmus, das bei Marcellus Empiricus (de medic. 16,33) denselben Baum bezeichnet (nach P. Geyer, Spuren gallischen Lateins bei II areellus Empiricus, im Archiv f. lat. Lexicographie, Jahrgang 8, S. 471).

$\left.{ }^{3}\right)$ Sperebovm-Aesculus, ahd. G1. 5, 36; esculus spirbovm, Sum. 45, 67; ebenso bei der heiligen Hildegard 3,8. - Almertus Magnus bemerkt $(6,133)$, dass der. Mispelbaum fälschlich esculus genannt wurde. - Das Wort aesculus bezeichnet bei Purvius $(16,6,8)$ eine Eiche mit essbaren Früchten; das entsprechende griechische TVort płrós (Theophr. 3, 8, 2) bedentet nach v. Heldreicil Quercus Aegilops L., 
Sperberbaum. Sperwerbaum geworden ist. Von den Schriftstelleru des 16. Jahrhunderts wird unser Vogelbeerbaum (Sortus ancuparia L.) als wilder Speierling bezeichnet.

Mespilarios Capitulare 70, 78; mispilarios Invent. I, 23; II, 30; Mespilus germanica L., Mispel.

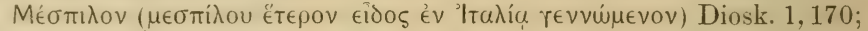

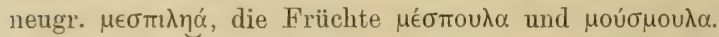

Mespilus setania Plin. 15, 20, 22; 23, 7, 73; die Frucht mespilum; it. nespolo und nespola; fr. nèflier und nèfle.

Die Mispel muss früher in grösserem Ansehen gestanden haben ils jetzt, wo sie, wenigstens in Norddeutschland, ihrer Früchte wegen kaum noch Beachtung findet, sondern meist als Zierstrauch gezogen wird. Sie ist sehr hart und trägt auch in rauhen Lagen Früchte; zu einer Zeit, wo das Obst seltener war, mag sie deshalb mit Recht geschätzt worden sein. ALBERTUS MAGNUS $(6,133)$ nennt den Baum mespilus. Der älteste deutsche Name ist nespelbaum ${ }^{1}$ ) (z. B. heilige HILDEGARD 3, 13); anch bei den Schriftstellem des 16. Jahrhunderts finclen wir denselben Namen wieder. Heute heisst er Mispelbaum. Im eigentlichen Griechenland kommt die Mispel nur kultiviert und überdies selten vor. In Italien und Südtirol wächst sie scheinbar wild; in diesem Zustande ist sie strauchig und stark dornig.

\section{Kirsche und Pflaume.}

Ceresarios diverwi generis Capitulare 70, 89; cerisarios Invent. II, 37: Prunus avium L., Siisskirsche; $P$. Cerasus L., Sauerkirsche, Baumweichsel; $P$. acida Dumortier, Strauchweichsel.

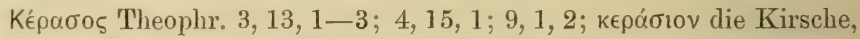

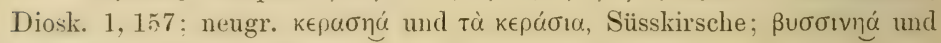

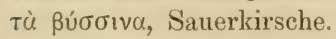

Cerasus der Römer, zuerst bei VARRO 1, 39, 2; it. ciregio, ciregiolo, Süsskirsche; amarasco, visciolo, Sauerkirsche; fr. cerisier, cerise und guignier, guigne.

Die Untersuchung ïber die Kirsche und ihre Verbreitung wird einigermassen dadurch erschwert, dass man über die Zahl der Arten und ihr natürliches Wohngebiet nicht vollkommen sicher orientiert ist.

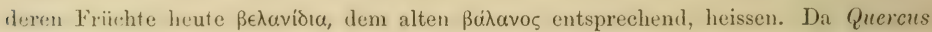
Aegilops in Italien nicht vorkommt, so muss unter aesculus eine andere Eiche verstanden sein, und zwar eine Form von Quercus Robur L. (E. H. L. Krause, Die indogermanischen Namen der Birke und Buche etc., Globus Bd. 62, 1892, No. 11, S. 162$)$.

$\left.{ }^{1}\right)$ Merkwürdigerweise scheint eine Verwechselung zwischen Mispel und Haselnuss vorgekommen zu sein: nespilun-Pontica gr., lat. avellana ahd. Gl. 5, 39; nespelun-Abellanae ahd. Gl. 6, 17; apellena mispilboim Sum. 53, 38; auch sonst mehrlach. 
Im Folgenden ist angenommen, dass Prunus acida eine selbstïndige Art und von $P$. Cerasus, der Sauerkirsche, verschieden sei; ${ }^{1}$ ) sie gilt als die einzige der drei oben genannten Arten, welche Ausläufer treibt, und ist eben daran leicht zu erkennen. Für unseren Zweck kommt von dieser Art nur die Varietiit Marasca Host in Betracht, die zur Bereitung des "Maraschino" dient und in Dalmatien und den Nachbargebieten wild vorkommt.

Nach der Erzïhlung des PLinius (15, 25, 30) soll Lucullus die Kirsche nach Rom gebracht haben; diese Nachricht ist aber unsicher. und es lässt sich aus ihr höchstens die Zeit der Einführung entnehmen, etwas vor der Mitte des ersten Jahrhunderts v. Chr. Dazu stimmt, dass die Kirsche zuerst bei VARRO erwähnt wird; die neue Obstsorte fand dann sehr günstige Aufnahme und wurde zugleich sehr rasch weiter verbreitet, so dass schon PLINIUs berichten konnte, sie gedeihe in Britamien, in Belgien und am Rhein. Der Oberrhein (Elsass und Baden) ist auch wenigstens e in Centrum für die Verbreitung der Kirschen in Deutschland gewesen und gehört gegenwärtig noch zu unseren reichsten Kirschenländern.

Weiter nach Osten muss man edlere Kirschenrassen früher gekamnt haben als in Rom. THEOPHRAST beschreibt den Baum, den er

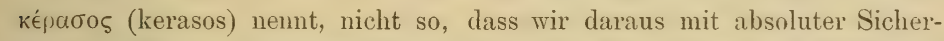
heit dịe Kirsche erkennen könnten, aber da Diphilos von Siphnos (hei Athen. 2, 51 b), der vor 281 v. Chr. gelebt hat, also ein Zeitgenosse

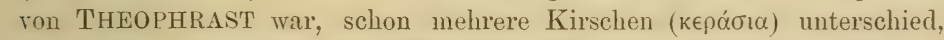
so wird man das képaбos bei THEOPHRAST wohl als Kirschbaum deuten mïssen. Aus der Beschreibung folgt dann aber, da der Baum schlank und hoch genannt wird, dass die Süsskirsche gemeint ist.

Dann würde also wohl die Süsskirsche nach Rom gebracht worden sein. Nach dem Namen müsste man es annehmen, denn die Namen der Süsskirsche sind in allen lebenden europäischen Sprachen direkt oder indirekt aus кépaбos oder cerasus abgeleitet, und weiter hin nach Osten heisst die Süsskirsche armenisch keraseni, kurdisch keras, ghelìs (harte und weiche Form desselben Wortes) tatarisch (in der Krim) kirës, (im Kaukasus) kiljus (F. TH. KÖPPEx, Geographische Verbreitung der Holzgewächse des europäischen Russlands etc., Bd. 1, St. Petersburg 1888, S. 281, 282). Wenn man aber diese Reihe von Namen ansieht, so kommt man unwillkürlich auf den Gedanken, ob denn кép $\alpha \sigma o \varsigma$ wirklich ein griechisches, und nicht vielmehr ein einer asiatischen Sprache, dem Eranischen oder Kurdischen, entlehntes Wort sei, wie KöPPEN andeutet (a. a. O. S. 282). Besondere Gründe sprechen nicht dagegen. im Gegenteil erscheint KöPPExs Annahme viel natürlicher als diejenige

1) Nach K. Koch, Dendrologie, Bd. 1, Erlangen 1869, S. 110 ff, S. 112 ff und E. Kоенne, Deutsche Dendrologie, Stuttgart 1893, S. 308. 
ron HEHs, der, gestiitzt auf das Zeugniss des Grammatikers SERrIL's, ${ }^{1}$ ) behauptet, die Alten hätten den Kirschbaum und den Kornelkirschbaum miteinander verwechselt, und der damn кє́paбos als die kleinasiatische

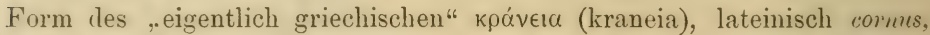

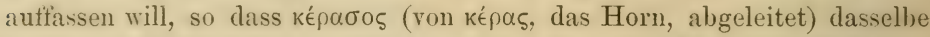
bedeuten soll wie das lateinische cornus (von cornu, das Horn); beide Namen sollen dam die horuartige Beschaffenheit des Holzes der beiden Bäume zum Ausdruck bringen. Nun hat der Kirschbaum zwar schönes Werkholz, aber hornartig wird es niemand nennen wollen, und ausserdem lïsst sich aus rlenjenigen Stellen, wo кpávєı oder cornus erwälnt werden, eine Terwechselung zwischen diesem und dem Kirschbaum nicht konstatieren. Vielmehr beschreibt THEOPHRAST seine männliche und weibliche кpúvela $(3,12,1$ und 2) hinreichend genau, damit wir in der ersten unsere Kornelkirsche, Cormus mus L., in der zweiten unseren Hartriegel, Cormus sur:minea L., erkennen können; die Namen männlich und weiblich sind điesen beiden Pflanzen durch lange Zeiten verblieben. Auch dasjenige,

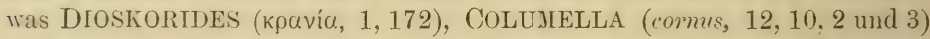
und Plinils (comus 15, 22, 31 und sonst vielfach) über die Komelkirsche sagen, lässt nicht darauf schliessen, dass sie diese mit der eigentlichen Kirsche verwechselt hätten.

Aber nicht der Name allein spricht dafür, dass die Römer die Siisskirsche kultivierten, auch die von PLINIUS $(15,25,30)$ gegebene Beschreibung von Kirschenrassen lässt Süsskirschen érkennen, die noch heute kultiviert werden: „von den Kirschen sind die Apronianischen am rötesten, am dunkelsten sind die Lutatischen, die Caecilianischen aber auch rund. (?) Die Junianischen haben einen guten Geschmack, aber fast nur unter ilırem Baum, denn sie sind so zart, dass sie den Transjort nicht vertragen können. Der Vorrang gebührt dẻn hürtlichen (Knorpelkirschen, duracina), die Campanien die Plinianischen nennt, in Belgien (?) aber den Lusitanischen (portugiesischen), ebenso an den Ufern les Rheins; diese haben eine dritte Farbe aus schwarz (dunkel, nigro) und rot und grün, so dass sie aussehen, als ob sie immer im Reifen wïren (similis maturescentibus semper). Vor weniger als 5 Jahren katmen diejenigen auf, die man Lorbeerkirschen (laurea) nennt, von nicht unangenelnmer Bitterkeit, wie sie dem Lorbeer eigentümlich ist. Es giebt auch Macedonische von einem kleinen Baum, der selten über drei Ellen linausweht, und Zwergkirschen mit einem noch kleineren Strauch." Das wïre schon eine nicht geringe Mannichfaltigkeit! Die Knorpelkirschen und die bunten lassen sich olme Bedenken als Süsskirschen ansprechen, :lber unter den übrigen giebt es auch solche, die man als Sauerkirschen denten kïmnte, z. B. die Apronianischen, die Caecilianischen und die Lrrbeerkirschen. Giebt es denn sonst kein Zeugnis dafür, dass die

1) Man vergleiche die folgende Anmerkung. 
Römer die Sauerkirsche gekaunt haben? Allerdings, und zwar bei TERGIL, Georg. 2, 17: hier erzïhlt der Dichter, dass einige Bäume sich durch Samen fortpflanzen; "anderen sprosst aus der Wurzel ein dichter Wald, wie den Kirschen und Ulmen ". ${ }^{1}$ ) Die in Italien vorkommende Ulme, Ulmus campestris L., treibt in der That Wurzelausläufer. Wir miissen daher annehmen, dass VERGIL richtig beobachtet hat; dam aber ist die Kirsche, von der er spricht, eine Sauerkirsche, nämlich die in der Überschrift genannte Strauchweichsel. Da die Römer in der Kunst des Pfropfens und Okulierens wohl bewandert waren, so komiten sie Strauchweichsel als Unterlage für andere Kirschen benutzen; aber ebensowohl konnten sie Rassen dieser Kirsche gezüchtet haben.

Wenn Karl der Grosse verlangte, dass „Kirschen verschiedener Art" in seinen Gürten gebaut werden sollten, so war diesem Befehle ohne Schwierigkeit nachzukommen, und wir können mit Bestimmtheit sagen, dass daraufhin Süsskirschen gepflanzt worden seien; ob auch Sauerkirschen, lässt sich nicht mit voller Sicherheit entscheiden.

Wir wollen nun versuchen die allmähliche Verbreitung der Kirsche zu verfolgen. Im CGL III wird sie nur sehr selten erwïhnt, und zwar in deı Hermeneumata einnal in dem Abschnitt über den Nachtisch (K€pakıov cerasium 316,31; in den iibrigen Abschnitten de secundu mensa steckt sie vielleicht in dem allgemeinen Begriff poma, Obst) und zweimal

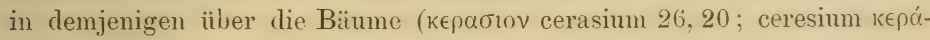
Giov 358,80 ); in den Glossaren kommt sie zweimal vor (cerosin . i . cerasia 556, 29; 620,54). Häufiger findet sie sich in den lateinischdeutschen Glossaren, woraus man wohl auf einen allmählich zunehmenden Anbau schliessen darf. Thre älteren Namen sind kurse, kirswa, hrise und kirse, cherse. ${ }^{2}$ )

Die heilige HILDEGARD spricht nur von cerasus $(3,6)$, so dass es nicht ganz sicher ist, was sie meint, vermutlich die Süsskirsche. ALBERTUS MAGNUS spricht auch nur von cerasus im 6. Buch, wo er von den Bïumen handelt, und zwar erwähnt er nur den Namen (6, 88), weil sie allen bekannt ist; auch in 7. Buch ist nur von cerrsas die Rede. Auch

1) "Pullulat ab radice aliis densissima silva, ut cerasis ulmisque."

An diese Stelle Vergils schliesst sich die Bemerkung des Servius: „Hoc (sc. cerasum) autem etiam ante Lucullum erat in Italia, sed durum, et cornum appellabatur" (nach Hehn, S. 326). Es ist mindestens fraglich, ob der in der zweiten Hälfte des vierten Jahrhunderts unserer Zeitrechnung lebende Grammatiker sich eingehend mit den von den Römern gebauten Obstarten beschäftigt, oder sie überhaupt nur gekannt hat. Wahrscheinlich hielt er die Kirsche für eine veredelte Rasse der Kornelkirsche. Ähnlich wie Servius drückt sich auch Isidor aus (Orig. 17, 7, 16); seine Etymologien sind als gewaltsam hinreichend bekannt und gewürdigt.

2) Kirsbaum-cerasus ahd. Gl. 5,34; kirssa-cerasium ahd. G1. 6.15; cerasus kersboum Vlt. S. 370; cerasum kersa Vlt. S. 371 ; cerasus criseboum Prag. Gl. S. 470 ; - Sum.: cerasus chersebovm 39, 24; cerasus kersb. 45, 64; cerusa kirse 55, 64. 
dieser cerms muss wohl als Süsskirsche gedeutet werden, denn an einer anderen Stelle $(3,80)$, wo er von sauren Früchten spricht, erwähnt er anch saure Kirschen, die amarena genannt werden (im Strassburger Codex steht cmarella): diese können nach seiner Meinung nicht süss werden. weil die reifende (verdauende) W:̈rme das natürlich Feuchte in ihnen nicht überwinden kann (,.Quod enim illa non dulcescunt, nulla causa est, nisi (juia calor digestivus in eis vincere humidum naturale non potest"). $\mathrm{Da}$ ist denn wohl nicht daran zu zweifeln, dass lier eine saftige Sauerkirsche gemeint ist. KONRAD voN MEGENBERG erwähnt die Kirsche ïherhaupt nicht. Im 16. Jahrhundert werden sehr viele Kirschen gebaut. Monstrositäten und wirkliche Rassen; unter diesen werden Cerasir acilla, saure Kirschen oder Amarellen genannt.

Wir fanden also bei ALBERTUs MAGNUs die Sauerkirsche zum ersten Male deutlich genannt und zwar unter dem Namen amarena oder amarella. Unter ähnlichem Namen kommt sie schon in einer Handschrift des 12. Jahrhunderts vor: amarellus wichselb.(oum) Sum. 46, 8, dem Weichsel ist die älteste deutsche und noch bestehende Benennung der Sauerkirsche. ${ }^{1}$ ) Amarellus, amarella und amarena können sehr wohl zusammenhängen mit amarasco oder marasco, Namen, welche die Strauchweichsel bei Venedig, Triest und in Dalmatien noch führt. Wichsel aber ist ein rerhältnismässig neues $\mathrm{W}$ ort; stellen wir uns die Namen der eigentlichen Sauerkirsche, Prumus Cerasus L., zusammen (vornehmlich nach KöPPEx. a. a. O. S. 283, 284), so erhalten wir von Westen nach Osten fortschreitend folgende Reihe: französisch guigne (aus guisne für wisne), italienisch risciola, deutsch vichsel, Weichsel, litauisch wyszma, polnisch wiśnia, russisch

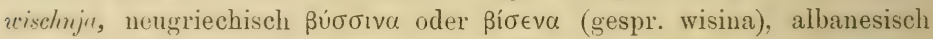
ryssine, türkisch wischene, wonach im Tatarischen der Krim wischne, jscher, imeretinisch und mingrelisch khwischna. Da nun die Sauerkirsche oder Baumweichsel ihr natïrliches Wohngebiet in Kleinasien und am Kaukasus hat, so scheint sie bei der Wanderung aus ihrer asiatischen Heimat nach Europa ebenso wie die Süsskirsche ihren asiatischen Namen mitgenommen zu haben, der damn im Muncle der verschiedenen Völkerschaften rerschiedene Umgestaltungen erfahren musste. Über Italien scheint dir Sauerkirsche ihren IVeg aber nicht genommen zu haben.

Prunarios diversi generis Capitulare 70, 76; prumarios Invent. II, 33; Prumes domesticr L., Pflaume, Zwetsche;2) I'. insititia L.. Kriechenpflaume, Haferschlehe.

1) Die duftenden Schösslinge von Prunus Mahaleb L., die zu Pfeifenrohren etc. benutzt werden, werden auch "Weichsel" genannt, und dem entsprechend der ganze Strauch und seine Früchte Weichselkirsche. Diese Benennung ist aber erst spät entstanden.

2) Der Name Zwetsche ist entstanden aus Quetsche, dieses aus Quecke; quecken heisst wachsen, lebhaft und rasch wachsen, und wird namentlich von solchen Pflanzen gebraucht, dir sich durch kriechenden Wur\%-Istock oder durch Wurzelauslänfer ver- 


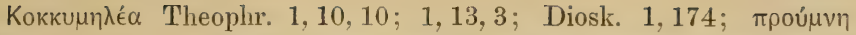

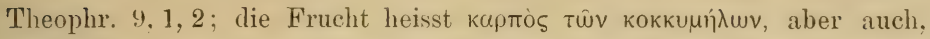

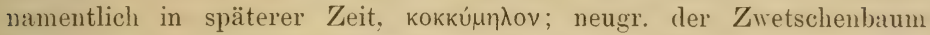

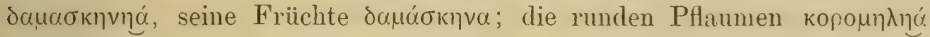

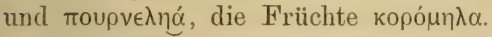

Prunus der Baum, prunum die Pflaume bei den Römern; it. pruno, susino, susino domestico, die Zwetsche susina; fr. prunier und prune.

Die Zwetsche stammt aus Vorderasien; die Kriechenpflaume ist hier im Norden, wo man sie nur an Dorfstrassen oder in unmittelbarer Nähe von Gehöften findet, verwildert, hat aber möglicherweise schon in Siiddeutschland, jedenfalls in Südosteuropa, Heimatsrecht. Die Alten haben die beiden genamnten Arten nicht strenge voneinander unterschieden. aber was sie damascener Pflaume oder Pflaume von Damaskus nennen (Plin. 15, 13, 12), ist unsere Zwetsche mit ihren verschiedenen Rassen. COLUnELla unterscheidet neben der Zwetsche eine wachsgelbe Pflaume (10,404; cereola pruna); PLINIt's $(15,13,12)$ kennt schon eine grosse Menge verschieden benannter Pflaumenrassen.

Wir werden gewiss annelmmen dürfen, dass in den Gärten Karls des Grossen die beiden genannten Pflaumenarten vorhanden waren, vielleicht in mehreren Rassen. Die heilige HILDEGARD $(3,7)$ unterscheidet ros:mumen, yurten slehen, kriechen und die wilde Art, ${ }^{1}$ ) unsere Schlehen. Die ros: prumen ${ }^{2}$ ) werden wohl identisch sein mit den "Roszpflaumen" bei HIERONYJIS BOCK, TABERNAEIONTANUS und anderen, die ron dunkler Farbe sind und wegen ihrer Grösse so genamnt wurden; garten slehen und kriechen werden runde Pflaumen sein, von denen einige später Haferschlehen hiessen.

ALBERTUS MAGNus $(6,201)$ zählt unter prums verschiedene Pflaumen nach Grösse und Farbe auf, auch die grüne und die damascener Pflaume. Ausserdem spricht er wiederholt von einem cinus genamnten Baum, den er meist mit prunus zusammen nennt; aus 3, 7 geht hervor, dass cinus zum Steinobst gehört und in den Glossaren ${ }^{3}$ ) wird das Wort durch "Kriechbaum" übersetzt. Wir müssen darin also die runde Pflaume sehen, die damals sehr bekannt und verbreitet gewesen sein muss, denn

mehren, wie die Zwetsche es thut (K. E. H. Krause, Quetsche, Zwetsche, Prunus domestica L, Jahrbuch des Vereins für niederieutsche Sprachforschung, Jahrgang 1886, Heft 12, Norden und Leipzig, 1887, S. 97-105).

1) „Omne autem genus prunibaumes, sive sit roszprumen, sive garten slehen, sive kriechen et silvestre genus."

9) Prume kommt für Pflaume auch sonst vor: prinus prumboom Sum. 45,66; prinus phrumbovm Sum. 39, 23; sonst ist pfloumbovm, phlumbovm der althochdeutsche Name des Pflaumenbaumes: prignus pfloumborm (Vlt. S. 378); prinus phlumbovm (Prag. Gl. S. 476). - Der lateinische Name prinus für Pflaume ist später ganz in Vergessenheit geraten.

3) Cinus chriechboum od. crihboum od. krichboum (Vlt. S. 370; Prag. Gl. S. 470 ; Sum. 46,4 und sonst). 
ALBERTLS MAGNLS verzichtet $(6,88)$ ausdrücklich auf eine Beschreibung dieser und der Kirsche; da er diese Pflaume in dem Teile des 7. Buches $(7,154-170)$, das dem Obstgarten gewidmet ist, überhaupt nicht erwähnt, wohl aber die Kirsche, so könnte man vermuten, dass sie zu seiner Zeit keine besondere Kultur erfahren habe, sondern wild gewachsen sei. Dargegen spricht aber das yarten slehen der heiligen HILDEGARD.

Bei den Schriftstellern des 16. Jahrhunderts finden wir schon viele PHaumenrassen nambaft gemacht; heute werden noch viel mehr gezogen, und es giebt bis weit nach Norden hinauf kaum einen Bauerngarten, in dem nicht wenigstens ein Pflaumenbaum stünde.

\section{Pfirsich und Aprikose.}

Persicarios diversi generis Capitulare 70,80 ; persicarios Invent. I, 24; II, 31 .

Es ist sehr wohl möglich, dass zu Karls des Grossen Zeit in Deutschland verschiedene Rassen des Pfirsichs kultiviert worden sind, und es ist zugleich wahrscheinlich, dass damals die Aprikose mit zu den Pfirsichen gerechnet wurde, ebenso wie es im 16. Jahrhundert geschah. Albertus MAagnus $(6,199)$ nemt den Pfirsichbaum persicu, seine Frucht persicum; die Aprikose stellt er unter die Pflaumen und nemnt sie prunum armenum $(6,201)$. Bei der heiligen HILDEGARD fehlt die A priknse, sie führt nur den persichbaum an (3,5. - HEHN (S. 345-348) hat die Geschichte des Pfirsichs und der Aprikose sehr eingehend behandelt, so dass man nichts auderes thun kanu als ihm nachschreiben. Nach ihm waren beide Früchte den älteren griechischen Schriftstellern nicht bekannt; erst als das römische Kaiserreich sich über Kleinasien hinans erstreckte, gelangten sie zur Kenntnis der Römer. Im ersten Jahrbundert unserer Zeitrechnung finden wir sie in den römischen Gärten, jat den Pfirsich sogar in den Gärten Südfrankreichs (CoLUsr. 10, 411; PLIN. 15, 11, 12).

Amygdalus persica L., Pfirsich.

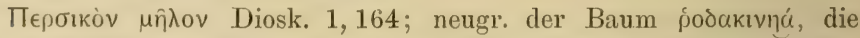
Früchte tú jodúkıva (entstanden durch Umstellung aus cluracinre, das etwa "Ḧ̈rtling", wegen des festen Fleisches, bedeutet; rergl. HEHN S. 347$)$.

Persicus Colum. 5, 10, 19 u. 20; 9, 4, 3; persica arbor Plin. 12, 3, 7; $15,13,13$; persicum malum Colum. 10,409-412; Plin. 15, 11, 12 u. 13 und sonst mehrfach; it. persico, pesco und persica, pesca; fr. pêche.

Die ältesten deutschen Namen sind pjersic, persic; bei den Tätern deer Botanik Pfersing, später Pfirsch und Pfirsich. HIERONymus Bock unterscheidet schon drei Rassen: "gemein weilz saftig, gantz gäl, gantz bliitroht durch aufz"; "̈hnlich bei den übrigen Schriftstellern des 16. Jahrlounderts. 
Prunus armeniaca L., Aprikose.

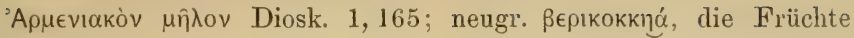

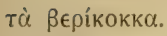

Armeniaca arbor Colum. 11, 2, 96; Plin. 16, 25, 42; armeniacum malum Colum. 5, 10, 19 ; prunum armeniacun Plin. 15, 13, 12 ; it. der Baum albicocco, arbricoceso, armeniaco, armellino, meliaco etc., die Frucht allicocea. arbricocca, armeniaca; fr. abricot.

DIOSKORIDES unterscheidet neben den eigentlichen P.firsichen, den persischen Äpfeln $(1,164)$, kleinere, die armenischen Äpfel, die auf römisch frühreife (praecocia) genaunt werden; ${ }^{1}$ ) er rechnet also die Aprikose zu den Pfirsichen. Dasselbe thun die meisten Botaniker des 16. Jahrhunderts, die ihre frühere Reifezeit durch den Namen St. Johamns Pfersing ausdrücken; um Johanni reift die Aprikose aber höchstens in Süddeutschland. Au anderen Namen sind zu bemerken: Möllelein, ${ }^{2}$ ) Molleten bei HiERonraus Bock, der hinzufügt: „der kleine gäle Sommer oder Johanns Pfersing“. Marillen ist im 16. Jahrhundert der gewöhnliche Name der Aprikose, auch noch im 18., und ist es in Ungarn stellenweise noch jetzt.

Der Name Aprikose ist durch eine Reihe von Wandlungen aus dem lateinischen praecox entstanden. Statt mala prarcocia wurde liurz mraecocia gesagt, und dieses Wort verwandelte sich bei den Griechen

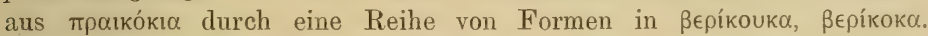
Duraus wurde im Munde der Araber mit dem vorgesetzten Artikel alburquiq. Als die Araber sich auf den Inseln des Mittelmeeres, in Süritalien und Spanien ansiedelten, da ging dies Wort in seiner arabischen Form in die Sprachen der besiedelten Länder über. So kam es, dass es nach Italien in der Form albercocco, albicocco etc. zurückkehrte. In Spanien verwandelte es sich in albaricoque, daraus wurde im Französischen abricot, und ans diesem Worte haben wir Deutschen Aprikose gemacht (nach HEHN, S. 347). Zu Anfang des vorigen Jahrhunderts (WEINJrAvr, Phytanthozaiconographie, Br. 3, Regensburg 1742, S. 332) schrieb man noch Abricose, und meinte damit die Rasse mit süssem Kem.

Pfirsich und Aprikose werden in Deutschland viel gezogen, auch ein Bastard aus beiden, die Pfirschaprikose. In Süddeutschland bilden sie freistehende Bäume, in Norddeutschland lassen sie sich nur an Nauern und an Bretterwänden ziehen und bedürfen während der kalten Frühjahrsnächte sehr häufig eines besonderen Schutzes. Viel müheloser reifen sie den Sïdeuropäern; Italien und Griechenland sind wegen ihrer vielen und schönen Rassen, namentlich von Pfirsichen, berühmt und bekannt.

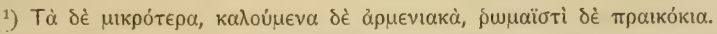

2) "Möllelein" ist ein Diminutivum von Morelle, das eine Kirschenart und ausserdem, in Süddeutschland und Schlesien, die Aprikose bedeutet. Das Diminutivum wird nur für Aprikose gebraucht (nach Grinns Wörterbuch). 


\section{Maulbeere und Feige.}

Morarios Capitulare 70, 84; Invent. I. 27; II. 35; Morns nigro L.. Maulbeerbaum.

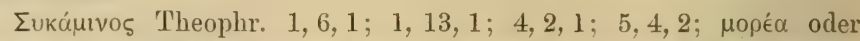

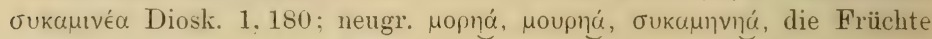
Eıvómoupa (die weissen Maulbeeren heissen $\mu$ oûpa).

Morus der Römer, die Frucht momum; it. moro nero; fr. mûner, mûre.

Der Maulbeerbaum stammt aus den Ländern südlich vom Kaukasus und ist, wie es scheint, schon ziemlich früh nach Griechenland gebracht worden. Da er mit der Sykomore, dem egyptischen Maulbeerbaum

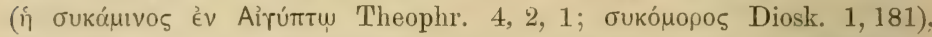
Ficus Sycomorus L., verwechselt wurde, und seine Frucht mit derjenigen ron Brombeeren und Himbeeren, so ist es nicht immer leicht zu entscheiden, welche Pflanze bei einem alten Schriftsteller jedesmal gemeint ist, wenn er morus oder morum nennt. Dass bei den Römern der schwarzfrüchtige Maulbeerbaum gebaut wurde, geht mit Sicherheit daraus hervor, dass die Frucht bei HORAZ (Sat. 2, 4, 22) und MATTIAL (1,72,5; $8,64,7$ ) schwarz genannt wird, bei VERGIL (Ecl. 6, 22) und CoLUMELLA $(10,402)$ blutig (sunguineus). Der weissfrüchtige Maulbeerbaum, Morus alba L., ist erst spät nach Italien gekommen und noch viel später nach Deutschland. HIERoxijus BOcK kennt beide Arten ron Maulbeeren, die nach ihm beide im Etschland wachsen; am Rheinstrome kam aber zu seiner Zeit allein die schwarze Maulbeere vor.

Das Wort morum wurde nicht nur, wie schon bemerkt, bei den alten Schriftstellern, sondern auch noch viel später, selbst noch bei A LberTus Magvis $(6,143)$, ausser für die Maulbeere auch noch für Brombeere und Himbeere gebrancht; häufig wird aber, um die Maulbeere sicher zu bezeichnen, der Zusatz celsi gemacht: mora celsi, während mora bati die Frucht des einheimischen Strauchs bedeutet. ${ }^{1}$ ) In den

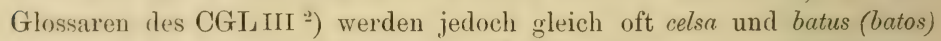
als morn domestica, also "gebaute Naulbeere" gedleutet. Da unsere Brombeerbiische sich für die Kultur nicht besonders eignen, so könnte man hier wohl an eine Kultur der Himbeere (Rubus idaeus L.) denken, namentlich da die Himbeeren im hentigen Griechenland nach FRAAS

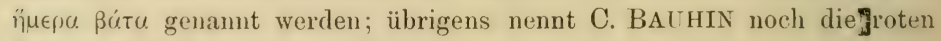
Früchte des Erdbeerspinats momum (vergl. oben S. 131).

$\left.{ }^{1}\right)$ Mora mulberen Königsb. Gloss.; ahd. Gl. 6, 19; mora celsi mûrberen Königsb. Gloss.; Colm. Gloss. 492, wo sich auch noch die Glosse "celsus mûrbôm" findet (217). Diese ist deshalb von Interesse, weil danach das Wort celsa des CGLiII (vergl. die folgende Aum.) als Plural von celsum die firüchte des Baumes celsus bedeuten kann. - Morobati bramberen Königsb. Gloss.

g) Celsa mora domestica 631,$533 ; 538,17 ; 581,39$ ete. etc.; batus mora domesticà 631,$31 ; 543,60 ; 580,48$ etc. etc. 
AlBertus Magre's $(6,143)$ erwähnt, dass die Blätter des Maulbeerbaums als Futter für die Seidenraupe benutzt werden und fügt hinzu, dass die als Surrogat benutzten frischen und jungen Salatblätter ${ }^{1}$ ) (lactucae recentes et juvenes) keine besondere Seide lieferten. Nach Norden hin hat sich der Maulbeerbaum weit iiber die Grenzen von Deutschland hinaus verbreitet, wem auch uur in einzelnen Exemplaren; diese gedeilhen aber meistens recht gut und bringen in warmen Jahren reife und süsse Früchte, freilich nie in solch überschwïnglicher Fülle, wie man es beispielsweise im südlichen Tirol sieht.

Ficus Capitulare 70, 87; Ficus carica L., Feigenbaum.

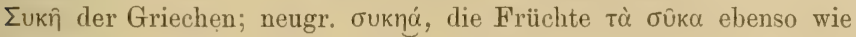
im Altertum.

Ficus der Römer; it. fico; fr. figue.

Das natürliche Wolnngebiet des Feigenbaumes erstreckt sich über die Kü̈sten des Mittelmeeres bis nach Syrien und Südarabien. Seine Domesticierung ist zuerst in Südarabien und Syrien gelungen: die domesticierte Form erreichte dann im südlichen Syrien die Mittelmeerküste und wurde ron dort aus durch die Phönicier verbreitet..2) Bei den Griechen wird der Feigenbaum zuerst etwa 700 v. Chr. erwähnt. In Italien spricht die Sage schon von einem Feigenbaum bei der Gründung Roms; sicher gehört aber die Feige zu den ältesten Kulturpflanzen der Römer.

Ein eigentlich deutscher Obstbaum ist die Feige nie geworden, dazu ist Deutschlands Klima zu kühl. Indessen sieht man hier im Norden den Feigenbaum im Freien ausdauern. Meist bleibt er niedrig und buschig wie in Kiel (alter Kirchhof) und Husum (am Schloss), und trägt dann auch nur kleine und nicht reifende Frïchte. Bei besonderer Pflege wird er stärker. Im Schlossgarten von Geiting, Kreis Flensburg, wo er am Spalier gezogen wird, bringt er zuweilen reife und süsse Früchte, ebenso in Augustenburg (Briefl. Mitteilung von Regierungsrat Petersen in Schleswig).

\section{Der Weinstock.}

Vitis vinifera $\mathrm{L}$.

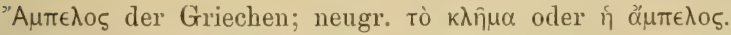

Vitis der Römer; it. vite; fr. vigne.

$\left.{ }^{1}\right)$ Dass Seidenraupen mit Lattichblättern gefüttert werden können, wird jetzt (Ende Januar 1894) in den Zeitungen als neueste Entdeckung gefeiert.

$\left.{ }^{2}\right)$ Sehr genaue Auskunft über den Feigenbaum findet man bei H. GRAF zU SolusLатваси, Die Herkunft, Domestication unł Verbreitung des gewöhnlichen Feigenbaums (Ficus Carica L.), in Abhandlungen der Königl. Ges. d. Wiss. zu Göttingen, Phys. Klasse, Bd. 28 vom Jahre 1881, Göttingen 1882; H. Graf zd Solms-Ladbach, Die Geschlechtsdifterenzierung bei den Feigenbäumen, in Botauische Zeitung, 43. Jahrg. 1885, S. $513 \mathrm{ff}$. 
НЕн. hat dem Weinstock eine sehr eingehende Stuclie gewidmet (KulturpHtanzen etc. S. 59-79) und dabei dessen Verbreitung bis in die Gegenwart rerfolgt. Über den Streifzug, den der Weinstock früher eimmal nach Norden unternommen hat, besitzen wir eine sorgfältige Schilderung von J. B. NORDHOFF (Der vormalige Weinbau in Norldeutschland. Zweite Ausgabe mit Nachträgen und Zusätzen, Münster 1883). Hier ist also kaum etwas anderes $\mathrm{zu}$ thum, als schon eimmal gesagtes noch einmal sagen; dadurch würde man aber dem Leser den Genuss an den oben genannten Abhandlungen verderben.

Karl der Grosse muss schon einen entwickelten WVeinbau vorgefunden haben, denı in seinen Erlassen kommen Bemerkungen über das Pflanzen des Weinstocks nicht vor, wohl aber Verordnungen über die Behandlung der Weimberge und des Weines (Capitulare 8 und 62). Ganz besonders sorgfältig beschäftigt sich ALBERTUS MAGNUS mit dem Treinstock. Er widmet ihm eine sehr eingehende Beschreibung (6, 236-256) und vergleicht ihn dabei mit einer grossen Zahl anderer Pflanzen: ausserdem giebt er aber $(7,171$ - 182) sehr genaue Vorschriften über seine Behandlung im Weingarten.

Auch in der Provinz Schleswig-Holstein hat es früher Weinberge gegeben, von denen noch die Namen erhalten sind: je einen bei den Kliistern Ütersen und Preetz und einen im Lande Oldenburg. Bei J. B. NORIHOFF (a. a. O. S. 30) hat eine Zeitungsnotiz aus dem Jahre 1843 Aufnahme gefunden, wonach bei dem Bau der Altona-Kieler Eisenhahn im Esinger Moor wohlerhaltene Weinreben ausgegraben wurden; es handelt sich hier aber um entrindete Eichenzweige. Dass damals die gefundenen Zweige falsch bestimmt worden waren, wurle sofort von J. F. SCHOr w erkannt, aber leider nicht in Deutschland publiciert.

\section{Mandel, Kastanie, Walnuss und Haselnuss.}

Amandalarios Capitulare 70, 83; Amygdulus commuis L., Mandelbaum.

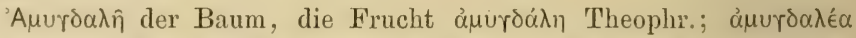

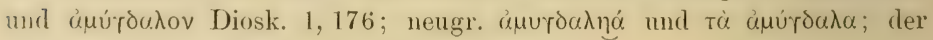

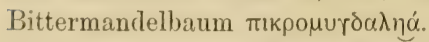

Amygdala der Baum Colum. 5, 10, 20; 9, 4,3; Plin. 15, 22, 24 und sonst vielfach; die Frueht heisst mex Graeca Colum. 5, 10, 12 ; Plin. 23, 8, 76; die bittre Mandel nux amara Colum. 7, 13, 1; Plin. 15, 7, 7; 20, 17, 72 11. 7:3; sonst unterscheidet Plinius süsse und bittere Mandeln als am!ygdalue dulaes und amarae; it. mandorlo, mandolo, die Frucht mandorla; fir. amandier und amande.

CATr) (8,2) führt die Mandel als griechische Nuss (nux Groecu) auf; da derselbe Name auch bei verschiedenen anderen Schriftstellern rorkommt, so darf man ihn wohl als Beweis dafür amehmen, dass die Rïmer den Mandelbaum von den Griechen erhalten haben. Die Griechen 
selbst hatten ihn aus Asien bezogen; heute ist er in Italien und Griechenland verwildert.

In späteren Jahrhunderten schrieb man amandola statt amygdala: ${ }^{1}$ ) aus amandola sind das deutsche Mandel, sowie das franzësische amande und das italienische mandola hervorgegangen. Die heilige HILDEGARD $(3,10)$ hat aber schon wieder amygdalus, ALBERTUS MAGNus $(6,16-18)$ amigdalıs, ebenso wie die Kräuterbücher des 16. Jahrhunderts.

Am Rhein und in der bayrischen Rheinpfalz sieht man Mandelbüume genug und hier reifen auch ihre Friichte leidlich; nach Norddeutschland sind sie wenig gelangt, dem sie scheinen noch empfindlicher als der Pfirsich zu sein.

('astanearios Capitulare 70,79; Castanea rescu Gaertner (Furnc: Castanea L.), echte Kastanie.

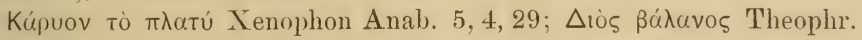

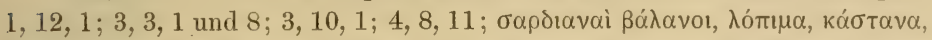

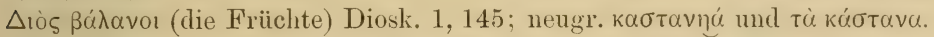

Castanea der römischen Schriftsteller; die Frucht heisst custanea mux; it. eastagno, marone; fr. châtaignier, maronnier und châtaigne, marron.

Die Heimat der echten Kastanie haben wir anf der Balkanhalbinsel und in Asien zu suchen; THEOPHRAST giebt an $(3,3,1)$, dass sie auf den Bergen Macedoniens wachse. Im Laufe der Jahrhunderte hat sie sich weiter nach Westen hin so gut akklimatisiert. dass man schon im südlichen Tirol glauben kömnte, natürliche Kastanienwälder zu sehen; indessen müssen hier diejenigen Büume, welche essbare Früchte liefern sollen, besonders gepfropft werden. Auch hier im Norden sieht man stattliche Kastanienbäume, sogar an Chausséen werden sie gepflanzt; ihre Früchte reifen aber nur ausnahmsweise.

Die heilige HILdeGaRD $(3,12)$ führt für die Kastanie den Namen Lestenbaum, der sich noch in rerschiedenen deutschen Mundarten findet; bei ALBERTus MagiNus $(6,47)$ heisst sie castanea, bei KONRAI) VoN MEGENBERG $(4 \mathrm{~A}, 10)$ ausserdem kestenpaum.

Die Rosskastanie, Aesculus Hippocastanum L., stammt aus Asien; sie gelangte am Ende des 16. Jahrhunderts von Konstantinopel nach Wien, und hat sich von da aus rasch fast über ganz Europa verbreitet. Walnuss, Nuss.

Nucarios Capitulare 70, 88; Invent. I, 26; II, 32; Juyluns regia L.,

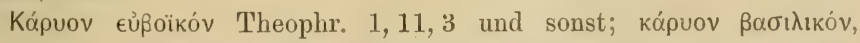
кúpuov $\pi \epsilon \rho \sigma ı o_{v}$ Diosk. 1, 178; neugr. der Baum kupvơñó, die Nüsse $\tau \grave{\alpha} \quad k \alpha \rho u ́ \delta 1 \alpha$.

Nux juglans oder einfach juglans der Römer; it. noce; fr. noix.

1) CGL III: tasia . i . amandula 578, 2; amigdola . i . amandola 586, 24 unten; 607,$16 ;$ - tasia ist wohl die mux Thasia bei Plivius 15, 22, 24. 
Bei den Griechen hiess der Nussbaum überhaupt kapúa, die N'uss kúpvov: durch ein hinzugesetztes Adjectivum konnte man damn genaure angeben, welche Nuss man meinte; die jetzt in Griechenland für Wralnussbatum und Walnuss gebrauchten Ausdrücke entsprechen dem Worte kapúdıov, das ehemals „kleiner Nussbaum" und „kleine Nuss" bedentete. Un die Zeit des 9. Jahrhunderts unserer Zeitrechnung, vielleicht aber schon früher, wurde der Nussbaum auf Griechisch kupvodévopov, auf lateinisch arbor nucarius, noquarius, auch einfach nux genamnt; die Nuss

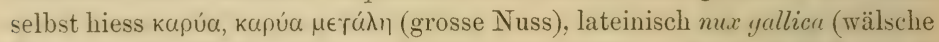
Nuss, unsere Walnuss), mu grandis (grosse Nuss), auch einfach uux. ${ }^{1}$ )

Althochdeutsch heisst die Walnuss nuz, der Baum nuzbaum; die heilige HIIDEGARD $(3,3)$ schreibt aber schon nuszlam, wie wir es jetzt noch thun.

Der Nussbaum, den wir Asien zu verdanken haben, gedeiht in Süddeutschland rortrefflich, ähnlich in Mitteldeutschland. Bei uns im Norden sieht man ihn seltener, und doch scheint er den Anbau lohnen zu können, denn es giebt auch hier Nussbäume, die an Grösse und Fruchtbarkeit hinter denen des Rheinlandes kaum zurückstehen.

Arellanarios Capitulare 70,82; avelanurios Invent. I. 25; II, 34; Corylus Avellana L., Haselnuss, und C. tubulosa Willd., Lambertsnuss.

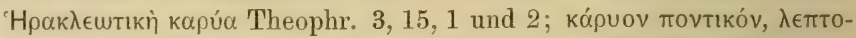

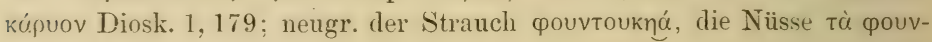
тoúkı oder $\lambda \in \pi$ тока́рua.

Corylus Colum. 7, 9, 6; Plin. 16, 18, 30; 17, 10, 13 und sonst; die Haselnuss heisst ganz allgemein nux avellana, bei PLINIUS nu, abellana; it. norciolo, nocciuolo, avellano; fr. coudrier, noisetier, die Nuss noisette, areline.

Ob diejenige Nuss, welche Karl der Grosse in seinen Gärten anzupflanzen befihl, und die nach den Inventarien in mehreren Gärten schon angepflanzt war, unsere gewöhnliche Haselnuss oder die lambertsche Nuss war, lïsst sich kaum mit Sicherheit entscheiden. Da aber die Haselnuss in den meisten Gegenden Deutschlands, wenigstens in den bergigen, nicht selten ist, so könnte wohl die lambertsche Nuss gemeint sein. Man unterschied früher die einzelnen Arten von Corylus nicht genau oder ïberhaupt nicht, so dass es nicht der Mühe lohnt, eine Trennumg der Arten vornehmen zu wollen. Beliebt ist die Haselnuss von jeher gewesen und vielfich ist sie anch angepflanzt worden. In den Gïrten der Pastorate bildet sie hier in der Provinz hin und wieder, namentlich aber in Dänemark, schattige Laubgänge, die eine oder mehrere Seiten des Gartens umfassen.

1) CGL III: cariodendo arbore nucario 5̌5̆, 14; cariadendron . i . noquarius 5811,50 ; cariatentron nucis gallica 588,8 ; ̈̈hulich 609,4 ; cariame gallin idest nuce grande 620,52 ; carias idest nuces 5555,$20 ; 619,48$; - cariamagalin . i nuce glande

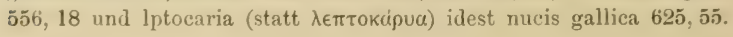


Die Namen der Haselnuss sind zahlreich. In der Zeit vom 3. bis 5. Jahrhundert und vielleicht etwas länger brauchte man die alten

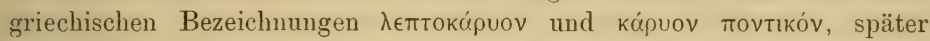
kapúdıv; im Lateinischen brauchte man ausser avellana noch nucella und nucilla, sowie nux minor. ${ }^{1}$ ) Dass die Haselnüsse im ältesten Dentsch als nespelun oder nespilun bezeichnet wurden, oder dass Hasel und Mispel mit einander verwechselt worden sind, ist schon bei der Mispel bemerkt. Sonst kommt hasel vor, meist als Übersetzung von corylus. $\left.{ }^{2}\right)$ Die heilige HILDEGARD $(3,11)$ sagt haselbaum; ALBERTUS MAGNUS $(6,150$ und 151) nennt den Baum corilus, die Nuss avellana. Ob auesperina und aresperma, die beide mit haselbere oder haselbir übersetzt werden, ${ }^{3}$ ) wirklich zur Haselnuss gehören, erscheint zweifelhaft.

\section{Die Pinie.}

\section{Pinos Capitulare 70,86; Pinus Pinea L.}

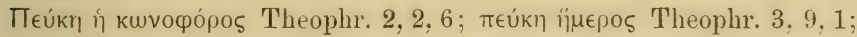

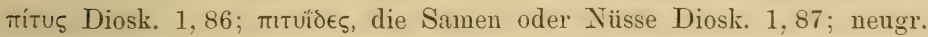

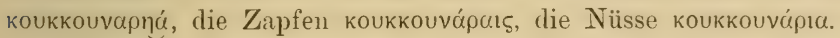

Pinus (in hortis pulcherrima) Vergil Ecl. 7,65; pinus culta Ovid Ars. am. 3,692 ; pinus Colum. 7, 9, $6 ; 9,5,6$; Plin. an vielen Stellen; pinea nux Colum. 5, 10, 14; Plin. 15,10,9 und sonst vielfach; it. pino, pino domestico; die Nüsse pinoceh, pignoli; fr. pignon, pin cultivé.

Die Pinie lässt sich bei den griechischen Schriftstellern erst in verhältnismässig später Zeit mit Deutlichkeit erkennen. MIan darf daraus schliesen, dass sie Griechenland ursprünglich fremd war; etwa 400 Jahre vor Chr. mag sie aus Asien nach Griechenland gebracht sein. Nach Italien kam sie dann naturgemäss noch später, wie auch aus ihrer Erwähnung bei den lateinischen Schriftstellern hervorgeht. In Italien wird sie mehrfach als Baum der Gürten genannt; derjenige Baum, der bei den Römern pinaster, wilde Pinie, heisst, ist wahrscheinlich Pinus Pinaster L. oder eine verwandte Art, und nicht, wenigstens nicht ausschliesslich, die Kiefer (J. F. SCHOUw, Italiens Nadelhölzer etc. in Hornsch. Arch. II, 1, S. 25); es ist sehr wohl möglich, dass unter den pinos des Capitulare Pinus Pinaster $\mathrm{L}$. oder $P$. Laricio Poiret zu verstehen ist.

In Deutschland hat die Pinie, ebensowenig wie der Lorbeer und die Feige, festen Fuss fassen und sich heimisch fühlen können. Selbst

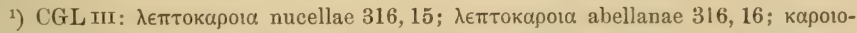

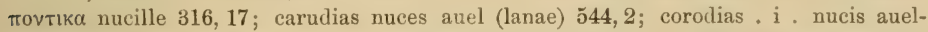
lanae arbor uel auellana 581,49; auellana nux minor 587, 2; 607,24; carucia nucis minor 588, 56; 609, 32; pontica . i . auellana 572, 49.

2) Sum: Corilus hasel 39,42 ; corilus haselboum 45,40 und sonst; Colm. Gloss.: nux pontica avellawa hazelnoth 518.

${ }^{3}$ ) Königsb. Gloss.: avesperma haselbere, elehencuti; Colm. Gloss.: auesperina haselberen 88; Sum.: auesperina haselbir 54,1.

v. Fischer-Bexzox, altd, Gartenflora. 
in Südtirol. wo doch sonst manche Pflanze aus südlicheren Breiten und wärmeren Klimaten nicht nur ein erträgliches, sondern sogar ein gutes Auskommen findet, gedeiht die Pinie nur mangelhaft. ALBERTL's MAGNLS, der die Pinie auf seinen Reisen nach Rom kennen gelernt hatte, beschreibt sie unter dem Namen pimus $(6,5)$ sehr genau; die Täter der Botanik nennen sie lateinisch pinus domestica, deutsch Fiechtenbaum. Hartzbaum etc.

\section{Bemerkungen über unsere Getreidearten.}

Die ältesten Getreidearten sind die Gerste und der Weizen; sie werden bei HOsER und HERODOT mehrfach erwähnt. THEOPHRAST kennt von beiden schon eine ganze Menge von Rassen, die wiederum ein Beweis für eine alte und lange dauernde Kultur sind. Ausser den genannten Getreidearten werden bei Griechen und Römern noch gebaut: der Spelt in mehreren Rassen, Hirse und Kolbenhirse. Roggen kommt erst bei PLINIUS und GALEN vor. Hafer wurde früher in Griechenland und Italien wenig gebaut und kommt auch im heutigen Griechenland nur wenig vor: als Hauptpferdefutter wurde im Altertum die Gerste. daneben der Spelt, gelegentlich der Weizen benutzt. Der Windhafer und der Taumellolch waren den Alten wohl bekannt und wurden als lästiges Unkraut von ihnen gefürchtet, ebenso wie der bei uns nicht rorkommende Walch (Aegilops orata L.); alle drei gelten bei ihnen als Entartungen von Gerste und Weizen und von Getreide überhaupt. Es mögen nun zunächst, um eine Übersicht über die verschiedenen Namen zu gewimnen, die einzelnen Getreidearten mit ihren griechischen und lateinischen, neugriechischen, italienischen und französischen, sowie mit ihren botanischen Namen folgen; das griechische oîtos und das lateinische jrumentum sind ebenso wie unser Getreide oder Korn unbestimmte Ausdrücke, deren Bedeutung sich nach der hauptsächlich angebauten Getreideart einer Gegend richtet und also nicht immer mit absoluter Sicherheit festzustellen ist.

\section{W eizen, Triticum vulgare Villars.}

Tupós Homer Il. 8, 187; 10, 569 etc.; Od. 19, 536; Herodot 1, 193;

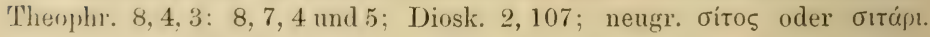

Triticum Cato 34 und 35; Varro 1, 2, 6; Colum. 2, 6, 1 und 2; 2, 8: 2, 9, 1-13; Plin. 18, 7, 12 und sonst vielfach; it. firmento, formento; fir. froment. 
Eine geringere Weizenrasse heisst bei den Römern siligo; Cato 35; Colum. 2, 9, 3 u. 5 u. 13; Plin. 8, 8, 20; 8, 9, 20; 8, 10, 20 und sonst.

Dieser Siligo-Weizen zeichnete sich durch Weisse, aber geringes Gewicht aus, Colum. 2, 9, 13, lieferte aber gutes Brot (in pane praecipua Colum. 2, 6, 1); CoLumella hält ihn deshalb für eine Entartung des Weizens (vitium tritici), die jedoch für einen nassen Boden und ein feuchtes Klima passend sei; man brauche diesen Weizen nicht aus der Ferne zu holen, denn aller Weizen verwandle sich auf sumpfigem Boden nach der rritten Saat in Siligo-Weizen. ${ }^{1}$ )

Der Name siligo hat sich in der italienischen Bezeichnung für Winterweizen, siligine, erhalten.

\section{Spelt, Dinke1, Triticum Spelta L.}

Der Begriff Spelt ist hier aus praktischen Gründen etwas weit gefasst und umschliesst mehrere Triticumarten, wie den Emmer, T. licoccum Schrank, und das Einkorn, T. monococcum L., die beide neben dem eigentlichen Spelt erwähnt, aber auch oft untereinander verwechselt werden.

Zєı́丿 Homer, neben Gerste als Pferdefutter erwähnt Od. 4, 41, neben Weizen und Gerste Od. 4, 604; Theophr. 2, 4, 1; 8, 1, 3; Diosk. 2, 111.

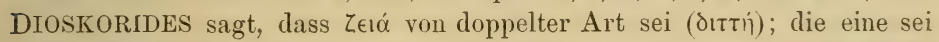

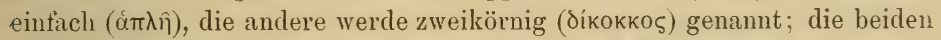
Arten lassen sich ohne Zwang als Einkorn und Emmer deuten.

"Oגupa Homer neben Gerste als Pferdefutter II. 5, 196 und 8, 564; Theophr. 8, 1, 3; Diosk. 2, 113 . HERODOT $(2,36)$ wundert sich darüber, dass die Egypter, während andere Menschen sich von IVeizen und Gerste

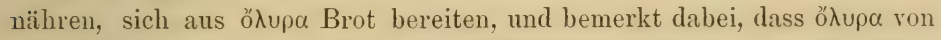

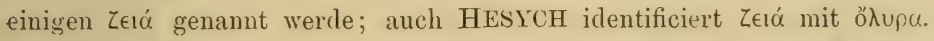

Típ $\eta$ Theophr. $1,6,5 ; 8,1,3$, wird von SPRENGEL als Einkorn gedeutet.

Far Verro 1, 2,6; Vergil Georg. 1, 219; Colum. 2, 6, 3; semen adoreum Colum. 2, 6, 1 u. 3; adoreum Colum. 2, 8, 1; 2, 9, 1; far adoreum Colum. 2, 9,3. COLUMELLA betrachtet adoreum als Gattungsnamen und unterscheidet von ihm vier Arten $(2,6,3)$; PLINIUS $(18,8,19)$ nennt als die gewöhnlichsten (volgatissima) Getreidearten far, dlas die Alten adoreum nannten, siligo und triticun; als für Egypten, Syrien, Cilicien, Kileinasien und Griechenland eigentümlich führt er sea, olyra und tiphe an; da er sagt, dass diejenigen, welche zea benutzen, kein far haben, so hält er beide für verschieden von einander; er führt noch eine Art ron Getreide an, arinca, die beiden Gallien eigentümlich, aber auch in Italien läufig ist $(18,8,19$; arinca Galliarum propria copiosa et Italiae est). aus der sich ein sehr schmackhaftes Brot (dulcissimus panis) backen

1) "Nam omne triticum solo uliginoso post tertiam sationem convertitur in siliginem", Colum. 2, 9, 13. 
lïsst $(18,10,20, \S 92)$; später $(22,25,57)$ teilt er mit, dass olyra auch rrinca genannt werde; endlich erwähnt er noch $(18,7,11)$, dass es in Gallien eine Art von far gebe, die dort brace, von den Römern sandala genannt werde; vielleicht gehört hierher scandula im Edictum Dioeletian i 1,8 (Edictum Diocletiani etc., anni p. Chr. CCCI, ed TH. ILOMMSEN, Berlin 1893, 4${ }^{\circ}$; mit Erläuterungen von H. BLÜMNER; daselbst S. 9 und 64).

Spelta kommt, wie es scheint, nicht vor dem 3. Jahrhundert unserer Zeitrechnung vor; CGL III: spelta őhupa 357, 2; Edict. Diocl.: spelta 1. 7 ; scandula sive spelta 1,8; Glossare des CGL III : triticus . i . spelta 579,$8 ; 630,10$; tredecus spelta 596, 8 ; it. spelta, farro, scandella; fr. épeautre.

Gerste, Hordeum vulgare L., vierzeilige, H. hexastichum L., sechszeilige und $H$. distichum L., zweizeilige.

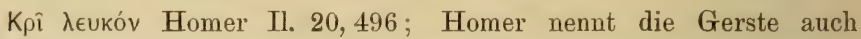
єủpurpués, breitwachsend, was auf die zweizeilige Gerste bezogen worden ist; крıөń Herodot 2,36 u. 77; Theophr. 8,4,1 u. 2; hier werden mehrere Arten, zwei- und mehrzeilige, unterschieden; Diosk. 2, 108; neugr. к $\rho-$ $\theta$ ápl; im heutigen Griechenland werden vier- und sechszeilige Gerste gebaut und sind unter allen Getreidearten die rerbreitetsten; ihre Körner sind das gewöhnliche Pferdefutter. Die dicht gesäte Gerste mit kaum entwickelten Ähren dient frisch gemïht als Grünfutter, getrocknet als Heu (v. Heldreich).

Hordeum der Römer; COLdjella $(2,9,14)$ unterscheidet sechszeilige Gerste (herestichum) und $(2,9,15)$ zweizeilige (distichum), die auch galatische genannt wird; die letztere rühmt er besonders. Das Samenkorn der Gerste wird von den Kornspelzen meist fest umschlossen, fällt also beim Dreschen nicht aus diesen Spelzen heraus, wie beispielsweise der Weizen. Die Alten fassten die Sache so auf, als ob die Gerste äberhaupt keine Spelzen habe; THEOPHRAST nennt das Gerstenkorn nackt (ruprós, $8,4,1)$, CoLUMella sagt $(2,9,14)$, es sei von keiner Spelze umkleidet (nulla vestitum palea granum). Dass die Gerste das älteste Nahrungsmittel unter den Getreidearten sei, versichert Plinius $(18,7,14$; antiquissimum in cibis hordeum); zwei- und melhrzeilige Gerstenarten erwähnt er 18, 7, 18. - It. Die vierzeilige Gerste heisst or $z$, die sechszeilige orzo maschio, die zweizeilige orzola; fr. orge.

\section{Roggen, Secale cereale $\mathbf{L}$.}

Roggen war den alten Griechen unbekannt. GALEN (de alim. fitcult. 1, 13) erwähnt ihn zuerst; auf den Äckern Thraciens und Macedoniens hatte er eine Getreideart gesehen, die in allen Stücken der

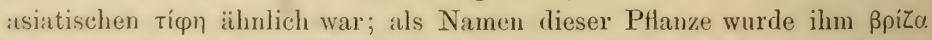
genannt; das aus dem Mehl gefertigte Brot war schwarz und roch un- 
angenehm. Im heutigen Griechenland wird Roggen nur wenig und meist nur des langen Strohes wegen kultiviert; er heisst бíк $\alpha \lambda_{l}$ oder $\beta p i ́ \alpha$.

Secale Plin. 18, 16, 40; die Tauriner am Fusse der Alpen nennen dieses Getreide, das von sehr geringem Werte ist (deterrimum) und zur blossen Abwehr des Hungers dient, asia; PLINIUs sagt, dass es ertragreich (nascitur qualicumq̨ue solo cum centesimo grano), von schlankem Halm und dunkelfarbig sei, aber schwer wiege; um den herben Geschmack (amaritudinem) zu mildern, mische man Spelt (jar) hinzu, aber auch so bekomme es dem Magen nicht gut. Edict. Diocl.: centenum sive sicale 1, 3; CGL III : $\beta \rho i Z \alpha$ secale 430, 7. -.- In Norditalien wird der Roggen gelegentlich gebaut und segale oder segala genaunt; fr. seigle.

Hirse, Panicum miliaceum L. und Kolbenhirse, P. italicum L.

1. Hirse; kérХ๐oऽ Theophr. 8, 1, 1 u. 4; Diosk. 2, 119; neugr. кєХрí. Milium Cato 6, 1; Varro 1, 57, 2; Colum. 2, 7, 1; 2, 9, 17; Plin. 18, 10, 24; it. miylio, je nach der Farbe der Körner mit dem Zusatz bianco, giallo, nero, rosso; fr. millet, mil.

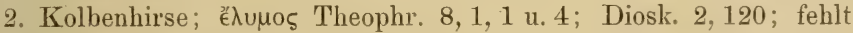
im heutigen Griechenland.

Panicum Cato 6, 1; Colum. 2, 7, 1; 2, 9, 17; Plin. 18, 10, 25; it. panigo; fr. panic.

Es giebt noch ein griechisches Wort für Hirse, $\mu \in \lambda i v \eta$, das schon bei HERODOT $(3,117)$ und XENOPHON vorkommt; DIOSKORIDES $(2,120)$ und GALEN (de aliment. facult. 1,15) identificieren es mit der Kolben-

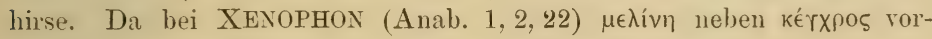
kommt, so kann es auch hier die Kolbenhirse bedeuten.

Hafer, Avena sativa L.

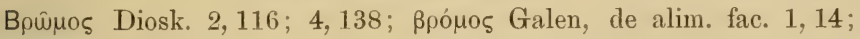

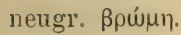

Avena Colum. 2, 11, 1 u. 9 ; it. avena; fr. avoine.

DIOSKORIDES behandelt den Hafer durchaus als Arzneimittel. Nach Coludella wird der Hafer gesät, um grün oder als Heu verfüttert zu werden. Da COLUMELLA einen Teil stehen lässt, um Saat zu gewinnen, so hat man hier wohl an den Saathafer und nicht an den Windhafer zu denken. GALEN hat den Hafer in Kleinasien in grossen Mengen gebaut gesehen; dort wurde er als Futter für das Zugvieh benutzt, diente aber auch zur Bereitung von Nahrung. Dass der Hafer allmählich an Verbreitung zunahm, folgt aus seiner Erwähnung im Edictum Diocletiani 1,17. In Griechenland wird der Hafer sehr wenig gebant, weil die Pferde mit Gerste gefuittert werden; in Italien dagegen wird er als Pferdefutter gesät.

An sehr vielen Stellen, wo Hafer bei den Alten erwähnt wird, haben wir zu denken an den 


\section{W ind hafer, Avena fatua L.}

Möglichermeise gehört hierher ßpónos bei Theophr. 8, 9, 2; THEOPHRAST zählt an dieser Stelle Pflanzen auf, die dem Weizen oder der

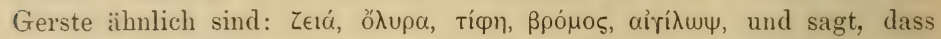
von diesen Zєı́ am kräftigsten sei, aber den Boden am meisten aussauge wegen der vielen tiefgehenden Wurzeln und wegen der vielen Halme; ebenso sagt er von $\beta p o ́ \mu o \varsigma$ und $(8,9,3)$ von airíi $\omega \psi$, dass sie den Boden wegen ihrer vielen Wurzeln und Halme aussaugen. Aber während er die Samen von Zeı́ als leichtverdaulich und angenehm zu essen rühmmt.

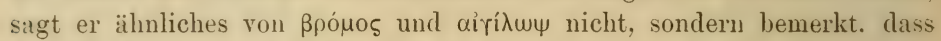
diese beiden als wild und nicht als Kulturpflanzen zu betrachten seien

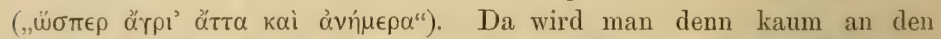
Saathater denken können. - Der Windhafer wird im heutigen Griechen-

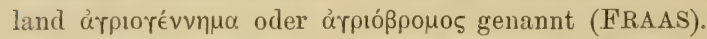

CATo empfiehlt $(37,5)$ den Hafer, arenc, auszurupfen, wird also wohl den Windhafer meinen. Sicher wird man diesen zu nehmen haben bei VERGIL, wenn er Ecl. 5,37 von arence steriles (unfruchtbarem Hafer) und Georg. 1, 226 ron vanae avenae (leerem oder taubem Hafer) spricht; auch an anderen Stellen mag der Windhafer gemeint sein. In Italien heisst er avena salvatica; fr. avoine sauvage, folle avoine.

Endlich möge noch ein Getreideunkraut erwähnt werden, das als Medicinalptlanze bei den Alten in Ansehen stand und rielfach für giftig gehalten wurde, der

\section{Taumelloleh, Lolium temulentum L.}

"Alpa Theophr. 2, 4, 1; 8, 8, 3; THEOPHRAST glaubt, dass Weizen und auch Gerste in Taumelloch ausarten; Diosk. 2, 122: später (Geopon.

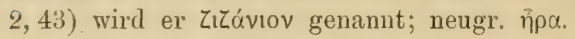

Lolium der Römer; die Römer fürchteten den Lolch sehr (injelix lolium, Verg. Ecl. 5, 37, Georg. 1, 154) und durch ein besonderes Sieb wurde sein Same vom Getreide gesondert (Colum. 8, 5, 16); VARRO aber (3. 9, 20) und Columella $(8,4,1)$ empfehlen den Lolch als Hühnerfutter; it. loglio und loglio inebbriante; fr. ivraie.

Von den hier vorgenommenen Deutungen kïnnte diejenige, welche ¿̇unos mit rer Kolbenhirse identificiert, vielleicht etwas gewagt erscheinen. Die Alten laben aber bestimmt zwei Hirsearten unterschieden, ron denen die eine, kérxpos, ganz allgemein als die gewöhnliche Hirse betrachtet wird; die Kolbenhirse gehört in China zu den ïltesten Kúultur1,flanzen (AlP'H. INE CANDOLLE, S. 478) und wird in Nordchina, am Amur, in Persien, am Kaukasus und an manchen Stellen Europas im Grossen gebaut, in Asien offenbar seit alten Zeiten; es liegt also nichts (iewagtes in der Anuahme, dass die Alten schon die Kolbenhirse gekannt und auch gelegentlich gebaut haben, umsoweniger als Schouw (Die 
Erde, die Pflanzen und der Mensch ete. Leipzig 1851, S. 4:3) sie auf einem Wandgemälde in Pompeji erkannt hat.

Eine Deutung der Namen, welche die Alten für die Getreidearten gebraucht haben, wird durch zwei Umstände wesentlich erschwert; einmal dadurch, dass die uns überlieferten Beschreibungen ausserorientlich kurz und nach unseren Begriffen ziemlich inhaltsleer sind, und zweitens dadurch, dass in Griechenland und Italien für dieselben Getreidearten stets verschiedene Namen benutzt werden, Namen zwischen denen sich, mit Ausnahme vielleicht von $\mu \in \lambda i v \eta$ und milium, ein sprachlicher Zusammenhang überhaupt nicht nachweisen lïsst. Da ist es denn von ganz besonderem Werte, dass in den Hermeneumata des CGLIII in den Abschnitten über Laudwirtschaft (de agricultura), uiber Feldfrïchte (de leguminibus) etc. die Getreidearten mit ihren griechischen und lateinischen Namen einander gegenuibergestellt werden, denn die Abfassung dieser Hermeneumata reicht bis ins dritte Jahrhundert unserer Zeitrechnung zurïck. Die oben vorgenommenen Deutungen stimmen durchans zu denen, welche uns die Hermeneumata bieten, und zu den hente noch gebräuchlichen Vulgärnamen. ${ }^{1}$ )

Die oben gegebene Zusammenstellung lehrt, dass die allgemeinen Bezeichnungen oîtos und frumentum in Griechenland und Italien an der am häufigsten gebauten Getreideart, dem WVeizen, haften geblieben sind. ebenso wie Korn in vielen Gegenden Deutschlands ausschliesslich den Roggen bedeutet. Eine Änderung in der Bedeutung hat auch das Wort żí, Spelt, erfahren. HERUDOT hält den Spelt für ein minderwertiges Getreide, aber bei HowER und HEsIOD fiihnt das Gefilde oder der Erdboden das Epitheton Z zídwpos, Zeiú spendend. Es ist schon frühzeitig versucht worden, dies Wort als "lebenspendend" zu deuten, aber

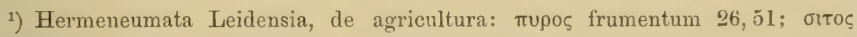

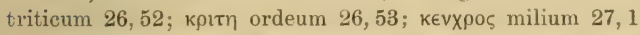

Hermeneumata Monacensia, de leguminibus: pyros frumentum 193,36; sitos triticum 193, 47; criti ordeum 193,48; cenchros milium 193, 56; olura far 193, 57 ; erazizamon lolium 193, 59.

Hermeneumata Einsidlensia, de leguminibus, eine spätere Bearbeitung der

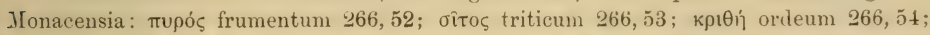

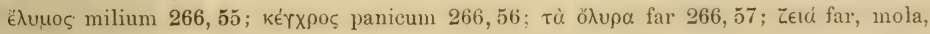

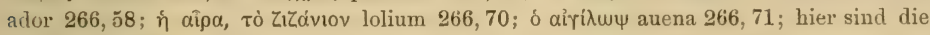
griechischen Namen für milium und panicum miteinander verwechselt.

Hermeneumata Stephani, de agricultura: frumentum $\pi u \rho o ́ \varsigma 356,19$; triticum

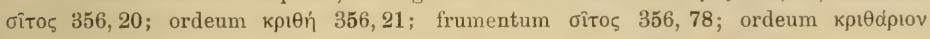

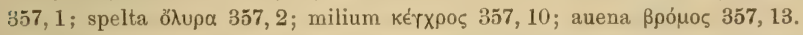

Hermeneumata Vaticana, de floribus (dieser Abschnitt ist verschmolzen mit

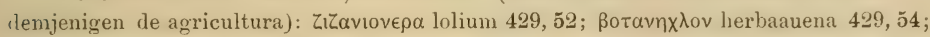

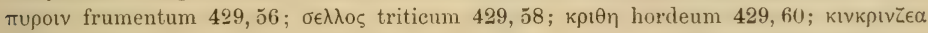

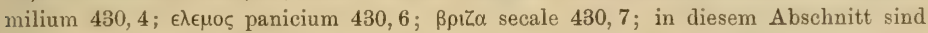
die Namen zum Teil stark entstellt; besonders interessant ist die Erwähnung des Roggens. 
damit thut man der Sprache Gewalt an. Wenn Zeí, wie von Sprachforschern angegeben wird, mit dem sanskritischen yar zusammenhängt. das Getreide, Gerste bedeutet, und wemn Gerste das älteste Getreide ist. so muss man annehmen, dass Zeı́ die Bedeutung Gerste, Getreide noch hatte, als es in die Verbindung Zeídwos eintrat; später, als vollkommenere Gerstenrassen als die ursprüngliche hinzukamen, und als der Weizen bekannt wurde, rerlor Zelá seine Bedentung und wurde damı auf ein minderwertiges Getreide übertragen.

Was uns die Römer über den Getreidebau in Deutschland überliefert haben, ist nicht sehr viel. CAESAR (Bell. Gall. 4,1) sagt, dass die Germanen „nicht viel von Getreide, sondern grösstenteils von Milch und Fleisch leben "; ${ }^{1}$ ) welches Getreide gebaut wurde, führt er nicht an. Bei PLixits, $(18,17,44)$ finden wir aber den Hafer angegeben: „Eine Hauptentartung des Getreides ist der Hafer, und die Gerste artet in ihn aus, so dass er selbst als Getreide dient, da ja die Völker Germaniens ihn säen und ron keinem anderen Brei leben (als ron Haferbrei)“. ") Da PLivics den Hafer (Windhafer) im wesentlichen nur als listiges Ackerunkraut kannte, so musste es auf ihn Eindruck machen, wemn er in Germanien ganze Haferfelder sah und erfuhr, dass Hafersamen eine Hatuptnahrung der Bewohner ausmachten. Von TAciTus erfahren wir. dass auch Gerste vorkam und ausserdem noch ein Getreide, das ebensı wie die Gerste zur Bierbereitung diente,") also wahrscheinlich Weizen. der schon früh in Gallien gebaut wurde und von da mit den Römern nach Deutschland kam oder kommen musste. In Gallien wurde aber ausser Weizen (siligo, Plin. 18, 8, 20) auch Spelt (arinca) und Kolbenhirse (panicum Plin. 18, 10,25) gebaut, die von da aus gleichfalls in Deutschland eindrangen. Die Einwanderung der Getreidearten brauchte aber nicht allein von Westen her zu erfolgen, denn auch im Osten wurden, wie aus der oben gegebenen Übersicht folgt, IV eizen, Spelt und Hirse gebaut. Der Hafer hat seinen Weg nach Mittel- und Nordeuropa genommen, ohne vorher Italien oder Griechenland zu berühren, vielleicht auch die Gerste; für den Roggen wird man eine ähnliche Wanderung gleichfalls amehmen muissen, aher da das Wort siligo, das ursprünglich eine Weizenrasse bezeichnete, allmählich für Roggen gebraucht wurde. und wir nicht genau wissen, wann dies Wort seine Bedentung änderte, so) lässt sich der Roggen auf seiner Wanderung nur schwer verfolgen.

1) "Neque multum frumento, sed maximam partem lacte atque pecore vivunt."

2) "Primum omnium frumenti vitium avena est, et hordeum in eam degenerat sic ut ipsa frumenti sit instar, quippe cum Germaniae populi serant eam neque alia pulte vivant."

$\left.{ }^{3}\right)$ "Potui humor ex hordeo aut frumento, in quandam similitudinem vini corruptus;" Germ. 23. 
Im Breviarium und im Capitulare Karls des Grossen finden wir eine ganze Menge von Gretreidearten angegeben. Um die Übersicht zu erleichtern und die Darstellung etwas abzukürzen, mögen die bei der heiligen HiLdegaRD (heil. Hild.), bei Albertes Maginus (Alb. MI.) und KONRAD von MEgenber(* (Konr. v. MI.) genamnten Getreidearten gleich hinzugefügt werden, ebenso die althochdeutschen und mittelhochdeutschen Namen; die Seitenzahlen beim „Breviarium" beziehen sich auf Pertz, Monumenta etc., Bd. 3.

Amnona Breviarium S. 177, entspricht unserem Getreide oder Kiorn, wird auch für Abgaben gebraucht, die in Korn geleistet wurden; ist unbestimmt, aber wahrschcinlich Weizen.

Frumentum Breviarium S. 178; da triticum nicht vorkommt, so wird man frumentum als Weizen deuten dürfen.

Triticum vulgare Vill.; triticum heil. Hild. 1,1; Alb. M. 7,127 u. 128; finmentum Alb. II. 6,348-350; wize ahd. Gl. 7,30; weice Sum. 44,45.

ALBERTUS MAGNUS braucht triticum und frumentum als ganz gleichbedeutend. KONRAI VON MEGLABERG $(5,40)$ übersetzt frumentum mit korn, von dem er dreierlei unterscheidet: rokkenkorn, waizenkiom und tinkl.

Spelta Breviarium S. 178. Triticum spelte L., im weiteren Sinne: spelta heil. Hild. 1, 5; Alb. M. 6, 351; spelza ahd. G1. 7, 30; dinchil Vlt. S. 379; dinchel Sum. 34, 37; - far Alb. M. 7, 127 u. 128; spelza ahd. Gl. 24, 18; amer Sum. 34, 38; - adoreum Alb. M. 7, 58 u. 127 u. 128.

Sigilis Breviarium S. 178, 180; verschrieben für siliginis;

Secale cereale L.; siligo heil. Hild. 1, 2; Alb. M. 6, 127 u. 128 und sonst.; roceo Vlt. S. $37 y$; roggo ahd. Gl. 23, 34; rokke Sum. 44, 46; rogke Sum. 34,36; (sigale vel sigalo vel magudaris, rogke).

Wann siligo zuerst als Bezeichnung des Roggens genommen ist, lässt sich nicht ganz genau feststellen; schwankend war der Gebrauch noch ziemlich spät, denn in den von HOFFMANN herausgegebenen althochdeutschen Glossen $(7,31)$ wird dinkil noch mit siligo glossiert und $(15,16)$ dinchelinbrot mit siligineits (sc. panis). Man nimmt jedoch allgemein an, dass der Gebrauch zu Karls des Grossen Zeit oder jedenfalls zu Anfang des 9. Jahrhunderts konstant war. ALBERTus MAGNus spricht wiederholt davon, dass siligo sich in frumentum oder triticum rerwandle $(2,26 ; 4,92 ; 5,55)$ oder ungekehrt. Er wird bei PLinfls oder GALEN hierüber gelesen haben und hat dann vertrauensvoll das Gelesene wiederholt. Zu seiner Zeit aber war siligo ausschliesslich für Roggen in Gebrauch; wenn man jedoch an solche Verwandlungen glaubt, und der (x̀laube daran ist auch jetzt noch keineswegs ganz verschwunden, so ist es am Ende gleichguiltig, ob Weizen in Roggen oder in eine geringere Weizenrasse ausartet.

Ordeum Breviarium S. 178, Hordeum vulgare L;

hordeum heil. Hild. 1, 4; ordeum Alb. M. 6, 399 u. 400 und sonst; 
ordeum und gerst Konr. v: M. 5, 54; gersta ahd. Gl. 7, 31; gerste Sum. 34,$42 ; 44,47$.

Arena Breviarium S. 178; Avena sativa L;

avena heil. Hild. 1, 3; Alb. M. 6, 420; 7, 127 u. 128; habero Vlt. S. 368 ; haber Sum. 44,48 .

Bei der heiligen HILDEGARD und bei ALBERTUS MA(iNUs wird der Hafer noch als Brotkorn genannt: die heilige HILDEGARD kemnt auch Haferbier $(3,27)$.

IIilinm Capitulare 44 u. 62 ; Panicum miliaceum L;

hirs heil. Hild. 1, 9; Konr. v. M. 5, 41; milium Alb. M. 6, 357; Komr. v. MI. 5, 41; hirse Vlt. S. 376; herse ahd. G1. 22, 1; hirse vel grivze Sum. 34, 39 .

Panicium Capitulare $4 \pm$; panigum Capitulare 62: Panicum italicum L: venich heil. Hild. 1, 10; Konr. v. M. 15, 41; panicum Alb. M. 6, 357 ; Konr. v. M. 5, 41; venich Sum. 63, 30; penit Sum. 49,56; fenich Sum. 34,$\left.40 ; 23,32 .{ }^{1}\right)$

AlBERTLS MAGNUS fasst die Hirsearten zusammen unter dem Namen gerguers, KoNRAD VON MEGENBERG unter gegmes.

Seit Karls des Grossen Zeit haben sich in Deutschland die Rassen res Getreides sehr vermehrt, die Arten aber nicht. Der aus Amerika stammende Mais ist nach Norddeutschland nicht rorgedrungen und ist in Sïddentschland keineswegs häufig. Ein wichtiges Getreide ist für Nordileutschland aber der Buchweizen (Polygonum Fagopyrum L.) geworden, iler seit dem 15. Jahrhundert in Urkunden vorkommt (E. H. L. Kra us e, PHanzengeographische Übersicht der Flora von Mecklenburg, Güstrow 188t, S. 124). Eine in früherer Zeit gebaute, jetzt aber unbeachtete Getreirleart ist aber noch zu erwähnen. die Bluthirse (Panicum sanguiwrıle L.), die jetzt, namentlich im östlichen Deutschland, als Acker- und Gartenumkraut rorkommt: sie ist frïher von den Wenden gebaut worden und hat sich mit ihnen verbreitet (E. H. L. Krause, a. a. O. S. 120). Endlich sei noch auf eine inländische Getreideart aufmerksam gemacht, die anfängt in V'ergessenheit zu geraten, das Mammi- oder Schwadengras (Glycerir fluituns R. Br.). Dieses Gras ist nie gebaut worden; es wächst aber an Wassergräben und Teichrïnlern und wurde zur /eit der Reife gesammelt.

1) Das Wort „Fenchelhirse“ ist willkürlich und falsch gebildet. 


\section{Anhang I.}

1) Aus den „Hermeneumata“ des Corpus Glossariorum Latinorum, Bd. 3, Leipzig 1892. A. De floribus, über Blumen; B. De oleribus, über Gemüse.

2) Zwei Inventare Kaiserlicher Gärten aus dem Jahre \$12.

3) Kapitel 70 des „Capitulare de villis".

4) Entwurf zu einem Klostergarten aus dem 9. Jahrhundert.

5) Der „Hortulus“ des Walafridus Strabus; Inhaltsïbersicht.

6) Glossae Theotiscae. 



\section{Aus den „Hermeneumata"}

des Corpus Glossariorum Latinorum, Bd. 3, Leipzig 1892.

Der Text der Hermeneumata ist zum Teil reich an Entstellungen und Veränderungen, so dass eine Deutung der überlieferten Namen nicht immer ohne weiteres möglich ist; diese Namen mussten deshalb in den nachfolgenden Abschnitten, die von Blumen und Gemüsen handeln, vorher auf eine Form gebracht werden, die sich als die ursprüngliche und richtige betrachten lïsst. Da DIOSKORIDES und PLINIUS, vielleicht auch COLUMELLA dem Schreiber der Hermeneumata direkt oder indirekt bekamnt gewesen zu sein scheinen, so war die Herstellung der richtigen Schreibung meist nicht schwierig; nur bei Ausdrücken allgemeineren Inhalts, wie Spross etc., war es nicht immer leicht, das ursprüngliche Wort zu finden, und ebenso war es schwierig, unter den möglichen sprachlichen Formen diejenige zu ermitteln, die der Abfassungszeit der Hermeneumata entsprach. Hier hat die stets bereite Hülfe meines Kollegen Dr. A. FUxCK wiederholt eingreifen müssen. Um dem Leser einen Einblick in die vorgenommenen Änderungen zu verschaffen, sind im Nachfolgenden der iiberlieferte und der verbesserte Text einander gegenüber gestellt, der erstere links, der letztere rechts. Die Abschnitte „de oleribus" sind aus den ältesten drei Hermeneumata entnommen und selbst wieder nach ihrem Alter geordnet, so dass das älteste voransteht.

Das Edictum Diocletiani (ed. TH. ModnIses, Berlin 1893, $4^{0}$; mit Erlüuterungen von H. BLÜMNER) aus dem Jahre 301 n. Chr., ein Maximaltarif für Getreide- und Lebensmittelpreise etc., Arbeitslöhne etc., liefert uns sehr wichtige Aufschlüsse über das Leben der damaligen Zeit. Die den einzelnen Gegenständen hinzugefügten Preise sind namentlich deshalb von Wichtigkeit, weil sie uns ein Urteil erlauben über die Wertschätzung, die man damals einzelnen Pflanzen, Gemüsen etc., zuteil werden liess. Im Folgenden ist gelegentlich auf das Edict verwiesen.

Bei den folgenden Pflanzenverzeichnissen ist bei solchen Pflanzen, die schon im Vorhergehenden behandelt siud, durch eine neben den 
Namen gesetzte Zahl auf die betreffende Seite des Textes verwiesen; Namen, die ihre Deutung noch nicht im Vorhergehenden gefunden haben. sind durch eine bezifferte Anmerkung berücksichtigt.

\section{A. De floribus, über Blumen.}

\section{Hermeneumata Monacensia, CGLIII, S. 192, 23-35.}

Die Hermeneumata Einsidlensia, die eine Überarbeitung der Monacensia darstellen, enthalten auch einen Abschnitt „de floribus“, S. 266. 21-46. In diesem kommt jedoch nichts vor, was zur Erklärung der in den Monacensia angegebenen Blumennamen dienen könnte, vielmehr scheint der Ïberarbeiter sich in einiger Verlegenheit befunden zu haben;

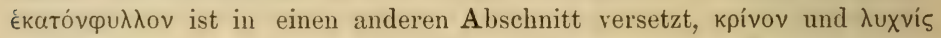
sind gar nicht berücksichtigt. In den Hermeneumata Montepessulana finden sich im Verzeichnis der Bäume 6 Blumennamen (S. 301, 14-19),

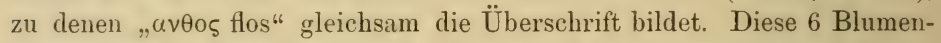
namen, die im folgenden ihre Erklärung und Rechtschreibung mit finden,

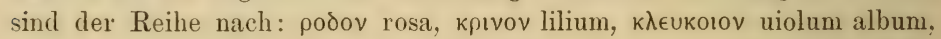

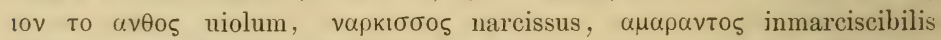
(d. h. unverwelklich). Endlich enthalten die Hermeneumata Vaticana S. 429, 14 ff. einen Abschnitt "de floribus"; dieser ist jedoch mit demjenigen "de leguminibus" verschmolzen und enthält ausser Rose, Lilie und Leucoium nur griechische Namen ohne lateinische Übersetzung.

23 Pereanthon de floribus anthi flores

25 anthos flos

centifolium centifolium

rosa rosa

erinon lilium

iuchinis rosa greca

30 lon uiola purpurea

amaranton amarantum

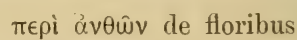

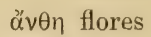

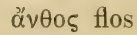

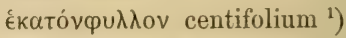

pódov rosa 34

кpivov lilium 33

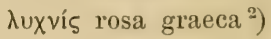

iov viola purpurea 40

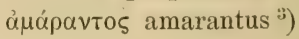

2) Diese Lesart findet sich in den Hermeneumata Einsidlensia 265,58 in dem

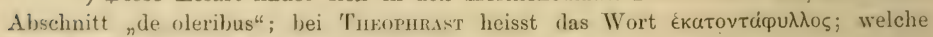
Pflanze hier gemeint sein kam, ist zweifelhaft; es könute die gefüllte Gartenrose sein, aber auch die gefüllte Blume des Granatapfels; vergl, oben S. 35.

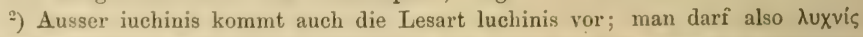
lesen; wahrscheinlich ist die Gegeniiberstellung von lyehnis und rosa graeca entnommen aus Puinius 21, 4, 10, §18; vergl. S. 43.

3) Die Deutung dieses Namens ist unsicher. Pluvius erwähnt 21, 8, 23 u. 39 eine P'flanze cmarrutus, die aus südlicheren (regenden stammt und sich durch Farbenpracht und Unverwelklichkeit auszeichnet. Dieser amarantus ist schon im 16. Jahrhundert ats der Hahnenkamm, Celosin cristata L., gedeutet worden, dessen schöngefirbter Jliitenstaul seine Farbe heim Trocknen behält; die von Pusics angegelıene Fabel, lass die netrockncte Bliite in Winter, nachdem sie mit Wasser befeuchtet worden ist, 
32 narcissus narcissus

micon papauer

melilotum melilotum

35 leucoion uiola vóркเббоక narcissus 37

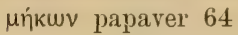

$\mu \in \lambda$ í wTov melilotum $^{1}$ )

$\lambda \in$ eúóiov viola 40 .

\section{B. De oleribus, über Gemüse.}

a) Hermeneumata Leidensia, CGL III, S. 16, 13-47.

$13 \Pi \epsilon \rho \iota \lambda \alpha \chi \alpha v \omega v$ Deoleribus $\lambda \alpha x \alpha v \alpha$ olera

15 кaùı colicula

$\mu \alpha \lambda \alpha x \in$ malbe

$\sigma \in \cup \tau \lambda \alpha$ beta

$\epsilon \lambda$ iov asparagum

kıv $\alpha \rho$ or cardi

$20 \lambda \omega \beta 1 \alpha$ fasioli

amwpivov lappa

коһокıv $\theta$ ar cucurbitae

$\sigma ı \kappa \imath \downarrow \imath \alpha$ cucumeres

$\pi \in \pi \omega v$ реро

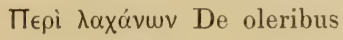

$\lambda a ́ x \alpha v \alpha$ olera

кau入ía colicula ")

$\mu \alpha \lambda \alpha ́ \chi \alpha ı$ malvae 127

$\sigma \epsilon \hat{\tau} \tau \lambda \alpha$ betae 129

E $\lambda \in \iota_{0}$ asparagus 124

кıvápal cardi od. cardui 121

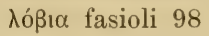

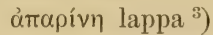

коภокúv $\theta$ a cucurbitae 89

бเкúdı cucumeres 92

$\pi \dot{\pi} \pi \omega v$ реро ${ }^{*}$ )

wieder auflebt, wird auch getreulich reproduciert; das Ganze reduciert sich vielleicht darauf, dass die getrockneten Stengel im Wasser erweicht werden mussten, damit sie sich in Kränze einfiigen liessen. Indessen erwähnt Dioskonines $(4,47)$ ein helichrysum. das nach ihm auch amarantus geuaunt wird; dieses hält man für Guaphalium Stoechas: L., eine Strohblume oder Ewigkeitsblume, die in Südeuropa und Nordafrika wildwächst. aher auch als Gartenzierpflanze dient; wahrscheiulicher ist es, dass diese gemeint ist, da sie nach Dioskorides zum Bekränzen der Götterbilder diente und noch heute in

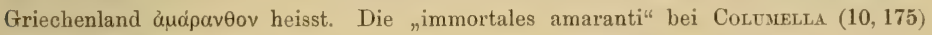
gehören wohl auch hierher.

$\left.{ }^{1}\right)$ Wahrscheinlich der gelbblühende und wohlriechende Melilotus des Drosko-

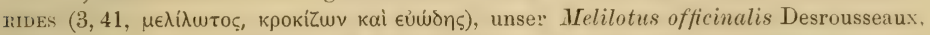
der heute in Italien meliloto und meliloto odoroso genannt wird, und dessen blühende Zweigspitzen in den Apotheken als Summitates s. Flores Meliloti geführt wurden.

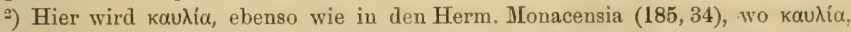
кра́uß $\alpha$ und coliculi als gleichbedeutend genommen werden, den Kohl bedeuten sollen: vergl. S. 108.

$\left.{ }^{3}\right)$ Die hier genannte Pflanze ist unser Labkraut oder Kleblraut, Galium Aparine L., das ein lästiges Getreideunkraut werden kann; als solches wird es oft erwähnt, z. B. Verg. Georg. 1, 153. Es erscheint uns etwas eigentümlich, das Labkraut unter die Gemüse aufgenommen zu sehen; aber Plinius sagt $(21,17,64)$ von ihm: "Circa Opuntem est herba etiam homini dulcis", was vielleicht auf seine Essbarkeit zu bexiehen ist. Man kann sich übrigens leicht ïberzeugen, dass die jungen Sprossen unserem Spinat sehr ähnlich schmecken.

†) Ob hier die JIelone oder die Wassermelone gemeint ist, lässt sich wohl nicht entscheiden. In den Herm. Montepessulana (317,49 u. 50) werden pepo und melopepo nebeneinander erwähnt. Da im Edict. Diocl. (6,30-32) ein pepo ebensoviel wie ein geringerer und halbsoviel wie ein besserer melopepo kostet, so scheint pepo dort die Wassermelone zu sein, und wahrscheiulich ïberall, wo pepo ueben melopepo rorkommt. 


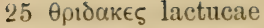

$\sigma \theta \in \rho ı s$ intiba

papavot radices

pa甲avıঠєS armoratia

ßouviades napi

30 rovridar rape

бтафuגıvor pastinace

$\mu \alpha \rho a \theta \rho o v$ apetillum

$\pi \rho \alpha \sigma \alpha$ porri

кронік сере

35 бкорд $\alpha$ aleum

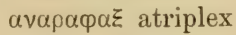

$\theta \rho \omega z ı \mu \alpha$ escariole

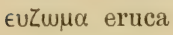

$\pi \in$ ravov ruta

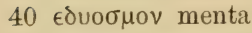

$\sigma \in \lambda$ เvov apium

$\mu \mathrm{I} \theta \epsilon \in$ nepete

$\imath \pi \pi 0 \sigma \in \lambda \imath v o v$ olysatrum

aviv $\theta$ ov anethum

$45 r \lambda \in \chi \omega \nu$ poleium

$\theta \rho \cup \mu \beta \alpha$ satureia

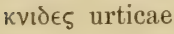

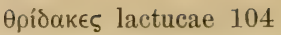

б'́pı intybus od. intubus 105

páqavor radices 114

рафаvîdes armoratia 114

ßouviádєৎ napi 112

rorrúdar rapae 113

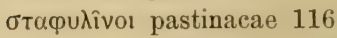

$\mu \alpha \dot{\alpha} \alpha \theta \rho o v$ aretillum ${ }^{1}$ )

$\pi \rho \alpha \dot{\sigma} \alpha$ porri 141

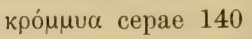

бкópodov allium 142

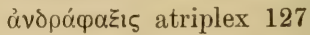

$\tau \rho \dot{z} z ı \alpha$ escariola 105

єủZwuov eruca 107

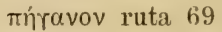

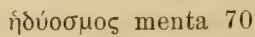

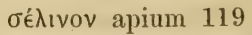

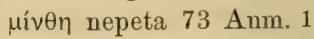

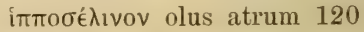

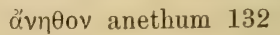

rภท́xwv poleium 72

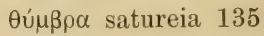

кvídes urticae 88.

b) Hermeneumata Monacensia, CGL III, S. 185, 32-67.

32 perilachanon de oleribus

lachana holera

caulia crambia coliculi

35 molochia malbe

crambus grassica

scutla beta

colochinte cucurbite

sycidia cucumeres

40 lobia faciola

rafunu radices

gongulas rapas

bumades napos

stafilini pastinace

45 simbron sisinbrun

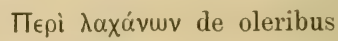

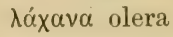

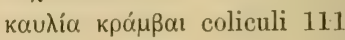

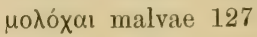

кра́ $\mu \beta \eta$ brassica 108

$\sigma \in \hat{\tau} \tau \lambda \alpha$ betae 129

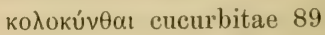

бเкúঠı $\alpha$ cucumeres 92

入óßıа fasioli 98

póquvoı radices 114

rorrúlar rapae 113

ßouviádes napi 112

бтафuภîvoเ pastinacae 116

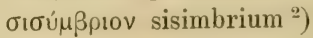

$\left.{ }^{1}\right)$ An dieser Stelle sind zwei Worte ausgefallen. Es muss heissen:

$\mu \alpha \rho \alpha \theta \rho v^{2}$ feniculum 132, und

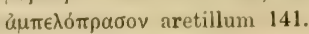

2) Im Edict. Dioçl. 6, 24 wird sisimbriorum fascis, also ein Bündel oder Bund von Sicymbrium 'rwähnt, das 20 Stiick enthält ; Bu, wask deutet sisimbria als Brumen:- 
46 camodafni laurocina

talassocrambis magacia

lohia suriace

ormenon cyma

50 elion sparagun

prason porrum

prasocarton porruseptibin

prasacefalon porro capitatum

cromia cepe

55 scordon aleu

afroscordon ulficu

cnides urtice

petroselinon oleastrum

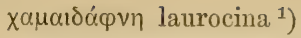 \\ $\theta \alpha \lambda \alpha \sigma \sigma о к \rho \alpha ́ \mu \beta \eta$ magacia $\left.{ }^{2}\right)$ \\ $\lambda$ óßı suriacae 98 \\ öpuєvos cyma ${ }^{3}$ ) \\ Ė $\lambda \in \mathrm{I}_{\mathrm{S}}$ asparagus 124 \\ $\pi \rho \alpha ́ \sigma o v$ porrum 141

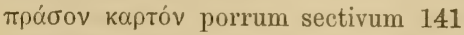

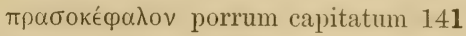 \\ кро́ $\mu \mu$ а сераe 140 \\ бкópodov allium 142 \\ ג’甲робко́родоv ulpicum 142 \\ кvíঠes urticae 88 \\ $\pi \in \tau$ робє́ $\lambda$ ıvov olusatrum ${ }^{4}$ )
}

kresse. Vielfach bedeutet aber sisimbrium eine Art der Minze, die auch als Gewürz an Speisen gethan wurde. Da aber im Edict. Diocl. 6, 48 ein Bund gemischter Würzkräuter von 8 Stiick (condimentorum praenisquorum fascis n. octo) ausserdem genaunt wird, und da hier in den Herm. MLonac. weiter unten Minze $(186,2)$ und Würzkräuter (condimenta, 186,4) aufgeführt werden, so ist es möglich, dass sisimbrium hier als Brunnenkresse zu deuten ist. Die Römer kannten nach Dioskonides 2, 1らó die Brunnenkresse und assen sie; die Stengel konnten also sehr wohl gesammelt und zum Kauf angeboten werden. Der Umstand, dass ein Bund von sisimbrium 20 Stück, ein solches von Würzkräutern 8 Stück enthält, spricht auch für die Deutung als Brunnenkresse.

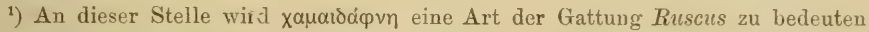
haben, deren junge Sprossen als Spargel gegessen wurden und noch werden. Am gebräuchlichsten waren die Sprossen von Ruscus aculeatus L., dem Mäusedorn, wilde

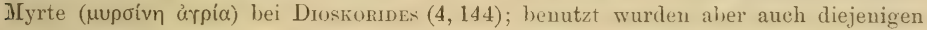
von Ruscus Hypoglossum L. und R. Hypophyllum L., die von den Alten Zwerg-

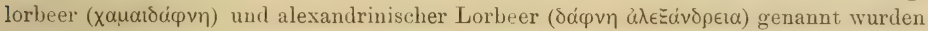
(Dioskorides 4, $145 \mathrm{u} .147$ ), und in Italien noch heute lauro alessandrino heissen. --

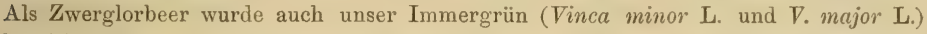
bezeichnet, das in Südeuropa wild wächst; es wurde früher vinca pervinca genannt (bica peruica . i . camedafne CGL III 554,29; 618,57 und sonst vielfach) und hiess bis auf die Gegenwart in den Apotheken Vinca oder Pervinca.

${ }^{2}$ ) Das Wort magacia scheint sonst nicht vorzukommen; da das griechische Wort Meerkohl bedeutet und mit olus marinum, Meergemüse, übersetzt wird, ( $\theta \alpha-$ $\lambda \alpha \sigma \sigma o к \rho \alpha \mu \beta \eta$ olus marinum CGLш 265,26), so ist wohl eine Art von Meeresalgen gemeint, vielleicht Ulva Lactuca L.

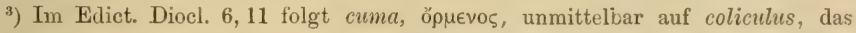
daselbst für Kohl gebraucht wird; die cumae werden bundweise verkauft, und sind wahrscheinlich dort, ebenso wie hier, die Frühlingstriebe des Kohls.

4) Welche Pflanze hier gemeint sei, ist nicht leicht zu bestimmen; aber wahrscheinlich ist es doch das schwarze Gemüse, olus atrum. (Smyrnium Olusatrum L.), das früher in sehr grossem Ansehen stand; eine sehr nahe verwandte Pflanze (Smyrnium perfoliatum Mill.) wurde in ähnlicher Weise, aber seltener benutzt. Verwechselt wurden beide Pflanzen miteinander. Droskorides führt als Namen des schwarzen

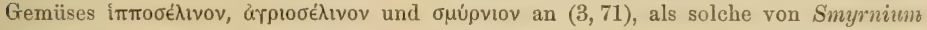

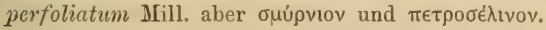

v. Fischer-Benzon, altd, Gartenflora. 
59 maratron feniclu

60 lapaton rumice andrachin portulaca crusolaxana atriplice troxima scaria thydracas lactuce

65 ocimon ocimon serides intubi cardamon nasturcium.

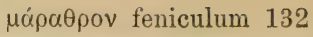

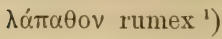

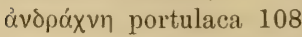

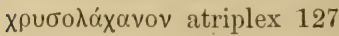

трúzıนa escaria 105

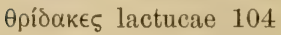

ükıноv осіmum 134

$\dot{\sigma} \in \operatorname{é} 1 \delta \in \varsigma$ intubi 105

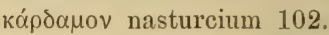

CGL III, S. 186, $1 \div 24$.

1 euzomon eruca iduosmos menta origanon cunela archymata condimenta

5 thymba saturiae thymon timon selimon apium piganon ruta cyminon cyminum

10 cinaras cardum andraplexia atriplex acrimonia tariones pepon melo erpulon serpillum

15 minthi nepeta

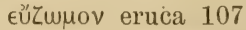

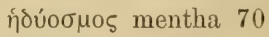
ópíravov cunela ${ }^{2}$ )

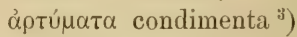
$\theta u ́ \mu \beta \rho \alpha$ satureia 135

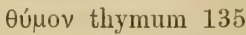

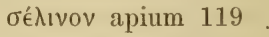

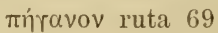

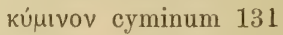
кıvópaı cardi 121

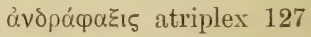
åкрєно́vєธ turiones ${ }^{4}$ ) Tértwv melo 93

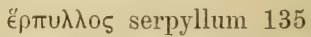

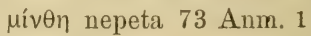

$\left.{ }^{1}\right)$ Von den Arten der heutigen Gattung Rumex wurden die Blätter früher selır viel gegensen, nicht nur diejenigen der verschiedenen Sauerampferarten, sondern auch die jungen Blätter von $R$. aquaticus L., $R$. Hydrolapathum Huds. ete. und namentlich von $R$. Patientia L. (englischer Spinat), der sehr viel in Klostergärten gezogen wurde; die letztgenamnte Pflanze, deren bittere Wurzel statt des Rhalarbers al Alfiihrungsmittel geloraucht wurile, hiess frïher Rhabarbarum monachorum verum, echter Mönchsrhabarber.

2) Origanum vulgare L., Dosten, und verwandte Arten. Droskonides (3, 29)

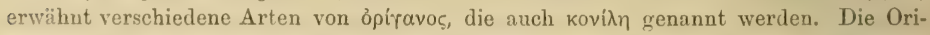
ganumarten werden noch heute in Griechenland und Italien als Würze an Speisen grethan und heissen daselbst píravn (auf Kreta ảpíravos) und origano oder rigamo.

$\left.{ }^{3}\right)$ Gewürzkrïuter verschiedener Art.

4) Nach dem zweiten Teil des CGL, 223, 57, bedeutet ¿̇kpóspuov dasselbe wie cacumen rami, also eine Zweigspitze oder einen jungen Trieb, die auch turio heissen. Das Wort turio kommt schon bei Columeli vor $(12,48$, 5: lauri turiones), der sonst statt dessen cacumen benutzt, wie $12,9,3$, wo er die cacumina rubi, die jungen Zweigyitz-n ler Bromberstrüucher und Endiviensalat (benso winzumachen empfiehlt wie den gewöhnlichen Salat (lactuca); an derselben Stelle wird die cyma von Thymian, Satureia, Origanum und einer wilden Senfart (armoracia, pl.) für dieselbe Behandlung namhaft gemacht; vergl. oben S. 109 und Herm. Montep. 317, 26 u. 27. 
16 agriolaxanon holos rusticum amboloprason aretillum anithon anetum corion coriandrum

20 gliscon puleum filla folia arodria tiriones leptolachanon fabataria tili fenu grecum. ảrpıodáxavov olus rusticum ${ }^{1}$ ) a $\mu \pi \in \lambda o ́ \pi \rho \alpha \sigma o v$ aretillum 141

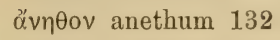

кópıov coriandrum 133

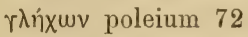

$\varphi u ́ \lambda \lambda \alpha$ folia ${ }^{2}$ )

ảkpódpua turiones ${ }^{3}$ )

$\lambda \in \pi$ Todáxavov fabataria ${ }^{4}$ )

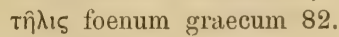

c) Hermeneumata Montepessulana, CGL III, S. 316, 67-74.

$67 \Pi_{\epsilon \rho \imath} \cdot \lambda \alpha \chi \alpha v \omega v$ De oleribus $\lambda a x a v a$ holera кauৗos cauliculus

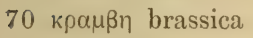
$\tau \in \cup \tau \lambda \alpha$ beta $\tau \in U \tau \lambda$ ov beta ко入окчv $\theta$ เ $\alpha$ cucurbitas

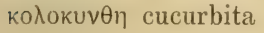

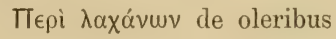

$\lambda \alpha ́ x \alpha v \alpha$ olera

kaùós cauliculus 111

кра́ $\mu \beta \eta$ brassica 108

$\tau \in \hat{\tau} \tau \lambda \alpha$ betae, Plural von

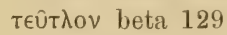

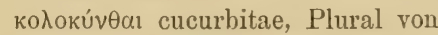

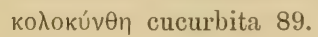

\section{CGL III, S. 317, 1-51.}

1 papavov radix

rovruגi

Bouviadaıs napi

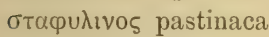

$5 \pi \rho \alpha \sigma \sigma o v$ porrum

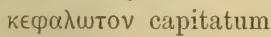

pópavoś radix 114

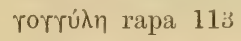

ßouviód€ৎ napi 112

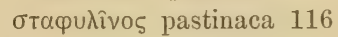

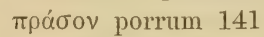

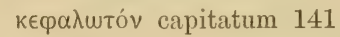

1) Vielleicht darf man aus der Art und Weise, wie im heutigen Griechenland

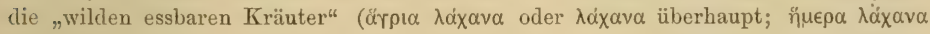
sind die kultivierten Küchenkräuter) geschätzt werden, einen Schluss auf alte Zeiten machen; man hat jedoch zu hedenkeu, dass die vielen und strengen Fasten der griechischorthodoxen Kirche den Genuss von Gemüsen sehr gefördert haben. Bei v. HeLdreich, Die Nutzpflanzen Griechenlands, Athen 1862, ist ein Anhang, S. 74-83, den Xáxava allein gewidmet, auf den hier verwiesen werden muss.

$\left.{ }^{2}\right)$ Das. Wort folium allein (PLIN. 12, 12, 25) bedeutet ebenso wie malabathron

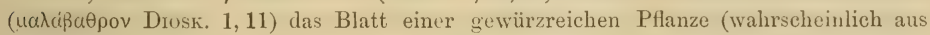
der Lorbeerfamilie) aus Südasien, das an Speisen gethan und auch zu Salben benutzt wurde. Apicius benutzt oft folium und malabatron nebeneinander.

$\left.{ }^{3}\right)$ Siehe Anmerkung ${ }^{4}$ auf S. 178.

4) Der Sinn dieser Glosse hat sich nicht ermitteln lassen; $\lambda \in \pi \tau 0 \lambda \alpha ́ x \alpha v o v$ bedeutet ein kleines oder dünnes Gemüse; fabatarium scheint an der Stelle, wo es allein vorkommt (Scriptores Hist. Augustae; Lampridius Heliog. 20,7) eine Schiissel zu bedeuten; beides stimmt nicht zusammen. - In Norddeutschland werden den grossen Bohnen (faba), wenn sie abgeblüht haben, meistens die Stengelspitzen ausgebrochen; man glaubt dadurch eine bessere Bohnenernte zu bekommen. Die ausgebrochenen Spitzen, die ein oder zwei Blätter tragen, werden vielfach als Gemüse gekocht und gegessen. Dieser Gebrauch muss sehr alt sein; vielleicht hängt die Glosse hiermit zusammen. 
7 kapтov sectinum

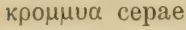

бкорбоv aleum

10 кviठ» urtica

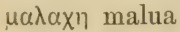

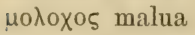

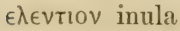

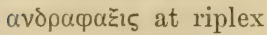

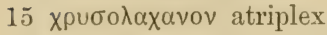

$\theta \rho 1 \delta \alpha z$ lactuca

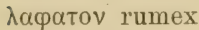

$\sigma \in \rho i s$ intuba.

кıv $\alpha \rho \alpha$ cardus

$20 \beta$ itov blitum

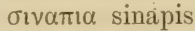

$\tau \rho о z ı \mu \alpha$ acetaria

wKıнov ocimum

$\mu 1 \sigma 0 \delta$ เіגov ocimum

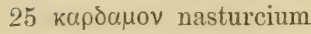

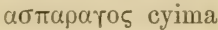

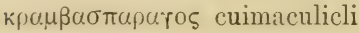

$\lambda \omega \beta \iota \alpha$ fasioli

$\lambda \alpha \mu \psi \alpha v \eta$ lampsanum

30 uı ${ }$

optravov origanum

oplravis

$\tau \lambda \eta \eta x \omega v$ puleium

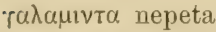

$35 \pi \eta$ ravov ruta

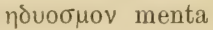

карто́v sectivum 141

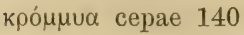

бкópoঠov allium 142

кvíon urtica 88

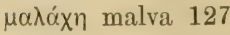

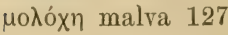

É $\lambda$ Éviov inula 63

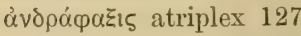

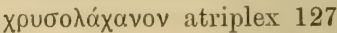

$\theta \rho \hat{\imath} \delta \alpha \xi$ lactuca 104

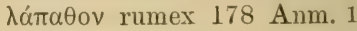

бе́pıs intubus 105

кıvóp $\alpha$ cardus 121

$\beta \lambda i ́ \tau o v ~ b l i t u m ~ 129$

бivami sinapis 108

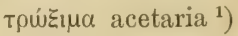

ükıно оcimum 134

$\mu$ $\sigma o ́ \delta o u \lambda o v$ ocimum ${ }^{2}$ )

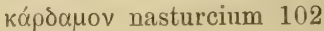

ảomáparos cyma ${ }^{3}$ )

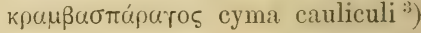

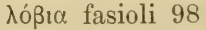

$\lambda \alpha \mu \psi \alpha ́ v \eta$ lampsana ${ }^{4}$ )

Ė $\lambda \in \operatorname{los}$ ảomáparos asparagus 124

ópíravov origanum 178 Anm. 2

ỏpıravis ${ }^{5}$ )

rлńxwv poleium 72

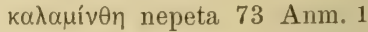

$\pi$ ŕravov ruta 69

ๆ̇úoouov mentha 70

1) Im zweiten Bande des CGL finden wir auch acetaria $\tau \rho \omega z \mu \alpha \alpha(13,41)$ und

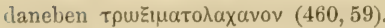

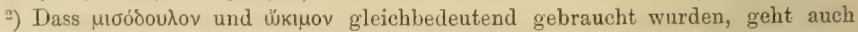
aus Geopon. 11, 28 hervor. Das ükıนov, unser Basilie oder Basilienkraut, führte auch

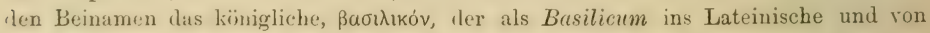
da ins Deutsche übergegangen ist.

$\left.{ }^{3}\right)$ MIan vergl. S. 125 und S. 177 Anm, 3, S. 178 Anm. 4.

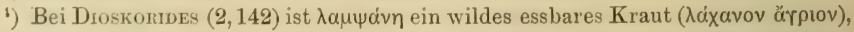
das nahrhafier und dem Magen nützlicher ist als Ampfer ( $\lambda \alpha \dot{\pi} \alpha \theta 0 v)$, und dessen Blätter and Stengrel gekroht gegessen werden. Da der weisse Senf (Sinapis alba L.) nach $\therefore$ Hr:blisun in (irimchenland hïufig wild wächst und in ter angegebenen Weise be-

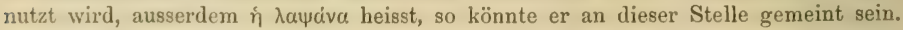

5) Dieses Wort ist nach Note 8, S. 317, von zweiter Hand hinzugefügt; entnommen ist es vielleicht aus Dioskorides 3, 42, wo von einem Kraut $\mu a \dot{j}$ ov die Rede ist, das auch borravis genannt wird; welche Pflanze hier gemeint ist, hat sich nicht genau ermitteln lassen. 
$37 \quad \theta u \mu \beta \rho \alpha$ satureia

$\epsilon \cup \measuredangle \omega \mu \alpha$ eruca

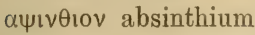

$40 \alpha \rho \tau \mu \alpha \tau \alpha$ condimenta

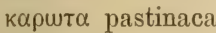
daukos pastinaca

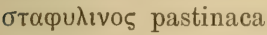

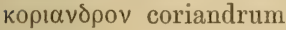

$45 \alpha v \delta \rho \alpha \chi v \iota$ porcacla бıкио cucumeres $\alpha v \eta \theta 0 v$ anethum $\alpha \mu \eta \in \lambda \circ \pi \rho \alpha \sigma o v$ aretillum $\pi \in \pi \omega v$ pepo

$50 \mu \eta \lambda о \pi \epsilon \pi$ о melopepo $\mu \alpha \rho \alpha \rho \rho o v$ faniculum $\theta$ ú $\mu \beta \rho \alpha$ satureia 135

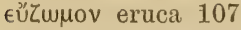

àuivetov absinthium 75

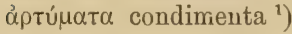
карштóv pastinaca 116 ঠaûkos pastinaca 116

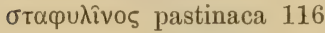
корí $\alpha \delta \rho \circ$ coriandrum 133

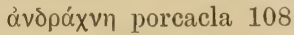
бเкúol cucumeres 92

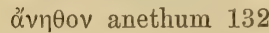

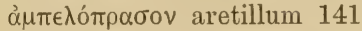
Tértuv pepo 175 Anm. 4

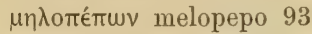

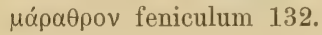

\section{Zwei Inventare Kaiserlicher Gärten}

aus dem Jahr 812.

Abgedruckt aus „Beneficiorum fiscorumque regalium describendorum formulae“, G. H. PERTZ, Monumenta Germaniae historica etc., Bd. 3, Hannover 1835, S. 175 ff. Dieses Document enthält Anordnungen, wie Inventare über Meierhöfe etc. aufzunehmen seien; man kann es deshalb, wie auch von GAREIS geschehen, Berichtsformulare nennen; früher hiess es "Breviarium".

Bei jedem lateinischen Pflanzemnamen ist hier und im folgenden $\mathrm{Ab}$ schnitt durch eine Zahl auf die Seite verwiesen, wo er eingehender behandelt ist. Vor die Namen sind Nummern gesetzt, einmal um ein sicheres Citieren zu ermöglichen, zweitens um den Vergleich mit der Übersetzung zu erleichtern.

\section{Inventar I,}

vom Garten des Hofgutes (fiscus dominicus) Asnapium ${ }^{2}$ ) (Pertz,

$$
\text { a. a. O. S. 179). }
$$

De herbis hortulanis quas repperimus, id est 1) lilium 33, 2) costum 73. 3) mentam 70,4$)$ petresilum 120,5 ) rutam 69,6 ) apium 119, 7) libesticum 66,8$)$ salviam 133 , 9) satureiam 135,10 ) savinam 80 , 11) porrum $141,12)$ alia 142,13$)$ tanazitam 74,14$)$ mentastrum 72,15$)$ coliandrum

1) Gewürz und Würzkräuter.

2) Die ehemalige Lage dieses Gutes ist nicht bekannt. 
$133,16)$ scalonias 139,17 ) cepas 139,18 ) caules 108,19 ) raracaules $110,20)$ vittonicam 77.

De arboribus: 21) pirarios 145, 22) pomarios 144, 23) mispilarios $148,24)$ persicarios 154,25$)$ avelanarios 160,26 ) nucarios 159,27 ) morarios 156, 28) cotoniarios 146.

\section{Bericht}

über die Gartenpflanzen, die wir gefunden haben, nämlich 1) Lilie, 2) Frauenminze, 3) Krauseminze, 4) Petersilie, 5) Raute, 6) Sellerie, 7) Liebstöckel, 8) Salbei, 9) Bolmenkraut, 10) Sadebaum, 11) Porree, 12) Knoblauch, 13) Rainfarn, 14) wilde Minze, 15) Koriander, $16 \%$. 17) Zwiebeln, 18) Kohl, 19) Kohlrabi, 20) Betonika.

Über die Biiume: 21) Birnbäume, 22) Apfelbäume, 23) 'Mispelbäume, 24) Pfirsichbäume, 25) Haselnusssträucher, 26) Nussbäume, 27) Maulbeerbäume, 28) Quittenbäume.

\section{Inventar II,}

vom Garten des Hofgutes Treola ${ }^{1}$ ) (Pertz, a. a. O. S. 180).

De herbis hortulanis, id est 1) costum 73, 2) mentam 70, 3) livesticum 66,4 ) apium 119,5 ) betas 129,6 ) lilium 33,7 ) abrotanum 74 , 8) tanezatum 74,9$)$ salviam 133,10$)$ satureiam 135, 11) neptam 72 , 12) savinam 80,13 ) sclareiam 134,14 ) solsequia 106,15$)$ mentastrum 72 , 16) rittonicam 77,17 ) acrimonia 76,18 ) malvas 127,19$)$ mismalras 63 (glossa: id est altea quod dicitur ibischa), 20) caulas 108, 21) cerfolium 126, 22) coriandrum 133, 23) porrum 141, 24) cepas 139, 25) scalonias 139, 26) brittolas 141, 27) alia 142.

De arboribus: 28) pirarios diversi generis 145, 29) pomarios div. (sen. 144, 30) mispilarios 148, 31) persicarios 154, 32) nucarios 159, 33) prunarios 152 , 34) avelanarios 160,35$)$ morarios 156,36 ) cotoniarios 146,37$)$ cerisarios 148.

Bericht

iiber die Gartenpflanzen, nümlich 1) Frauenminze, 2) Krauseminze, 3) Liebstöckel, 4) Sellerie, 5) Mangolt, 6) Lilie, 7) Eberraute, 8) Rainfarn, 9) Salbei, 10) Bohnenkraut, 11) Katzenminze, 12) Sadeloaum, 13) Muskatellersalbei, 14) Cichorie, 15) wilde Minze, 16) Betonika, 17) Odermennig, 18) Malve, 19) Eibisch, 20) Kohl, 21) Kerbel, 22) Lírianter, 23) Porree, 24 und 25) Zwiebeln, 26) Schnittliuch, 27) Knoblauch.

Über die Bïmme: 28) Birnbäume verschiedener Art, 29) Apfelb:̈ume verschiedenex Art, 30) Mispelbäume, 31) Pfirsichbäume, 32) Nussbäume, 33) Pflaumenbäume, 34) Haselnussstrïucher, 35) Maulbeerbüume, 36) Quittenbäume, 37) Kirschbäume.

1) Die ehemalige Lage dieses Gutes ist nicht bekannt. 


\section{Kapitel 70 des „Capitulare de villis (vel curtis) imperialibus".}

G. H. Pertz, MIonumenta Germaniae historica etc. Bd. 3 S. 186, 187.

70. "Volumus quod in horto omnes herbas habeant, id est 1) lilium 33,2 ) rosas 34,3 ) fenigrecum 81,4 ) costum 73,5 ) salviam $133,6$ ) rutam 69,7 ) abrotanum 74,8 ) cucumeres 92,9$)$ pepones 93 , 10) cucurbitas 89,11 ) fasiolum 98,12 ) ciminum 131,13$)$ rosmarinum 136, 14) careium 131, 15) cicerum Italicum 101, 16) squillam 81, 17) gladiolum 43,18 ) dragantea 51,19$)$ anesum 133,20 ) coloquentidas 54, 21) solsequium 106, 22) ameum 66, 23) silum 65, 24) lactucas 104,25$)$ git 132,26 ) eruca alba 107,27$)$ nasturtium 102, 28) parduna 59, 29) puledium 72, 30) olisatum 120,31) petresilinum 120, 32) арium 119, 33) leuisticum ${ }^{1}$ ) 66, 34) savinam 80, 35) anetum 132, 36) fenicolum 132, 37) intubas 105,38 ) diptamnum 67, 39) sinape 108, 40) satureiam 135,41$)$ sisimbrium 70,42 ) mentam 70,43 ) mentastrum 72,44 ) tanazitam 74,45$)$ neptam 72,46$)$ febrefugiam 62, 47) papaper 64, 48) betas 129,49$)$ vulgigina 56,50 ) mismalvas (ibischa id est alteas) ) 63 , 51) malvas 127,52 ) carvitas 116,53 ) pastinacas 117,54 ) adripias 127 , $55)$ blidas 129,56 ) ravacaulos 110,57 ) caulos 108,58 ) uniones 139 , 59) britlas 141,60 ) porros 141,61 ) rarlices 113,62 ) ascalonicas 139 , 63) cepas 139,64$)$ alia 142,65$)$ warentiam 82,66 ) cardones 121, 67) fabas majores 100,68$)$ pisos Mauriscos 95, 69) coriandrum 133, 70) cerfolium 126, 71) lacteridas 58, 72) sclareiam 134.

Et ille hortulanus habeat super domum suum 73) Jovis barbam 79.

De arboribus volumus quod habeant 74 ) pomarios diversi generis 144, 75) pirarios div. gen. 145, 76) prunarios div. gen. 152, 77) sorbarios 147,78$)$ mespilarios 148,79$)$ castanearios 159,80$)$ persicarios div. gen. 154,81 ) cotoniarios 146,82 ) avellanarios 160, 83) amandalarios 158, 84) morarios 156, 85) lauros 47, 86) pinos 161, 87) ficus 157. 88) nucarios 159,89$)$ ceresarios div. gen. 148. Malorum nomina: gozmaringa, geroldinga, crevedelli, spirauca, dulcia, acriores, omnia servitoria, et subito comessura, primitiva. Perariciis servatoria trium et quartum genus, dulciores et cocciores et serotina."

70. "Wir wollen, dass man im Garten alle Kräuter habe, nämlich 1) Lilie, 2) Rosen, 3) Griechisch Heu, 4) Frauenminze, 5) Salbei, 6) Raute, 7) Eberraute, 8) Gurken, 9) Melonen, 10) Flaschenkiirbisse,

1) Die Lesart leiusticum, die nur dadurch entstanden ist, dass der Schreiber den Punkt fälschlich über den ersten statt über den dritten Strich gesetzt hat, ist zu verwerfen, da sich sonst immer leuisticum findet.

2) Zusatz von späterer Hand. 
11) Stangenbohnen, 12) Kreuzkümmel, 13) Rosmarin, 14) Kümmel, 15) Kïhererbsen, 16) Mleerzwiebel, 17) Schwertlilie, 18) Drachenwurz, 19) Anis, 20) Koloquinten, 21) Cichorie, 22) Ammi, 23) I Laserkraut, 24) Salat, 25) Schwarzkïmmel, 26) Rauke, 27) Kresse, 28) Klette (oder Pestwurz), 29) Polei, 30) Schwarzes Gemüse, 31) Petersilie, 32) Sellerie, 33) Liebstöckel, 34) Sadebaum, 35) Dill, 36) Fenchel, 37) Endivien, 38) Diptam, 39) Senf, 40) Bohnenkraut, 41) Krauseminze, 42) Bachminze, 43) wilde Minze, 44) Rainfarn, 45) Katzenminze, 46) Mutterkraut, 47) Mohn, 48) Mangolt, 49) Haselwurz, 50) Eibisch, 51) Malven. 52) Möhren, 53) Pastinakwurzel, 54) Gartenmelde, 55) Amarant, 56) Kohlrabi, 57) Kíohl, 58) Sommerzwiebeln, 59) Schnittlauch, 60) Porree. 61) Rettich, 62 u. 63) Zwiebeln. 64) Kuoblauch, 65) Krapp, 66) Artischocken (oder Weberkarden), 67) grosse Bohnen, 68) Kapuzinererbsen, 68) Koriander, 70) Kerbel, 71) Springkraut, 72) Muskatellersalbei. Und der Gärtner soll auf seinem Hause 73) Hauslauch haben. Von Bäumen wollen wir, dass man habe 74) Apfelbäume verschiedener Art, 75) Birnbäume versch. Art. 76) Pflaumenbäume versch. Art, 77) Speierlinge, 78) Mispelbäume, 79) Edelkastanien, 80) Pfirsichbäume versch. Art, 81) Quittenbäume, 82) Haselnusssträucher, 83) Mandelbäume, 84) Maulbeerbäıme, 85) Lorbeerbäume, 86) Pinien, 87) Feigenbäume, 88) Nussbäume, 89) Kirschbäume versch. Art. Namen der Äpfel: Gozmaringer, Geroldinger, Crevedeller, Spirauker, süsse, säuerliche, alle Daueräpfel und solche, die rasch gegessen werden müssen, die Frühreifen.

Der letzte Satz ist so arg entstellt, dass er sich nicht übersetzen lïsst. PERTz meint, dass nach Aufzählung der Apfelrassen, die gebaut werden sollten, nun auch die Birnen hätten dran kommen müssen, und dass der Sinn des Satzes etwa folgender sein könne: Von den Birnbäumen, die haltbare Birnen (servatoria) tragen, soll man drei oder vier Sorten haben, süssere und reifere (?) und spätreife.

\section{Entwurf zu einem Klostergarten}

aus dem 9. Jahrhundert.

In „Bauriss des Klosters St. Gallen vom Jahr 820“ 1 ) befindet sich auf der östlichen Seite oben neben der Wohnung der Ärte ein Garten mit Heilpflanzen, unten neben der Wohnung des Gärtners und

$\left.{ }^{1}\right)$ Im Facsimile herausgegeben und erläutert von Ferdin and Keller, Zürich, bei JLeier und Zeller, 1844, $4^{0}$; mit einer lithographierten Tafel. - Dierauer, Ther di. Gartenumlagen in St. Gallischen Klosterplan vom Jahre 830 (mit einer Taf.l); Bericht iib)r clie Thätigkeit der St. Gallischen natw. Ges. während d. Vereinsjahres $1872-73$, St. Gallen 1874 , S. $434-446$. 
seiner Gehülfen ein Garten mit Gemüsepflanzen. Jerles Beet dieser beiden Gürten trägt einen Pflanzennamen. Nördlich rom Gemüsegarten liegt der Friedhof, zivischen dessen Gräbern neben eine stetig wiederkehrende, arabeskenartige Figur die Namen ron Obstbäumen hineingeschrieben sind.

Der Garten der Heilptlanzen hat seinen Eingang am Westende der Südseite; an jeder Seite befinden sich je zwei Beete, die zusammen eine Art Einfriedigung bilden. Beginnen wir an der Südwestecke und schreiten nach Norden und dementsprechend weiter fort, bis wir wieder an den Eingang gelangen, so passieren wir folgende PHanzen:

1) lilium $33,{ }^{1}$ ) Lilie; 2) rosas 34 , Rosen; 3) fasiolo 98, eine Art Bohnen; 4) sataregia 135, Bohnenkraut; 5) costo 73, Frauenminze; 6) fena graeca 81, Griechisch Heu; 7) rosmarino 136, Rosmarin; 8) menta 70 , Minze.

Der innere Teil des Gartens ist durch einen Mittelgang mit der Aufschrift "herbularius" in eine nördliche und südliche Hälfte mit je vier Beeten geteilt. Beginnen wir wieder im Westen, so trägt die südliche Reihe folgende Pflanzen:

9) salvia 133 , Salbei; 10) ruta 69 , Raute; 11) gladiola 43 , Schwertlilie; 12) pulegium 72, Polei; die nördliche Reihe folgende:

13) sisimbria 70 , Krauseminze; 14) cumino 131, Krenzkümmel; 15) lubestico 67, Liebstöckel; 16) feniculum 132, Fenchel.

Der Gemüsegarten, „hortus“, ist mit einer Einfriedigung versehen: in der Mitte der Westseite befindet sich der Eingang. Durch einen Mittelgang mit der Aufschrift „hic plantata holerum pulchre nascentia vernant" (hier spriessen die hübsch aufwachsenden Gemüsepflanzen) wird der von einem breiten Wege umschlossene Garten ebenso wie oben in eine nördliche und südliche Hälfte geteilt: jede von dieser besteht aus 9 Beeten. Verfahren wir wie oben angegeben, so erhalten wir folgende Pflanzen :

1) cepas $140, Z$ wiebeln; 2) porros 141 , Porree; 3) apium 119 , Sellerie; 4) coliandrum 133, Koriander: 5) anetum 132, Dill: 6) papaver 64, Moln; 7) radices 113, Rettiche; 8) magones ${ }^{2}$ ) 6t, Mohn: 9) betas 129, rote Beet oder Mangolt; 10) alius 142, Knoblauch; 11) ascolonias 138, eine Art Zwiebeln; 12) petrosilium 120, Petersilie; 13) cerefolium 126, Kerbel; 14) lactuca 104, Salat; 15) sataregia 135, Bohnen-

1) Die beigefügten Zahlen verweisen auf die Seiten dieses Buches.

2) Der Herausgeber, Ferdinand KeLter, will magones unter Anlehnung an das italienische majugole als JIohrrübe deuten; inclessen ist es fraglich, ob zwischen den beiden genannten Worten ein sprachlicher Zusammenhang überbaupt besteht. Der Molnsamen heisst machones (Sum. 40, 79), magonus (L. Diefexpuch, Glossarium ete. 1857, S. 343); im CGL II finden sich die Formen michonus und mahunus als Namen des Mohns. 
kraut: 16) pastinachus 116, Pastinakwurzeln oder M[ohrrüben: 17) caulas 108, Kohl; 18) gitto 132, Schwarzkümmel.

Die Bäume des Begräbnisplatzes sind unregelmässig verteilt. Bègimnen wir am Westrande und gehen jedesnal von Norden nach Süden, so erhalten wir 5 Reihen, von denen die erste 6 , die zweite und dritte je 2, die vierte 3 und die fünfte 2 Bäume enthält. Die Namen des ursten, zweiten und vierten Baumes sind nur unvollständig erhalten.

1) Mal ...., vielleicht malus oder malinus ${ }^{1}$ ) 144 , Apfelbaum; 2) ... perarius $\left.{ }^{2}\right)$ 145, Birnbaum: 3) prunarius 152, Pflaumenbaum: 4) pinus ") 161, Pinie: 5) sorbarius 147, Speierling: 6) mispolarius 148, Mispelbaum: 7) laurus $4 \overline{7}$, Lorbeer: 8) castenarius 159, Edelkastanie: 9) ficus 157. Feigenbaum: 10) guduniarius 146, Quittenbaum: 11) persicus 154, Pfirsichbaum: 12) avellenarius 160, Haselnussstrauch: 13) amendelarius 158, Mandelbaum: 14) murarius 156, Maulbeerbaum: 15) nugarius 159, Nussbaum.

Ob alle hier genannten Pflanzennamen richtig gelesen sind, und ob nicht vielmehr eine erneute Prüfung der Handschrift etwas veränderte Namen ergeben würde, mag dahingestellt bleiben. Sie bieten in der hier mitgeteilten Form eine Reihe von Eigentümlichkeiten. Auffallend sind die vielen Ablative: fasiolo, costo, rosmarino, cumino, lubestico, gitto: ferner die Formen sataregia und fenagraeca für saturegia und fenigraecum oder fenograecum: endlich guduniarius für cotoniarius, nugarius für nucarius, murarius für morarius etc. Mran erhält den Eindruck, als ob die rerschiedenen Namen aus dem Gedächtnis in die einzelnen Beete hineingeschrieben wären; dafür spricht auch der Umstand, dass der Mohn im Küchengarten unter zwei verschiedenen Namen, papaver und magones, rorkommt, sowie dass sataregia unter den Heilpflanzen sowohl wie unter den Gemüsen genannt wird, endlich dass Elyerraute, Bufbohne, Gurke und andere sehr gewöhnliche Pflanzen fehlen.

Der Herausgeber des Baurisses, FERDinand KELLER, glaul, dass der Bauriss direkt durch die Capitularien Karls des Grossen beeinHlusst worden sei. Bei Besprechung der Obstbäume, (S. 35) bemerkt er: „Alle diese Bäune sind der Reihe nach aus dem Capitulare de villis ah)geschrieben;"“ den ersten nimmt er jedoch aus. Wemn ein solches Abschreiben wirklich stattgefunden haben sollte, so ist nicht recht zu heareifen, weshalb das gewöhnliche Wort für Apfelbaum, pomarius, mit rinem seltenen Wort vertauscht worden ist; iusserdem ist die Reihenfolge des Capitulare nicht imnegehalten und statt der dort gebrauchten

1) Der Herausgeber will malarius ergänzen; diese Form kommt aber nirgendwo sonst vor; bei Diefinizacir, Novum glossarium etc. 1867, findet sich S. 244 die Glosse malinum affoltren.

2) Auf dem Grundriss selbst befinden sich vor perarius einige Punkte; die Form perarius statt pirarius kommt auch sonst vor.

${ }^{3}$ ) pinus ist Deutung des Herausgebers und fehlt bei Dienater. 
Namen finden sich andere, veränderte, mindestens seltene. Auf S. 4 teilt der Herausgeber mit, dass mehrere auf dem Pergament fast ausgelöschte Baum- und Pflanzennamen sich mit Hülfe des Capitulare de villis hätten enträtseln lassen. Auch dies ist nicht weiter wunderbar. denn zu Anfang des 9. Jahrhunderts werden in allen Benedictinerklöstern die Nutzpflanzen ziemlich dieselben lateinischen Namen geführt hahen; auf die Aussprache dieser Namen konnte allerdings die Muttersprache der Mönche Einfluss haben, und dadurch auch auf die Schreibweise.

Endlich sagt der Herausgeber (א. 11), „dass der Baumeister, der den Plan entwarf, die für die Klöster in den Capitularien Karls des Grossen aufgestellten Regeln und Vorschriften genau berücksichtigte." Auch hieraus lässt sich ein Einfluss von Karls des Grossen Capitularien auf den Verfertiger des Baurisses mit Sicherheit nicht herleiten; denn der Baumeister konnte als Benedictinermönch recht wohl in seinem Bauriss alle die Regeln und Vorschriften durch seine Zeichnumgen zum Ausdruck bringen, die derjenige Benedictinermönch, der das eine oder andere Capitulare entwarf, schriftlich zum Ausdruck brachte.

Der Bauriss des Klosters St. Gallen ist niemals zur Ausführung gelangt, sondern ein Idealplan eines begüterten Klosters geblieben.

\section{Der Hortulus.}

des Walafridus Strabus.

Walafridus Strabus, ein Schwabe, besuchte die Schule zu Fulda. Im Jahre 825 befand er sich als Mï̈nch im Benedictinerkloster Reichenau und wurde dort 842 im Alter von 35 Jahren zum Abt erwählt. Ludwig der Deutsche schickte ihn im .Jahre 849 als Gesandten an seinen Bruder Karl den Kahlen nach Frankreich; auf dieser Reise starb er, nur 42 Jahre alt (Meyer III, S. 422 ff.).

Der "Hortulus" (das Gärtchen), dessen letzte Ausgabe wir F. A. REUSS verdanken, ${ }^{1}$ ) ist ein Gedicht von 444 Hexametern. Es zerfällt in 25 Abschnitte; im ersten, der Torrede $(1-75)$, singt Walafridus dem ländlichen Leben und dem Acker- und Gartenbau ein Loblied; dann erzählt er, wie er ein Fleckchen vor seiner Thür von Nesseln gereinigt, gedüngt, bewässert und bepflanzt habe; im Schluss (429-444)

$\left.{ }^{1}\right)$ Walafridi Strabi Hortulus. Accedunt analecta ad antiquitates florae germanicae etc. auctore F. A. Reuss, MI. D. Wirceburgi $1834,8^{\circ}$. 
widmet er sein Gedicht dem Abte Grimaldus von St. Gallen. Die besungenen Pflauzen sind der Reihe nach: 1) Salvia, 76-82, Salbei; 2) ruta, 83-90, Raute; 3) abrotanum, 91-98, Eberraute; 4) cucurbita, 99-151, Flaschenkürbis; hier wird 114 die Erle, alnus, erwähnt; 5) pepones, 152-180, Melonen; 6) absinthium, 181-196, Wermut; 7) marrubium. 197-207, Andorn; 8) jeniculum, 208-216, Fenchel; 9) gladiola, 217-228, Iris, Schwertlilie; in 220 wird das Gartenveilchen, viola nigella, erwähnt; 10) libysticum, 229-234, Liebstöckel; 11) cerefolium, 235-247, Kerbel; 12) lilium, 248-261, Lilie; 13) papaver, 262-274, Mohn; 14) sclarea, 275-283, Muskatellersalbei; in 281 wird die Frauenminze, hortensis costus, erwähnt; 15) mentha, 284-299, Minze, Krauseminze: in 292 wird der Attich oder Zwergholunder, ebulus, erwähnt; 16) pulegium, 300-326. Polei; 17) apium. 327-336, Sellerie; 18) betonica, 337-358, Betonika; 19) agrimonia, 359-368, Odermennig; 20) ambrosia, 368-374: wahrscheinlich die krausblättrige Form des Rainfarns; 21) nepeta, 375-386, Katzenminze; 22) raphanus, 387-391, Rettich; 23) rosa, 392-428, Rose; hier wird die Lilie mehrfach erwähnt. Endlich wird noch im Schlussgedicht, 434, der Pfirsichbaum, persicus, genannt.

\section{Glossae Theotiscae,}

alii Codici Canonum Ecclesiasticorum, Seculo IX. adscriptae. (Commentarii de rebus Franciae orientalis et Episcopatus Wirceburgensis etc. auctore

J. G. ab Eckhart. Wirceburgi 1729 fol. . Tom. II, p. 980, 981).

Im Folgenden steht man. für manipulus, eine Handvoll; das im Codex benutzte Zeichen für Drachme: $\dot{\sim}$ ist durch dr. ersetzt. Die althochrleutschen Namen sind im Codex über die lateinischen geschrieben, so wie es hier nachzuahmen versucht ist; in diesen Namen entspricht das ru oder uu unserem w. Nur denjenigen Namen, die im Vorherrehenden noch keine Erklärung gefunden haben, ist eine solche in der Form von Anmerkungen hinzugefügt. - Die althochdeutschen Namen sind cursiv gedruckt.

„Pulvis contra omnes febres et contra omuia venena, et omnium serpentium morsus, et contra omnes augustias cordis et corporis. Recipit haec ex radicibus,

vuizuuurz

diptamni partes duas, et ex speciebus herbisque subscriptis tertia pars. rosses $\operatorname{minza}$

fiat: Salvia man. II. Mentastro man. I. Lauindulae man. II. Appio 
vuizminza

sem. dr. II. Foeniculo sem. dr. II. Nepeta man. I. Pipinella ${ }^{1}$ ) man. II. turnella

gundereba

tillisamo

Tormentilla ${ }^{2}$ ) man. I. Acero $^{3}$ ) man. I. Aneti seminis dr. I. Gamendrea ${ }^{4}$ ) man. I. Ruta unc. I. Centauria ${ }^{5}$ ) man. I. (amipiteus ${ }^{6}$ ) man. I. dnctret

erdbrama

tosta

cholsamo

Centonodia $^{7}$ ) man. I. Frassafolia ${ }^{5}$ ) man. I. Origano ${ }^{9}$ ) man. I. Cauli sem. funneucirpila

dr. I. Solsequia man. I. Jua ${ }^{10}$ ) man. I. Bislingua ${ }^{11}$ ) man. I. Petrounegerich chraneunito

selini sem. dr. I. Plantagine $\left.{ }^{12}\right)$ man. I. Aitiotidus ${ }^{13}$ ) dr. I. Sparga ${ }^{14}$ ) Iteinpreha

man. I. Quinquefolia ${ }^{15}$ ) man. I. Saxifragae ${ }^{16}$ ) sem. dr. I. Vincareinefano similiter

tossica ${ }^{17}$ ) man. I. Hyssopi sem. dr. I. Tanaceto man. I. Benedicta ${ }^{15}$ ) denicleta gartminza

hanoffamo

man. I. Agrimonia ${ }^{19}$ ) man. I. Menta nigra ${ }^{20}$ ) man. I. Canape sem. madalger

dr. I. Basilisca ${ }^{21}$ ) man. I. Alleluia ${ }^{22}$ ) man. I. Cerofolio sem. dr. I. Ituina cuenula unerimuota

Sauina ${ }^{23}$ ) man. I. Satureia man. I. Absinthio man. I. Artemisia gатеииа

man. I. Millefolio ${ }^{24}$ ) man. I. Febrefugia ${ }^{25}$ ) man. I. Nimphaea ${ }^{26}$ ) man. I. Puleium ${ }^{27}$ ) man. I.

De pigmentis vero Zaduar ${ }^{28}$ ) dr. IIII. Cinnamum ${ }^{2 y}$ ) dr. I. Gingiber ${ }^{30}$ ) dr. I. Costo ${ }^{31}$ ) dr. I. Reopontico ${ }^{32}$ ) dr. (fehlt). Pipere ${ }^{33}$ ) dr. I. Gentiana ${ }^{34}$ ) dr. I. Gariofilae ${ }^{35}$ ) dr. I.

Fac pulverem subtilissimum, dabis bibere ad omnes necessitates cum vino calido vel aqua calida, quantum cum tribus digitis capere potest, mustum ${ }^{36}$ ) tillessano, dosto, foeniculi sem. (ntron, ${ }^{37}$ ) betenia, ${ }^{35}$ ) mago, $\left.{ }^{39}\right)$ polei, apii semen, petroselini, cumin, cinnamomum, ${ }^{239}$ ) gingiber, ${ }^{30}$ ) galangan, $\left.{ }^{40}\right)$, figa. $\left.{ }^{+1}\right)$

Infusio capitis mirra ${ }^{42}$ ), savina, marrubium, huosuuur $z$, apium, foeniculum, thus masculinum, ${ }^{43}$ ) halasalz, ${ }^{44}$ ) erdebuh..45)

1) Pimpinella Saxifraga L., Pimpernell, Bibernell; die Apotheker führten früher die Blätter als Herba Pimpinellae. 2) Tormentilla erecta L.; "Herba Tormentillae". 3) Glechoma hederacea L., Gundermann, Gundelrebe. ") Teucrium Chamaedrys L., Gamander. ${ }^{5}$ ) Erythraea Centaurium L., Tausendgüldenkraut; altes Fiebermittel. 6) Ajuga Chamaepitys Schreb.; „Herba Chamaepityos". ") Polygonum aviculare L., Vogelkuöterich; der übergeschriehene Name enthält einen Schreib- oder Lesefehler; ein alter deutscher Name ist wegetrede; lateinische Namen giebt es viele: centumnodia, sanguinaria efc. ${ }^{8}$ ) Die Blätter der Erdbeere (fr. fraisier), die sonst fragefolia heissen (Sum. 62,18). 9) Origanum vulgare L., Dosten. ${ }^{10}$ ) Ajuga Iva Schreb., dessen Blätter noch heute in manchen Gegenden den Namen "Iwakraut" führen. ${ }^{11}$ ) Ruscus Hypoglossum L., Zäpfchen- oder Bonifaciuskraut; "Herba Bislinguae". 12) Plantago major L. und P. lanceolata L., Wegerich. ${ }^{13}$ ) Juniperus communis L., Wachholder, in Österreich „Kranewitt"; Aitiotidus ist eine Entstellung von üркєUӨ૦५. 
$\left.{ }^{14}\right)$ sparga, heirbesurvz Sum. 23, 50. ${ }^{15}$ ) Potentilla reptans L.; „Herba Pentaphylli“. 16) Saxifraga granulata L., Steinbrech; ،lie Zwiebelchen uannte man früher Samen (semen). ${ }^{17}$ ) Vincetoxicum officinale Mnch., Schwalbenwurz. 18) Wahrscheinlich Geum urbanum L., das im Volksmunde noch vielfach Benedictenkraut heisst; die Z̈herschrift ${ }_{n}$ similiter" ist ohne Sinn. ${ }^{19}$ ) Agrimonia Eupatorium L., Odermennig; heisst auch "Leberklette"; (ler erste Teil der Überschrift ist nicht verständlich. ${ }^{20}$ ) Hier wird eine relatir kahle Jinze gemeint sein, wahrscheinlich Mentha piperita L. ${ }^{21}$ ) Bei Hoffunaxx, ahd. Gl. 6, 36 steht: madelger-basilica; basilisca muss wohl für eine Art von Arum genommen werden, denn bei Alnertus Mfagies $(6,290)$ wird basilicus oder basiliscus direkt mit dracontea und serpentaria identificiert; dasselbe geschieht Sum. 54, 64: basilisca, naternworz. Auch an Ocymum basilicum L. könnte man denken, das vielfach, allerdings in späterer Zeit, basilicon allein genannt wird (ALBERTus DLanves 6, 293). Das Wort madalger, das nach Grimms Wörterbuch ein Eigenname ist, wurde später auf Gentiana cruciata L. und kleinere Enzianarten übertragen (T.в., Bucк etc.). ${ }^{22}$ ) Oxalis acetosella L., Sauerklee; alleluia, panis caculi (statt ('uculi), lisen, suramphe (Sum. 53, 17); alleluia, gotisampher (statt gouchesampher) (Sum. 54, 35); im 16. Jahrhundert ist der Name häufig. ${ }^{23}$ ) Stuina ist eine sonst nicht vorkommende Bezeichnung des Sadehaums, vielleicht verschrieben. ${ }^{21}$ ) Achillea Jillefolium L., Schafgarbe; die alte Bezeichnung lautet meist garwa (millefolium, garwa Sum. 11,45). ${ }^{25}$ ) Chrysanthemum Parthenium Pers., Bertram, Mater, Mutterkraut; (febrifuga, metere Sum. 57, 5 und sonst vielfach). ${ }^{26}$ ) Im Wasser wachsendes Kraut; vergl. unten S. 208. ${ }^{27}$ ) Mentha Pulegium L. ${ }^{28}$ ) Curcuma Zedoaria Rose., deren Wurzel als lange Zittwerwurzel (Radix Zedoariae longa) in den Handel kommt. ${ }^{29}$ ) Die Rinde des Zimmtbaumes, Cinnamomum zeylanicum Blume und C. Cassia Blume. ${ }^{30}$ ) Ingwer, die Wurzel von Zingiber officinale Rose. ${ }^{31}$ ) Kostwurz, die Wurzel von Costus speciosus Sm. ${ }^{32}$ ) Die Wurzel von Rheum Rhaponticum L.; "Radix Rhapontici". ${ }^{33}$ ) Die Beeren von Piper nigrum L.; die vom Fruchtfleische befreiten weissen Samen geben den weissen Pfeffer. ${ }^{31}$ ) Wahrscheinlich die Wurzel von Gentiana lutea L., jedenfalls von irgend einer Enzianart. ${ }^{35}$ ) Die vor dem Aufblüheu gesammelten uxd getrockneten Blumenknospen des Gewürznelkenbaumes, Caryophyllus aromaticus L. ${ }^{36}$ ) Most. ${ }^{37}$ ) Marrubium vulgare L.; der gewöhnliche Name ist Andorn. ${ }^{38}$ ) Betonica officinalis L., Betonika. ${ }^{39}$ ) Mohn. ${ }^{40}$ ) Die Wurzel von Alpinia Galanga Sw., Galgantwurzel; "Radix Galangae". "1) Feige; carica, figa Sum. 61, 9. "2) Das Harz, "Myrrhe“, von Balsamodendron Kataf Kunth. ${ }^{43}$ ) Thus masculinum war ein besonder's geschätzter Weihrauch (CGL m: tus masculo tusbonum 595,69 ; thus masculus idest thus bono 629,64 ; tus masculi idest tus quod inarabia

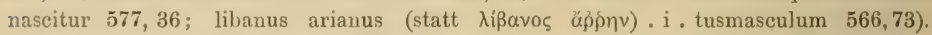
Dioskonides sagt $(1,81)$, dass der Weihrauch in Arabien entstehe ( $\gamma \in v v a ̂ \tau \alpha$ l Èv 'Apaßía)

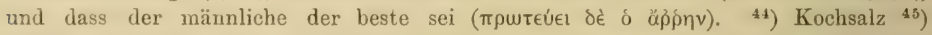
Glechoma hederacea L., Gundelrebe, die oben acer genannt wurde (Anm. 3); man muss dann erd-ebuh lesen, wo das zweite Wort Epheu bedeuten kann (ephov hedera ahd. G1. 6, 32; edero ebov Vlt. S. 372; edera, ebhov Sum. 6,67; edera, ebehowe Sum. 61,53), das Ganze also Erd-Epheu, Hedera terrestris; der letzte Name dient sehr viel zur Bezeichnung der Gundelrebe. 


\section{Anhang II.}

Die Pflanzemmamen in der „Phỵsica” der heiligen Hildegard. 

Die heilige HILDE(iARI) stammt aus ritterlichem Geschlecht und wurde im Jahre 1ors zu Bechelleim an der Nahe geboren. Seit ihrem achten Jalue lebte sic im Kloster der Benedictinerimnen zu Disibodenherg. nahm hier später den Schleier und wurde 1136 zur Äbtissin eben dieses Klosters erwählt. 11 ts bezog sie mit einigen ihrer Schmestern ein auf ihren Antrieh neu erhautes Ḱloster auf dem St. Ruprechtsherge bei Bingen, wo sie 117 a ihr Leben beschloss (nach Meyer III. S. 517).

Die gesammelten Werke der heiligen HILI)EGARD sind vor kurzem in einer neuen Ausgabe als 197. Band der Patrologie ${ }^{1}$ ) erschienen. Diejenige Schrift, welche friiher den Titel ,.Physica" a) führte, heisst jetzt: "Subtilitatum diversarum naturarum creaturarum libri novem". und füllt in der neuen Ausgabe die Columnen 1117-1352. Der 'Text ist von Dr. C. Darémberg, Bibliothekar an der Mazarinschen Bibliothek, nach einer Handschrift der kaiscrlichen Bibliothek zu Paris redigiert und mit dem Text der Strassburger Ausgabe ron 1533 rerglichen worden: die Vorrede und die Anmerkungen mit der Deutung der Namen stammen von Dr. F. A. REUSS, ehemals Professor der Nedicin in Würzburg. Es ist fraglich, ob nicht noch allerlei zu ändern und zu verbessen'n gewesen wïre, denn rie neut Ausgabe von 1882 enthïlt nicht ganz wenig Druckfehler und wahrscheinlich auch nicht wenig Lesefehler. Die deutschen TVürter, und von denen giebt es recht viele, sind an manchen Stellen verlesen oder verschrieben, z. B. bemuntz $(1,135)$ neben berlwurtz in demselben Kapitel, während 3,2 berurer steht; stembrecha $(1,136)$ neben steinbrechen $(1,68)$. und stembrecha und steinbrecka $(1,162)$; pruma als Ǩapiteliiberschrift und Anfangswort $(3,50)$ neben dem richtigen pryme etc. Hier könnte ein Germanist, der mit unseren Nutzpflanzen leidlich vertraut ist, sich noch grosse Verdienste erwerben;

1) Patrologiae cursus completus; series latina prior, accurante I. P. Migne. Tom. 197, Sancta Hildegardis Abbatissa. Paris 1882.

2) Physica S. Hildegardis. Elementorum, Fluminum aliquot Germaniae, Metallorum, Leguminum, Fructuum et Herbarum: Arborum, et Arbustorum: Piscium denique, Volatilium et Animentium terrae naturas et operationes IV Libris mirabili experientia posteritati tradens. Argentorati 1533. (Nach Meyer II, S. 271).

v. Fischer-Benzon, altd. Gartentlora. 
demn die Physica, die allerdings ein medicinisches IVerk darstellt, enthiilt die Anfänge einer deutschen Pflanzen- und Thierkunde, und ist für die Geschichte unserer Nutzpllanzen ebenso wichtig, wie die sieben Bücher "de vegetabilibus" ron ALBERTUS MAGNUS.

Eine Deutung derjenigen Pflanzennamen, welche in der Physica (ler heiligen HILDEGARL) rorkommen, ist schon von SPRENGEL rersucht morden (KURT SPRENGEL. Geschichte der Botanik, Bd. I, Altenburg und Leipzig 1817. S. $200-202$ ); er legte jedoch dem Wurke keinen besonderen TVert bei und seine Deutungen sind sämtlich ohne Begriundung, lassen sich also kaum verwerten.

Von sehr viel grösserer Wichtigkeit sind die Deutungen, welche ERIST MEIER in seiner Geschichte der Botanik, Bd. 3, S. 524-536. rerïffentlicht hat. Er hat allerdings den mangelhaften Text der Strasslurger Ausgabe benutzen müssen, verfügte aber schon über sehr viel mehr Hülfsmittel als SPRExGEL zu Gebote standen: er lionnte die gleich zu erwähnende Arbeit von REuss benutzen und ausserdem eine grosse Anzahl ron gedruckten Glossaren. Mauche seiner Deutungen sind rlurch den besseren Text der neuen Pariser Ausgabe bestätigt worden.

Am eingehendsten hat sich wohl F. A. REUSS, Professor der Medicin an der Universität Würzburg, mit den Pflanzennamen der heiligen HILDEGARD beschäftigt. Zuerst in den "Analecta ad antiquitates Horae Germanicae", die als Anhang seiner kleinen Schrift "Walafridi Strabi Hortulus". Würzburg 1834, hinzugefügt sind: auf S. 76-80 werden die Namen der Kräuter und Bäume aufgeführt und in Form ron Anmerkungen werlen die Deutungen gegeben, zum grössten Teile leider anch ohne Begründlung, vielfach mit Anlehuung an SPRENGEL; darauf in einer mir nicht zugänglichen Schrift „De libris physicis S. Hildegardis, commentatio historico-medica, Wirceburgi 1835", deren Inhalt aber in die neue Pariser Ausgabe der Werke der heiligen HILDEGARD übergengangen ist. Diese nene Ausgabe kündigte MEYER in der Vorrecle zum 4. Bande seiner Geschichte der Botanik als im Jahr 1857 bereits erschienen an: vielleicht ist die Ausgabe von 1882 ein Neudruck, und die oben gerügten Fehler sind dann diesem Neudruck zum grössten Teile zur Last zu legen. Die Deutungen von REuss waren für die Zeit von 1857 als erschïpfend zu betrachten, man darf sich aber nicht wundern, wenu einige von ihnen sich mittlerweile als unrichtig erwiesen haben.

Die neuesten Deutungen erschienen im Jahre 1882, und zwar an ciner Stelle, wo man sie kaum suchen würde, nämlich in "Analecta Sacrat spicilegio Solesmensi parata ediclit Joannes Baptista Card. Pitra, Episcopus 'Tusculanus S'. E. R. Bibliothecarius. Tom. VIII. Nova S. Hildegardis opera. Parisiis 1882"; Herr Bibliothekar Dr. W etzel hatte di. Freundlichkeit, mich auf dieses Buch aufmerksam zu machen. Hier spricht der Cardinal PITRA, S. 496, 497, von der unbekamnten Sprache, in rer die heilige HU,DE(;ARI) etwa 1000 Wörter, teils mit lateinischer, 
teils mit deutscher Ü̈bersetzung niedergeschrieben hat, und auf S. 498 . bis 502 giebt er unter dem Titel "S. Hildegardis Herbarium" die Deutung von 180 darin enthaltenen Pflanzennamen, so zwar, dass jede der in 5 Columnen geteilten Seiten in der ersten Columne die Nummer enthält, welche der betreffende Name im Codex führt; in der zweiten die lateinischen und deutschen Namen, welche denen der fremden Sprache linzugefügt sind (latina Hildegardis nomina); in der dritten die Namen der fremden Sprache (lingua ignota); in der vierten die Deutungen des Cardinals PIT'RA (recentiorum vocabuli) und endlich in der fuinften Columne die Namen aus der nenen Pariser Ausgabe von 1882 (ex libro subtilitatum etc.). Da die Namen der ersten Columne alphabetisch geordnet sind, so ist ihre Durchsicht und Benutzung sehr erleichtert; es kommen unter ihnen solche vor, die in der neuen Ausgabe fehlen and teilweise sich nicht deuten lassen, teilweise aber eine wertvolle Ergänzung zu den schon bekamnten darbieten. Für die Deutungen (non mediocris laboris fructus S. 496) ist die gleich zu erwähnende Arbeit WILHELII GRIMIS benutzt, ausserdem aber natürlich auch, da die nene Ausgabe der "Physica" in der Patrologie erwähnt wird, dasjenige, was REt'ss dieser Ausgabe hinzugefügt hat; im allgemeinen stimmen deshall, diese Deutungen zu denen von REuss.

Mit der "lingua ignota" der heiligen HILDEGARD hat sich schon

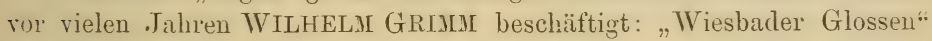
in II oritz Ha upt's Zeitschrift für deutsches Alterthum, Bd. 6, Leipzig 1s48, S. 321-340. GRIn[ behandelt nur 80 Pflanzenuamen, No. 184 bis 263 , S. 323, 324, und fügt deu meisten eine eingehendere Erläuterung hinzu. Über die "lingua ignota" urteilt er nicht sehr freundlich: er hält sie für ein willkïrliches Machwerk.

Für uns ist die "Physica" der heiligen HILDEGARD besonder's wichtig durch die zahlreichen darin vorkommenden deutschen Pflanzennimmen. Diese finden sich namentlich in der Pariser Ausgabe und zwar im ersten Buche "De plantis" und im dritten "De arboribus". In der Strassburger Ausgabe war die Einteilung eine andere; daselbst wurden (wach MEYER) die Kräuter abgehandelt in Buch 2, "De naturis et effectibus leguminum, fructuum et herbarum“. die Büume in Buch 3, „De naturis et effectibus arborum arbustorum et fruticum, fructuumque eorundem." Diese Einteilung ist keineswegs strenge durcbgeführt, es finden sich sogar in jedem der beiden Buicher Dinge, die überhaupt nicht lineingehöreu. Im Folgenden sind jedoch alle vorkommenden Namen ohne Unterschied behandelt.

Um dem Leser die Übersicht möglichst zu erleichtern, ist die alphabetische Reihenfolge gewählt; man reisst dadurch zwar vielfach Verwandtes auseinander, aber das ist am Ende zu ertragen, um so mehr, als in einer systematischen Anordnung viele Namen iiberhaupt nicht unterzubringen gewesen wären. Im Folgenden bedeuten die nicht ein- 
geliammerten Zahlen Buch und Kalpitel der Pariser Ausgale: komut eine Pflanze in einem Kapitel vor, ohne in der Überschrift genamnt zu sein. so ist die Nummer des betreffenden Kapitels in runde Klammern () eingeschlossen: in eckigen Klammern [] stehen Buch und Kapitel der Strasshurger Ausgahe. Die deutschen Namen, soweit ich sie erkemen konnte, sind cursir gedruckt, die lateinischen gesperrt. An Abkiirzungen sind ausser den schon bekannten noch die folgenden gebraucht:

Pitra ist den Pflunzennamen hinzugefügt, die in dem von Cardinal PITRA redigierten „S. Hildegardis Herharium“ rorkommen, und

(irimm denjenigen, die sich in den von W. GRIJIs herausgegebenen „Wiesbader Glossen" finden.

Ein Verweisen von einem Namen auf den anderen liess sich nicht ganz vermeiden: in der Regel ist jedem Namen eine Deutung hinzugefïgt, trotzdem aber auf die Stelle verwiesen, wo genanere Auskunft zu finclen ist. Die ursprüugliche Einteilung in zwei Bücher, ron denen eines die Pflanzen (Kräuter), das andere die Büume behandelt, ist beibehalten worden, obgleich die heilige HILDE(iARD selbst diese Einteilung seh. wenig strenge innegehalten hat. Dass eine und dieselbe Pflanze unter zwei rerschiedenen Namen aufgeführt wird, ist eine Thatsache, die sich ausser bei der heiligen HILDE(iARI) bei fast allen Schriftstellern findet, die ihre Aufzeichnungen nicht durch ein Pflanzen-System kıntrolieren konnten.

\section{Erstes Buch. \\ Von den Kräutern (de plantis).}

A brotanum $(106,126) ;[2,117]$; Artemisia Abrotanum L., Stabwurz; vergl. Stagwurtz.

Absinthium $(109,64)$ : 2, 119]: Artemisia Absinthium L., Wermut; vergl. Wermuda.

Acer Pitra: wahrscheinlich der lateinische Name von Gunderelu, das man vergleichen wolle.

A cetum 183; Essig, Weinessig (acetum vini est); weiterhin ist ron einem eszigkalp die Rede, das im Essig liegt; hiermit sind wohl Algen- oder Pilzvegetationen in Essig gemeint.

Ackeleia (210) und acoleia 132, dasselbe wie Agleia 132; [2, 140]; Aquilegia vulgaris L., Akelei.

Agrimonia $114 ;(126 ; 3,30) ;[2,123]$; Agrimonia Eupatorium L., Odermenuig.

Alant 95; Enula $[2,67]$; Inula Helenium L., Alant.

Alentidium 124; [2, 132]; ist dem Texte nach identisch mit $G(t-$ mandrea, Teucrium Chamaedrys L., das auch heute noch Gamander heisst. 
Allium 79; $(63,90) ;[2,46]$; Allium sativum L., Knoblauch. Aloё 174 u. 224; $(13) ;[3,6]$; Aloe vulgaris Lam., Aloe.

Alstureh 80; A schalonia $[2,47]$ : ungewiss, vielleicht unscre Schalotte: vergl. S. 139.

Ainphora 41 : [2, 27]: Rumex Acetosa L., Sauerampfer: acidula amphera Sum. 60, 5 (11. Jahrh.); acitula ampfro Sum. 21, 15.

Ancorn $(174 ; 124)$, dasselbe wie

Audron 33: Marrubium [2, 82]: Marrubium vulgare L., Andorn; die

Form antron kam schon oben S. 190 vor; auch findet sich marrubium antron unter den Glossen zum Macer (14. Jahrh.) bei Mone, Anzeiger zur Kunde der teutschen Vorzeit etc. Bd. 8, S. 97.

Anetum $(67,66) ;[2,32]$; Anethum graveolens L.; vergl. Dille. A piago (59); $[2,104]$; Melissa officinalis L.; vergl. Binsuga.

Apium (69); $[2,34]$; Apium graveolens L., Sellerie.

A quileja Pitra; vergl. Ackeleia.

Aristologia longa (111) im Zusatz aus [2, 70]: (167): Aristolochii

longa L.; im Text von 126 kommt aristologia allein vor.

Artemisia 107; $[2,71]$ : Artemisia vulgaris L., Beifuss: vergl. Biboz. Arundo Pitra; Arundo Phragmites L., Schilfrohr.

A sarum 212; (66): [थ, 167]: Asarum europaeum L., Haselwurz, die man vergleichen wolle; im Text von 114 steht a serum.

Aschalonia, Alslench $80 ;[\because, 47]$ : ungewiss, vielleicht unsere Schalotte; vergl. S 139.

Astrencin 167: $[2,161]$ : Imperatoria Ostruthium L., Meisterwurz; hiess im 16. Jahrhundert Astrenz, während Astrantia major L., die von den Viitern der Botanik Imperatoria nigra genannt wurde, schwartz Astrenz hiess; astricum astrenza Sum. 60,32; ostricion gerese vel ostriz Sum. 66,45 .

Atich (120); Sambucus Ebulus L., Attich; vergl. Hatich.

Attriplex 104: [, 115]: Atriplex hortensis L., Gartenmelde; vergl. Melda.

Babela 97: Malva $[2,107]$ : Malva silvestris L., Käsepappel; vor dem Genuss der rohen Pflanze wird gewarnt, "quia slimecht est"; gekocht dagegen als mus: wird sie Leuten mit schwachem Magen empfohlen. Bachiminza $(126 ; 67)$ und

Bartmmytza $75:[2,+1]$ : Mentha aquatica L., Bachminze; eimmal bacymntza, einmal bachmyntzta und einmal bachmyncza geschrieben; Sisimb) ria bei Pitra kam zu dieser und der folgenden Pflanze als Synonym gezogen werden.

Bir ls a mi t a $195:(3,5):[\because, 45]$ : Tanacetum Balsamita L., Frauenminze. Balsamon 177 ; $[3,5]$; echter Balsam, stammt vom Balsambaum, Balsamondendron gileadense Kunth.

Basilia (212): vielleicht Ocymum Basilicum L.. Basilie. ebenso wie Basilica $(126 ; 173 ; 3,5)$. 
Basilise a 230: wahrscheinlich eine Arumart. wie Arum italicum L.. das noch-hente im Elsass gebaut wird; vergl. S. 53.

Bathemia 128: Pandonia [2.135]: Betonica officinalis L., Betmie: diese sehr geschätzte Pflanze hat sehr vielfache Namensentstellungen erfahren; in 37 steht bathemam, in 3,5 bathemen und bachenia.

Benedicta 163: [2. 162]: Geum urbanum L.. Benediktenkraut: bei Albertus Magnus $(6,470)$ benedicta oder gariofilata.

Bronin 127: Dactylosa [2. 134] : Pateonia officinalis L.. Päonie: Lronir paeonia ahd. Gl. 6,33; in den Libris Dynamidiorum S. 456 (nach Meyer III. S. 496) wird Dactylus als Synonym von Paeonia genannt. Berexink Pitra: mbekannt. wem es nicht pervinca. unser Immeroriun sein kann.

Bertram 18: (144: 169): Piretrum [2, 21]: die Pflanzenglossare geben meist piretrum bertram, womit nichts anzufangen ist; der Name Bertrem haftet an rerschiedenen Pflanzen: Bertramswurzel. Radix Prrethri, ist die Wurzel von Anacyclus officinarum Hayne; diese kann hier kaum gemeint sein. da Gesunden und Krranken empfohlen wird. levtram zu essen. doch kommt, man zu keiner sicheren Entscheidung. weil die Bertramswurzel gebraucht wird, um Essig einen besseren Geschmack zu verleihen. Mit Bertram wird auch Chrysanthemum Parthenium Pers. bezeichnet, das auch LIater und Metra heisst; vergl. Metra.

Brment= 135: (3, 2) $)$ [2. 142]: Meum athamanticum Jaçuin. Bärenwurz: Albertus Magnus (6.272) nemnt die Pflanze meu oder radix ursi: hei den Vätern der Botanik heisst sie Bärwurtz.

Bibmella 131: (3. 23): [2. 139]: Pimpinella Saxifraga L.. Pimpernell. Bibernell: im Text von 17 und 167 steht bibinella wie bei Pitra. Biboz 107; Artemisia vulgaris L., Beifuss.

Binsuga 59; A piago [2, 104]; Melissa officinalis L., Melisse.

Bilst 110: [2, 120]: Hyoscyamus niger L.. Bilsenkraut: der lateinische Name dieser Pflanze war früher jusquiamus, eine Entstellung ron ioбkúquos. \%. B. bei ALBERTus Mra(iNo's (6.362): jusquiamus. litive Sum. 62,42 ; jusquiamus, bilse Sum. 57, 32.

Birelum/ 166: |2.167|: Tormentilla erecta L.. Blutkraut: im T'exte steht: birckwurtz quae est blutwourtz.

Bisantia Pitra: unbekannt.

Biwerwurtz (146); Aristolochia Clematitis L.; vergl. Bywervurtz. lilat ndonia (123: 100): |2.131|: Verbascum Thapsus L.: vergl. Wulena. Blutwurtz (166); 'Tormentilla erecta L.; vergl. Birckwurtz.

Bobermlla 58: Physalis Alkekengi L.. Schlutte: der Name Boberelle finclet sich in dieser Bedentung noch bei HIERONYJus BOcK, TABERAAEmoNTANis etc.; lateinische Namen dieser Pflanze aus dem 16. Tahrlmurlert sind Halicacabum. Alkekengi und Solanum vesicarium. 
Borith 201: [2.72]: eine saftreiche Pflanze. deren gequetschte Blätter gegen Augenleiden etc. empfohlen werden; ist nicht zu bestimmen; bei ALBERTUs MA(rNes (6.396) wird eine Pflanze borith erwähnt. die zum Waschen ron Leinen gebraucht werden kann: diese soll nach JEsSEN Salsola fruticosa L. sein. die an den Kïisten des Mittelmeeres wächst. bei der heiligen HILDEGARD also nicht gemeint sein kimn.

Brachwurtz 54; (164; 166); Esula [2, 100]; Euphorbia Esula L.; die Wurzel und deren Rinde war seit alten Zeiten officinell: „Radix et Cortex radicis Esulae s. Tithymali": unter demselben Namen gingen Wurzel und Rinde von Euphorbia Cyparissias L. - Eusole hrechur: Sum. 62, 7 .

Bramber, wächst auf.

Brema 169; $[2,177]$; Rubus sp., Brombeerbusch mit seinen Frïchten. Brionia (43); 204; [2, 87]; Bryonia sp., Zaunrübe; vergl. Stichwurtz.

Bumcrasse 73; [2,39]; Nasturtium officinale R. Br., Brunnenkresse.

Burtel 74; Portulaca [2, 40]; Portulaca sativa Haw., Portulak; portulaca burcella Sum 63,42.

Butyrum 181; Butter; die Butter der Kühe wird als besser und gesunder bezeichnet als diejenige der Schafe und Ziegen.

Bynerwertz 146: Rustica $[2,152 \mid$ : Aristolochia Clematitis L.. Osterluzei (Entstellung aus Aristolochia): aristolocia binererz Sum. 21, 22.2: bei HIERONYaUs Bock heisst sie Biberwurtz: der Name ist noch hente gebränchlich. - Rustica ist eine ungewöhnliche Bezeichnung.

Ca lamentum (143): [2. 149]: Nepeta Cataria L.. Katzenminze wder eine Art von Calamintha; vergl. Nebetta und S. 73 Anm. ${ }^{1}$

Camphora (112); Kampher; stammt von Cinnamomum Camphora Blume.

Cannabus $(11,137) ;[2,16]$; Cannabis sativa L., Hanf; vergl. Hantj. Cardo 228; [2.176]: unsicher: kann eine Distel oder distelähnliche Pflanze sein. anch die Weberkarde. Dipsacus fullonum L.. bei Pitril steht Kartclo.

Cardus, (99); [2, 108]; tam lenis quam hirsutus; vergl. Distel.

Cardus niger' (51); [2.98]; ein ungewöhnliches Synonym von Wulfiesmilch, das man vergleichen wolle.

Carpobalsam um Pitra: Früchte des Balsambaums. Balsamondendron gileadense Kunth, die früher als Balsamkörner oder Carpobalsamum officinell waren.

Catzenzagel 216; Equisetum arvense L., das noch im 16. Jahrhundert Katzenzagel hiess.

Caulis (84); [2,51]; Kohl; vergl. Kole.

Centaurea 125: [2, 135]: Erythraea Centaurium Persoon. Tausendgüldenkraut; ist hier im weiteren Sinne zu nehmen, so dass die kleineren Arten mit einbegriffen sind: centauria. ertgull Sum. ⒉ 2.5; 
centauria maior: fibercrut Sum. 56, 46; centauria minor, ertgalle Sum. 56, 47 .

Cepe (83); [2, 49]; eine Art Zwiebel; vergl. Unlauch.

Cerifolium (70:90): [2.35]: Anthriscus Cerefolium Hoftn.. Kerbel: vergl. Kirbele.

Chelidonia (138): $[2.145\rceil$ : Chelidonium majus L.. Schiollkraut: vergl.

Grintururtz; im Text von 114 steht Chelidonia major, bei Pitra Celidonia.

Chinus Pitra: ob Cinus gemeint sein kann. der spätlateinische Name

für die Kriechenpflaume, Prunus insititia L.?

Ci cu la (161): [2, 159]: ein ungewöhnlicher Name für Salvia Sclarea L.. Muskatellerkraut; vergl. Scharleya.

Cicuta Pitra; Conium maculatum L.; rergl. Scherling.

Cinnamo in um (15); vergl. Cynamomum.

Cithysus (108): [2.118]: Synonym für Klee. ungewöhnlich: vergl. Cle. Citocatia $(15,133.167$ u. 3,5): [थ, 141] : Euphorbia Lathyris L., vergl. Springwurtz.

Citterncurtz albus (130); vergl. Sichterwurtz alba.

(le 118: Cithysus $[2,118]$ : Trifolium pratense L.. Wiesenklee: „ad pascua pecorum utile."

Clettu 98: La pp a [2, 109]: Arctium Lappa L., Ǩlette, sämtliche Arten einbegriffen; lappa, chlettu Sum. 22. 58; lappa, cletto Sum. 62, 51: eine Cletta maior wird 60 erwähnt: bei Pitra steht cletdo.

Consolida 145: $[2,151]$ : Symphytum officinale L., Beinwell: Symphytum majus und Consolida major der Kirüuterbüicher: die Apotheken führten bis auf die Gegenwart: Radix, Herba et Flores Symphyti s. Consolidae majoris. Im Text von 126 und 140 steht Consolida major.

Circullsubel 144: [2, 150]: Erodium moschatum l'Héritier, Reiherschnabel: acus nuscata, rranichsmbil Sum. 53, 25: die getrockneten Blätter wurden in den Apotheken als "Herba Moschatae s. Acus muscatae" geführt.

Crrmo: 72: Nasturtium |2, 38|: Lepidium satirum L., Gartenkresse: bei Pitra steht cresso.

Cristiana 28 ; $|2,25|$ : von ReUss als Helleborus niger L., schwarze Nieswurz, gedeutet: wahrscheinlicher ist es Orobus tuberosus L., der im Elsass heute noch Christianswurz heisst.

Oubebo $26:\{2,23 \mid$ : die Beeren von Piper Cubeba Lin. fil., Cubeben. (' и с и r b it a (87) : [2, 55]: Cucurbita lagenaria L., Flaschenkürbis; vergl. Kurbesa.

('ym in um (17) : |丷, 201) : Cuminum Cyminum L., Kreuzkiummel; vergl. Kumel.

(y y1 a mom um 20): (133): [3, 20]: die Rinde von Cimmanomum zeylanicum Blume. Zimmt. 
Dactylosa $(127) ;[2,134]$; Paeonia officinalis L.; vergl Beonia.

Danmurt in der Kapitelübersicht als Titel ron 53: nach JESSEN. Die deutschen Volksnamen der Pflanzen, Galeopsis Tetrahit L.

Daunvurtz 53; [2, 99]; douvrz GRDINI 216; war nicht zu ermitteln.

Dinemarcha 142: [2, 148]: Taleriana officinalis L., Baldrian: das Wort Denemarcha oder Demmarck (TABERNAEMIONTANUS). denmarcka bei Pitra, wird im 16. Jahrhundert noch vielfach für Baldrian gebraucht. Dictama Pitra, Dictamnus $(66 ; 115)$, dasselbe wie Dictampnus 115 ; (117); $[2,124]$; Dictamnus albus L., Diptam. Dille $67 ;(33,90)$; Anetum [2,32]; Anethum graveolens L., Dill.

Distel, tam laevis tam stechelechter 99: Cardus tam lenis quam hirsutus $[-2,108]$ : diejenige Distel. welche laeris. „id est une stechel," genamnt wird, schadet und nützt gesumlen Menschen nichts, wenn sie gekocht genossen wird: schwachen Menschen schadet sie sowohl roh wie gekocht. Hier darf man vielleicht an die Artischocke, Cynara Scolymus L., denken, von der es fast stachellose Rassen giebt. Nach dem Schlusse des Kapitels scheint der sterhelechter. Distel identisch zu sein mit vehedistel, unserer Mariendistel, Carduus Marianus L.

Julu 5르: stignus $[2,97]$ : nach JEsSEx, Die deutschen Tolksnamen der Pflanzen, Atropa Belladonna L., die Tollkirsche; stignus ist eine Entstellung von strychnus; wenn dolo nicht gebraucht wäre, so hätte man an Solanum nigrum L., den Nachtschatten, denken können; nach dem Text ist die als dolo bezeichnete Pflanze sehr giftig; die Deutung von JESSEN wird wohl richtig sein.

Dornella $160 ;(112) ;[2,158]$; Tormentilla erecta L.; vergl. S. 189 , wo dieselbe Pflanze turnella genannt wird.

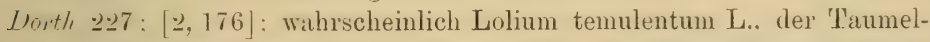
lolch, der hei Tabernaeyontaxus Dort und Durt heisst: lolium. tord Sum. 49, 64.

Dost 112; (164); O rigan um $[2 ; 121]$; Origanum vulgare L., Dosten. Dudelkolbe 221; Typha sp., Rohrkolben.

Inmi Pitra: MEIER erwälnt (III, S. 5:31) ein porrum concurum, das im Text dume porrum genannt wird, daher vermutlich eine Art Zwiebel. Ebich 140; [2, 146]; Hedera Helix L., Epheu.

Ebulus (120); 229; [2, 128]; Sambucus Ebulus L.; vergl. Hatich.

Entiana Pitra; vergl. Gentiana.

Enula (95); [2,67]; Inula Helenium L.; vergl. Alant.

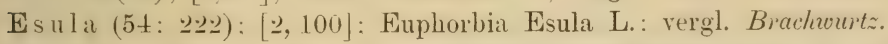

Eirue 170: Fragaria vesca L.. Erdbeere: erthere-fragum ahd. Gl. 6. 19: fraga-ertbere Sum. 56, 76 .

Ertpeffer 168: $(3,11)$ : $[2.168]$ : Sedum acre L., Steinpfeffer: wird als Fiebermittel empfohlen; als solches hat er lange gedient.

Euforbium und Euphorbium $(3, \tilde{5})$; vielleicht Euphorbia Esula L., vergl. Brachuurtz. 
Euter messeln (180): Urtica urens L., Bremnessel: heisst im 16. Tahnhundert noch Eitemesel und Ileiternessel (TABERNAEIONTANI'S).

Faba 7; [2,7]; Vicia Faba L., Grosse Bohne, Bufbohne.

Fann 47: Filix [2.92]: Polystichum Filix mas Roth, Wurmfarn. Wird als Mittel zu: Bannung böser Geister und des Teufels gerühmt.

Febrifuga (111: 116): [2.125]: Chrysanthemum Parthenium Pers.: vergl. Metra.

Feniculum 66, ausserdem lı̈̈̈fig: $[3,31]$ : Anethum Foeniculum L.. Fenchel.

Fenugra ecum 36; [2, 84]; Trigonella Foenum graecum L., Griechisch Heur.

Ficaria 207: [2, 164]: vielleicht Ranunculus Ficaria L.. Feigmurz: ficaria, fine: Sum. 22, 34: der gewöhnliche Name der Feigwurz ist Chelidonia minor.

Filix (47); $[2,92]$; Polystichum Filix mas Roth; vergl. Farn.

Foenugraecum (13); vergl. Fenugraecum.

Frasica (44); $[2,89]$; unsicher; vergl. Wuntwurtz.

Frideles anga 134: nac! Grinn etwa die Pflanze, die man "Lieb:ingel:" nennt, Myosotis sp., Vergissmeinnicht; wird als unkrut bezeichnet, „nec ad medicinam valet"; bei Pitra steht frideles ocha.

Finffblat 55: Quinque folium [2. 101]: Potentilla reptans L., Fingerkraut.

Fung i 172: S'chwämme. Pilze: es werden rerschiedene namhaft gemacht. aber die Arten zu bestimmen ist nicht möglich; die Pilze, welche auf der Erde wachsen (qui super terram nascuntur), sind dem Menschen nicht zuträglich, wohl aber solche, die auf stehenden oder liegenden Büumen wachsen, denn diese sind etwas zur Speise tauglich (arl cibum hominis aliquantum boni sunt) und wirken zuweilen auch als Medicin. Der Pilz, der auf dem Walnussbaum wächst. dient als Wurmmittel: Pilze, die auf der Buche, dem Holunder. der Weile, dem Birnhaum und der Espe wachsen, dienen rerschiedenen Zwecken.

G a langa $(13 ; 126)$, oder

Gialgan 13, ausserdem häufig: Galanga $[2,17]$ : Galgant, die Trurzel von Alpinia Galanga Sw.

Gamandrea 124; Alentidium [2, 132]; Teucrium Chamaedrys L., Gamander; das Synonym Alentidium scheint sonst nicht rorzukommen.

(ianphora 40: $|3,9|$ : Kampher, stammt von Dryolbalanops Camphora Colebr.

Gariofiles $27 ;[2,24]$ oder

Gariofyli (126: 111). die getrockneten Blumenknospen, Gewürznelken,

von Caryophyllus aromaticus L.; vergl. Nelchin.

Gurra 113: MLillefolinm |2, 122): Achillea Nillefolium L., Schafgarhe. 
Gelisia (152); [2, 153]; führt den deutschen Namen nyesewurtz und wird als Nittel gegen gicht und gelsucht empfohlen; vergl. Nyesewurtz.

Genseline 149: nach dem noch heute gebrauchten Namen Potentilla anserina L.; wird als unkrut bezeichnet; die Apotheken führten davon Radix et Herba Anserinae s. Argentinae.

Gentiana 31; [2, 80 bis $]$; irgend eine Enzianart, vielleicht Gentiana cruciata L.

Gerla 199; [2,62]; da gerla anklingt an Gierlein, Görlin, Gerlin, Namen der Zuckerwurzel, Sium Sisarum L., so hat man es als diese deuten wollen, vielleicht mit Recht; wahrscheinlich gehört hierher girol bei Pitra.

Gingebern Pitra; Ingwer; vergl. Ingeber.

Gladiola (118); $[2,127]$; gladiolus. Pitra; der lateinische Name für die gebrauchten Irisarten; vergl. Swertula.

Grensing 147; grensich Pitra; grensinc-potentilla ahd. Gl. 21, 19, und potentilla, grensinc Sum. 23, 25; da die Apotheken das Kraut von Potentilla argentea L., als Herba Argentinae s. Potentillie führten. so kann Potentilla argentea L. recht wohl gemeint sein; Potentilla anserina L. wird übrigens heute auch noch Grensing genannt.

Es giebt noch eine Pflanze, die grensinc genannt wurde, nämlich die Seerose, Nymphaea albal L. : grensinc-Nymphaca cet. ahd. Gl. 6.31: nimphea, grensinc Sum. 23, 11; nimphea, grensing Sum. 63, 18; jedoch scheint diese nach den Worten der heiligen HILIDE(iARD ausgeschlossen zu sein.

Grintwurtz 138; Chelidonia [2, 145]; Chelidonium majus L., Schöllkraut; der Name Grintwurtz ist für diese Pflanze nicht mehr gebräuchlich (heute versteht man darunter die Wurzel von Rumex obtusifolius L,), kommt aber in alten Zeiten auch sonst vor: scellinur: vel grintwrtz-Chelidonia major, ahd. Gl. 6,32.

Gunderche 105: (139): Glechoma hederace: L., Gundermann, Gundelrebe : der alte lateinische Name dieser Pflanze war a cer: gundereba-Acero vel acer ahd. Gl. 6, 34; acer, gundereba Sum. 60, 7 ; acro, gunderebe Sum. 21, 14; acer, gundram Sum. 53, 33 und sonst.

Hunif 11: hemif Pitra: Cat nnabus $[2,16]$ : Canmabis sativus L., Hant. Hartenauce 22.: Hypericum perforatum L., Hartheu: harthor-Hypericum ahd. Gl. 7, 2 ; hardenhoune-Hypericum ahd. Gl. 21, 23; ipiricum, hardenhowe Sum. 62, 36; ipericon, haternowe Sum. 57, 29.

Hartz 187; stammt von versehiedenen Nadelhölzern.

Haselwurt 48: [2,95]: ha:elwrz Pitral; Asarum europaeum L.. Haselwvurz.

Hatich 120: Ebulus [2, 128]: Sambucus Ebulus L., Zwergholunder; der gewöhnliche Name ist Attich: im Text selbst kommt atich ror: bere atich.

Herba A aron 49; [2, 96]; Arum maculatum L., Aronsstab, Aron. 
Herbat Gicht 153: [․ 15t]: die Strassburger Ausgabe hatte hier fillum, wie noch in der neuesten am Ende von Cap. 13 steht; es giebt so viele Kräuter. die als Heilmittel der Gicht angesehen wurden, dass man auf eine bestimmte Wahl verzichten muss.

Hermodactylus (46): $\mid 2,91\rfloor$ : Colchicum antumnale L., Zeitlose: vergl. Heylleubt.

Heydelbere (171), unsere Heidelbeere, Vaccinium Mryrtillus L.: vergl. Waltbere.

Heylleubt 46 : Hermoda ctylus |2, 91]: Colchicum autumnale L., Zeitlose: heilhortito-Hirmendactila ahd. Gl. 7,5; heilhoibedo- Hermodactilus. i. e. allium agreste, also wilder Lauch: dieselbe Bezeichnung kımmt im CGL. III vor, z. B. ermodactulus alius agrestis 589,66: hirmendactilica, heilhocbeto Sum. 62, 26; ermodactili, hentloceh Sum. 62. 8: ermodictoli, citelose Sum. 56, 6it: ermodictilus. citlose Sum. 22, 14.

Ihiresuntz 213: Pencedanm Cervaria Cuss., deren Wurzel noch heute Hirschwurz heisst.

Hirces kunga Pitra; ob hirces zunga? vergl. Hirtzunge.

Hirs 9: Panicum miliaceum L., Hirse: kommt noch eimmal, 19:3, unter dem Namen Milium vor.

Hirt:sucam 34: Elaphomyces granulatus Fries, Hirschbrunst, Hirschbrunstkugelschwamm; Boletus cervinus der Apotheken.

Hivtzunge 30: Scolopendria $[2,81]$ : Scolopendrium vulgare Sm.. Hirschzunge: Scolopendrium und Lingua cervina der Apotheken.

Honiguntz (60) und sonst häufig, hunigwurtz (40), huneckwurtz (37), der deutsche Name von Liquiricium, das man vergleichen wolle.

Hoppho 61: Humulus [2,7t]; Humulus Lupulus L., Hopfen; schïtzt durch seine Bitterkeit die Getränke, denen er zugesetzt wird, rorm Verderben: 3, 2ૉ wird angegeben, wie man Bier aus Hafer, hoppen und Eschenblättern brauen müsse.

Hordeum 4; $[2,4]$; Hordeum vulgare L., Gerste.

Hufflatte ma jor ㄴ10: [-2.169]: Pet:sites officinalis Mönch. Pestilenzwurtz; im Text rom Calp. 195 heisst die Pflanze hufflatich major; bei Pitrit steht luflatdecha.

Hufflatta min or 211; [2, 170]; Tussilago Farfara L., Huflattich.

Humela $50:(212):|2,94|$ : scheint nicht mit $\mathrm{Humulus}$ irlentisch zu sein und ist unsicher; Sum 9,58 steht Humula, alant, aber es ist. sehr zweifelhaft, ob hier überhaupt eine Pflanze gemeint ist.

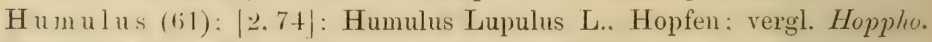
Humadnm 151: $|2,17: 3|$ : darf mam wohl ohne Bedenken als unser Hühnerdarm. Alsine media L.. nehmen.

Ilusmosz und husmuox: (115): irgend ein auf Dächern wachsendes Moos. oder eine dasellost wachsende Flechte.

Ilus:nurtz 42: Sempervivum tectorum L.. Hauslauch; der Schluss des Kilpitels stimmt ïherein mit C:1p. 203. dis die Überschrift S e mperviva trïgt. 
Hiymelslos:el 209: [2. 166]: Primula officinatis Jacq. od. P. elatior Jilc1.. Himmelsschlüssel. Schlüsselblume.

Hyssopus $65 ;(15,115,169) ;[2,30]$; Hyssopus officinalis L., Ysop; im Text wird der Name Ysophus und Yssopus geschrieben; im Text von 104 steht ys opa.

Ingeber 15; Zinziber $[2,19]$; Amomum Zingiber L., Ingwer.

Irs Illyrica (67): wabrscheinlich Iris florentina L.. deren Wurzel als Veilchenwurzel bezeichnet wird; hier ist auch nur von der Wurzel, Radix irs Illyricae, die Rede.

Juncus 158; rielleicht Butomus umbellatus L., Wasserveilchen, oder Scirpus lacustris L., Seebinse; von der ersteren führten die Apotheken Radix et Semina Junci floridi, von der letzteren Radix Junci maximi.

Kappus (84), Bezeichnung für unseren "Kopfkohl".

Kicher 190; [2, 10]; Kichera Pitra; Cicer Arietinum L., Kichererbse.

Kirbele 70: Kirrela Pitra: Cerifolium [2, 35] : Anthriscus Cerefolium Hoffm., Kerbel.

Kole 84; Caulis, et Wendelkoel, et rubea e cules [2,51]; Brassica oleracea L.; es werden ausser lappus noch mehr Rassen genannt: kochkole und weydenkole; was weydenkole und das wendelkoel der Strassburger Ausgabe bedeuten sollen, ist unklar, um so mehr, als hier falsche Lesarten oder Schreibarten vorzuliegen scheinen; die Erwähnung des Rotkohls, rubeae caules, ist immerhin zu beachten. Kranchsnabel (144; 155), vergl. Cranchsuabel.

Kumel 17; Cyminum [2, 20]; Cuminum Cyminum L., Kreuzkümmel. Limbexa š̃: Cucurbita [2.55]: Cucurbita lagenaria L., Flaschenkürbis. L a c 180; Milch von Kühen, Ziegen und Schafen.

Lactucae $(90) ;[2,60]$; Lactuca sativa L., Salat; vergl. Latich.

Lactucae agrestes $91 ; 198 ;[2,61]$; da der Genuss dieses Krautes den Menschen unsimnig machen soll, so kamn hier der in den Rheingegenden vorkommende Giftlattich, Lactuca virosa L., recht wohl gemeint sein.

Lactucae silvestres (92); [2, 63]; Lactuca Scariola L.; vergl, wilde Latich.

Lanaria (68), Synonym von Blandonia und vullena, die man vergleichen wolle.

La pa cium Pitra: wahrscheinlich Rumex obtusifolius L.. dessen Wurzel ebenso wie die einiger anderer Rumexarten als Radix Lapathi acuti officinell war.

L a p pa (98); [2, 109]; Aretium Lappa L., Klette; vergl. Cletta.

Latich 90): Lactuca e $[2,60]$ : Lactuca sativa L.. Salat, Kopfsalat; hier wird von Latich domesticae geredet und empfohlen, dem Salat Dill, Essig und Knoblauch hinzuzufügen.

Latich, wilde 92; Silvestres lactucae $[2,63]$; Lactuca Scariola L., wilder Lattich. 
Luted, (s1): Porrum $[2,48]$ : Allium Porrum L., Porree. Dieselben Namen wiederholen sich in 8.2 , nur bildet Lauch hier die Überschrift: Lauch 82; Porrum [2, 50]; omnis lauch qui carus est [a]ut hol, ut surige et prieslauch et planza et similes; hier sind Laucharten gemeint, die sich durch rïhrige oder hohle Blätter auszeichnen: eine solche ist schon als Alslauch nambaft gemacht, Cap. 80, eine andere folgt in Cap. 83 unter dem Namen Unlauch oder Cepe; man kann also an dieser Stelle seiner Phantasie etwas freien Lauf lassen. Zunächst ist jedoch zu bemerken, dass über surige gar nichts bekannt ist. Prieslan $\%$, das auch in Cap. $10 \pm$ vorkommt, bedentet den Schnittlauch. Allium Schoenoprasum L., der noch heute an vielen Orten Brisslauch oder Brieslauch heisst. I'lunza ist unbestimmt, kann sowohl Zwiebel wie Schnittlauch bedeuten: cepae, pllanze rel snitelovih Vlt. S. 370: cepa, lovch; cepe, phlanza Prag. Gl. S. 470 ; cepe, phlanze vel snitlovch Sum. 4,6 .

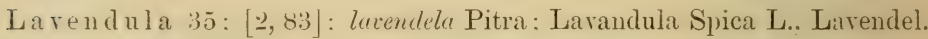
Lens 8; (13); [2, 8]; len is Pitra; Ervum Lens L., Linse.

Leristicum $(139 ; 66)$; $[2,36]$; Levisticum officinale Koch, Liebstöckel; vergl. Lubestuckel; im Text von 100 steht libisticum.

Lilim 62; [2, 106]; könnte die weisse Lilie sein, die im Cap. 23 als lilium vorkommt: das Wort lilim scheint sonst nicht rorzukommen : dagegen findet sich lielu: liela-Vitisalba ahd. G1. 22, 39: vitis alba. liela Sum. 64,12; vitis alba ist aber die Zaunrübe, Bryonia.

Li $]$ ium 23; $[2,77]$; Lilium candidum L., weisse Lilie.

Jinsumo 150: $[2,15]$ : Leinsamen. kommt noch einmal in Cap. $19+$ als Semen Lini vor: Samen von Linum usitatissimum L.

Liquiricium 19 und sonst häufig: $[2,2 \cdot 2]$ : die Wurzel ron Glycyrrhiza glabıra L., Süssholzwurzel, Radix Liquiritiae: kommt vielfach unter dem deutschen Namen Honigwur zor: bei Pitra steht Liquaricia.

Lubesturkel 139): Levisticum [2, 36]: Levisticum officinale Koch. Liebstöckel: Pitra hat Lubisticum.

Lungvurtz (126), Lunchurz Pitra, dasselbe wie

Lunckwurcz 29; [2,80]; Pulmonaria officinalis L., Lungenkraut.

II a l va (97); [2, 107]; Malva silvestris L.; vergl. Babela.

II a dragora 56 : $|\underline{2}, 102|$ : Mandragora vermalis Bert. und verwandte

Arten. Alraun. Alraunwurzel: vergl. Verhandlungen d. Berliner anthropol. Gesellschaft für 1891, S. $726-746$.

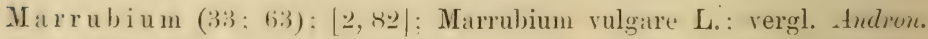
Matra Pitra; dasselbe wie Metra, das man vergleichen wolle.

Nel 178; Honig.

Melda 104: A triplex |․ 115|: Atriplex hortensis L., Gartemmelde. Menewa Pitra; vergl. Menua. 
II enna 102 ; $[2,113]$; wahrscheinlich verschrieben für menua, das man vergleichen wolle.

Mentha magna et $\mathrm{minor},(76$ u. 77); [2, 42 u. 43]; vergl. Myntza $\mathrm{major}$ und $\mathrm{minor}$.

Héma 102, (130): [2. 113]: möglicherweise ist Menua oder Menva identisch mit der Menwel- oder Mengelwurtz bei HrERoNyMUs Bock. TABERNAEmontanus etc.; damm wäre es Rumex obtusifolius L., stumpfblättriger Ampfer.

Meranda 184; eine Wein- oder Bierkaltschale.

Merlinsen 200. (15): unsere Wasserlinsen oder Entenflott. Lemma sp.

Merrech, Merwh, Merreclich 119: R a p h a n u m [2.59]: Cochlearia Armoracia L., Meerrettich.

Metra 116: Febrifuga [2, 125]: Chrysanthemum Parthenium Pers.. Mater, Bertram.

Meygelana oder Meygiluna 159: [2. 157]; ist nicht zu ermitteln gervesen: derselbe Name kommt 6.71 unter den Vögeln (fliegenden Thieren) ror. Milium 193; [2, 13]; Panicum miliaceum L., Hirse.

Millefolium 113, (66. 111. 126): [2. 122]: Achillea Millefolium L.. Schafgarbe; vergl. Garwa.

Minewrz Grimm und Pitra; vielleicht dasselbe wie Menua.

Mirrha oder Myrha 176; [3, 7]: Myrrhe. Harz von Balsamodendron Kataf Kunth.

Mistel $(3,2)$; birbaumes mistel; Viscum album L., Mistel; viscum piri $[3,20]$.

Morkut 148; Pastinaca 200; $[2,66]$; Pastinaca sativa L., Pastinak. Mose 3,57; Flechten und Moos auf Baumstämmen.

Musetha 165 ; nicht zu ermitteln.

Musore 117; Pilosella [2. 126]: Hieracium Pilosellat L., Habichtskraut; die Apotheken fülnten Herba et Flores Pilosellae s. Auriculae muris. Mynta major 76 : Mentha: quale magna [2. 42]; wallischeinlich eine kultivierte Form, Krauseminze.

Myntza minor 77; Mentha minor $[2,43]$; wahrscheinlich Mentha arvensis L.. Ackerminze.

Myrrha, Myrrhe, vergl. Mirrha.

Nachetschade 121: Natzcado Pitra: Solatrum [2. 129)|; Solanum nigrum L., Nachtschatten.

Nilsturtium ( 72 ): […38]: Lepidium sitivum L.. Gartenkresse; vergl. Crasso.

Neluetta 143, (142): Ca lam en t u m [2, 149]; Nepetal Cataria L.. Katzenminze, oder eine Art von Calamintha.

Nelelin 27. (21), (3.53); Gariofiles [^, 24]; Gewürznelken, die getrockneten Blumenknospen von Caryophyllus aromaticus L.

Nessewrz Pitra; vergl. Nyesewurtz. 
Nimmolum (15): [2. 19]: soll einer Medicin zugesetzt werden, wenn es an weissem Pfeffer fehlt: unbekannt.

Nimphia oder Nimphya 215; die nymphaea der Alten ist unsere weisse Seerose. Nrmphaea alba L. : das WVort nymphaca änderte aber später seine Bedentung und diente zur Bezeichnung von im WVasser liegenden T'Hanzen: nimfea erloa longa flos ejus purpureus est CGLIII 593,7 : ähnlich 614, 55 und 626,65; die rote Blume lässt sich als diejenige von Polygonum amphibium L. deuten. - Die weisse Seerose hiess im Mittelalter nenuphar.

Nux muscata 21, $(13,212) ;[3,2]$; Nuzmuscata Pitra; Muskatnuss. Samen von Myristica moschata L.

Nyesewurtz 152; Gelisia $[2,153]$; den deutschen Namen würde man whe Bedenken als weisse Nieswurz oder Germer, Teratrum album L., nehmen können; einige Bedenken verursacht aber der lateinische Gelisia; nessinor -Gelisia ahd. Gl. 7,3; gelisia, nessewr Sum. 62, 21; nessium $z$-Sprintilla ahd. Gl. 23, 17; sprintilla vel celia, niesewurz Sum. 40, 27; sprintilla, nieswrz Sum. 23,49; es liegt also die Möglichkeit vor, dass Gelisia Nieswurz bedeutet, und dass nessiwr z und nessewrz einem Schreibfehler ihre Entstehung verdanken.

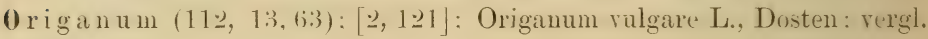
Dost.

Ova 185: Eier ${ }^{\circ}$ verschiedener Art.

Pandonia $(128: 195)$ : $|2,135|$ : Betonica officinalis L. : vergl. Buthuiu. Paparer 96; Papaver somniferum L., Mohn.

Pastinaca ㄴ(1): [2. (66) $]$ : Pastinaca sativa L.. Pastinak: vergl. Morkmt. Pefjerkrut 38, (3, 2 u. 3. 3): [2. 26 ] : Lepidium latifolium L.. Pfefferkraut: scheint gleichbedeutend zu sein mit Pfeffertruch (13).

Pepo [2. 56]: Cucumis Melo L.. Melone: fehlt in der neuen Ausgabe. P'etroselinum 6s: $[2,38]$ : Petroselimm sativum Hoftmann. Putersilie. P'effertruch (13) und

Pheffererut Pitra; vergl. Pefferlimet.

Pilosella (117, (i6): [2. 126]: Hieracium Pilosella L.: vergl. Musom. Piper 16, $(3,5)[3,4]$; die Beeren von Piper nigrum L., schwarzer Pfeffer.

L'iper album (1:3. 15, 111), weisser Pfeffer, heissen die rom Fruchtfleische befreiten Beeren des schwarzen Pfeffers.

Piretrum $(18 ; 13) ;[2,21]$; mehrdeutig, vergl. Bertram.

Pis a $6,(13) ;[2,6]$; Pisum arvense L., Erbse.

P'lautago (1111). (3, 5): [2, 112]: Plantago inajor L. : vergl. Wegeri.\%. Planza (82); eine Art Lauch; vergl. unter Lauch.

Plionia 22.5: |2.171]; wahrscheinlich verschrieben für Peonia. was auch aus der beschriebenen Anwendung zu folgen scheint: vergl. Beonia.

Poleya 126, (161); $[2,68]$; Mentha Pulegium L., Poleiminze. 
Polypodium 205, (13, 113, 114, 126); Polypodium vulgare L.; die Wurzel. Radix Polipodii der Apotheken, wird Engelsüss genamnt: vergl. Steinfarn.

Porrum 81, [2, 48] und (82), [2,50]; Porree und Lauch; vergl. Lauch. Portulaca (74); [2, 40]; Portulaca sativa Haw., Portulak; vergl. Burtel. Prieslauch, Prieselauch (82), (104); Priseloch Pitra; unser Schnittlauch; vergl. unter Lauch.

Psaffo 208; ganz unbekannt.

Psillium 24; [2,78]; Plantago Psyllium L. oder P. arenaria W. K.; die Samen dieser Pflanzen kamen als Flohsamen. Semen Psyllii. in den Handel.

(Duenulc 32. (129, 1:30): Serpillum [2. s1 bis]: Thymus Serlyyllum L.. Feldthymian, Quendel.

Quinquefolium (55); $[2,101]$; Potentilla reptans L., Fingerkraut; vergl. Funfiblatt.

Radix (89); $[2,58]$; Raphanus sativus L., Rettich; vergl. Retich. Rapa (88); [2,57]; Brassica Rapa L., weisse Rübe; vergl. Ruba. Rat phat um (119), (195): [2. 59] : Cochlearia Armoracia L.. Aleerrettich: vergl. Merrech.

Rasela 226: [2.17t]: im Text steht eimmal Ruzela; im westlichen Deutschland wird Rhinanthus Crista galli L.. unser Kilapper oder Klappertopf, Rassel genannt; man darf daher wohl diese Pflanze als die gemeinte annehmen.

Rutde 12: Zizania [2.64]: die angefuilnte Pflanze ist giftig. aller dem Vieh nicht weiter schädlich: als Fliegengift wird sie schliesslich genaunt: der deutsche Nime bedeutet mach GRunss Wïrterluch Unkraut überhaupt, der lateinische (oder griechische, Zizóvıov) wird vorzugsweise auf Lolium temulentum L.. den Taumellolch. angewendet: dieser dürfte daher gemeint sein; ratin-Zizania vel lolium ahd. Gl. 7, 34; lolium. raten Sum. 11, 13; lolium rade Sum. 66, 23.

Retich ș: Rahdich Pitra: Radix [2.58]: Raphamus sativus L.. Rettich. Reumatica Pitra: wird Sum. 23, 36 und 63,51 mit chranchesnabel und cranechesnabel übersetzt; vergl. Cranchisnabel.

Reynfain 111; Tan a c tum [2, 70]; Tanacetum vulgare L., Rainfarn.

Rifellere 219. (111): ist nicht sicher zu bestimmen; wenn es eine Beere ist. die mit einem besonderen Instrument „Rifel“ (vielleicht Rechen oder Kamm) gepflückt wird, so kann es die Heidelbeere sein.

Ringella (122), [2, 130] und

Ringula 122: Calendula officinalis L.. Ringelblume: im Text kommt ringeln als Genitiv Pluralis vor.

Rissa und Riza 164: Rubea [2.163]; entwerler eine Art ron Galium, wie Galium Aparine L., das zuweilen als Rubea minor bezeichnet wird (Königsb. und Colm. Glossar), oder auch die Färberröte (S. \$2); die Bezeichnung risza ist sonst nicht bekannt.

v. Frscher-Benzos, altd, Gartenflora. 
Ritgras Pitra; eine Carexart, Riedgras.

Roemesgrasz (85); $[2,52]$; nicht zu ermitteln; vergl. Wiszgrasz.

Roemische II entha (78); $[2.44 \mid$ : und Romische Myntzo (78). Romischmyluta (175). Romexseminzu Pitra. disselbe wie Rossemyntza, das man vergleichen wolle.

Rosa 22; [2, 76]; Gartenrose überhaupt, Rosa gallica L. etc.

Rossemynta is: Mentha silvestris L.. wilde Minze: Wildeminsa Pitra: sie kommt in vielfachen Abänderungen vor, von denen einige als Herba Menthae equinae und Herba Menthae romanie officinell waren: den Nimen Mentha equina allein führte früher auch die Ackerminze. Irentha arvensis L., den Namen Mentha romana auch die Frauenminze. Tanacetum Balsamita L.

Ruba 88; Rapa [2,57]; Brassica Rapa L., weisse Rübe.

Rubea (164); [2, 163]; vielleicht Galium Aparine L., das Lab- oder Klebkraut; vergl. Risza.

Rustica $(146) ;|2,152|$ : Aristolochia Clematitis L., Osterluzei; rergl.

Bywerwurtz.

Ruta 64. $(15,111,195)$; $[2,29]$; Ruta graveolens L.. Raute, Weimraute. S al 182; [1,3]; Kochsalz.

Salbeia Pitra, dasselbe wie

Salvia (63) und sonst mehrfach; [2, 28]; Salviat officinalis L., Salbei: vergl. Selba.

S a r co Pitra, unbekannt.

Sanicula 45; $[2,90]$; Sanicula europaea L., Sanikel.

Sanikela Pitra; der deutsche Name von Sanicula europaea L.

Satereia 155, [2, 156]: Saturea Pitra: Satureja hortensis L., Saturei, Bohnenkraut.

S'axifrica $(1: 36),(13,68): \mid 2,143]$; Saxifraga granulata L., Steinbrech; vergl. Steinbrecha.

Scamphonia (214); $[2,172]$; dasselbe wie

Scampina 214: wahrscheinlich die Wurzel der weissen Nieswurz, Veratrum album L., die von HIERONYsus Bock Scampanierwurzel genannt wird, im Kräuterbuch von MATTIOLI Scampanienwurzel. hei TABERNAEMONTANUS (nach C. BALHIN) Schampanienwurzel, mol die noch heute Schampanierwurz heisst; elleborum, scamponie Sum. 66, 14; elleborum nigrum, suart scamponie Sum. 66, 15.

Scavina Pitra; unbestimmt; ob zum Vorhergehenden?

Sicharteyn 161; Cicula [2, 159]; Salvia Sclarea L., Muskatellerkraut, Scharlachsalbei.

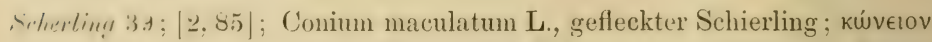
der Griechen, cicuta der Römer; die Blätter gingen früher als Herba Cicutae.

Selba $63 ;[2,28]$; Salvia officinalis L., Salbei. 
Semen lini 194; $[2,15 \mid$; der Same rom Flachs, Linum usitatissimum L.; vergl. Linsamo.

Semperviva 203; [2, 86]; Sempervivum tectorum L. : vergl. Hu\&zurtz. Senti" herba 9:3; Sin a p is [0, 64]; Sinapis alba L., weisser Senf, dessen Blätter früher gegessen wurden; vielleicht auch Sinapis arvensis L.. Ackersenf.

Surpillum (32); [2. 81 bis]: Thymus Serpyllum L., vergl. Quemela.

Sementz (63); ganz unsicher; bei TABERNAEMONTANUs heisst Scrophularia nodosa L., Sewwurtz; es giebt aber noch mehr Pflanzen, die auch so heissen: die Wurzel der weissen Nieswurz heisst heute noch Sauwurz.

Sirliterwurtz 129 und 130, hiess in der Strassburger Ausgabe cittervurtz und wurde als eine Art von Rumex gedeutet; Rumex heisst auch bei TABERNAEMONTANUS Zitterwurtz. Die neue Lesart sichterwurtz und die Lesart sitderur zei Grimm und Pitra macht diese Deutung unwahrscheinlich. Vielleicht haben wir es hier mit einem vergessenen Wort zu thun. In den Glossaren des CGLIII finden wir eleborus niger siterus 589,73, fast ebenso 611,33 und 623,35; siterus ist aber kein lateinisches Wort; ferner: sitim r-Elleborum nigrum ahd. G1. 6, 27; sittinwurz elleborum, Graft Spr. 6, 168, worauf Grimm schweigend verweist; elleborum nigrum, suterur sum. 22, 26. Nimmt man einen Zusammenhang zwischen den angeführten Worten an, der keineswegs ausgeschlossen ist, so würde Sichterwurtz Nieswurz bedeuten, und wir hätten danr

Sirltenurtz nigra 129; [2. 136]; Helleborus niger L., schwarze Nieswurz.

Siditeruut: alba 130; [2, 137]; Veratrum album L., weisse Nieswurz. Siligo 2; [2,2]; Secale cereale L., Roggen.

Sin a pe 94, (15); [2,65]; Senfkörner, die Samen von Sinapis nigra L..

Semen Sinapis der Apotheken.

Sin a p is (93); $[2,64]$; Sinapis alba L. vergl. Senff herba.

Sinza Pitra; unbekannt.

Sisimbria Pitra; vergl. Bachmyntza.

Sitderwer Grimm und Pitra; vergl. Sichtemwurtz.

Simergele Grimm und Pitra; nach Grimm heisst Ranunculus Ficaria L. noch heute in einigen Gegenden "Smergel".

Suicleloch Pitra; Allium Schoenoprasum L., Schnittlauch; vergl. Prieslauch.

Solatrum (121); [2, 129]; Solanum nigrum L., vergl. Nachtschade. Solsequium (60); $[2,105]$; Cichorium Intybus L.; vergl. Sunnewirbel. Spelta 5; $[2,5]$; Triticum Spelta L., Spelt oder Spelz. Spelio Pitra; der deutsche Name der vorhergehenden Pflanze Spelta. Spica 25, 202, (13); [2, 79]; wahrscheinlich der untere Teil des Stengels ron Nardostachys Jatamansi DC., der als Spica Nardi s. Nardus 
indicil fruiher ein berilhmtes Heilmittel war. jetzt aber kaum noch rorkommt; er gleicht etwas einem borstigen Schweif; spica. nardispic Sum. 58. 52; spicat nardi. kuttenstert Sum. 66. 18; diese Deutung wird bestätigt durch Spica nardus bei Pitra.

sprimencets 13:3, (37), (3.5); Citocatia $\mid 2.141\rceil$; Euphorbia Lathyris L.. kreuzblättrige Wolfsmilch.

Stagwurtz 106; Abrotanum [2, 117]; Artemisia Abrotanum L., Eberraute, Stabrvurtz.

Steinlweetur 136, (68). (162); Saxifrica $[2.143]$; Saxifraga granulatil L.. körniger Steinbrech; die Zwiebelchen, früher Samen genannt, waren ein gepriesenes Mittel gegen den Blasenstein. - Die Lesart Stembrecha der neuen Ausgabe, die einem Schreib- oder Lesefehler ihre Entstehung verdankt, ist zu verwerfen, um so mehr, als im Cap. 162 Steynbrecha und Steinbrecka gelesen wird, im Cap. 68 Steinbrecken, wo die Strassburger Ausgabe Saxifrica hat.

Strinfum 3.12; steinum Pitra ; Polypodium [3.13]; Polypodium rulgare L.. Engelsüss; polipodium, steinum Sum. 58,56; ähnlich 23. 30. Stichwurtz 43; Brionia $[2,87]$; Bryonia alba L. und B. dioica Jacq.. Zaunriibe.

Stign us (5ㄹ); [2, 97]; Atropa Belladomna L.. Tollkirsche; rergl. Inolu. Storax (114); Harz vom Storaxbaum, Styrax officinalis L.

Stowknubel 162. (126); [2. 160)]; wegen seiner Anwendung gegen Blasenstein oder Harnbeschwerden wahrscheinlich Geranium Robertianum L., Ruprechtskraut. das anch bei Hienoryarts Bock, ebenso wie im Text von 114 Storckenselnabel heisst.

Stramonia (161), Datura Stramonium L., Stechapfel.

Stur 197. (126); [2.5t]; Amarantus Blitum L.; blitus, stur Sum. 21.37;

blicus, stur; (beta, beizcol) Sum. 54, 49.

Stutgras 86, 196; $[2,53]$; ist nicht zu ermitteln gewesen.

Sulfur oder Sulphur 188; Schwefel.

Sunnewirbel 60; [2, 105]; Cichorium Intybus L., Cichorie.

Suregrasz (85); $[2,52]$; unbestimmt; vergl. Wiszgras.

Swertula 118; Gladiola $[2,127]$; eine Irisart, deren Blätter und Wurzeln als Heilmittel benutzt werden; welche Art aber. lässt sich nicht gan\% sicher feststellen:

Sysemera 37; 3,59. Die zweite der angeführten Stellen $(3,59)$ ist der Sichluss des iiber die Luft handelnden Katpitels [1. 7] der Strasshurger Ausgabe und beginnt mit den Worten "de eo quod dicitur sysemera". Dann heisst es ferner: "Im Frühling und Herbst ist die Luft seyger 1.1. h. lingsam tröpfehirl. zähflüssig. matt) wie der WVein und sondert eine grwisse ,albuga" al) (1nundam albuginem dimittit); das ist die "sysemerce. Es handelt sich also um die Bedeutung des Wortes "albugo". Nun spricht die heilige HILDEGARD am Schlusse des Kapitels, das iiber den biboz $(1,107)$ handelt, von der "albugo ovi": 
dem Eiweiss. Wir werden also richtig gehen, wenn wir unter der „allougo" der Luft eine Substanz verstehen. die mit dem Eiweiss eine gewisse Ähnlichkeit hat. also eine schleimige, weissliche Masse. Derartige Massen, die der Volksmund in Norddeutschland auch wohl Sternschnuppen nennt, werden von den aufgequollenen Eileitern des Frosches gebildet. Raubrögel, welche ein Froschweibchen gefressen haben. brechen nachher die Eileiter unverdant wieder aus, die damı durch Wasseraufuahme sehr stark aufquellen.

Symes $157 ;[2,170]$; nicht zu ermitteln; ob Simse?

Tanacetum $(111,15)$; $[2,70]$; Tenacetum Pitra ; Tanacetum rulgare L.; vergl. Reynfan.

Thus 175; $[3,8]$; Weihrauch. stammt ron Boswellia serrata Roxb.

Thy mus 222 ; $[2,181]$; Thymus vulgaris L., Thymian.

Tormentilla (15); Tormentilla erecta L.; vergl. Birckunutz und Lurnella.

Triticum 1; $[2,1]$ : Triticum vulgare L., Weizen.

Cersbotde Grimm und Pitra; wird von Grimm identificiert mit beresbotu, das nach Graff Spr. 3, 81 identisch ist mit zizania; kann also ein Getreideunkraut sein.

Ugera 137 ; $[2,144]$; ganz unbekannt.

Lnlauch 83; Cepe $[2,49]$; eine Art Zwiebel, vielleicht Allium Cepa L.. die Sommerzwiebel. Ist unlauch gleich unio?

Urtica 100, (66); [2, 111]; Urtica dioica L., Nessel, Bremmessel; wird gekocht als Speise empfohlen; es ist auch die Rede ron einer ardens urtica und am Schlusse des Kapitels von einer urens urtica, ebenso wie in Cap. 115 und 139, also von einer brennenden Nessel, was genau dem eyter neszel (180) entspricht und wahrscheinlich unsere Urtica urens L. bedeutet.

I ehedistel 206, (99); $[2,110]$; Carduus Marianus L., Mariendistel; heisst noch bei HIERONYMUS BOcK $u$. a. Vehedistel.

Venich 10; $[2,14]$; Panicum italicum L., Kolbenhirse.

Venechil Pitra; Fenchel; vergl. Feniculum.

Vepres (164); Dornstrüucher überhaupt, insbesondere Brombeerbüsche; vepres, brame Sum. 19, 45; vepres bramen Sum. 59, 10; an der angeführten Stelle wird herba veprium erwähnt.

Verbena (154); [2. 155]; Verbena officinalis L.. Eisenkraut; vergl. Ysena.

Vichlona $[2,9]$ und

Vigliona 189; eine Art Lupine; lupinum, ficbone Sum. 22, 53; lupini amari, vicbon Sum. 57, 41.

Viola 103; $[2,113]$; Viola odorata L., Veilchen.

Vis cum piri (212); Viscum album L., Mistel.

U cltbere 171; [2,179]; waltbere, quae etiam heydellere vocantur, scilicet quae nigrae sunt, also unsere Heidelbeere, Vaccinium Myrtillus L. 
Wentech 101; Plantago [2, 112$]$; Plantago major L.. Wregerich; ausser diesem, der rorzugsweise gebraucht wurde, hat man auch Plantago lanceolata $\mathrm{L}$. benutzt.

Weggrasz (85); [2,52]; vergl. Wiszgras.

Termula 109; Absinthium [2, 119|; Artemisia Absinthium L. Wermut.

Weydenkole (8t), wird mit lochliole zusammengestellt; was es bedeutet, weiss man nicht.

TWeyt 208; $[2,165]$; Isatis tinctoria L., WVaid.

Wichim 192; [1, 12]; Vicia sativa L., Wicke.

Wichwurtz 173; ganz unbekannt.

Wilde latich 92; Silvestres lactuca e $[2,63]$; Lactuca Scariolit L.. wilder Salat; wahrscheinlich die Stammform des Gartensalats; die Apotheken führten seine Blätter als Herba Lactucae silvestris s. Scariolae.

Wildeminsa Pitra; entspricht dem lateinischen Mentastrum; Mentha silvestris $\mathrm{L}$.; vergl. Rossemyntzu.

Winda 5T; $\lceil 2,103 \mid$; wahrscheinlich Convolvulus arvensis L. oder C. sepium L., Ackerwinde oder Zaunwinde.

Wisela 191; [2, 11|; Liselun Grimm und Pitra; scheint eine Hïlsenfiucht zu sein; möglicherweise eine Entstellung aus Fasiolus. Phaseolus. wie Grimm annimmt.

Triszgras 85; [2,52]; der gleichlautende Text der Strassburger Ausgabe hatte als Überschrift Weggrasz et Suregrafz et Roemesgrasz; diese drei Namen scheinen hier in Wiszgras zusammengefasst zu sein; gemeint sind Kräuter, die sich ron Gesunden und Kranken essen lassen ebenso wie melda und latichen; sichere Deutungen sind hier nicht möglich; Weggrasz wird für Polygonum aviculare L., den Vogelknïterich, gehraucht, der sonst wegetrele, spuregras, sanguinaria etc. Sum. 23, 45 u. 57) genannt wird; aber dies Kraut dient nur als Heilmittel und ist wohl niemals gegessen worden.

Woljesrelegena 156; wird meist als Arnica montana L.. Wolverlei. gedeutet; Grimm schweigt aber; die Deutung ist mindestens msicher. rla die Pflanze als giftig geschildert wird: wahrscheinlich ist Aconitum Lycoctonum L. gemeint, das im 16. Jahrhundert Wolfswurtz hiess uud zum Töten von IVölfen und Hunden benutzt wurde.

Wulfiesmilel, 51; Cardus niger [2.98]; nicht zu ermitteln; Wulfiesmilch, wiirden wir geneigt sein als Euphorbia zu nehmen. aber dazu jasst Cardus niger durchius nicht: in der Kapitelühersicht steht woolffswurtz, indes wird dadurch die Sache nicht klarer.

IFullem 123; Blandonia [2. 131]; Verbascum Thapsus L.. Kïnigskerze, Wollkraut; im Text von 111 steht vullena.

IHuntum 4 ; Frasica [2.89); möglicherweise Euphrasia officinalis L.. Augentrost; solleilu-Frasia ahd. Gl. 24.4; Euphrasia-selbheila Sum. 62. 5. Ibischa 141; $[2,147]$; Althaea officinalis L., Eibisch. 
Ysenc 154; V erbena $[2,155]$; Verbena officinalis L., Eisenkraut.

Zinziber (15) und sonst mehrfach; [2, 19]; Amomum Zingiber L., Ingwer; vergl. Ingeber; in 3,33 steht zengeber.

Zituar 19 und sonst vielfach; $[2,18]$; die Wurzel von Curcuma Zedoaria Rosc., Zittwerwurzel; in 117 steht zitwar.

$\mathrm{Ziz}$ an ia (12); $[2,64]$; Lolium temulentum L.; vergl. Ratcle.

Zucker 179; Zucker; es kommt auch zucharum (15) und zuccarum (140) vor.

Zugelnich 217, unbekaunt.

\section{Drittes Buch.}

\section{Von den Bäumen (de arboribus).}

In der folgenden Aufzälllumg sind die Kapitel 56-60 ausgelassen; 57, de mose, das von Moos und Flechten handelt, und 59, de Sysemera, sind im vorhergehenden Buch mit genamnt; 56. de fiumo, hiudelt vom Holzrauch, 58, de unguento Hilarii, von einer Salbe; 60 enthält ein Recept gegen Skropheln (contra orfimas).

Abies 23; [3, 32]; Abies pectinata DC., Edeltanne.

Acer Pitra. kann statt für Gunclereba auch der lateinische Name für den Massholder oder Feldahorn sein; mazaltra-Acer ahd. Gl. 6, 2 ; mazzolter-Acer ahd. Gl. 38, 33.

Affaldra 1; (2 u. 57) Malus [3, 19]; Pirus Malus L., Apfelbaum.

Agenbanm 51; in der Kapitelübersicht steht Hagenbum! vielleicht die

Hagebuche, Carpinus Betulus L.

Ahorn 30; Platanus [3, 40]; Acer Pseudoplatanus L., Ahorn; bei

Grimm und Pitra steht ahornenbovm.

Alnus (29); $[3,39]$; Alnus glutinosa Gaertn.; vergl. Avla.

A mydalus 10; [3, 28]; Amygdalus communis L., Mandelbaum.

Arla 29; Alnus [3, 39], Alnus glutinosa Gaertn., Eller, Erle.

Asch 27; Fraxinus [3, 37]; Fraxinus excelsior L., Esche.

Aspa 28; Tremulus |3, 38|; Populus tremula L.. Espe. Zitterpappel.

$\boldsymbol{B}$ aumwolle (24); [3. 34]; das unverständliche bouvel der Strassburger Ausgabe ist in der neuen durch Baumwolle ersetzt.

Birbaum 2; Pirus [3, 20]; Pirus communis L., Birnbaum.

Bircka 32; Vibex $[3,42]$; Betula alba L., Birke.

Bontzilerbaum 18; [3, 18]; in qua magna Bonezider crescit; MEYER III.

S. 526, hält Bonezider für eine Verstümmelung von Poma Citri, 
gewiss mit Recht; dann ist der Baum Citrus medica L., Citronenbaum.

Buxus 22, (15) [3, 31]; Buxus sempervirens L.. Buchsbaum.

Carpinus Pitra; Carpinus Betulus L.; vergl. Hagenbucha.

Castanea (12): [3. 13]; Castanear vesca Gaertner; rergl. Kestenbaum. Cedrus 19; [3. 10|: da Zweige und Früchte frisch benutzt werden sollen,

wohl kamm etwas anderes als Juniperus communis L.. Wachholder.

Cerasus 6; [3. 24]: Prunus Cerasus L. und P. arium L.. Kirschham. Cornus (40); [3, 85]; Cornus mas L.; vergl. Erlizbaum.

Corylus (11); [3, 29]; Corylus Avellana L.; vergl. Haselbaum.

Cutinbavm Grimm und Pitra; vergl. Quittenbaum.

Cypressus 20; $[3,11]$; Cupressus sempervirens L., Cypresse.

Datilbaum 17; Phoenix dactylifera L., Dattelpalme.

Elren; 1, 118 wird cinis elren, Asche der Eller erwähnt; vergl. Arla. Erlizbrum 40: Cornus [3, 85]; Cornus mas L., Kornelkirsche; heisst in

Württemberg noch heute Erlitze; arlezburm-Cornus ahd. Gl. 6. 5.

Esculus (8); [3, 26]; Sorbus domestica L. ; vergl. Spirbaum.

Fagus 26; $[3,36]$; Fagus silvatica L., Buche.

Fulbarm 39; unsicher; es wird angegeben. dass es schädlich sei. die

Frucht dieses Bammes zu essen, sonst könnte man an irgend eine Pappel denken, deren Knospen noch heute volkstümlich Felbaumknospen genannt werden; Felber ist ein alter Name für Weide; vergl. Melbaum.

Firloum 14; [3, 15]; Ficus carica L.. Feigenbaum; als Frucht des

Feigenbaums (fructus ficus) wird 1,95 vigim genannt.

Ficus (1,95), Pitra; der lateinische Name von Fickbaum.

Foll,rum 38; in der zu Anfang des Buches gegebenen Übersicht über

die Kapitel steht Sulbaum; beide Namen harren noch der Deutung. Fomhajf 33; war nicht zu ermitteln.

Fraxinus (27); [3, 37]; Fraxinus excelsior L.; vergl. Asch.

Fusarius Pitra; der lateinische Name des Spindelbaumes; vergl. spinelbaum.

Circten slehen (7); $|3,25|$; eine Rasse vou Prunus insititia L.; vergl. Prunibaum.

Gillmm 45; Gelbholz geht noch als Name der Berberize, Berberis vulgaris L.; vergl. Meltzbaum.

Gichtbaum 55; unsicher; ob Ribes nigrum L., Gichtbeere?

$\boldsymbol{\boldsymbol { U }}$ agenbuchu 35; [3,44]; Carpinus Betulus L., Hagebuche.

Hanelpeffe (52); die Frucht der Heckenrose, Rosa canina L.

Har-lanm 48; [3.51]; in der Kapitelübersicht steht Haubann; bei NEDNICH

finden sich Harholz und Haubeere als Synonym von der Trauben-

kirsche. Prunus Padus L.; vielleicht ist dieser Baum gemeint.

Hurtbrogelbum 4 ; ; vielleicht der Hartriegel, Cornus sanguinea L.

Irisollonem 11; Corylus [3. 29]; Corylus Avellana L.. Haselstrauch. 
Ilolderbaum 44; [3.48]; Sambucus nigra L., Holunder; nach MESER, III. S. 527. wird die Blüte des Holunders in [3.48] cirlim genannt; in der neuen Ausgabe steht zechen; 1,172 wird holder erwälint.

Hyfía 52; Rosa canina L., Heckemrose; die Frucht wird hanelpefje genannt; der ältere lateinische Name der Heckenrose ist tribulus; tribulus. lieffoldra Sum. 18.35; tribulus, hiephalter Sum. 39. 49; hiejeltraTribulus ahd. Gl. 6, 6 .

Ifï $4 \overline{7} ;[3.50]$; Ulmus campestris L., Ulme. Rüster. Bei HIERoNTyIt's BOCK heisst die Ulme „Rüstholz. Vlmerbaum, Yffenholtz". bei TABERNaEmontanls "Rustbaum, Lindtbast. Tlmenbaum. Effenbaum". Dem deutschen Worte lifje oder Eifje entspricht das lateinische (?) ipies: ipies . ulmus CGL III, 546, 70.

Julex Pitra; unbekannt; von Pitra als Betula alba L.. Birke. gedeutet; ob verlesen für Vibex?

Jun i perus Pitra; Juniperus communis L.; vergl. Wacholderbaum.

Kiestenbum 12; Castan ea [3, 13]; Castanea resca Gaertner. Kastanie. Fivechen ( 7 ); eine Rasse der Gartenpflaume, Prunus insititia L.; vergl. Prunibaum.

L a urus 15; [3. 16]; Laurus nobilis L.. Lorbeerbaum; die Beeren heissen Lorber $(1,174)$; als deutscher Name steht bei Grimm und Pitra Lorbere.

Lentiscus Pitra; wahrscheinlich der Mastixbaum. Pistacia Lentiscus L.. der das Mastix genannte Harz lieferte; bei den Griechen hiess er бxîvos. bei den Römern Lentiscus. Merkwürdigerweise übersetzen die Pflauzenglossare. wenigstens bis zum 12. Jahrhundert, lentiscus mit melbann: melebovm-Prinus gr. lat. lentiscus ahd. Gl. 5. 36; ferner lentiscus, melbovm Sum. 39, 40; lentiscus melb. Sum. 45, 82. Wenn Prinus nicht verschrieben ist für $\sigma$ xîvos, so steht es hier in einer ungewöhnlichen Bedeutung, denn das griechische tpîvos bedeutet eine Eichenart (Quereus coccifera L. und verwandte), und das spätlateinische prinus steht rielfach statt prunus, Pflaumenbaum (prinus. phumboom Sum. 39, 23; prinus, prumbovm Sum. 45,66).

Lorbere Grimm und Pitra; Laurus nobilis L., Lorbeer.

II a lus (1); $[3,19]$; Pirus Malus L.; vergl. Affaldra.

Muscel 41; da in der Kapitelübersicht Mazeldru steht. so darf man Muscel wohl als verschrieben betrachten; dann haben wir es zu thun mit Acer campestre L.. Feldahorn oder Massholder; mazaltra-Acer ahd. Gl. 6,2 ; acer, mazolter Sum. 45,54 .

Helburm 39; die Kapitelübersicht hat Melboum, während das 39. Kapitel von Felbum handelt; wahrscheinlich ist Felbaum verschrieben, denn ron einer Frucht (fructus) der Pappel wird man im 12. Jahrhundert kaum gesprochen haben. In den Sumerlaten. 39, 40 und 45. 82, findet sich die Glosse "lentiscus, melbovm"; hier wird man doch wohl an den Lentiscus der Römer. den Mastixbaum (Pistacia Lentiscus L.). 
denken mïssen, demn Lentiscus war ein bekimnter Name. Bei den Schriftstellern des 16. Jahrhunderts finden wir einen kleinen und einen grossen Melbaum oder Mälbaum. Der kleine ist Viburnum Lantana L.. der grosse Sorbus Aucuparia L.. unser Vogelbeerhaum. Meltzbaum 45; $[3,49]$; auch Gelbaum genannt, das man vergleichen wolle. Mirica (50); [3,52]; Sarothamnus scoparius Koch; vergl. Pryme. Mirtelbaum 42; $[3,46]$; Myrica Gale L.. Gagel. wird zum Bierbratuen benutzt. und kamm deshall, die Mrrte nicht sein. Die Gilossare ïlyersetzen mirtus mit porse oder ähnlich (mirtus, borse Sum. $5 \tau, 54$; mirtus porsze Colm. Gloss. 482); Pors oder Porst ist der niederdeutsche Name des (iagels. Die Sitte. Bier mit Gagel zu hrauen. war üher West- und Nordwestdeutschland. Mecklenburg. Dänemark und Norwegen verbreitet. Die Blätter der. Pflanze wurden in den Apotheken als Folia Myrti brabanticae gefuihrt; im 16. Jihrhundert hiess der Gagel auch "deutsche Myrte". Teutona myrtus (Nathan Chytraeus. Botanoscopium. v. 67 ; herausgegeben von E. H. L. Krause. Archiv d. Ver. d. Freunde d. Ntg. in Necklenburg, 33. Jahr; Neubrandenburg 1880 , S. $318 \mathrm{ff}$.)

Norus Pitra. der lateinische Name von

Mulbanm 9; Mulbertom [3. 27]; Morus nigra L.. schwarzer Maulheerbaum.

Mrurica Pitra, wahrscheinlich dasselbe wie Mirica oder Pryme, das man vergleichen wolle.

Vespelbaum 13; [3, 14]; Mespilus germanica L., Mispel.

Nuszbaum 3; Nuszbovm Pitra; Nux $[3,21],(1,100)$; Juglans regia L., IValnuss.

Oleybarm 16; [3, 17]; Olea europaea L., Ölbaum.

O) ru us Pitra; zieht man die Pflanzenglossare zu Rate. so findet man () ru us niemals durch Esche iibersetzt: dagegen findet man Hinweise auf den Ahorn, z. B. linborm-Ornus ahd. Gl. 6, 3 ; ebenso Sum. 12, 22.2; ornus, limbovm Sum. 12, 32; 39, 44; 45, 59; ornus, aornboim Sum. 58, 13. Es könnte also ornus recht wohl ein latinisiertes Ahorn sein. Limbovm oder linboum ist vielleicht identisch mit Leinbaum bei HIEInNyuls BOCk. der fol. 400 hei Besprechung des Ahorns sagt. dass ".las wild geschlecht Leinbaum" genannt werde; dam wïrde man is wohl als Acer Pseudoplatanus L. deuten müssen; der Spitzahorn. Acer platanoides L.. führt auch die Namen Lenne und Lünne. die nach ( irimms Wörterbuch gleichen Ursprung mit lin oder lim in limbov" haben.

Paliurus P'itra; vielleicht Rhamnus Paliurus L., der schon seit alten Zeiten als heilkräftig berühmt war und im Orient und in südeuropa zu Hause ist; möglicherweise auch nur Bezeichnung eines Dornstrauchs überhaupt; palvirus, hagen vel ageleia vel hagenbinta vel wechalter Sum. 12, 52 u. 53 (ageleia gehört nicht hierher; wachalter ist juni- 
perus, vachlhalder); paliurus, felwar Sum. 39, 55; palivrus, hagen Sum. 45,45 .

Palma 61 ; nach dem T'ext nichts anderes als der in Cap. 17 genanute Datilbaum, Phoenix dactylifera L., Dattelpalme.

Persichbaum 5. (1, 13); Persicus [3, 23]; Amygdalus persica L.. Pfirsich.

Pic e a (52; Picea excelsa Link, Rottanne oder Fichte; im Text von Caj). 1.j werden Tannzapfen, pinapele, erwähnt.

Pin us Pitra; Pinus silvestris L., Kiefer, Föhre.

Pirus (2); [3, 20]; Pirus communis L.; vergl. Birbaum.

Platanus (30); [3,40]; Acer Pseudoplatanus L.; vergl. Ahom.

Prinus Pitra; dasselbe wie Prunus; vergl. Prunibaum, und Lentiscus am Ende.

Prunibaum 7; Prunus [3, 25]; Prunus domestica L. und P. insititia L.. Zwetsche und Pflaume; erwähnt werden: rosspmomen, garten shen und liriechen; im 16. Jahrhundert hiessen besonders grosse. dunkelblatue oder schwarze Pflaumen „Rofzpflaumen" (BOcK, MATT., TAB.); die beiden anderen Namen werden als Rassen der Gartenpflaume zu deuten sein.

P'yme 50; Mirica $\lfloor 3,52\rfloor$; Sarothamnus scoparius Koch. Besen- oder Pfriemenginster. Im Text kommt eimmal Prymen vor. wïhrend Kapiteliiberschrift und das Anfangswort des Kapitels Pruma lauten; hier liegt jedenfalls ein Schreib- oder Lesefehler vor; mirice, phrimmen Sum. 39, 59. Mirica oder Myrica bedeutet sonst auch Heide; jedoch scheint diese Bedeutung nach der Anwendung, die von der Pflanze gemacht werden soll, hier ausgeschlossen zu sein.

Quercus 25, $(1,40)$; $[3,35]$; Quercus Robur L., Eiche.

Quittenbaum 4; Quotanus [3.22]; Cydonia vulgaris Pers.. Quitte.

Riscus Pitra; wahrscheinlich der lateinische Name des Holunders. Sambucus nigra L.; holdir-Sambucus vel riscus ahd. Gl. 6, 5; riscus, holer Sum. 39, 53; riscus holenter Sum. 15, 23.

Roszprumen (7), eine Pflaumenrasse; vergl. Prunibaum.

Salewida 37; Salix Caprea L., Sahlweide.

Salix (30); vielleicht Salix Caprea L., Sahlweide.

S'ang u in arius Pitra; der spätlateinische Name des Hartriegels. Cormus sanguinea L.; hartrugil-Sanguinarius ahd. Gl. 6, 1; sanguinarius, hartrugelin holz Sum. 15, 75; sanguinarius, haritugil Sum. 45, 57.

Savina $(21)$; $[3,30]$; Juniperus Sabina L., vergl. Sybenbaum.

Srlulbaum 49; ist unkrut und taugt nicht als Arzmeimittel; Frucht und Samen gelten für giftig; bei NEנNICH ist Schulweide ein Synonym von Ligustrum vulgare L.. Liguster; vielleicht ist dieser Strauch gemeint.

Slehen (53), die Frucht von

Spinae 53; $[3,54]$; Prunus spinosa L., Schlehe, Schwarzdorn. 
Syinellum oder sp:mnelbum :34; [3.43]; Evonymus europaeus L.. Spindeloder Spillbaum; der ältere lateinische Name war Fusarius; fusarius, spindelbovm Sum. 39, 23; fusarius, spinlbovm Sum. 45, 41.

spirbaum 8; Esculus [3, 26]; Sorbus domestica L., Speierling.

Stmlu Pitra; ausser Staude kann dies Wort nach Graff Spr. 6. 651 auch noch sentis und rubus. also Dornstrauch überhaupt bedeuten; vielleicht ist es als der deutsche Name für Spinae zu nehmen.

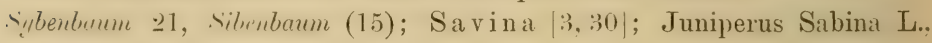
Sadebaum.

Taxus (31); [3, 41]; Taxus baccata L., vergl. Ybenbaum.

Tilia 24; $[3,34]$; Tilia europaea L., Linde.

Tremulus (28); $[3,38]$; Populus tremula L.; vergl. Aspa.

Tribulus 63, (52); Rosa canina L.; vergl. Hyffa.

Vibex (32); [3, 42]; Betula alba L.; vergl. Bircka.

Vimin a Pitra; eine Weidenart; wida, vimen ahd. Gl. 6, 5.

Titis 54; [3, כ̃ ]; Vitis vinifera L., Weinstock. Im Text der Strassburger Ausgabe wird Vinum Franconicum und Hunonicum erwähnt; der erste ist Frankenwein. der zweite Rhein- oder Moselwein; der Pagus Hunonicus, von dem der Name Hunsrück kommt. lag zwischen Rhein, Mosel und Nahe (nach Meyer, III. S. 534, 535).

ITacholderbaum 43; [3. 48]; Juniperus communis L., Wachholder.

Wirla 36 ; irgend eine WVeidenart; Frucht und Saft der Pflanze werden bitter genannt; die Erwïhnung der Frucht macht die Deutung unsicher; vergl. jedoch Vimina; als Frucht könnten auch Insektengallen genommen sein.

Ybenbaum 31; Taxus [3, 41]; Taxus baccata L., Eibe, Taxus. 


\section{Nachtrag zu Seite 95.}

\section{Über citrulus.}

Das Wort citrulus ${ }^{1}$ ) ist ein Diminutivum von citreum oder citrium, die Citrone, und bedentet deshalb wörtlich eine kleine Citrone "); es fehlt in allen älteren Glossaren und kommt zuerst bei ALBERTUS MaginUs. also im 13. Jahrhumdert, vor. Welche Pflanze ALBERTUs MAgrus mit ritmlus meint, ist nicht leicht zu entscheiden, denn die Angaben. die er dariiber macht. sind meist eingestrent in die Bemerkungen. die er über die Gurke, cucumer, mitteilt $(6,314)$. Hier sagt er, dass die Gurke in ihrem gegliederten Stengel (crura multis nodis conjuncta) nicht nur mit dem Kürbis, sondern auch mit der Nelone und dem ritrulus übereinstimme; dass die Samen der Gurke kleiner seien als diejenigen des Kürbis. von Gestalt (in figura) wie die Kerne von Äpfehn und Birnen. aber grösser, und dass sie so seien wie diejenigen von citnulus $^{3}$ ) und Melone; dass der Samen der Gurke besser sei als der Samen von citmilu. Der folgende Paragraph (6, 315) beginnt dann: „Der citrulus aber ist ein grüiner pepo (Melone) von ebener Rinde; aber der pepo ist gewöhn-

1) Citrulus ist nicht ins Deutsche übergegangen, in Italien heisst die Gurke aber noch heutigen Tages citriolo, citriuolo, cetriolo, cetriuolo, wïhrend dort das Wort cocomero ganz ausser Gebrauch gekommen ist.

2) Citrium bedeutet die Citronatcitrone, die Frucht von Citrus medica L., und nicht unsere gewöhnliche Citrone, die richtiger Limone genannt werden müsste (vergl. Hену, S. 357 fit.). Die Citronatcitrone erreicht eine sehr anselmliche Grösse, demn sie kann $15 \mathrm{~cm}$ lang werden und noch länger. Bei Apicius (De re coquinaria, erl. SchUсH, 2. Aufl., Heidelberg 1874) wird eine einzige Citrone, citrim, in einem verschlossenen Topfe aufbewahrt $(1,21)$; die Gerichte, die er daraus herstellt (3, 75; 4, 175), würden unserem Gaumen nicht munden (uns würde schon das liquamen, Fischfett, anwidern, das diesen und so vielen anderen Gerichten zugesetzt wird), aber daraus dürfen wir doch nicht schliessen, dass an den genannten Stellen keine Citrone, sonlern eine Gurke gemeint sei. Überdies wird in den Glossaren des CGL II citrium als Citronatcitrone gedeutet (citrium poma cedri 588,31). Die Citronatcitrone war teuer: im Edictum Diocletiani, 6,75, kostet eine sehr grosse, citrium maximum, 24 Denare, eine kleinere, sequens, 16 Denare, während 2 grössere Melonen (melopepones maiores; 6,30$) 4$ Denare kosten. Eine Citrone kostete also 8 und 12 Mal so viel als eine Melone: das war allein schon ein Grund sie zu essen. Wïrde bei uns jemand indische Vogelnester in den IIund nehmen, wemn sie billig wären?

$\left.{ }^{3}\right)$ Diese Bemerkung verbietet es, den citrulus als Wassermelone zu deuten. 
lich gelb und von unebener Oberfläche, gleichsam als wäre er aus scheibenförmigen Halbkreisen zusammengesetzt." Dann folgt eine Angibe der medicinischen Wirkungen des ritrulus: der Genuss von citrulus, Melone etc. erzengt chronische Fieber; der citrulus aber hat das Gute, dass solche. die ron plötzlicher Entkräftung (Ohmmacht) befillen werden, (habentes syncopim). wieder zu sich kommen, wemn sie ihn riechen; er stillt den Durst, und seine Blïtter helfen gegen den Biss toller Hunde. Mit diesen Angaben ist nicht viel zu machen, nur geht daraus mit Sicherheit hervor. dass der citrulus zu den Cucurbitaceen gehört; ob er aber eine Gurken- oder eine Melonenrasse ist, bleibt zweifelhaft. Man wïrde am ehesten geneigt sein sich für eine Melonenrasse zu entscheiden, aber bei der Schwierigkeit, welche die Zucht der Melone damals bieten musste, will uns das auch nicht ïbermässig wahrscheinlich vorkommen. Wrir wollen deshalb zunïchst untersuchen. was man im 16. Jahrhundert unter citrulus verstand.

MATTIOLI (Comm. S. 395, 398) gebraucht citmlus als lateinische ïbersetzung ron cedruolo, das in Toscana zur Bezeichnung einer kurzfriichtigen Gurkenrasse gebraucht wurde; lange Gurken hiessen daselbst malmolo longo, in übrigen Italien coromero serpentino. Im Krïuterbuch (fol. 156 B) sagt er unter der Überschrift „Gurcken Cummers: „Der Cucumern seind zwey Geschlecht: Das Erste ist allhie im Behmerland, sehr wohl bekannt, etliche nernens Citrulum, darumb, dasz es der Gestallt nach den kleinen Citronen gleich sihet, sind die gemeine kleine Gurken. Die Nürnberger heissens Kümmerlinge." 1 )

„Dis ander nennet man Anguinam, sind lange, krumme. holkeelichte Gurcken. an der Rinde weilser und rauher. Beyde Geschlecht rergleichen sich am Geschmack und Samen. In Blettern haben sie ein vnterscheidt. dimn der langen Gurcken Bletter sind scharpff und rauhe, wie in den Melaunen."

CAESAlPINUS (De plantis libri 16, Florentiae 1583; nach C. BAUHIX, P'inax, S. 310) sagt. dass die gewöhnliche Gurke, cucumis, allgemein (vulgo) ritreolus genannt werde; die lange Gurke cucumis longus, nennt er citreolus alter forma anguis, also etwa Schlangengurke.

OTTO Brunfers bespricht in einem Anhange zu seinen Herbarum vivae eicones. Strasshurg 15:32 (de vera herbarum cognitione appendix) die Pflanzmmanen im zweiten Buche des DIOSKoRIDES. Hier bemerkt er (S. 17), dass cucmmis nur in Italien bekamnt (notus) sei, in Deutschland gar nicht. Etwas weiterhin fügt er hinzu, dass die Citronengurke.

$\left.{ }^{1}\right)$ Dieses Wort hat mit "verkümmern" nichts zu thun; es hängt vielmeln" zusammen mit cueumer und berleutet wörtlich „,kleine Gurke“ (KLLGE, Etymol, Wörterb. unter Gurke); Kümmerling wird auch von WEIsmaxs für Gurke gebraucht (Phytan- Inzaticonographia, B1. „2, Regenshurg 1789, S. 282); im sïdlichen und südwestlichen D)utschland (Olerbayern, Schwaben, südlichen Teil rom Grossherzogtum Hessen) wird vielfach Kukumer, Kummer, Gummer statt Gurke gesagt. 
die einige citriolus, andere citrullus nennen, die allgemein citrion heisse und in Salaten und Suppen gebraucht werde. bei DIOSKORIDES nicht erwälnt werde.') BRUNFELS scheint also unter cucumis eine langfrïchtige Gurke zu verstehen.

Aus dem Gesagten geht hervor, dass im 16. Jahrhundert eine kurzfrïichtige Gurkenrasse die gewöhnlichere und am meisten verbreitete war. Dasselbe ergiebt sich aus den Abbildungen der Krïuterbücher; dem eine kurzfrüchtige Gurke wird jedesmal zuerst abgebildet. daneben eine langfrüchtige. bei welcher der allgemeine Name für Gurke mit einem Zusatz, anguimu: etc. versehen ist. Es fragt sich daher. welche Gestalt die Gurke bei Albertus Magnus hat.

Bei Besprechung des Citronenbaumes $(6,51)$, Citrus medica $I_{\text {., }}$ den er redrus nemut. sagt er: "dieser bringt gelbe, längliche, grosse Früchte hervor. die fast die Gestalt ${ }^{2}$ ) einer Gurke annehmen" (quae facit poma crocea oblonga magnil. quae fere figuram cucumeris praetendunt). Merkw ïrdigerweise vergleicht er die Citronatcitrone mit der Gurke. wïhrend sonst das Umgekehrte zu geschehen pflegt; ihm scheint also der Zusammenhang zwischen ritrulus und der Citrone entgangen zu sein. Wir hätten daher Grund seinen citrulus als eine Melonenrasse zu nehmen. dem die Gurke, die er beschreibt. muss nach dem Gesagten kurzfrüchtig gevesen sein. Es wäre freilich auch denkbar, dass die Gurke, die ALBERTUS MAGNUS in Italien gesehen hatte. ihm so verschieden von der in Deutschland gebauten rorgekommen wäre. dass er eine besondere und von der Gurke verschiedene Frucht daraus machen zu müssen glaubte. Wir wollen die Sache aber lieber unentschieden lassen.

KONRAD YON MEGENBERG sagt von seinem citullus (5, 22). dass er nahezu wie die Melone gestaltet sei. Er modificiert also das, was ALBERTUS MAGNUS berichtet. in dieser Beziehung ziemlich bedeutend. und da er sonst nichts von der Gurke sagt, diese aber im 14. Jahrlundert gewiss ebenso häufig war wie die Melone. so tragen wir kein Bedenken, seinen citrullus oder erdapfel als Gurke zu deuten. Das Wort Erdapfel findet sich mehrfach als deutscher Name von '"urumi*; als solcher' von citrulhus erscheint er zum ersten Nale bei KONRAD.

1) „De Citrino Cucumere, quem alii Citriolum, alii Citrullum, uulgo Citrion, quo in acetariis et Monestris utuntur, non fit mentio apud Dioscor." - Monestris muss verdruckt sein für minestris; minestra bedeutet Suppe.

9) Albertus Magnus nennt die Gestalt der Citronatcitrone und der Gurke cylindrisch oder säulenförmig $(3,32)$ : ,id autem, quod vocatur pomum cedrinum et cucumer et quaedam alia, columnalia sunt: quae figura crescit ex circulo, regulariter super lineam perpendicularem in centro stantem moto." An einer anderen Stelle $(3,22)$ sagt er: "Columna autem generatur ex circulo sursum super lineam rectam moto." Es hat etwas Überraschendes, wenn man sieht, dass schon im 13. Jahrhundert ein Cylinder durch Bewegung eines Kreises lïngs einer in seinem Jittelpunkte errichteten Senkrechten erzeugt wird; diese Auffassung des Cylinders findet heute nur mühsam Eingang in unsere Schulen. 
Das Wort citrullus kommt auch in einem lateinischen Gedichte Saxonia vor, das einem Tidericus Langen zugeschrieben wird, aber nach K. E. H. KRAUSE (Allgemeine Dentsche Biographie, Bd. 29. S. 239) vielmehr Heinrich Rosla zuzuschreiben ist; dadurch wird die Abfassung dieses Gedichtes in das Ende des 13., oder in den Anfang des 14. Jahrhunderts zurückgeschoben. Der betreffende Vers lautet:

"Sunt ibi nonnullis fabae, melonesque citrulli." ")

Hier muss man ritrulli als Apposition zu melones ziehen und etra übersetzen :

"Dort (in Niedersachsen) sind an manchen Orten Bufbohnen und Gurken,"

denn dass man zu der genannten Zeit im heutigen Westfalen eine MLlonenrasse im Freien sollte gebaut hahen, ist aus verschiedenen Gründen nicht glaublich. Wäre etwas Derartiges geschehen, so wäre es sicherlich etwas Seltenes genesen; dagegen spricht aber eimmal die Zusammenstellung mit der Buf'bohne. und zweitens bedentet das für die Häufigkeit des Vorkommens gebranchte Wort nommlli keineswegs selten, sondern entspricht vielmelır unserem ,.manche“. Ausserdem ist die Melone keine Frucht für einen Banernmagen, und bei der Arbeit. die dem Bauem :tus der Bestellung ron Feld und Garten erwuchs. blieh ihm schwerlich clie Zeit, der empfindlichen Melone die ilı notwendige Pflege zu teil werden zu lassen.

Bedenken könnte das W'ort melomes erregen, das in der That Melone bedeutet. Es ist aber sehr wohl möglich, dass Heinrich Rosla die Schrift ..de Vegetabilibus" von ALBERTI's MAGrus gekamut hat; dam wäre die Zusammenstellung ron melones und citrulli nicht so merkw ïrdig. namentlich nicht. wenn man sich den $Z$ wang des Versmasses wirkend denkt.

Während also der Name citrulus bei ALBERTUS MAGNLS sich nicht sicher deuten lässt. scheint er in den folgenden Jahrhunderten für die (iurke gebraucht worden zu sein. ebenso wie im 16. Jahrhundert, wo ex zugleich bei einigen Schriftstellern die Wassermelone bezeichnet (in (ler Form citrullus). Aber neben diesen beiden Bedeutungen läuft etwat rom 15. Jahrhundert an noch eine andere: man nahm ritrulu: als Diminutivum von rirer, das anch citer geschrieben wurde (vergl. DIEFENBAcHs' (ilossarium); deshall, findet man in lateinisch-deutschen Pflanzen"Iossatren aus späterer Zeit citrulus durch kirher übersetzt, sogar durch "rirlir". Der. Sprung von der Kichererbse zur Wicke ist am Ende nicht s) Gruss, wemn man erst den ron der Giuke zur Kicher gemacht hat.

1) H. Mrusosrus junior, Rerum Germanicarum T'om. III., Bd. 1, S. 808. 


\section{Register ${ }^{1}$}

\section{der deutschen Pflanzennamen.}

Bemerkung: Namen aus der Zeit vor dem 16. Jahrhundert sind mit kleinem Anfangsbuchstaben gedruckt. - Gleichklingende Buchstaben, wie e und k, f und v, $i$ und y etc. wolle man an der Stelle suchen, die ihnen im Alphabete zukommt; das althochdeutsche uu oder vu ist wie w behandelt. - Übersetzungen lateinischer und griechischer Pflanzennamen sind nur in seltenen Fällen aufgenommen worden.

Abendrot 107.

Abricose 155.

Absinth 75 .

ackeleia h. H. 196, 197.

Ackermennig 77.

Ackerminze 69, 71, 72a, $207,210$.

Ackersenf 115, 211.

Ackerwinde 214.

Ackerwurz 49.

Åckeröapfel 146.

affaldra, affaltra 145,215 , 217.

agenbaum h. H. 215.

agleia h. H. 196.

ahorn h. H. 215, 219.

Ahorn 215, 218.

ahornenbovm h. H. 21 .

Akelei 196.

alant h.H. 196, 201.

Alant, wahrer 63, 196.

Allermannsharnisch 47.

Aloe 197.

Alpenveilchen $\mathbf{5 6}$ a.

Alraun, Alraunwurzel 206. alslauch h.H. 138, 197, 206.
Althee 63.

Amarant 127, 129, 184.

Amarellen 152.

amer 169.

Ammi 65, 66, 184.

grosses 66 .

Ampfer, stumpf blättriger 61, 207.

amphora h. H. 197.

Andorn 77, 188, 190, 197.

andron h. H. 77, 197, 206.

Anemone 87.

Angurie 95.

Anis 117, 132, 133, 184.

antron 189.

Apfel 144.

Apfelbaum 144, 182, 184, $186,215$.

wilder 145 .

Apfelrose 35.

apfil $\mathbf{1 4 5}$.

apholtra 145.

Aprikose 154, 155.

Aristolochia 57.

arla h. H. 215, 216.

Aron 203.
Aronsstab 203.

Artischocke 121, 184, 201.

spanische 121.

arwiz $99 \mathrm{a}^{2}$

asch h. H. 215, 216.

aschalonia h. H. 138.

Aschlauch 138.

aschloch, aschlovch 138, 139.

asclovch 138

aspa h. H. 215, 220.

astrencia h. H. 197.

Astrenz 197.

schwartz 197.

atich h. H. 197, 203.

Attich 188, 197, 203.

auerute 75 .

Augentrost 214.

Aurine 62.

babela h. H. 128, 197, 206. bachenia h. H. 77, 198.

bachminza h. H. 197.

Bachminze 69, 70, 184, 197.

bachmyntza h. H. 71, 197, 211.

$\left.{ }^{1}\right)$ In diesem und in den beiden folgenden Registern bedeutet $\mathrm{a}^{1}, \mathrm{a}^{2}$ etc. Anmerkung 1, Anmerkung 2 etc.; ein einfaches a verweist auf die Schlusszeilen der letzten Anmerkung der vorhergehenden Seite, oder auf die einzige Anmerkung der angeführten Seite. - Die Adjective sind im allgemeinen hinter die zugehörigen Substantive gestellt.

v. FisCher-Benzon, altd, Gartenflora. 
Baldrian 201.

Ballota 77, 78.

Balsam 71 .

krauser 71 .

Balsambaum 197, 199.

Balsternak 117.

Bärenwurz 198.

Basilie 134, 180a 2, 197.

Basilikum 133, 134, 135 a.

bathema h. H. 77, 198.

bathenia h. H. 77, 198, 208.

Baumweichsel 148.

baumwolle h. H. 215.

Beet, rote 129, 185.

Beifuss 75, 76, 197, 198.

Beinwell 200.

Benedictenkraut 190, 198. beonia h. H. 198, 201, 208.

Berberize 216.

beresboto 213.

berewinka h. H. 198.

Bertram 62, 190, 198, 207, 208.

Bertramswurzel 198.

berwurtz h. H. 198.

Besenginster 219.

betenia 189 .

Betonie 77, 198.

Betonika 5, 76, 77, 182, 188, 190.

bibenella, bibinella h. $\mathrm{H}$. 198.

bibenna 950.

Bibernell 115̆, 135 a, 189, 198.

klein welsch 13ว̆a.

Biberwurtz 57, 199.

biboz 76, 197, 198.

bieza 129 .

bifuz 76 .

bilsa h. H. 198.

bilse, bilisa 198.

Bilsenkraut 198.

Binetsch 130.

binsuga h. H. 197, 198.

bira 146.

birbaum 146, 215, 219.

bircka a. H. $215,220$.

birckwurtz h. H. 198, 213.

Birke 215, 217.

Birnbaum 145, 182, 184, 186, 215.

wilder $72 \mathrm{a}, 145$.
Birne 144.

Birnquitte 146.

Bittermandelbaum 158.

biwerwurtz h. H. 57, 198.

Blattkohl 111.

Blumenbinse $46 \mathrm{a}^{2}$.

Blumenkohl 110, 111, 112.

Blumen-Köhl Tab. 112.

Blumenköl Matt. 111.

Bluthirse 170.

Blutkraut 198.

blutwurtz h. H. 198.

boberella h. H. 198.

Bocksbart 122, 123.

Bockshornklee 81, 98.

Bohne 2, 5, 95, 96, 100, 185. egyptische 100 .

griechische 100.

grosse $98,100,149 \mathrm{a}^{4}$, 184, 202.

Bohnenkraut 5, 133, 135, 182, 184, 185, 210.

Bolle 139.

Bone, türkische Krtb. 99. bonezider h. H. 45 .

Bonifaciuskraut 189 .

bontziderbaum h. H. 215.

Boretsch 134.

Borgel 108.

brachwurz h. H. 199, 201.

bramber h. H. 199.

breitleteche 60 .

brema h. H. 199.

Brennnessel 88, 202, 213.

grosse 88.

kleine 88 .

Brisslauch 141, 206.

Briszlauch 141.

Brodtwurz 132.

Brombeerbusch 199, 213.

Brombeere 156.

Brumsilk 135.

Brunnenkresse 102, 103, $176 \mathrm{a}^{2}, 199$.

Buche 216.

Buchsbaum 23, 47, 49, 216.

Buchweizen 170.

Bufbohne $96 \mathrm{a}^{2}, 100,201$, 224.

burncrasse h. H. 103, 199.

Burre (dän.) $60 \mathrm{a}^{3}$.

burtel h. H. 199, 209.

Burtzel 108.
Buschbohne 99.

byfôth 76 .

Byren, Byrn 146.

Byrnbaum 146.

bywerwurtz 57, 198, 199, 210.

\section{Cardone 121.}

catzenzagel h. H. 199.

Centifolie 34, 36.

cherse 151.

chichera $99 \mathrm{a}^{2}$.

chlette 60 .

chlobeloch 142 a.

cholsamo 189.

chraneuuito 189.

chren, chrene 114.

Christianswurz 200.

Christrose 63.

Cichorie 104, 106, 182, 184, 212.

Citrone 221, 223.

Citronatcitrone $221 \mathrm{a}^{2}$, 223.

Citronenbaum 216, 223.

Citronengurke 223.

Citronenkraut 137.

Citronenmelisse 137.

Citrullen 95.

citterwurtz h. H. 200, 211.

cle h. H. 200.

cletta h. H. 60, 200, 205.

clette 60 .

clive 60 .

clobelouch 142 a.

comyn 131.

conele 16, 135.

cranchsnabel h. H. 200 , 205, 209.

crasso, cresso h. H. 102, $200,207$.

crecemorensâth 117.

Cubeben 200.

cuenula 189.

cumin 189

cutinbavm h. H. 216.

Cypresse 74, 75, 216.

Cypresz Krtb. 75.

danwurtz. h. H. 201.

datilbaum h. H. 216, 219.

Dattelpalme 216, 219.

dauwurtz h. H. 201.

denemarcha h. H. 201. 
denicleta 189.

Dill 2, 104, 132, 184, 185, 201.

dille h. H. 197, 201.

dinchel, dinchil 169 .

Dinkel 169.

dinkil 169.

Diptam 67, 68, 184, 201.

kretischer 67.

Diptamdosten 67.

distel h. H. 199, 201.

Distel 199.

Dittam Bock 68 .

dnctret 189.

dolo h. H. 201, 212.

dornella h. H. 201, 213.

Dornstrauch 213, 218, 220.

dorth h. H. 201.

dost h. H. 201, 208.

Dosten $178 \mathrm{a}^{2}$, 189, 201, 208.

dosto 189.

Drachenwurz 51, 184.

Dragon 51.

drakenwort 52.

Drakonkraut Tab. 52.

druswurz 144.

dudelkolbe h. H. 201.

dumi h. H. 201.

Dünenrose 37.

ebech, ebich h. H. 201.

Eberraute 2, 5, 69, 74, 182, 183, 188, 212.

Eberreis 74 .

Edelkastanie 184, 186.

Edeltanne 215.

Effenbaum 217.

effi 120.

Eibe 220.

Eibisch 63, 182, 184, 214.

Eiche $147 \mathrm{a}^{3}, 217,219$.

Eierpflanze 143.

Einkorn 163.

Eisenhart 78.

eisenkraut K. 78 .

Eisenkraut 78, 213, 215.

Eiternessel 89, 202.

Eller 215, 216.

elren h.H. 216.

Emmer 163.

Endivie 104, 105, 114, 184.

Engelsüss 209, 212.
Entenflott 207.

entiana h. H. 201.

Enzian 203.

epf K. 120.

Epheu 201.

ephich 120.

eppe 120.

Eppich 119.

Erbse 95, 99 a 2 208.

graue 95 .

preussische 95 .

erdapfel K. 95.

erdapfel 95.

erdaphil 93.

Erdbeere 189, 201.

Erdbeerspinat 127, 130, 156.

erdbrama 189.

erdebuh 189 .

Erdgalle 62.

Erdkastanie 126.

Erle 188, 215.

Erlitze 216.

erlizbaum h. h. 216.

Ernrose 128.

erpere h. H. 201.

ertappel 93.

erthappl 93.

ertpeffer h. H. 201.

Erwe $96 a^{2}$.

Erweissen 97.

Escariol 105.

Esche 215, 218.

Esdragon 51.

Espe 215.

Essigrose $34 \mathrm{ff}$.

eueritte $\mathbf{7 5}$.

euerute $\mathbf{7 5}$.

Ewigkeitsblume $175 \mathrm{a}$.

eyter neszel h. H. 88, 202, 213.

Färberröte 82, 209.

farn h. H. 202.

Faseln 99.

Fäselen 97, 99.

Feige 156, 157.

Feigenbaum 23, 157, 184, 186, 216.

Feigwurz 62, 202.

felbaum h. H. 216, 217.

Felber 216.

Feldahorn 215, 217.

Felderbse 95.
Feldkümmel 131.

Feldmohn 65.

Feldthymian 135, 209.

Fenchel 104, 117, 132, 135 a, 184, 185, 188, 202, 213.

Fenchelhirse 170a.

fenich 170.

Fetthenne 79.

Feuerlilie 33, 34.

Fichte 219.

fickbaum h. H. 216.

Fichtenbaum Krtb. 162.

figa 189.

Fimmel 88.

Fingerkraut 202, 209.

Flachs 85, 211.

Flaschenkürbis. 23, 89 ff., $183,188,200,205$.

Fläschen Kürbs 92.

Flechten 204, 207.

Flöhkraut 72.

Flohsamen 209.

Föhre 219.

folbaum h. H. 216.

fornhaff h. H. 216.

Frauenminze 69,70,73,182, 183, 185, 188, 197, 210.

frideles auga h. H. 202.

funffblatt h. H. 202, 209.

Gagel 48, 218.

gaizvenichel K. 66.

galgan h. H. 210.

Galgant 202.

Galgantwurzel 190.

Gamander 189, 202.

gamandrea h. H. '196, 202.

gareuua 189.

Gartenbohnen 98, 104.

Gartenerbse 97.

Gartenkerbel 126.

Gartenkresse 102, 200, 207,

Gartenmelde 127, 130, 184, 197, 206.

Gartenminze 71.

Gartenmohn 65.

Gartenpflaume 217, 219.

Garten-Rapuntzel, zam 118.

Gartenraute 69.

Gartenrose $174 \mathrm{a}^{1}, 210$.

Gartensalat 214.

Gartenscariol 105.

Gartenscharlach 134. 
gartenslehen h.H. 153, 216, 219.

Gartenspargel 124.

Gartenthymian 135.

Gartenveilchen 188.

gartminza 189.

garwa 190, 202, 207.

Gauchbrot 123.

gelbaum h. H. 216, 218.

Gelbholz 216.

Gelbe Wurzel 116.

Gemüse, schwarzes 119,120, $177 \mathrm{a}^{4}, 184$.

gensekrut h. H. 203.

gerla h. H. 203.

Gerlein 118, 203.

Germer 208.

Gertwurz 75.

gersta, gerste 170 .

gerst K. 170.

Gerste 96, 162, 163, 164, 165, 168, 204.

Gesichterbohne 100.

Gewürznelken 202, 207.

Gewürznelkenbaum 190.

Geyerlein 118.

gichtbaum h. H. 216.

Gichtbeere 216.

Gierlein 118, 203.

Giftlattich 205 .

Gilgen 34, 35 .

blaw 45 .

weiss 34 .

gingebern h. H. 203.

Girgele 118.

girol 203.

githerut h. H. 204.

Gladiolus 38, 46.

Goldblume 13, 42.

Grolddistel 121 a.

Goldlack 39, 41, 112.

Goldlilie 34.

Görlein 119, 203.

Gottesvergessen 78.

Granatapfel 13, Blüte 35, $174 \mathrm{a}^{1}$.

Gren 115.

grensing h. H. 203.

Gretje, fine 82.

Griechisch Heu 81, 183, 185, 202.

Grindlattich 59, 61 .

Grindwurzel 61. grintwurtz h. H. 61, 200, 203.

Gritzelmörlein 118.

Grosse Bohne 98, 179 $\mathrm{a}^{4}$, 184, 202.

Gummer 222a.

Gundelrebe 189, 190, 203. gundereba 189, 215.

gunderebe h. H. 196, 203.

Gundermann 189, 203.

Gurke 5, 89, 92, 183, 221 ff.

Guter Heinrich 127.

Haardolde, koptische 66 .

haber, habero 170.

Habichtskraut 207.

Hafer 96, 162, 165, 168, 204.

Haferschlehe 152, 153.

Haferwurzel 122.

hagdorn K. 36.

Hagebuche 215, 216.

hagenbaum h. H. 215.

hagenbucha h. H. 216.

Hahnenkamm $174 \mathrm{a}^{3}$.

hanelpeffe h. H. 216, 217.

haneph 88.

Hanf 87, 199, 203.

türkischer 59.

hanff h. H. 199, 203.

hanif $88,203$.

hanofsamo 189.

harbaum h. H. 216.

Harholz 216.

hartbrogelbaum h. H. 216.

hartenauwe h. H. 203.

Hartheu 203.

Hartriegel 150, 216, 217.

hartz h. H. 203.

Hartzbaum Krtb, 162.

hasel 161.

haselbaum h. H. 161, 216. haselbere, haselbir 161.

Haselnuss $148 \mathrm{a}^{1}, 158,160$, 161.

Haselstrauch 216.

Haselnussstrauch 182, 184, 186.

haselwurtz h. H. 5̃7, 203.

Haselwurz 56, 184, 197, 203.

Hasenohren $68 \mathrm{a}$.

hatich h. H. 197, 20I, 203.

haubaum h. H. 216.

Haubeere 216.
Hauslauch 79, 184, 204.

Hauswurz 79.

Heckenrose 35 ff., 216, 217.

Hederich 115.

Heide 219.

Heidelbeere 204, 209, 213.

heidenrettich 115 .

heidenrub 115.

Heiligenpflanze 74, 75 .

Heiternessel 89, 202.

helegeberen 55 .

hemp 88.

henp 88.

Herbstrose 128.

herse 170.

Heu, griechisches 82, 183, 185.

heydelbere h. H. 204, 213.

heylheubt h. H. 204.

hiefeltra 35 .

hieffaldra 35 .

hilgeberen $\mathbf{5 5}$.

Himbeere 156.

Himmelschlüșsel 205.

Himmelschwertel 45.

hintlofte 106.

hintloifte 106.

hintlope 106.

hirceswurtz h. H. 204.

hirs, hirse 170, 204.

Hirschbrunst 204.

Hirschbrunstkugelschwamm 204.

Hirschwurz 204.

Hirschzunge 204.

Hirse 162, 165, 166, 204, 207.

hirtzswam h. H. 204.

hirtzungen h. H. 204.

hobwurz K. 57.

holder h. H. 217.

holderbaum h. H. 217.

Holunder 217, 219.

holworz 57.

Honigapfel 145.

honigwurz h. H. 204, 206.

Hopfen 204.

Hopfenkeime 125.

hoppho h. H. 204.

Hornungsblume 38 .

weisse 41 a.

hranca 55 .

huf 60 . 
hufflatich h. H. 204.

hufflatta h. H. 61, 204.

Huflattich 60, 204.

Hühnerdarm 204.

Hundskürbis 56 .

huneckwurtz h. H. 204.

hunsdarm h. H. 204.

huntespere 144.

huosuuurz 189.

husmosz, -muosz h. H. 204.

huszwurtz h. H. 79, 204, 211.

Hyacinthe 38, 39.

hyffa h. H. 35, 217, 220.

hymelsloszel h. H. 205.

ibesche 64 .

ibischa 182, 183.

Jenbär (dän.) 81.

iffa h. H. 217.

Igelkolben $46 \mathrm{a}^{2}$.

iiserenbart 78 .

Immergrün $177 a^{1}, 198$.

ingeber h.H. 203, 205, 215.

Ingwer 190, 205, 215.

Johanneskraut 79.

Johannisbrot 146 .

Iris 43, 188, 212.

isenare 78 .

isenbart 78 .

isenhart 78 .

isere 78 .

isinchlete 78 .

isp K. 137.

Iwakraut 189.

Kaffeeerbse 101.

Kalmus 49.

Kamille, römische 62.

Kampfer 199, 202.

Kappes 111.

Kappeskraut 111.

kappus h. H. 111, 205.

Kapuzinererbse 97, 184.

Karde 121. wilde 122.

Karotte 116.

kartdo h. H. 199.

Käsepappel 127, 128, 197.

Kastanie 158, 217. echte 159.

Kastanienbaum 159.

Kattenkēs 128.
Katzenkraut 70 .

Katzenminze 70, 72, 182,

184, 188, 199, 207.

Katzenzagel 199.

kemen 131.

Kemp (holländ.) 88.

kempenkrut 88.

Kerbel 126, 135 a, 182, 184, $185,188,200,205$.

spanischer 127.

welscher 127.

Kerbelrübe 126.

kersa 151.

keruele 126 .

kervola 189.

kestenbaum h. H. 159, 216, 217.

kestenpaum K. 159.

khren $\mathbf{1 1 5}$.

kicher, kichera h. H. 101, 205.

Kicher $96 \mathrm{a}^{2}, 99 \mathrm{a}^{2}, 101,224$.

Kichererbse 96, 101, 184, $205,224$.

kicherkraut K. 101.

Kiefer 72a, 161, 219.

kirbele, kirvela h. H. 200, 205.

Kirschbaum 149 ff., 182, $184,216$.

Kirsche $148 \mathrm{ff}$.

Apronianische Plin. 150.

Cäcilianische Plin. 150.

Junianische Plin. 150.

Lusitanische Plin. 150.

Lutatische Plin. 150.

Plinianische Plin. 150.

kirse, kirssa 151.

Klapper, Klappertopf 209.

Klatschrose $64,87$.

Klebkraut $60 \mathrm{a}^{1}, 82,175 \mathrm{a}^{3}$, 210.

kledere 82.

Klee 200.

Klette 59, 184, 200, 205.

Klingelmöhren 119.

Klingelrüblein 119 .

Knoblauch 142, 143, 182, 184, 185, 197.

Knorpelkirsche 150. kochkole h. H. 111, 205, 214.
Kohl 108 ff., 129, 182, 184,

186, 199.

Aricischer Plin. 110

brauner 111.

Bruttischer Plin. 110

Cumaner Plin. 110.

grüner 111.

krauser 111, 120.

Lacuturrischer Plin. 111.

Pompejanischer Plin. 110

römischer 111, 112, 129

Sabellischer Plin. 110.

Tritianischer Plin. 109, $110,111$.

Köhl 111.

Köhlkraut 111.

Kohlrabi 110, 182, 184. über der Erde 110. unter der Erde 112.

Kohlrübe 112.

Kolbenhirse 162, 165, 166, $168,213$.

kole h. H. 111, 199, 205.

Köll 135.

Koloquinte 54, 184.

Königskerze 214.

Kopfkohl 108, 109, 111, 205.

Kopfsalat 104, 205.

Körbel 126, 127.

Körffel 126, 127.

Koriander 132, 133, 182, $184,185$.

schwarzer 132.

Kornelkirsche $150,151 \mathrm{a}^{1}$, 216.

kornpluom, rôteu K. 85 .

Kornrade 85, 132.

Kostwurz 190.

kranchsnabel 205.

Kranewitt 189.

Krapp 184.

krässelkraut K. 80.

Krauseminze 69, 70, 182, 184, 185, 188, 207.

Krauskohl 111.

Kraut 111, 129.

Kren, Kreen 114, 115.

kress K. 102.

Kresse 102, 184. orientalische 102 .

Kreuzkümmel 66, 131, 184, 185, 200, 205 . 
kriechbaum 153.

kriechen 153, 217, 219.

Kriechenpflaume 152, 153, 200.

krise 151.

Krupbohne 99.

kumel h. H. 200.

Kümmel 131, 184.

römischer 131 .

Kummer 222 a.

Kümmerling 222.

Kumpstkohl 111.

kurbesa h. H. 91, 200, 205.

Kürbis 23, $89 \mathrm{ff}$., 221.

gemeiner 91, 92.

kurbiz 93.

kürbiz K. 91.

Kürbs 92.

indianischer 92.

küten, gemain 147.

kutina 147.

Kütte 147.

Labkraut $10,60 \mathrm{a}^{1}, 175 \mathrm{a}^{3}$, 210.

lactukenkraut K. 105.

Lambertsnuss 160.

Laserkraut 65, 184.

latich h. H. 105, 205, 214. wilde h. H. 205.

lauch h. H. 206, 208, 209.

Lauch 137, 141, 208, 209.

Lavendel 133, 136, 206.

lavendela h. H. 206.

Leberklette 77, 190.

Lein 85 .

Leinbaum 218.

Leinsamen 206.

Lenne, Lönne 218.

Lerchensporn, hohlwurzliger 57.

leteche, grofz 60.

letteche 60 .

Leucoium 174.

levestock 67.

Levkoje 39, 40.

Liebäugel 201.

Liebstöckel 2, 65, 67, 182, 184, 185, 188, 206.

Liguster 219.

Lilgen 45.

Lilie 2, 33, 174, 182, 183, 185, 188.
Lilie, weisse 33, 206.

lilig K. 34.

lilim h. H. 206.

linbovm, limbovm 218.

Linde 220.

Lindtbast 217.

linsamo h. H. 206, 211.

Linse $96 \mathrm{a}^{2}, 101,206$.

Lolch 166.

lorber, lorbere h. H. 217.

Lorbeer 13, 23, 47, 48, 186, 217.

Lorbeerbaum 184, 217.

Lorbeerkirsche Plin. 150.

lubesteche 67 .

lubestuckel h. H. 67. 206.

lubistechel 67 .

Lupine 213.

lunckwurtz, lung'wurtz h. H. 206.

Lungenkraut 206.

madalger 189 .

mâgenkraut K. 65 .

magesamo 65 .

mago 65, 189.

Mährrettich 115.

Majoran 133, 135, 136.

IIais 170.

Malve 127, 128, 182, 184.

man 65 .

Mandel 158.

bittre 158 .

süsse 158 .

Alandelbaum 158, 184, 186, 215.

Mangolt 112, 127, 129, 130, $182,184,185$.

Mannagras 170 .

manua 115.

Maredig 115.

Maressig 115.

Margenröslein 43.

Märgenröslein 43.

Markkohl 110.

IIariendistel 201, 213.

Marillen 15ó.

marobel K. 78 .

Marrak 115.

Marretig 115.

Märzveilchen 40.

mascel h. H. 217.

Masch, Maschel 88.
Massholder 215, 217.

Mastixbaum 217.

Mater 62, 190, 198, 207.

matra h. H. 206.

matre 62.

Maulbeerbaum 145, 156, 182, 184, 186.

egyptischer 156.

schwarzer 145, 156, 218.

weisser 156.

Maulbeere 156. schwarze 156.

weisse 156 .

Mäusedorn 124, $177 \mathrm{a}^{1}$.

mäuszwivel K. 81.

mazeldra h. H. 217.

Meerrettich 114, 115, 116, 207, 209.

Meerzwiebel 81, 184.

Meier, Meyer 130.

Meisterwurz 121, 197.

melbaum h. H. 216, 217.

Melbaum, Mälbaum 218.

grosser 218.

kleiner 218.

melda h. H. 197, 206, 214.

Melde 127, 129.

Melilotus 175a ${ }^{1}$.

Melisse 78, 133, 135a, 137, 198.

Helone 89, $93 \mathrm{ff}, 17 \mathrm{a}^{3}$, $183,188,208,22 \mathrm{lff}$.

meltzbaum h. H. 216, 218.

Mengelwurtz 207.

menua, menewa h. H. 61, 206, 207.

menua, mênva 11 .

Menwelwurtz 207.

meriratich 114.

merlinsen h. H. 207.

merratich 114.

Merrätich, Merrhetich 115. merrech h. H. 114, 207, 209.

merredich h. H. 114, 207. merredik, merretich 114 . merrich h. H. 114, 207.

Mertzenveiel 40.

metere 62.

metra h. H. 62, 198, 202, 206, 207.

meygilana h. H. 207.

mimewrz h. H. 207. 
Minthe, welsche 73 .

Minze 69, 185, 188.

wilde $69,72,182,184$, 210.

mirredich 114.

mirtelbaum h. H. 48, 218.

Mispel 146, 147, 148, 218.

Mispelbaum $147 \mathrm{a}^{3}, \quad 148$, $182,184,186$.

mistel h. H. 207.

Mistel 207, 213.

Mohn 5, 13, 64, 86, 184, $185,188,190,208$.

Möhre 116 ff. 184 .

Mohrrübe 10, 116, 186.

Möllelein 155.

Molleten 155.

Monatsrose 37.

MIönchsrhabarber 178 a ${ }^{1}$.

Moorwötteln 117.

Moos 204, 207.

morach 117.

more 117.

Morelle 144, 145̌ a 2.

Morgenrot 107.

morkrut h. H. 207, 208.

mose h. H. 207.

mulbaum, mulberbaum h. H. 218 .

IIüntz, unser Frawen 73.

Muskatellerkraut 134, 200, 210.

Muskatellersalbei 133, 134, $182,184,188$.

Muskatnuss 208.

Muskatrose 37.

musore h. H. 207, 208.

Iutterkraut 62, 184, 190.

myntza h. H. 71, 207.

romische h. H. 72, 210.

Myrrhe 190, 207.

Myrrhenkerbel 126, 127.

Myrte 47, 48.

nachtscate, nahtscate 144 .

nachtschade h. H. 144, 207, 211.

Nachtschatten 143, 144, 201, 207.

schwarzer 143.

Nachtviole 41.

naderwort 52.

Nägelveiel, gelb 41 .
Nappen 113.

lange 113.

runde 113.

Narcisse 37.

gelbe 37 .

weisse 37 .

Narcissenröslein 38.

nebetta h. H. 199, 207.

nelchin h. H. 202, 207.

nespelbaum 148, 218.

nespelun, nespilun $148 \mathrm{a}^{1}$, 161.

Nessel 87, 88, 213.

nessewrz h. H. 207.

nezzel, kriechisch K. 88.

Nieswurz 62.

grüne 62 .

schwarze 63, 200, 211.

weisse 208, 210, 211.

nimmolum 208.

Nuss 15ั9, 160.

lambertsche 160 .

Nussbaum 160, 182, 184, 186.

nuszbaum h. H. 160, 218.

nuz 160 .

nuzboum 160.

nyesewurtz h. H. 203, 207, 208.

Oberkohlrabi 110.

Odermennig 5, 76, 182, 188 , 190, 196.

oleybaum h. H. 218.

Ölbaum 218.

wilder $72 \mathrm{a}$.

Ölmagen 6 .

öpffel, Indianisch 92.

Orant 84.

Osterlilie 37.

Osterluzei 57, 199, 210.

\section{Päonie 198.}

Papenplatte 73.

Pappel 216, 217.

Pappeln 128.

römische 128.

Pasternak 117.

Pastinak 116, 117, 207, 208.

Pastinakwurzel 117, 118, $184,186$.

patönig K. 77.

paum, wunderleich K. 59 . pedeme 95 .

pefferkrut h. H. 104, 208.

peffertruch h. H. 208.

peipôz K. 76.

penih 170.

pepele, grote 64 .

Perlzwiebel 142.

persic 154.

persichbaum h. H. 154, 219.

Pestilenzwurz 60, 204.

Pestwurz 59, 60, 184.

Peterlein 120.

Petersilie 119, 120, 135a, 182, 184, 185, 208.

Petersill 120.

Pfebe 95 .

pfedem K. 95.

pfedema, phedemo 95.

Pfeffer 190.

schwarzer 208.

weisser 208.

pfefferkraut -K. 69 .

Pfefferkraut 102, 103, 135, 208.

Pfefferkümmel 131.

Pfefferminze 69, 70.

pfeffertruch h. H. 208.

Pferdebohne 100.

Pferdeeppich 120.

pfersic 154

Pfersing 154 .

Pfingstlilie 37.

Pfirsich 154, 219.

Pfirsichbaum 154, 182, 184, 186, 188.

Pfirsch 154.

Pfirschaprikose 155 .

Pflaume 152, 153, 219.

damascener 153.

gelbe 153.

grüne 153.

Pflaumenbaum 153, 154, 182, 184, 186, 217.

pfloumbovm $153 \mathrm{a}^{2}$.

Pfriemenginster 219.

pheffercrut h. H. 208.

phlumbovm $153 \mathrm{a}^{2}$.

Pillenkraut 58.

Pillennessel 88.

Pilze 202.

Pimpernell 115, 135็a, 189, 198.

Pimpernellrose 37. 
Pinie 161, 184, 186.

pipoz 189.

pirbaum, pirpaum 146.

pirn 146.

pirnküten K. 146.

planza h. H. 206, 208.

plionia h.H. 208.

Polei $69,72,184,185,188$, 189.

Poleiminze 69, 208.

poleya h. H. 208.

popele 128.

Porree 104, 141, 182, 184, 185, 206, 209.

Pors, Porst 49, 218.

Portulak 107, 108, 135a, 199, 209.

prieslauch h. H. 141，206, 209, 211.

Provinzrose 37.

prume $153 \mathrm{a}^{2}$.

prunibaum h. H. $153 \mathrm{a}^{1}$, $216,217,219$.

pryme h. H. 218, 219.

psaffo h. H. 209.

Purzella 108.

Quecke 152a.

Quede 147.

Quendel 209.

quenula h. H. 209, 211.

Quetsche $152 \mathrm{a}^{2}$.

Quitte 13, 144, 146, 219.

Quittenbaum 147, 182, 184, $186,216,219$.

\section{Radies 114.}

Radieschen 113.

rahdich h. H. 209.

Rainfarn 69, 74, 182, 184, $188,209$.

Raps 112.

rasela, razela h. H. 209.

Rassel 209.

ratde h. H. 132, 209, 215.

rätich 115 .

Rättich 114.

Rauke 107, 184.

Raute 2, 67, 69, 104, 135 a, $182,183,185,188,210$.

Reiherschnabel 200.

reinefano 189 .

reinevane 74 . retich b. H. 113, 209.

Rettich 2, 113, 114, 184, 185, 188, 209.

reynevane 74 .

reyneuar 74 .

reynfan h. H. 209, 213.

Rhabarber $177 \mathrm{a}^{1}$.

Ricinus 58.

Riedgras 210.

rifelbere h. H. 209.

Ringelblume 104, 106, 107, 209.

ringele $107 \mathrm{a}^{2}$.

ringella h. H. 209.

Ringelrose 107.

rungula h. H. 107, 209.

ritgras h. H. 210.

risza, riza h. H. 209, 210.

rocco, roggo 169 .

Rode 82.

roemesgrasz h. H. 209, 214.

roemische mentha 210 .

Roggen 96, 162, 164, 169, 211.

rogke, rokke 169 .

Rohrkolben 201.

Rokka 101.

romischmyntza h. H. 210.

rôs $\mathrm{K} .36$.

Rose 2, 13, 34 ff., 174, 183, $185,188$.

gefüllte $34 \mathrm{ff}$.

gelbe 37 .

rote $35 \mathrm{ff}$.

weisse 36,37 .

rôsendorn K. 36.

Rosenkohl 110.

rôsenpaum K. 36 .

rosinkol 112.

Rosmarin 133, 136, 184, 185.

rossemyntza h. H. 72, 209, 214.

rosses minza 188.

Rosskastanie 159.

roszhuf 60 .

Roszpflaume Krtb. 153, 219.

roszprumen h.H. 153, 219.

Rote Beet 129, 185.

Rote Rübe 129.

Röte 82.

Rotkohl 112, 205.
Rottanne 219.

ruba h. H. 113, 209, 210.

Rübe 112, 113.

gelbe 116.

lange 113.

rote 129 .

runde 113 .

weisse $112,209,210$.

Rübsen 112 .

Ruchgras $81 \mathrm{a}^{2}$.

Runkelrübe 129 .

Ruprechtskraut 212.

Rustbaum 217.

Rüster, Rüstholz 21\%.

Saat-Platterbse 96.

Saatwucherblume 42.

Sadebaum 80, 18:, 184, 220.

Safflor 82, 84.

Safran 84 .

Sahlweide 219.

Salat 104, 114, 184, 185, 205.

wilder $64,214$.

Salatblätter 157.

salbeia h. H. 210.

Salbei $2,73,133,182,183$, $185,188,210$.

salewida h. H. 219.

salvei K. 133.

Sanikel 210.

sanikela h. H. 210.

satereia h. H. 135.

Saturei 135, 210.

Saubohne $96 \mathrm{a}^{2}, 100$.

Sauerampfer 61, 135 a, $178 \mathrm{a}^{1}, 197$.

Sauerkirsche 148, $150 \mathrm{ft}$.

Sauerklee 190.

Sauwurz 211.

savenbom, savinbom 81 .

Savoyenkohl 110.

Scampanierwurzel 210.

Scariol 105.

zahme 105.

Schafgarbe 190, 202, 207.

Schalotte 138, 139, 197.

Schampanierwurz 210.

Scharlachsalbei 134, 210.

scharleya h. H. 200, 210.

scharleye 134.

Schattenmorelle 144. 
Schellkraut 61.

Schellwurz 61.

scherling h. H. 200, 210.

Schierling, gefleckter 210 .

Schilfrohr 197.

Schlangengurke 222.

Schlangenlauch 142.

Schlangenmord 123.

Schlangenwurz 51.

Schlehen 153, 219.

Schlüsselblume 205.

Schlutte 198.

Schmerbel 127.

Schmerwurzel 56 .

Schneeglöckchen 41 a.

Schneetropfen 41 a.

Schnittlauch 135a, 141, 182, 184́, 206, 209, 211.

Schöllkraut 61, 200, 203.

schulbaum h. H. 219.

Schulweide 219.

Schwadengras 170.

Schwalbenwurz 61, 190.

Schwämme 202.

Schwarzdorn 219.

Schwarzes Gemüse 184.

Schwarzkümmel 131, 132, 184, 186.

Schwarzwurzel 12:, 123.

Schwertel $43 \mathrm{ff}$.

blaw 45 . geel 46 .

Schwertlilie $43 \mathrm{ff}$., 86,184 , $185,188$.

Scorzonerwurzel 123.

Seebinse 205.

Seerose 203, 208. weisse 208.

Seifenkraut 84.

Seifenwurzel 84. egyptische 84 . levantische 84 . spanische 84 .

selba h. H. 133, 210.

Sellerie 114, $119 \mathrm{ff}, 182$, 184, 185, 188, 197.

Senf $107,184$. schwarzer 108. weisser $108,115,180 \mathrm{a}^{3}$, 211.

senft' h. H. 108, 211. senif, haimisch K. 108. Sesamon $96 \mathrm{a}^{2}$.
Sesel 66.

seuenbom 81 .

seuwurtz h. H. 211.

Sewwurtz 211.

sibenbaum h. H. 220.

sichterwurtz h. H. 200, 211.

Siebengezeit 82 a.

Siegwurz 46.

sigminz K. 78.

Silermontan 66.

Simse 213.

sitderwrz h. H. 211.

slangwurz 53.

slatenkraut K. 45.

slehen h. H. 219.

Smergel 211.

smergela h. H. 211.

snideloch h. H. 211.

sniteloch 141.

snitelouch 141.

Sommerthürlein 4ta.

Sommerzwiebel 139, 140, 184, 213.

Sonnenwirbel 106.

Sophie, brēdn 73.

smalln 73, 133.

Spargel 98, 124.

wilder 124 .

Spargen 123, 125.

Speierling 146, 147, 184, $186,220$.

wilder 148.

Spelt $96,162,163,167,168$, 211.

Spelz 211.

spelza 169, 211.

Sperbenkraut, klein 135 a.

Sperberbaum 148.

sperebaum 147.

Sperwerbaum 148.

Spierling 147.

Spillbaum 220.

Spinat 127, 128, 130, 175a2 . englischer $178 \mathrm{a}^{1}$.

Spinatpflanzen $127 \mathrm{ff}$.

Spindelbaum 216, 220.

spinelbaum h. H. 216, 220.

spirbaum h. H. 216, 220.

spirbaum 147.

Spitzahorn 218.

Springkraut 58, 184.

springwurtz h. H. 200, 212.

Springwurz 58.
Stabwurz 74, 196, 212.

stagwurz h. H. 75, 196, 212.

Stangenbohnen 184.

Stechapfel 212.

Stechnelke 43.

Steckrübe 112, 113, 114.

Steigfaseln 99.

Steinbrech 190, 210.

körniger 212.

steinbrecha h. H. 210, 212.

steinfarn, steiwarn h. H. 209, 212.

Steinpfeffer 201.

steinpreha 189.

Stengelkohl 110.

Sterckkraut 84.

stichwurtz h. H. 56, 199, 212.

Stickwurz 56.

St. Johanns Pfersing 155.

Stockrose 128.

Stoppfelrübe Tab. 113.

Storaxbaum 212.

storckenschnabel 212 .

storcksnabel h. H. 212.

Strauchweichsel 148, 151.

Streichkraut 84 .

Strohblume 175a.

studa h. H. 220.

stuina 189.

stur, sture $129 \mathrm{a}, 130,212$.

stutgrasz h. H. 212.

sulbaum h. H. 216.

sunnewirbel h. H. 106, 211, 212.

sunneuuirpila 189.

suregrasz h. H. 212, 214.

surige h. H. 206.

Süssdolde 126.

Süssholz 206.

Süsskirsche $148 \mathrm{ff}$.

swertelkraut K. 45 .

swertlinch K. 45.

swertula h. H. 44, 203, 212.

sybenbaum h. H. 81, 219, 220.

Sykomore 156 .

symes h. H. 213.

Taumellolch 132, 162, 166, 201, 209.

Tausendgüldenkraut 62 , 189, 199. 
Taxus 220.

Teufelszwirn 56.

Thymian 133, 135.a, 213.

tillessamo, tillisamo 189 .

Tollkirsche 144a, 201, 212.

tosta 189.

Totenblume $10 \%$.

Traubenhyacinthe 38 .

Traubenkirsche 216.

Trippmadam 135a.

Tulpe 112.

turnella 189.

uersbotde h. H. 213.

uiselun h. H. 214.

Ulme 151, 217.

Ulmenbaum, Ulmerbaum 217.

unlauch h. H. 200, 206, 213. uniän (dän.) 140.

uniun (ndd.) 140.

vehedistel h. H. 201, 213.

Veiel 40.

geel od. gelb 41 .

welsch 41.

Veielwurtz 45.

Veilchen 39, 40, 213.

Veilchenwurzel 86, 205.

veltdorn K. 36 .

veltisp K. 135.

veltmage 65 .

venich 170,213 .

venichil h. H. 213.

Vergissmeinnicht 202.

Vexiernelke 42, 43.

vichbona, vigbona h. H. 213 .

vigim $h$. H. 216.

vinterut 75 .

viol K. 40.

Viol 40.

Viol matternal 42.

Viole 39.

Vogelbeerbaum 148, 218.

Vogelknöterich 189.

Wachholder 80, 81, 189, 216,220 .

wacholderbaum h. H. 21\%, 220.

Waid 82, 83, 214.

waitkraut K. 83.

Walch 162.
Waldmeister $81 \mathrm{a}^{2}$.

Waldminze 72.

Walnuss 158, 159, 218.

Walnussbaum 160.

waltbere h. H. 213.

Wasserampfer 129.

Wasserliesch $46 \mathrm{a}^{3}$.

Wasserlilie 46.

Wasserlinse 207.

Wassermelone $94,175 \mathrm{a}^{3}$, 221.

Wasserschwertel 46 .

Wasserschwertlilie 45.

Wasserveilchen $46 \mathrm{a}^{2}, 205$.

Wau 82, 83.

uuazaruuurz 189.

Weberkarde 121, 18f, 199. uuegerich 189.

wegerich h. H. '214.

Wegerich 189, 208, 214.

wegetrede 189, 214.

Wegetritt $122 \mathrm{a}^{2}$.

weggrasz h. H. 214.

Wegwarte 106.

weice 169 .

Weichsel $152 \mathrm{a}^{1}$.

Weide 216, 220.

Weihrauch 190, 213.

Weinraute 69, 210.

Weinrose 35.

Weinstock 15\%, 220.

Weisskraut 108, 111.

Weissminze 73.

Weisswurzel 122 .

weit 83 .

weithagen K. 36 .

weitwurz 8.3.

Weizen $96,16 \%, 163,16 \%$, $168,169,213$.

weizpapel K. 64 .

wendelkoel h. H. 205 .

uuerimuota 189 .

wermuda h. H. $75,196,214$. wermuot $\mathrm{K}$. 75 .

Wermut 75, 188, 196, 214. weydenkole h. H. 111, 205, 214.

weyt h. H. 83, 214.

wichim h. H. 214.

wichsel 152.

wichselboum 152.

wichwurtz h. H. '214.

Wicke 214, "2? wida h. H. 220 .

Wiesenklee 200.

Wiesenkümmel 131.

wilde latich h. H. 214.

wildeminsa h. H. 210, 214.

winda h. H. 214.

Windhafer 162, 166, 168.

Winterveiel 42.

Winterviole 42.

Winterzwiebel 138, 140.

Wirsing 110.

wisela h. H. 21 f.

wirzgrasz h. H. 210, 212 214.

witcol 112

wize 169 .

vuizminza 189.

vuizuuurz 188.

wizwurz 68 .

wolfesgelegena h. H. 214.

Wolfsmilch, kreuzblättrige $58,212$.

Wolfswurtz 214.

Wollkraut 214.

Wolverlei 214.

woremworth 75 .

wrincrut 75 .

Wruke 112.

Wucherblume, grosse 42. wulffesmilch h. H. J99, 214 . wullena h. H. 198, 205, 214. Wunderbaum 58 .

Vundkraut 80 .

wuntwurtz h. H. '21):, 214.

Wurmfarn 202.

Wurmkraut 74.

Wurzel, gelbe 116 .

Würzpflanzen $133 \mathrm{ff}$.

ybenbaum h. H. 20(1).

ybischa h. H. 64, 214.

Yffenholtz 217.

ysena h. H. 78, 21:3, 2,1..

Ysop 133, 137, 20\%.

ywesche 64 .

Zäpfenchenkraut 1 \&?.

Zaunrübe 54, 55, 125, 199, 206, 212.

Zaunwinde 214.

Zeckenkörner 59.

Zeitlose 38, 204.

Zimmt 200 . 


\section{$-\quad 235$}

Zimmtbaum 190. Zimmtrose 37.

Zipolle 139.

Zirmet 66.

Ziser 101.

Zisererbse 101.

Zitterpappel 215.
Zitterwurtz 211.

Zittwerwurzel 190, 215.

zituar, zitwar h. H. 215.

Zuccomarin 92.

Zuckerrose $39 \mathrm{ff}$.

Zuckerwurzel 110, 118, 203.

zugeluich h. H. 215.
Zwergholunder 188, 203.

Zwerglorbeer $177 \mathrm{a}^{1}$.

Zwetsche 152, 219.

Zwetschenbaum 153.

Zwiebel 137, 139, 182, 184, 185, 200, 201, 206, 213. 


\section{Register}

\section{der lateinischen Pflanzennamen.}

Bemerkung: Die Namen des Capitulare sind fett, die heute gebräuchlichen wissenschaftlichen Pflanzennamen mit grossem Anfangsbuchstaben gedruckt; Synonymen, die nur in sehr geringer Anzahl vorkommen, sind nicht besonders kenntlich gemacht. - Die Namen der Pharmakopöe sind durch einen Stern *ausgezeichnet; bei herba, radix etc. gilt dieses Zeichen für alle damit verbundenen Namen.

abies h. H. 215.

Abies pectinata DC. 215.

abrotanum 2, 74, 137a, 182, 183, 188, 196, 212.

abrotonum Colum. 74. absinthium $75,181,188$, 189, 196, 214.

acer 196, 203, 215.

Acer campestre L. 217.

platanoides L. 218.

Pseudoplatanus L. 215, 218, 219.

acero 189.

acetaria 180.

Achillea millefolium L. 190, 202, 207.

acoleia h. H. 196.

Aconitum Lycoctonum L. 214.

acoron Plin. 46, 49.

acorus Gloss. 46.

acorus Matt. 50.

Acorus Calamus L. 49.

acrimonia 5, 76, 182.

adoreum 16.3, 169.

adripia 3.

adripias $127,183$.

Aegilops ovata L. 162.

aegoceras Plin. 82.

aesculus 147 .

Aesculus Hippocastanum L. 159. affrissa Gloss. 52.

agre Gloss. 88.

agriocardamon Bock 103.

agrius Gloss. 88.

agrimonia $77,188,189,196$.

Agrimonia Eupatoria L. 76, 190, 196.

Agrostemma coronaria L. 43.

Githago L. 85, 132.

aitiotidus 189.

Ajuga Chamaepitys Schreb. 189.

Iva Schreb. 189.

aizoum Plin. 79.

alcea K. 64.

alentidium h. H. 196, 202.

alleluia 189.

alia 142, 181, 182, 183.

alius $143,185$.

ortulanus 143.

alkekengi 198.

alleus 143.

allium 138, 142, 143, 176, $177,1 \times 1), 197$.

punicum 142.

Allium Ampeloprasum L. 142.

ascalonicum I. 138.

Cepa L. 139, 213.

fistulosum L. 140.

Porrum L. 141, 206.
Allium sativum L. 142, 197.

a) vulgare Don 142 .

b) Ophioscorodon Don 142.

Schoenoprasum 141, 206, 211.

Victorialis L. 47. alnus 188, 215.

Alnus glutinosa Gärtn. 215. aloe h. H. 197.

Aloe vulgaris L. 197.

Alpinia Galanga Sw. 190, 202.

Alsine media L. 204.

altea 64, 182, 183.

althaea Plin. 63.

Althaea officinalis L. 63, 214.

rosea Cav. 128.

amandalarios 158, 183.

amandola 159.

amaracum Plin. 135.

amaracus Colum. 135.

amarantus 174.

amarantus Diosk. 175 a.

immortalis Colum. 175 a.

Amarantus Blitum L. 129, 212.

amarellus 152.

amarena Alb. M. 152.

ambrosia Walafr. 74, 188. amendelarius 186 . 
ameum $66,183$.

amigdalus 159 .

amilia $122 \mathrm{a}^{1}$.

Ammi copticum L. 66 .

majus L. 66 .

ammium alexandrinum

Tab. 66 .

Amomum Zingiber L. 205, 215.

amygdala 158.

amygdalae amarae 158 .

dulces 158.

amygdalus 159, 215.

Amygdalus communis $\mathrm{L}$. $158,215$.

persica L. 154, 219.

Anacyclus officinarum

Hayne 198.

Anagallis arvensis L. 79.

anemone coronaria Plin. 87.

Anemone coronaria L. $8 \%$.

anethum 2, 132, 176, 179, 181.

Anethum Foeniculum L. 132, 202.

graveolens L. 132, 197, 201.

segetum v. Heldr. 133.

anetum $132,183,185,189$, $197,201$.

anesum 133, 183.

anguina Matt. 222.

anguria Matt. 95.

anisum 133.

Aegyptiacum Colum. 133.

annona 169.

* anthos $136 \mathrm{a}^{2}$.

Anthriscus Cerefolium

Hoffm. 126, 200, 205.

aphrodisia Diosk. 46.

aphros Plin. $86 \mathrm{a}^{3}$.

apiacon Cato 109, 120.

apiago h. H. 197, 198.

apiastrum Colum. 137.

apium $119,120,176,178$,

$181,182,183,185,188$,

$189,197$.

agrest 119 a.

crispum 120.

hortense 120.

palustre 120 .

risus $119 \mathrm{a}$.

rusticum 119 a.
Apium graveolens L. 119, 197.

Petroselinum L. 120.

appium 180.

apsinthium Plin. 75.

Aquilegia vulgaris L. 196. aquileja h. H. 197.

arbor armeniaca Colum. 155.

malvae Alb. M. 128.

mirabilis Alb. M. 59.

nucarius Gloss. 160 .

persica Plin. 154.

arcion Plin. 59.

Arctium Lappa L. 59, 200. 205.

aretillum 141, 176, 179, 181.

argemone Plin. 87.

arinca Plin. 163, 168.

aristolochia Plin. 57.

Aristolochia Clematitis L. 57, 198, 199, 210.

longa L. 57, 197.

aristologia 57, 197.

longa h. H. 57, 197.

armon Plin. 116.

* armoracia 114, 115, 116.

armoratia 114, 115, 176.

armoratio 115.

armoriaca 115.

Arnica montana L. 214. artemisia $62,76,189,197$. artemisia tagantis 74 .

Artemisia Abrotanum L. $69,7 i, 196,212$.

Absinthium L. 75, 196, 214.

arborescens L. 75.

Dracunculus L. 51.

vulgaris L. 76, 197.

Arum Dracunculus L. 51 , 52.

italicum L. 52, 198.

maculatum L. 52, 203.

arundo h. H. $19 \%$.

Arundo Phragmites L. 197. asara baccara 57 .

asaron Plin. 56.

asarum 57, 197.

Asarum europaeum L. 56, $15 \%, 203$.

ascalonicas $138,139,140$, 183. aschalonia h. H. 138, 197.

asclepias Gloss. 52.

asclonium 138.

ascolinum 138.

ascolonias 185 .

asia Plin. 165.

asolinum 138.

asparagi 125.

asparagus $124,125,175$, $177,180$.

sativus Colum. 125.

Asparagus acutifolius L. 124.

aphyllus L. 12t.

horridus L. 124.

officinalis L. 12f, 125.

astonium 138.

Astrantia major L. 197.

Athamanta cretensis L. $117 \mathrm{a}$.

atiron 80.

atriplex $3,127,176,178$, 180.

sylvestris baccifera Clus. 130.

sylvestris mori fructu C. Bauh. 131.

Atriplex hortensis L. 127, 197, 206.

Atropa Belladonna L. 144a, 201, 212.

attriplex h. H. 197, 206.

avelauarios $160,182$.

avellana 161 .

avellanarios $160,183$.

avellenarius 186.

avena 65 .

sterilis 166.

vana 166.

avena $165,167 \mathrm{a}, 170$.

Avena fatua L. 166.

sativa L. $165,170$.

auesperina 161 .

auvesperma 161.

auricula asinina Gloss. 52 .

leporis Gloss. 68.

bacas giniperi 81 .

* baccae juniperi 81 .

baccar Plin. 56.

baceara Gloss. 56.

baccaris Vergil. 56 a.

bagas geniperi 81 . 
balaustium Plin. $35 \mathrm{a}^{\text {? }}$.

Ballota nigra L. 78 .

ballote Plin. 78 .

balsamita $\pi 1,73,19 \pi$.

Balsamodendron Kataf.

Kunth 190, 207.

gileadense Kunth 197 , 199.

balsamon h. H. 197 .

balsamum 71 .

paiustre 71 .

barba hirci Camer. 123.

barba Jovis 79 .

barbula hirci Matt. 123.

bardana 59,60 .

bardo 60 .

bardona 60 .

barentia Gloss. 82.

basilia, basilica h. H. 197.

basilicon Alb. MI. 134́.

basilicum $180 \mathrm{a}^{2}$.

basilicus Alb. M. 53.

basilisca 189, 198.

basiliscus Alb. MI. $53 \mathrm{a}^{1}$.

batus 156 .

bechion Plin. 60.

bedegar (arab.) 35.

benedicta 189, 198.

Berberis vulgaris L. 216 .

beta 129, 175, 176, 179 .

Beta vulgaris L. 129.

betas $129,182,183,185$.

betonica 77,188 .

Betonica officinalis L. i⿱一, 190, 198, 208.

Betula alba L. 215, 21\%, 220.

bisantia h. H. 198.

bislingua 189 .

bismalva 64 .

bistorta 54 .

blandonia h. H. 198, 205, 214.

bleta 129 .

blidas $129,183$.

blitum 129, 180.

rubrum Krtb. 130.

Blitum virgatum L. 130 .

blitus 129.

*boletus cervinus 204 .

borago Alb. M. 134.

borith (arab.) 85, 199.

Borrago officinalis L. 134.
Boswellia serrata Roxb. 213. brace Plin. 164.

brassica 109, 111, 176, 179 . cauliflora Matt. 111.

Cypria Matt. 111. prolifera florida Tab. 112.

Brassica Napus L. 112. nigra Koch 108. oleracea L. $108 \mathrm{ff}$., 112. Rapa L. 112, 209, 210.

brionia h. H. 56, 199, 212. britanica 129 .

britlas 141, 183.

brittola 141, 182.

brittula 141 .

* bryonia alba 56 .

* nigra 56.

* baccis nigris 56 .

Bryonia alba L. 55, 212. cretica L. 55 .

dioica L. 55, 212.

buceras Plin. 82.

Bunium Bulbocastanum L. 126.

ferulaceum Sibth. et Sm. 126.

buphthalmus Plin. 42.

Butomus umbellatus $\mathrm{I}$. $46 \mathrm{a}^{2}, 205$.

butracion $119 \mathrm{a}$.

buxus $49,216$.

Buxus arborescens Lam. 49 . sempervirens L. 49, 216 . suffruticosa Lam. 49.

Cachrys eretica Lam. 136. Libanotis L. 136.

cactos Plin. 121.

caepa Ascalonia Matt. 139. fissilis Matt. 141.

sectilis Matt. 141.

caerefolium Plin. 126.

calamentum h. H. 199, 207.

Calamintha officinalis

Mönch $73 \mathrm{a}^{1}$.

Nepeta Clairv. $73 \mathrm{a}^{1}$.

* calamus aromaticus 50.

calamus odoratus Plin. 49. calendula 107.

Calendula officinalis L. 106 , 209.

caltha $107 \mathrm{a}^{2}$.

camipiteus 189. camphora h. H. 199.

canabis 87 .

canape 189.

canava 87.

cannabis 87 .

Cannabis sativa L. 87,199 , 203.

cannabus 87, 199, 203.

caputium Alb. M. 111.

cardamine Diosk. 103.

cardo h. H. 199.

fullonicius Gloss. 122.

cardones 121, 183.

cardus, carduus 121, 175 , $178,180$.

cardus h. H. 199, 201.

niger h. H. 199, 214.

Carduus Marianus L. 201, 213.

carectum 45.

eareium 131, 183.

careum 131.

Carex sp. 210.

cariota $116 \mathrm{a}^{1}$.

carpinus h. H. 216.

Carpinus Betulus L. 215, 216.

carpobalsamum h. H. 199.

Carum Carvi L. 131.

carota Gloss. 117.

carrucas $116 \mathrm{a}^{1}$.

Carthamus tinctorius L. 84 .

carvitas 116, 117, 183.

Caryophyllus aromaticus L. 190, 202, 207.

castanea 159, 216, 217.

Castanea vesca Gärtn. 159, 216, 217.

castanearios $159,183$.

castenarius 186.

* eataputia major 58.

* minor 58.

caulas $108,182,186$.

caules 108, 182.

rubeae h. H. 112, 205.

cauliculus 109, 111, 125, 179.

cauli rapa $110 \mathrm{a}^{2}$.

caulis $109 \mathrm{ff}$, 199, 205.

crispus Gloss. 111.

caulorapa $110 \mathrm{a}^{2}$.

eaulos 108, 183.

caulus 189 
cedrus h. H. 216.

cedrus Alb. MI. 223.

celidonia 200.

Celosia cristata I. $174 \mathrm{a}^{3}$. celsa 156 .

celsus $156 \mathrm{a}^{1}$.

centaurea h. H. 199.

centauria 189.

centauria minor 62,63 .

centaurium minus 62 .

centenum ed. Diocl. 165.

centifolia Plin. 35.

centifolium Gloss. 35, 175.

centinodia $122 \mathrm{a}^{2}$.

centonia 75 .

centonica 75 .

centonodia, centumnodia 189.

cepa $138,140,176,17 \%$ $180,185$.

fertilis C. Bauh. 138 .

minuta Gloss. 141.

cepas ascalonicas 138,139 , $140,183$.

scalonias 139, 140, 182. cepe h. H. 200, 206, 213.

cerasium 151.

acidum Krtb. 152.

cerasus $148 \mathrm{ff}$., 216.

Ceratonia Siliqua L. 146. cerefolium 119, 185, 188.

* hispanicum 127.

ceresarios div. gen.148,183. ceresium 151.

cerfolium 126, 182, 183. cerifolium h. H. 200, 205. cerisarios $148,182$.

cerofolio 189.

chaerephyllum Colum. 126. Chaerophyllum bulbosum I. 126 .

chamaeleuce Plin. 60.

Cheirantus Cheiri L. 41, 112.

chelidonia 61, 200, 203.

major 61, 200.

minor 62, 202.

* chelidonium magnum 61.

* minus 62 .

Chelidonium majus L. 61, 200, 203.

Chenopodium album L. 127. Bonus Henricus L, 127. chervillum 119.

chinus h. H. 200 )

Chrysanthernum coronarium L. 13, 42.

Leucanthemum L. 42.

Parthenium Pers. 62, 190, 198, 202, 207.

segetum L. 43.

cibula, cibulla Gloss. 141. cicer 96a', 99a $\mathrm{a}^{2}, 101,224$. arietinum Colum. 101. domesticum Alb. MI. 101. punicum Colum. 101. silvestre 101.

Cicer arietinum L. 101, 205. cicercula 96 .

cicerum Italicum 101, 183. cichorium Plin. 106.

Cichorium divaricatum Schousb. 106.

Endivia I. 105.

Intyluus L. 106, 211, '212. pumilum Jacq. 106.

cici Plin. 58.

cicorea $106 \mathrm{a}^{2}, 106 \mathrm{a}^{3}$. cicula h. H. 200, 210. cicuta h. H. 200, 210. * cicutaria odorata 12\%. cidonius 147.

ciminum 131, 183. cinara Colum. 121. cinnamamum 189, 200. Cinnamomum Camphora Blume 199, 202.

Cassia Blume 190. zeylanicum Blume 190 , 200.

cinnamum 189.

cinus 153, 200.

cirifolium 126.

citer 224.

cithysus h. H. 200.

citocacia etc. $58 \mathrm{a}^{3}, 200$, 212.

citonius Alb. MI. 147.

citreolus 222.

alter forma anguis 222 .

citreum 221.

citriolus 223.

citrion Brunf. 223.

citrium 221.

maximnm $221 \mathrm{a}^{2}$.

citrulus Alb. M. 95, $221 \mathrm{ff}$. citrullus $95,223 \mathrm{ff}$.

Citrullus Colocynthis

Schrad. 54.

vulgaris Schrad. 94.

Citrus medica L. 216, 221 $\mathrm{a}^{2}$, 223.

Clematis Vitalba L. 56.

cnecos Plin. 84.

Cochlearia Armoracia L. 114, 207, 209.

coctanus 147.

coctus nidus Gloss. 58.

Colchicum autumnale L. 204.

coliandrum 133, 181, 185. colicula 175.

coliculi 15, 111, 176.

colocynthis Plin. 54.

coloquentidas 54, 183.

colubrina Gloss. 52, 54.

condimenta $177 \mathrm{a}, 178,181$.

Conium maculatum L. 200, 210.

consolida h. H. 200 .

major 200.

conula $16,135$.

Convolvulus arrensis $\mathrm{L}$. 214.

sepium L. 214.

corcodrillion Gloss. 52.

coriandrum 133, 179, 181, $282,283$.

Coriandrum sativum L. 133. corilus, corylus 161.

cornus 150,216

Cornus mas L. 150, 216. sanguinea L. 150, 216, 219.

Coronaria tomentosa $\mathrm{R}$. Br. 43.

coronopus 147.

corruda 124, 125.

* cortex radicis esulae 199.

Corydalis cava L. 57.

corylus 160, 216.

Corylus Avellana L. 160 , 216.

tubulosa Willd. 160.

costo 189.

costum $73,181,182,183$. costus 3, 185.

hortensis Walafr. 73, 188. hortorum 73. 
Costus speciosus Sm. 73, 190.

cotanus, cottanus 147.

cotoniarios 146, 182, 183. crassula Alb. MI. 80).

crissonus Gloss. 103.

hortensis Gloss. 103.

cristiana h. H. 200.

crocus Alb. MI. 84 .

hortensis Alb. MI. 84 .

croton Plin. 58.

cubebo h. H. 200.

cucumer $93,221 \mathrm{ff}$.

eucumeres 92, 183.

cucumis $92,175,176,181$,

22) $\mathrm{ff}$.

citrinus Brunf. $223 \mathrm{a}^{1}$.

longus Caesalp. 222.

Cucumis Melo L. 93, 208.

sativus L. 92.

cucurbita 89, 175, 176, 179,

188, 200, 205.

indica Krtb. 92.

silvatica 54 .

silvestris Plin. $54 \mathrm{a}^{1}$.

Cucurbita lagenaria L. $89 \mathrm{ff}$, 200, 205.

Pepo L. 92.

cueurbitas 89, 183.

cuma $177 a^{3}$.

cuminum 131, 185.

Cuminum Cyminum L. 131, $200,205$.

cunela 178.

cunila Plin. 135.

nostras Colum. 135.

Cupressus sempevirens L. 216.

Curcuma Zedoaria Rosc. 190, 215.

curmus $147 \mathrm{a}^{2}$.

Cyclamen europaeum $\mathrm{L}$. 56 a.

Cydonia vulgaris Pers. 146, 219.

cyma 109, 111, 177, 180.

armoraciorum Colum.114. cauliculi 180 .

cyminum 131, 178, 200, 205.

cynamomum h. H. 200.

Cynara Cardunculus L. 121.

Scolymus L. 121, 201. cypressus h. H. 216.

cytonius K. 147.

dactylosa h. H. 198, 201.

dactylus 198.

damasonium 103.

damassonium 103.

Datura Stramonium L. 212.

daucus 117.

creticus 117.

Daucus Carota L. 10, 116. decrecium, decretium 16.

decreticum 16.

dendrolibanon 136.

dictama h. H. 201.

dictamnum Verg. 68.

dictamnus 68, 201.

creticus 68 .

Dictamnus albus L. 68, 201. dictampnus h. H. 68, 201. didimus 68 .

dipsacus Plin. 121.

Dipsacus fullonum Mill. 121, 199.

silvestris Mill. 122.

diptamnum 67, 183.

diptamnus 69, 188.

dolichos 98 .

Dolichos 98.

Catjang L. 99.

melanophthalmus DC. 98. dorchadion Gloss. 52. draco hortensis Camer. 51. draconcellus Matt. 51. dracontea Gloss. 52. dracunculus Plin. 53a ${ }^{1}$. hortensis Matt. 51.

dragantea 51, 183. dragontea Gloss. 52. drauoca $60 \mathrm{a}^{3}$.

Dryobalanops Camphora Colebr. 202.

duracina 150, 154 .

ebulus 188, 201, 203. elaphoboscon Plin. 117.

Elaphomyces granulatus Fries 204.

eleborites 63 .

elelisphacos Plin. 76, 133. eliotropium 106, 107.

endivia 105.
* enula 63, 196, 201.

* campana 63. erba ficaria Gloss. 144.

Erodium moschatum

L'Hérit. 200.

eruca $107,176,178,181$.

eruca alba 107, 183.

Eruca sativa Lam. 107.

Erucaria aleppica Gaertn. 102.

Ervum Ervilia L. $96 \mathrm{a}^{2}$.

Lens L. 101, 206.

Erytraea Centaurium Pers. 62, 189, 199.

escaria 178.

escariola $105,176$.

esculus $147,216,220$.

esula h. H. 199, 201.

enforbium h. H. 201.

euiscus Gloss. 64.

eupatoria Plin. 76.

eupatorium Gloss. $7 \pi$.

* veterum 77.

Euphorbia 214.

Cyparissias L. 199.

Esula L. 199, 201.

Lathyris L. 58, 200, 212. euphorbium h. H. 201.

Euphrasia officinalis L. 214.

Evonymus europaens L. 220.

faba $3,5,96,98,100,189 \mathrm{a}^{4}$, 202, 224.

faba acetata s. acetosa 100 . fracta s. fressa 100.

major 100.

pilata 100.

fabas majores 100, 183.

fabataria 179 .

fagus h. H. 216.

Fagus Castanea L. 159.

silvatica L. 216.

far 163, 164, 167a, 169.

adoreum Colum. 163.

farfugium Plin. 60.

faselus $99 a^{2}$.

faseolus 98, 104.

fasiolo 185 .

fasiolum 98, 183.

fasiolus $98,99 \mathrm{a}^{2}, 175,176$, $180,214$.

febrefugia $62,189$. 
febrefugiam $62,183$.

febrifuga h. H. 202, 207.

fel terrae 63.

fenagraeca 185.

fenicolum 132, 183.

feniculum 132, 176, 178, 181, 185, 188, 202, 213.

fenigrecum $81,183$.

fenugraecum h. H. 202.

ficaria h. H. 202.

fieus 157, 183, 186, 216.

Ficus carica L. 157, 216. Sycomorus L. 156.

filix h. ㅍ. 202.

* flores auriculae muris 207. consolidae majoris 200. meliloti $175 \mathrm{a}^{1}$.

pilosellae 207.

symphyti 200.

flos 174 .

flos Jovis Bock 43.

foeniculum 132, 189 .

foenugraecum h. H. 202.

foenum graecum 82, 179.

folia 179 .

* folia myrti brabanticae 218.

follonicatoria Gloss. 86

Fragaria vesca L. 201.

fragefolium 189.

frasica h. H. 202, 214.

frassafolia 189.

fraxinella 69 .

fraxinus h. H. 215, 216.

Fraxinus excelsior L. 215, 216.

frumentum 169, 162, 167.

fungi $\mathbf{h}$. H. 202.

fusarius $h$. H. $216,220$.

galanga h. H. 202.

galangan 189.

Galanthus nivalis L. 41 a.

Galeopsis Tetrahit L. 201.

Galium Aparine L. 60a ${ }^{1}$. $82,175 \mathrm{a}^{3}, 209,210$.

gamendrea 189.

ganphora h. H. 202.

gariofilae 189.

gariofilata 198.

gariofiles, gariofyli h. H. 202, 207.

gariofilus agrestis 57. gauda Alb. M. 83.

gegrues, gerguers 170 .

gelisia h. H. 203, 208.

gentiana 189, 201, 203.

Gentiana cruciata L. 190, 203.

lutea L. 190.

Geranium Robertianum L. 212.

getion Plin. 138, 140.

Geum urbanum L. 190, 198.

gingiber 189.

git $132,183$.

gith 132 .

gitto 186.

gladiola $43,44,185,188$, 203,212 .

gladiolum 43, 183.

gladiolus $43 \mathrm{ff}$., 203.

aquosus Alb. II. 45.

hortensis Gloss. 44.

lacustris Clus. $46 \mathrm{a}$ ?

paludensis Gloss. 46.

palustris Krtb. $46 \mathrm{a}^{2}$.

Gladiolus communis L. 38 , 43,46 .

floribundus Jacq. 47.

psittacinus Hook. 47.

glastum Plin. 83.

Glaucium corniculatum

Curt. 64

Glechoma hederacea L. 189, 190, 203.

Glyceria fluitans R. Br. 170.

Glyeyrrhiza glabra L. 206.

Gnaphalium Stoechas L. 17ia.

guduniarius 186 .

Gypsophila Arrostii Guss. 85.

fastigiata I. 85 .

Struthium L. 84.

habrotonum femina Plin. 77. mas Plin. 74 .

halicacabum 198.

hedera terrestris 190.

Hedera Helix L. 201.

* helenium 63.

helleborites 62 .

Helleborus niger L. 63, $200,211$.

viridis $\mathrm{L} .62$. helichrysum Diosk. 175a.

heracleum Gloss. 75.

heraclion Plin. 86a ${ }^{3}$.

herba Aaron h. H. 203.

divae Mariae 73.

gicht h. H. 204.

lanaria Plin. 84.

leporis Alb. M. 57.

sabina Plin. 80 .

sacra 78.

scelerata 119a.

senff h. H. 211.

varia ut serpens Gloss.

52.

veprium h. H. 213.

* herba acus muscatre 200.

anserinae 203.

argentinae 203.

auriculae muris 207.

bislinguae 190 .

chamaepityos 189.

consolidae majoris 200 .

crassulae majoris 80 .

endiviae 105.

fabariae 80 .

gallitrichi 134 .

hesperidis 42 .

hormini 134.

hormini sativi 134 .

lactucae silvestris 214.

menthae equinae 209.

menthae romanae 209.

moschatae 200.

pentaphylli 190 .

pilosellae 207.

pimpinellae 189.

potentillae 203.

scariolae 214.

scariosae 105.

sclareae 134 .

symphyti 200 .

telephii 80.

tormentillae 189.

violae damascenae 42 .

violae matronalis 42 .

hermodactylus h. H. 204 .

hesperis Plin. 42.

Hesperis matronalis L. 41 .

hibiscus Plin. 63.

hierabotane Plin. 78.

Hieracium Pilosella L. 207.

208.

hipposelinon 121. 
horminum Plin. $134 \mathrm{a}^{1}$.

hordeum 164, 167 a, 169, 204.

distichum Colum. 164.

hexastichum Colum. 164.

Hordeum distichum L. 164.

hexastichum L. 164.

vulgare L. 164, 169, 204.

humela b. H. 204.

humulus h. H. 204.

Humulus Lupulus L. 204. hyacinthus Colum. 39.

hyacinthus Plin. 46.

caeruleus Colum. 39.

ferrugineus Colum. 39, 46.

niveus Colum. 39.

Hyacinthus orientalis L. $38,39$.

Hyoscyamus niger L. 198.

Hypericum perforatum L. 203.

hyssopus 137, 189, 205.

Hyssopus officinalis L. 137, 205.

ibiscus Gloss. 64 .

imperatoria nigra 197.

Imperatoria Ostruthium L. 121, 197.

indivia 105.

intiba 105.

intubas 105, 183.

intubus $105,176,178,180$. agrestis Plin. 106.

erraticus Plin. 106.

silvaticus Plin. 106.

intyba 105.

intybus 105, 176 .

inula 63,180 .

Inula Helenium L. 63, 196, 201.

Jovis barbam 79, 183. ipies 217.

iris 43 .

graeca Colum. 43.

illyrica Colum. 43.

illyrica Gloss. 44.

paludosa lutea $K r t b$. 46 . silvestris lutea $\mathrm{Krtb}$. 46 .

Iris florentina L. 43, 45, $86,211$.$) .$

germanica L. $43,45,86$. Pseudacorus I. 45.
Iris sambucina I. 45 .

irins Gloss. 86

irs illyrica h. H. 205.

isatis 83 .

Isatis tinctoria L. 83, 214. iua 189.

juglans 159.

Juglans regia $\mathrm{L} .159,218$.

iulex h. H. 217.

juncus h. H. 205.

juncus floridus Krtb. $46 \mathrm{a}^{2}$.

juniperus h. H. 217.

Juniperus communis L. 81, 189, 216, 217, 220.

Sabina L. 80, 219, 220.

jusquiamus 198.

lacterida 3.

lacteridas 58, 183.

lactuca 104, 105, 176, 178, 180, 185, 205.

agrestis h. H. 205.

silvestris h. H. 205, 214.

lactucas 104, 183.

Lactuca Scariola L. 64, 205, 214.

Scariola L., var. sativa. 104, 205.

virosa L. 205.

lampsana 180.

lanaria h. H. 205.

lapacium 59, 205.

lapathon Plin. 61.

lapathum 61 .

lappa 60, 175, 200, 205.

inversa 77.

incisa 77.

Lappa minor DC. 59.

officinalis All. 59.

tomentosa Lam. 59.

lappatium Alb. MI. 61.

* lappula hepatica $7 \%$.

lapsana Gloss. 114.

Laserpitium siler L. (6.).

lathyris Plin. 3, 58.

Lathyrus sativus L. 96.

Lavandula officinalis Chaix 1336.

Spica L. 136, 206.

Stoechas I. 1366.

Lavatera arborea L. 128, 129.

lauendula h. H. 136, 206. lauindula 188.

laurocina 177.

lauros 47, 183.

laurus 47, 186, 217.

Laurus nobilis L. 47, 217.

laurustinus 48 .

Ledum palustre L. 49.

Lemna sp. 207.

lens $102,206$.

lenticula 101, 102.

lentiscus h. H. 217.

lepidium 104.

lepidium latifolium Krtb. 104.

Lepidium latifolium L. 103, 208.

sativum L. 102, 200, 207.

leucoium 40, 41 .

aureum Krtb. 41.

bulbosum Tab. 41 a.

candidum Colum. 40.

luteum Krtb. 41.

Leucoium vernum L. 41 a.

lenisticum 66, 183.

levisticum h. H. 67, 206.

Levisticum officinale Koch 66, 206.

libesticum 66, 181.

libisticum 2, 206.

libysticum Walafr. 67, 188.

ligusticum 6 \%

Ligusticum, Levisticum L. 66.

Ligustrum vulgare L. 219.

lilium 2, 33, 174, 181, 182, $183,185,188,206$.

album Plin. 33.

candidum Verg. 33.

celinum Gloss. 44.

purpureum Gloss. 44.

Lilium bulbiferum L. 33. candidum L. 33, 206.

* lingua cervina 204 .

limmm 85.

Linum usitatissimum L. 85, $206,211$.

liquiricium h. H. 204, 206.

livesticum 67, 182.

livisticum Alb. M. (i).

Lobelia I)ortmanna L. $46 \mathrm{a}^{2}$.

lobia 98.

lolium 166, 167 a.

infelix 166. 
亡̇olium temulentum L. 132, 166, 201, 209, 215.

lubestico 185.

lubisticum h. H. 206.

lutum 83.

croceum Verg. 83.

lychnis Plin. 43.

lychnis coronaria Krtb. 43 .

magacia 177.

magones 185.

maiorana 135.

malabatron $179 \mathrm{a}^{2}$.

malache $12 \%$.

malinus 186.

malva $106 \mathrm{a}^{3}, 127,128,175$, 176, 180, 197, 206.

IIalva neglecta Wallr. 127, 128.

silvestris L. 127, 128, 197, 206.

malvas $127,182,183$.

malvavisca Alb. MI. 64.

malum 145 .

armeniacum Colum. 155. cotoneum 146.

cydonium Colum. 146.

persicum 154.

praecox 155 .

strutheum 146.

malus $145,186,215,217$.

mandragora b. H. 206.

Mandragora vernalis Bert. 206.

marathrum Colum. 132.

marrubium 77, 188, 189, 197, 206

album 78 .

nigrum 78.

Marrubium vulgare L. if, 190, 197, 206.

mater herbarum 76 .

* matricaria 62.

Matricaria Parthenium L. 62.

matrona Gloss. 62.

Jatthiola incana R. Br. 40. maura 144.

maurella 144 .

melanthium 132.

melilotum 175 .

Melilotus caeruleus Lam. 82 a.
Melilotus officinalis Desr. $175 a^{1}$.

melimela Plin. 145.

Melissa officinalis L. is, 137, 197, 198.

'melissophyllum 137.

melittaena Plin. 137.

melo $93 \mathrm{ff} ., 178$.

melones citrulli 224.

melopepo 93, 175a, 181, $221 \mathrm{a}^{2}$.

inenna h. H. $20 \%$.

menta $70,176,178,180$, 185.

corymbifera 73 .

graeca 73.

nigra $71,189$.

saracenica 73 .

mentam 70, 181, 18:, 183.

mentha $188,210$.

* equina $72,210$.

magna h. H. 207.

minor h. H. 207.

* romana 72, 210.

Mentha aquatica L. 69, 70, 197.

arvensis L. 69, 72 a, 210. crispa L. 69.

piperita L. 69, 190.

Pulegium L. 69, 72, 190. 208.

rotundifolia L. 69.

silvestris L. 69, 72, 210, 214.

mentastrum 72, 181, 182, 183,188

mespilarios 148, 183.

mespilum 148.

mespilus Alb. II. 148.

setania Ylin. 148.

Mespilus germanica L. 148, 218.

meu Alb. M. 198.

Meum athamanticum Jacq. 198.

milium 165, 167, 170, 204. 207.

millefolium Gloss. 35, 74.

millefolium 189, 202, 207.

millemorbia Gloss. 144.

mirica h. H. 218, 219.

mirra 189.

mirrha, myrrha h.H. 207. mirtus Alb. MI. 48.

mispilarios 148, 182.

mispolarius 186.

mismalvas $63,182,183$.

moloche 127.

moloche agria Plin. 63.

mora bati 156 .

celsi 156.

domestica 156.

morarios 156, 182, 183.

morella 144.

morum 156.

morus $156,218$.

Morus alba L. 156.

nigra L. 156, 218.

murarius 186.

murica h. H. 218

murra Plin. 126.

murris Plin. 126.

Muscari comosum Mill. 38, 39.

musetha h. H. 207.

Iyosatis sp. 202.

Myrica Gale I. 48, 217.

myriophyllum 35 .

Myristica moschata L. 208.

Myrrhis odorata Scop. 126.

* major 127.

myriza Plin. 126.

myrtus 48 .

teutona 218.

Myrtus communis L. 48 .

napo Alb. MI. 113.

napus $112,113,118,176$, 179.

major Gloss. 113.

narcissus 37, 175.

Narcissus poeticus L. 37 .

Pseudonarcissus L. 37 .

serotinus $\mathrm{L}$. 37.

Tazetta L. 37.

Nardostachys Jatamansi

DC. 211.

* nardus indica 211.

nardus rusticus 56 .

nasturcium 102, 178, 180.

aquaticum Alb. M. 103.

nasturtium 102, 103, 183,

200, 207.

agreste Bock 103.

aquaticum Bock 103.

hortulanum Gloss. 103. 
Nasturtium officinale R. Br. 103, 199.

Nelumbium speciosum Willd. 100.

nenuphar 208.

nepeta $72,73 \mathrm{a}^{1}, 176,178$, 180, 188, 189.

Nepeta Cataria L. 70, 72, 199, 207.

neptam 72, 182, 183.

nigella Alb. JI. 85, 132.

nigella Krtb. 132.

Nigella sativa L. 132.

nimphaea 189.

nimphia, nimphya h. H. 208.

noquarius 160 .

nucarios 15̃9, 182, 183.

nucella, nucilla 161 .

nugarius 186.

nux $160,218$.

abellana Plin. 160.

amara 158.

avellana 160 .

castanea 159.

gallica 160.

Graeca 158.

grandis 160 .

juglans 159.

minor 161 .

muscata h. H. 208.

pinea 161.

Thasia Plin. 159a.

nymphaea 208.

Nymphaea alba L. 203, 208.

ocimum 134, 178, 180.

Ocimum Basilicum L. 134, 190, 197.

minimum L. 134.

oculus porci Alb. MI. 123.

Olea europaea L. 218.

oleaster $72 \mathrm{a}$.

olera $175,176,179$.

oleratum 120.

* oleum castoris 59.

palmae Christi 59.

ricini 59 .

olisatum $3,120,183$.

olisatrum 120.

oliserus 120 .

olixatrum 120 .

olosatrus 120.

olus atrum $3,120,176,177$. olus marinum $177 \mathrm{a}^{2}$. rusticum 179.

olyra 163, 164.

ordeum $167 \mathrm{a}, 169$.

origanum 180, 189, 201, 208.

Origanum Dictamnus L. 67 .

MIajorana L. 135.

vulgare L. $178 \mathrm{a}^{2}, 189$, 201, 208.

ornus h. H. 218.

Orobus tuberosus L. 200.

orpinum Alb. M. 80.

ostrucium 103.

Oxalis Acetosella I. 190.

oxylapathum 61 .

Paeonia officinalis L. 198, 201.

palacalon Gloss, 16, 138. paliurus h. H. 218.

pallacana Plin. 16, 138, 140.

palma h. H. 219.

palma Christi Krtb. 59.

panax Plin. 67.

pandonia 77, 198, 208.

panicium 170, $167 \mathrm{a}$.

panicum $165,167 \mathrm{a}, 168$, 170.

Panicum italicum I. 165 , $170,213$.

miliaceum L. 165,170 , 204, 207.

sanguinale L. 170.

panigum 170.

papaver $64,86,175,183$, 185, 188, 208.

papaver erraticum Plin. 64 . campestre AJb. MI. 65.

hortense Alb. MI. 65 .

Papaver Argemone I. 64.

dubium I. 64.

Rhoeas L. 64, 87.

somniferum L. 64, 208.

parada Gloss. 59.

partuna 59, 183.

parthenium Plin. 62.

* parthenium 62.

pastinaca $116,117,118,176$,

179, 181, 207, 208.

agrestis 116 .

edomita Colum. 116.
Pastinaca sativa L. 117,118 , 207, 208.

pastinaeas 117, 183.

pastinachus 186 .

peonia 208.

pepo $93 \mathrm{ff}$., 175, 181, 208, 222.

pepones 93, 183, 188.

perarius 186.

percula $141 \mathrm{a}$.

peristereon Plin. 78.

perpressa 56 .

persicarios div. gen. 154, 182, 183.

persicum Alb. M. 154.

persicus 154, 186, 188, 219.

persolata Plin. 59.

personacea Diosk. 60 .

personatia 60.

* pervinca $177 \mathrm{a}^{1}, 198$.

Petasites officinalis Mönch 60, 204.

petresilinum 120, 183.

petresilum 120, 181.

petroselinon Plin. 120.

petroselinum 120, 189.

Petroselinum sativum Hoffm. 120, 208.

petrosilium 185 .

Peucedanum Cervaria Cuss. 204.

phaselus Colum. 98.

phaseolus $97 \mathrm{a}^{1}, 98,214$.

Aegyptiacus Tab. 99.

albus Americanus Tab.

99.

americanus C. Bauh. 99.

Brasilianus Tab. 99 .

peregrinus C. Bauh. 99.

vulgaris C. Bauh. 99.

Phaseolus 98.

vulgaris L. 98 .

phasganion Plin. 46.

phasiolus Plin. 98.

phasoli Matt. 99.

Phoenix dactylifera I. 216, 219.

Physalis Alkekengi L. 198. picea h. H. 219.

Picea excelsa Link 219.

pilosella h. H. 207, 208.

pimpinella italica minor Krtb. 135 a. 
Pimpinella Anisum L. 133. | poligonia $122 \mathrm{a}^{2}$.

Saxifraga L. 115, 189, Polygonum amphibium L. 198.

pinaster $72 \mathrm{a}, 161$.

pinos 161, 183.

pinus $72 \mathrm{a}, 161,162,186$, 219.

culta Ovid 161.

domestica 162.

hortorum $72 \mathrm{a}$.

Pinus Laricio L. 161.

Pinaster L. 161.

Pinea I. 161.

silvestris L. 219.

piper $189,208$.

album 208.

apium Diosk. 46.

Piper Cubeba Lin. fil. 200.

nigrum L. 190, 208.

piperitis 104 .

pipinella 189.

pirarios div. gen. 145, 182, 183.

piraster $72 \mathrm{a}$.

piretrum h. H. 198, 208.

pirum 146.

pirus 146, 215, 219.

Pirus communis L. 145, $215,219$.

Cydonia L. 146.

Malus L. 144, 215, 217.

salicifolia II. B. 145 .

pisos Mauriscos 95, 183.

Pistacia Lentiscus L. 217.

pisum 96, 208.

Pisum arvense I. 96, 97, 208.

elatius Steven 97.

sativum L. 97.

pitonion Gloss. 52.

plantago 189, 208, 214.

Plantago arenaria L. 209.

Coronopus I. 66 a.

lonceolata L. 189, 214.

major L. 189, 208, 214.

Psyllium I. 209.

platanus h. H. 215, 219.

plionia h. H. 208.

plistolochia Plin. 63.

poleium 176, 179, 180.

J Iartis 68 .

poleya h. H. 208. 208.

aviculare L. $122 \mathrm{a}^{2}, 189$, 214.

Bistorta L. 54 .

Fagopyrum I. 170.

polypodium h. H. 209, 212.

Polypodium vulgare L. 209, 212.

Polystichum Filix mas Roth 202.

pomarios div. gen. 144, $182,183$.

pomarius $145 \mathrm{a}$.

pomum $145 \mathrm{a}$.

Populus tremula L. 215, 220.

porcacla 181.

porcillaca Plin. 108.

porros $141,183,185$.

porrum 138, 141, 176, 177,

179, 181, 182, 206, 209.

agreste 142 .

capitatum 141, 177, 179 .

concavum h. H. 201.

sectile 141 .

sectivum 141, 177, 180.

tonsile 141.

Potentilla anserina L. 203.

argentea L. 203.

reptans L. 190, 202, 209.

Poterium Sanguisorba L. 135 a.

portulaca 178, 199, 209.

Portulaca oleracea L. 108.

sativa Haw. 199, 209.

praecocia 155.

prassium Alb. MI. 78.

pretula 141.

Primula elatior Jacq. 205.

officinalis Jacq. 20 .

prinus $153 \mathrm{a}^{2}, 219$.

proserpinale Gloss. 52.

prunarios div. gen. $152 \mathrm{ff}$., $182,183$.

prunarius 186 .

prunum 153.

armeniacum Plin. 155.

armenum Alb. II. 154.

cereolum Colum. 155 .

prunus 153, 219.

Prunus acida Dum. 148 ff.
Prunus acida var. Mrarasca

Host 149.

armeniaca L. 155.

avium L. 148 ff., 216.

Cerasus L. 148 ff., 216.

domestica L. 152 ff., 219.

insititia I. $152 \mathrm{ff}$., 200, 216, 217, 219.

Mahaleb L. $152 \mathrm{a}^{1}$

Padus L. 216.

spinosa L. 219.

pseudoacorum Krtb. 46.

pseudoiris Krtb. 46.

psillium h. H. 209.

Ptychotis coptica DC. 66.

puledium 72, 183.

pulegium 72, 185, 188.

puleium 72, 189.

Pulmonaria officinalis $\mathrm{L}$. 206.

purgaturia Gloss. 58 $\mathrm{a}^{1}$.

pyrethrum Apicius 52.

quercus h. H. 219.

Quercus Aegilops L. 147 $\mathrm{a}^{3}$. coccifera L. 217.

Robur L. 148 a, 219.

quinquefolia 189.

quinquefolium h. H. 202, 209.

quotanus h. H. 147, 219.

rabigudium, radigudium 115.

radices $113,183,18$.

radicula Plin. 84.

radistria Gloss. 114.

radix $2,113,114,176,179$, 209.

hortulana Gloss. 114.

lanaria Colum. 84.

Syriaca Colum. 113.

* radix acori adulterini 45.

acori palustris 45 .

anserinae 203.

argentinae 203.

asari 57.

bistortae 54 .

bryoniae 56 .

colubrinae 54 .

consolidae majoris 200 .

crassulae majoris 80 .

dictamni 68 . 
*adix diptamui 68.

dracunculi ǒ3.

esulae 199.

fabariae 80 .

fraxinellae 68 .

galangae 190 .

junci floridi 205.

junci maximi, 205 .

lapathi acuti $61,205$.

liquiritiae 206.

nardi rusticani 57.

oxylapathi 61 .

polypodii 209 .

pseudacori 45.

pyrethri 198.

rhapontici 190.

serpentariae majoris $\mathbf{5 3 .}$

serpentariae vulgaris ru-

brae 54 .

symphyti 200.

telephii 80.

tithymali 199.

ursi 198.

vulgaginis 57 .

zedoariae louga 190.

Ranunculus Ficaria L. 62 , 202, 211.

sceleratus L. 119 a.

rapa $112,113,118,176$, 179, 209, 210.

raphanum 114, 207, 209.

raphanus 113, 114, 116,

188.

major 115.

minor 115.

marinus 115 .

montanus 116 .

* rusticanus 115.

rusticus 115 .

vulgaris 115 .

Raphanus sativus L. 113, 209.

Raphanistrum L. 114, 115.

rapum 112, 113.

ravacaules 110, 182.

ravacaulos 110, 183.

reopontico 189.

Reseda luteola L. 83.

reumatica h. H. 209.

* rhabarbarum monachorum verum $178 \mathrm{a}^{1}$.

Rhamnus Paliurus L. 218.
Rheum Rhaponticum I. Ruseus 177 a . 190.

Rhinanthus Crista galli L. 209.

rhoeas Plin. 64, 87.

Ribes nigrum L. 216.

ricinus Plin. 58.

Ricinus communis L. 5ร8.

riscus h. H. 219.

robilia alba et grossa 97.

ros Verg. 136.

rosa $2,34,174,188,210$.

graeca Plin. 43, 174.

luteola Colum. 35, 37.

MIariana Bock 43.

punicea Colum. 35 .

silvestris Alb. MI. 35.

ultramarin Bock 128.

Rosa alba L. 36.

arvensis Huds. 36 .

canina L. 3̆, 216, 217, 220.

centifolia L. 34.

cinnamomea L. 37.

gallica L. 34,36 .

moschata Mill. 37.

pimpinellifolia L. 37.

rubiguinosa L. 35 .

sempervirens L. 34 .

rosarius 35,36 .

rosas $34,183,185$.

rosmariuum 136, 183.

rosmarinus 136, 185̃.

Rosmarinus officinalis L. 136.

ros maris Ovid 136.

rubea h. H. 209, 210.

major 82.

minor 82.

rubia Plin. 3, 82.

Rubia tinctorum L. 82.

Rubus 199.

Idaeus L. 156.

rumex 61, 178.

Rumex 211.

Acetosa L. 197.

aquaticus L. 129, 178 $\mathrm{a}^{1}$.

Hydrolapathum Huds.

$178 \mathrm{a}^{1}$.

obtusifolius L. 61, 115, 205, 207.

Patientia L. 178 $\mathrm{a}^{1}$. aculeatus L. $124,177 \mathrm{a}^{1}$.

Hypoglossum L. 177 a ', 189.

Hypophyllum L. $177 a^{1}$. rustica h. H. 199, 210.

ruta $2,69,176,178,180$, 185, 188, 189, 210.

Ruta graveolens L. 69, 210.

rutam 69, 181, 183.

sabina 81 .

sagmen 78.

salix h. H. 219.

Salix Caprea L. 219.

Salsola fruticosa L. 85a, 199.

salvia $2,133,185,188,210$. romana 73 .

Salvia calycina Sibth. 133. Horminum I. 134.

officinalis L. 133, 210.

Sclarea L. 134, 200, 210.

triloba L. 133.

salviam 133, 181, 182, 183.

Sambucus Ebulus L. 197, 201, 203.

nigra L. 217, 219.

sampsuchum Plin. 135.

sampsucum Colum. 135.

sandala 164 .

sandix 83.

sanguinaria $122 \mathrm{a}^{2}, 189,214$. sanguinarius h. H. 219.

sanicula h. H. 210.

Sanicula europaea L. 210.

Santolina Chamaecyparissus L. 75.

santonica 75 .

saponaria Alb. II. 84.

Saponaria officinalis I. 84. sarco h. H. 210.

Sarothamnus scoparius Koch 218, 219.

sataregia 185.

satereia h. H. 135, 210.

saturegia Alb. MI. 135.

Satureja hortensis L. 135, 210.

Satureiam 135, 176, 178 , $181,182,183,189$.

Savinam $80,81,181,182$, $183,189,219,220$. 
saxifraga 189.

Saxifraga granulata L. 190, 210, 212.

saxifrica h. H. $210,212$. scalonia Gloss. 16, 140.

sealonias 139, 140, 182.

scamphonia, scampina h. $\mathrm{H}$. 209.

scandula ed. Diocl. 164.

scariola 105.

scavina h. H. 210.

scilla 81 .

Scilla bifolia L. 39 .

maritima L. 81 .

Scirpus lacustris L. 207.

sclarea 188.

sclareiam 134, 182, 183.

scolopendria h. H. 204.

* scolopendrium 204.

Scolopendrium vulgare $\mathrm{Sm}$. 204.

scolymus Plin. 121 a.

Scolymus hispanicus L. $121 \mathrm{a}$.

maculatus L. $121 \mathrm{a}$.

scordion, scordon Gloss. 143.

scorzonera 123.

Scorzonera hispanica L. 123.

scylla 81 .

secale 165,167 a.

Secale cercale L. 165, 169, 211.

sedum Plin. 79.

Sedum acre L. 79, 201. purpureum Link 80 . reflexum L. 135 a.

Telephium L. 79.

segetalis Diosk. 47.

semen adoreum 163 .

* semen ammeos cretici 66 . ammeos veri 66 .

ammeos vulgaris 66 .

cataputiae majoris 59 .

endiviae 105.

hesperidis 42 .

junci floridi 205.

lini h. H. 206, 211.

psyllii 209.

ricini 59.

scariosae 105.

seseleos 65 .
* semen sileris montani 65 . sinapis 211.

violae damascenae 42.

violae matronalis 42 .

semperviva h. H. 79, 204, 211.

sempervivum 15.

Sempervivum tectorum I. 15, 79, 204, 211.

senecio 103.

senecium 103.

septegrania Gloss. 58.

serpentaria 54.

serpentaria Alb. M. 53.

serpentina 52 .

serpillum b. H. 209, 211.

serpyllum 135, 178.

servilla Krtb. 119.

servillum Krtb. 119.

Sesamum indicum L. $96 \mathrm{a}^{2}$. orientale L. $96 \mathrm{a}^{2}$.

sicale ed. Diocl. 165.

sigilis 169 .

sil Plin. 65.

siler montanum Alb. JI. 66.

Siler montanum Crautz 65.

silicia Plin. 82.

siligo 168, 168, 169.

siligo h. H. und Ålb. MI. 169, 211.

siliqua Colum. 82.

siliqua 146.

Graeca 146.

silum 65, 183.

silus Gloss. 65.

montanus Gloss. 65.

sisileus Gloss. 65 .

sinape 108, 183, 211.

sinapi 108.

sinapis 108, 180, 211.

Sinapis alba L. 108, 180a ${ }^{4}$. arvensis L. 115, 211.

nigra L. 108, 211.

sinza h. H. 211.

siser $117,118$.

erraticum Plin. 118.

sativum Plin. 118.

sisimbria 185, 197, 211.

sisimbrium 102, 176, 177 a.

sisimbrium $70,183$.

sisymbrium 71,75 .

sisymbrium alterum Diosk. 103.
Sisymbrium Nasturtium I. 103.

Sium Sisaron I. 118, 203. smilax hortensis 99 .

smyrnion 121.

Smyrnium Olusatrum I. 120. $177 a^{4}$.

perfoliatum IIill. $177 \mathrm{a}^{4}$.

solanum Plin. 143.

vesicarium 198.

Solanum humile Bernh. 143.

Melongena L. 143.

nigrum L. 143, 201, 207, 211.

villosum Lam. 143.

solata 144.

solatrum 144, 207, 211.

solidago minor Gloss. 44.

solsequia $106,107,182$, 189.

solsequium 106, 183, 211. minus 107.

Sonchus asper L. 105.

sorbarios $147,183$.

sorbarius 186.

sorbum 147.

sorbus 147.

Sorbus aucuparia L. 148, 218.

domestica L. 147, 216, 220.

sparagus Alb. II. 126.

sparga 189.

Sparganium ramosum Hucls. $46 \mathrm{a}^{2}$.

spelta 164, 167 a, 169, 211.

sphacos Plin. 133.

spica h. H. 211.

nardus h. H. 212.

* spica nardi 211.

spinachia Alb. II. 130.

spinacia 130.

Spinacia oleracea L. 130.

spinae h. H. 219, 220.

sponsa solis $106,106 \mathrm{a}^{2}, 107$.

squilla Alb. MI. 81.

sqillam 81, 183.

Stachys germanica L. 68 a. staphylinus 117, 118.

sticados 136 .

stignus h. H. 201, 212.

storax h. H. 212.

stramonia h. H. 212. 
strignum, strignus 144.

stycados 136.

Styrax officinalis L. 212.

summitates meliloti $175 \mathrm{a}^{1}$. suriace 98, 177.

symphytum majus Krtb. 200.

Symphytum officinale L. 200.

tanacetum 189, 209, 213.

Tanacetum Balsamita L. 70, $73,197,210$.

vulgare L. 74, 209, 213. tanacipan 74 .

tanazita 3 .

tanazitam $74,181,183$. tanezatum 74, 182.

tasia Gloss. 159 a.

taxus h. H. 220.

Taxus baccata I. 220.

telephion Plin. 79.

Teucrium Chamaedrys L. 189, 196, 202.

tharchun (arab.) 51.

thus h. H. 213.

masculinum 189.

thymbra 13 .

thymum 135, 178.

thymus h. H. 213.

Thymus vulgaris L. 135, 213.

Serpyllum L. 209, 211.

tilia h. H. 220.

Tilia europaea L. 220.

timbra 135 .

tinus Plin. 48.

tiphe 163.

tithymalus 58 .

major 58.

tormentilla 189, 213.

Tormentilla erecta L. 189 , 198, 201, 213.

tragopogon Plin. 122. purpureum Matt. 128.

Tragopogon crocifolius L. 123.

porrifolius L. 122.

pratensis L. 123.

tremulıs h. H. 215, 220.

tribulus 35, 217, 220.

Trifolium pratense L. 200.
Trigonella Foenum graecum L. 81, 202.

triticum 162, $167 \mathrm{a}, 169$, 213.

Triticum dicoccum Schrank 163.

monococcum L. 163.

Spelta L. 163, 169, 211. vulgare Vill. 162, 169, 213.

turiones $178,179$.

tussilago Plin. 60.

Tussilago Farfara L. 60, 204.

Petasites L. 60.

Typha sp. 201.

Vaccinium Mryrtillus L. 213.

Valeriana officinalis L. 201. venerea Diosk. 46.

vepres h. H. 213.

Veratrum album L. 208, $210,211$.

Verbascum Thapsus L. 198, 214.

verbena $78,213,215$.

verbena Alb. M. 78.

Verbena officinalis L. 78 , 213, 215.

verbenaca Plin. 78.

uetonica Gloss. 77.

vettonica Plin. 77.

ugera h. H. 213.

vibex h. H. 215, 217, 220.

Viburnum Lantana L. 218. Tinus L. 48.

Vicia Faba L. 100, 202. sativa L. 214.

victorialis femina 47. longa 47.

mas 47.

rotunda 47.

vimina h. H. 220.

* vinca $177 \mathrm{a}^{1}$. pervinca $177 a^{1}$.

Vinca major L. $177 \mathrm{a}^{1}$. minor L. $177 \mathrm{a}^{\prime}$. vincatossica 189 .

Vincetoxicum officinale Mönch 190.

viola $39,175,213$. alba Plin. 40. crocea Alb. MI. 40, 41. viola lutea Krtb. 41.

lntea Plin. 41.

matronalis Diosk. 42.

nigella Walafr. 40, 188.

nigra Verg. 40.

pallens Verg. 40.

purpurea 40, 174.

vera Alb. II. 40.

Viola odorata L. 40, 213.

Thessala Boiss, et Sprun. 40.

virgo pastoris Alb. II. 122.

virgo pastoris Mat. Silv. $122 a^{2}$.

viscum piri h. H. 207, 213.

Viscum album L. 207, 213. uismalva Gloss. 64 .

viticella Alb. JI. 56 .

vitis 157,220 .

alba Plin. 55.

alba Alb. II. 56.

nigra Plin. 55.

* vitis alba 56 .

Vitis vinifera L. 157, 220. vitrum Caes. 83.

vittonicam 5, 77, 182.

Ulmus campestris L. 151, 217.

ulpicum 142, 143, 177.

Ulva Lactuca L. $177 \mathrm{a}^{2}$. ungula caballina Alb. MI.

57.

unio Colum. 3, 139 a, 140.

uniones 139, 140, 183.

urtica $88,176,177,180$, 213.

ardens h. H. 213.

graeca Alb. MI. 88.

urens h. H. 213.

Urtica dioica L. 88, 213. pilulifera L. 88 .

urens L. 88, 202, 213.

usteralis 71 .

waisdo 83 .

uva canina 144 .

lupi Alb. MI. 144.

lupina 144.

uuarantia 82.

warentia 3 .

warentiam $82,183$.

uuasdus 83.

vulgago Gloss. 56. 


\section{- 249 -}

vulgigina $56,183$.

xiphion Plin. 46.

yreos 45. ysophus, yssopus h. H. 205. ysopus 137.

zaduar 189.

zea 163 .
Zingiber officinale Rose. 190. zinziber h. H. 205, 215. zion 16.

zizania $65,209,215$. 


\section{Register}

\section{der griechischen Pflanzennamen.}

Bemerkung: Die neugriechischen Pflanzennamen sind nicht besonders kenntlich gemacht, da manche von ihnen mit den altgriechischen ganz übereinstimmen. Der Artikel ist durchweg fortgelassen.

¿ßрóтovov Theophr. 74.

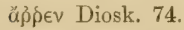

$\theta \hat{\eta} \lambda$ U Diosk. 75.

arroúpta 92.

årкuvápa 121.

àrpı́ßpous 166.

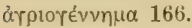

ảrpıodáxavov 179.

àroıotétııov 120, $177 \mathrm{a}^{4}$.

átizwov $15,79$.

$\mu e_{\gamma} \alpha$ Diosk. 79.

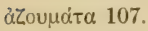

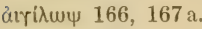

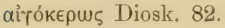

aip $\alpha, 166,167$ a.

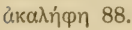

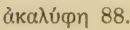

äkopov Diosk. 46.

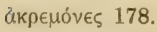

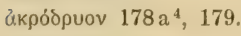

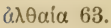

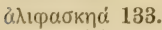

auápakov Diosk. 135.

¿щú́pakoక Theophr. 135.

¿иน́раvтоৎ 174.

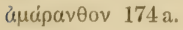

«цu Diosk. 66.

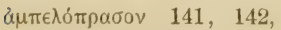
$176 \mathrm{a}^{1}, 179,181$.

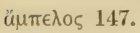

入єบหท่ อัอ.

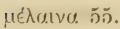

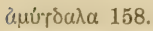

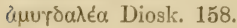

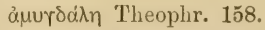

$\alpha \mu u \gamma \delta \alpha \lambda \hat{\eta}$ Theophr. 158.

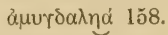

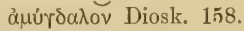

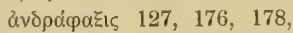
180.

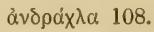

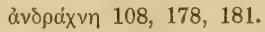

ăvทำ 132, 176, 179, 181.

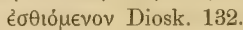

ณ̈ทเซov 133.

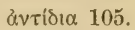

ära.ivn 10, 60, 175.

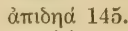

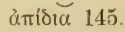

ämเov 145 .

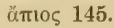

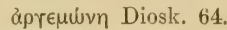

apíravos $178 \mathrm{a}$.

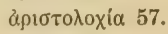

ӓркєıюv Diosk. ธั9.

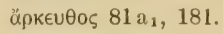

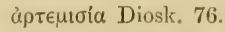

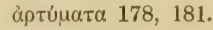

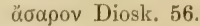

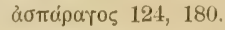

Ë $\lambda \in \operatorname{los} 124,180$.

öpelos Athen. 124.

$\pi € \tau \rho \alpha \hat{o}$ క Diosk. 124.

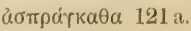

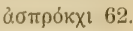

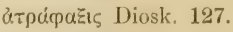

à.pứvı 64.

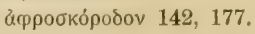

$\alpha x \lambda \alpha \delta\rceil \eta \alpha 145$.

åx $\alpha^{\prime} \delta 1 \alpha 145$.

¿xpós 145.

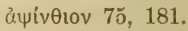

Baïná 47.

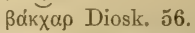

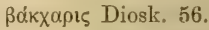

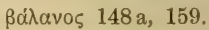

$\Delta$ tós 159 .

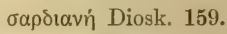

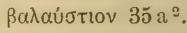

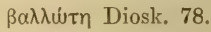

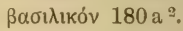

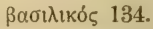

$\beta \alpha \dot{\tau} \alpha$ ท̆ $\mu \in \rho \alpha 156$.

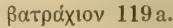

$\beta \in \lambda \alpha v i \delta ı \alpha$ 148a.

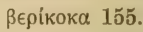

Вєрікокка 155.

$\beta \in \rho$ เкоккทd 155.

вєрікочка 155.

ßńxıv Diosk. 60.

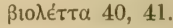

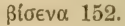

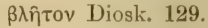

$\beta \lambda i \tau \alpha 129$.

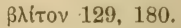

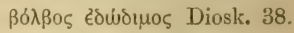

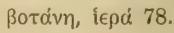

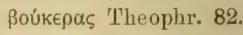

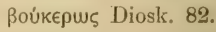

ßouviós 112, 113, 176, 179.

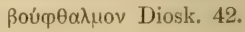




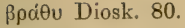

$\beta \rho i z \alpha 164,165,167$ a.

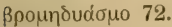

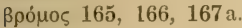

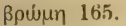

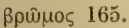

Búơıเva 148, 152.

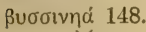

rńசvov 138, 140.

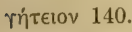

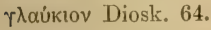

r內ńxuv 72, 176, 179, 180.

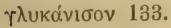

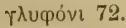

$\curlyvee \lambda$

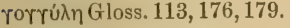

ñuєроక Diosk. 112.

rorrulis 'Theophr. 112.

roulid 112.

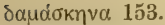

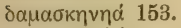

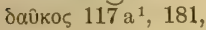

ठафкі́ 116.

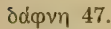

$\alpha \lambda \in \xi \alpha ́ v \delta \rho \in 1 \alpha 177 \mathrm{a}^{1}$.

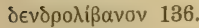

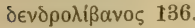

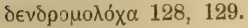

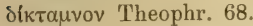

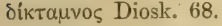

$\Delta$ ı่̀ $\beta \alpha \dot{\lambda} \alpha$ vos 159.

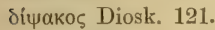

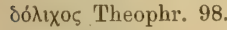

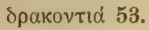

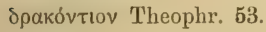

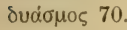

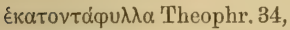
$174 \mathrm{a}^{2}$.

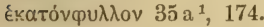

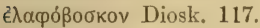

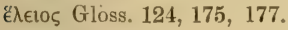

Ė̉

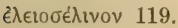

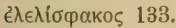

Ėก́viov 63, 180.

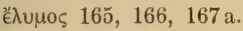

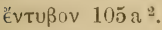

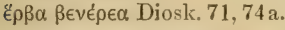

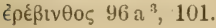

E̊ $\pi \pi \cup \lambda \lambda \circ$ 135 178.

ärptos. Diosk. 71.

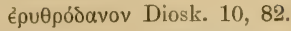

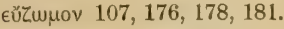

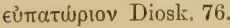

乙є1d $163,166,167,168$.

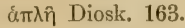

ঠі́коккоక Diosk. 163.

Zizáviov 166, 167 a, 209.

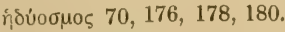

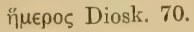

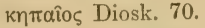

ărptos Diosk. 72.

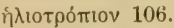

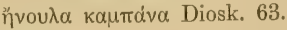

ทึ $\rho \alpha 166$.

$\theta \alpha \lambda \alpha \sigma б о к \rho \alpha \jmath \mu \beta \eta 177$.

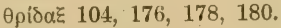

àroia Diosk. 64.

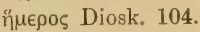

$\theta \rho$ өакіvп 104.

$\theta u ́ \mu \beta \rho \alpha 135,176,178,181$.

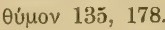

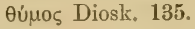

¡ß̈́бкоక Diosk. 63.

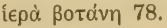

iov $39,174$.

$\lambda$ ¿eukov Theophr. 40.

uéldav Theophr. 40.

порqupoûv Diosk. 40.

i $\pi \pi \circ \sigma \in \lambda_{\lambda}$ เvov $120,176,177 \mathrm{a}$.

ipts Theophr. 43.

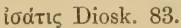

какочßа Gloss. 140.

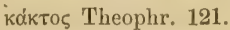

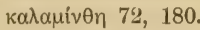

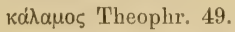

à

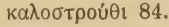

каvváßı 87.

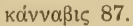

кápঠauov 102, 178, 180.

кópos Diosk. 131.

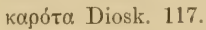

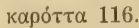

картóv $116 \mathrm{a}^{2}$.

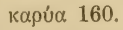

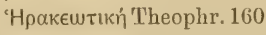

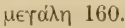

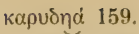

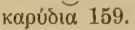

kapúdiov 160, 161.

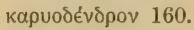

ка́рuov 159, 160.

ßабıגıóv Diosk. 159.

єủßoïкóv Theophr. 159.

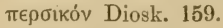

$\pi \lambda \alpha \tau u ́$ Xen. 159.

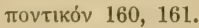

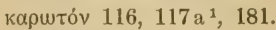

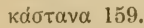

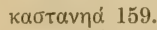

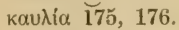

кauגiov Diosk. 125.

kau入ós 179.

кóxрuऽ 136

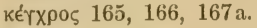

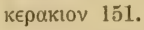

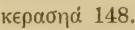

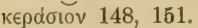

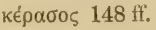

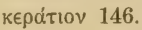

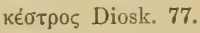

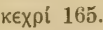

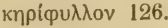

кíkı 58.

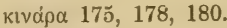

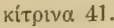

кเхúpเov 106.

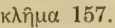

кvíơ 88, 176, 177, 180.

кvíkos Diosk. 84.

кขทิкоక Theophr. 84.

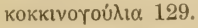

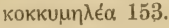

коккú $\mu \eta \lambda$ ㅇ 153.

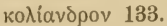

ко入окบӨı́, 89, $175,176$.

år $\rho เ \alpha$ อ็.

коภóкuv $\theta \alpha 179$.

airós Diosk. 54.

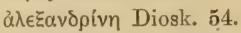

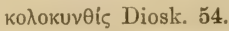

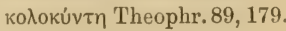

кovín 178 $\mathrm{a}_{2}$.

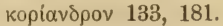

корiavvov Theophr. 133.

Kópıv 133, 179.

коро́ $\mu \eta \lambda \alpha 153$.

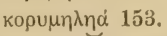

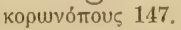

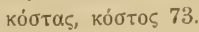


коบккıа́ 100.

кочккоuvápals 161.

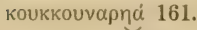
кочккоuvápıа 161. коบкоußaí 140.

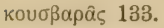

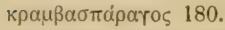
кос́ивฤ 15, 108, 111, 176, 179.

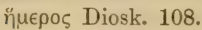
кра́vє1а Theophr. 150.

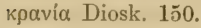

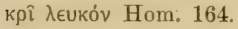
€Ủคuqués Hom. 164.

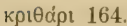
крıө்́ 164, 167a. кpivov $33,174$.

ßабıไıкóv Diosk. 33. крivos 33, 43.

крเóৎ 101.

крониúঠt 140.

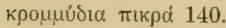

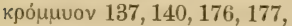
180.

бxiotóv Theophr. 140.

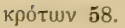

кúauos $96 \mathrm{a}^{3}, 100$.

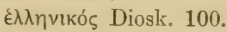

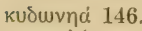

кuঠuvía 146.

кuớuvia 146.

кúนเvo 131.

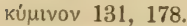

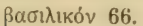

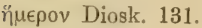
кuvópa 121, 175, 178. кúvetov 210.

$\lambda \alpha \theta$ oûpı 96.

$\lambda$ גөupí Diosk. 58.

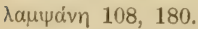

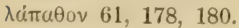

$\lambda$ ci $\pi \pi \alpha$ Diosk. 60.

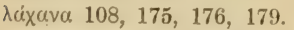
üpla 104a, 179a ${ }^{1}$.

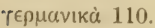

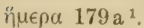

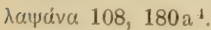

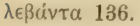

$\lambda \in$ Bovoid 127.

$\lambda \in$ eíptov 33.

$\lambda \in \pi i \delta$ iov Diosk. 103.

$\lambda \in \pi \circ v \tau i d i 27$.

$\lambda$ กттокúpunv $160,161$. $\lambda \in \pi \tau o \lambda \alpha ́ x a v o v 179$.

入єuкóïov 40, 175.

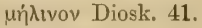

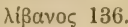

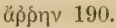

$\lambda_{i} \beta \alpha v \omega \tau$ is Theophr. 136.

$\lambda_{\imath} \beta a v w \tau i \zeta \zeta$ Diosk. 136.

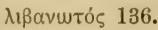

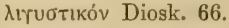

$\lambda \imath v \alpha, \rho t 85$.

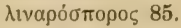

גivov 85.

$\lambda o ́ \beta 1 \alpha .98,175,176,177,180$.

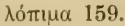

גuxvis 43, 174.

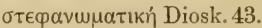

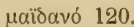

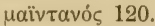

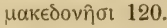

$\mu \alpha \lambda \alpha ́ \beta \alpha \theta \rho o v$ Diosk. $179 \mathrm{a}^{2}$.

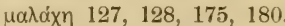

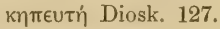

$\mu \alpha v \tau$ Zoupávo 135.

$\mu \alpha v \tau \eta \lambda i \delta \alpha 42$.

$\mu \alpha \dot{\rho} \alpha \theta \rho \circ{ }^{2} 132,176,178,181$.

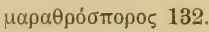

ud́pov $180 \mathrm{a}^{5}$.

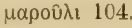

щачрокои́ккı 132.

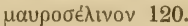

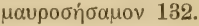

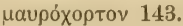

$\mu \in \lambda \alpha \dot{v} \theta$ ıov Diosk. 132.

$\mu \in \lambda i ́ \lambda \omega \tau o v 175$.

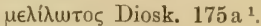

$\mu \in \lambda i \mu \eta \lambda \alpha \mathbf{1 4 5}$.

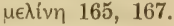

$\mu \in \lambda ı \sigma \sigma o ́ p u \lambda \lambda o v 137$.

$\mu \in V \in Z$ ÉS 40.

$\mu \in \sigma \pi ı \lambda \eta \dot{\alpha} 148$.

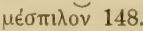

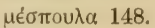

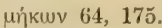

ùpuions Diosk. $86 \mathrm{a}^{3}$.

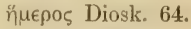

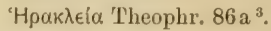
potás Diosk. 64.

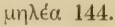

$\mu \eta \lambda \lambda \dot{\alpha} 144$.

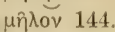

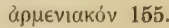

кuঠúvinov 146. $\pi \in \rho \sigma i k o ́ v 154$.

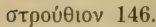

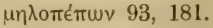

$\mu$ iv $\theta \alpha$. Theophr. 70.

$\mu$ iv $\theta n$ Gloss. $73 \mathrm{a}^{1}, 176,178$.

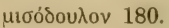

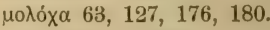

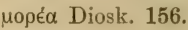

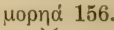

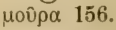

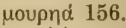

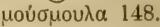

$\mu$ น́каv $\theta \alpha 124$.

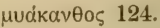

uup̧pís Diosk. 126.

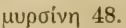

ảrpía Diosk. 177a ${ }^{1}$.

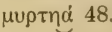

vơpঠoక ăr

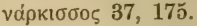

vómu 108.

vєрока́рдано 103.

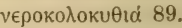

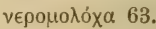

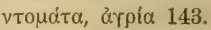

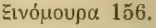

Eipíov 38, 43, 46.

Eupic Diosk. 43.

ő $\alpha 147$.

oื้xขท 145.

oỉ $\alpha$, oû 147.

őไ $\rho \rho \alpha 163,166,167 \mathrm{a}$.

ỏ $\pi \dot{\omega} \rho \alpha 145$ a.

ỏíravis 180.

ỏíravov 178, 180.

ópiravos $178 \mathrm{a}^{2}$.

öpuevos 177.

őputvov Diosk. 134.

őputvov Theophr. $134 \mathrm{a}^{1}$.

őoßos $96 \mathrm{a}^{8}$.

б̆б $\pi \rho \downarrow \alpha 101$.

oủov 147.

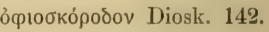

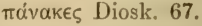

$\pi \alpha v \tau \tau \alpha \dot{\rho} \rho \alpha 129$.

$\pi \alpha \pi \alpha \rho \circ 0 v \alpha \alpha 64$.

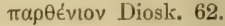

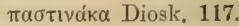

$\pi \in \pi \delta$ via 93 . 


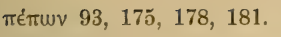
örptos $55 \mathrm{a}$.

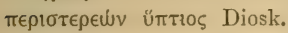
78.

$\pi \in \tau \alpha$ oitns Diosk. 60 .

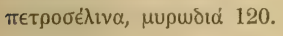

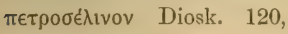
177.

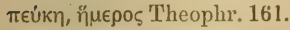
кшvoфópos Theophr. 161.

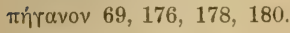

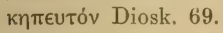

$\pi i Z \dot{\epsilon} \lambda \lambda_{1} \alpha .95$.

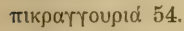

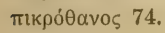

$\pi เ \kappa \rho о \mu \cup \gamma \delta \alpha \lambda$ 구 158.

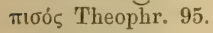

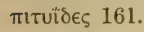

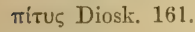

$\pi \lambda \alpha \tau \in \alpha \dot{\alpha} 59$.

$\pi \lambda \alpha \tau u \mu \alpha v \tau u \lambda i \delta \alpha 59$.

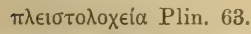

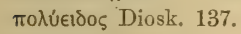

$\pi 0 u \rho v \in \lambda \eta \dot{\alpha} 153$.

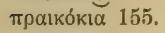

$\pi \rho \alpha \dot{\alpha} \alpha, \tau \alpha \dot{\alpha} 141$.

$\pi \rho \alpha$ otov 77.

$\mu \epsilon^{\prime} \gamma \alpha$ Diosk. 78.

$\mu \in e \hat{\lambda} \alpha$ V Diosk. 78.

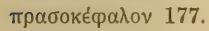

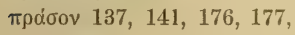
179.

картóv 141, 177, 180.

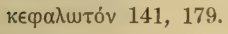

$\pi$ กิvoร 217.

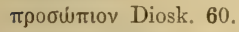

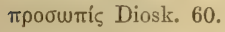

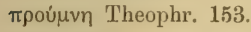

$\pi v$ zópı 49.

$\pi$ Úદos Theophr. 49.

$\pi u ́ p \in \theta \rho o v$ Diosk. 52.

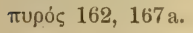

ärptos Diosk. 62.

pasíkı $106 \mathrm{a}^{1}$.

$\eta \dddot{\mu} \mu \rho \alpha .105$.

paíßıь 112.

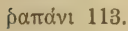

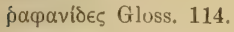

¡রфavís 113.

arpia Diosk. 114.

§óquvos Theophr. 108.

ớqavos 114, 179. $\operatorname{e\beta i\theta t\alpha } 101$.

jiravn $178 \mathrm{a}^{\circ}$.

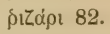

фовít $\alpha 101$.

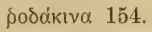

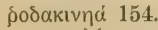

fódov 34, 174.

polós Theophr. 64.

ро́ка 107.

คоบิкณ 107.

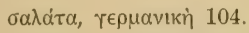

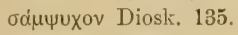

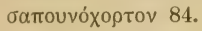

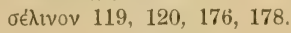

ärptov Diosk, $119 \mathrm{a}$.

бépı $105,176,178,180$.

ảrpía Diosk. 106.

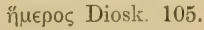

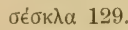

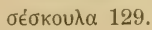

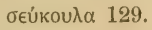

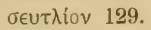

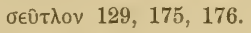

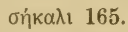

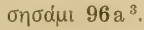

бท̆бauov $96 \mathrm{a}^{3}$.

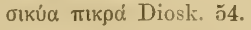

бıкúঠı 175, 176.

бі́кบоక $92,181$.

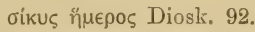

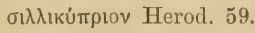

бivamı 108, 180.

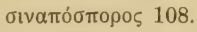

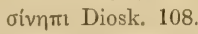

бiбapov Diosk. 117, 118.

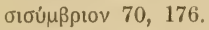

Ẽ $\tau \in \rho$ v Diosk. 103.

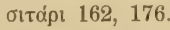

бîtoక $162,167$.

бítos 162.

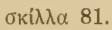

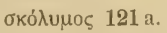

бко́рбоv 142.

бKópodov 137, 142, 176, 177, 180.

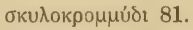

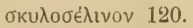

бкиภóхортоv 77.

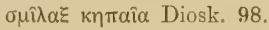

бuúpviov 120, $177 \mathrm{a}^{4}$.

боиิ $\beta \alpha 147$.

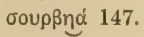

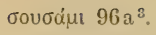

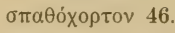

бтаvókı 130.

ärpı 127.

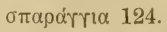

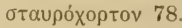

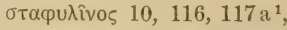
$118,176,179,181$.

ärptos 116.

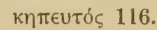

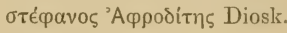
71.

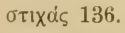

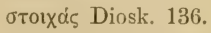

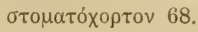

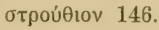

oтpoveíov 84.

бтроu日ós $86 \mathrm{a}^{3}$.

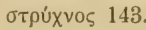

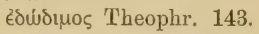

күாаî̄ Diosk. 143.

бтúpvoৎ 143.

бטิкณ 157.

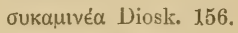

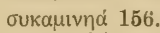

бuкámivos Theophr. 156.

Ėv Airúrtw Theophr. 156.

бบкทิ 157.

бบкท人่ 157.

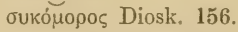

бфákos Theophr. 133.

бфарárria 124.

бxivos 217.

Taxivi $96 \mathrm{a}^{2}$.

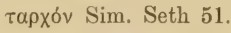

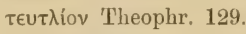

入єบкóv 129.

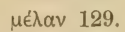

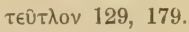

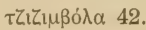

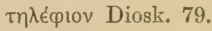

$\tau \hat{\eta} \lambda ı$ 82, 179.

$\tau \hat{\jmath} \lambda$ U 82.

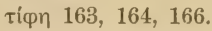

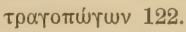

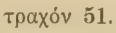

$\tau \rho \iota \alpha v \tau \alpha \dot{q} \varphi \lambda \lambda \alpha 34$.

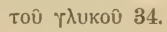

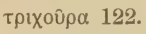

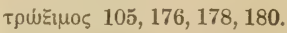

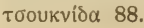




\section{- $254-$}

v́ákıvos Diosk. 38. บ́র์ktv $\theta$ os poet. 44,46 .

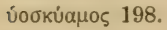

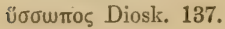

факท́ 101.

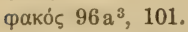

pdíravov 46.

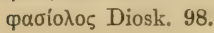

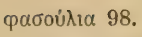

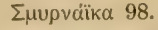

pทrós Theophr. $147 \mathrm{a}^{3}$.

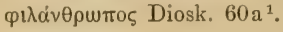

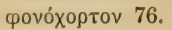

qouvтouknd 160.

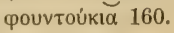

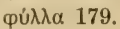

$\chi \alpha \mu \alpha \iota \delta \alpha \dot{\varphi} \eta 177$.

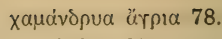

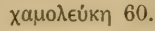

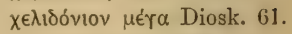

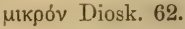

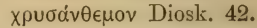

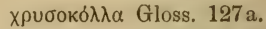

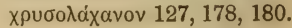

w̌кınov Theophr. 134, 178, 180. 
Im Verlage von

\section{Lipsius \& Tischer in Kiel und Leipzig}

sind von

\section{Dr. Paul Knuth}

erschienen : Geschichte der Botanik I. Teil (die Zeit vor Linné) in Schleswig-Holstein. Mk. 1.60. II. Teil (die Zeit nach Linné) $157 \mathrm{~S}$. Gr. $8^{0} \mathrm{Mk} .4$.

Preis für 2 Theile in einem Bande Mk. 5.60. Grundzüg’e einer Entwicklungsgeschichte der Pflauzenwelt in Gr. $8^{0}$. Preis Mk., 1.20.

Die Pflanzenwelt der nordfriesischen Inseln. Gemeinverständlich dargestellt. 39 S. Gr. $8^{0}$.

Preis Mk. 1.—.

Ueber blütenbiologische Beobachtungen. $24 \mathrm{~S}$. Gr. $8^{0}$ mit 26 Abbildungen. Preis Mk. -.80.

Blumen und Insekten auf den nordfrie-

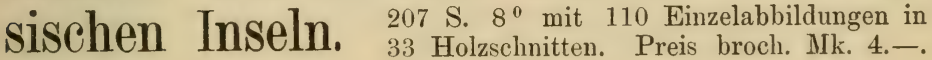

\section{Blumen und Insekten auf den Halligen.}

(Bloemen en Insecten op de Halligen) 31 S. mit 1 Karte. Preis brosch. Mk. -80 .

\section{Chr. Konr. Sprengel,}

Das entdeckte Geheimnis der Natur.

Ein Jubiläums-Referat. 107 S. $8^{0}$ mit 4 Tafeln. Preis Mk. 1.-. 


\section{Lipsius \& Tischer in Kiel und Leipzig}

ist ferner erschienen:

Ueber die Structur der Tintinnen-Gehiiuse. Von R. Biedermann. Preis Mk. 2.

Die Heimat. Monatsschrift des Vereins zur Pflege der Natur- und Landeskunde in Schleswig-Holstein, Hamburg und Lübeck. Jahrgang III 1893, 12 Hefte 3 Mk.

Die geologische Bodenbeschaffenheit Schleswig-Holsteins mit besonderer Beriicksichtigung der erratischen Bildungen in ihren Grundziigen. Von Dr. Hippolyt J. Haas, Professor an der Universität Kiel. Für die Gebildeten aller Stände gemeinfasslich dargestellt. Mit 31 Abbildungen im Text. Preis geheftet Mk. 3; gebunden Mk. 4.

Beitrïge zur Kenntniss der liasischen Brachiopodenfauna von Siidtirol und Venetien, mit 4 lith. Tafeln. Von

Dr. Hippolyt J. Haas, Professor an der Universität Kiel. Preis Mk. 12.

Warum fliesst die Eider in die Nordsee? Ein Beitrag zur Geographie und Geologie des Schleswig-Holsteinischen Landes. Von

Dr. Hippolyt J. Haas, Professor an der Universität Kiel. Mit einer Kartenskizze. Preis Mk. 1.

Naturgeschichte. Von Friedr. Junge, Hauptlehrer in Kiel. Erster Theil: Der Dorfteich als Lebensgemeinschaft nebst einer Abhandlung über Ziel und Verfahren des naturgeschichtlichen Unterrichts. Zweite verbesserte und vermehrte Auflage. Mk. 2.80; gut gebunden

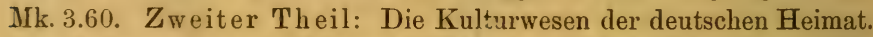
Eine Lebensgemeinschaft um den Menschen. Erste Abtheilung: Die Pflanzenwelt. Mk. 3; gut gebunden Mk. 3.80 .

Mittheilungen aus dem mineralogischen Institut der Universität Kiel. Von Dr. J. Lehmann, Professor an der Universität Kiel. Bd. I, Heft 1. Preis Mk. 4. Bd. I, Heft 2. Preis Mk. -.75. Bd. I, Heft 3, Preis Mk. 1.50. Bd. I, Heft 4, Preis Mk. 6.25. Untersuchungen iiber die Entstehung der altkristallinischen Schiefergesteine mit besonderer Bezugnahme anf das sächsische Granulitgebirge, Erzgebirge, Fichtelgebirge und bairischböhmische Grenzgebirge. Von Dr. J. Lehmann. Mit 5 lithogr. Tafeln und einem Atlas. Preis Mk. 75.

Die Abstammungslehre und die Errichtung eines Institutes fïir Transformismus. Ein neuer, experimenteller, phylogenetischer Forschungsweg von Dr. Robert Behla. $8^{\circ}$. (VII, 60 S.). Mk. 2.

Florae germanicae pteridophyta. Enumerat Erwin Schulze, Quedlinburgensis. VIII, 29 S. $8^{0} . \quad$ Mk.,- 80. 




